\title{
ANÁLISE TEÓRICO-EXPERIMENTAL DE ESTRUTURAS COMPOSTAS DE PÓRTICOS DE AÇO PREENCHIDOS COM ALVENARIA DE CONCRETO CELULAR AUTOCLAVADO
}

\author{
RITA DE CÁSSIA SILVA SANT'ANA ALVARENGA
}

Tese apresentada à Escola de Engenharia de São Carlos, da Universidade de São Paulo, como parte dos requisitos para obtenção do título de Doutor em Engenharia de Estruturas

ORIENTADORA: $\operatorname{Prof}^{\underline{a}}$ Dra. Helena Maria Cunha do Carmo Antunes CO-ORIENTADOR: Prof. Dr. Roberto Márcio da Silva

São Carlos 
Análise teórico-experimental de estruturas compostas de pórticos de aço preenchidos com alvenaria de concreto celular autoclavado / Rita de Cássia Silva Sant'Ana Alvarenga. -- São Carlos, 2002.

Tese (Doutorado) -- Escola de Engenharia de São Carlos-Universidade de São Paulo, 2002.

Área : Engenharia de Estruturas.

Orientador: Profa. Dra. Helena M. C. Carmo Antunes. Co-orientador: Prof. Dr. Roberto Márcio da Silva.

1. Alvenaria estrutural. 2. Pórticos preenchidos. 3. Estruturas de aço. 4. Análise experimental e numérica. I. Título. 
Aos meus pais Francisco e Conceição. Ao meu marido Liszt e aos meus filhos Arthur, Thales e Thais, companheiros de todos os momentos. 


\section{AGRADECIMENTOS}

À Professora Helena M. C. Carmo Antunes, pelo apoio e pela orientação ao desenvolvimento deste trabalho.

Ao Professor Roberto Márcio da Silva, pelo incentivo, pela orientação e, sobretudo, pela amizade.

Ao Professor Paulo J. B. B. Lourenço, pela acolhida em Portugal, pela eficiente orientação e pelas sugestões.

Aos Professores do Departamento de Engenharia Civil da Universidade Federal de Viçosa, em Viçosa, MG, especialmente aos do Setor de Estruturas, por terem tornado possível a execução desta tese.

Ao Engenheiro Roberto Coelho, pelo acompanhamento dos ensaios experimentais e pelas sugestões.

À Juliana, pelo aprendizado conjunto na primeira série de ensaios experimentais.

Aos colegas do Departamento de Estruturas da EESC/USP, da EEUFMG e da UMinho, pelo convívio, pela amizade e pela colaboração; em especial, aos Engenheiros Agustin Orduña e Luis Ramos, da UMinho, e ao Professor Reginaldo Carneiro da Silva, colega da UFV e da USP, pelo companheirismo.

Aos funcionários do Departamento de Engenharia de Estruturas da EESC/USP, da EEUFMG e da UMinho, pela presteza e assistência.

Aos funcionários do LAEES Erik, Geraldo e Hidelbrando e ao mestrando Késio, pela colaboração na execução dos ensaios experimentais, e aos Professores Francisco Carlos Rodrigues e Edgar Mantilla Carrasco, pelo trabalho dedicado ao laboratório.

À CAPES, pelo auxílio financeiro.

À Codeme Engenharia, pela doação dos pórticos de aço, e à empresa Sical, pela doação dos blocos e da mão-de-obra para execução das paredes ensaiadas. 


\section{SUMÁRIO}

LISTA DE FIGURAS................................................... xii

LISTA DE TABELAS...................................................... $\mathrm{xxv}$

LISTA DE ABREVIATURAS E SIGLAS.............................. xxix

LISTA DE SÍMBOLOS.................................................... $\mathrm{xxx}$

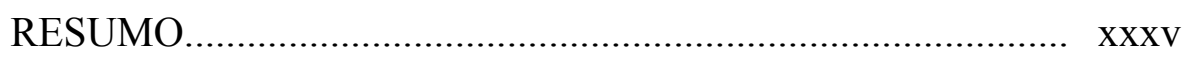

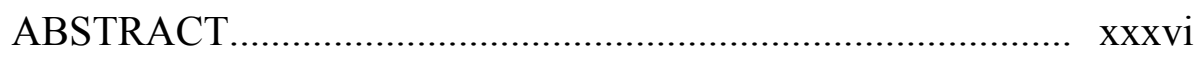

1. INTRODUÇÃ

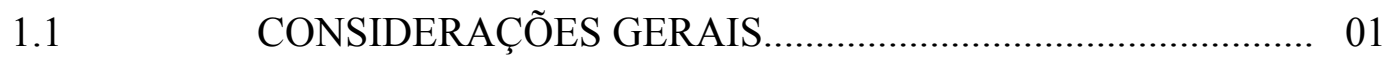

1.2 ANÁLISE E PROJETO DE PÓRTICOS PREENCHIDOS 03 COM ALVENARIA.

1.3 COMPORTAMENTO DE PÓRTICOS PREENCHIDOS.......... 06

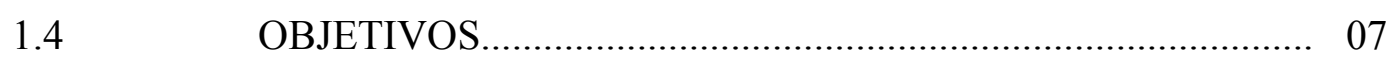

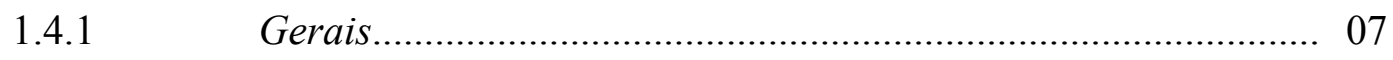

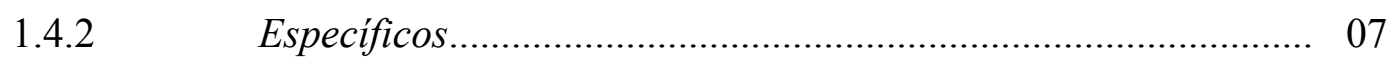

ORGANIZAÇÃO DO TRABALHO ..................................... 08

CONTEXTUALIZAÇÃO DO TRABALHO............................ 11

2. REVISÃO DE LITERATURA........................................ 12

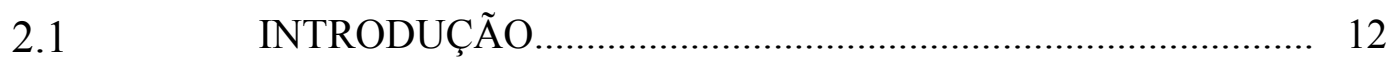


2.1.2 Pórticos Preenchidos.

2.2.2 Avaliação Teórica do Comportamento de Pórticos Preenchidos a Partir da Rigidez Relativa Pórtico-Painel.

2.2.3 Avaliação Empírica do Comportamento de Pórticos Preenchidos a Partir da Rigidez Relativa Pórtico-Painel......

2.2.4 Avaliação do Comportamento de Pórticos Preenchidos Segundo a Teoria da Elasticidade.....

2.2.5 Avaliação do Comportamento de Pórticos Preenchidos Utilizando o Método dos Elementos Finitos.

2.2.6 Avaliação Experimental do Comportamento de Pórticos Preenchidos. 
3.3.3.2 Ligações com argamassa polimérica (Ciment-cola) 46

3.3.4 Sistema de Carregamento: Pórtico de Reação 47

3.3.5 Instrumentação dos Protótipos. 49

3.4 EXECUÇÃO DOS ENSAIOS DE PÓRTICOS. 55

3.4.1 Ensaios de Pórticos de Aço Sem Preenchimento. 55

3.4.2 Ensaios de Pórticos de Aço Preenchidos com Alvenaria... 56

3.4.3 Ensaios de Caracterização da Alvenaria e Argamassa. 57

3.4.3.1 Ensaios de prismas à compressão 57

3.4.3.2 Ensaios de prismas ao cisalhamento 59

3.4.3.3 Ensaios de compressão em cilindros de argamassa. 60

3.4.3.4 Ensaios de tração por compressão diametral em cilindros de argamassa.

3.5.1 Resultados Referentes aos Ensaios do Pórtico TIPO I.

3.5.1.1 Desenvolvimento dos ensaios e modos de ruptura.

3.5.1.2 Descolamento da interface pórtico-painel.

3.5.1.3 Análise de tensão e deformação.

3.5.1.4 Influência do ferro-cabelo. 
3.5.2.1 Desenvolvimento dos ensaios e modos de ruptura. 87

3.5.2.2 Descolamento da interface pórtico-painel 94

3.5.2.3 Análise de tensões e deformações. 97

3.5.2.4 Influência da abertura na parede. 99

3.5.3 Influência da Relação Altura/Comprimento dos Pórticos na Rigidez e Resistência de Pórticos Preenchidos.. 103

ALGUMAS CONSIDERAÇÕES SOBRE OS RESULTADOS 106 EXPERIMENTAIS

4. AVALIAÇÃO TEÓRICA DO COMPORTAMENTO DOS PROTÓTIPOS......................................................... 108

4.1 OBTENÇÃO DOS DESLOCAMENTOS LATERAIS DOS PROTÓTIPOS ............................................................... 108

4.1.1 Determinação do Comprimento de Contato PórticoPainel............................................................................... 109

4.1.2 Determinação da Largura da Barra Diagonal Equivalente........ 110

4.1.2.1 Variação do comprimento da diagonal comprimida ................. 110

Determinação do Deslocamento Lateral.................................. 111

4.2 DETERMINAÇÃO DAS CARGAS DE RUPTURA DO PAINEL ........................................................................ 112

4.2.1 Segundo Smith e Carter......................................................... 112

4.2.1.1 Ruptura por fissuração da diagonal......................................... 112

4.2.1.2 Ruptura por cisalhamento ao longo das juntas de argamassa .......................................................................... 113

4.2.1.3 Ruptura por esmagamento nos cantos comprimidos.................. 114 
4.2.2.1 Ruptura por fissuração da diagonal.

4.2.2.2 Ruptura por cisalhamento ao longo das juntas de argamassa

4.2.2.3 Ruptura por esmagamento nos cantos comprimidos.

4.2.3 Segundo prescrições italianas-DM 16/01/96: "Prescrições Técnicas para Estruturas Sujeitas a Sismos" e Cir.10/04/97N.65.......

4.2.3.1 Ruptura por fissuração da diagonal.

4.2.3.2 Ruptura por cisalhamento ao longo das juntas de argamassa.

4.2.3.3 Ruptura por esmagamento nos cantos comprimidos 
5.3.2.3 Interface viga-pilar, pórtico-alvenaria e alvenariaalvenaria .................................................................... 135

5.3.2.4 Conexão protótipo-pórtico de reação (rolos)............................. 136

5.3.3 Modelos Constitutivos Utilizados na Análise Numérica............ 136

5.3.3.1 Modelo constitutivo para a alvenaria ........................................ 136

5.3.3.2 Modelo constitutivo para as interfaces..................................... 141

5.3.3.3 Modelo constitutivo para o pórtico de aço.................................. 145

5.3.4 Propriedades da Alvenaria e Argamassa Utilizadas na Análise Numérica ............................................................................ 145

5.3.5 Resultados da Análise Numérica para os Protótipos................. 150

5.3.5.1 Protótipo TIPO I............................................................... 150

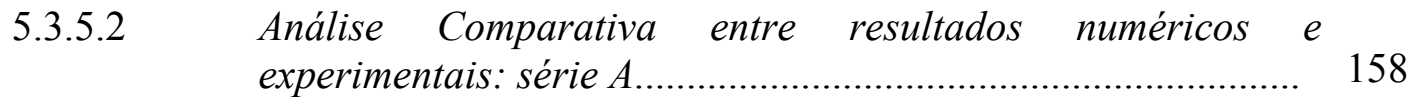

5.3.5.3 Protótipo TIPO II com paredes sem abertura.......................... 164

5.3.5.4 Análise Comparativa entre resultados numéricos e experimentais: Série B com paredes sem abertura.................... 187

5.3.5.5 Protótipo TIPO II: paredes com abertura............................... 193

5.3.5.6 Análise comparativa entre resultados numéricos e experimentais: Série B, paredes com abertura....................... 216

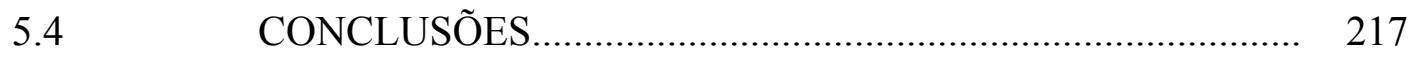

6. ESTUDO PARAMÉTRICO........................................... 220

6.1 RELAÇÃO ALTURA/COMPRIMENTO (H/L) .................... 221

6.2 RIGIDEZ DA LIGAÇÃO VIGA-PILAR .................................. 225 
6.3 RIGIDEZ RELATIVA PÓRTICO-PAINEL DE ALVENARIA 229

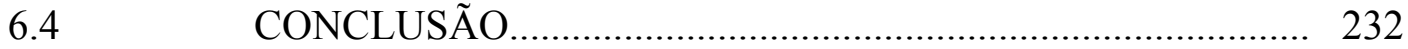

7. PROPOSTA PARA ANÁlISE DE PÓRTICOS PREENCHIDOS COM ALVENARIA.............................. 234

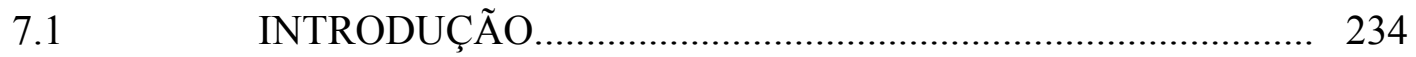

7.2 RESISTÊNCIA LATERAL DE PÓRTICOS PREENCHIDOS.. 235

7.2.1 Modos de Ruptura ......................................................... 235

7.2.2 Resistência à Compressão da Alvenaria em Estado Biaxial........................................................................ 235

7.2.3 Resistência Efetiva do Painel de Alvenaria .............................. 236

7.2.4 Modelo Proposto................................................................... 238

7.2.4.1 Ruptura por fissuração da diagonal: modelo de bielas e tirante para o painel de alvenaria.................................................... 238

7.2.4.2 Ruptura por esmagamento dos cantos comprimidos................ 244

7.2.4.3 Ruptura por esmagamento no centro do painel, considerando a resistência efetiva...

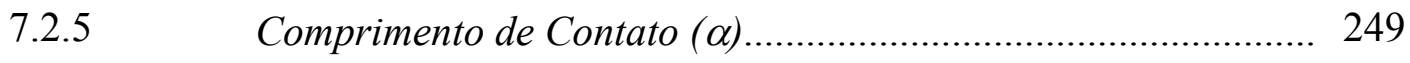

7.2.6 Validação do Modelo Proposto............................................. 250

7.2.6.1 Comparação com os resultados do estudo paramétrico............ 251

7.2.6.2 Comparação com os resultados de Braguim............................ 258

7.2.6.3 Comparação com os resultados de Smith e Carter.................... 260

7.3 AVALIAÇÃO DA LARGURA EFETIVA DE PAINÉIS DE PÓRTICOS PREENCHIDOS................................................... 263 
7.3.2 Obtenção da Largura Efetiva da Diagonal Equivalente.

ANEXO A Investigação Experimental de Painéis Pré-Fabricados de Alvenaria.

ANEXO B Sistema de Aquisição de Dados e Calibração da Instrumentação..

ANEXO C Ensaios para Caracterização dos Painéis de Alvenaria e de Argamassas.

ANEXO D Descolamento da Interface Pórtico-Painel.

ANEXO E Deformações nas Regiões dos Extensômetros.

ANEXO F Soluções de Sistemas Não-Lineares e Critérios de Convergência...........................................................................

ANEXO G Tabelas com Valores das Cargas de Ruptura Obtidos pelo Método Proposto, pelas Modelagens Numéricas e pelos Métodos Teóricos 


\section{LISTA DE FIGURAS}

FIGURA 1.1 - Exemplos de alvenaria confinada..................................... 5

FIGURA 2.1 - a) Sistema pórtico-parede. b) Comprimento de contato das interfaces, em sistemas solicitados a ações horizontais 18

FIGURA 2.2 - Modelo de análise proposto por Stafford Smith............. 19

FIGURA 2.3 - Resistência da diagonal equivalente em função de $\lambda L$, Smith, 1966.................................................................. 20

FIGURA 2.4 - Modos de ruptura da alvenaria em sistemas de pórticos de aço-painéis de alvenaria

FIGURA 2.5 - Ábaco para painel de alvenaria: resistência à tração da diagonal equivalente $\mathrm{x} \lambda L$, Smith e Carter (1969).....

FIGURA 2.6 - Ábaco para painel de alvenaria: resistência ao cisalhamento da diagonal equivalente $\mathrm{x} \lambda L$, Smith $\mathrm{e}$ Carter (1969) .

FIGURA 2.7 - Ábaco para painel de alvenaria: resistência ao esmagamento do cantos carregados.

FIGURA 2.8 - Largura efetiva da diagonal equivalente

FIGURA 3.1 - Pórticos ensaiados: a) TIPO I: relação altura/comprimento $=0,83$ e b) TIPO II: relação altura/comprimento $=0,51$

FIGURA 3.2 - $\quad$ Base engastada.......................................................... 39

FIGURA 3.3 - $\quad$ Ligações semi-rígidas. Cantoneiras parafusadas................ 39

FIGURA 3.4 - Tirantes.......................................................................... 39

FIGURA 3.5 - Croquis do pórtico TIPO II............................................. 40

FIGURA 3.6 - Trecho de parede com extremidade livre............................ 44

FIGURA 3.7 - Características do "ferro-cabelo": a) detalhe do ferrocabelo e b) seção transversal de uma fiada de bloco com ferro-cabelo soldado à mesa do pilar...

FIGURA 3.8 - Sistema de aplicação de carga (cilindro hidráulico)........... 47

FIGURA 3.9 - Croquis do conjunto protótipo-pórtico de reação............... 49

FIGURA 3.10 - Instrumentação dos ensaios: a) paredes sem aberturas ou painéis e b) paredes com aberturas (instrumentação adicional) 
FIGURA 3.11 - Transdutor de deslocamento lateral global....................... 51

FIGURA 3.12 - Transdutor de deslocamento da diagonal central: a) visão geral e b) detalhe.

FIGURA 3.13 - Transdutores de deslocamentos horizontal e vertical superior e relógios comparadores

FIGURA 3.14 - Relógio comparador central ortogonal à parede................ 54

FIGURA 3.15 - Extensômetros: a) roseta do canto superior direito e b) roseta do canto inferior esquerdo................................... 55

FIGURA 3.16 - Ensaio pórtico TIPOI........................................................ 56

FIGURA 3.17 - Prismas de meio bloco/bloco inteiro/meio bloco: a) argamassa de traço 1:3:7,5 e b) argamassa Ciment-cola. Dimensões: $\mathrm{mm}$.

FIGURA 3.18 - Ensaio de prisma à compressão......................................... 58

FIGURA 3.19 - Esquema do sistema de reação........................................... 59

FIGURA 3.20 - Diagrama força-deslocamento para o pórtico sem preenchimento e para os sistemas pórtico-parede da série A.

FIGURA 3.21 - Modos de ruptura referentes aos dois primeiros ensaios com juntas de assentamento de argamassa no traço 1:3:7,5 de cimento, cal e areia e ferros-cabelo na interface (ensaios $1 \mathrm{~A}$ e $2 \mathrm{~A})$

FIGURA 3.22 - Modo de ruptura referente ao ensaio com juntas de assentamento com argamassa Ciment-cola e interface com ferros-cabelo (ensaio 3A)

FIGURA 3.23 - Modo de ruptura referente ao ensaio com juntas de assentamento com argamassa Ciment-cola e interface com ferros-cabelo (ensaio 4A)

FIGURA 3.24 - Modo de ruptura referente ao ensaio com juntas de assentamento com argamassa Ciment-cola e interface sem ferro-cabelo (ensaio 5A)

FIGURA 3.25 - Modo de ruptura referente ao ensaio com juntas de assentamento com argamassa Ciment-cola e interface sem ferros-cabelo (ensaio 6A)

FIGURA 3.26 - Diagrama força-deslocamento ensaios 1A e 2A ................ 71

FIGURA 3.27 - Diagrama força-deslocamento ensaios 3A e 4A................ 71

FIGURA 3.28 - Diagrama força-deslocamento ensaios 5A e 6A................ 71

FIGURA 3.29 - Diagrama força-deslocamento para o ensaio 5A, carregamento e recarregamento. 
FIGURA 3.30 - Diagramas força-deslocamento para o pórtico TIPO I sem preenchimento, obtidos através de ensaios realizados antes e depois dos ensaios de pórticos preenchidos.

FIGURA 3.31 - Disposição da instrumentação para medida dos descolamentos.

FIGURA 3.32 - Diagrama força-descolamento dos cantos tracionados: canto superior direito (Rel 01, DT 05, DT 04 e Rel 02).... 75

FIGURA 3.33 - Diagrama força-descolamento dos cantos tracionados: canto inferior esquerdo (Rel 03, Rel 04, Rel 05 e Rel 06) 76

FIGURA 3.34 - Disposição dos extensômetros e do DT 03........................ 78

FIGURA 3.35 - Eixos de referência............................................................. 78

FIGURA 3.36 - Diagramas força-deformação diagonal central do painel ensaios da série A............................................................ 80

FIGURA 3.37 - Diagrama força-deslocamento para os ensaios da série A com e sem ferros-cabelo

FIGURA 3.38 - Descolamento máximo ocorrido na interface, localizado no canto inferior direito (tracionado), para os ensaios com ferros-cabelo (3A) e 4A) e sem ferros-cabelo (5A e $6 \mathrm{~A}$ ), para quatro níveis de carga.

FIGURA 3.39 - Diagrama força-deformação no extensômetro diagonal inferior (EXT 03) para ensaios com e sem ferros-cabelo.... 83

FIGURA 3.40 - Influência do tipo de argamassa utilizada para assentamento dos blocos e interface na rigidez de pórticos preenchidos com alvenaria

FIGURA 3.41 - Valor da dimensão da abertura do descolamento do canto inferior direito (tracionado) para ensaios com argamassa traço $1: 3: 7,5$ de cimento, cal e areia (1A e $2 \mathrm{~A}$ ) e com argamassa Ciment-cola (3A e 4A)

FIGURA 3.42 - Diagrama força-deformação no extensômetro diagonal inferior (EXT 03) para ensaios com argamassa traço $1: 3: 7,5$ de cimento, cal e areia (1A) e para argamassa Ciment-cola (4A).

FIGURA 3.43 - Diagrama força-deslocamento para o pórtico sem preenchimento e para os sistemas pórtico-parede ensaiados

FIGURA 3.44 - Modos de ruptura referentes aos dois primeiros ensaios: juntas de assentamento e interface de argamassa Cimentcola: a) ensaio $1 \mathrm{~B}$ e b) ensaio $2 \mathrm{~B}$.

FIGURA 3.45 - Modos de ruptura referentes aos ensaios de parede com abertura de 150 × $90 \mathrm{~cm}^{2}$ : a) ensaio 3B e b) ensaio 
FIGURA 3.46 - Diagrama força-deslocamento para os ensaios 1B e 2B, correspondentes as paredes sem abertura de blocos de CCA.

FIGURA 3.47 - Diagrama força $x$ deslocamento para os ensaios 3B e 4B, correspondentes as paredes com abertura, de blocos de CCA.

FIGURA 3.48 - Diagrama força-descolamento dos cantos tracionados: canto superior direito (Rel 01, DT 05, DT 04 e Rel 02).... 95

FIGURA 3.49 - Diagrama força-descolamento dos cantos tracionados: canto inferior esquerdo (Rel 03, Rel 04, Rel 05 e Rel 06).. 96

FIGURA 3.50 - Diagramas força-deformação diagonal central do painel (encurtamento) - Ensaios da série B (ensaios 1B e 2B)..... 98

FIGURA 3.51 - Diagramas força-deslocamento para os pórticos preenchidos com parede sem abertura (ensaios 1B e 2B) e com parede com abertura (ensaios 3B e 4B)

FIGURA 3.52 - Deslocamento relativo horizontal entre as faces verticais da abertura

FIGURA 3.53 - Deslocamento relativo vertical entre as faces horizontais da abertura

FIGURA 3.54 - Esquema do estado de tensões nos cantos da abertura: a) comportamento dos cantos e b) elementos diferenciais localizados nos cantos 1 e 2 e direção principal

FIGURA 3.55 - Descolamento máximo horizontal da interface pórticopainel.

FIGURA 3.56 - Diagramas força-deformação diagonal canto inferior direito do painel - Ensaios da série B

FIGURA 3.57 - Diagramas força-deslocamento para os sistemas $\mathrm{H} / \mathrm{L}=0,83$ - TIPO I (ensaios $5 \mathrm{~A}$ e $6 \mathrm{~A}$ ) e $\mathrm{H} / \mathrm{L}=0,51$ - TIPO II (ensaios 1B e 2B)

FIGURA 3.58 - Diagrama força-descolamento dos cantos tracionados: canto superior direito (Rel 01, DT 05, DT 04 e Rel 02).... 106

FIGURA 5.1 - Comportamento uniaxial dos materiais: a) elasticidade não-linear genérica, b) material elastoplástico perfeito, c) material com deformação plástica e encruamento e d) material com deformação plástica e amolecimento.

FIGURA 5.2 - Estratégias de modelagem para estruturas de alvenaria: a) alvenaria simples, b) micromodelagem detalhada, c) micromodelagem simplificada e d) macromodelagem. Fonte: LOURENÇO (1996) 
FIGURA 5.3 - Elemento finito utilizado para o pórtico de aço - Elemento finito plano para estado plano de tensões, de quatro nós, com integração de Gauss 2 x 2

FIGURA 5.4 - Elemento finito utilizado para painel de alvenaria Elemento finito plano de três nós para estado plano de tensões, com integração de um ponto de Gauss

FIGURA 5.5 - Elemento finito utilizado para as interfaces viga-pilar, pórtico-alvenaria e alvenaria-alvenaria. Elemento para estado plano de tensões, de quatro nós com dois pontos de integração de Lobatto.

FIGURA 5.6 - Elemento finito utilizado para a ligação protótipo-pórtico de reação (rolos): a) topologia, b) deslocamento e c) esforço.

FIGURA 5.7 - Superfície de plastificação dada pela combinação das superfícies Rankine e Von Mises

FIGURA 5.8 - Comportamento típico de materiais quasifrágeis submetidos à carregamento uniaxial e definição de energia de fratura: a) carregamento à tração e b) carregamento à compressão.

FIGURA 5.9 - Comportamento típico das juntas bloco-argamassa: a) ruptura por tração, modo I $\left(G_{f}^{I}\right)$ e b) ruptura por cisalhamento, modo II $\left(G_{f}^{I I}\right)$

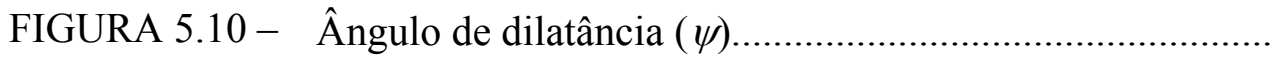

FIGURA 5.11 - Modelo geral para as interfaces desenvolvido por LOURENÇO (1996).

FIGURA 5.12 - Modelos utilizados para as interfaces nas análises numéricas realizadas nesta tese: a) interface alvenariaalvenaria e b) interface pórtico-alvenaria. Unidades: $\mathrm{N} / \mathrm{m}^{2}$

FIGURA 5.13 - Diagrama tensão-deformação uniaxial para o painel de alvenaria, na tração e na compressão.

FIGURA 5.14 - Malhas utilizadas na análise numérica do sistema TIPO I: a) painel de alvenaria, b) pórtico de aço, c) interfaces viga-pilar, pórtico-alvenaria e alvenaria-alvenaria e d) malha completa

FIGURA 5.15 - Resultados da análise numérica dos ensaios 5A e 6A: ação horizontal de $60 \mathrm{kN}$ : a) diagrama forçadeslocamento, b) deslocamentos incrementais, c) tensões principais máximas, d) tensões principais mínimas, e) deformações principais máximas e f) deformações principais mínimas. Unidades: (Newton e metro).

FIGURA 5.16 - Resultados da análise numérica dos ensaios 5A e 6A: 
ação horizontal de $175 \mathrm{kN}$ : a) diagrama forçadeslocamento, b) deslocamentos incrementais, c) tensões principais máximas, d) tensões principais mínimas, e) deformações principais máximas e f) deformações principais mínimas. Unidades: (Newton e metro).

FIGURA 5.17 - Resultados da análise numérica dos ensaios 5A e 6A: ação horizontal de $250 \mathrm{kN}$ : a) diagrama forçadeslocamento, b) deslocamentos incrementais, c) tensões principais máximas, d) tensões principais mínimas, e) deformações principais máximas e f) deformações principais mínimas. Unidades: (Newton e metro)

FIGURA 5.18 - Resultados da análise numérica dos ensaios 5A e 6A: ação horizontal de $316 \mathrm{kN}$ : a) diagrama forçadeslocamento, b) deslocamentos incrementais, c) tensões principais máximas, d) tensões principais mínimas, e) deformações principais máximas e f) deformações principais mínimas. Unidades: (Newton e metro)

FIGURA 5.19 - Diagramas força-deslocamento para os ensaios 5A e 6A, obtidos através dos ensaios experimentais e da modelagem numérica.

FIGURA 5.20 - Comprimento dos descolamentos verticais dos cantos tracionados.

FIGURA 5.21 - Comprimento de contato nas interfaces comprimidas pórtico-painel.

FIGURA 5.22 - Deformações principais máximas no canto inferior comprimido obtidas numérica e experimentalmente (ensaio 5A)

FIGURA 5.23 - Deformações principais mínimas no canto inferior comprimido, obtidas numérica e experimentalmente (ensaio 5A)

FIGURA 5.24 - Deformações principais máximas no canto superior comprimido, obtidas numérica e experimentalmente (ensaio 5A)

FIGURA 5.25 - Deformações principais mínimas no canto superior comprimido, obtidas numérica e experimentalmente (ensaio 5A)

FIGURA 5.26 - Malhas inicialmente utilizadas na análise numérica do sistema TIPO II, para a representação dos ensaios $1 \mathrm{~B}$ e 2B: a) painel de alvenaria; b) pórtico de aço; c) interfaces viga-pilar, pórtico-alvenaria e alvenaria-alvenaria e d) malha completa

FIGURA 5.27 - Tensões principais máximas resultantes da modelagem 
dos nsaios 1B e 2B. Unidades (Newton e metro)

FIGURA 5.28 - Malhas utilizadas na análise numérica do protótipo TIPO II: a) painel de alvenaria; b) pórtico de aço; c) interfaces viga-pilar, pórtico-alvenaria e alvenaria-alvenaria e d) malha completa.

FIGURA 5.29 - Resultados da análise numérica do sistema TIPO II Ensaios 1B e 2B, para uma ação de $40 \mathrm{kN}$.

FIGURA 5.30 - Resultados da análise numérica do sistema TIPO II Ensaios 1B e 2B, para uma ação horizontal de $40 \mathrm{kN}$ : a) tensões principais máximas, b) tensões principais mínimas, c) deformacões principais máximas e d) deformações principais mínimas. Unidades: ( Newton e metro).

FIGURA 5.31 - Resultados da análise numérica do sistema TIPO II Ensaios 1B e 2B, para uma ação de $100 \mathrm{kN}$.

FIGURA 5.32 - Resultados da análise numérica do sistema TIPO II Ensaios 1B e 2B, para uma ação horizontal de $100 \mathrm{kN}$ : a) tensões principais máximas, b) tensões principais mínimas, c) deformações principais máximas e d) deformações principais mínimas. Unidades: ( Newton e metro).

FIGURA 5.33 - Resultados da análise numérica do sistema TIPO II Ensaios 1B e 2B, para uma ação de 172 kN.

FIGURA 5.34 - Resultados da análise numérica do sistema TIPO II Ensaios 1B e 2B, para uma ação horizontal de $172 \mathrm{kN}$ : a) tensões principais máximas, b) tensões principais mínimas, c) deformações principais máximas e d) deformações principais mínimas. Unidades: ( Newton e metro)

FIGURA 5.35 - Resultados da análise numérica do sistema TIPO II Ensaios 1B e 2B, para uma ação de $242 \mathrm{kN}$

FIGURA 5.36 - Resultados da análise numérica do sistema TIPO II Ensaios 1B e 2B, para uma ação horizontal de $242 \mathrm{kN}$ : a) tensões principais máximas, b) tensões principais mínimas, c) deformações principais máximas e d) deformações principais mínimas. Unidades: (Newton e metro)

FIGURA 5.37 - Resultados da análise numérica do sistema TIPO II Ensaios 1B e 2B, para uma ação de $40 \mathrm{kN}$

FIGURA 5.38 - Resultados da análise numérica do sistema TIPO II Ensaios 1B e 2B, para uma ação horizontal de $40 \mathrm{kN}$ : a) tensões principais máximas, b) tensões principais 
mínimas, c) deformações principais máximas e d) deformações principais mínimas. Unidades: (Newton e metro)

FIGURA 5.39 - Resultados da análise numérica do sistema TIPO II Ensaios 1B e 2B, para uma ação de $100 \mathrm{kN}$

FIGURA 5.40 - Resultados da análise numérica do sistema TIPO II ensaios 1B e 2B, para uma ação horizontal de100 kN: a) tensões principais máximas, b) tensões principais mínimas, c) deformações principais máximas e d) deformações principais mínimas. Unidades: (Newton e metro)

FIGURA 5.41 - Resultados da análise numérica do sistema TIPO II ensaios 1B e 2B, para uma ação de $172 \mathrm{kN}$..

FIGURA 5.42 - Resultados da análise numérica do sistema TIPO II ensaios 1B e 2B, para uma ação horizontal de 172 kN: a) tensões principais máximas, b) tensões principais mínimas, c) deformações principais máximas e d) deformações principais mínimas. Unidades: (Newton e metro)

FIGURA 5.43 - Resultados da análise numérica do sistema TIPO II Ensaios 1B e 2B, para uma ação de $268 \mathrm{kN}$

FIGURA 5.44 - Resultados da análise numérica do sistema TIPO II Ensaios 1B e 2B, para uma ação horizontal de 268 kN: a) tensões principais máximas, b) tensões principais mínimas, c) deformações principais máximas e d) deformações principais mínimas. Unidades: (Newton e metro)

FIGURA 5.45 - Diagramas força $\mathrm{x}$ deslocamento para os ensaios 1B e 2B, obtidos através dos ensaios experimentais e da modelagem numérica

FIGURA 5.46 - Comprimento do deslocamento, sistemas TIPO II e ensaios $1 \mathrm{~B}$ e $2 \mathrm{~B}$.

FIGURA 5.47 - Comprimento do deslocamento, sistemas TIPO II e ensaios $1 \mathrm{~B}$ e $2 \mathrm{~B}$......

FIGURA 5.48 - Comprimento de contato nas interfaces comprimidas pórtico-painel.

FIGURA 5.49 - Deformações principais máximas no canto inferior comprimido, obtidas numérica e experimentalmente (ensaio 1B)

FIGURA 5.50 - Deformações principais mínimas no canto inferior comprimido, obtidas numérica e experimentalmente 
(ensaio 1B)

FIGURA 5.51 - Deformações principais máximas no canto superior comprimido, obtidas numérica e experimentalmente (ensaio 1B)

FIGURA 5.52 - Deformações principais mínimas no canto superior comprimido, obtidas numérica e experimentalmente (ensaio 1B)

FIGURA 5.53 - Malhas utilizadas na análise numérica do sistema TIPO II, para a representação dos ensaios 3B e 4B: a) painel de alvenaria; b) pórtico de aço; c) interfaces viga-pilar, pórtico-alvenaria e alvenaria-alvenaria; e d) malha completa.

FIGURA 5.54 - Resultados da análise numérica do sistema TIPO II Ensaios 3B e 4B, para uma ação de $18,3 \mathrm{kN}$

FIGURA 5.55 - Resultados da análise numérica do sistema TIPO II Ensaios 3B e 4B, para ação horizontal de 18,3 kN: a) tensões principais máximas, b) tensões principais mínimas, c) deformações principais máximas e d) deformações principais mínimas.

FIGURA 5.56 - Resultados da análise numérica do sistema TIPO II Ensaios 3B e 4B, para uma ação de 40 kN.

FIGURA 5.57 - Resultados da análise numérica do sistema TIPO II Ensaios 3B e 4B, para ação horizontal de $40 \mathrm{kN}$ : a) tensões principais máximas, b) tensões principais mínimas, c) deformações principais máximas e d) deformações principais mínimas.

FIGURA 5.58 - Resultados da análise numérica do sistema TIPO II Ensaios 3B e 4B, para uma ação de $160 \mathrm{kN}$.

FIGURA 5.59 - Resultados da análise numérica do sistema TIPO II Ensaios 3B e 4B, para ação horizontal de $160 \mathrm{kN}$ : a) tensões principais máximas, b) tensões principais mínimas, c) deformações principais máximas e d) deformações principais mínimas.

FIGURA 5.60 - Resultados da análise numérica do sistema TIPO II Ensaios 3B e 4B, para uma ação de $240 \mathrm{kN}$.

FIGURA 5.61 - Resultados da análise numérica do sistema TIPO II Ensaios 3B e 4B, para ação horizontal de $240 \mathrm{kN}$ : a) tensões principais máximas, b) tensões principais mínimas, c) deformações principais máximas e d) deformações principais mínimas.

FIGURA 5.62 - Malhas utilizadas na análise numérica do sistema TIPO 
II, para a representação dos ensaios 3B e 4B: a) alvenaria, verga e contraverga; b) pórtico de aço; c) interfaces verga-alvenaria, contraverga-alvenaria, viga-pilar e 206 pórtico-alvenaria; e d) malha completa..

FIGURA 5.63 - Resultados da análise numérica do sistema TIPO II Ensaios 3B e 4B, para uma ação de 23,3 kN.

FIGURA 5.64 - Resultados da análise numérica do sistema TIPO II Ensaios 3B e 4B, para ação horizontal de $23,3 \mathrm{kN}$ : a) tensões principais máximas, b) tensões principais mínimas, c) deformações principais máximas e d) deformações principais mínimas.

FIGURA 5.65 - Resultados da análise numérica do sistema TIPO II Ensaios 3B e 4B, para uma ação de 41,3 kN.

FIGURA 5.66 - Resultados da análise numérica do sistema TIPO II Ensaios 3B e 4B, para ação horizontal de 41,3 kN: a) tensões principais máximas, b) tensões principais mínimas, c) deformações principais máximas e d) deformações principais mínimas.

FIGURA 5.67 - Resultados da análise numérica do sistema TIPO II Ensaios 3B e 4B, para uma ação de $76,5 \mathrm{kN}$.

FIGURA 5.68 - Resultados da análise numérica do sistema TIPO II Ensaios 3B e 4B, para ação horizontal de $76,5 \mathrm{kN}$ : a) tensões principais máximas, b) tensões principais mínimas, c) deformações principais máximas e d) deformações principais mínimas.

FIGURA 5.69 - Resultados da análise numérica do sistema TIPO II Ensaios 3B e 4B, para uma ação de 188 kN.

FIGURA 5.70 - Resultados da análise numérica do sistema TIPO II Ensaios 3B e 4B, para uma ação de $188 \mathrm{kN}$ : a) tensões principais máximas, b) tensões principais mínimas, c) deformações principais máximas e d) deformações principais mínimas.

FIGURA 5.71 - Diagrama força-deslocamento para o sistema TIPO II Ensaios 3B e 4B, primeira e segunda modelagens.

FIGURA 6.1 - Modelos de sistemas de pórticos-preenchidos utilizados no estudo paramétrico.

FIGURA 6.2 - Diagrama força-deslocamento para diferentes relações $\mathrm{H} / \mathrm{L}$ e ligações viga-pilar articuladas

FIGURA 6.3 - Diagrama força-deslocamento para diferentes relações $\mathrm{H} / \mathrm{L}$ e ligações viga-pilar semi-rígidas.

FIGURA 6.4 - Diagrama força-deslocamento para diferentes relações 
$\mathrm{H} / \mathrm{L}$ e ligações viga-pilar rígidas.

FIGURA 6.5 - Diagrama força-deslocamento para diferentes relações $\mathrm{H} / \mathrm{L}$ e diferentes rigidezas para as ligações viga-pilar..

FIGURA 6.6 - Forças correspondentes à fissuração da diagonal para as relações $\mathrm{H} / \mathrm{L}$ analisadas.

FIGURA 6.7 - Forças correspondentes ao esmagamento dos cantos comprimidos para as relações $\mathrm{H} / \mathrm{L}$ analisadas.

FIGURA 6.8 - Forças correspondentes ao esmagamento dos cantos comprimidos para as relações $\mathrm{H} / \mathrm{L}$ analisadas.

FIGURA 6.9 - Diagrama força-deslocamento para diferentes relações $\mathrm{H} / \mathrm{L}$ e diferentes módulos de deformação para alvenaria.... 230

FIGURA 6.10 - Diagrama força-deslocamento para diferentes relações H/L e diferentes módulos de deformação para alvenaria.... 231

FIGURA 7.1 - Sistema pórtico-parede submetido a uma ação diagonal $\mathrm{F} / \cos \theta$..

FIGURA 7.2 - Distribuição triangular de tensões no comprimento de contato pórtico-painel.

FIGURA 7.3 - Modelo de bielas e tirantes para a representação do painel de alvenaria.

FIGURA 7.4 - Distribuição de tensões de tração no centro do painel.

FIGURA 7.5 - Obtenção da tensão de esmagamento no centro do painel, considerando-se a tensão efetiva nesta região.

FIGURA 7.6 - Análise comparativa dos resultados obtidos das diversas relações $\mathrm{H} / \mathrm{L}$ analisadas - Força de fissuração da diagonal $\mathrm{H} / \mathrm{L}=0,51-\mathrm{f}_{\mathrm{t}}=0,13 \mathrm{MPa}$, nas demais relações $\mathrm{H} / \mathrm{L}$ $\mathrm{f}_{\mathrm{t}}=0,26 \mathrm{MPa}$

FIGURA 7.7 - Análise comparativa dos resultados obtidos das diversas relações H/L analisadas - Forças de esmagamento dos cantos comprimidos

FIGURA 7.8 - Análise comparativa dos resultados obtidos para módulos de deformação da alvenaria iguais a $875 \mathrm{MPa}, 1312,5$ $\mathrm{MPa}, 1750 \mathrm{MPa}, 2625 \mathrm{MPa}$ e $3500 \mathrm{MPa}$ - Força de fissuração da diagonal

FIGURA 7.9 - Análise comparativa dos resultados obtidos para módulos de deformação da alvenaria iguais a $875 \mathrm{MPa}, 1312,5$ $\mathrm{MPa}, 1750 \mathrm{MPa}, 2625 \mathrm{MPa}$. e $3500 \mathrm{MPa}-$ Esmagamento dos cantos comprimidos

FIGURA 7.10 - Força de esmagamento nos cantos comprimidos, considerando-se as ligações viga-pilar: articuladas, semi- 
rígidas e rígidas

FIGURA 7.11 - Comparação entre os valores obtidos para a força correspondente à fissuração da diagonal através do modelo experimental de BRAGUIM (1989), dos modelos teóricos e da proposta desta tese

FIGURA 7.12 - Comparação entre os valores obtidos para a força correspondente ao esmagamento dos cantos comprimidos através do modelo experimental de BRAGUIM (1989), dos modelos teóricos e da proposta desta tese

FIGURA 7.13 - Pórtico analisado: a) geometria e b) seção transversal dos pilares.

FIGURA 7.14 - Comparação entre os valores obtidos para a força correspondente à fissuração da diagonal através dos modelos teóricos e da proposta desta tese, para um pórtico de três pavimentos de concreto armado.

FIGURA 7.15 - Comparação entre os valores obtidos para a força correspondente ao esmagamento dos cantos comprimidos, através dos modelos teóricos e da proposta desta tese, para um pórtico de três pavimentos de concreto armado....

FIGURA 7.16 - Tramo de pórtico preenchido com alvenaria submetido a carregamento diagonal

FIGURA 7.17 - Diagrama genérico força $\mathrm{x}$ deslocamento para pórticos preenchidos: (-) modelagem numérica não-linear do sistema pórtico-painel e (-) modelagem numérica linear do pórtico com diagonal birrotulada equivalente.

FIGURA 7.18 - Largura da diagonal equivalente correspondente ao início do carregamento.

FIGURA 7.19 - Largura da diagonal equivalente correspondente à força de fissuração: modelo proposto, análise linear e modelo de Hendry - Ealvenaria=875 MPa, $1312,5 \mathrm{MPa}, 1750$ $\mathrm{MPa}, 2625 \mathrm{MPa}$ e $3500 \mathrm{MPa}$.

FIGURA 8.1 - Edifício idealizado por BRAGUIM (1989) - a) arranjo em planta das vigas e colunas, b) arranjo das paredes resistentes à esforços horizontais, c) vista transversal e d) vista longitudinal.

FIGURA 8.2 - Edifício idealizado por BRAGUIM (1989) - Ações devidas ao vento, segundo prescrições da NBR 6123

FIGURA A.1 - Painéis pré-fabricados armados de CCA: a) perspectiva, b) seção transversal e c) armadura.

FIGURA A.2 - Modos de ruptura referentes aos ensaios de parede com painéis pré-fabricados armados de CCA: a) ensaio 5B e b) ensaio 6B. 
FIGURA A.3 - Diagrama força-deslocamento dos ensaios 5B e 6B, correspondentes a painéis pré-moldados armados de CCA 285

FIGURA A.4 - Análise comparativa entre os diagramas forçadeslocamento para os ensaios com blocos (ensaios $1 \mathrm{~B}$ e 2B) e com painéis pré-fabricados (5B e $6 \mathrm{~B})$.

FIGURA B.1 - Conversor de dados A/D............................................. 288

FIGURA D.1 - Disposição da instrumentação para medida dos descolamentos.

FIGURA D.2 - Diagrama força-descolamento do canto superior esquerdo tracionado (Rel 01, DT 05, DT 04 e Rel 02)..................... 300

FIGURA D.3 - Diagrama força-descolamento do canto inferior direito tracionado (Rel 03, Rel 04, Rel 05 e Rel 06) ............... 301

FIGURA D.4 - Diagrama força-descolamento do canto superior esquerdo tracionado (Rel 01, DT 05, DT 04 e Rel 02)

FIGURA D.5 - Diagrama força-descolamento do canto inferior direito tracionado (Rel 03, Rel 04, Rel 05 e Rel 06)

FIGURA E.1 - Diagrama força-deformação vertical no canto inferior comprimido (extensômetro 01).

FIGURA E.2 - Diagrama força-deformação horizontal e diagonal no canto inferior comprimido (EXT 02 e 03) e diagonal central (EXT 04)

FIGURA E.3 - Diagrama força-deformação nas direções horizontal, vertical e diagonal do canto superior direito do painel (EXT 05, EXT 06, EXT 07)...

FIGURA E.4 - Diagrama força-deformação nas direções vertical e diagonal do canto inferior direito do painel (EXT 02, EXT 03) e diagonal central comprimida (EXT 04).

FIGURA E.5 - Diagrama força-deformação nas direções horizontal, vertical e diagonal do canto inferior direito do painel (EXT 05, EXT 06, EXT 07)

FIGURA F.1 - Formulação incremental direta........................................... 319

FIGURA F.2 - Formulação iterativa - Técnica de Newton Raphson......... 321

FIGURA F.3 - Curvas força $\mathrm{x}$ deslocamento(a) contínuo e monotonicamente crescente e b) errático.......................... 322

FIGURA F.4 - Método do controle de deslocamento ("arc-length control"): a) "snap-Through" 


\section{LISTA DE TABELAS}

TABELA 2.1 - Aproximação Empírica para obtenção da largura da diagonal equivalente (MAINSTRONE,1971).................. 26

TABELA 3.1 - Características dos ensaios de pórticos preenchidos realizados................................................................. 34

TABELA 3.2 - Características geométricas do pórtico TIPO I.................. 38

TABELA 3.3 - Características geométricas do pórtico TIPO II................. 41

TABELA 3.4 - Características Geométricas do pórtico de reação............... 48

TABELA 3.5 - Deslocamentos obtidos nos seis ensaios da série A para um ação de 50 kN aplicada................................................ 64

TABELA 3.6 - $\quad$ Rigidez obtida nos seis ensaios da série A para uma ação de $50 \mathrm{kN}$ aplicada ...................................................... 65

TABELA 3.7 - Cargas de ruptura e deslocamentos laterais globais do conjunto.

TABELA 4.1 - Deslocamentos laterais teóricos dos protótipos TIPO I e TIPO II $(\mathrm{cm} / \mathrm{kN})$.

TABELA 4.2 - Quadro-resumo das cargas de ruptura teóricas do protótipo TIPO I..............................................................

TABELA 4.3 - Quadro-resumo das cargas de ruptura teóricas do protótipo TIPO II.............................................................

TABELA 4.4 - Quadro-resumo das cargas de ruptura do painel de alvenaria obtidas através de análises experimental e téorica, na série de ensaios A..

TABELA 4.5 - Quadro-resumo das cargas de ruptura do painel de alvenaria obtidas através de análises experimental e téorica, na série de ensaios B

TABELA 5.1 - Propriedades dos materiais utilizados na análise numérica

TABELA 5.2 - Valores da rigidez obtida nos ensaios experimentais e nas modelagens numéricas realizadas $(\mathrm{kN} / \mathrm{mm})$.

TABELA 6.1 - Forças correspondentes aos modos de ruptura para cada uma das relações $\mathrm{H} / \mathrm{L}$ (unidade $\mathrm{kN}$ ).

TABELA 6.2 - Forças correspondentes aos modos de ruptura para cada umo das raloñ̃as $H / T$ a nom um das módulos da 
uma das relações $\mathrm{H} / \mathrm{L}$ e para um dos módulos de deformação adotados para o painel de alvenaria (unidade $\mathrm{kN})$

TABELA 7.1 - Acréscimo da força de esmagamento em relação à ligação articulada (\%), para ligações viga-pilar semi-rígidas e rígidas.

TABELA 7.2 - Valores dos parâmetros de rigidez relativa e comprimentos de contato para os pórticos analisados, relativos a cada um dos módulos de deformação da alvenaria utilizados no estudo paramétrico

TABELA 7.3 - Valores das cargas de ruptura obtidos nos ensaios experimentais, na modelagem numérica, nos métodos teóricos da literatura e na proposta deste trabalho $(\mathrm{kN})$

TABELA 7.4 - $\quad$ Relação entre os valores das forças de ruptura obtidos nos ensaios experimentais, na modelagem numérica e nos métodos teóricos da literatura e os valores obtidos na proposta do presente trabalho

TABELA 7.5 - Características dos elementos componentes dos pórticos ensaiados.

TABELA 7.6 - Características elástico-geométricas do pórtico de concreto e do painel de alvenaria.

TABELA 7.7 - Cargas de ruptura por fissuração da diagonal e por esmagamento dos cantos comprimidos para as análises efetuadas. Unidade: $(\mathrm{kN})$

TABELA 7.8 - Valores obtidos para a largura da diagonal equivalente a partir da análise numérica linear, para a força correspondente à fissuração da diagonal.

TABELA 7.9 - $\quad$ Largura da diagonal equivalente correspondente à força de fissuração da diagonal segundo a proposta apresentada, a análise numérica linear e a proposta de Hendry

TABELA 7.10 - Relação entre a largura da diagonal equivalente correspondente à força de fissuração da diagonal, segundo a proposta apresentada e a análise numérica linear efetuada, e entre a proposta apresentada e a proposta de Hendry

TABELA $8.1-$ Seções transversais de vigas e pilares.

TABELA B.1 Calibração do transdutor de pressão

TABELA C.1 - Resultados obtidos para os ensaios de prismas à compressão. 
TABELA C.3 - Resultados dos ensaios de compressão em cilindros de argamassa......

TABELA C.4 - Resultados dos ensaios de tração por compressão diametral em cilindros de argamassa de $10 \times 20 \mathrm{~cm}^{2}$

TABELA C.5 - Obtenção do módulo de deformação para prismas de argamassa Ciment-cola.

TABELA E.1 - Deformação nos cantos comprimidos dos painéis nos ensaios realizados

TABELA E.2 Tensões e deformações principais nos cantos comprimidos dos painéis obtidos nos ensaios realizados... 310

TABELA E.3 -

TABELA E.3

TABELA E.4 -

TABELA G.1 -

TABELA G.2 Deformação nos cantos comprimidos dos painéis nos ensaios realizados.

Tensões e deformações principais nos cantos comprimidos dos painéis obtidos nos ensaios realizados...

Valores das cargas de ruptura obtidos pelo método proposto, pelas modelagens numéricas e pelos métodos teóricos da literatura, para módulo de deformação da alvenaria igual a $875 \mathrm{MPa}$. Unidade $(\mathrm{kN})$.

Relação entre os valores das forças de ruptura obtidos na modelagem numérica e nos métodos teóricos da literatura e os valores obtidos na proposta apresentada neste trabalho - Mod. Deform. Alvenaria $=875 \mathrm{MPa}$

TABELA G.3 - Valores das cargas de ruptura obtidos pelo método proposto, pelas modelagens numéricas e pelos métodos teóricos da literatura, para módulo de deformação da alvenaria igual a $1312,5 \mathrm{MPa}$. Unidade $(\mathrm{kN})$

TABELA G.4 - Relação entre os valores das forças de ruptura obtidos na modelagem numérica e nos métodos teóricos da literatura e os valores obtidos na proposta apresentada neste trabalho. Relação entre os métodos teóricos - Mod. deform. alvenaria $=1312,5 \mathrm{MPa}$

TABELA G.5 - Valores das cargas de ruptura obtidos pelo método proposto, pelas modelagens numéricas e pelos métodos teóricos da literatura, para módulo de deformação da alvenaria igual a $1750 \mathrm{MPa}$. Unidade $(\mathrm{kN})$.

TABELA G.6 - Relação entre os valores das forças de ruptura obtidos na modelagem numérica e nos métodos teóricos da literatura e os valores obtidos na proposta apresentada neste trabalho. Relação entre os métodos teóricos - Mod. deform. alvenaria $=1750 \mathrm{MPa}$

TABELA G.7 - Valores das cargas de ruptura obtidos pelo método proposto, pelas modelagens numéricas e pelos métodos 
teóricos da literatura, para módulo de deformação da alvenaria igual a $2625 \mathrm{MPa}$. Unidade $(\mathrm{kN})$

TABELA G.8 - Relação entre os valores das forças de ruptura obtidos na modelagem numérica e nos métodos teóricos da literatura e os valores obtidos na proposta apresentada neste trabalho. Relação entre os métodos teóricos - Mod. deform. alvenaria $=2625 \mathrm{MPa}$

TABELA G.9 - Valores das cargas de ruptura obtidos pelo método proposto, pelas modelagens numéricas e pelos métodos teóricos da literatura, para módulo de deformação da alvenaria igual a $3500 \mathrm{MPa}$. Unidade $(\mathrm{kN})$

TABELA G.10 - Relação entre os valores das forças de ruptura obtidos na modelagem numérica e nos métodos teóricos da literatura e os valores obtidos na proposta apresentada neste trabalho. Relação entre os métodos teóricos - Mod. Deform. Alvenaria $=3500 \mathrm{MPa}$ 


\section{LISTA DE SIGLAS E ABREVIATURAS}

$\begin{array}{ll}\text { CCA Concreto Celular Autoclavado } \\ \text { ASTM "American Society for Testing and Materials" } \\ \text { EPT } & \text { Estado Plano de Tensão } \\ \text { MEF } & \text { Método dos Elementos Finitos } \\ \text { DT } & \text { Transdutor de Deslocamento } \\ \text { EXT } & \text { Extensômetro } \\ \text { CP } & \text { Corpo-de-Prova }\end{array}$




\section{LISTA DE SÍMBOLOS}

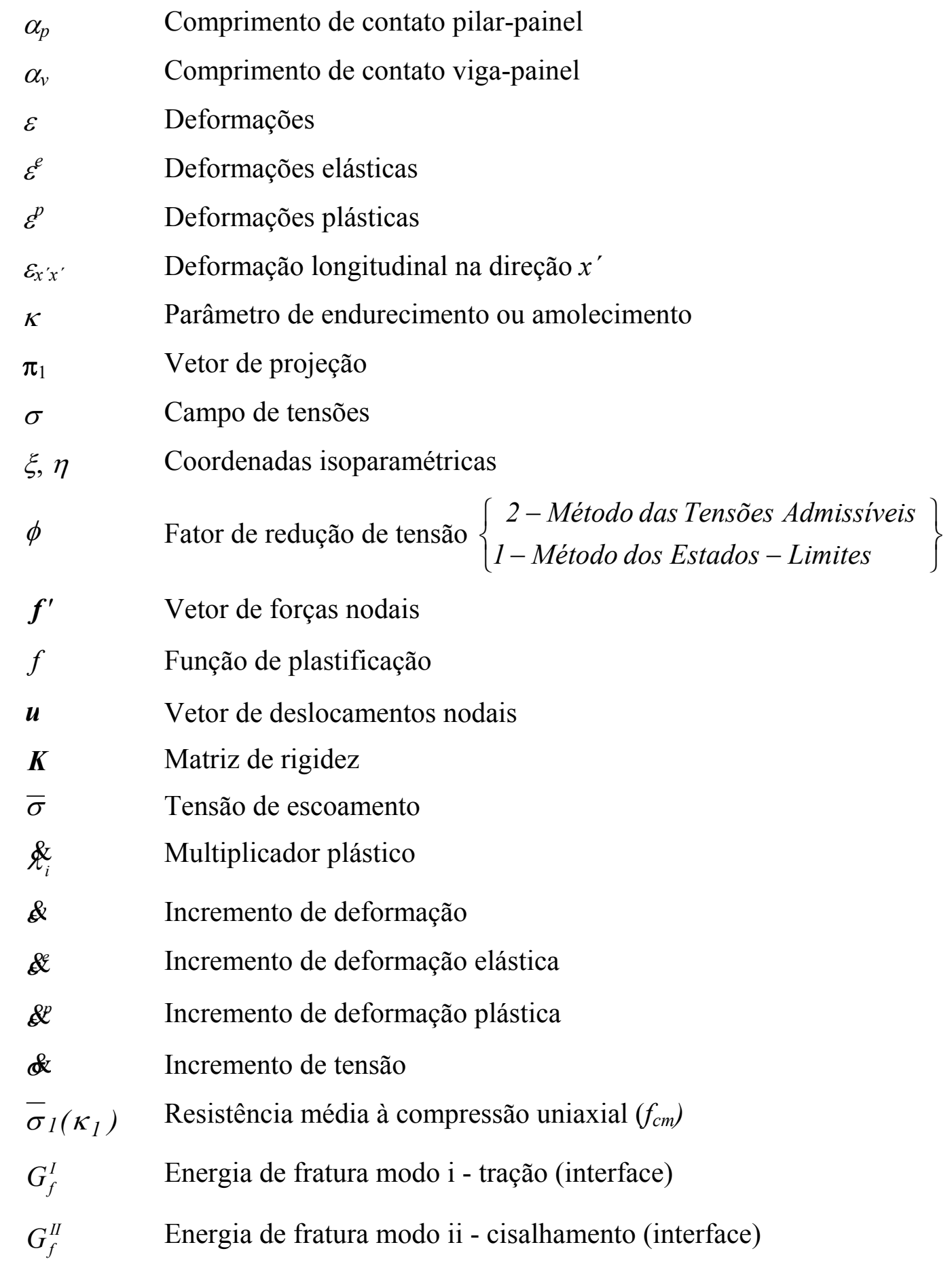




\begin{tabular}{|c|c|}
\hline$f_{c}^{*}$ & Resistência à compressão da alvenaria em estado biaxial \\
\hline$R_{g}$ & Resistência interna de fabricação do instrumento \\
\hline$R_{\text {cal }}$ & Resistência da placa do sistema de aquisição de dados \\
\hline$k^{\prime}$ & Constante do instrumento \\
\hline$\theta$ & Ângulo de inclinação da diagonal do painel com a horizontal \\
\hline$\alpha$ & Comprimento de contato da viga com o painel \\
\hline$\mu$ & Coeficiente de atrito da argamassa \\
\hline$\phi$ & Ângulo de atrito entre as superfícies \\
\hline$\psi$ & Ângulo de dilatância \\
\hline$\eta$ & Relação entre as duas tensões principais \\
\hline$\beta$ & $\begin{array}{l}\text { Coeficiente de majoração da força de esmagamento dos cantos } \\
\text { comprimidos, em função da rigidez da ligação viga-pilar }\end{array}$ \\
\hline$\theta^{\prime}$ & Ângulo de inclinação da diagonal do pórtico com a horizontal \\
\hline$\varepsilon_{1}, \varepsilon_{2}$ & Deformações principais \\
\hline$\sigma_{1}, \sigma_{2}$ & Tensões principais \\
\hline$v_{a l v}$ & Coeficiente de poisson da alvenaria \\
\hline$\sigma_{c}$ & Tensão de compressão no centro do painel \\
\hline$v_{c}^{*}$ & Fator de eficiência para resistência efetiva à compressão \\
\hline$\sigma_{c c}$ & $\begin{array}{l}\text { Tensão de compressão no centro do elemento finito situado em um } \\
\text { canto comprimido }\end{array}$ \\
\hline$\tau_{x y}$ & Tensão de cisalhamento no centro do painel \\
\hline$\Delta d$ & Variação de comprimento da diagonal \\
\hline$\sigma_{d t}$ & Tensão de tração na diagonal no centro do painel \\
\hline$\lambda l^{\prime}$ & Parâmetro de rigidez relativa \\
\hline$\sigma_{n}$ & Tensão normal \\
\hline$\theta_{p}$ & Direções principais (entre $0^{\circ}$ e $90^{\circ}$ e entre $90^{\circ}$ e $180^{\circ}$ ) \\
\hline$v_{s}$ & Coeficiente de Poisson do aço \\
\hline$\sigma_{t}$ & Tensão tangencial \\
\hline$v_{t}^{*}$ & Fator de eficiência para a resistência efetiva à tração \\
\hline$\sigma_{x x}$ & Tensão normal na direção x \\
\hline$\varepsilon_{x x}$ & Deformação longitudinal na direção $\mathrm{x}$ \\
\hline$\varepsilon_{x y}$ & Distorção entre os eixos x e y \\
\hline
\end{tabular}




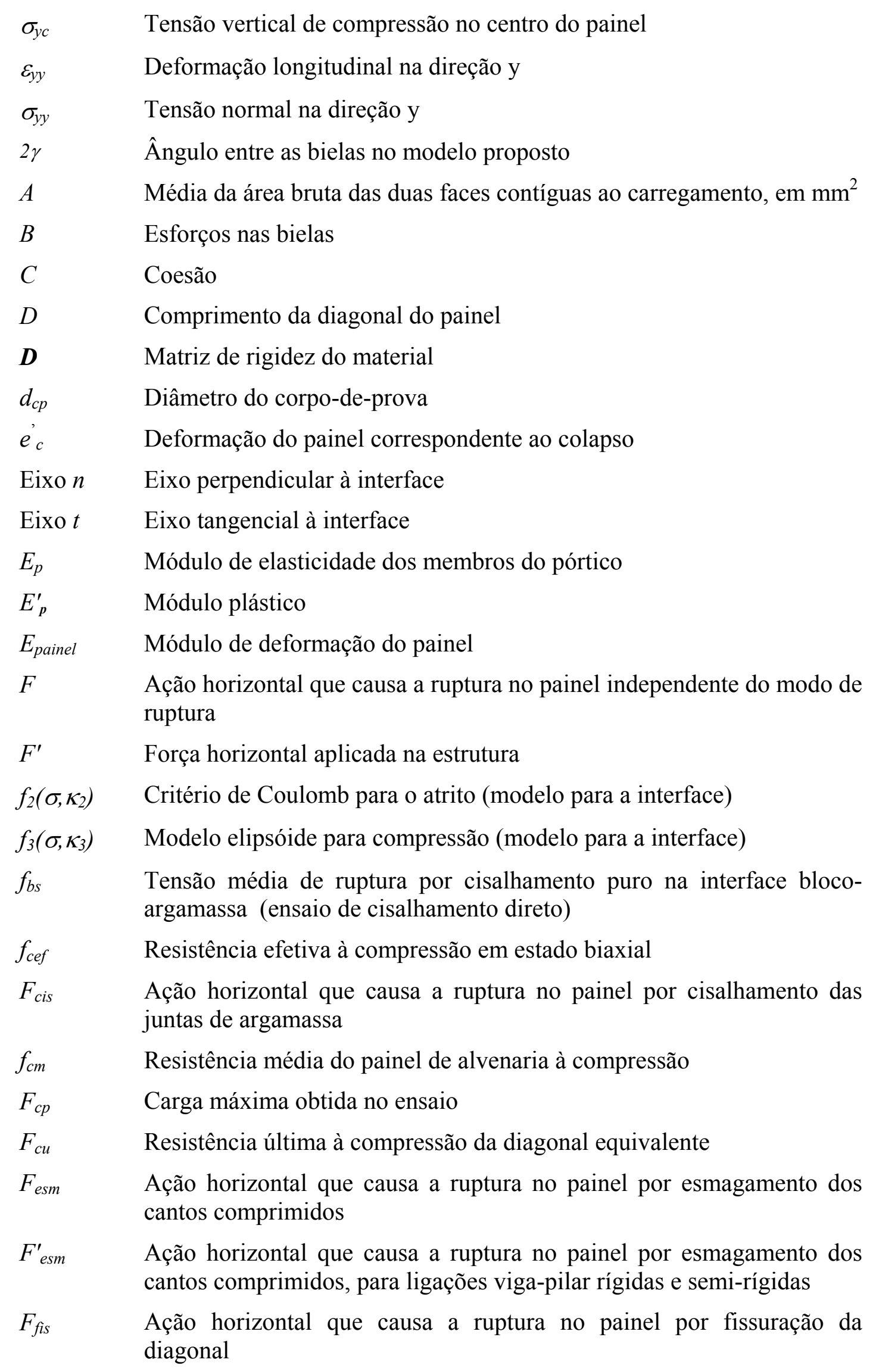




\begin{tabular}{|c|c|}
\hline$f_{k c}$ & Resistência característica à compressão do painel \\
\hline$f_{s}$ & Resistência ao cisalhamento do painel de alvenaria \\
\hline$f_{t}$ & Resistência média do painel de alvenaria à tração \\
\hline$f_{t}\left(\sigma, \kappa_{l}\right)$ & Limitador de tração, modelo para a interface ("tension cut-off") \\
\hline$F_{t d}$ & $\begin{array}{l}\text { Resistência à tração por compressão diametral, expresso em mpa, com } \\
\text { aproximação de } 0,05\end{array}$ \\
\hline$f_{\text {tef }}$ & Resistência efetiva à tração da alvenaria \\
\hline$f_{v k o}$ & Resistência característica ao cisalhamento puro \\
\hline$F_{x}$ & Força axial na direção $\mathrm{x}$ \\
\hline$G_{c}$ & Energia de fratura à compressão para blocos de alvenaria \\
\hline$G_{f}$ & Energia de fratura à tração para blocos de alvenaria \\
\hline$g_{i}$ & Função plástica potencial \\
\hline$h$ & Altura do painel \\
\hline$H$ & Altura do pórtico \\
\hline$h_{d}$ & Altura da diagonal equivalente \\
\hline$I_{o}$ & Momentos de inércia da viga do pórtico \\
\hline$I_{p}$ & Momentos de inércia dos membros do pórtico \\
\hline$I_{p^{\prime}}$ & Momentos de inércia das colunas do pórtico \\
\hline$J_{2}$ & Segundo invariante do tensor desviador \\
\hline$K_{1}, k_{2}, k_{3}$ & Rigidezas dos apoios elásticos (protótipo-pórtico de reação) \\
\hline$K_{a l v}$ & Rigidez da interface alvenaria-alvenaria \\
\hline$K_{\text {palv }}$ & Rigidez inelástica das interfaces viga-alvenaria e pilar-alvenaria \\
\hline$K_{v p}$ & Rigidez das ligações viga-pilar \\
\hline$L$ & Comprimento do pórtico \\
\hline$l$ & Comprimento do painel \\
\hline$L^{\prime}$ & Comprimento do pilar entre eixos \\
\hline$l_{c p}$ & Altura do corpo de prova \\
\hline$m$ & $\begin{array}{l}\text { Coeficiente de majoração da tensão de compressão devido ao estado } \\
\text { biaxial de compressão }\end{array}$ \\
\hline $\boldsymbol{P}_{r a}$ & Matriz de projeção segundo Rankine \\
\hline $\boldsymbol{P}_{v m}$ & Matriz de projeção segundo Von Mises \\
\hline$p_{x}$ & $\begin{array}{l}\text { Ordenada máxima da força por unidade de comprimento, distribuída no } \\
\text { comprimento } \alpha \text {, na direção } \mathrm{x}\end{array}$ \\
\hline$P_{y}$ & $\begin{array}{l}\text { Ordenada máxima da força por unidade de comprimento, distribuída no } \\
\text { comprimento } \alpha \text {, na direção y }\end{array}$ \\
\hline
\end{tabular}


$R \quad$ Força resultante na direção da diagonal

$r \quad$ Fator de rigidez para ligação viga-pilar $(1 \geq \mathrm{r} \geq 0)$

$R_{\text {cis }} \quad$ Ação diagonal que causa a ruptura no painel por cisalhamento das juntas de argamassa

$R_{\text {esm }} \quad$ Ação diagonal que causa a ruptura no painel por esmagamento dos cantos comprimidos

$R_{\text {fis }} \quad$ Ação diagonal que causa a ruptura no painel por fissuração da diagonal

Área da seção transversal

$t \quad$ Espessura do painel

Esforços no tirante

t Tração nos elementos de interface

$u_{x} \quad$ Deslocamento do nó, na direção $x$ ou polinômio de deslocamento

$u_{y} \quad$ Deslocamento do nó, na direção $y$ ou polinômio de deslocamento

$w \quad$ Largura da diagonal equivalente

$w_{e c}^{\prime} \quad$ Largura da diagonal equivalente uniformemente tracionada para avaliar a resistência última do pórtico preenchido

$w^{\prime}{ }_{e k} \quad$ Largura da diagonal equivalente uniformemente tracionada para avaliar a rigidez do pórtico preenchido

$w_{e t}^{\prime} \quad$ Largura da diagonal equivalente uniformemente tracionada para avaliar a carga correspondente à primeira fissura do painel 


\title{
RESUMO
}

\author{
ALVARENGA, R.C.S.S. (2001). Análise teórico-experimental de estruturas \\ compostas de pórticos preenchidos com alvenaria. São Carlos, 2001. 342p. Tese \\ (Doutorado) - Escola de Engenharia de São Carlos, Universidade de São Paulo.
}

Apresenta-se neste trabalho um estudo sobre o comportamento de estruturas de pórticos preenchidos por painéis de alvenaria submetidos a ações horizontais, considerando a contribuição da alvenaria na rigidez global da estrutura. Este estudo envolveu uma série de ensaios experimentais com protótipos de aço em escala real, utilizando-se blocos de concreto celular autoclavados; a macromodelagem numérica pelo método dos elementos finitos; a aplicação do conceito da diagonal equivalente; e a realização de um estudo paramétrico, considerando-se pórticos com diferentes relações altura/comprimento, visando à obtenção de recomendações práticas para análise de pórticos preenchidos. Essas recomendações são apresentadas na forma de uma proposta para determinação da carga de ruptura em painéis de pórticos preenchidos com alvenaria, utilizando-se o modelo de bielas e tirantes. Os resultados obtidos com a aplicação desta proposta foram comparados com os dos modelos experimentais e teóricos disponíveis na literatura, comprovando-se a eficiência e praticidade em sua utilização.

Palavras-chave: alvenaria estrutural; pórtico preenchido; estruturas de aço; análise experimental e numérica. 


\section{ABSTRACT}

ALVARENGA, R.C.S.S. (2001). Theoretical-experimental analysis of masonry infilled frames structures. São Carlos, 2001. 342p. Thesis (Doctorate) Engineering School of São Carlos, University of São Paulo - Brazil

This work presents a study of the behavior of masonry infilled frames structures, subjected to horizontal actions, regarding the contribution of the masonry to the structure global stiffening. The study consists of tests, in real size, in steel frames infilled with structural blocks of autoclaved aerated concrete; of the macromodeling using the finite element method; of the application of the concept of equivalent diagonal struts and of the realization of a parametric study, regarding frames with different ratios height/length, aiming to get design recommendations for the analysis of infilled frames. These recommendations are presented as a proposal for determining the cracking load in panels of infilled frames with masonry, utilizing the strut-and-tie model. The results obtained with this proposal are compared with tests and predictions derived from approximate theoretical analyses, proving the efficiency and practicality in their utilization.

Keywords: masonry; infilled frame; steel structure; experimental and numerical analysis. 


\section{INTRODUÇÃO}

\section{1 - CONSIDERAÇÕES GERAIS}

Em estruturas de aço ou de concreto armado freqüentemente se utilizam painéis de alvenaria como elementos de vedação, sem dar a devida atenção à contribuição destes como elementos estruturais. No entanto, as propriedades e os detalhes construtivos da associação de pórticos e painéis podem ter grande influência no comportamento global da estrutura.

No projeto de estrutura de pórtico preenchido com painéis de alvenaria, uma clara decisão deve ser tomada com relação à participação ou não dos painéis na resistência da estrutura quando submetida a ações verticais e horizontais.

Se os painéis não forem participar do sistema estrutural, deverão ser suficientemente isolados do pórtico, que, ao mesmo tempo, será responsável pela estabilidade dos painéis quando atuarem ações horizontais fora do plano da estrutura, tais como vento ou sismo. A conexão painel-pórtico deverá, então, ser projetada de modo a proporcionar uma ancoragem adequada do painel quando submetido a essas ações. 
Entretanto, caso o painel seja ligado ao pórtico, de forma a interagir estruturalmente, o sistema resultante é conhecido como pórtico preenchido (infilled frame), constituindo-se no objeto de estudo desta tese.

A estrutura composta resultante do preenchimento de pórticos de aço ou de concreto armado com painéis de alvenaria apresenta comportamento significativamente diferente do de cada um deles isoladamente. Os painéis de alvenaria interagem em seus planos com as barras fletidas de aço ou concreto, e a capacidade de carga dos pórticos aumenta consideravelmente, em virtude do enrijecimento destes pela presença dos painéis. Estes, que são rígidos e resistentes à compressão, mas relativamente pouco resistentes à tração, podem servir de barras comprimidas em combinação com as vigas e pilares resistentes à flexão e aos esforços axiais.

Nas últimas cinco décadas, vários pesquisadores em todo o mundo têm estudado o comportamento de pórticos preenchidos por diversos materiais, demonstrando o aumento de rigidez das estruturas compostas e, conseqüentemente, redução dos deslocamentos horizontais destas.

As tentativas de obtenção de procedimentos de cálculo para estimar o comportamento do conjunto pórtico-painel, entretanto, não geraram resultados de aplicação prática imediata. Apesar de comprovações a respeito da economia e eficiência de pórticos preenchidos, os projetistas estruturais ainda relutam em considerar a alvenaria como elemento resistente. Isso pode ser explicado pela carência de ferramentas de projeto e de uma teoria universalmente aceita para análise e projeto desses sistemas. 


\section{2 - ANÁlise E PROJETO DE PÓRTICOS PREENCHIDOS COM ALVENARIA}

Em edifícios de concreto armado, em geral se adotam sistemas estruturais constituídos de pórticos rígidos e, ou, núcleos de paredes de concreto armado, que compõem as caixas de escadas e poços de elevadores. Essa solução está associada à grande facilidade de moldagem de estruturas de concreto armado, o que permite o enrijecimento do nó, de modo a considerá-lo rígido, sem custos adicionais consideráveis para a obra.

Em edificações de aço, a rigidez de uma ligação viga-pilar é obtida através de um arranjo específico dos elementos de ligação, que, via de regra, eleva consideravelmente o custo da estrutura, tendo em vista o aumento no consumo de aço e no volume de recursos humanos alocados para fabricação e montagem dessas ligações. Assim, a opção de trabalhar com elementos de contraventamento, adequadamente dispostos em planos verticais, surge como uma possibilidade para a redução do custo. Entretanto, esse arranjo estrutural apresenta o inconveniente de limitar a concepção arquitetônica, tendo em vista que restringe os locais para alocação de aberturas relativas às portas e janelas. Além disso, a presença de elementos inclinados reduz a velocidade de assentamento da alvenaria quando colocada no mesmo plano do contraventamento, uma vez que tal procedimento exige o corte diagonal dos blocos ou painéis de alvenaria. Existe, ainda, o risco de ocorrer o descolamento da alvenaria no contato com as barras de contraventamento, caso o encunhamento não tenha sido executado de forma adequada.

Uma alternativa viável para enrijecimento de estruturas metálicas, que permite contornar os problemas citados no parágrafo anterior, é a substituição dos elementos de contraventamento por painéis de alvenaria, na maioria das vezes já presentes nas edificações de aço, considerando-os como barras diagonais equivalentes. Esse procedimento é também adequado quando se utiliza estrutura de concreto armado, tendo em vista o aumento de rigidez e resistência produzido na estrutura composta resultante. No entanto, não existe padronização de procedimentos de cálculo que oriente de maneira segura sua utilização. 
Embora a importância do efeito dos painéis em estruturas de pórticos preenchidos seja reconhecida na Europa, é difícil encontrar regras precisas de projeto sobre a interação entre as partes. Os painéis são geralmente representados como elementos não-estruturais para simplificar a análise. $\mathrm{O}$ uso de tal modelo pode negligenciar alguns efeitos importantes no caso de sismos, como:

- Acréscimo da rigidez no plano e redução do período fundamental de vibração das estruturas, pela presença dos painéis.

- A imediata conseqüência do ponto anterior é o aumento da intensidade da ação prevista na estrutura, que tem geralmente um baixo período de vibração.

- Efeitos de torção devidos à distribuição não-uniforme dos painéis.

O Eurocode 6 - Projeto de Estruturas de Alvenaria - trata sobre Alvenaria Confinada, prescrevendo a adoção das hipóteses consideradas para alvenaria armada, desprezando-se a resistência das armaduras à compressão, além de ignorar a resistência das armaduras a esforços transversais. Prescreve ainda que a alvenaria confinada deve ser executada com elementos horizontais e verticais de concreto armado ou alvenaria armada, dispostos de forma a limitar a deformação da alvenaria quando sujeita a ações no seu plano. Os elementos de concreto armado ou alvenaria armada devem ser executados depois que a parede de alvenaria tenha sido construída e devem ser amarrados entre si, figura 1.1.

Os códigos normativos italianos prescrevem, na Circ. de 10/04/97, n. 65, e DM de 16/01/96: "Prescrições Técnicas para Estruturas em Regiões Sísmicas”, que é necessário identificar os elementos não-estruturais que podem interagir com a estrutura interferindo na sua rigidez e, ou, resistência. Essa interação pode estar relacionada a um aumento de resistência ou a efeitos indesejáveis. 


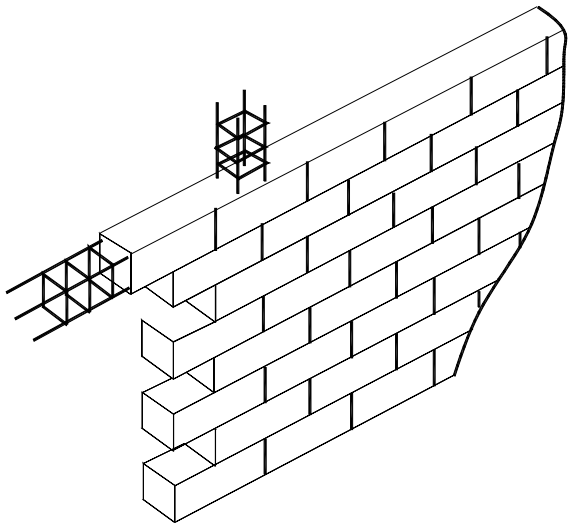

a) Alvenaria confinada com elementos de alvenaria armada

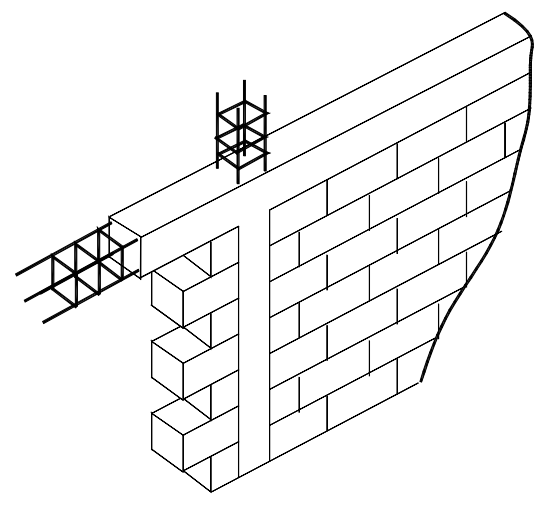

b) Alvenaria confinada com elementos de concreto armado

FIGURA 1.1 - Exemplos de alvenaria confinada

No caso de estruturas de pórticos preenchidos com alvenaria, a presença da alvenaria tanto pode contribuir para a rigidez da estrutura como, também, induzir a situações estruturais não regulares, em virtude da assimetria das paredes em planta.

Nesse caso, o projetista deve investigar a possibilidade de usar dois diferentes modelos (com painéis e sem painéis) e, então, considerar os casos mais desfavoráveis para o projeto dos elementos estruturais, quando sujeitos a ações sísmicas.

Esses códigos apresentam um modelo de treliça equivalente, cujos painéis são substituídos por barras birrotuladas, de mesma espessura do painel e altura igual a 1/10 do comprimento da diagonal do pórtico. O uso dessas prescrições exige que sejam satisfeitas as seguintes recomendações:

- A interface pórtico-painel seja adequadamente conectada de modo que as tensões possam ser transmitidas do pórtico para o painel;

- A relação altura/comprimento do pórtico deve ser maior que 0,50 e menor que 2,0 ;

- A relação altura/espessura do pórtico deve ser menor que 20; e

- Os painéis não devem possuir aberturas. 
No capítulo 4 será apresentado o cálculo dos protótipos segundo essas prescrições.

\section{3 - COMPORTAMENTO DE PÓRTICOS PREENCHIDOS}

Vários estudos analíticos e experimentais foram realizados em pórticos individuais preenchidos com alvenaria. O complexo mecanismo de interação entre as partes foi identificado por POLYAKOV (1956,1960). Devido ao grande número de parâmetros altamente variáveis que afetam o comportamento de pórticos preenchidos, são geralmente utilizadas análises aproximadas para esse tipo de estrutura.

Diversas técnicas analíticas foram propostas, sendo a mais simples e a mais estudada aquela referente ao conceito da barra diagonal equivalente. Esse conceito foi originalmente proposto por POLYAKOV (1956) e, posteriormente, refinado por STAFFORD-SMITH $(1962,1966,1967 a, 1967 b)$ e STAFFORD-SMITH e CARTER (1969).

Neste método, o pórtico preenchido com alvenaria é modelado como um pórtico equivalente contendo uma diagonal fictícia comprimida substituindo o painel de alvenaria. As propriedades da barra diagonal são funções do comprimento de contato entre o painel e as vigas e pilares do pórtico que o contorna. Este método está descrito detalhadamente no capítulo 2 .

Neste trabalho, apresenta-se uma contribuição à consideração em projeto de pórticos preenchidos com alvenaria. A partir de estudos teóricos, experimentais e numéricos, seguidos de uma parametrização, é apresentada uma proposta para obtenção da força horizontal que provoca a ruptura do painel, permitindo, assim, considerar a contribuição da alvenaria na rigidez e resistência dos pórticos.

Para o desenvolvimento deste estudo, foi utilizado o método das bielas e tirantes, tendo em vista que a alvenaria pode ser idealizada a suportar cargas por um conjunto de campos unidirecionais de tensões de compressão interligados por tirantes. Estes, por sua vez, são também campos unidirecionais de tensões de tração na alvenaria. 
Os resultados obtidos através da proposta aqui apresentada foram comparados com os resultados dos ensaios experimentais e numéricos realizados nesta tese e com outros experimentais e teóricos disponíveis na literatura, comprovando a eficiência e praticidade na utilização desta proposta.

Apresenta-se, ainda, uma proposta empírica para avaliação da largura da diagonal equivalente, com o objetivo de considerar os pórticos preenchidos por painéis de alvenaria como pórticos contraventados por barras diagonais equivalentes, de mesmo material do painel. Nos casos analisados, os resultados obtidos foram satisfatórios. No entanto, é necessário que seja estudado maior número de casos de modo a tornar a proposta o mais abrangente possível.

O fato de substituir os elementos de contraventamento por painéis de alvenaria proporciona economia no peso de aço e rapidez na execução das paredes, quando comparada com a alvenaria executada no plano do contraventamento.

\section{4 - OBJETIVOS}

Apresenta-se a seguir o objetivo geral desta tese, bem como os objetivos específicos necessários ao cumprimento do objetivo geral.

\subsection{1 - GERAL}

- Estudar o comportamento de estruturas aporticadas de aço enrijecidas com alvenaria, através de ensaios experimentais, modelagens numéricas e análises teóricas disponíveis na literatura, visando propor recomendações práticas de projeto para consideração da alvenaria na rigidez do conjunto.

\subsection{2 - ESPECÍFICOS}

- Estudar os métodos analíticos que possibilitem a substituição dos painéis de alvenaria por diagonais equivalentes, visando efetuar comparações. 
- Realizar ensaios em protótipos de aço preenchidos por alvenaria de concreto celular autoclavados, em escala real, com ou sem aberturas, variando o tipo de argamassa de assentamento, o tipo de ligação pórticopainel e a relação altura/comprimento do pórtico.

- Efetuar modelagens numéricas dos ensaios experimentais mais representativos de pórticos preenchidos com alvenaria, através de análise não-linear utilizando o software DIANA 7.2.

- Realizar um estudo paramétrico para pórticos com diferentes relações altura/comprimento.

\section{5 - ORGANIZAÇÃO DO TRABALHO}

No capítulo 2, apresenta-se uma revisão de literatura sobre análise de pórticos preenchidos por painéis de alvenaria, abordando métodos teóricos, empíricos e numéricos, além de avaliações experimentais disponíveis na literatura. É apresentado o método da barra diagonal equivalente, os modos de ruptura e o comportamento destes sistemas, além de expressões empíricas para obtenção da largura da diagonal equivalente.

No capítulo 3 são descritos os ensaios realizados em dois pórticos de aço, em escala real, variando diferentes parâmetros, como: o tipo de argamassa, o tipo de ligação pórtico-painel, a relação altura/comprimento do pórtico e a existência de abertura no painel. Foram realizados um total de 16 ensaios em dois protótipos de aço, e nesse capítulo são apresentados os resultados obtidos e as conclusões retiradas dos ensaios experimentais.

No capítulo 4 são apresentadas as previsões teóricas de comportamento dos painéis em estudo, baseadas nos métodos desenvolvidos por SMITH e CARTER (1969) e SMITH e RIDDINGTON (1977) e pelas prescrições italianas DM 16/01/96 e Circ. de 10/04/97, n. 65. Os dois protótipos são calculados à luz desses métodos teóricos, e os resultados são comparados com aqueles obtidos experimentalmente. 
No capítulo 5 é mostrado o desenvolvimento da modelagem numérica dos ensaios experimentais realizados, efetuada através de análise não-linear pelo Método dos Elementos Finitos, utilizando-se o software DIANA versão 7.2. São descritas as modelagens dos protótipos e apresentados os modelos constitutivos adotados para a alvenaria e interfaces, as propriedades da argamassa e alvenaria utilizadas na análise numérica e os elementos finitos utilizados. Os resultados numéricos são comparados com os resultados experimentais, no que se refere a rigidez, tensões, deformações, descolamentos e efeitos da abertura.

No capítulo 6 são apresentados os resultados de um estudo paramétrico realizado, de forma a avaliar e identificar os efeitos dos principais parâmetros que afetam o comportamento de pórticos preenchidos. Foram modelados pórticos preenchidos com relações altura/comprimento iguais a 0,$51 ; 0,60 ; 0,70 ; 0,83$; e 1,00 , variando o tipo de ligação viga-pilar (articuladas, rígidas e semi-rígidas) e a relação de rigidez entre o pórtico e o painel de alvenaria. São apresentadas curvas força-deslocamento para as diversas análises efetuadas, enfocando os parâmetros avaliados em cada caso.

Como resultado de todo o trabalho de tese, apresenta-se no capítulo 7 uma proposta para determinação da carga de ruptura em painéis de pórticos preenchidos com alvenaria e uma expressão empírica para obtenção da largura da diagonal equivalente, de forma a considerar o pórtico com barras diagonais birrotuladas em substituição ao painel de alvenaria.

Os resultados obtidos com a aplicação desta proposta são comparados com os resultados experimentais obtidos nesta tese e por BRAGUIM (1989) e com os resultados teóricos de SMITH e CARTER (1969), de SMITH e RIDDINGTON (1977) e com as prescrições italianas descritas em: "Prescrições Técnicas para Estruturas em Regiões Sísmicas”, Circ. de 10/04/97, n.65, e DM de 16/01/96.

No capítulo 8 são apresentadas as considerações finais, abordando as conclusões retiradas deste estudo. A boa "performance" de sistemas de pórticos preenchidos é mais uma vez comprovada, quando se comparam as forças de projeto devidas ao 
vento em um pórtico de um edifício de quatro pavimentos, projetado por BRAGUIM (1989), calculadas segundo a NBR 6123, com os valores das forças horizontais correspondentes à ruptura dos painéis, calculadas pelo método proposto nesta tese $\mathrm{e}$ por aqueles disponíveis na literatura.

Este estudo permite concluir que, nesse caso, a força de ruptura da diagonal é cerca de 10 vezes superior à força horizontal máxima de projeto devida ao vento, aplicada no eixo da viga de um pórtico, comprovando mais uma vez o bom funcionamento da alvenaria como elemento de contraventamento, não ocorrendo sequer o descolamento da interface pórtico-painel, para este nível de carga. São ainda apresentadas sugestões para trabalhos futuros, de forma a dar continuidade a este assunto, que é bastante amplo, tanto do ponto de vista teórico quanto de ensaios experimentais necessários.

Os resultados de dois ensaios de pórticos preenchidos com painéis pré-fabricados de concreto celular autoclavado (CCA), dispostos verticalmente e interligados por argamassa polimérica, tipo colante, são apresentados no Anexo A. Esses ensaios foram realizados a título de investigação experimental, de forma a confrontar o comportamento dos painéis pré-fabricados com o de blocos de CCA. Os resultados obtidos apontam maior carga de ruptura para os ensaios de pórticos preenchidos com blocos.

No Anexo B são expostos o sistema de aquisição de dados AQDADOS utilizado nos ensaios experimentais e a calibração dos instrumentos.

No Anexo C, apresentam-se os resultados detalhados dos ensaios de caracterização da alvenaria e argamassa realizados. Foram executados ensaios de compressão simples e diametral em cilindros de argamassa, além de ensaios à compressão simples e ao cisalhamento em prismas constituídos por bloco-meio bloco-bloco, serrados longitudinalmente. 
São apresentados no Anexo D os resultados dos ensaios experimentais referentes ao descolamento da interface pórtico-painel. Para permitir uma melhor avaliação do comportamento da parede como uma biela, foi realizado o estudo experimental e numérico do comprimento do descolamento entre pórtico e painel, avaliando-se, assim, o comprimento efetivo que permanece em contato, por onde são transmitidas as tensões de compressão na interface entre pórtico e painel.

Os diagramas força-deformação nos extensômetros, obtidos nos ensaios experimentais, são mostrados no Anexo E. A partir das deformações nos extensômetros são obtidas as tensões nas direções deles, bem como os valores das tensões e deformações principais.

No Anexo F são apresentados os procedimentos incrementais e iterativos para resolução do problema não-linear. São, também, apresentados os critérios de convergência usuais.

As tabelas com os valores das cargas de ruptura obtidos pelo método proposto, pelas modelagens numéricas e pelos métodos teóricos disponíveis na literatura são mostradas no Anexo G.

\section{6 - CONTEXTUALIZAÇÃO DO TRABALHO}

Esta pesquisa de tese foi desenvolvida através de um trabalho conjunto entre a Escola de Engenharia de São Carlos - EESC/USP, a Escola de Engenharia da UFMG e a Universidade do Minho, Portugal. Os ensaios experimentais foram realizados no LAEES - Laboratório de Análise Experimental de Estruturas, da Escola de Engenharia da Universidade Federal de Minas Gerais, e a modelagem numérica foi realizada na Universidade do Minho. 


\section{REVISÃO DE LITERATURA}

\section{1 - INTRODUÇÃO}

\subsection{1 - ALVENARIA ESTRUTURAL}

A alvenaria vem sendo utilizada como um dos principais materiais de construção desde a antigüidade. Utilizando-se blocos de material como argila, pedra e muitos outros, foram construídas obras que até hoje se encontram em condições de utilização. Como exemplos famosos podem ser citados: a Pirâmide de Queóps, construída em blocos de pedra; o Farol de Alexandria, com altura superior a 130 m; a Catedral de Reims, de arquitetura gótica, constituída de grandes vãos, utilizando-se apenas estruturas comprimidas; e o edifício Monadnock, construído em Chicago no final do século passado, com 16 pavimentos.

No entanto, apenas a partir do século XX a alvenaria passou a receber tratamento científico baseado no cálculo racional, deixando de lado o tratamento puramente empírico recebido até então. 
Na década de 50, a utilização da alvenaria ganhou novo impulso após a realização de uma série de experimentações na Europa. Foi construído na Suíça, em 1951, um edifício de 13 pavimentos em alvenaria não-armada, com paredes internas de $15 \mathrm{~cm}$ de espessura e externas de $37,5 \mathrm{~cm}$. Foram construídos diversos edifícios na Inglaterra, Alemanha e Suíça e também nos Estados Unidos, onde é utilizada a alvenaria armada em regiões sujeitas a sismos.

No Brasil, por muitos anos a alvenaria estrutural foi pouco utilizada em virtude de fatores como maior domínio da tecnologia do concreto armado por parte de construtores e projetistas e pouca divulgação do assunto nas universidades durante o processo de formação do profissional.

Os primeiros edifícios em alvenaria estrutural foram construídos em São Paulo na década de 60, utilizando-se blocos vazados de concreto, de até quatro pavimentos. $\mathrm{Na}$ década de 70 foram construídos edifícios em alvenaria armada de 12 pavimentos. Em 1977, construíram-se os primeiros edifícios em alvenaria não-armada constituídos de nove pavimentos, utilizando-se blocos sílico-calcários, com as paredes estruturais com $24 \mathrm{~cm}$ de espessura.

\subsection{2 - PÓRTICOS PREENCHIDOS}

Os efeitos benéficos da associação de pórticos com painéis de alvenaria têm sido relatados por diversos pesquisadores em todo o mundo nas últimas cinco décadas, através de investigações isoladas em várias instituições. A interação resultante dessa associação pórtico-painel proporciona rigidez adequada ao pórtico, que é flexível e, de maneira recíproca, aumenta a ductilidade do painel. Depois de fissurado, um painel de alvenaria é capaz de absorver ações horizontais e manter-se deslocado para ações muito maiores que aquelas que conseguiria atingir sem a presença do pórtico (DAWE e SEAH, 1989).

Geralmente, a literatura apresenta uma gama de material, de dimensões para os pórticos, e de procedimentos usados no estudo de pórticos preenchidos com 
alvenaria. Assim, as formulações adotadas por vários pesquisadores têm, também, variado largamente e, como conseqüência, existe grande variedade de técnicas analíticas para avaliar a rigidez e a resistência de pórticos preenchidos.

\section{2 - DESENVOLVIMENTO HISTÓRICO}

Um fato que contribuiu para o desenvolvimento do estudo de alvenaria como preenchimento de pórticos submetidos a ações laterais ocorreu no Edifício Empire State, em Nova York, após a sua conclusão. Durante uma tempestade com rajadas de vento excedendo a $145 \mathrm{~km} / \mathrm{h}$, observou-se o início de fissuras em vários painéis de alvenaria nos pisos 29 e 42 . Registraram-se também fissuras na interface pórticopainel de alvenaria. Os extensômetros fixos nos pilares não registraram deformações no pórtico antes do início das fissuras no painel, apesar da presença de forte vento.

Isso foi explicado pela alta rigidez dos painéis de alvenaria, que dessa forma evitou distorções no pórtico de aço. Quando os painéis foram solicitados além de sua capacidade de fissuração, iniciou-se um processo de perda de rigidez. Conseqüentemente, os extensômetros começaram a registrar deformações, indicando que o pórtico de aço havia iniciado sua participação na resistência à ação do vento. Devida à interação entre pórtico-painel, o conjunto continuou a resistir fortemente as ações laterais, mesmo na presença de fissuras no painel (RATHBUN, 1938).

POLYAKOV (1956) publicou pesquisas referentes a pórticos preenchidos submetidos a cargas elevadas. Nestas, foram apresentados resultados de ensaios em modelos reduzidos, realizados entre 1948 e 1953, para avaliar a resistência à tração e ao cisalhamento da alvenaria utilizada como preenchimento. Para determinar a resistência de pórticos com preenchimentos, foram realizados 65 ensaios em escala maior. Trinta e dois ensaios foram realizados em pórticos quadrados de $1200 \mathrm{~mm}$ e os demais, em pórticos retangulares com comprimento e altura de $3000 \mathrm{~mm}$ e 2000 $\mathrm{mm}$, respectivamente. Foram investigados efeitos como: tipos de blocos, traços da argamassa, métodos de aplicação de cargas (monotônico ou cíclico) e painéis com aberturas. Para avaliação deste último efeito, foram utilizados oito protótipos. 
POLYAKOV (1960) descreveu três estágios de comportamento de pórtico com preenchimento submetido a carregamento. No primeiro estágio, o painel de alvenaria e as barras da estrutura reticulada comportam-se como uma unidade monolítica. Esse estágio termina quando surgem as primeiras fissuras entre o painel e as barras do pórtico. Essas fissuras são observadas nas interfaces do painel-pórtico, com exceção de pequenas regiões onde as tensões de compressão são transmitidas do pórtico para o painel, nos dois cantos diagonalmente opostos.

O segundo estágio é caracterizado por um encurtamento da diagonal comprimida e alongamento da diagonal tracionada. No final deste estágio surgem fissuras no painel ao longo da diagonal comprimida. As fissuras usualmente aparecem, de forma escalonada, nas juntas horizontais e verticais.

No terceiro estágio, a estrutura composta continua a resistir a incrementos de carga, apesar das fissuras na diagonal. Estas continuam a aumentar, e novas e maiores fissuras aparecem, encerrando este estágio, uma vez que o sistema não possui mais capacidade para suportar acréscimos de carga.

Como os resultados experimentais foram comparados com modelos de comportamento elástico para o painel, eles não foram conclusivos. Assim, a técnica foi aplicada somente para o primeiro estágio de comportamento do painel, como descrito anteriormente. Posteriormente, realizaram experimentos em modelos de pórticos de aço preenchidos com alvenaria de três tramos e três pavimentos, com painéis quadrados de $1200 \times 1200 \mathrm{~mm}$. Com base no comportamento experimental da interface pórtico-painel, POLYAKOV (1960) sugeriu que o painel fosse substituído por uma diagonal comprimida.

Paralelamente aos trabalhos de Polyakov, foram desenvolvidos ensaios experimentais por THOMAS (1953) e WOOD (1958), e os resultados obtidos comprovaram a significativa contribuição do painel à rigidez e à resistência de pórticos preenchidos. Em 1955, WHITNEY et al. (1955), nos Estados Unidos, publicaram trabalho referente à resistência das estruturas sujeitas a esforços oriundos 
de explosões atômicas. O sistema estrutural investigado consistiu de pórticos de concreto armado de um pavimento e um tramo preenchidos por painéis de alvenaria ou de concreto, submetidos a ações horizontais elevadas. Considerando os pilares do pórtico como flanges e o painel como alma, utilizou-se a Teoria de Vigas para determinar a resistência.

A partir de 1957, BENJAMIN e WILLIAMS (1957,1958) e WOOD (1958) analisaram os resultados experimentais de WHITNEY et al. (1955) e outros obtidos com pórticos de concreto armado, ou de aço, preenchidos por painéis de concreto ou de alvenaria, sujeitos a cargas laterais que simulam ações de vento e sismo. Foram unânimes em afirmar a respeito do aumento da rigidez dos pórticos proporcionada pela presença dos painéis .

\subsection{1 - CONCEITO DA BARRA DIAGONAL EQUIVALENTE}

O conceito da barra diagonal equivalente foi introduzido por POLYAKOV (1956) e desenvolvido por HOLMES (1961) e, posteriormente, refinado por STAFFORDSMITH (1962, 1966, 1967a, 1967b) e STAFFORD-SMITH e CARTER (1969), MAINSTONE (1971) e LIAUW e LEE (1977). Neste método, o pórtico preenchido com alvenaria é modelado como um pórtico equivalente contendo uma diagonal fictícia comprimida substituindo o painel de alvenaria.

HOLMES (1961) propôs um método para determinação das deformações e resistência de pórticos preenchidos com base no conceito da diagonal equivalente, considerando uma diagonal com espessura e módulo de deformação iguais ao do painel e comprimento de contato igual a um terço do comprimento da diagonal. Ele concluiu que, no colapso, o deslocamento lateral do pórtico preenchido é bastante menor do que no caso de pórtico sem preenchimento. Além disso, as barras do pórtico permaneceram elásticas até a carga de colapso. A ação horizontal correspondente ao colapso é dada a seguir: 


$$
F=\frac{24 E_{p} I_{p}^{\prime} e_{c}{ }^{\prime} d}{h^{3}\left(1+\frac{I_{p^{\prime}}}{I_{o}} \cot \theta\right) \cos \theta}+S f_{c m} \cos \theta
$$

em que $I_{p^{\prime}}$ e $I_{o}$ são os momentos de inércia do pilar e da viga do pórtico, respectivamente; $E_{p}$ é o módulo de elasticidade das barras do pórtico; $e_{c}$ é a deformação do painel correspondente ao colapso; $h_{d}$ e $d$ são a altura e o comprimento diagonal do painel, respectivamente; $\theta$ é o ângulo de inclinação da diagonal com a horizontal; e $S$ e $f_{c m}$ são, respectivamente, a área da seção transversal e a resistência última à compressão da diagonal equivalente.

HOLMES (1961) indicou que o valor de $t d / 3$, em que $t$ e $d$ são a espessura e o comprimento diagonal do painel, respectivamente, representa satisfatoriamente o valor de $S$ na determinação da resistência. Contudo, a avaliação teórica do deslocamento horizontal foi, em geral, menor que aquela medida experimentalmente.

Mais tarde, HOLMES (1963), realizando ensaios de um e dois pavimentos, constatou que houve aumento de rigidez da ordem de 300 a 400\% para estruturas preenchidas com painéis de concreto cuja resistência média à compressão era de $16 \mathrm{MPa}$. Para estruturas com resistência média à compressão de $3 \mathrm{MPa}$, obteve-se aumento de rigidez variando de 75 a 105\%. Comparando os resultados experimentais com valores teóricos, foi constatada uma média de $90 \%$ de precisão para os valores de cargas de colapso. Contudo, esse autor recomendou a realização de outros ensaios e o refinamento do método de cálculo por ele sugerido.

Usando uma formulação similar àquela utilizada por HOLMES (1961), STAFFORDSMITH (1962) estudou a rigidez lateral de pórticos preenchidos, substituindo o painel por uma diagonal equivalente. Assumindo a carga total aplicada próxima aos cantos comprimidos do painel, a largura efetiva da diagonal equivalente varia de $d / 4$ para painéis quadrados até $d / 11$ para painéis com relação comprimento/altura igual a 5. 
Realizando ensaios em seguida, STAFFORD-SMITH (1962) revelou que as conclusões anteriormente relatadas não correspondiam aos resultados experimentais e que a largura efetiva do painel era função do comprimento de contato entre o painel e o pórtico, figura 2.1. Concluiu, ainda, que o comprimento de contato era altamente dependente da rigidez relativa entre pórtico e painel.

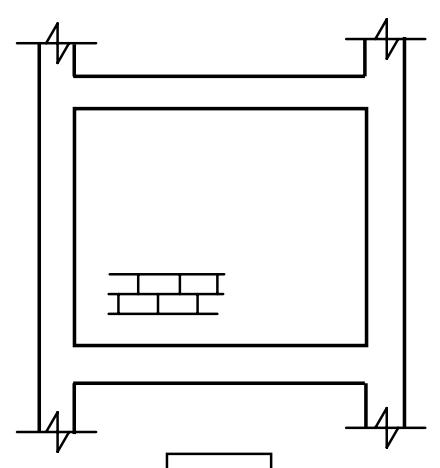

(a)

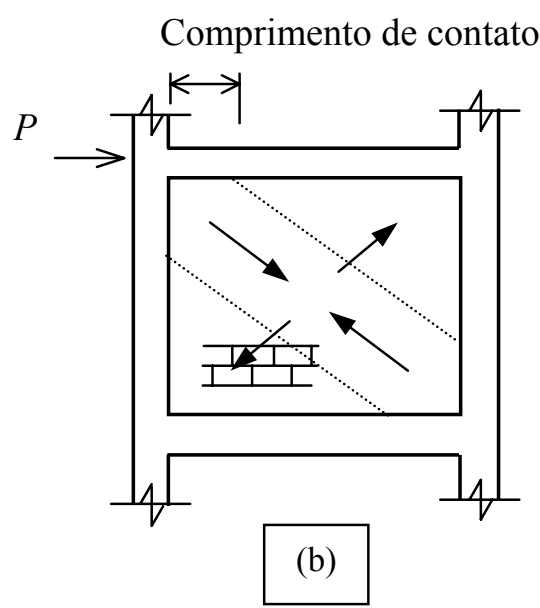

(b)

FIGURA 2.1 - a) Sistema pórtico-parede e b) comprimento de contato das interfaces, em sistemas solicitados a ações horizontais

\subsection{2 - AVALIAÇÃO TEÓRICA DO COMPORTAMENTO DE PÓRTICOS PREENCHIDOS A PARTIR DA RIGIDEZ RELATIVA PÓRTICO- PAINEL}

\section{a) PÓRTICOS QUADRADOS PREENCHIDOS}

STAFFORD-SMITH (1966) conduziu uma série de ensaios em pórticos quadrados de aço preenchidos com painéis de microconcreto de $150 \mathrm{~mm}$. A figura 2.2 ilustra a distribuição de forças e tensões ao longo do comprimento de contato entre o painel e o pórtico, adotado por esse autor. Utilizando a teoria da fundação em base elástica, ele estabeleceu uma relação entre o comprimento de contato da viga com o painel $(\alpha)$ e o parâmetro de rigidez relativa $\left(\lambda L^{\prime}\right)$, conforme as equações (2.2) e (2.3), ou seja: 


$$
\begin{aligned}
& \lambda L^{\prime}=L^{\prime} \cdot \sqrt[4]{\frac{E_{\text {painel }} t}{4 E_{p} I_{p} h}} \\
& \frac{\alpha}{L^{\prime}}=\frac{\pi}{2 \lambda L^{\prime}}
\end{aligned}
$$

em que $E_{\text {painel, }} t$ e $h$ são módulo de deformação, espessura e altura do painel, respectivamente. $E_{p} I_{p}$ e $L^{\prime}$ são, respectivamente, o produto de rigidez do pilar e o comprimento deste entre eixos.

Adotando uma distribuição triangular ou parabólica de tensões sobre o comprimento de contato $\alpha$, utilizando o método das diferenças finitas, foi determinado o campo de deformações ao longo do comprimento da diagonal. Pela integração da curva de deformações ao longo desse comprimento, obteve-se a largura da diagonal equivalente, definindo, assim, uma seção transversal para a barra diagonal que proporciona rigidez equivalente à do painel.

De posse do valor do comprimento de contato, tornou-se possível isolar o pórtico do painel e avaliar a parcela de carga suportada por cada componente do sistema pórtico-painel.

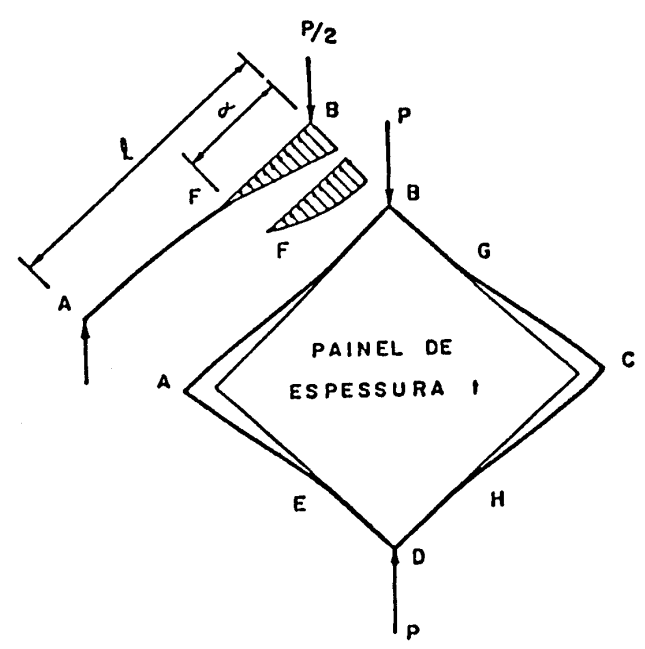

FIGURA 2.2 - Modelo de análise proposto por STAFFORD-SMITH 
STAFFORD-SMITH (1966) estabeleceu dois modos de ruptura:

1- Ruptura por fissuração repentina da diagonal comprimida, estendendo-se do centro aos cantos comprimidos do painel.

2- Ruptura por compressão, causada pelo esmagamento na região dos cantos carregados do painel.

Relacionando as tensões teóricas determinadas pelos métodos descritos nos parágrafos anteriores e a resistência do material do painel, STAFFORD-SMITH (1966) obteve duas curvas para estimar a resistência de pórticos preenchidos correspondentes a esses dois modos de ruptura, figura 2.3. As curvas permitem avaliar o modo e a carga de ruptura do painel, em função da geometria e características do material da estrutura. Para estruturas aporticadas mais rígidas, ou seja, valores de $\lambda L^{\prime} \leq 9,5$, o painel deve romper por fissuração repentina da diagonal, ao passo que em estruturas aporticadas mais flexíveis $\left(\lambda L^{\prime}>9,5\right)$ deve ocorrer ruptura por esmagamento dos cantos.

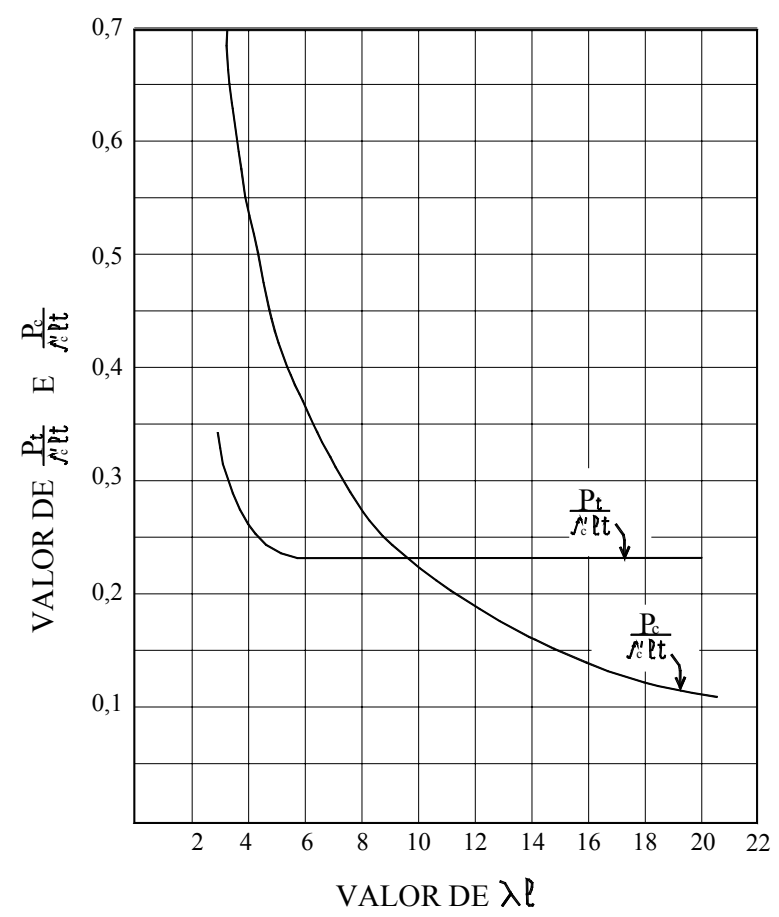

FIGURA 2.3 - Resistência da diagonal equivalente em função de $\lambda L^{\prime}$ (STAFFORD-SMITH 1966) 


\section{b) PÓRTICOS RETANGULARES PREENCHIDOS}

STAFFORD-SMITH (1967a,1967b) e SMITH e CARTER (1969) estenderam os trabalhos realizados para pórticos quadrados aos pórticos retangulares. Concluíram que a largura efetiva do painel atuando como uma diagonal era função de:

1- Rigidez relativa painel-pórtico;

2- Relação comprimento/altura do painel;

3- Relação tensão-deformação do material do painel;

4- Intensidade do esforço na diagonal.

Como refinamento do método de HOLMES (1961), aqueles apresentaram uma série de ábacos para determinar a largura efetiva da diagonal equivalente baseada nos parâmetros anteriormente descritos. Analogamente aos pórticos quadrados, a largura equivalente da diagonal foi expressa em função de $\lambda L^{\prime}$, equação (2.4):

$$
\lambda L^{\prime}=L^{\prime} \times \sqrt[4]{\frac{E_{\text {painel }} t}{4 E_{p} I_{p} h} \operatorname{sen} 2 \theta}
$$

em que $E_{\text {painel, }} h$ e $t$ são, respectivamente, o módulo de deformação, a altura e a espessura do painel. $E_{p} I_{p}$ e $L^{\prime}$ são, respectivamente, o produto de rigidez do pilar e o comprimento do pilar entre eixos, e $\theta$ é o ângulo de inclinação da diagonal do painel com a horizontal.

Tendo em vista que a largura efetiva da diagonal equivalente não é constante, mas variável com o carregamento e com as propriedades descritas anteriormente, STAFFORD-SMITH e CARTER (1969) produziram ábacos para estimar a largura da diagonal equivalente. Estimando a resistência lateral de pórticos preenchidos, esses autores propuseram examinar todos os possíveis modos de ruptura para o pórtico e o painel.

Os modos de ruptura para o pórtico incluíam ruptura por tração no pilar, ruptura por cisalhamento de vigas e pilares e ruptura nas ligações. Se o pórtico possui resistência 
adequada, painéis de concreto ou argamassa podem romper por um ou ambos os modos:

1 - Fissuração por tração da diagonal carregada.

2 - Esmagamento do painel nos cantos carregados.

Geralmente, a ocorrência de fissuração da diagonal não define a resistência última do sistema, uma vez que é possível aumentar a carga até a ocorrência de ruptura por esmagamento nos cantos carregados. Para painéis de alvenaria, os modos de ruptura podem ser um dos seguintes:

1- Fissuração por cisalhamento ao longo da interface entre bloco e argamassa.

2- Fissuração por tração através das juntas de argamassa e blocos de alvenaria.

3- Esmagamento local dos blocos e argamassa nos cantos comprimidos.

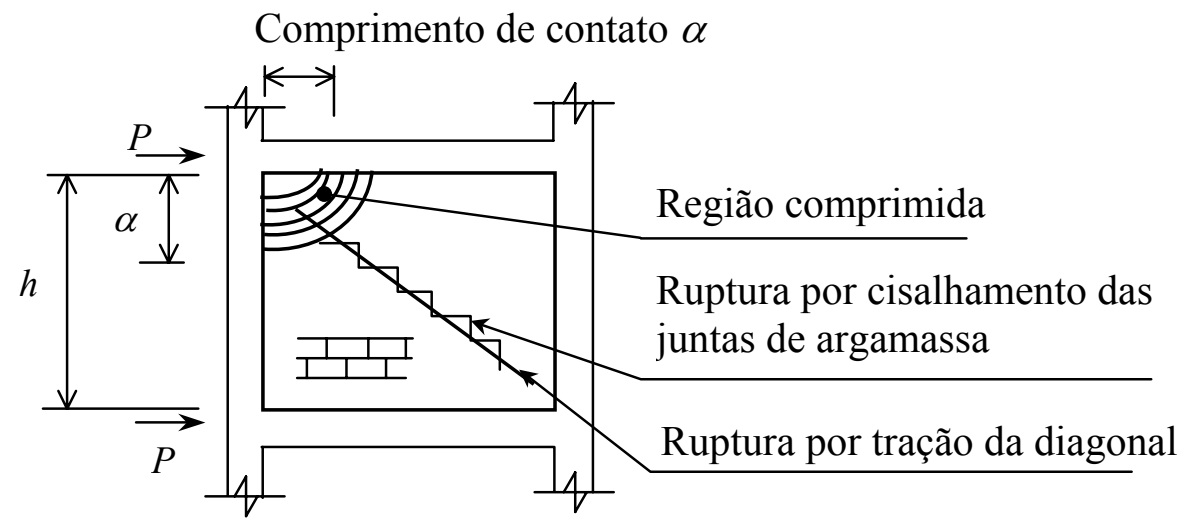

FIGURA 2.4 - Modos de ruptura da alvenaria em sistemas de pórticos de aço-painéis de alvenaria

Os modos 2 e 3 descritos acima são similares àqueles para painéis homogêneos de concreto. Entretanto, a disposição horizontal dos blocos e a argamassa, inerentes aos painéis de alvenaria, introduzem um modo de ruptura adicional - Modo 1. O modo de ruptura resulta, parcialmente, da geometria da estrutura, que por sua vez influencia os valores de tensões normais e de cisalhamento e a resistência à tração da diagonal equivalente. Quanto maior a relação comprimento/altura do painel, menor a 
possibilidade de ruptura por tração na diagonal. O modo de ruptura é função também da área de cisalhamento, do coeficiente de atrito interno e da resistência à tração diagonal da alvenaria.

Associado a cada modo de ruptura do painel de alvenaria, foi construído um ábaco em função dos parâmetros: $\lambda L^{\prime}$, parâmetro de rigidez relativa; $h / l$ relação altura/comprimento do painel e coeficiente de atrito da argamassa, figuras 2.5, $2.6 \mathrm{e}$ 2.7. As variáveis $f_{b s}^{\prime}, f_{t}$ e $f_{c}$ representam a resistência média do painel de alvenaria ao cisalhamento, à tração e à compressão, respectivamente.

O método proposto foi estendido aos pórticos preenchidos de múltiplos pavimentos e aplicado a uma estrutura, em escala real, de 3 pavimentos.

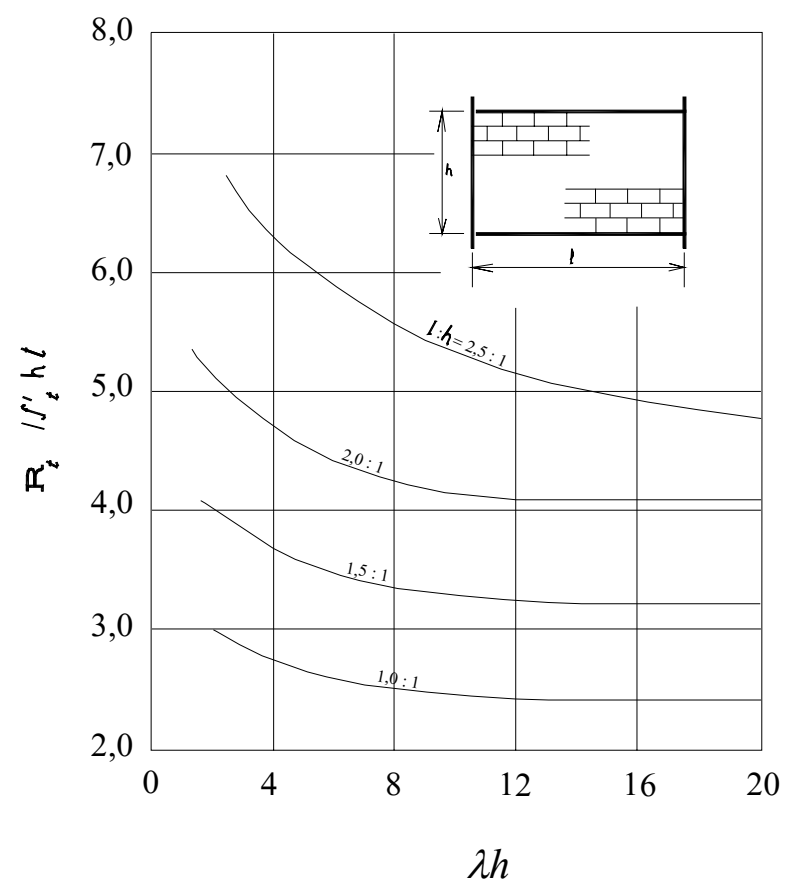

FIGURA 2.5 - Ábaco para painel de alvenaria: resistência à tração da diagonal equivalente $\mathrm{x} \lambda L^{\prime}$ (SMITH e CARTER, 1969) 


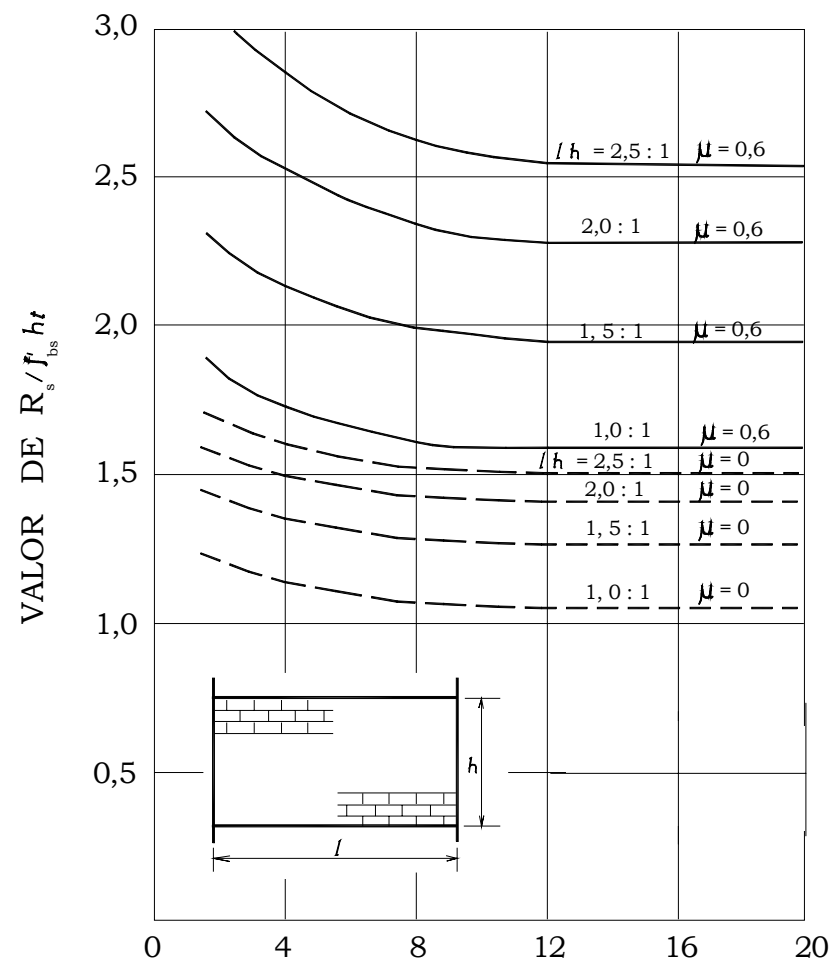

FIGURA 2.6 - Ábaco para painel de alvenaria: resistência ao cisalhamento da diagonal equivalente $\mathrm{x} \lambda L^{\prime}$ (SMITH e CARTER, 1969)

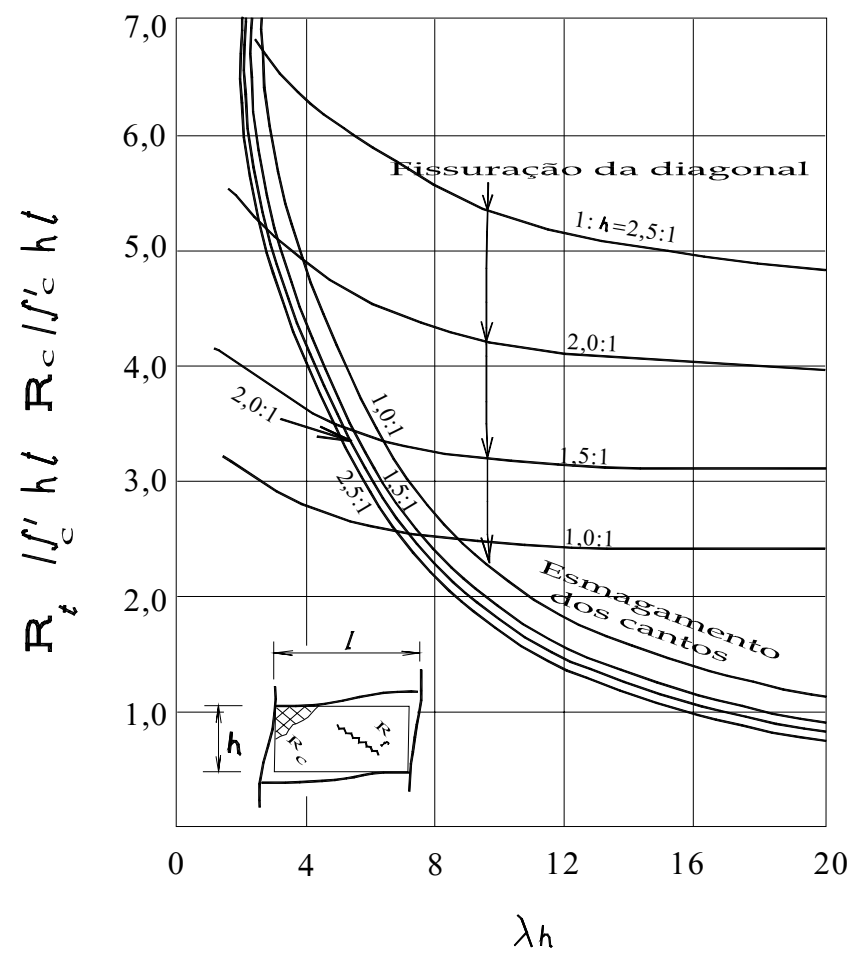

FIGURA 2.7 - Ábaco para painel de alvenaria: resistência ao esmagamento do cantos carregados (SMITH e CARTER, 1969) 


\subsection{3 - AVALIAÇÃO EMPÍRICA DO COMPORTAMENTO DE PÓRTICOS PREENCHIDOS A PARTIR DA RIGIDEZ RELATIVA PÓRTICO- PAINEL}

MAINSTONE (1971) apresentou resultados de uma extensa série de ensaios em pórticos preenchidos com microconcreto e blocos. Ele estudou as prováveis variáveis que influenciam a consideração estrutural do painel, concluindo que a variação de comportamento de pórticos preenchidos é muito maior que as consideradas pelas análises teóricas conhecidas. Fatores como folga inicial entre pórtico e painel e variação nas propriedades elásticas e de resistência de painéis podem resultar em larga variação no comportamento entre protótipos com as mesmas características.

Para fins de projetos, entretanto, MAINSTONE (1971) também adotou o conceito da barra diagonal equivalente, embora acreditasse que o conceito só se aplicava a ações inferiores àquelas correspondentes ao surgimento das primeiras fissuras no painel. Plotaram-se os resultados dos ensaios anteriormente referidos versus o parâmetro de rigidez $\lambda L^{\prime}$, obtendo a largura da diagonal equivalente uniformemente tracionada $w_{e k}^{\prime}, w_{e t}^{\prime} e w_{e c}^{\prime}$, empiricamente formulada para avaliar a rigidez, a carga correspondente à primeira fissura e a resistência última do pórtico preenchido, respectivamente. Os resultados são apresentados na tabela 2.1 , em que $w^{\prime}$ representa a largura da diagonal do painel e os demais parâmetros foram definidos no item 2.2.2. De posse da largura da diagonal, pode-se analisar a estrutura equivalente e avaliar a sua rigidez.

Esse mesmo autor também concluiu que, se a interface pórtico-painel estiver bem preenchida, a contribuição do pórtico para a rigidez elástica e para a resistência do conjunto é desprezada e, conseqüentemente, poder-se-ia desprezar a avaliação da rigidez do pórtico até a carga referente ao surgimento das primeiras fissuras. Com base nos estudos analíticos e experimentais de KADIR (1974), HENDRY (1981) propôs uma relação semi-empírica para largura da diagonal equivalente, $w$, equação (2.5): 


$$
w=\frac{1}{2} \sqrt{\left(\alpha_{l}^{2}+\alpha_{h}^{2}\right)}
$$

TABELA 2.1 - Aproximação empírica para obtenção da largura da diagonal equivalente (MAINSTONE,1971)

\begin{tabular}{|c|c|}
\hline \multicolumn{2}{|c|}{ Para $\lambda L^{\prime}<5$} \\
\hline BLOCOS CERÂMICOS & BLOCOS DE CONCRETO \\
\hline$\frac{w_{e k}^{\prime}}{w^{\prime}}=0,175\left(\lambda L^{\prime} h\right)^{-0,4}$ & $\frac{w_{e k}^{\prime}}{w^{\prime}}=0,115\left(\lambda L^{\prime} h\right)^{-0,4}$ \\
\hline$\frac{w_{e t}^{\prime}}{w^{\prime}}=0,170\left(\lambda L^{\prime} h\right)^{-0,4,}$ & $\frac{w_{e t}^{\prime}}{w^{\prime}}=0,255\left(\lambda L^{\prime} h\right)^{-0,4}$ \\
\hline$\frac{w_{e c}^{\prime}}{w^{\prime}}=0,56\left(\lambda L^{\prime} h\right)^{-0,875}$ & $\frac{w_{e c}^{\prime}}{w^{\prime}}=0,84\left(\lambda L^{\prime} h\right)^{-0,875}$ \\
\hline$\frac{w_{e k}^{\prime}}{w^{\prime}}=0,16\left(\lambda L^{\prime} h\right)^{-0,3}$ & Para $\lambda L^{\prime}>5$ \\
\hline$\frac{w_{e t}^{\prime}}{w^{\prime}}=0,15\left(\lambda L^{\prime} h\right)^{-0,3}$ & $\frac{w_{e k}^{\prime}}{w^{\prime}}=0,16\left(\lambda L^{\prime} h\right)^{-0,3}$ \\
\hline$w^{\prime}$ & $\frac{w_{e t}^{\prime}}{w^{\prime}}=0,22\left(\lambda L^{\prime} h\right)^{-0,3}$ \\
\hline$w^{\prime}$ & \\
\hline
\end{tabular}

Como mostrado na figura 2.8, a expressão (2.5) assume uma distribuição idealizada de tensões sobre a largura do canto carregado, assim como uma tensão uniforme na largura $w$. Os comprimentos de contatos $\alpha_{l}$ e $\alpha_{h}$ podem ser obtidos por um dos métodos apresentados anteriormente. 


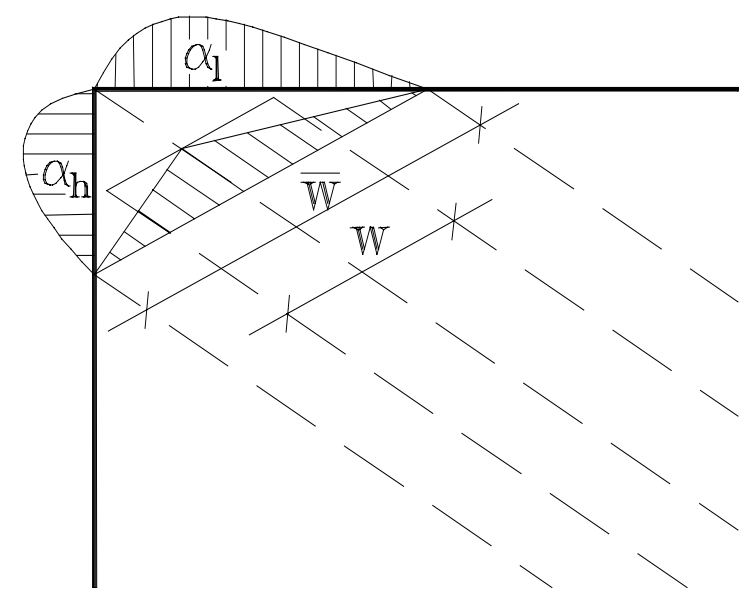

FIGURA 2.8 - Largura efetiva da diagonal equivalente

\subsection{4 - AVALIAÇÃO DO COMPORTAMENTO DE PÓRTICOS PREENCHIDOS SEGUNDO A TEORIA DA ELASTICIDADE}

SACHANSKI (1960) propôs um modelo analítico, calibrado por resultados de ensaios, considerando forças de contato entre o pórtico e o painel, de forma a representar a interação entre as partes. Utilizando a compatibilidade de deslocamentos entre pórtico e painel, determinaram-se as forças nos vínculos considerados. O painel foi tratado como uma membrana elástica, e os coeficientes de rigidez do pórtico foram determinados pela integração de tensões determinadas através do Método das Diferenças Finitas. Conhecidas as forças de contato, foi proposta uma função de tensão para análise do painel.

LIAUW (1970) examinou o comportamento de pórticos preenchidos teórica e experimentalmente. A formulação teórica foi a partir da determinação dos coeficientes da função de Airy, expressos na forma de séries de Fourier, para determinar a tensão e deformação no pórtico e no painel.

Deve ser observado que ambas as formulações anteriormente comentadas só podem ser aplicadas para um conjunto monolítico pórtico-painel. Além disso, o painel é considerado isotrópico, homogêneo e elástico, quando, na verdade, é não-homogêneo e anisotrópico. 


\subsection{5 - AVALIAÇÃO DO COMPORTAMENTO DE PÓRTICOS PREENCHIDOS UTILIZANDO O MÉTODO DOS ELEMENTOS FINITOS}

Utilizando o Método dos Elementos Finitos na solução de problemas de pórticos preenchidos, KARAMANSKI (1967) obteve resultados melhores que os obtidos até então, pelo fato de serem as condições de contorno do problema satisfeitas exatamente. Entretanto, foram assumidas as hipóteses de que o pórtico suporta somente tensões axiais e é infinitamente flexível na direção perpendicular aos eixos de suas barras. Essas hipóteses, associadas ao fato de que não é admitida separação entre pórtico e painel, de certa forma inibiram o uso de sua técnica.

O avanço da técnica dos elementos finitos para análise estrutural conduziu muitos pesquisadores ao uso deste método, a fim de examinarem o complexo comportamento de pórticos preenchidos, podendo ser citados: MALLICK e SEVERN (1967), RIDDINGTON e STAFFORD-SMITH (1977), KING e PANDEY (1978), LIAUW e KWAN (1982), RIVERO (1982), DAWE e CHARALAMABOUS (1983), DHANASEKAR e PAGE (1986) e JAMAL et al. (1992).

Muitas dificuldades surgiram neste tipo de análise, principalmente no que diz respeito à separação entre pórtico e painel, ao atrito na interface, à resistência da ligação pórtico-painel e à geometria.

BARUA e MALLICK (1977) usaram o método dos elementos finitos para analisar pórticos, levando em conta a deformação axial dos elementos do pórtico, o deslizamento na interface pórtico-painel e considerando a isotropia do material do painel. Assim, sugerem expressões para o comprimento de contato e cargas de ruptura em função do parâmetro de rigidez relativa introduzido por STAFFORDSMITH (1966) e comparam os resultados com análises experimentais.

RIDDINGTON e STAFFORD-SMITH (1977, 1978), conduzindo uma série de análises numéricas, mostraram que as tensões críticas se relacionam às rupturas por 
cisalhamento e tração, que ocorrem no centro do painel. A interação entre pórtico e painel foi modelada introduzindo pares de nós independentes na interface pórticopainel. Esses pares de nós foram conectados através de uma matriz de ligação introduzida diretamente na matriz de rigidez. Separações entre as duas partes indicam tensões de tração na ligação, e nesse caso a ligação é removida e a estrutura, reavaliada. Este modelo também leva em conta o atrito na interface.

Baseados nos resultados deste trabalho, STAFFORD-SMITH e RIDDINGTON (1978) apresentaram equações para aplicação prática em projetos. A aplicação dessas equações em projetos de pórticos preenchidos leva em consideração a tensão admissível dada pelas normas correntes, tendo sido ilustrada por STAFFORDSMITH e COULL (1991).

Um aprimoramento dessa técnica foi feito por KING e PANDEY (1978), que utilizaram um elemento de junta para levar em conta a separação e o contato e, ao mesmo tempo, também avaliar o atrito entre pórtico e painel. Este trabalho foi expandido por LIAUW e KWAN (1982) para incorporar o comportamento nãolinear tensão-deformação do pórtico e do painel.

DAWE e CHARALAMBOUS (1983) apresentaram uma nova técnica através do método dos elementos finitos, em que elementos de barras e de membrana foram utilizados para modelar o pórtico e o painel, respectivamente. Foi utilizada a condensação estática dos graus de liberdade internos do painel, mantendo-se apenas os graus de liberdade associados aos nós do pórtico. A interface entre o pórtico e o painel foi modelada com elementos de ligação rígidos, tendo sido adotada uma técnica iterativa. No final de cada iteração, esses elementos rígidos são checados e, se estiverem tracionados, a técnica da condensação estática é novamente utilizada para eliminar as rigidezas correspondentes a eles.

Nos estudos mencionados anteriormente, por razões práticas, macroelementos de estado plano de tensão foram usados para modelar o painel. Para alvenaria em particular, o uso de macroelementos que proporcionam relações constitutivas 
razoáveis para a alvenaria como um todo, envolvendo juntas de argamassa e unidades, pode reduzir significativamente o tamanho da malha de elementos finitos utilizada.

Simultaneamente a esses estudos, o desenvolvimento de macroelementos para a alvenaria tem sido intensamente estudado. PAGE (1978) desenvolveu um modelo de elementos finitos para blocos de alvenaria, e seu trabalho foi, posteriormente, refinado por DHANASEKAR et al. (1985) e DHANASEKAR e PAGE (1986). DHANASEKAR e PAGE (1986), LIAUW e LO (1988) e SCHMIDT (1989) realizaram análises de pórticos preenchidos por painéis usando modelos ortotrópicos não-lineares ou modelos de fendilhamento, considerando a alvenaria como um material homogênio. Recentemente, KHATTAB (1993) desenvolveu um modelo para paredes de alvenaria de blocos de concreto armado e grauteadas.

LOURENÇO (1996) desenvolveu e validou ferramentas numéricas para análise de painéis de alvenaria, considerados como estado plano de tensão, a partir de macro e micromodelações, com base no conhecimento das propriedades das juntas de argamassa e das unidades de alvenaria. Foi desenvolvido um micromodelo constitutivo para alvenaria não-armada, incluindo amolecimento e os mecanismos de ruptura por tração, cisalhamento e compressão. A partir de estudos de técnicas de homogeneização, um macromodelo foi desenvolvido e implementado para alvenaria, incluindo os comportamentos anisotrópicos elástico e inelástico.

MEHRABI e SHING (1997) utilizaram modelos de fissuração em elementos finitos, para representar os pórticos e unidades de alvenaria e modelos de interface com coesão e dilatância. Dessa forma, conseguiram simular os efeitos da estrutura e de seus mecanismos de ruptura, exibindo a ruptura dos painéis de alvenaria confinados nos pórticos e o deslizamento das juntas de argamassa.

SEAH (1998) apresentou uma técnica prática em que cada painel do pórtico é substituído por uma mola diagonal equivalente, que tem as características cargadeformação idênticas às do painel que ela substitui. A relação carga-deformação de 
cada painel do pórtico é primeiro determinada usando o método dos elementos finitos. Os resultados dessa análise são, então, utilizados para representar o comportamento carga-deformação da diagonal equivalente.

\subsection{6 - AVALIAÇÃO EXPERIMENTAL DO COMPORTAMENTO DE PÓRTICOS PREENCHIDOS}

Com poucas exceções, muitos dos trabalhos descritos anteriormente foram baseados em modelos reduzidos. MCBRIDE (1984), YONG (1984) e AMOS (1985) conduziram uma série de ensaios de pórticos de aço preenchidos com painéis de concreto, em escala real. Dentre os parâmetros investigados nesses estudos, concluíram que as condições de interface pórtico-painel afetam a resistência e o comportamento desses sistemas. A utilização de elementos de ligação entre pilar e painel foi ineficiente no aumento da resistência última, e a rigidez inicial pouco aumentou. Uma lacuna de $20 \mathrm{~mm}$ entre a face inferior da viga superior e a face superior do painel foi testada, por esses autores, que concluíram que há elevada perda para o sistema no que se refere à sua capacidade cisalhante.

Apesar dos estudos sobre o sistema de pórticos preenchidos, muitas normas de projeto não prescrevem recomendações para pórticos preenchidos. Isso tem restringido o uso de painéis como elementos resistentes a cargas laterais.

Usualmente, quando se projeta uma estrutura de pórtico de aço ou de concreto armado utilizando-se a alvenaria como elemento de vedação, dimensiona-se o pórtico para resistir a ações da gravidade e ações laterais, tomando precauções para evitar que a carga seja transferida para os painéis. Uma grande variedade de técnicas construtivas resultaram desse conceito, sendo a mais comum utilizar uma lacuna entre fundo de viga e painel, de modo que a viga possa se deformar livremente.

Entretanto, ensaios realizados por RIDDINGTON (1984) confirmaram que nem sempre esse conceito é verdadeiro. Enquanto a lacuna resulta em uma redução da rigidez e resistência, o painel ainda participa, resistindo a uma parcela da ação horizontal aplicada. Entretanto, a eficiência do painel na resistência lateral é 
seriamente afetada. Segundo DAWE e SEAH (1989), uma redução na resistência de $50 \%$ foi determinada para ensaios com as mesmas dimensões.

No Brasil, um trabalho pioneiro sobre pórticos preenchidos foi desenvolvido por BRAGUIM (1989), que realizou análises experimentais caracterizando as ligações semi-rígidas de pórticos de aço, e, posteriormente, verificou a influência das ligações no comportamento de pórticos preenchidos. Foram ensaiados 12 pórticos metálicos preenchidos por blocos de concreto, sendo seis com ligações viga-pilar articuladas e seis com ligações semi-rígidas.

Prosseguindo os trabalhos anteriores, BRAGUIM (1993) analisou numericamente pórticos de quatro pavimentos, combinando os tipos de ligações entre perfis e a inclusão dos painéis de alvenaria, utilizando o método da diagonal equivalente. Concluiu-se que a introdução de diagonais enrijece substancialmente a estrutura, quase que independentemente do tipo de ligação viga-pilar considerada.

FONSECA (1999) analisou painéis de alvenaria confinados em estruturas reticuladas, submetidos a ações horizontais. Foi realizada uma macromodelagem do conjunto e ensaiado um protótipo constituído por pórtico de aço preenchido com alvenaria, em escala real, com um vão e um pavimento. O protótipo foi analisado numericamente utilizando um modelo constitutivo que simula o comportamento nãolinear da alvenaria, concluindo-se pela elevada influência da alvenaria na rigidez do pórtico preenchido. Neste trabalho, dar-se-á continuidade a essa pesquisa.

MORONI et al. (1994) estudaram os carregamentos cíclicos resultantes de ações sísmicas. ATKINSON e HAMMONS (1997) investigaram a resistência à tração da alvenaria, chamando sua atenção a necessidade de prescrever esse comportamento nas análises de paredes sujeitas a ações horizontais no plano e flexões fora deste. 


\section{ENSAIOS EXPERIMENTAIS}

\section{1 - INTRODUÇÃO}

Avaliou-se experimentalmente o comportamento de pórticos de aço de perfis I soldados, preenchidos com alvenaria de concreto celular autoclavado, variando diferentes parâmetros, como: relação altura/comprimento dos pórticos, argamassa utilizada nas juntas, elementos componentes da interface pórtico-painel e existência ou não de aberturas nas paredes. Foi ainda avaliado experimentalmente, a título de investigação, o comportamento de painéis pré-fabricados de concreto celular autoclavado, cujo estudo se encontra no Anexo A.

\section{2 - DESCRIÇÃO DO PROGRAMA EXPERIMENTAL}

O programa experimental constou de 12 ensaios em pórticos de aço preenchidos com alvenaria e quatro ensaios em pórticos sem preenchimento, cujas características são apresentadas resumidamente na tabela 3.1, além dos ensaios de caracterização dos materiais. A influência da relação altura/comprimento no comportamento de pórticos 
preenchidos foi avaliada através de ensaios em dois protótipos de aço, em escala real, com relações H/L iguais a 0,83 (268 cm x $322 \mathrm{~cm})$ e $0,51(268 \mathrm{~cm} \times 522 \mathrm{~cm})$, sendo oito ensaios com cada pórtico.

Os pórticos trabalharam em regime elástico, enquanto a alvenaria foi ensaiada até o colapso, a fim de obter o seu modo de ruptura. Nas interfaces pórtico-painel utilizaram-se ferros-cabelo, na forma de estribos, soldados à mesa dos pilares, ou apenas argamassa polimérica, tipo colante.

TABELA 3.1 - Características dos ensaios de pórticos preenchidos realizados

\begin{tabular}{|c|c|c|c|c|c|}
\hline ENSAIO & $\begin{array}{c}\text { RELAÇÃO } \\
\text { H/L }\end{array}$ & ARGAMASSA & INTERFACE & MATERIAL & ABERTURA \\
\hline $01 \mathrm{~A}$ & 0,83 & $\begin{array}{l}1: 3: 7,5 \text { cimen- } \\
\text { to, cal e areia }\end{array}$ & Ferros-cabelo & $\begin{array}{c}\text { Blocos - } \\
\text { CCA }\end{array}$ & Não \\
\hline 02A & 0,83 & $\begin{array}{l}1: 3: 7,5 \text { cimen- } \\
\text { to, cal e areia }\end{array}$ & Ferros-cabelo & $\begin{array}{c}\text { Blocos - } \\
\text { CCA }\end{array}$ & Não \\
\hline $03 \mathrm{~A}$ & 0,83 & Ciment-cola & Ferros-cabelo & $\begin{array}{c}\text { Blocos - } \\
\text { CCA }\end{array}$ & Não \\
\hline $04 \mathrm{~A}$ & 0,83 & Ciment-cola & Ferros-cabelo & $\begin{array}{c}\text { Blocos - } \\
\text { CCA }\end{array}$ & Não \\
\hline $05 \mathrm{~A}$ & 0,83 & Ciment-cola & $\begin{array}{l}\text { Arg. Ciment- } \\
\text { cola }\end{array}$ & $\begin{array}{c}\text { Blocos - } \\
\text { CCA }\end{array}$ & Não \\
\hline 06A & 0,83 & Ciment-cola & $\begin{array}{l}\text { Arg. Ciment- } \\
\text { cola }\end{array}$ & $\begin{array}{c}\text { Blocos - } \\
\text { CCA }\end{array}$ & Não \\
\hline 01B & 0,51 & Ciment-cola & $\begin{array}{l}\text { Arg. Ciment- } \\
\text { cola }\end{array}$ & $\begin{array}{c}\text { Blocos - } \\
\text { CCA }\end{array}$ & Não \\
\hline 02B & 0,51 & Ciment-cola & $\begin{array}{l}\text { Arg. Ciment- } \\
\text { cola }\end{array}$ & $\begin{array}{c}\text { Blocos - } \\
\text { CCA }\end{array}$ & Não \\
\hline 03B & 0,51 & Ciment-cola & $\begin{array}{l}\text { Arg. Ciment- } \\
\text { cola }\end{array}$ & $\begin{array}{c}\text { Blocos - } \\
\text { CCA }\end{array}$ & $\operatorname{Sim}$ \\
\hline 04B & 0,51 & Ciment-cola & $\begin{array}{l}\text { Arg. Ciment- } \\
\text { cola }\end{array}$ & $\begin{array}{c}\text { Blocos - } \\
\text { CCA }\end{array}$ & Sim \\
\hline $05 \mathrm{~B}^{*}$ & 0,51 & Ciment-cola & $\begin{array}{l}\text { Arg. Ciment- } \\
\text { cola }\end{array}$ & $\begin{array}{c}\text { Painéis - } \\
\text { CCA }\end{array}$ & Não \\
\hline $06 \mathrm{~B}^{*}$ & 0,51 & Ciment-cola & $\begin{array}{l}\text { Arg. Ciment- } \\
\text { cola }\end{array}$ & $\begin{array}{c}\text { Painéis - } \\
\text { CCA }\end{array}$ & Não \\
\hline
\end{tabular}

*Ver Anexo A. 
As duas primeiras paredes foram moldadas utilizando uma argamassa de traço em volume 1:3:7,5 de cimento, cal e areia. A partir da terceira parede, utilizou-se argamassa polimérica, tipo colante. Foram ensaiadas paredes constituídas de blocos estruturais maciços de CCA, com resistência média à compressão de 4,5 MPa.

Para avaliação do comportamento de pórticos preenchidos com paredes contendo aberturas, foram realizados dois ensaios, ambos com abertura de $150 \times 90 \mathrm{~cm}$. As vergas e contravergas utilizadas nesses dois ensaios foram também de concreto celular autoclavado.

$\mathrm{Na}$ interface painel-fundo de viga, executou-se o encunhamento com argamassa no traço em volume 1:3 de cimento e areia, além de um aditivo expansor para argamassa de encunhamento na proporção de $1 \%$ sobre o peso de cimento. A espessura do encunhamento foi de $3 \mathrm{~cm}$, conforme recomendação do fabricante.

Além dos ensaios de pórticos preenchidos, realizou-se uma série de ensaios para caracterização do comportamento da alvenaria e argamassa.

- Ensaios à compressão em cilindros de argamassa com as seguintes dimensões: 5 $\mathrm{cm}$ de base e $10 \mathrm{~cm}$ de altura, $10 \mathrm{~cm}$ de base e $20 \mathrm{~cm}$ de altura e $15 \mathrm{~cm}$ de base e $30 \mathrm{~cm}$ de altura, segundo a NBR 5739 - Ensaio à compressão de corpos-de-prova cilíndricos de concreto - Método de ensaio; e NBR 7215 - Ensaio de cimento Portland - Método de ensaio. Os corpos-de-prova de 15 x $30 \mathrm{~cm}^{2}$ foram utilizados para cálculo do módulo de deformação.

- Ensaios à compressão diametral de cilindros de argamassa de $10 \mathrm{~cm}$ de base e 20 cm de altura, segundo a norma NBR 7222 - Argamassas e concretos Determinação da resistência à tração por compressão diametral de corpos-deprova cilíndricos.

- Ensaios à compressão de prismas, segundo a norma ASTM E447-97 - "Standard Test Method for Compressive Strength of Laboratory Constructed Masonry”.

- Ensaios ao cisalhamento de prismas segundo a NBR 14821 - Paredes de alvenaria estrutural - Determinação da resistência ao cisalhamento. 


\section{3 - MATERIAL E MÉTODOS}

\subsection{1 - PROTÓTIPOS DE AÇO}

Para avaliação do comportamento de pórticos de aço preenchidos com alvenaria, foram utilizados dois protótipos em escala real, TIPO I e TIPO II, compostos de perfis soldados, aço ASTM A36, com relações altura/comprimento iguais a 0,83 e 0,51 , respectivamente.

\subsubsection{1 - PÓRTICO TIPO I}

O pórtico TIPO I, figura 3.1a, possuía as características geométricas dadas pela tabela 3.2. Os protótipos apresentavam bases engastadas, projetadas em função das características do gabarito de furos da laje de reação do laboratório e segundo prescrições da norma NBR 8800. Cada pilar foi ligado rigidamente ao centro de uma chapa de aço de $220 \mathrm{~mm}$ x $600 \mathrm{~mm}$ e espessura de $63,5 \mathrm{~mm}$, que por sua vez foi soldada centrada sobre outra chapa de $1100 \mathrm{~mm}$ x $600 \mathrm{~mm}$, constituindo a base do pilar. Para fixá-la, foram utilizados parafusos passantes, de aço ASTM-A325, de 25,4 mm de diâmetro, com duas porcas em cada uma das extremidades de cada parafuso, conforme figura 3.2. Os perfis utilizados foram posicionados com a maior inércia no plano da estrutura.

As ligações viga-pilar foram feitas através de cantoneiras parafusadas com abas de $63,3 \mathrm{~mm} \times 6,3 \mathrm{~mm} \times 160 \mathrm{~mm}$ de altura, espessura e comprimento, respectivamente. Dois parafusos de $16 \mathrm{~mm}$, espaçados $75 \mathrm{~mm}$, simularam as ligações semi-rígidas, figura 3.3.

Foram utilizados tirantes ligando o topo de cada pilar ao piso do laboratório, em ambos os lados, a fim de evitar a perda de estabilidade e efeitos de excentricidade no sistema. Os tirantes eram constituídos por cabos de aço de $8 \mathrm{~mm}$ de diâmetro, com passadeira regulável e fixos ao piso através de uma cantoneira de abas iguais de 50 $\mathrm{mm}$, espessura de $6,3 \mathrm{~mm}$ e dois parafusos de aço ASTM-A325 com diâmetro de $25,4 \mathrm{~mm}$, figura 3.4. 


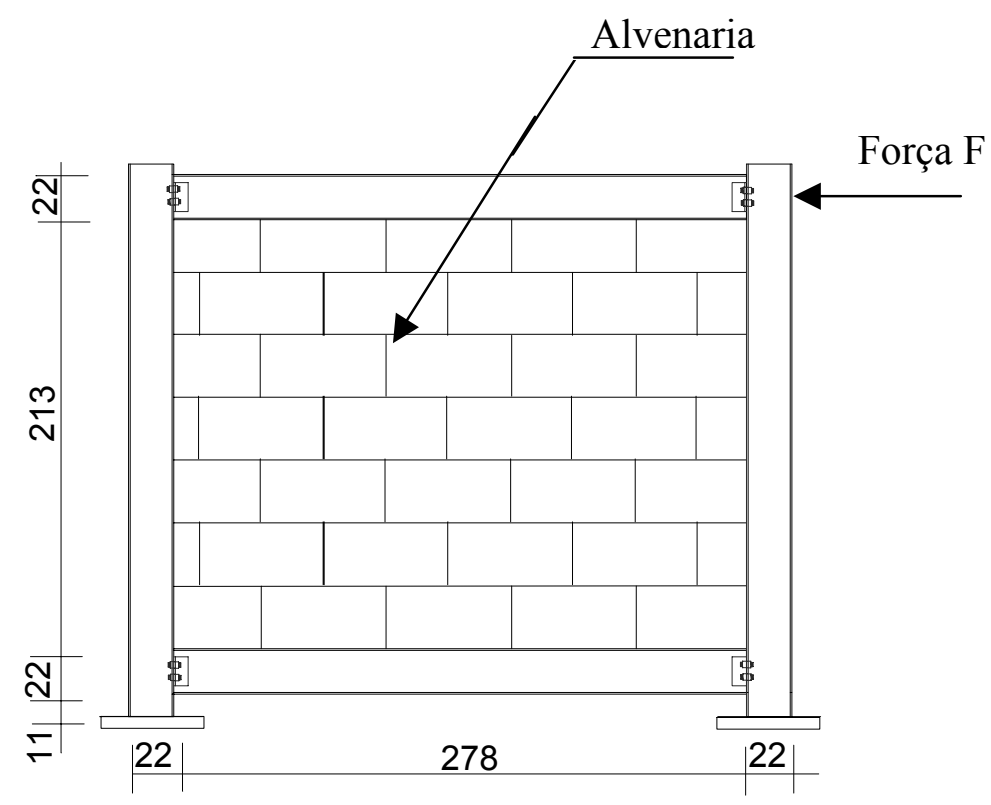

(a) Protótipo TIPO I $\quad(\mathrm{cm})$

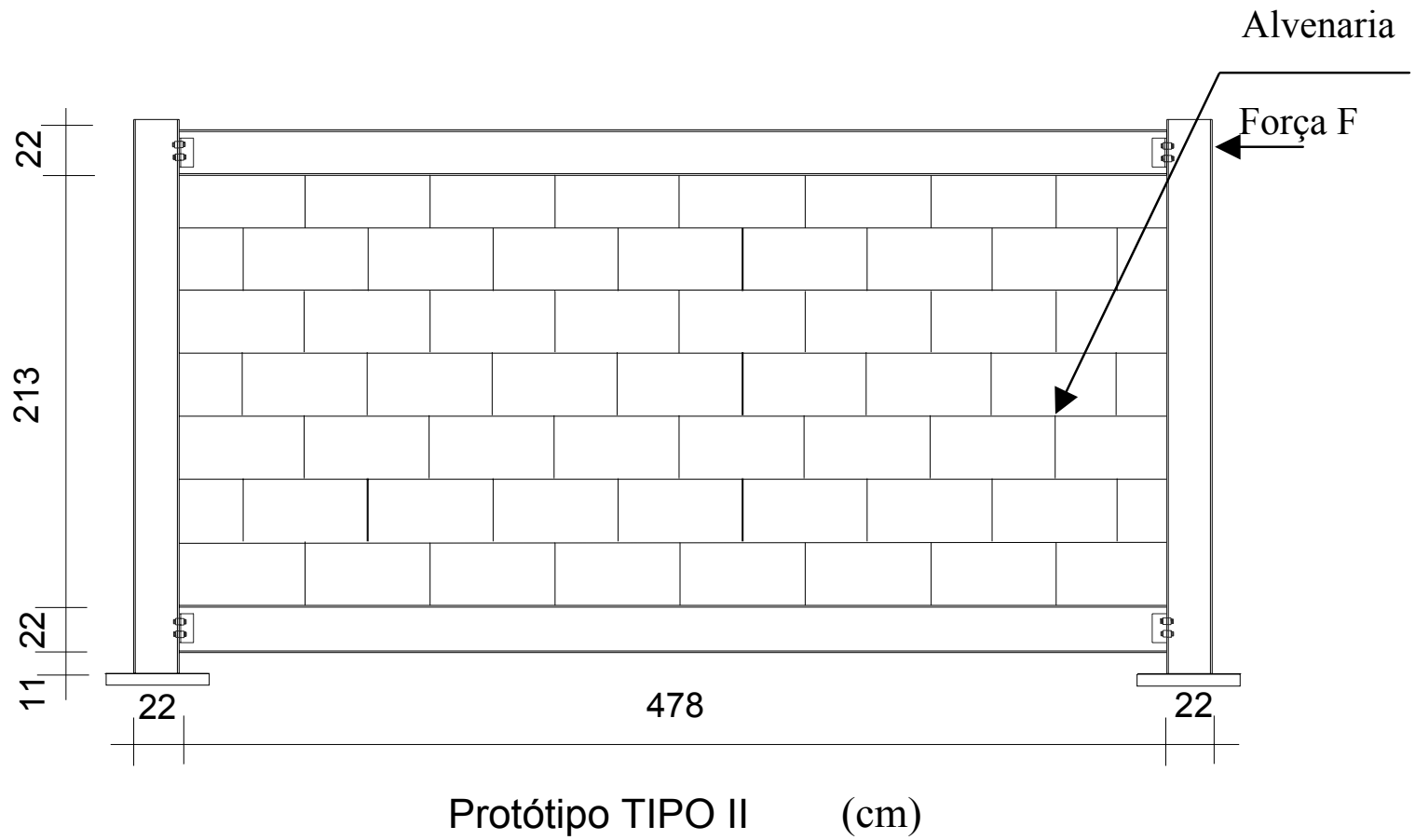

(b)

FIGURA 3.1 - Pórticos ensaiados: a) TIPO I: relação altura/comprimento=0,83 e b) TIPO II: relação altura/comprimento $=0,51$ 
TABELA 3.2 - Características geométricas do pórtico TIPO I

\begin{tabular}{|l|l|}
\hline CARACTERÍSTICA GEOMÉTRICA & ESPECIFICAÇÃO \\
\hline Comprimento dos pilares & $=268 \mathrm{~cm}$ \\
\hline Comprimento das vigas & $=300 \mathrm{~cm}$ \\
Altura da alma $\left(\mathrm{h}_{\mathrm{w}}\right)$ & $=204 \mathrm{~mm}$ \\
Espessura da alma $\left(\mathrm{t}_{\mathrm{w}}\right)$ & $=6,3 \mathrm{~mm}$ \\
Largura da mesa $\left(\mathrm{b}_{\mathrm{f}}\right)$ & $=200 \mathrm{~mm}$ \\
Espessura da mesa $\left(\mathrm{t}_{\mathrm{f}}\right)$ & $=8 \mathrm{~mm}$ \\
Ligação viga-pilar com cantoneiras & Altura das abas \\
parafusadas de abas iguais (Figura 3.3$):$ & $=63,3 \mathrm{~mm}$ \\
Comprimento & $=160 \mathrm{~mm}$ \\
Parafusos aço ASTM-A325 & 2 parafusos de $16 \mathrm{~mm}$ \\
(ligações semi-rígidas) & espaçados entre si $75 \mathrm{~mm}$
\end{tabular}

\subsubsection{2 - PÓRTICO TIPO II}

O pórtico TIPO II, figura $3.1 \mathrm{~b}$, projetado e executado para fins desta pesquisa, foi composto de perfis I soldados, aço ASTM-A36, possuindo as características geométricas, dadas pela tabela 3.3.

As bases do pórtico eram rigidamente engastadas, seguindo o modelo utilizado para o pórtico TIPO I. Foram também utilizados tirantes ligando o topo de cada pilar ao piso do laboratório, em ambos os lados, a fim de evitar perda de estabilidade e efeitos de excentricidade no sistema.

Na figura 3.5, apresenta-se um croquis do pórtico TIPO II. 


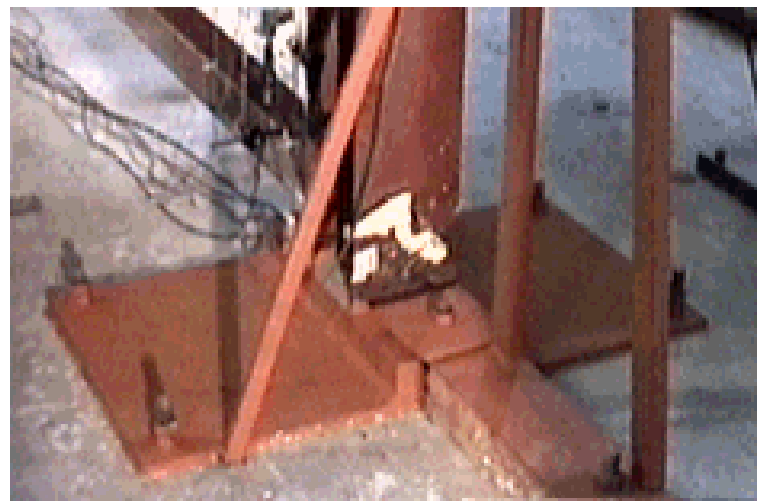

FIGURA 3.2 - Base engastada

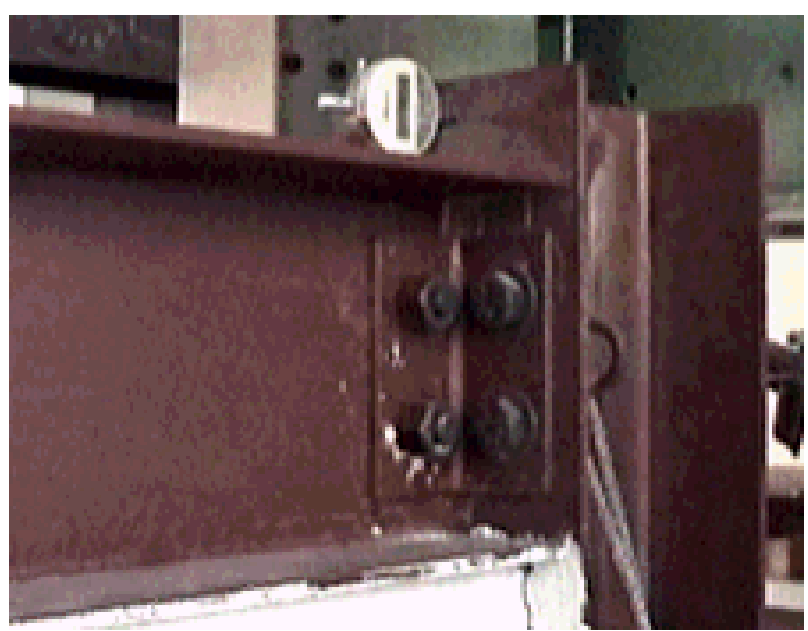

FIGURA 3.3 - Ligações semi-rígidas. Cantoneiras parafusadas
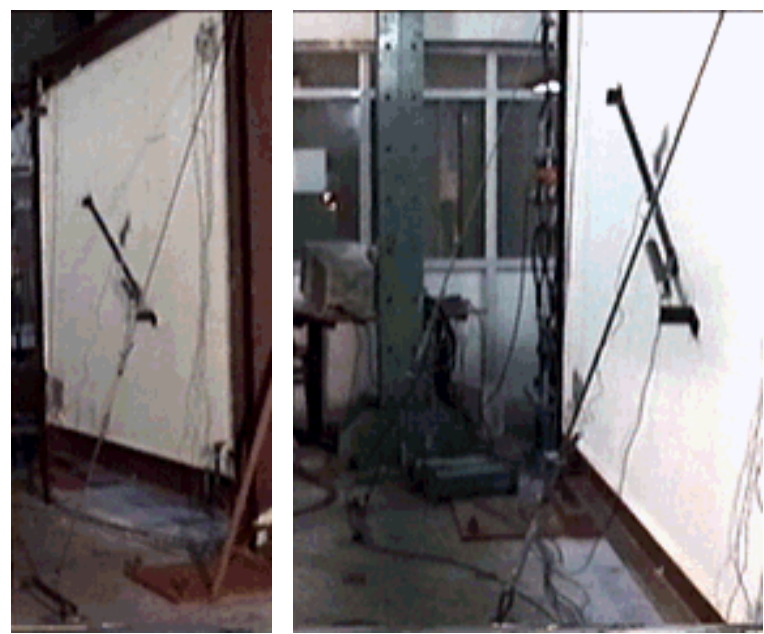

FIGURA 3.4 - Tirantes 
Análise Teórico-Experimental de Estruturas Compostas de Pórticos de Aço Preenchidos com 40 Alvenaria de Concreto Celular Autoclavado

CAPÍTULO 3 - Ensaios Experimentais 


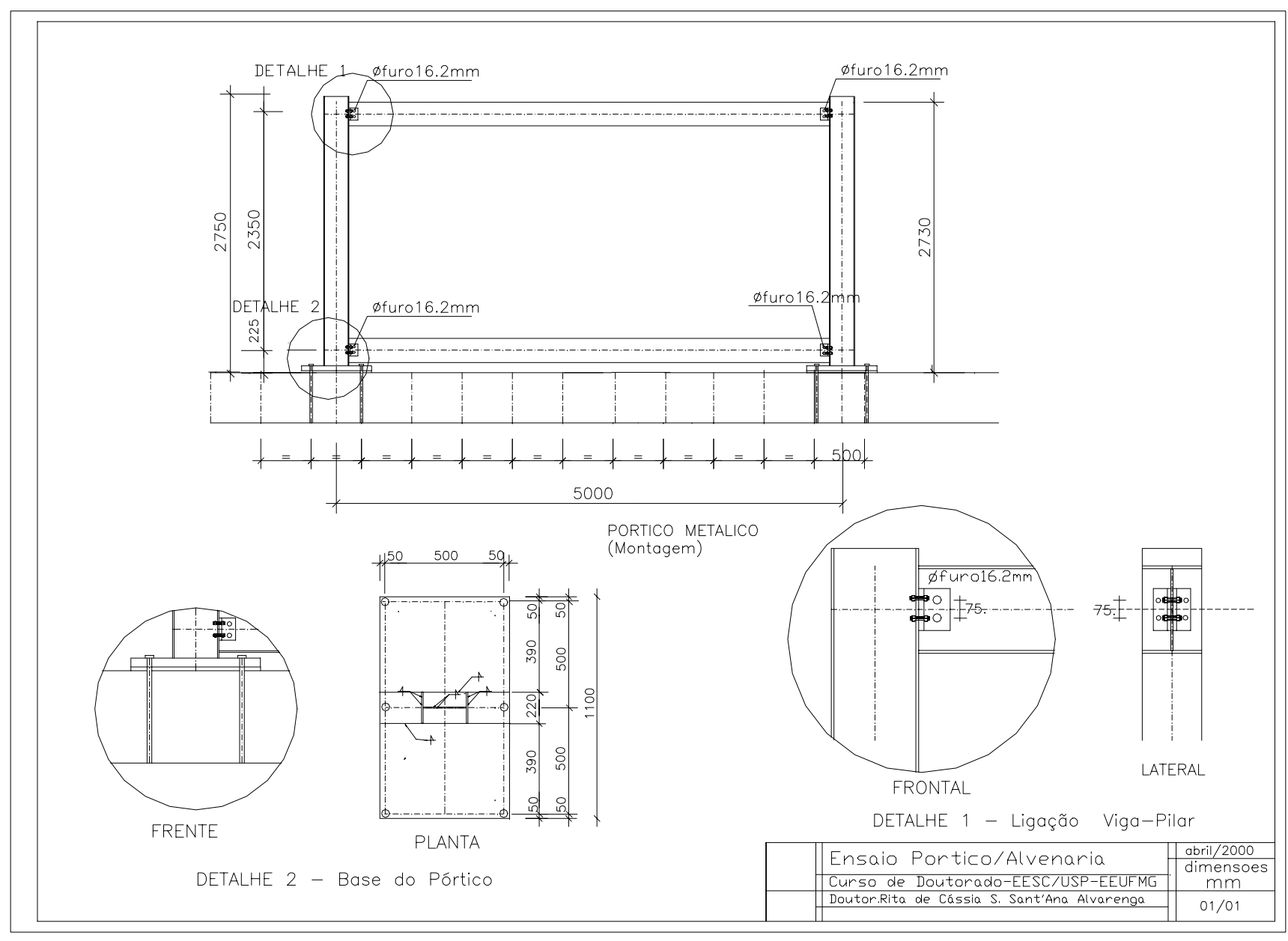

FIGURA 3.5 - Croquis do pórtico TIPO II 
TABELA 3.3 - Características geométricas do pórtico TIPO II

\begin{tabular}{|c|c|}
\hline CARACTERÍSTICA GEOMÉTRICA & ESPECIFICAÇÃO \\
\hline Comprimento dos pilares & $=268 \mathrm{~cm}$ \\
\hline Comprimento das vigas & $=500 \mathrm{~cm}$ \\
\hline $\begin{array}{l}\text { Seção transversal para vigas e pilares } \\
\qquad \begin{array}{r}\text { Altura da alma }\left(\mathrm{h}_{\mathrm{w}}\right) \\
\text { Espessura da alma }\left(\mathrm{t}_{\mathrm{w}}\right) \\
\text { Largura da mesa }\left(\mathrm{b}_{\mathrm{f}}\right) \\
\text { Espessura da mesa }\left(\mathrm{t}_{\mathrm{f}}\right)\end{array}\end{array}$ & 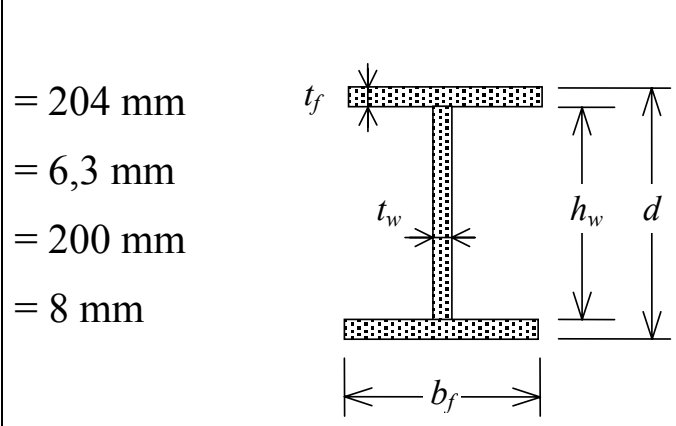 \\
\hline $\begin{array}{l}\text { Ligação viga-pilar com cantoneiras } \\
\text { parafusadas L de abas iguais: } \\
\qquad \begin{array}{l}\text { Espessura }\left(\mathrm{t}_{\mathrm{f}}\right) \\
\text { Comprimento } \\
\mathrm{d}\end{array}\end{array}$ & $\begin{array}{l}=6,3 \mathrm{~mm} \\
=140 \mathrm{~mm} \\
=63,5 \mathrm{~mm}\end{array}$ \\
\hline $\begin{array}{l}\text { Parafusos aço ASTM-A325 } \\
\text { (ligações semi-rígidas) }\end{array}$ & $\begin{array}{l}2 \text { parafusos de } 16 \mathrm{~mm} \\
\text { espaçados entre si } 75 \mathrm{~mm}\end{array}$ \\
\hline
\end{tabular}

\subsection{2 - PAREDES DE ALVENARIA}

Os blocos estruturais maciços de concreto celular autoclavado vêm sendo cada vez mais utilizados na confecção de paredes para preenchimento de pórticos de aço e de concreto armado. Esse fato se deve, principalmente, aos seguintes fatores:

- Homogeneidade.

- Baixo peso específico, em comparação com blocos de concreto usuais.

- Precisão de suas dimensões geométricas.

- Possibilidade de se trabalhar com frações de blocos, reduzindo, assim, as perdas.

- Isolamento térmico e acústico.

- Resistência.

- Durabilidade. 
Segundo a Norma Brasileira NBR-13438(1995), o concreto celular autoclavado é: "concreto leve, obtido através de um processo industrial, constituído por materiais calcários (cimento, cal ou ambos) e materiais ricos em sílica, granulados finamente. Esta mistura é expandida através da utilização de produtos formadores de gases, água e aditivos, se for o caso, sendo submetidos à pressão e temperatura através de vapor saturado. O concreto celular autoclavado contém células fechadas, aeradas e uniformemente distribuídas, devendo possuir densidade aparente de massa na faixa de 300 a $1000 \mathrm{~kg} / \mathrm{m}^{3} "$.

Neste trabalho, foram utilizados blocos estruturais maciços de concreto celular autoclavados da SICAL, com resistência média à compressão de 4,5 $\mathrm{MPa}$. A produção do concreto celular autoclavado é feita a partir de uma mistura de cimento, cal, areia, água e agente expansor (pó de alumínio). O alumínio reage com os componentes alcalinos do cimento liberando gás hidrogênio. A liberação deste gás expande a mistura formando inúmeras pequenas bolhas de ar, dispersas igualmente em toda a massa do material. A cura final do material ocorre em autoclaves, durante um período de aproximadamente 10 horas, em ambiente de vapor saturado à pressão de 12 atmosferas, originando o silicato de cálcio tetraidratado.

Os blocos utilizados na confecção dos painéis possuíam dimensões de 600 mm x 300 $\mathrm{mm} \times 150 \mathrm{~mm}$ e foram utilizados também nos ensaios de prismas, numa relação altura/espessura igual a 4 .

Tendo em vista que o processo construtivo da alvenaria é fortemente dependente da qualidade do material, bem como da mão-de-obra utilizada, procurou-se executar todos os painéis segundo as recomendações técnicas do fabricante de blocos. $\mathrm{O}$ preenchimento dos pórticos por painéis de alvenaria foi feito em quatro dias consecutivos. $\mathrm{Na}$ primeiro dia, aplicou-se argamassa Ciment-cola no contorno interno do pórtico, por meio de desempenadeira dentada, de modo a aumentar a rugosidade das faces que ficariam em contato com a alvenaria. No segundo dia, executou-se metade da parede, no terceiro a outra metade e no quarto o encunhamento do painel. 
A última fiada foi assentada com blocos de CCA, serrados de modo a manter uma folga de $3 \mathrm{~cm}$ entre o fundo da viga e os blocos dessa fiada. Para preenchimento dessa folga, utilizou-se um aditivo expansor para argamassa de encunhamento, na proporção de $1 \%$ sobre o peso do cimento, adicionado ao traço utilizado: 1:3, em volume de cimento e areia. $\mathrm{O}$ aditivo expansor plastifica as argamassas utilizadas nos encunhamentos, facilitando a sua aplicação nas frestas, aumentando a resistência e preenchendo totalmente os vazios.

Nas juntas foram utilizados dois tipos de argamassa de assentamento:

- Argamassa com traço em volume de material seco de 1:3:7,5, de cimento, cal hidratada e areia lavada média, respectivamente, conforme recomendações do fabricante dos blocos (duas primeiras paredes).

- Argamassa Ciment-cola (demais paredes).

No primeiro caso, fez-se a mistura prévia de cal e areia, constituindo a argamassa intermediária, permanencendo essa mistura em descanso por um período mínimo de 24 horas. A obtenção da argamassa final foi obtida por mistura, em betoneira, da argamassa intermediária e adição controlada de cimento, evitando, assim, a formação de grumos. A utilização de cal na argamassa tem como objetivo aumentar a flexibilidade e a trabalhabilidade, bem como a retenção de água.

As paredes foram pintadas com Hidrax, tinta à base de água e cal, para facilitar o acompanhamento dos ensaios, possibilitando melhor visualização das fissuras surgidas no decorrer destes.

Os dois primeiros ensaios de pórticos preenchidos, com argamassa de assentamento no traço 1:3:7,5, foram realizados com a idade de 20 e 28 dias, respectivamente. Já as paredes em que se utilizaram juntas de argamassa Ciment-cola foram ensaiadas com 14 dias de idade. 


\subsection{3 - INTERFACE PÓRTICO-PAINEL}

FONSECA (1999) estudou o comportamento de pórticos preenchidos com alvenaria considerando a vinculação na interface pórtico-painel constituída por aderência da argamassa de assentamento, com a junta vertical preenchida e utilizando o traço 1:2:9 de cimento, cal e areia. Esse tipo de ligação, em muitos casos, é suficiente para o bom desempenho da estrutura. No entanto, algumas situações da prática exigem a amarração da alvenaria aos pilares. Segundo o MANUAL DA SICAL (1999), como exemplo dessas situações, podem ser citados:

- Paredes sobre lajes em balanço, com ou sem viga de borda.

- Paredes de comprimento superior a $12,0 \mathrm{~m}$.

- Paredes com comprimento de 4 a $8 \mathrm{~m}$, sobre elementos estruturais muito deformáveis.

- Trechos de parede com uma extremidade livre (sem ligação com outra parede ou com outro pilar, em pelo menos metade da altura da parede), com comprimento inferior a $2 \mathrm{~h} / 3$; figura 3.6.

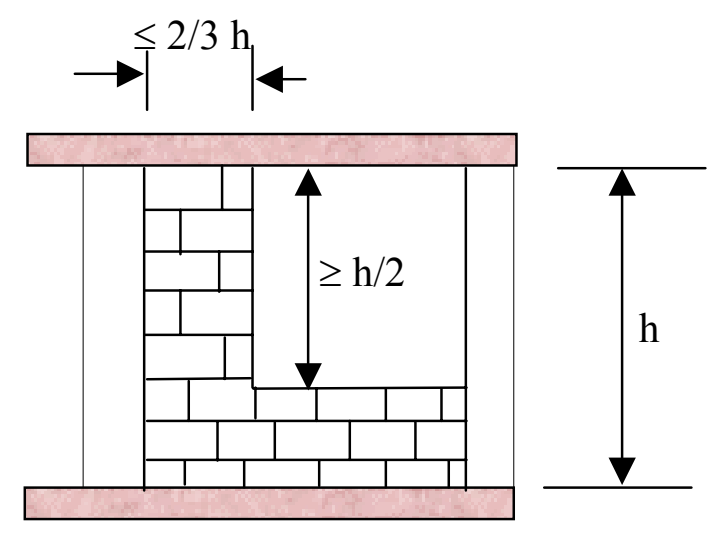

FIGURA 3.6 - Trecho de parede com extremidade livre

- Paredes submetidas a vibração contínua, por exemplo as que contêm arcondicionado suspenso ou que se ligam aos pilares-parede da caixa de elevadores.

- Paredes com extremidade superior livre, por exemplo em platibandas, paredes de varandas ou área de serviços. 
- Paredes do primeiro pavimento em edifícios sobre pilotis.

- Situações pouco comuns que podem gerar intensos esforços na interface pilar-alvenaria.

Neste trabalho, analisou-se a interface pórtico-painel utilizando dois tipos de ligação entre as partes: ligação com barras de aço (ferros-cabelo) e ligação com argamassa polimérica (argamassa Ciment-cola). Para o pórtico TIPO I, que possui relação altura/comprimento igual a 0,83 , foram realizados quatro ensaios utilizando ferrocabelo e dois ensaios sem o ferro-cabelo. Quando foram utilizados ferros-cabelo, trabalhou-se com dois tipos de argamassa de assentamento: argamassa traço 1:3:7,5 de cimento, cal e areia e argamassa Ciment-cola, efetuando-se dois ensaios com cada uma delas. Foram também realizados dois ensaios com argamassa Ciment-cola, porém sem o ferro-cabelo, totalizando-se seis ensaios com o pórtico TIPO I. Para o pórtico TIPO II, isto é, com relação altura/comprimento igual a 0,51 , utilizou-se argamassa Ciment-cola nas interfaces nos seis ensaios realizados.

\subsubsection{1 - LIGAÇÃO COM BARRAS DE AÇO (FERROS-CABELO)}

As amarrações foram executadas com um fio de aço liso (CA 60B), com $5 \mathrm{~mm}$ de diâmetro, na forma de retângulo, como ilustrado na figura 3.7a e b. Esse ferro, comumente denominado ferro-cabelo, foi soldado à mesa do pilar metálico a cada fiada.

Em estruturas de concreto armado, utiliza-se o ferro-cabelo na forma de $\mathrm{U}$, e as extremidades são embutidas nos pilares em pelo menos $5 \mathrm{~cm}$. A fixação dessas amarrações nos pilares normalmente é feita por ancoragem à base de epóxi, empregando-se, por exemplo, "compound adesivo" ou "sikadur", através de furos feitos nos pilares com broca de vídia (dois furos por amarração). Essas amarrações devem ser posicionadas na altura das juntas ímpares, a partir da terceira, considerando-se que a primeira seja a de assentamento da fiada de marcação. Nos 
casos mais críticos, citados anteriormente, deve-se posicionar o ferro-cabelo em todas as fiadas.

(a)

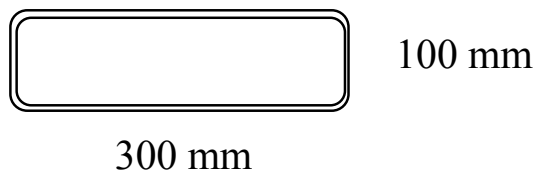

(b)

Perfil metálico

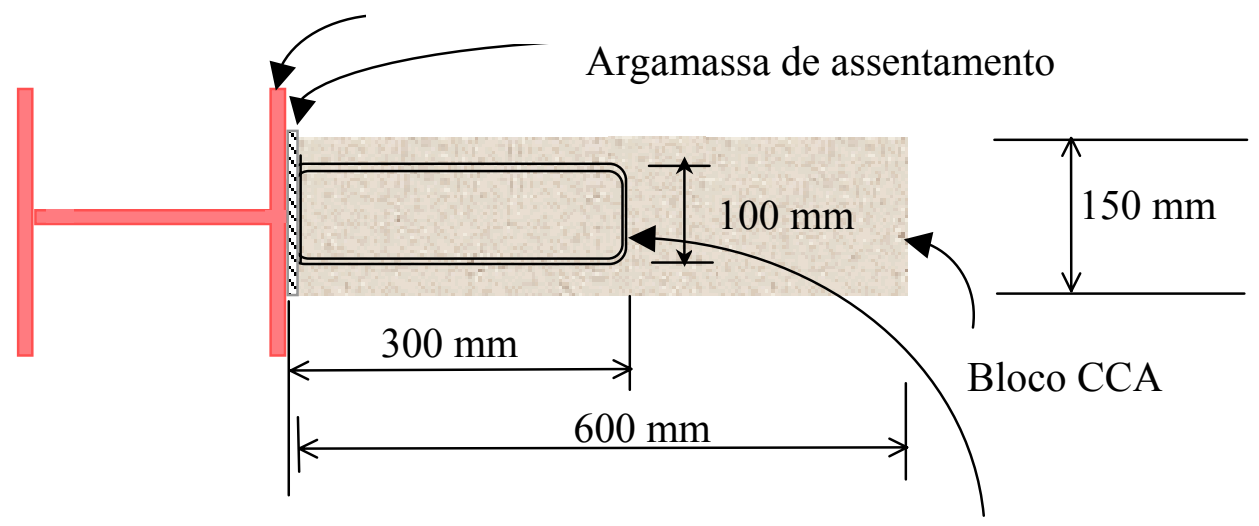

Ferro-cabelo

FIGURA 3.7 - Características do ferro-cabelo: a) detalhe do ferro-cabelo e b) seção transversal de uma fiada de bloco com ferro-cabelo soldado à mesa do pilar

\subsubsection{2 - LIGAÇÃO COM ARGAMASSA POLIMÉRICA (CIMENT-COLA)}

Utilizou-se argamassa polimérica, tipo Ciment-cola, na interface pórtico-painel, em todos os ensaios realizados, na presença ou não de ferros-cabelo. Inicialmente, foi aplicada uma camada de argamassa COLAFIX superadesiva ACIII, em todo o contorno interno do pórtico, a fim de aumentar a aderência. Essa argamassa superaderente, indicada para superfícies que requerem alta resistência ao cisalhamento, seguiu as recomendações do fabricante quanto ao preparo. É composta de agregados minerais, cimento Portland, dispersantes, plastificantes e polímeros. 


\subsection{4 - SISTEMA DE CARREGAMENTO: PÓRTICO DE REAÇÃO}

Foi projetado e construído, para fins deste estudo, um pórtico de reação de aço ASTM A36, contraventado no plano por uma barra birrotulada inclinada. Fora do plano, o travamento é feito por duas barras de perfis soldados, perpendiculares aos pilares e ligadas a um outro pórtico de reação, paralelo ao primeiro.

O carregamento aplicado nos ensaios consta de uma ação horizontal crescente, no eixo da viga superior do protótipo. Para isso foi utilizado um sistema de cilindro hidráulico, figura 3.8, fixado ao pórtico de reação e controlado por uma bomba hidráulica. O sistema mecânico foi conectado ao Sistema de Aquisição de Dados, permitindo a obtenção das leituras de carga a cada instante da aplicação.

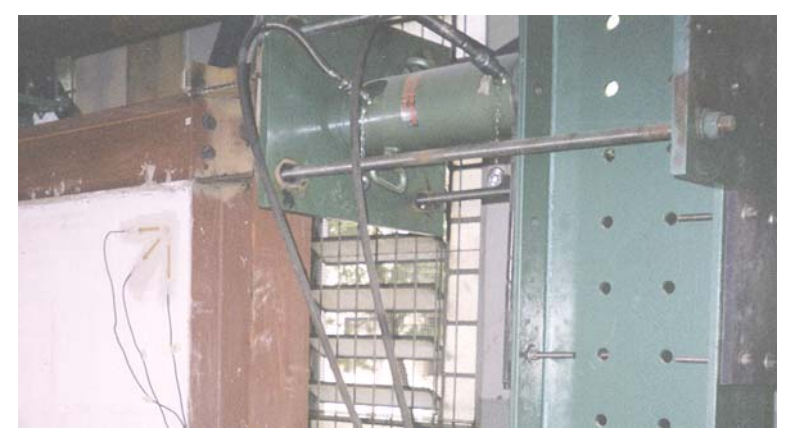

FIGURA 3.8 - Sistema de aplicação de carga (cilindro hidráulico)

A força foi aplicada na mesa externa do pilar na direção do eixo da viga, comprimindo-a. No ponto de aplicação da força ao pilar foram utilizados dois enrijecedores, de cada um dos lados da alma nas direções das mesas da viga superior do protótipo.

Para impedir o levantamento da viga superior, foram colocados rolos entre a face superior da viga do protótipo e a face inferior da viga do pórtico de reação. Assim, o deslocamento vertical ascendente do protótipo foi parcialmente impedido e, ao mesmo tempo, qualquer tendência de deslocamento horizontal foi liberada. 
Na tabela 3.4, apresentam-se as características geométricas do pórtico de reação, e na figura 3.9 é mostrado um croquis do conjunto protótipo TIPO I - Pórtico de reação.

TABELA 3.4 - Características geométricas do pórtico de reação

\begin{tabular}{|c|c|}
\hline CARACTERÍSTICA GEOMÉTRICA & ESPECIFICAÇÃO \\
\hline Comprimento dos pilares & $=315 \mathrm{~cm}$ \\
\hline Comprimento da viga & $=850 \mathrm{~cm}$ \\
\hline $\begin{array}{l}\text { Seção transversal dos pilares } \\
\qquad \begin{array}{r}\text { Altura da alma }\left(\mathrm{h}_{\mathrm{w}}\right) \\
\text { Espessura da alma }\left(\mathrm{t}_{\mathrm{w}}\right) \\
\text { Largura da mesa }\left(\mathrm{b}_{\mathrm{f}}\right) \\
\text { Espessura da mesa }\left(\mathrm{t}_{\mathrm{f}}\right)\end{array}\end{array}$ & 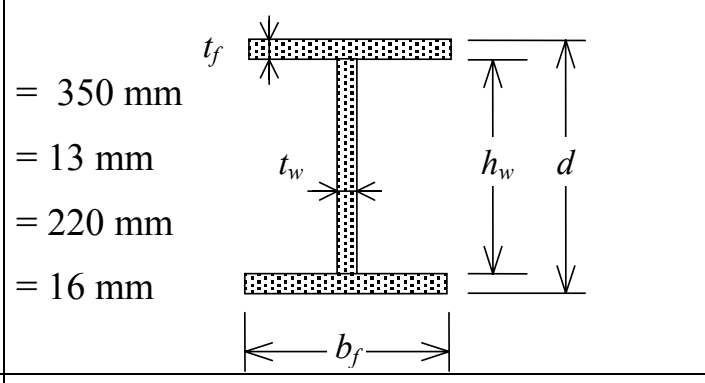 \\
\hline $\begin{array}{l}\text { Seção transversal da viga } \\
\qquad \begin{array}{r}\text { Altura da alma }\left(\mathrm{h}_{\mathrm{w}}\right) \\
\text { Espessura da alma }\left(\mathrm{t}_{\mathrm{w}}\right) \\
\text { Largura da mesa }\left(\mathrm{b}_{\mathrm{f}}\right) \\
\text { Espessura da mesa }\left(\mathrm{t}_{\mathrm{f}}\right)\end{array}\end{array}$ & 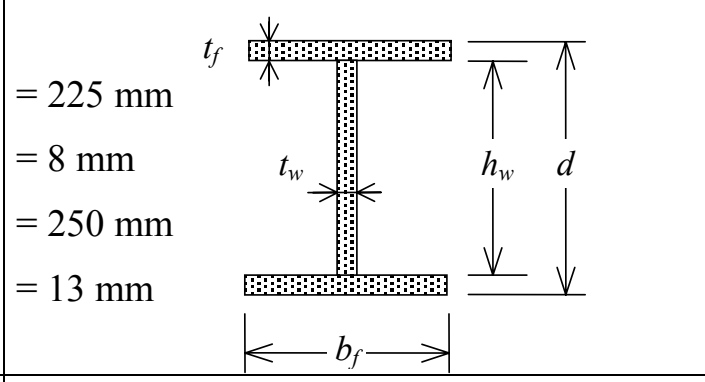 \\
\hline $\begin{array}{l}\text { Ligação viga-pilar com chapas de topo } \\
\text { soldadas na extremidade da viga e } \\
\text { parafusadas nos pilares: } \\
\text { Espessura }\left(\mathrm{t}_{\mathrm{f}}\right) \\
\text { Largura } \\
\text { Altura }\end{array}$ & 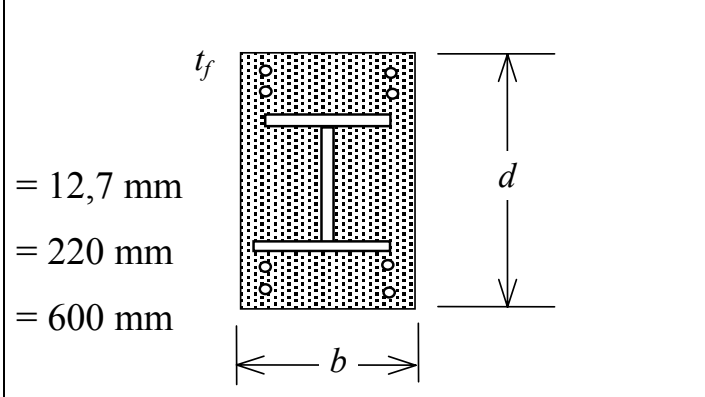 \\
\hline $\begin{array}{l}\text { Parafusos aço ASTM-A325 } \\
\text { (ligações semi-rígidas) }\end{array}$ & $\begin{array}{l}\text { - } 8 \text { parafusos sextavados de } 7 / 8 " \text { de } \\
\text { diâmetro/chapa } \\
\text { - comprimento 2" }\end{array}$ \\
\hline $\begin{array}{l}\text { Seção transversal do contraventamento } \\
\qquad \begin{array}{r}\text { Altura da alma }\left(\mathrm{h}_{\mathrm{w}}\right) \\
\text { Espessura da alma }\left(\mathrm{t}_{\mathrm{w}}\right) \\
\text { Largura da mesa }\left(\mathrm{b}_{\mathrm{f}}\right) \\
\text { Espessura da mesa }\left(\mathrm{t}_{\mathrm{f}}\right)\end{array}\end{array}$ & 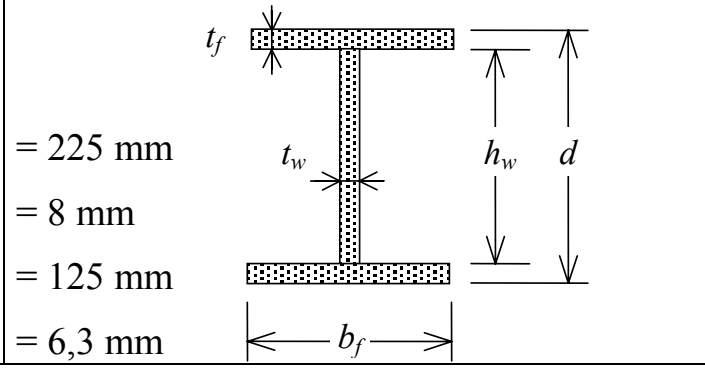 \\
\hline
\end{tabular}




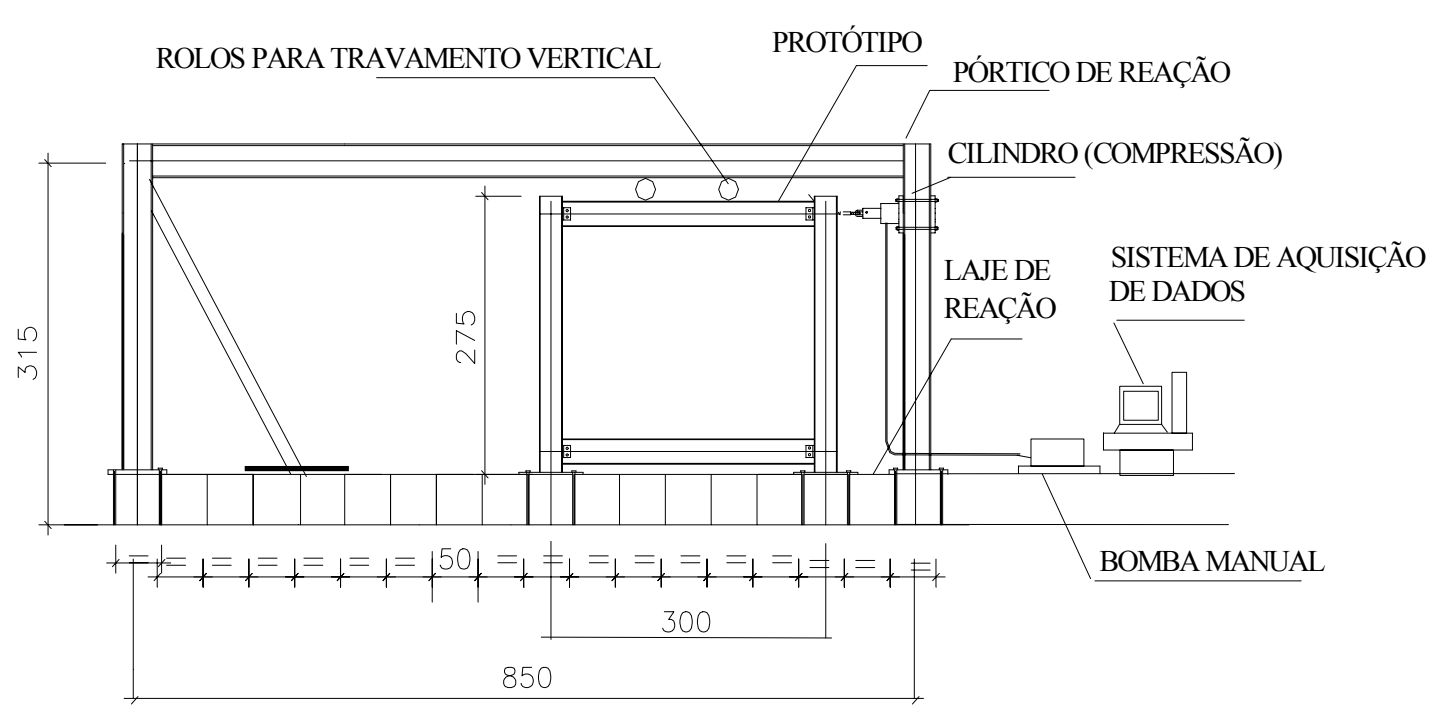

FIGURA 3.9 - Croquis do conjunto protótipo-pórtico de reação.

Dimensões $(\mathrm{cm})$

Para computar as respostas à ação do carregamento atuante sobre a estrutura, foram utilizados diferentes aparelhos e dispositivos, colocados em posições estratégicas na face frontal do conjunto pórtico-painel. A fim de medir as deformações e deslocamentos em diversos pontos do pórtico e da parede, foram utilizados cinco transdutores de deslocamento, oito extensômetros e oito relógios comparadores. A instrumentação das paredes sem aberturas é apresentada na figura 3.10a e a instrumentação da abertura o é na figura $3.10 \mathrm{~b}$. A figura 3.10c indica a legenda da figura 3.10a.

A mesma instrumentação foi utilizada para quase todos os ensaios, com exceção dos de painéis com abertura e dos ensaios de pórticos sem preenchimento. Nestes últimos ensaios foram utilizados três transdutores de deslocamento medindo, respectivamente, os deslocamentos laterais globais do protótipo e do pórtico de reação e o deslocamento do protótipo fora de seu plano. Nas paredes com 

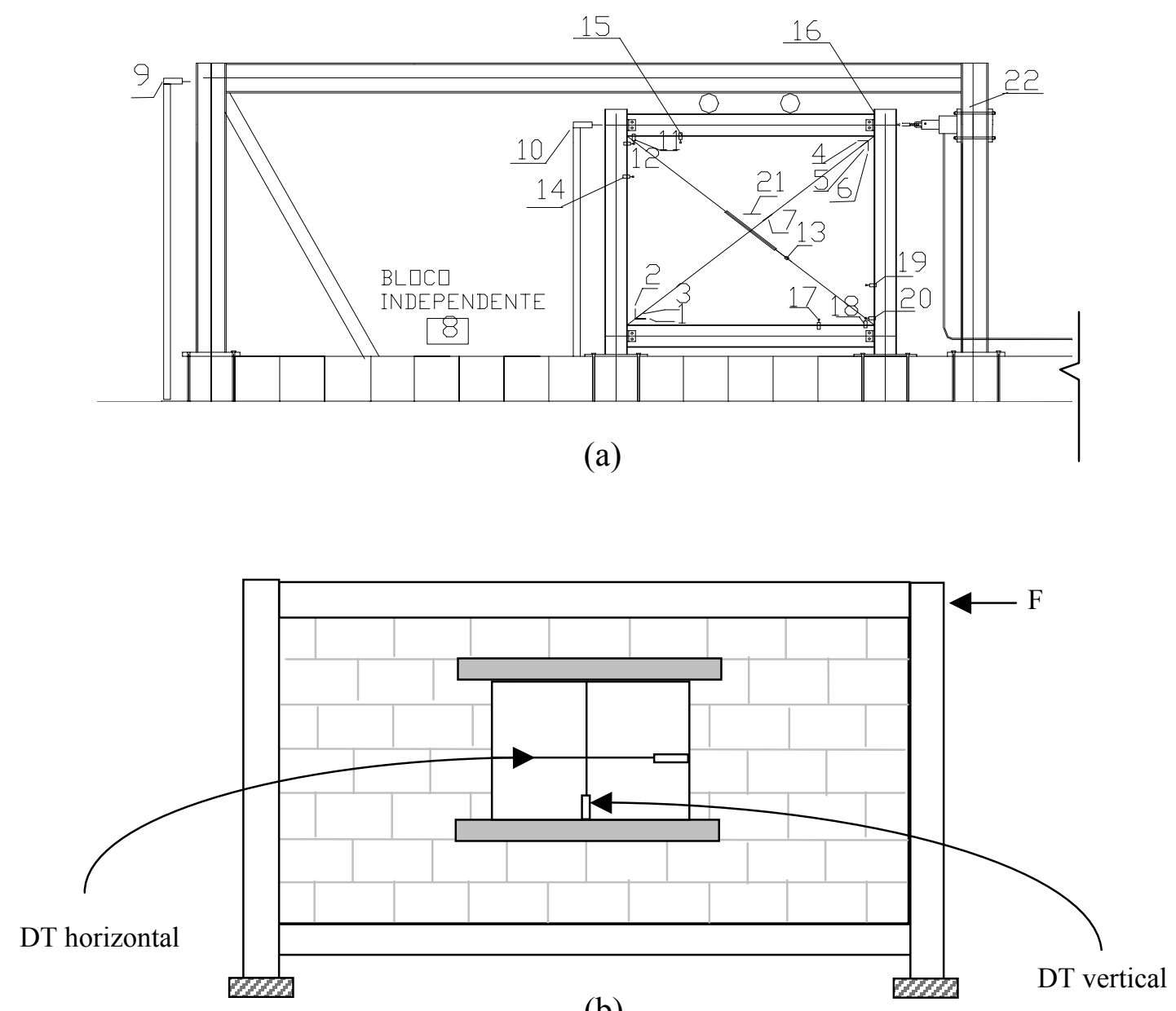

(b)

\begin{tabular}{|c|c|c|}
\hline 1 & : Extensômetro horizontal inferior & 12 : DT-horizontal superior \\
\hline 2 & : Extensômetro vertical inferior & 13 : DT-diagonal central \\
\hline 3 & : Extensômetro diagonal inferior & : Relógio comparador horiz. superior \\
\hline 4 & : Extensômetro horizontal superior & 15 : Relógio comp. vertical superior \\
\hline 5 & : Extensômetro diagonal superior & 16 : Relógio comp. cantoneira direita \\
\hline 6 & : Extensômetro vertical superior & : Relógio comparador vertical inferior \\
\hline 7 & : Extensômetro diagonal central & : Relógio comparador vertical inferior \\
\hline 8 & : Extensômetro bloco independente & : Relógio comparador horiz. inferior \\
\hline 9 & : DT-lateral global pórt. de reação & : Relógio comparador horiz. Inferior \\
\hline 10 & : DT-lateral global do protótipo & 21 : Relógio comp. flambagem lateral \\
\hline & : DT-vertical superior & 22 : Transdutor de pressão \\
\hline
\end{tabular}

FIGURA 3.10 - Instrumentação dos ensaios: a) paredes sem aberturas ou painéis, b) paredes com aberturas (instrumentação adicional) e c) legenda 
abertura, foram retirados o extensômetro e o transdutor de deslocamento (DT) da diagonal central e colocados dois DT's nas direções vertical e horizontal na abertura, figura $3.10 \mathrm{~b}$.

Para os pórticos preenchidos com alvenaria sem abertura, os transdutores de deslocamento foram utilizados para medir: os deslocamentos laterais globais do protótipo (DT 01) e do pórtico de reação (DT 02); as fissuras no centro da diagonal comprimida (DT 03); e o descolamento entre pórtico e painel em um dos cantos tracionados, isto é, os deslocamentos relativos entre pórtico e painel nas direções horizontal e vertical (DT 04 e DT 05).

O DT 01, marca TML, tipo SDP-50C, com capacidade de leitura de deslocamentos de até $50 \mathrm{~mm}$, voltagem de excitação recomendada de 1 a $2 \mathrm{~V}$ e sensibilidade de centésimo de $\mathrm{mm}$, foi colocado no pilar do protótipo na direção do eixo da viga superior, para medir o deslocamento lateral global do corpo-de-prova, figura 3.11.

O DT 02, com as mesmas características do DT 01, foi colocado no pilar do pórtico de reação na direção do eixo da viga, de modo a medir o deslocamento lateral global do pórtico de reação.

Em ambos os casos (DT's 01 e 02), utilizou-se um sistema de suporte totalmente independente do modelo pórtico-painel, de forma a eliminar possíveis interferências.

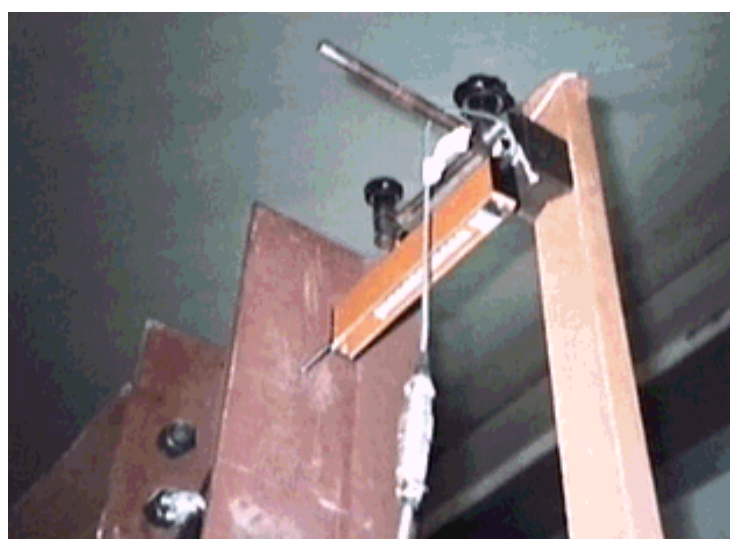

FIGURA 3.11 - Transdutor de deslocamento lateral global 
Foi colocado um transdutor de deslocamento DT 03 no centro do painel, na direção da diagonal tracionada, com as mesmas características de DT 01 e DT 02. Para fixação desse aparelho, utilizou-se um aparato que possibilita ampliar o comprimento a ser medido, figura 3.12 .
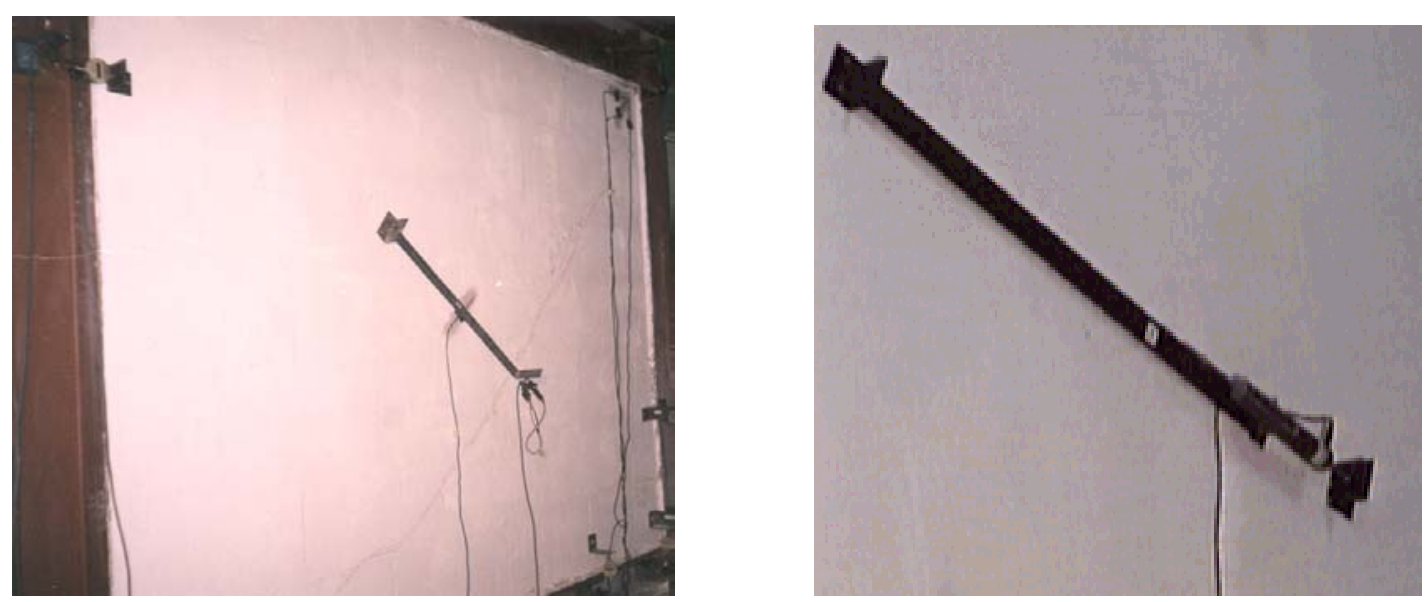

FIGURA 3.12 - Transdutor de deslocamento da diagonal central: a) visão geral e b) detalhe

Para fixação dos DT's, foram utilizados suportes magnéticos. Os DT's foram conectados ao Sistema de Aquisição de Dados por cabos tipo manga, compostos por pares de fios de 5 e $10 \mathrm{~m}$ de comprimento, trançados e envolvidos por blindagem.

Com o objetivo de mapear o descolamento pórtico-painel na interface correspondente à diagonal tracionada, foram utilizados dois transdutores de deslocamento (DT 04 e DT 05) e seis relógios comparadores de leituras digital e analógica, sendo quatro instrumentos em cada um dos cantos tracionados: superior esquerdo e inferior direito (face frontal).

Os DT's 04 e 05 foram fixados nas extremidades do pilar e da viga, respectivamente, para captar o descolamento entre pórtico e painel neste canto, ou seja, os deslocamentos relativos entre pórtico-painel nas direções horizontal e vertical. Ambos os transdutores eram da marca TML, tipo SDP, com capacidade de leitura de 
deslocamentos de até $25 \mathrm{~mm}$, voltagem de excitação recomendada de 1 a $2 \mathrm{~V}$ e sensibilidade de centésimo de mm, figura 3.13.

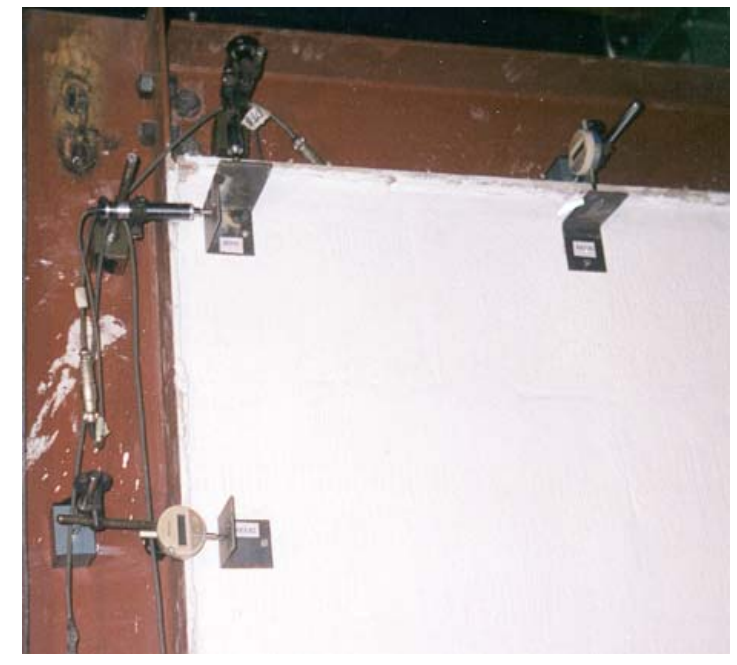

FIGURA 3.13 - Transdutores de deslocamentos horizontal e vertical superiores e relógios comparadores

Foram colocados dois relógios comparadores no canto superior esquerdo distantes 50 cm dos DT's ali posicionados, nas direções horizontal e vertical. No canto inferior direito do painel foram também instalados quatro relógios comparadores, sendo dois na horizontal e dois na vertical, distantes $50 \mathrm{~cm}$ um do outro, sendo um deles distante $10 \mathrm{~cm}$ do canto do conjunto pórtico-painel.

Um relógio comparador de leitura digital foi acoplado na ligação superior direita viga-pilar, para medir os deslocamentos relativos nessa região e avaliar os níveis de deformação da cantoneira. Foi ainda utilizado um relógio comparador digital no centro do painel, na direção ortogonal a ele, de modo a medir deslocamentos resultantes da instabilidade do conjunto pórtico-painel fora de seu plano, figura 3.14.

Foram utilizados sete extensômetros no painel de alvenaria, de forma a mapear a sua distribuição de deformações e, conseqüentemente, de tensões. Foram posicionados na face frontal do painel três extensômetros em cada um dos cantos comprimidos (superior direito e inferior esquerdo), formando uma roseta de deformações em 
ângulos $\theta$ em relação à horizontal iguais a $0^{\circ}, 37,5^{\circ}$ e $90^{\circ}$ para o pórtico TIPO I e $0^{\circ}$, $24^{\circ}$ e $90^{\circ}$ para o pórtico TIPO II, coincidindo com as direções horizontal, diagonal e vertical do painel, figura 3.15 .

$\mathrm{Na}$ região central e na direção da diagonal comprimida foi colocado um extensômetro para medir os níveis de deformação. Os extensômetros utilizados eram da marca Kyowa, do tipo KC-70-120-A1-11. A descrição do sistema de aquisição de dados e a calibração da instrumentação são apresentados no Anexo B.

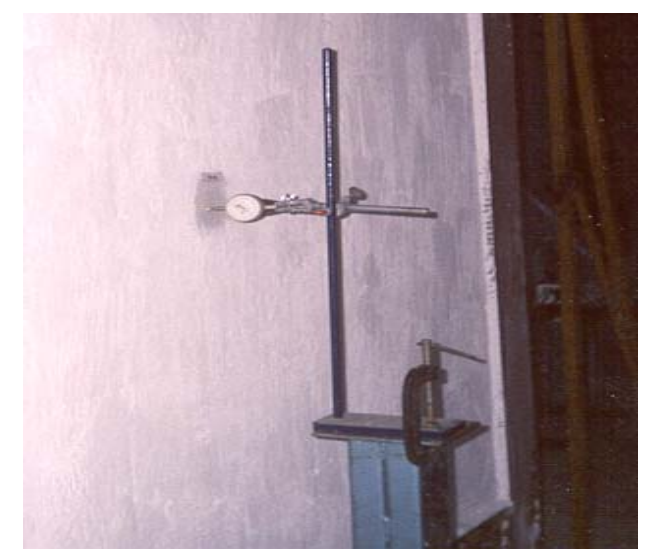

FIGURA 3.14 - Relógio comparador central ortogonal à parede

A fim de medir possíveis interferências térmicas presentes no ambiente de ensaio, foi fixado um extensômetro em um bloco independente com as mesmas características dos blocos utilizados na confecção das paredes. 

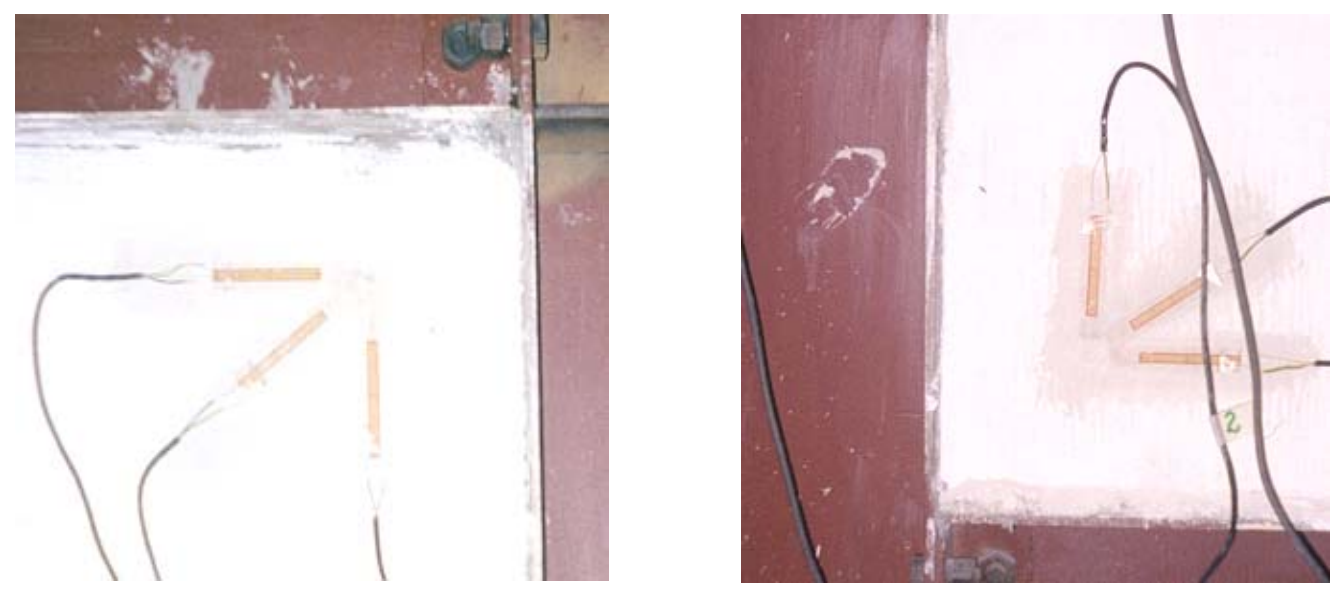

FIGURA 3.15 - Extensômetros: a) roseta do canto superior direito e b) roseta do canto inferior esquerdo

\section{4 - EXECUÇÃO DOS ENSAIOS DE PÓRTICOS}

Em todos os ensaios realizados foi aplicada uma ação horizontal no eixo da viga superior do protótipo, através de um sistema composto por cilindro hidráulico, célula de pressão e bomba. A ação foi aplicada de 10,0 em 10,0 kN. Nos ensaios de pórticos preenchidos, aplicou-se a ação horizontal até a ruptura do painel de alvenaria e de modo a manter o pórtico sempre em regime elástico.

Nos ensaios dos pórticos sem preenchimento, também tomou-se o cuidado de não ultrapassar o limite elástico destes. A cada etapa de aplicação do carregamento, os relógios comparadores, de leitura digital, eram lidos após um minuto do término do estágio. Em cada uma das etapas, o tempo gasto para leitura dos relógios variou entre cinco e sete minutos.

\subsection{1 - ENSAIOS DE PÓRTICOS DE AÇO SEM PREENCHIMENTO}

Ambos os pórticos foram ensaiados sem preenchimento, antes e depois da execução das paredes. Estes ensaios tiveram como objetivos:

- comprovar que os protótipos ensaiados trabalharam em regime elástico; 
- determinar a rigidez dos pórticos sem preenchimento e comparar este valor com a rigidez obtida por ocasião do preenchimento deles por alvenaria.

Os resultados obtidos são apresentados no item 3.5.

\subsection{2 - ENSAIOS DE PÓRTICOS DE AÇO PREENChIDOS COM ALVENARIA}

Foram realizados 12 ensaios de pórticos de aço preenchidos com alvenaria, sendo seis ensaios com o pórtico TIPO I e seis com o TIPO II, que possuem relação altura/comprimento iguais a 0,83 e 0,51 , respectivamente. A descrição das características adotadas em cada ensaio encontra-se na tabela 3.1. Na figura 3.16, apresenta-se o pórtico TIPO I, já devidamente instrumentado para ser ensaiado.

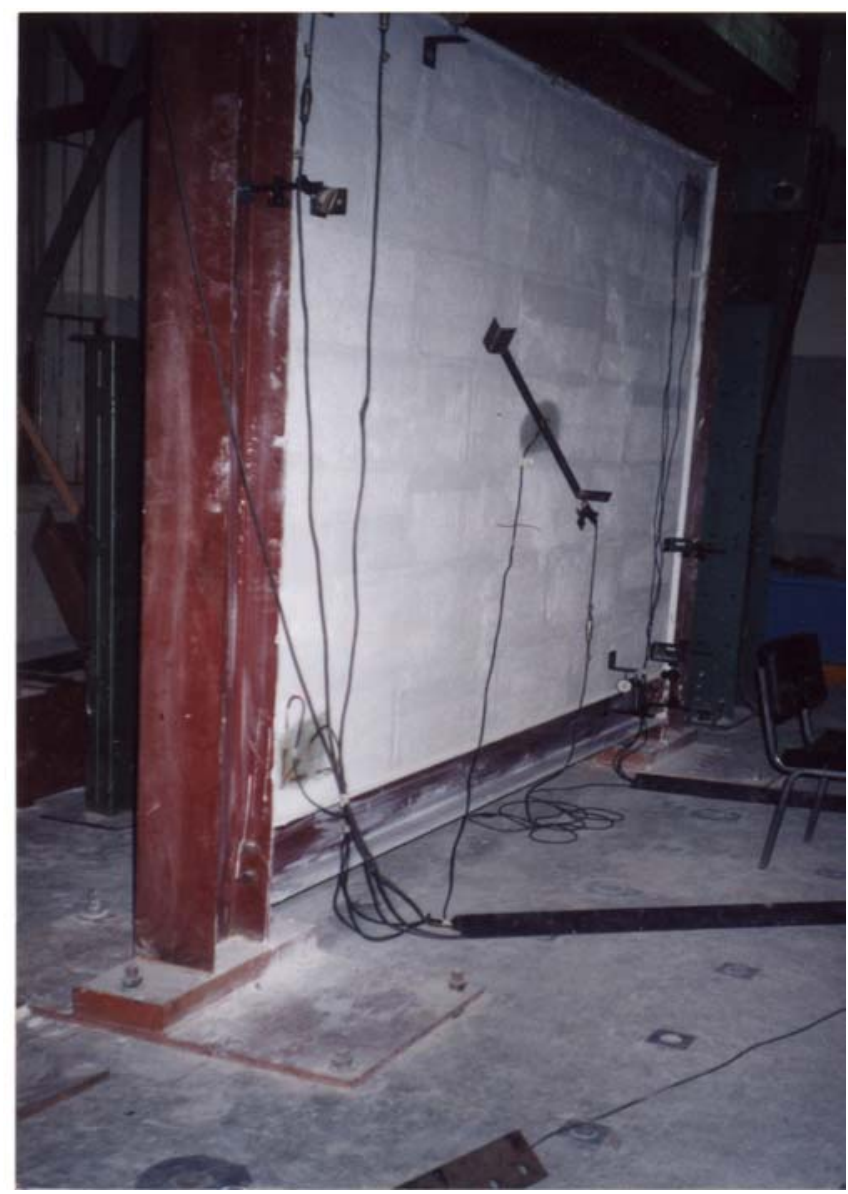

FIGURA 3.16 - Ensaio pórtico TIPO I 


\subsection{3 - ENSAIOS DE CARACTERIZAÇÃO DA ALVENARIA E ARGAMASSA}

Foram ensaiados prismas formados por blocos do mesmo lote daqueles utilizados na construção das paredes e argamassa da mesma mistura daquela utilizada nas juntas horizontais e verticais das paredes. Esses prismas foram ensaiados à compressão e ao cisalhamento, conforme descrito nos tópicos subseqüentes. Foi também obtido o módulo de deformação desses prismas.

Para caracterização da argamassa de assentamento, foram moldados cilindros de 5 $\mathrm{cm}$ de base e $10 \mathrm{~cm}$ de altura e de $15 \mathrm{~cm}$ de base e $30 \mathrm{~cm}$ de altura, ensaiados à compressão axial, e cilindros de $10 \mathrm{~cm}$ de base e $20 \mathrm{~cm}$ de altura, ensaiados à compressão diametral. Foram também obtidos os módulos de deformação inicial das argamassas utilizadas nas juntas e da argamassa do encunhamento, empregando-se cilindros de $15 \mathrm{~cm}$ de base e $30 \mathrm{~cm}$ de altura.

\subsubsection{1 - ENSAIOS DE PRISMAS À COMPRESSÃO}

Foram ensaiados corpos-de-prova segundo as prescrições da ASTM E447-97, constituídos de meio bloco/bloco inteiro/ meio bloco, figura 3.17. Os meios blocos foram serrados longitudinalmente e intercalados com um bloco inteiro, ligados por juntas horizontais de $10 \mathrm{~mm}$ e $5 \mathrm{~mm}$, para as argamassas de traço 1:3:7,5 e Cimentcola, respectivamente. A carga foi aplicada a uma velocidade média de 1,5 kN/s. Foi realizada a leitura dos instrumentos a cada etapa de $15 \mathrm{kN}$, após um minuto do instante em que se atingia a carga daquele estágio. Os resultados obtidos encontramse na tabela C.1, do Anexo C.

$\mathrm{O}$ valor médio da resistência à compressão de prismas executados com argamassa Ciment-cola foi de 2,60 MPa, correspondendo a uma eficiência de 0,58. Denominase eficiência a relação entre a resistência média à compressão dos prismas ensaiados e a resistência média à compressão dos blocos utilizados na confecção dos prismas. Nos ensaios realizados, esse valor foi de 4,5 MPa. Como grande parte dos ensaios foi 
realizada com argamassa Ciment-cola, esse valor foi adotado genericamente para efetuação do cálculo teórico e da modelagem numérica. Na figura 3.18, apresenta-se uma foto de um dos ensaios de prisma à compressão.
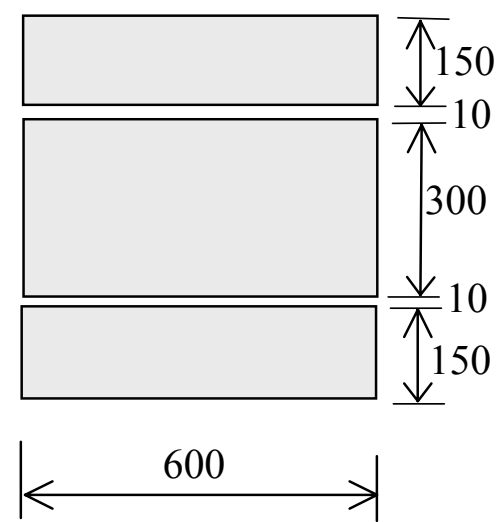

(a)
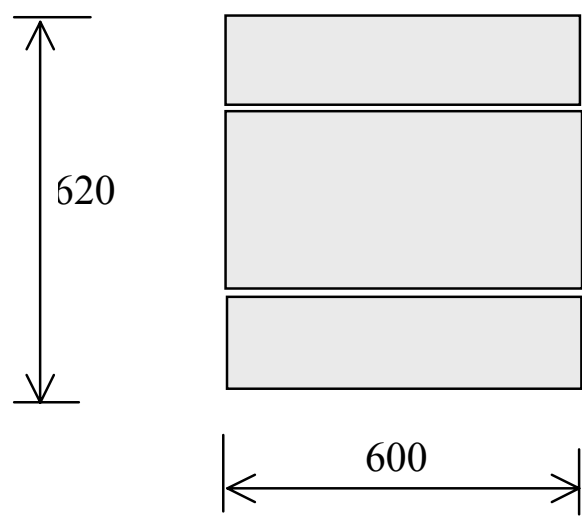

(b)

FIGURA 3.17 - Prismas de meio bloco/bloco inteiro/meio bloco: a) argamassa de traço 1:3:7,5 e b) argamassa Ciment-cola. Dimensões: mm

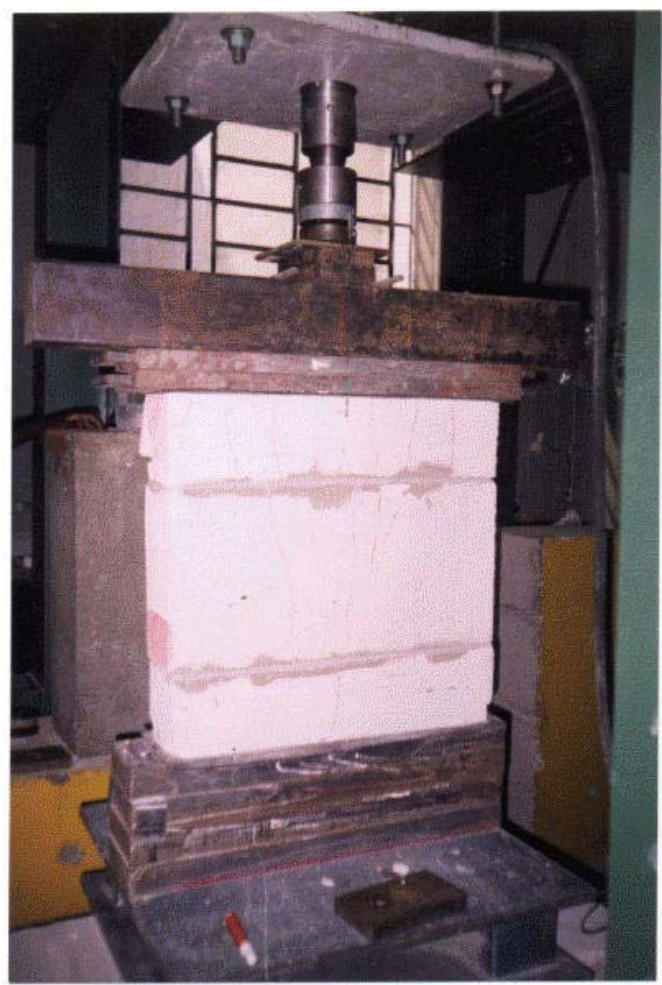

FIGURA 3.18 - Ensaio de prisma à compressão 


\subsubsection{2 - ENSAIOS DE PRISMAS AO CISALHAMENTO}

Foram moldados prismas com juntas de argamassa Ciment-cola, segundo as prescrições da NBR 14321 - Paredes de alvenaria estrutural - Determinação da resistência ao cisalhamento.

Utilizando-se prismas similares àqueles moldados para ensaios à compressão, foi idealizada uma montagem, a fim de ensaiá-los ao cisalhamento. Na figura 3.19, apresenta-se um croquis da montagem. $\mathrm{O}$ objetivo desses ensaios foi determinar a tensão convencional de cisalhamento da alvenaria utilizada na confecção dos painéis.

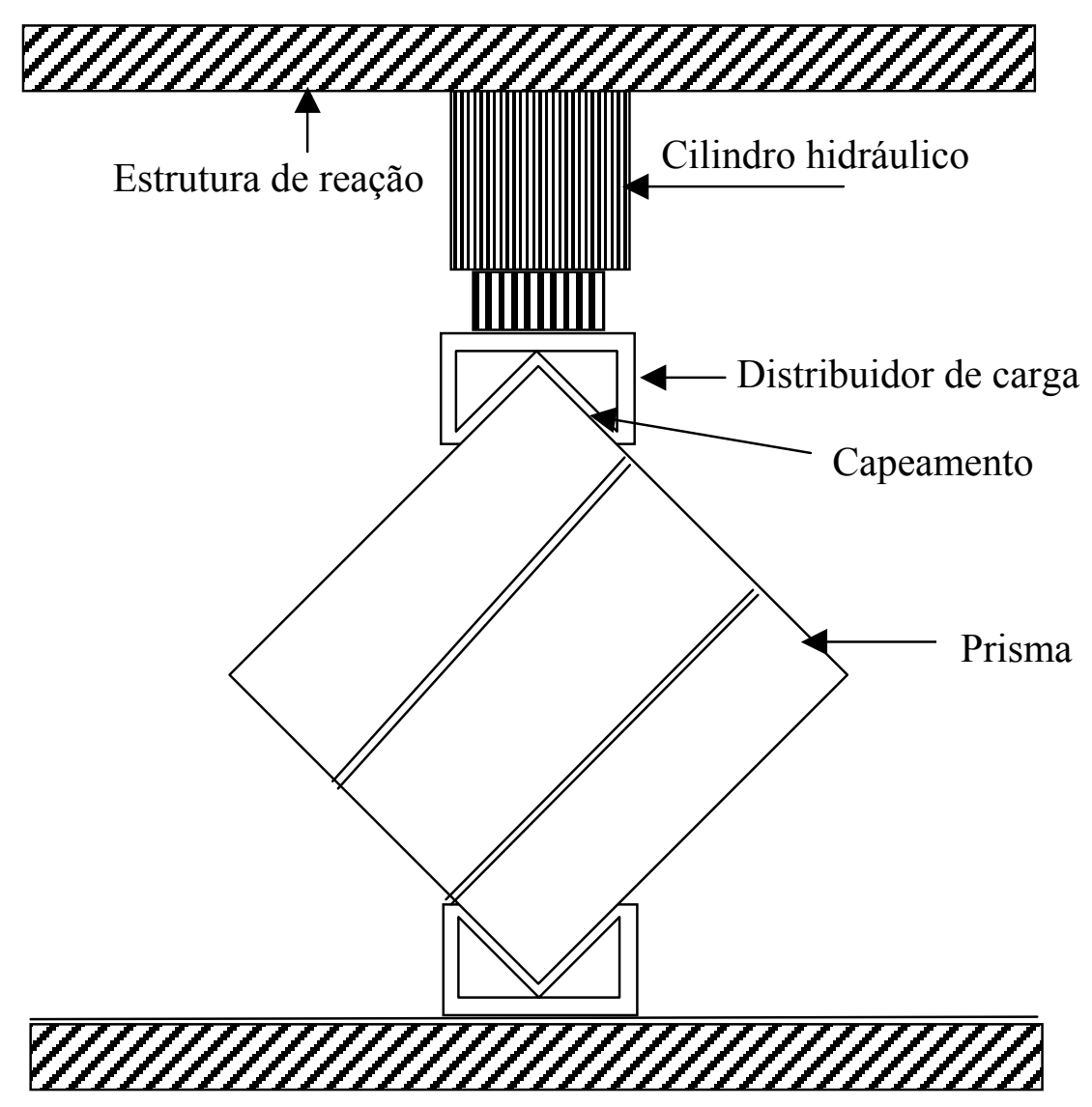

FIGURA 3.19 - Esquema do sistema de reação

A carga foi aplicada continuamente até a ruptura, de modo que a tensão de cisalhamento convencional se elevasse progressivamente à razão de $(0,25 \pm 0,05)$ $\mathrm{MPa} /$ segundo. 
A tensão de cisalhamento convencional $\left(f_{s}\right)$ é dada pela expressão (3.1):

$$
f_{s}=\left(0,7 F_{c p}\right) / A
$$

em que

$$
\begin{aligned}
& F_{c p}=\text { carga aplicada média }(\mathrm{N}) ; \mathrm{e} \\
& A=\text { média da área bruta das duas faces contíguas ao carregamento, em } \mathrm{mm}^{2} .
\end{aligned}
$$

Nestes ensaios foi obtido um valor médio de 0,30 MPa para prismas confeccionados com argamassa Ciment-cola.

Foram ainda realizados ensaios diretos de cisalhamento em prismas, cujos resultados também se encontram na tabela C.2. Nesse caso, foram obtidos valores médios para a tensão de cisalhamento puro de 0,07 MPa para prismas de argamassa de traço 1:3:7,5 de cimento, cal e areia e de 0,17 MPa para prismas de argamassa Ciment-cola.

\subsubsection{3 - ENSAIOS DE COMPRESSÃO EM CILINDROS DE ARGAMASSA}

Foram moldados corpos-de-prova cilíndricos de $5 \mathrm{~cm}$ de base e $10 \mathrm{~cm}$ de altura, 10 $\mathrm{cm}$ de base e $20 \mathrm{~cm}$ de altura e, ainda, $15 \mathrm{~cm}$ de base e $30 \mathrm{~cm}$ de altura, para ensaios à compressão. Os ensaios foram realizados segundo as prescrições da NBR 5738 Confecção e cura de corpos-de-prova de concreto, cilíndricos ou prismáticos Método de ensaio; NBR 5739 - Ensaio à Compressão de Corpos-de-Prova Cilíndricos de Concreto - Método de Ensaio e NBR 7215 - Ensaio de Cimento Portland - Método de Ensaio.

Para aplicação do carregamento, utilizou-se uma prensa hidráulica de resolução 0,5 $\mathrm{kN}$, aplicando a carga numa velocidade de $0,5 \mathrm{kN} / \mathrm{s}$ de $10,0 \mathrm{kN}$ em $10,0 \mathrm{kN}$ até a ruptura do cilindro, tendo o cuidado de espaçar os incrementos de carga em um minuto, efetuando inspeção visual no corpo-de-prova. 
Os resultados obtidos encontram-se na tabela C.3, do Anexo C. As letras A, B ou C que acompanham o número do corpo-de-prova, primeira coluna da tabela C.3, significam que o corpo-de-prova possui $5 \mathrm{~cm}$ de base e $10 \mathrm{~cm}$ de altura, $10 \mathrm{~cm}$ de base e $20 \mathrm{~cm}$ de altura ou $15 \mathrm{~cm}$ de base e $30 \mathrm{~cm}$ de altura, respectivamente.

Foi obtido o valor médio de 4,93 MPa para a resistência à compressão de cilindros de argamassa de traço 1:3:7,5 de cimento, cal e areia, aos 30 dias de idade. Para cilindros de argamassa Ciment-cola, o valor médio obtido foi de 8,87 $\mathrm{MPa}$, para idade mínima de 14 dias. Para a argamassa de encunhamento, foi obtido o valor médio para a resistência à compressão de $18,40 \mathrm{MPa}$.

Os módulos de deformação das argamassas de assentamento e do encunhamento foram ainda obtidos. Utilizaram-se dois transdutores de deslocamento, colocados nas laterais do cilindro, considerando a média dos valores medidos. Para módulo de deformação da argamassa de assentamento, o valor médio obtido foi de $4457 \mathrm{MPa}$.

\subsubsection{4 - ENSAIOS DE TRAÇÃO POR COMPRESSÃO DIAMETRAL EM CILINDROS DE ARGAMASSA}

Foram moldados corpos-de-prova cilíndricos de argamassa de $10 \mathrm{~cm}$ de base e $20 \mathrm{~cm}$ de altura, segundo as prescrições das normas citadas no item 3.4.3.3 (NBR 5738, NBR 5739 e NBR 7215). A resistência à tração em cilindros de argamassa foi obtida segundo as prescrições da NRB 7222 - Argamassas e concretos - Determinação da resistência à tração por compressão diametral de corpos-de-prova cilíndricos.

A carga de compressão ao longo da geratriz do corpo-de-prova cilíndrico foi aplicada continuamente a uma velocidade de $1,50 \mathrm{kN} / \mathrm{s}$ até a ruptura do corpo-de-prova.

A resistência à tração por compressão diametral foi calculada pela expressão 3.2, dada pela NBR 7222. Os resultados obtidos encontram-se na tabela C.4. 


$$
f_{t, D}=\frac{2 \times F_{c p}}{\pi \times d_{c p} \times l_{c p}}
$$

em que

$f_{t, D}=$ resistência à tração por compressão diametral, expressa em $\mathrm{MPa}$, com aproximação de 0,05;

$F_{c p}=$ carga máxima obtida no ensaio;

$d_{c p}=$ diâmetro do corpo-de-prova; $\mathrm{e}$

$l_{c p}=$ altura do corpo-de-prova.

Para cilindros de argamassa traço 1:3:7,5, foi obtida a média de $0,42 \mathrm{MPa}$ para a resistência à tração, e para cilindros de argamassa Ciment-cola a média foi de 0,92 MPa. 


\section{5 - TRATAMENTO DE DADOS E ANÁLISE DE RESULTADOS}

Os resultados dos ensaios realizados, obtidos através do sistema Aq Dados 4.0, foram filtrados e convertidos em tabela ASC II, para tratamento em softwares de planilhas eletrônicas, que disponibilizam maior número de recursos gráficos. A seguir são apresentados os resultados dos ensaios dos pórticos TIPO I e TIPO II.

\subsection{1 - RESULTADOS REFERENTES AOS ENSAIOS DO PÓRTICO TIPO I (SÉRIE A)}

\subsubsection{1 - DESENVOLVIMENTO DOS ENSAIOS E MODOS DE RUPTURA}

Apresentam-se, na figura 3.20, os diagramas força-deslocamento correspondentes aos ensaios do pórtico TIPO I sem preenchimento e preenchido com blocos de CCA, de acordo com os seis ensaios realizados, cujas características são descritas na tabela 3.1. Os ensaios de pórticos preenchidos foram conduzidos até a fissuração do painel de alvenaria.

A figura 3.20 sintetiza a grande contribuição à rigidez do conjunto introduzida pela presença dos painéis. Para uma força de $50 \mathrm{kN}$, os deslocamentos em cada um dos seis ensaios realizados são apresentados na tabela 3.5. O deslocamento médio dos seis ensaios foi de 1,60 mm, enquanto para o pórtico sem preenchimento foi de 20,26 $\mathrm{mm}$, sendo, portanto, 12,67 vezes superior ao primeiro. 


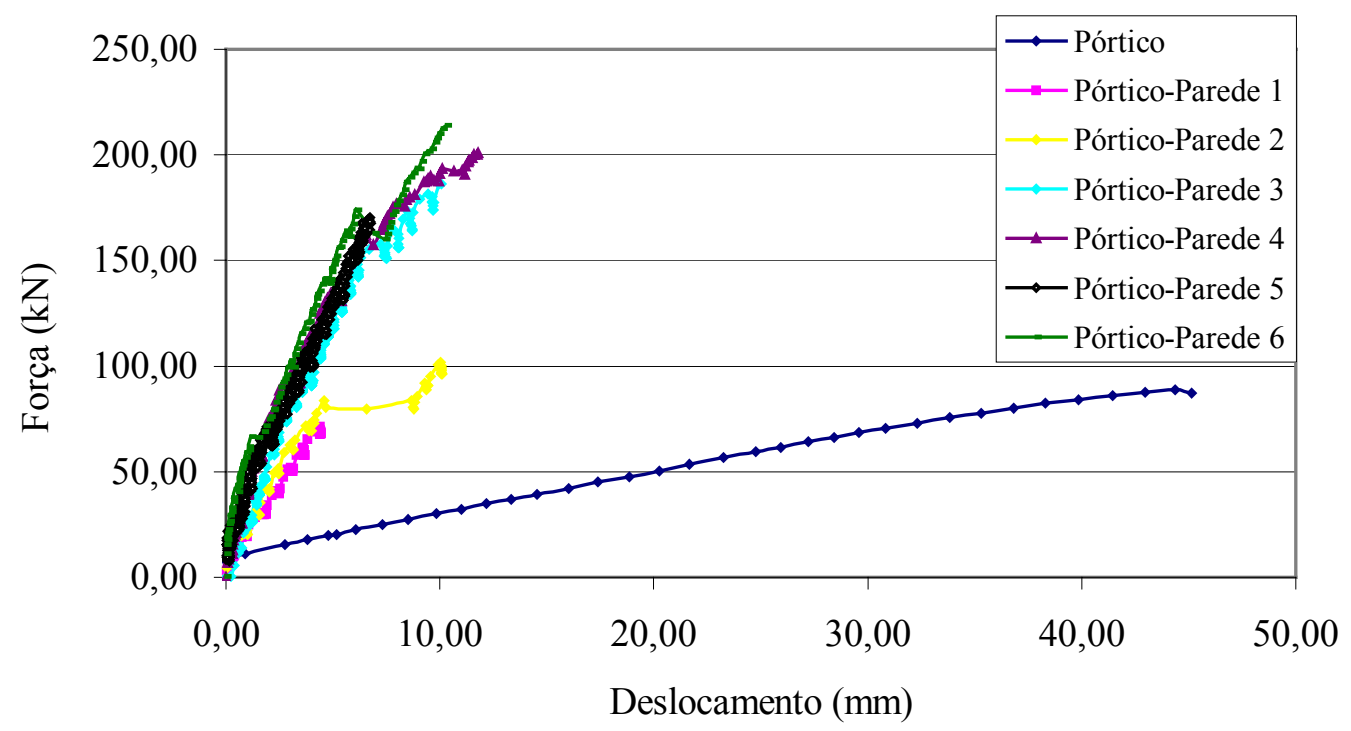

FIGURA 3.20 - Diagrama força-deslocamento para o pórtico sem preenchimento e para os sistemas pórtico-parede da série A

TABELA 3.5 - Deslocamentos obtidos nos seis ensaios da série A para uma ação de $50 \mathrm{kN}$ aplicada

\begin{tabular}{|c|c|c|}
\hline ENSAIO & $\begin{array}{c}\text { RELAÇÃO } \\
\text { DESLOCAMENTO } \\
(\mathbf{m m})\end{array}$ & $\begin{array}{c}\text { DESL. P. SEM PREENCHIMENTO / } \\
\text { DESLOCAMENTO PÓRTICO PREENCHIDO }\end{array}$ \\
\hline $1 \mathrm{~A}$ & 2,82 & 7,18 \\
\hline $2 \mathrm{~A}$ & 2,29 & 8,85 \\
\hline $3 \mathrm{~A}$ & 1,61 & 12,58 \\
\hline $4 \mathrm{~A}$ & 1,10 & 18,42 \\
\hline $5 \mathrm{~A}$ & 1,15 & 31,17 \\
\hline $6 \mathrm{~A}$ & 0,65 & 17,62 \\
\hline
\end{tabular}

Em termos de rigidez, os pórticos preenchidos apresentaram um valor médio de 39,3 $\mathrm{kN} / \mathrm{mm}$, ao passo que o pórtico sem preenchimento apresentou o valor de 2,46 $\mathrm{kN} / \mathrm{mm}$, sendo o pórtico preenchido 16 vezes mais rígido para este nível de carga. Os valores obtidos em cada um dos ensaios realizados encontram-se na tabela 3.6. 
TABELA 3.6 - Rigidez obtida nos seis ensaios da série A para uma ação de $50 \mathrm{kN}$ aplicada

\begin{tabular}{|c|c|c|}
\hline \multirow{2}{*}{ ENSAIO } & $\begin{array}{c}\text { RIGIDEZ } \\
\mathbf{( k N / m m )}\end{array}$ & $\begin{array}{c}\text { RELAÇÃO } \\
\text { RIGIDEZ PÓRTICO PREENCHIDO / } \\
\text { RIGIDEZ PÓRTICO SEM } \\
\text { PREENCHIMENTO }\end{array}$ \\
\hline $1 \mathrm{~A}$ & 17,73 & 7,21 \\
\hline $2 \mathrm{~A}$ & 21,83 & 8,87 \\
\hline $3 \mathrm{~A}$ & 31,06 & 12,63 \\
\hline $4 \mathrm{~A}$ & 45,45 & 18,48 \\
\hline $5 \mathrm{~A}$ & 43,48 & 17,67 \\
\hline $6 \mathrm{~A}$ & 76,90 & 31,26 \\
\hline
\end{tabular}

Nos dois primeiros ensaios, realizados aos 20 e 28 dias, respectivamente, utilizou-se argamassa de assentamento no traço em volume 1:3:7,5 de cimento, cal e areia, além de ferros-cabelo na interface pórtico-painel. A ruptura correspondente foi, em ambos os casos, por cisalhamento nas juntas de argamassa da alvenaria, conforme figura 3.21. As cargas de ruptura correspondentes aos dois primeiros ensaios foram de $71,23 \mathrm{kN}$ e $102,13 \mathrm{kN}$, respectivamente, e os deslocamentos horizontais máximos, de 4,41 $\mathrm{mm}$ e $9,96 \mathrm{~mm}$.

No primeiro ensaio, com uma carga de $20 \mathrm{kN}$, iniciaram-se as fissuras nas juntas internas de argamassa. Essas fissuras foram aumentando com o incremento gradativo do carregamento até que a força aplicada atingiu $70 \mathrm{kN}$ e a parede já poderia ser considerada não mais adequada para ser utilizada, em virtude do estado-limite de utilização atingido, com grande número de fissuras e aberturas consideráveis. Vale observar que todas as fissuras foram na argamassa, de forma escalonada, e os blocos se mantiveram praticamente intactos. Em virtude das fissuras no painel, as duas partes deste, separadas pelas fisssuras, tenderam a se acomodar nos cantos do pórtico. Dessa forma, praticamente não houve descolamento da interface. 
No segundo ensaio, mesmo aos 28 dias, esse comportamento se repetiu. Concluiu-se, através de ensaios complementares, que a argamassa utilizada não era adequada para os tipos de ensaios realizados, possuindo baixa resistência à tração e ao cisalhamento.

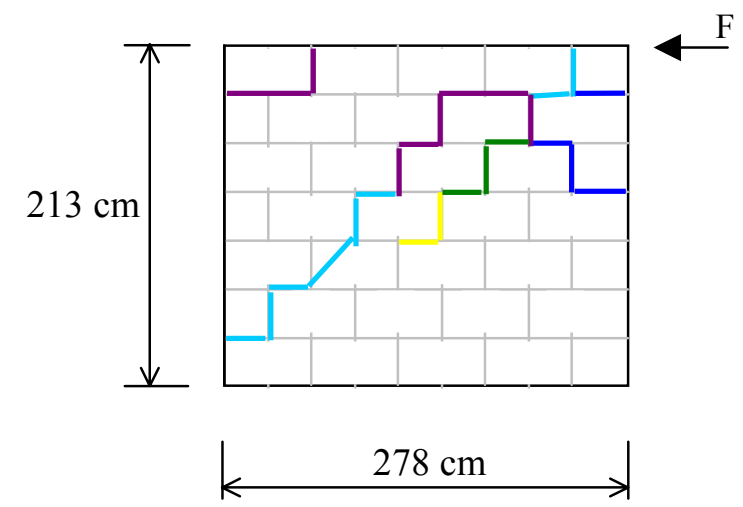

$20 \mathrm{kN}$
$213 \mathrm{~cm}$
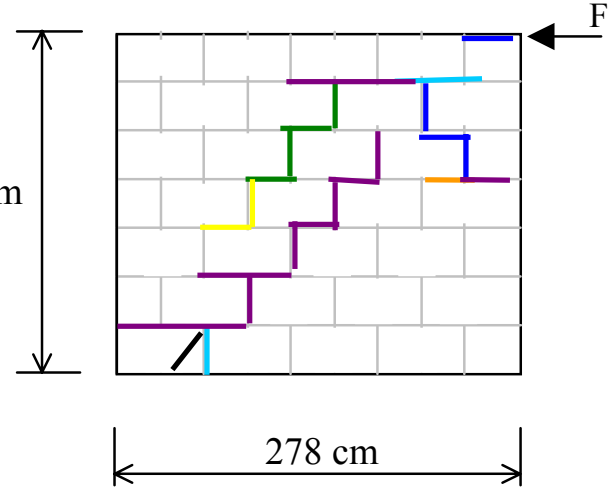

$70 \mathrm{kN}$
$90 \mathrm{kN}$

$100 \mathrm{kN}$

FIGURA 3.21 - Modos de ruptura referentes aos dois primeiros ensaios com juntas de assentamento de argamassa no traço 1:3:7,5 de cimento, cal e areia e ferros-cabelo na interface (ensaios $1 \mathrm{~A}$ e $2 \mathrm{~A})$

Nos quatro últimos ensaios no pórtico TIPO I foi utilizada argamassa Ciment-cola nas juntas de assentamento, com $5 \mathrm{~mm}$ de espessura. Como a argamassa Ciment-cola apresenta maior resistência à tração e ao cisalhamento que a argamassa convencional $(1: 3: 7,5)$, em todos os quatro casos houve aumento considerável da carga de ruptura em relação aos dois primeiros ensaios.

No terceiro e quarto ensaios foram utilizados ferros-cabelo nas interfaces pórticopainel e no quinto e sexto, utilizou-se apenas argamassa Ciment-cola. As cargas de ruptura e os deslocamentos laterais globais do conjunto, correspondentes aos quatro últimos ensaios, estão apresentados na tabela 3.7. 
TABELA 3.7 - Cargas de ruptura e deslocamentos laterais globais do conjunto

\begin{tabular}{|c|c|c|}
\hline ENSAIO & $\begin{array}{c}\text { CARGA DE RUPTURA } \\
\mathbf{( k N )}\end{array}$ & $\begin{array}{c}\text { DESLOCAMENTO LATERAL DO SISTEMA } \\
\text { PÓRTICO-PAINEL (mm) }\end{array}$ \\
\hline $3 \mathrm{~A}$ & 189,72 & 11,45 \\
\hline $4 \mathrm{~A}$ & 206,60 & 11,80 \\
\hline $5 \mathrm{~A}$ & 169,93 & 6,86 \\
\hline $6 \mathrm{~A}$ & 175,00 & 10,45 \\
\hline
\end{tabular}

No terceiro e quarto ensaios, o início do descolamento ocorreu para uma carga em torno de $35 \mathrm{kN}$. A presença do ferro-cabelo não impediu o descolamento da interface, tendo contribuído para retardá-lo, mas que, no entanto, continuou ocorrendo.

No terceiro ensaio, próximo à carga de ruptura, o canto superior do painel começou a sofrer esmagamento, mas a ruptura ocorreu por tração na diagonal, através de uma ruptura frágil, conforme representado na figura 3.22.

Observou-se ainda que, utilizando argamassa do tipo Ciment-cola, praticamente não surgiram fissuras nas juntas de argamassa até a carga de fissuração, com exceção do descolamento da interface. A parede funcionou durante todo o tempo como um painel monolítico, configurando-se a ruptura por tração na diagonal.

No quarto ensaio, quando a carga atingiu $100 \mathrm{kN}$, deu-se início ao esmagamento do canto superior comprimido e, com $165 \mathrm{kN}$, iniciou-se o esmagamento do canto inferior comprimido. Quando o sistema de aquisição acusou uma força de $200 \mathrm{kN}$, os cantos comprimidos já estavam esmagados, e o ensaio foi interrompido de forma a preservar a segurança das pessoas presentes e dos equipamentos utilizados, caracterizando, assim, ruptura por esmagamento dos cantos comprimidos, figura 3.23 . 


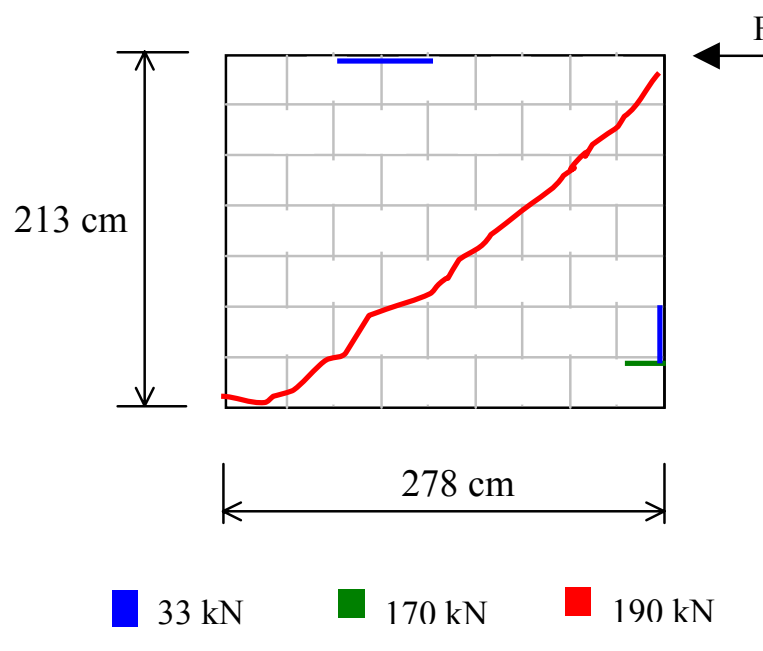

FIGURA 3.22 - Modo de ruptura referente ao ensaio com juntas de assentamento de argamassa Ciment-cola e interface com ferros-cabelo (ensaio 3A)

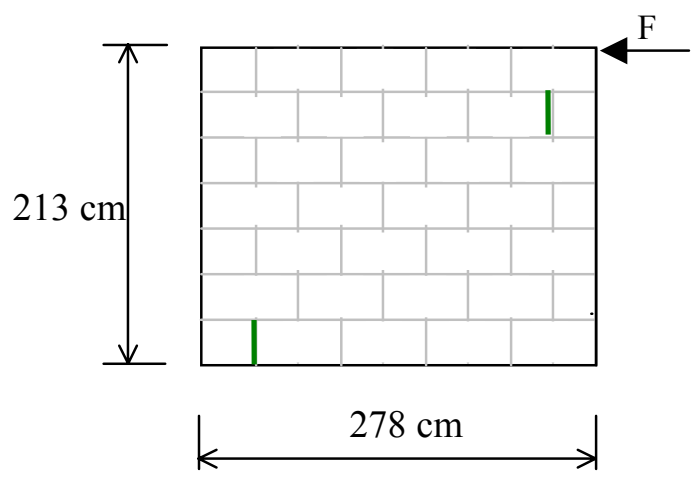

FRENTE PAREDE

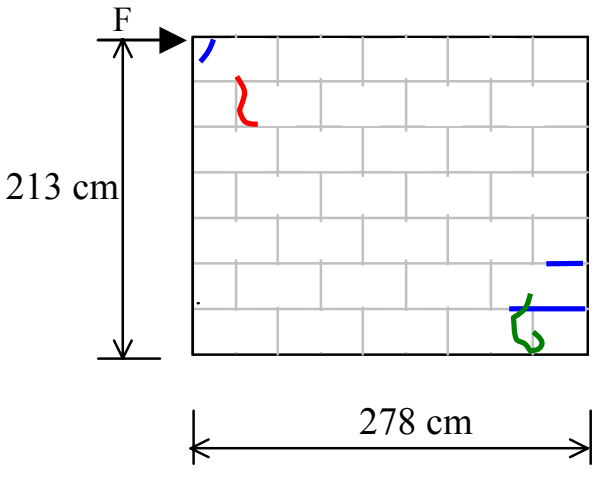

VERSO PAREDE

$100 \mathrm{kN} \quad 165 \mathrm{kN} \square 175 \mathrm{kN}$

FIGURA 3.23 - Modo de ruptura referente ao ensaio com juntas de assentamento de argamassa Ciment-cola e interface com ferros-cabelo (ensaio 4A)

Nos dois últimos ensaios da série A (TIPO I), a interface pórtico-painel foi executada utilizando-se apenas argamassa Ciment-cola. Com $20 \mathrm{kN}$ ocorreu o descolamento total da interface viga superior-painel e grande parte das interfaces pilar-painel, principalmente do lado oposto à aplicação da carga. Com $30 \mathrm{kN}$, restavam $110 \mathrm{~cm}$ do 
painel em contato com o pilar; quando a força atingiu $40 \mathrm{kN}$, as duas interfaces painel-pilar já estavam descoladas em toda a região tracionada. A última face a descolar foi a horizontal inferior, explicada pela ação do peso próprio da parede.

Nos dois ensaios, configurou-se ruptura frágil da diagonal tracionada. No quinto ensaio, após a ruptura da parede, esta foi recarregada, e a carga aplicada aumentou de $168 \mathrm{kN}$ para $220 \mathrm{kN}$, figura 3.24, indicando que mesmo após a ruptura a parede continuou absorvendo acréscimos de carga. $\mathrm{O}$ modo de ruptura do ensaio $6 \mathrm{~A}$ foi também por ruptura frágil da diagonal tracionada, figura 3.25.

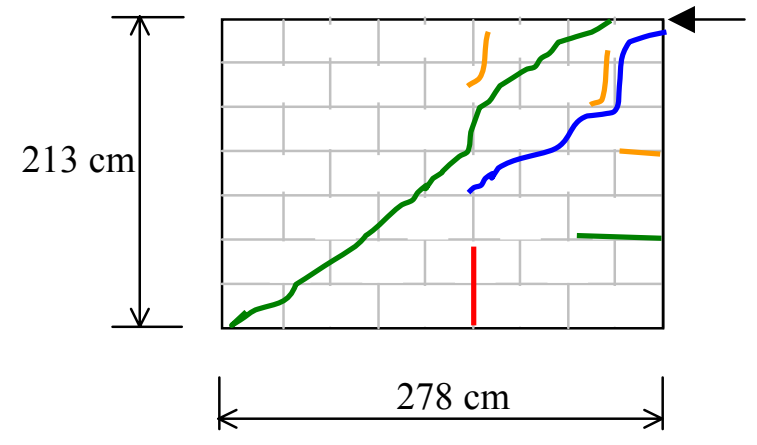

$150 \mathrm{kN}\left(2^{\circ}\right.$. ciclo $)$

$168 \mathrm{kN}\left(1^{\mathrm{o}}\right.$ ciclo $)$

$200 \mathrm{kN}\left(2^{\mathrm{o}} \cdot\right.$ ciclo $)$

$220 \mathrm{kN}\left(2^{\text {o. }}\right.$ ciclo $)$

FIGURA 3.24 - Modo de ruptura referente ao ensaio com juntas de assentamento de argamassa Ciment-cola e interface sem ferro cabelo (ensaio 5A)

Nos ensaios realizados, o relógio comparador colocado na ligação viga-pilar superior registrou os seguintes deslocamentos horizontais: $0,92 \mathrm{~mm}$ para os ensaios $1 \mathrm{~A}$ e $2 \mathrm{~A}$; $0,62 \mathrm{~mm}$ para o ensaio $3 \mathrm{~A} ; 0,32 \mathrm{~mm}$ para o ensaio $4 \mathrm{~A}$; e $1,08 \mathrm{~mm}$ para o ensaio $5 \mathrm{~A}$.

BRAGUIM(1993), estudando ligações, comprovou que, no caso de estruturas aporticadas de aço preenchidas com alvenaria, os tipos de ligação viga-pilar influenciam o enrijecimento dessas estruturas, porém em proporções menores, quando comparado com o enrijecimento proporcionado pelo painel. Nesse trabalho, para a mesma edificação com barras diagonais de contraventamento o pórtico com 
ligações rígidas apresentou cerca de $15 \%$ a mais de rigidez que o pórtico com ligações articuladas.

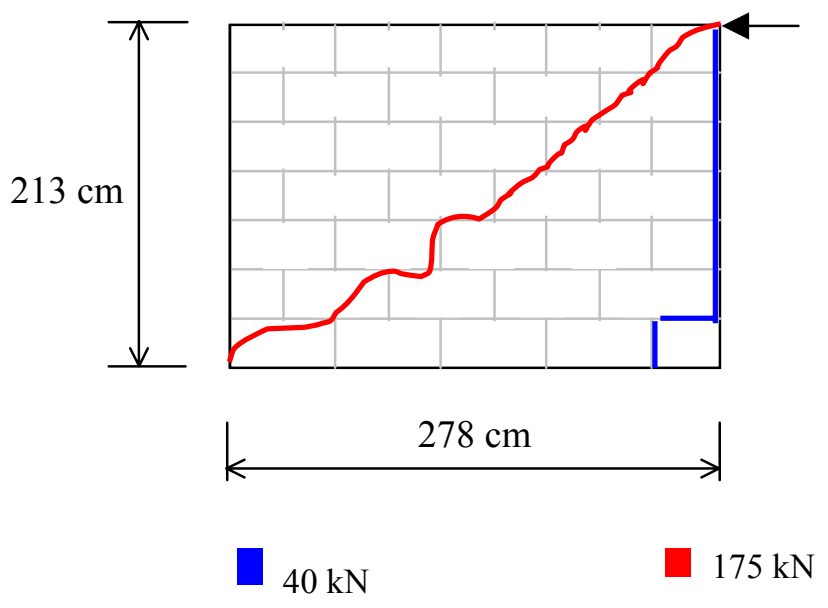

FIGURA 3.25 - Modo de ruptura referente ao ensaio com juntas de assentamento com argamassa Ciment-cola e interface sem ferros-cabelo (ensaio 6A)

Nas figuras 3.26, 3.27 e 3.28, apresentam-se os diagramas força-deslocamento para os ensaios $1 \mathrm{~A}$ e $2 \mathrm{~A}, 3 \mathrm{~A}$ e $4 \mathrm{~A}$ e $5 \mathrm{~A}$ e $6 \mathrm{~A}$, respectivamente, que foram pares de ensaios com as mesmas características. Os gráficos dessas figuras permitem a comparação entre dois ensaios realizados nas mesmas condições, comprovando-se que, de maneira geral, os resultados de ambos se aproximaram consideravelmente, no que se refere a rigidez e resistência.

Na figura 3.29, apresenta-se o diagrama força $\mathrm{x}$ deslocamento do ensaio 5A, no qual houve carregamento até a fissuração, seguido de descarregamento e posterior recarregamento até nova fissuração e, então, procedeu-se ao descarregamento. Podese comprovar por esse diagrama que a fissuração da diagonal não se constitui em um estado-limite último e a estrutura ainda absorve acréscimos de carga mesmo depois de fissurada, até a ocorrência do esmagamento dos cantos comprimidos. 


\section{Diagrama Força-Deslocamento}

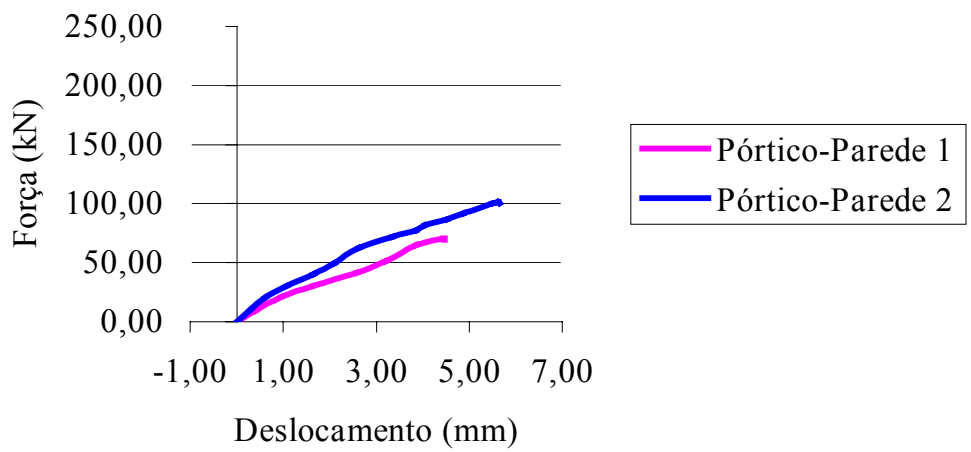

FIGURA 3.26 - Diagrama força-deslocamento (ensaios 1A e 2A)

\section{Diagrama Força-Deslocamento}

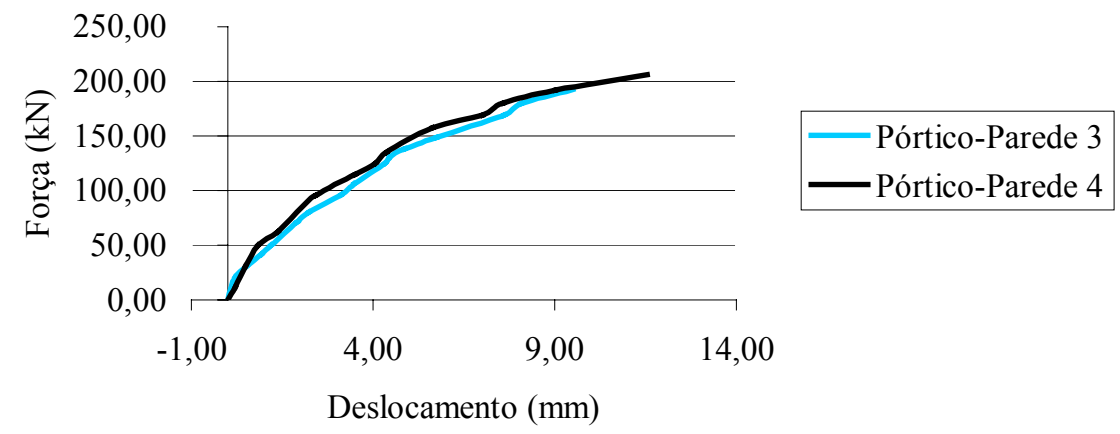

FIGURA 3.27 - Diagrama força-deslocamento (ensaios 3A e 4A)

\section{Diagrama Força-Deslocamento}

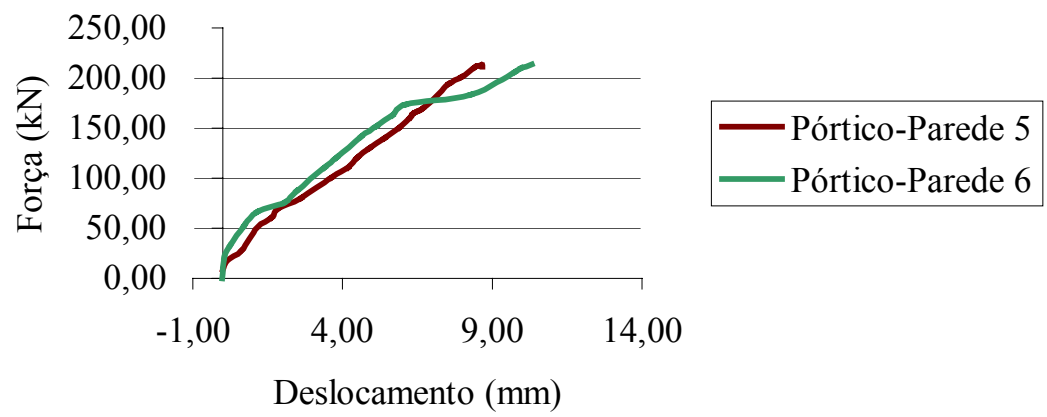

FIGURA 3.28 - Diagrama força-deslocamento (ensaios 5A e 6A) 
Diagrama Força-Deslocamento

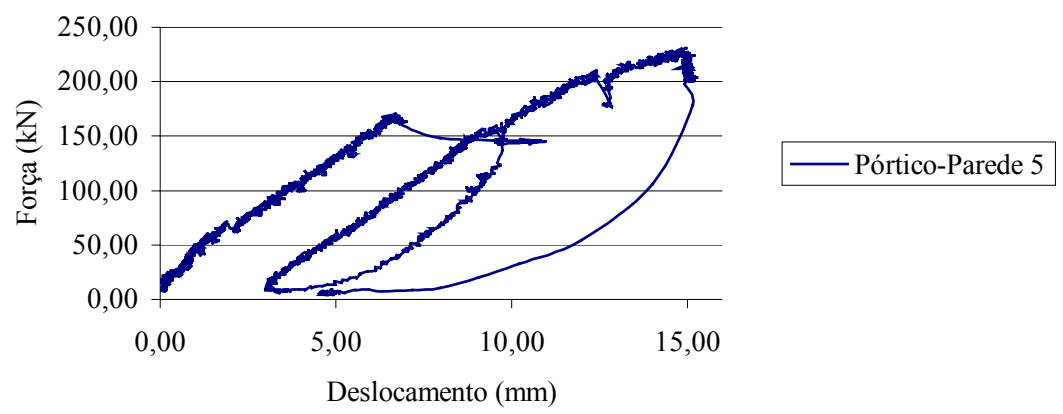

FIGURA 3.29 - Diagrama força-deslocamento do ensaio 5A, carregamentodescarregamento e recarregamento-descarregamento

Na figura 3.30 são apresentados os diagramas força-deslocamento obtidos através de ensaios do pórtico TIPO I sem preenchimento, realizados antes e depois dos ensaios de pórtico preenchido. Comparando as duas curvas, pode-se perceber que o pórtico realmente trabalhou no regime elástico durante os ensaios realizados com ele.

\section{Diagrama Força-Deslocamento}

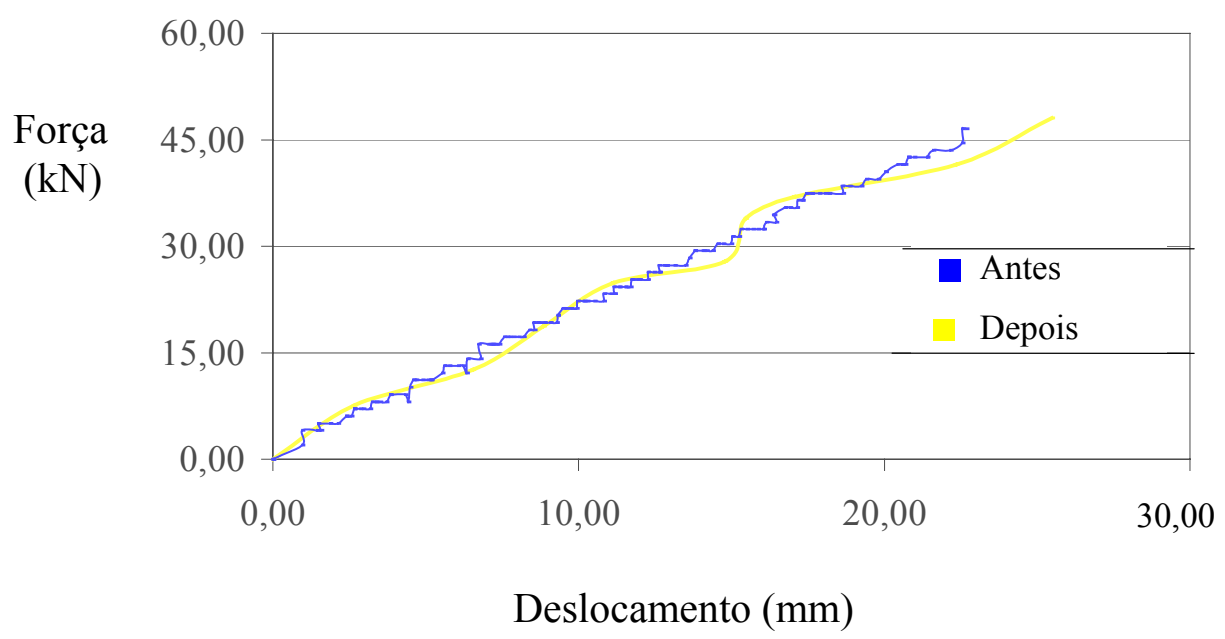

FIGURA 3.30 - Diagramas força-deslocamento para o pórtico TIPO I sem preenchimento, obtidos através de ensaios realizados antes e depois dos ensaios de pórticos preenchidos 


\subsubsection{2 - DESCOLAMENTO DA INTERFACE PÓRTICO-PAINEL}

Um estudo do comportamento da parede como uma biela foi realizado através de estudos experimentais e numéricos, em que se monitorou a interface pórtico-painel, por onde eram transmitidas as tensões de compressão do pórtico para a parede. Foram colocados transdutores de deslocamento e relógios comparadores nos cantos tracionados, nas posições indicadas na figura 3.31 .

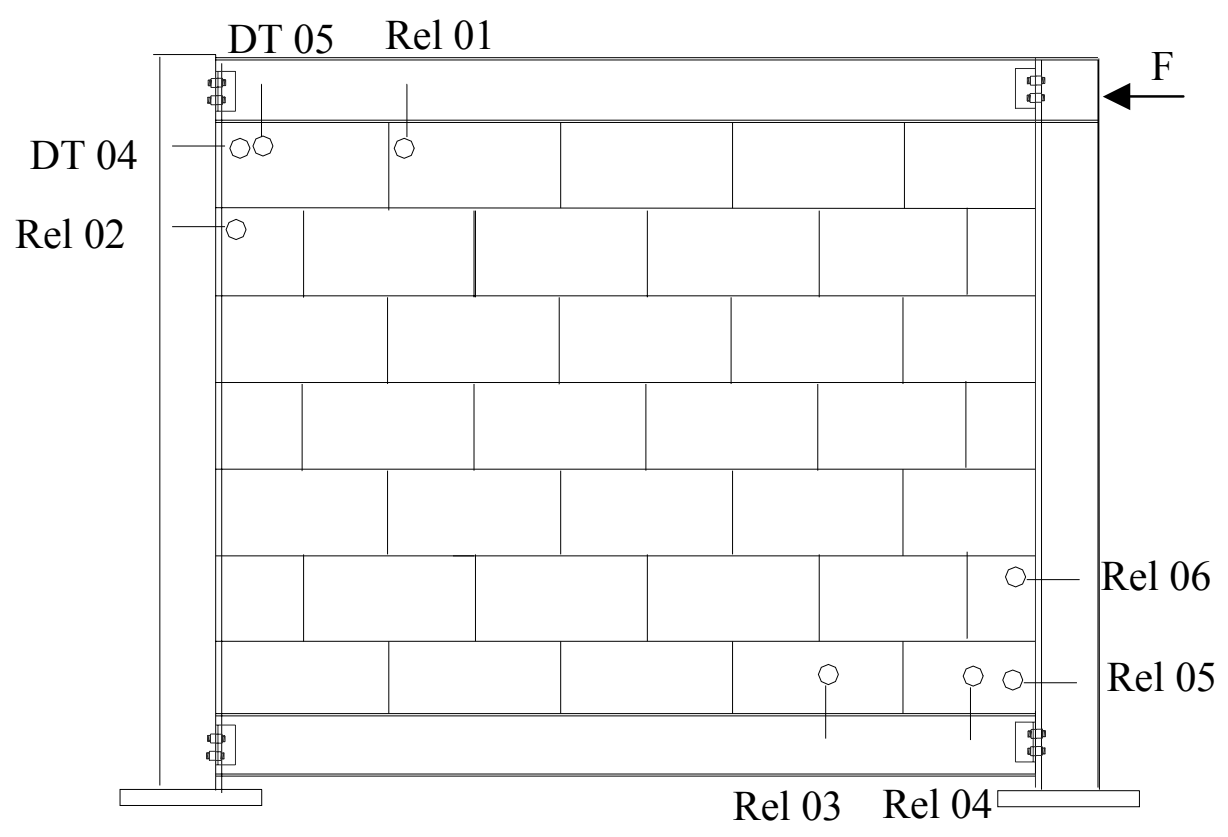

FIGURA 3.31 - Disposição da instrumentação para medida dos descolamentos

No Anexo D são apresentados os diagramas força-descolamento das paredes das séries A e B.

Nas figuras 3.32 e 3.33, apresentam-se os gráficos referentes à dimensão da abertura do descolamento medida nos ensaios da série $\mathrm{A}$, com relação aos dois cantos tracionados. Nessas figuras também estão identificados os seguintes níveis de cargas: $20 \mathrm{kN}, 60 \mathrm{kN}, 100 \mathrm{kN}$ e $170 \mathrm{kN}$. O termo "largura do descolamento" refere-se aos valores lidos nos instrumentos de medição, segundo a disposição destes nos ensaios experimentais. 
Pelos gráficos apresentados, nota-se que, para a carga de $20 \mathrm{kN}$, praticamente não surgiram fissuras na interface pórtico-painel. À medida que aumentou a carga, cresceu o descolamento. Para cargas inferiores a $100 \mathrm{kN}$, o descolamento máximo não ultrapassou $1 \mathrm{~mm}$. Para carga de $170 \mathrm{kN}$, que corresponde à ruptura por fissuração da diagonal nos ensaios 3A, 5A e 6A, os descolamentos assumiram valores de até $2,2 \mathrm{~mm}$. 


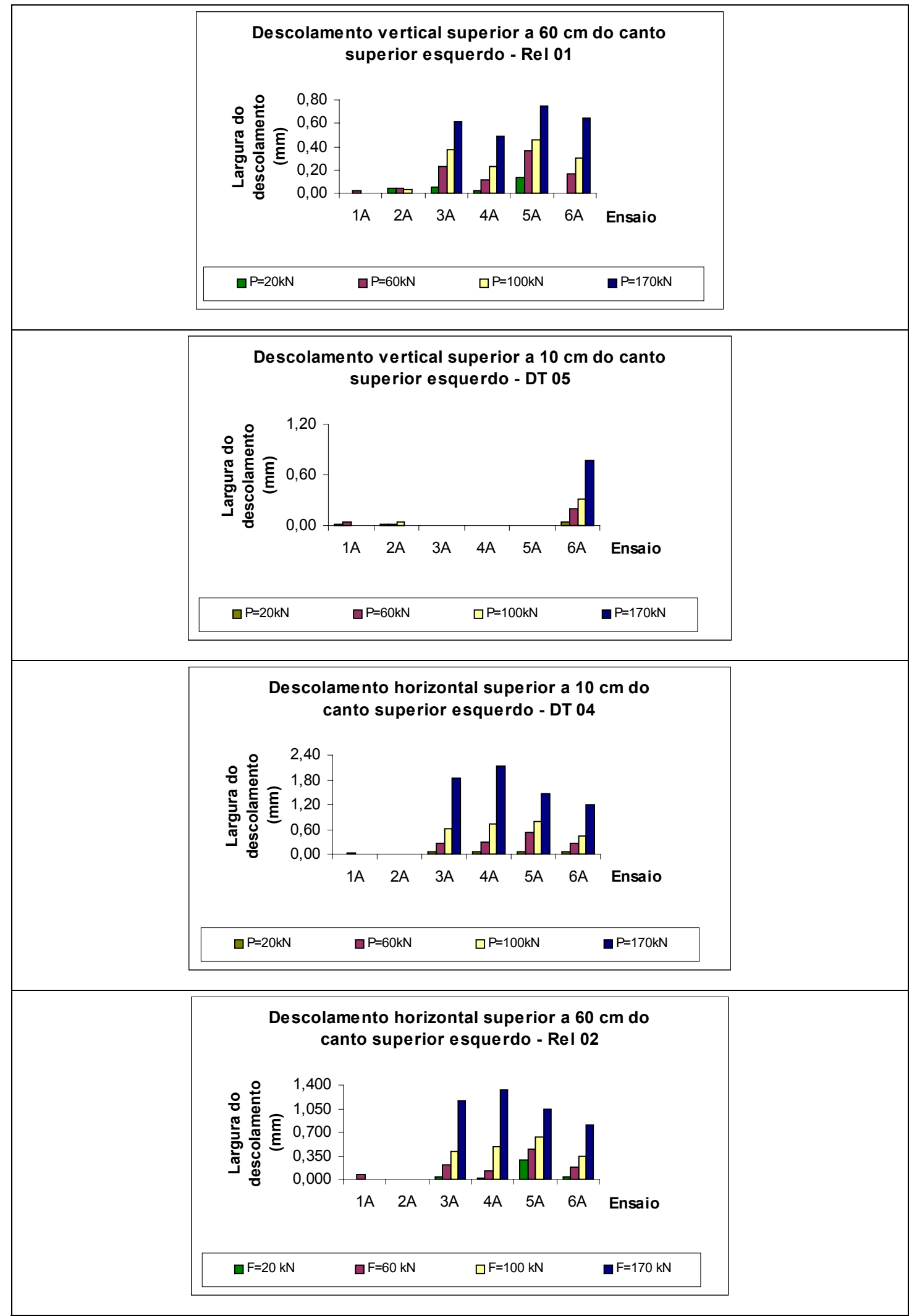

FIGURA 3.32 - Diagrama força-descolamento dos cantos tracionados: canto superior esquerdo (Rel 01, DT 05, DT 04 e Rel 02) 


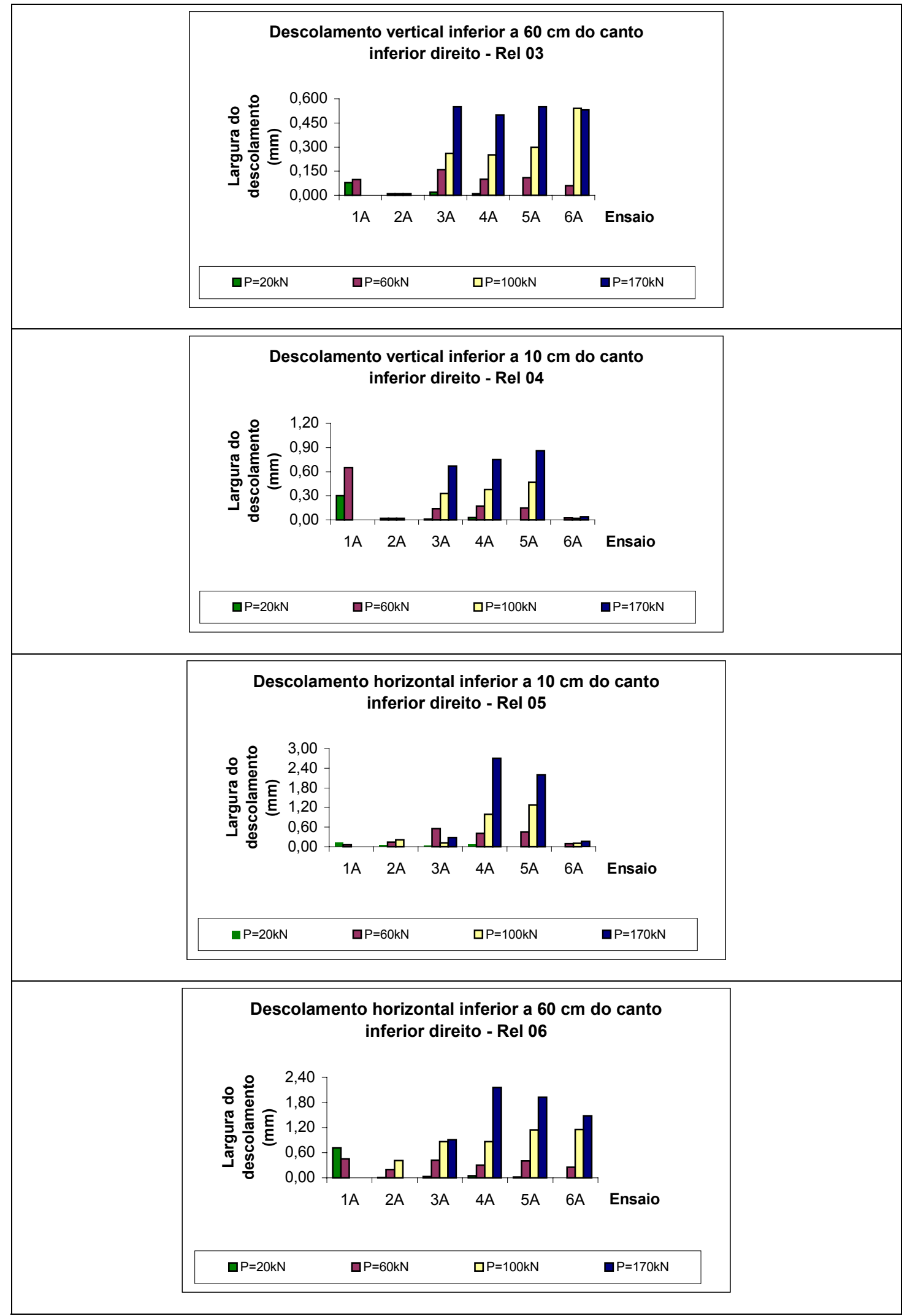

FIGURA 3.33 - Diagrama força-descolamento dos cantos tracionados: canto inferior direito (Rel 03, Rel 04, Rel 05 e Rel 06) 


\subsubsection{3 - ANÁLISE DE TENSÕES E DEFORMAÇÕES}

Os estados de tensão e de deformação nos painéis de alvenaria foram avaliados a partir dos resultados obtidos com os extensômetros colocados nos cantos comprimidos, formando rosetas de deformação, além de um extensômetro posto na diagonal central comprimida e de um DT associado a uma base de $90 \mathrm{~cm}$, disposto no centro do painel, na direção da diagonal tracionada, figura 3.34.

Os extensômetros formando as rosetas de deformação foram posicionados em ângulos de $0^{0}, 37,5^{\circ}$ e $90^{\circ}$ com a horizontal no pórtico TIPO I; e $0^{0}, 24^{0}$ e $90^{\circ}$, no pórtico TIPO II, coincidindo com as direções horizontal, vertical e diagonal do painel, conforme representado na figura 3.35 e nas expressões 3.3:

$$
\begin{aligned}
& \varepsilon_{0^{\circ}}=\varepsilon_{x} \\
& \varepsilon_{37,5^{\circ}}=\varepsilon_{\theta} \text { ou } \varepsilon_{24^{\circ}}=\varepsilon_{\theta} \\
& \varepsilon_{90^{\circ}}=\varepsilon_{y}
\end{aligned}
$$

Aplicando a equação de transformação de componentes de tensão, de $x y$ para $x^{\prime} y^{\prime}$, podese determinar o valor de $\varepsilon_{x y}$, equação 3.4 , tornando conhecido o estado de deformação nas paredes nas regiões dos extensômetros, tendo em vista que a deformação específica normal na direção do eixo $x^{\prime}$ e indicada por $\varepsilon_{\theta}$ é conhecida.

$$
\varepsilon_{\theta}=\varepsilon_{x} \cos ^{2} \theta+\varepsilon_{y} \operatorname{sen}^{2} \theta+\varepsilon_{x y} \operatorname{sen} 2 \theta
$$

As deformações principais apresentam as direções dadas pela equação 3.5 e podem ser calculadas pela equação 3.6 : 
$\operatorname{tg} 2 \theta^{\prime} 1,2=\frac{2 \times \varepsilon_{x y}}{\varepsilon_{1}-\varepsilon_{y}}$

$\varepsilon_{1,2}=\frac{\varepsilon_{x}+\varepsilon_{y}}{2} \pm \sqrt{\left(\frac{\varepsilon_{x}-\varepsilon_{y}}{2}\right)^{2}+\left(\varepsilon_{x y}\right)^{2}}$

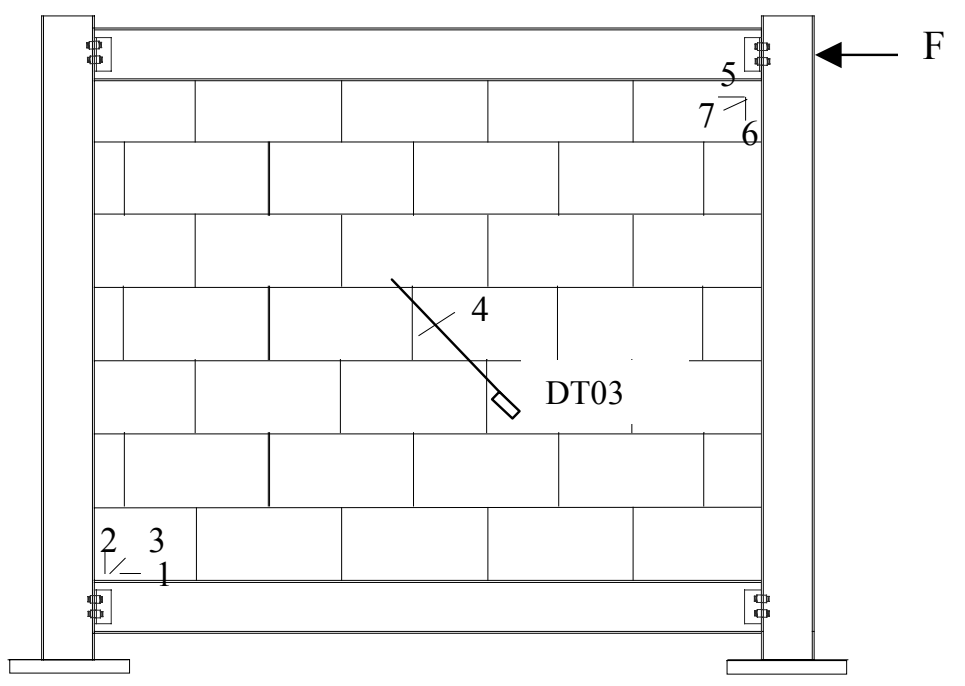

FIGURA 3.34 - Disposição dos extensômetros e do DT 03

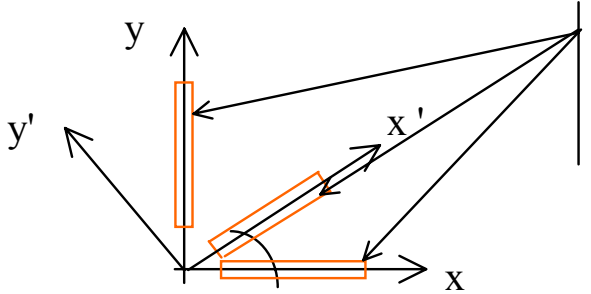

Extensômetros

FIGURA 3.35 - Eixos de referência 
Há dois valores de $2 \theta_{\mathrm{p}}$ com uma diferença de $180^{\circ}$, dados pela equação 3.4: um entre $0^{\circ}$ e $180^{\circ}$ e outro entre $180^{\circ}$ e $360^{\circ}$. Assim, têm-se dois valores de $\theta_{\mathrm{p}}$, um entre $0^{\circ}$ e $90^{\circ}$ e outro entre $90^{\circ}$ e $180^{\circ}$. Um desses valores conduz a uma deformação máxima e o outro a uma deformação mínima, as quais ocorrem em planos perpendiculares. Aplicando a Lei de Hooke Generalizada e tendo em vista que a parede se encontra em estado plano de tensão, pode-se obter o estado de tensão na parede, na região dos extensômetros, através das expressões 3.7:

$$
\begin{aligned}
& \sigma_{x}=\frac{E}{\left(1-v^{2}\right)}\left(\varepsilon_{x}+v \varepsilon_{y}\right) \\
& \sigma_{y}=\frac{E}{\left(1-v^{2}\right)}\left(\varepsilon_{y}+v \varepsilon_{x}\right) \\
& \tau_{x y}=G \times 2 \times \varepsilon_{x y}
\end{aligned}
$$

As tensões principais nas regiões dos cantos comprimidos são dadas pelas expressões 3.8:

$$
\sigma_{1,2}=\frac{\sigma_{x}+\sigma_{y}}{2} \pm \sqrt{\left(\frac{\sigma_{x}-\sigma_{y}}{2}\right)^{2}+\left(\tau_{x y}\right)^{2}}
$$

Os resultados obtidos com os extensômetros são apresentados no Anexo E, em que as figuras E.1 a E.7 exibem os diagramas força-deformação dos extensômetros, obtidos nos ensaios. 
Apresentam-se, na tabela E1, as deformações dos extensômetros para alguns níveis de carga obtidos nos ensaios realizados. A convenção de sinais adotada é compressãonegativa e tração-positiva.

A partir das deformações medidas nos extensômetros, são calculadas as tensões nas mesmas direções e as deformações e tensões principais. Na tabela E2 são apresentadas as direções, deformações e tensões principais na região dos cantos comprimidos do conjunto pórtico-painel, para quatro níveis de carga.

Para o centro do painel são conhecidas as deformações diagonais, fornecidas pelo extensômetro EXT 04 (diagonal comprimida) e pelo DT 03 (diagonal tracionada). Na figura 3.36, apresentam-se os diagramas força-deformação diagonal comprimida dos ensaios da série A. Nessa figura, pode-se notar o crescimento monotônico das deformações dos ensaios 3A, 4A, 5A e 6A, nos quais se utilizou argamassa Ciment-cola. Nos ensaios 1A e 2A, em que se utilizou argamassa no traço 1:3:7,5 de cimento, cal e areia, houve crescimento das deformações até o início da abertura das fissuras escalonadas, ao longo da diagonal comprimida. Com o surgimento dessas fissuras, houve diminuição das deformações, para posterior crescimento.

Diagrama Força x Deformação (Ext. 04)

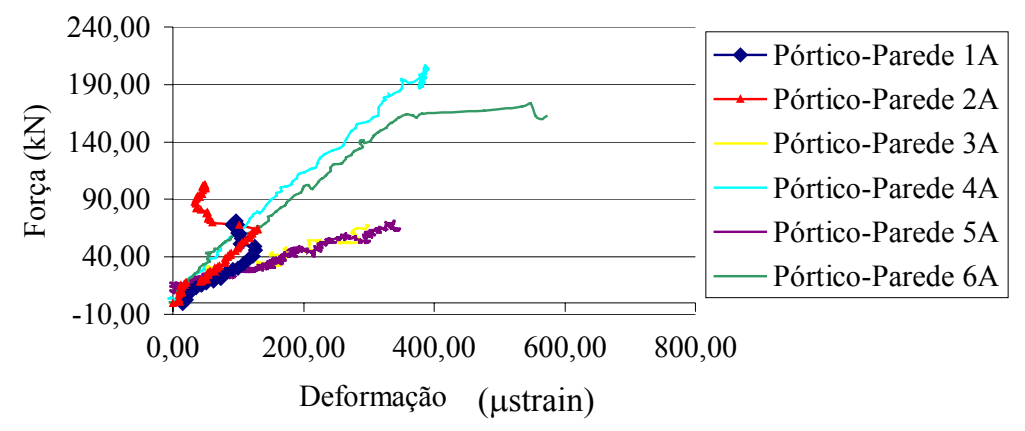

FIGURA 3.36 - Diagramas força-deformação diagonal central do painel - Ensaios da série $\mathrm{A}$ 


\subsubsection{4 - INFLUÊNCIA DO FERRO-CABELO}

Apresentam-se, na figura 3.37, os diagramas força $\mathrm{x}$ deslocamento dos ensaios 3A, 4A, $5 \mathrm{~A}$ e $6 \mathrm{~A}$, cujas paredes foram moldadas com argamassa polimérica, tipo Ciment-cola. Nos ensaios 3A e 4A, utilizaram-se ferros-cabelo nas interfaces, ao passo que nos outros dois foi usado apenas argamassa polimérica. Notou-se que a presença dos ferros-cabelo não afetou a rigidez global dos pórticos preenchidos e também não contribuiu para o aumento da resistência em termos de carga de ruptura.

No que se refere aos cantos tracionados, os descolamentos verticais continuaram a ocorrer mesmo quando se utilizou ferro-cabelo, como pode ser percebido pelos diagramas força-descolamento apresentados no Anexo D e pelas figuras 3.32 e 3.33 . Para forças aplicadas de até $100 \mathrm{kN}$, esses descolamentos atingiram um valor máximo inferior a $1 \mathrm{~mm}$. Com relação aos descolamentos horizontais, o valor máximo obtido foi de 3,6 mm, para uma força aplicada de $200 \mathrm{kN}$. Dessa forma, pode-se concluir que o ferro-cabelo pouco contribuiu para retardar o descolamento. Um dos possíveis motivos para a ocorrência desse fato foi o comprimento utilizado para o ferro: $30 \mathrm{~cm}$. Acredita-se que ferros-cabelo de maiores comprimentos apresentariam melhor desempenho. No entanto, esse resultado deve ser verificado com cautela, através de outros ensaios experimentais, realizando uma instrumentação cuidadosa desses elementos.

É importante assinalar que o ferro-cabelo resiste aos esforços de tração até o limite de resistência à compressão da alvenaria ou até o escorregamento desta. A partir daí, o ferro-cabelo que está envolvido pela argamassa passa a movimentar-se livremente pela junta horizontal.

Na figura 3.38, apresentam-se os valores do descolamento máximo ocorrido na interface (canto inferior direito) dos ensaios com ferros-cabelo (3A e $4 \mathrm{~A}$ ) e sem ferros-cabelo (5A e 6A). Como se pode notar, para um mesmo nível de carga os painéis com e sem ferroscabelo apresentaram comportamentos bastante próximos, demonstrando, assim, a não- 
influência dos ferros-cabelo, da forma como foi utilizado, no comportamento de pórticos preenchidos.

\section{Diagrama Força-Deslocamento}

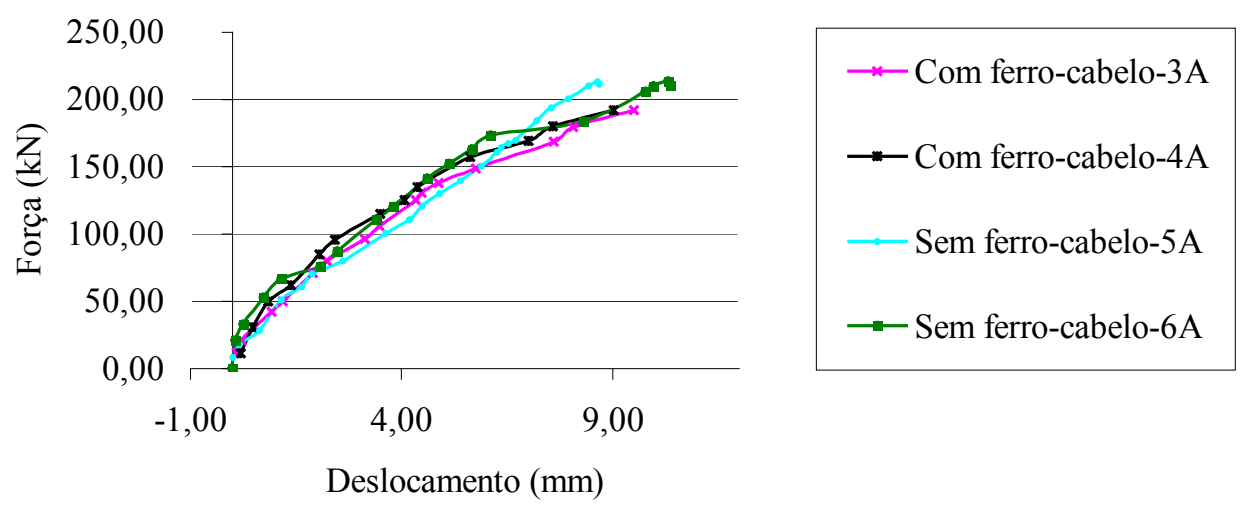

FIGURA 3.37 - Diagrama força-deslocamento nos ensaios da série A com e sem ferroscabelo
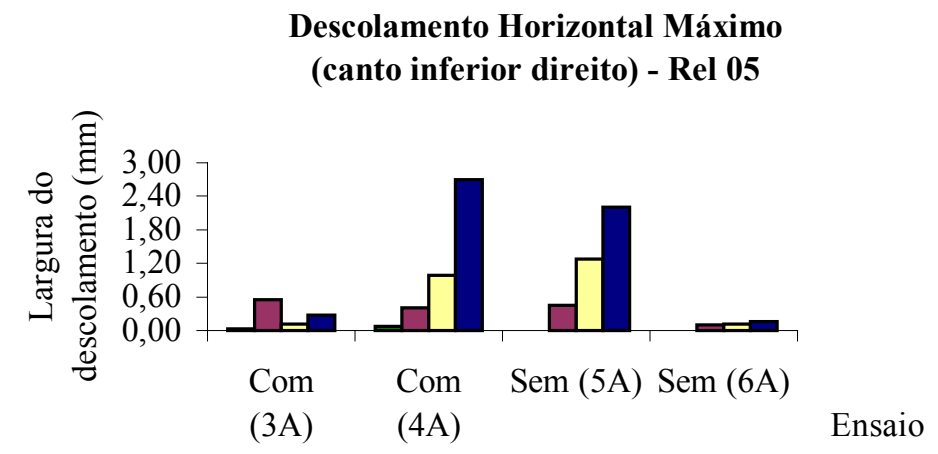

$\mathrm{P}=20 \mathrm{kN} \quad \square \mathrm{P}=60 \mathrm{kN} \quad \square \mathrm{P}=100 \mathrm{kN} \quad \square \mathrm{P}=170 \mathrm{kN}$

FIGURA 3.38 - Descolamento máximo ocorrido na interface, localizado no canto inferior direito (tracionado), dos ensaios com ferros-cabelo (3A e 4A) e sem ferroscabelo (5A e $6 \mathrm{~A})$, em quatro níveis de carga 
$\mathrm{Na}$ figura 3.39, apresentam-se os diagramas força-deformação na direção diagonal do painel, no canto inferior, nos ensaios 4A (com ferros-cabelo) e 5A (sem ferros-cabelo). Comparando os dois diagramas, é possível notar o comportamento não-linear de sistemas de pórticos preenchidos e a não-interferência dos ferros-cabelo na rigidez e resistência do sistema.

Diagrama Força x Deformação (Ext. 03)

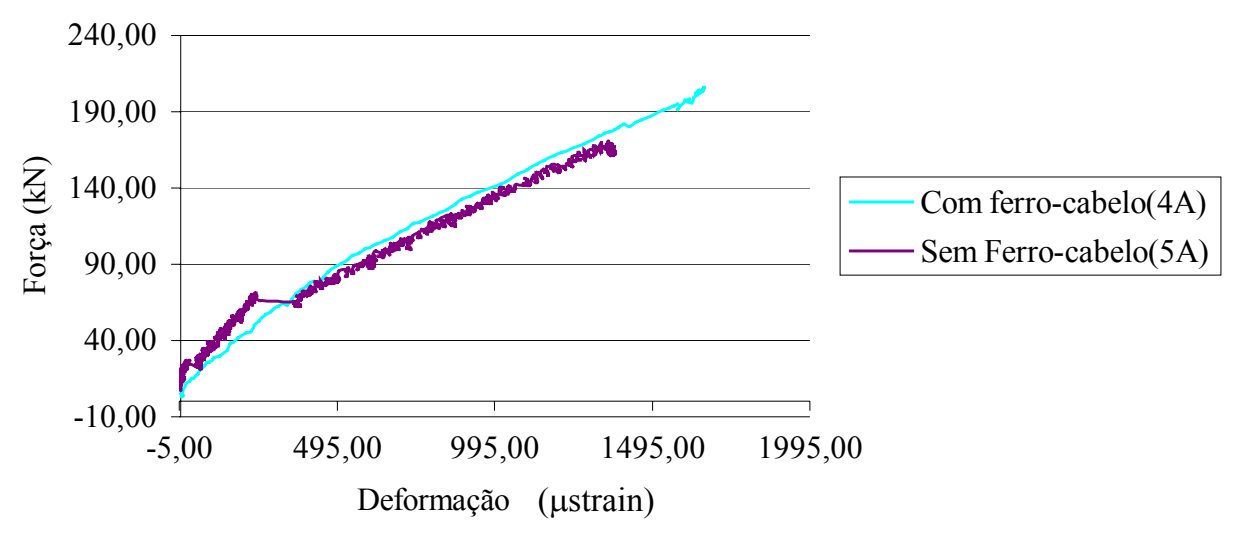

FIGURA 3.39 - Diagrama força-deformação no extensômetro diagonal inferior (EXT 03) dos ensaios com e sem ferros-cabelo

\subsubsection{5 - INFLUÊNCIA DO TIPO DE ARGAMASSA}

Os diagramas força-deslocamento apresentados na figura 3.40, relativos aos ensaios 1A, 2A, 3A e 4A, permitem efetuar uma avaliação da influência do tipo de argamassa na rigidez e carga de ruptura de painéis de pórticos preenchidos com alvenaria. Nos dois primeiros ensaios (1A, 2A), utilizou-se argamassa traço 1:3:7,5 de cimento, cal e areia; e nos outros dois foi usada argamassa polimérica, tipo Ciment-cola. Nos ensaios 1A e 2A, o modo de ruptura foi por cisalhamento e tração ao longo das juntas de argamassa, tendo em vista que a argamassa utilizada apresentou baixa resistência à tração e ao 
cisalhamento. As fissuras na diagonal iniciaram-se com baixas cargas e se propagaram com o acréscimo destas.

Nos dois ensaios seguintes, utilizando-se argamassa Ciment-cola, a resistência à tração e ao cisalhamento da argamassa aumentaram e não surgiram fissuras ao longo da diagonal.

Essa diferença de comportamento em função da mudança do tipo de argamassa é visível nos diagramas apresentados na figura 3.40. A carga de ruptura nos dois primeiros ensaios é de $71,23 \mathrm{kN}$ e $102,13 \mathrm{kN}$, respectivamente, enquanto nos ensaios com argamassa Ciment-cola esses valores elevaram-se para 189,72 kN e 206,60 kN. Desde o início do carregamento, pôde-se notar a maior rigidez nos ensaios com argamassa Ciment-cola. À medida que aumentou a carga, a rigidez dos painéis constituídos por argamassa traço 1:3:7,5 decresceu, tendo em vista que surgiram fissuras precoces, de forma escalonada, ao longo da diagonal comprimida. Nos painéis com juntas de argamassa Ciment-cola foram notáveis o comportamento homogêneo e a maior rigidez e resistência introduzidas ao sistema.

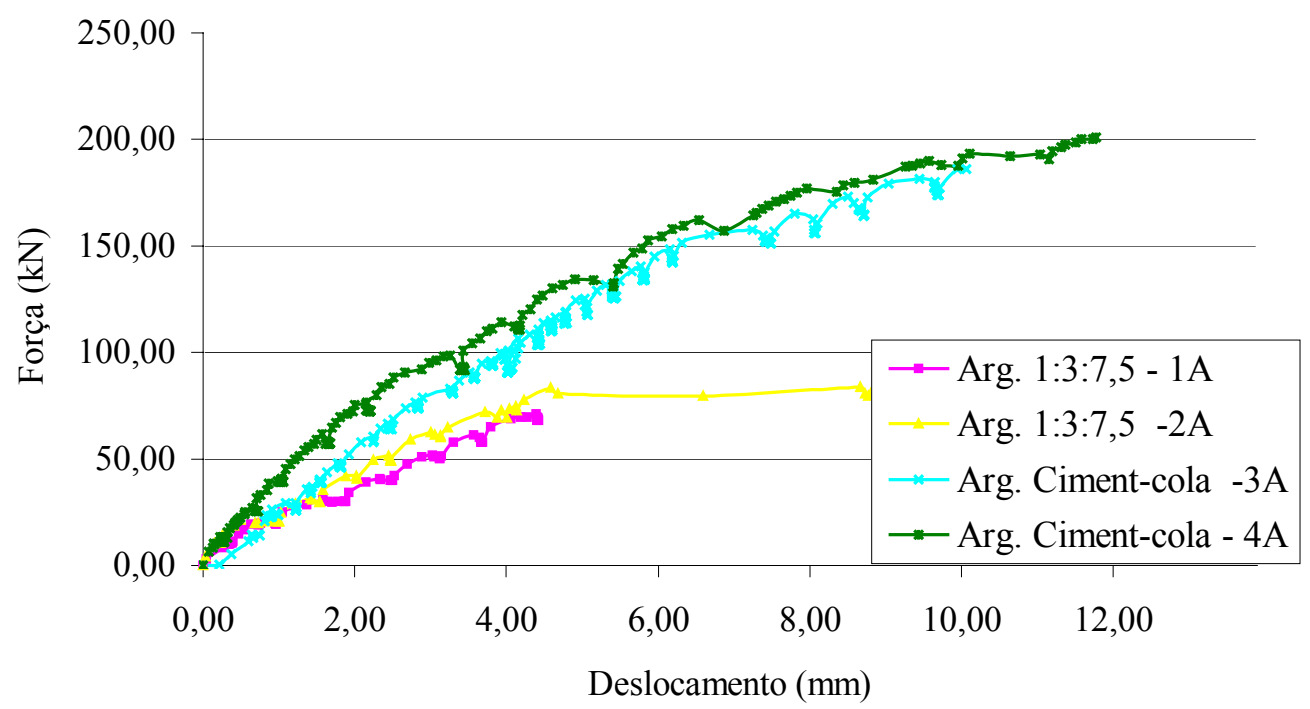

FIGURA 3.40 - Influência do tipo de argamassa utilizada para assentamento dos blocos e interface na rigidez de pórticos preenchidos com alvenaria 
Com relação ao descolamento, os dois tipos de argamassa proporcionaram comportamentos diferentes. No caso da argamassa de traço 1:3:7,5, o surgimento de fissuras escalonadas ao longo da diagonal do painel tende a produzir uma acomodação do painel junto ao pórtico, reduzindo o descolamento. Isso pode ser comprovado pelo diagrama apresentado na figura 3.41, em que para uma carga de de $60 \mathrm{kN}$ os ensaios com argamassa Ciment-cola apresentam maior descolamento. No entanto, as fissuras precoces que surgiram ao longo da diagonal comprimida inviabilizam a utilização da argamassa $1: 3: 7,5$.

\section{Descolame nto horizontal inferior a $10 \mathrm{~cm}$ do canto infe rior direito - Rel 05}

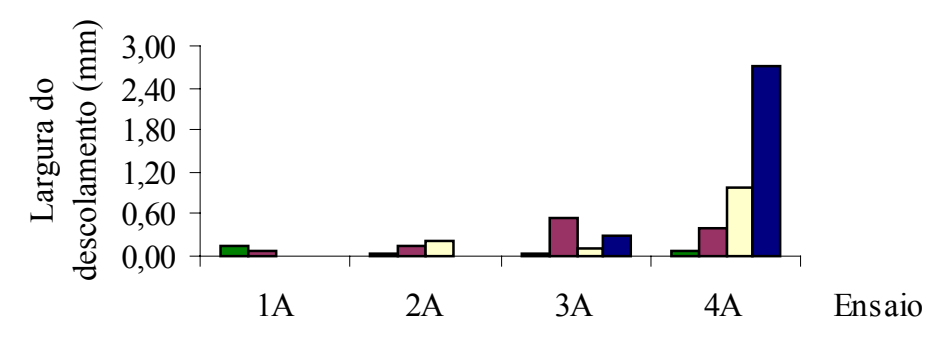

$\mathrm{P}=20 \mathrm{kN}$

$\square \mathrm{P}=60 \mathrm{kN}$

$\square \mathrm{P}=100 \mathrm{kN}$

$\mathrm{P}=170 \mathrm{kN}$

FIGURA 3.41 - Valor da largura do descolamento do canto inferior direito (tracionado) para ensaios com argamassa traço 1:3:7,5 de cimento, cal e areia (1A e 2A) e com argamassa Ciment-cola (3A e 4A)

Apresentam-se, na figura 3.42, os diagramas força-deformação na direção diagonal do painel, no canto inferior, nos ensaios 1A (argamassa 1:3:7,5) e 4A (argamassa Cimentcola). Mais uma vez, puderam-se perceber as vantagens, em termos de rigidez e resistência do painel, em se utilizar a argamassa Ciment-cola. 
Diagrama Força x Deformação (Ext. 03)

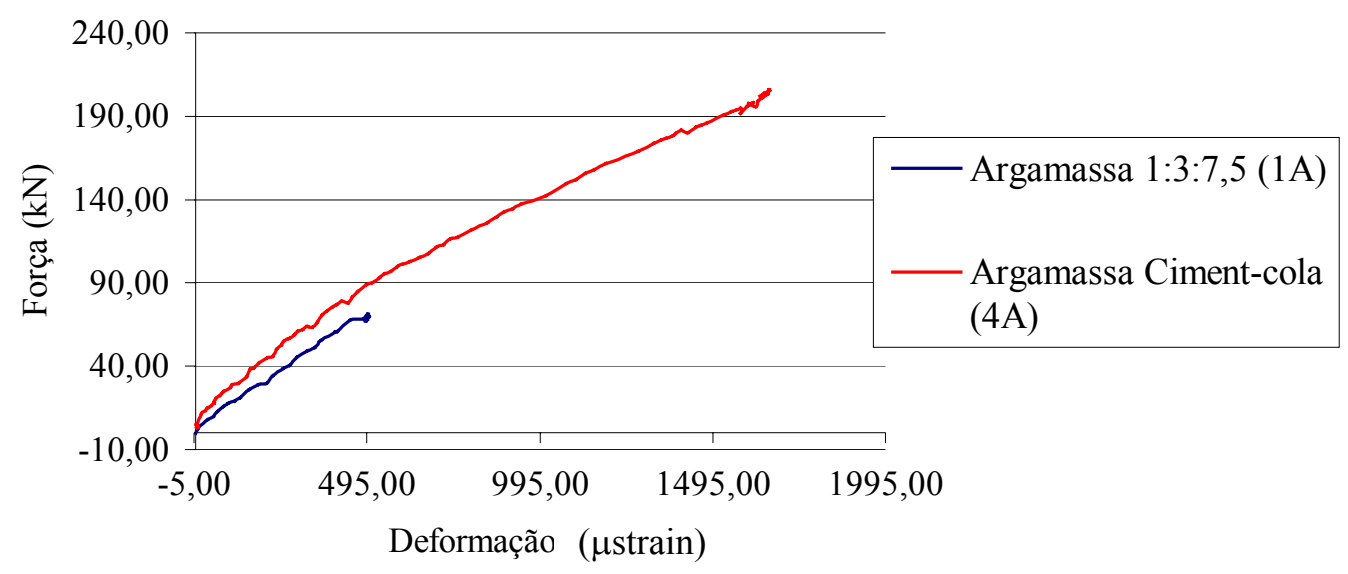

FIGURA 3.42 - Diagrama força-deformação no extensômetro diagonal inferior (EXT

03 ) dos ensaios com argamassa traço 1:3:7,5 de cimento, cal e areia (1A) e para argamassa Ciment-cola (4A) 


\subsection{2 - RESULTADOS REFERENTES AOS ENSAIOS DO PÓRTICO TIPO II}

\subsubsection{1 - DESENVOLVIMENTO DOS ENSAIOS E MODOS DE RUPTURA}

Apresenta-se, na figura 3.43, o diagrama força-deslocamento para o pórtico TIPO II sem preenchimento e para cada um dos ensaios do sistema de pórtico-parede realizados com esse pórtico (série B): dois com paredes sem aberturas e dois com paredes com abertura. Além desses, foram realizados mais dois ensaios de pórtico preenchido com painéis pré-fabricados, cujos resultados se encontram no Anexo A. Os ensaios foram conduzidos até a fissuração dos painéis de alvenaria.

Nessa série, todos os ensaios foram realizados com 14 dias de idade, e em todos eles se utilizou argamassa Ciment-cola para assentamento dos blocos e painéis de alvenaria de CCA. Nos dois primeiros ensaios, foi aplicada uma camada de reboco de $1,5 \mathrm{~cm}$ de espessura e $20 \mathrm{~cm}$ de largura ao longo das interfaces pilar-painel, deixando-se um espaçamento de $1 \mathrm{~cm}$ entre o reboco e o pilar, que foi preenchido com mastique, na face frontal da parede. Esse procedimento visou à avaliação do comportamento do mastique como elemento de vedação, de modo a minimizar visualmente o efeito do descolamento surgido nas interfaces tracionadas.

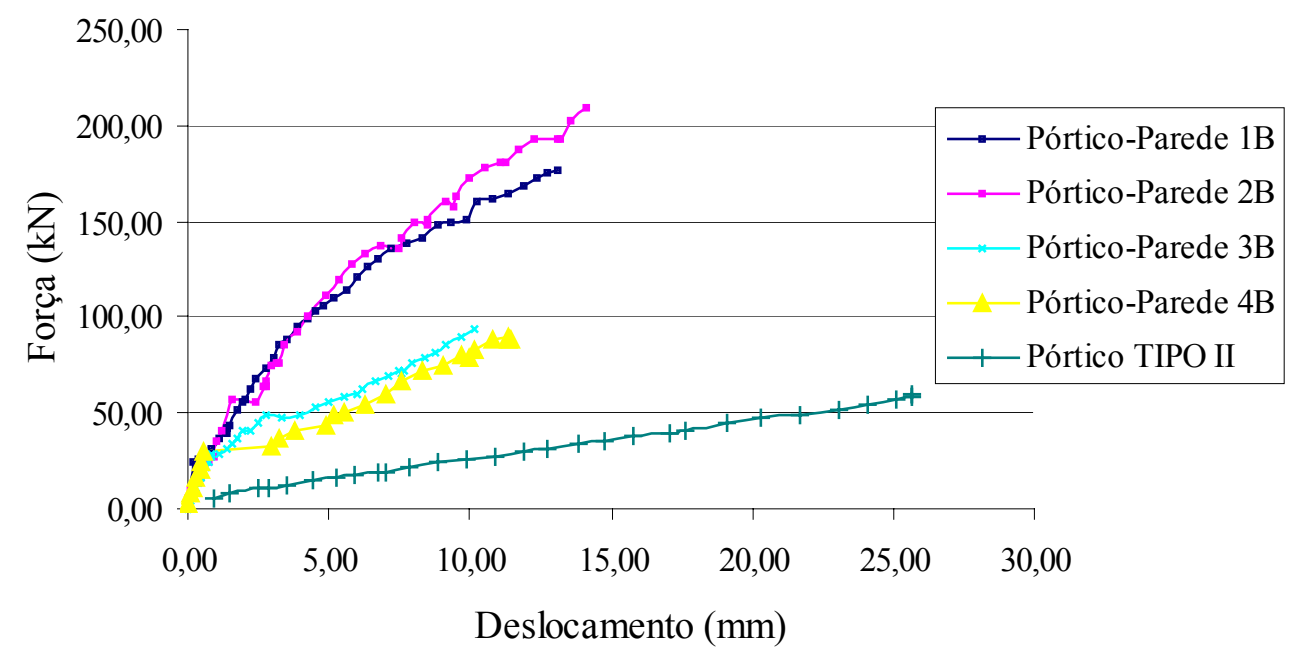

FIGURA 3.43 - Diagrama força-deslocamento do pórtico sem preenchimento e dos sistemas pórtico-parede ensaiados 
No primeiro ensaio, com uma carga de $30 \mathrm{kN}$ ocorreu o descolamento da parte inferior da parede, e com $50 \mathrm{kN}$ percebia-se claramente o comportamento desta como uma biela, tendo em vista que já havia ocorrido o descolamento da interface tracionada.

Observou-se que o descolamento vertical iniciou-se na interface oposta à aplicação da carga e se manteve maior que o da outra interface até uma carga de $60 \mathrm{kN}$, quando ocorreu inversão e o descolamento do lado da aplicação da carga tornou-se maior. Aos $80 \mathrm{kN}$, o comprimento de contato nas interfaces verticais comprimidas era de 60 $\mathrm{cm}$ e, na interface horizontal inferior, esse comprimento era de $50 \mathrm{~cm}$. A interface horizontal superior já estava completamente descolada, o que se atribuiu a uma acomodação da viga superior.

Aos $112 \mathrm{kN}$ a parede se mantinha praticamente intacta e o comprimento de descolamento era constante, até que aos $140 \mathrm{kN}$ iniciou-se o esmagamento dos cantos comprimidos, que continuou crescendo com a aplicação da carga. Com 150 $\mathrm{kN}$, partes de blocos dos cantos comprimidos começaram a se desprender, ocorrendo ruptura frágil por tração da diagonal para uma carga de $173 \mathrm{kN}$, figura 3.44a.

O segundo ensaio, com as mesmas características do primeiro, apresentou desenvolvimento também similar. Antes do início do ensaio, a parede já apresentava descolamento na interface painel-viga superior. Isso pode ter ocorrido devido à flecha surgida na viga inferior, tendo em vista o considerável comprimento do vão (5 $\mathrm{m})$.

Com carga de $90 \mathrm{kN}$, a parede, que até então se mantinha intacta, começou a fissurar. A primeira fissura foi vertical a meio metro da extremidade superior esquerda, iniciada a partir do encunhamento, na extremidade oposta à aplicação da carga. Com $100 \mathrm{kN}$, o mastique começou a se soltar, inicialmente do pilar de aço, uma vez que o aço apresenta menor aderência que o painel. Iniciou-se, também, um pequeno esmagamento na face posterior do painel, mas isso não resultou em mudanças visuais com o aumento da carga. 
Aos $110 \mathrm{kN}$, a parte do mastique que estava em contato com o painel também começou a se soltar. Esse descolamento precoce do mastique, tendo em vista que ele pode se deformar até $80 \%$ de sua largura inicial, deveu-se ao seguinte fato: como foi o segundo ensaio no qual esse procedimento foi aplicado, o mastique foi colocado com três faces em contato: uma face em contato com o aço (mesa do pilar), a segunda face em contato com a argamassa de reboco e a terceira em contato com a alvenaria (fundo). No entanto, o indicado é colocá-lo trabalhando em um só plano, ou seja, ele deveria ter sido fixado apenas nas laterais, e o fundo deveria ter ficado livre. Tal procedimento foi adotado nos ensaios posteriores.

Durante o segundo ensaio foram aplicadas cargas até $210 \mathrm{kN}$, e a parede não sofreu ruptura da diagonal tracionada. As fissuras presentes eram a vertical, comentada anteriormente, e outras ao longo do encunhamento, conforme mostrado na figura 3.44b. No entanto, o pórtico foi descarregado para que não ultrapassasse o seu limite elástico.

O terceiro e quarto ensaios da série B foram de paredes com abertura central de 150 x $90 \mathrm{~cm}^{2}$. As vergas e contravergas pré-moldadas de CCA, com armação, de $2 \mathrm{~m}$ de comprimento e seção transversal de $15 \times 30 \mathrm{~cm}^{2}$, foram colocadas no sentido da menor inércia, a fim de permitir a execução de mais uma fiada entre a verga e a viga superior.

No terceiro ensaio, executou-se o reboco nos mesmos moldes dos dois primeiros ensaios e foi utilizado mastique ao longo das interfaces verticais, porém o mastique foi colado só nos contatos com o pórtico e com a lateral do reboco, ficando livre o fundo da parede. Antes do início do ensaio, a interface parede-fundo de viga superior já apresentava fissuras visíveis.

Foi, inicialmente, aplicada uma carga até $30 \mathrm{kN}$, e em seguida o sistema foi descarregado. Novamente, iniciou-se a aplicação de carga de 10 em 10 kN. Com 20 $\mathrm{kN}$, o descolamento parede-fundo de viga havia se acentuado. Com $30 \mathrm{kN}$, surgiram as primeiras fissuras verticais, passando por junta e meio do bloco, a partir do canto 
inferior direito da abertura. Iniciou-se, também, o descolamento das interfaces pilarparede. As fissuras foram vistas na face posterior da parede, uma vez que a interface frontal estava preenchida por mastique, que impedia a visualização delas.

Com carga de $40 \mathrm{kN}$, as fissuras já existentes aumentaram o comprimento e a abertura. Surgiram ainda novas fissuras no canto superior esquerdo da parede. $\mathrm{O}$ surgimento dessas fissuras deveu-se à concentração de tensões transversais de tração nos cantos inferior esquerdo e superior direito da abertura, uma vez que estes tendem a formar ângulos maiores que $90^{\circ}$. A carga máxima aplicada foi de $95 \mathrm{kN}$, mas as fissuras já apresentavam abertura considerável.

O modo de ruptura correspondente foi por cisalhamento nas juntas de argamassa da alvenaria e tração e cisalhamento nos blocos, conforme figura 3.45a. Mesmo sendo uma parede contendo abertura, continuou a existir a configuração de uma biela, embora a carga de ruptura tenha diminuído consideravelmente. $\mathrm{O}$ mastique, que nessa parede foi colado apenas nas laterais, ficando o fundo livre, comportou-se bem até a máxima carga aplicada $(95 \mathrm{kN})$.

No quarto ensaio, com uma carga de $11 \mathrm{kN}$, ocorreu o descolamento da interface painel-viga superior, e deu-se início ao descolamento da interface tracionada pilarpainel. Com $30 \mathrm{kN}$, iniciaram-se as fissuras a partir do lado direito da contraverga. Com a carga de $40 \mathrm{kN}$, essas fissuras aumentaram e novas fissuras surgiram, a partir da extremidade direita da verga.

Quando a carga atingiu $60 \mathrm{kN}$, as fissuras já apresentavam $5 \mathrm{~mm}$ de abertura, e as extremidades superior direita e inferior esquerda da abertura já estavam rotuladas. $\mathrm{O}$ ensaio foi encerrado para uma carga de $70 \mathrm{kN}$, e o modo de ruptura correspondente foi por cisalhamento nas juntas de argamassa da alvenaria e tração nos blocos, conforme mostrado na figura $3.45 \mathrm{~b}$. 


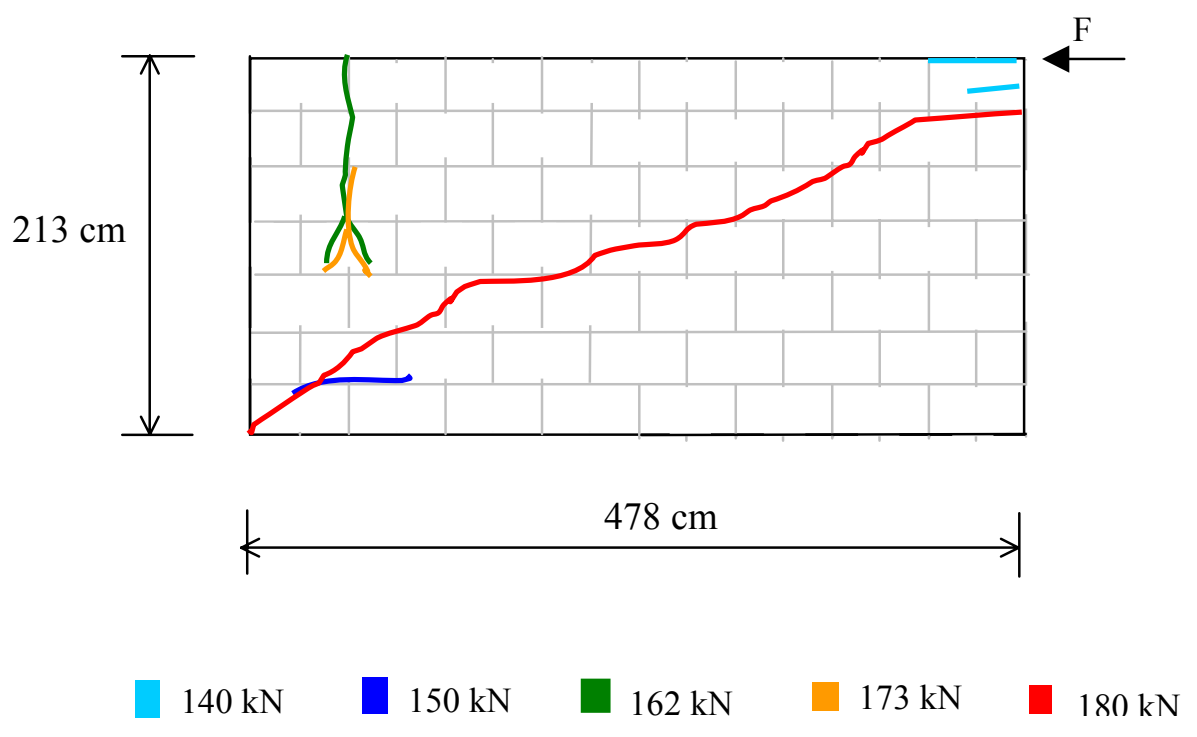

(a)

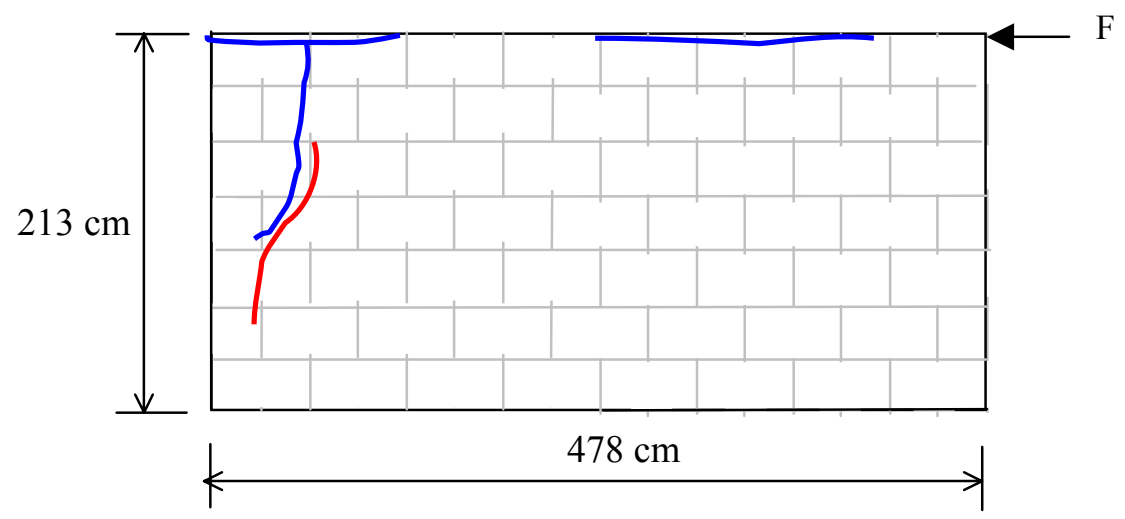

$90 \mathrm{kN}$

(b)

$118 \mathrm{kN}$

FIGURA 3.44 - Modos de ruptura referentes aos dois primeiros ensaios: juntas de assentamento e interface de argamassa Ciment-cola: a) ensaio $1 \mathrm{~B}$ e b) ensaio 2B

Esses ensaios permitiram avaliar a influência da presença de aberturas em paredes com funções estruturais. Pôde-se observar que a carga última decresceu consideravelmente e houve uma perda da rigidez do conjunto. Pode-se tentar minimizar esse problema quando se utilizam blocos vazados, enrijecendo o contorno da abertura, através de grauteamento. Esse procedimento não foi adotado nesses ensaios por não corresponder à solução utilizada em construções em que se utilizam blocos maciços de concreto celular autoclavados. 


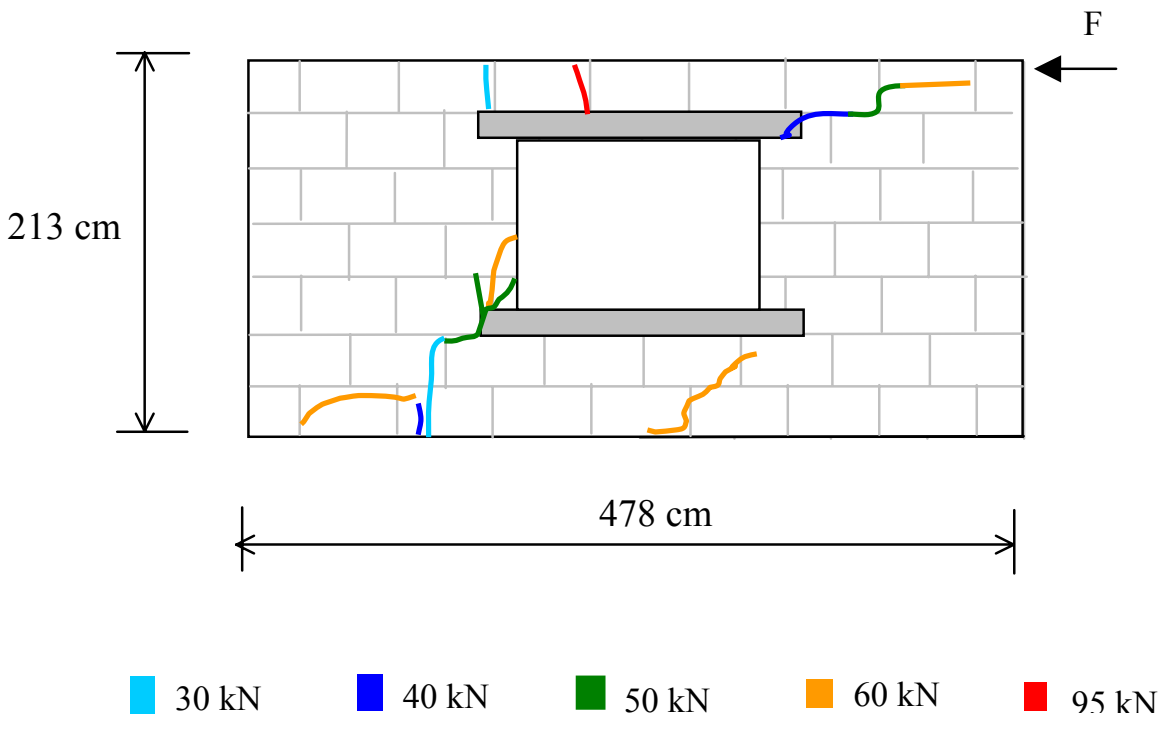

(a)

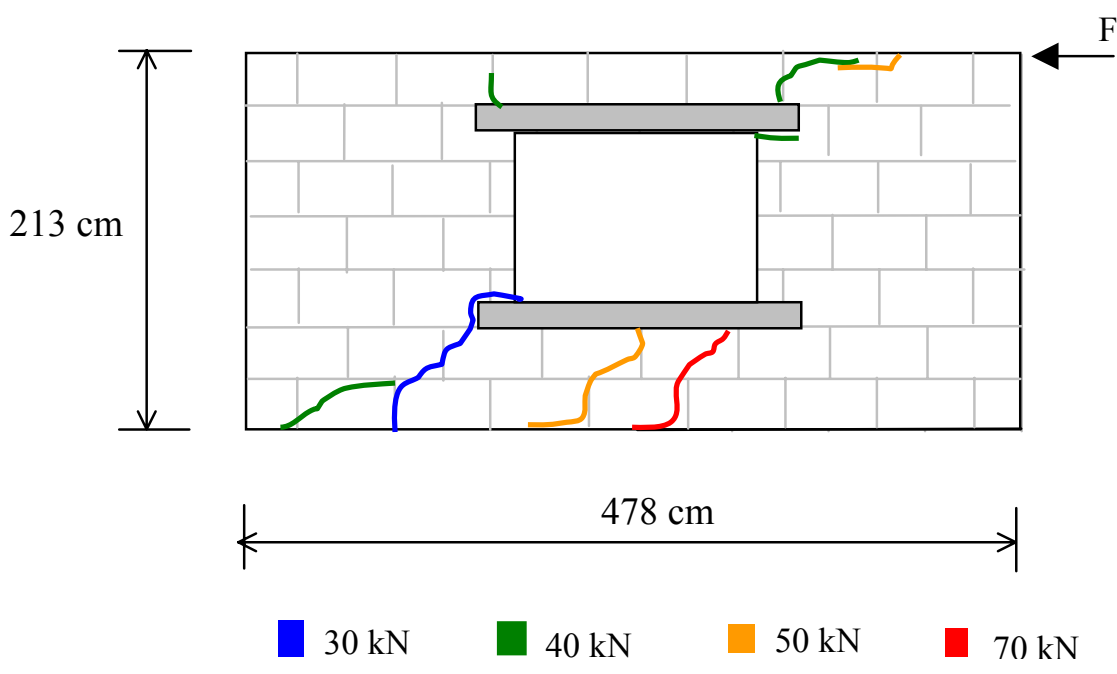

(b)

FIGURA 3.45 - Modos de ruptura referentes aos ensaios de parede com abertura de $150 \times 90 \mathrm{~cm}^{2}$ : a) ensaio $3 \mathrm{~B} \mathrm{e} \mathrm{b)} \mathrm{ensaio} \mathrm{4B}$

Nas figuras 3.46, 3.47 são apresentados os diagramas força-deslocamento horizontal no topo do pilar, na direção do eixo da viga, para cada tipo de ensaio realizado na série B. Em cada gráfico são apresentados dois ensaios de pórticos preenchidos com 
as mesmas características. Em cada figura, percebe-se comportamento semelhante entre os dois ensaios apresentados.

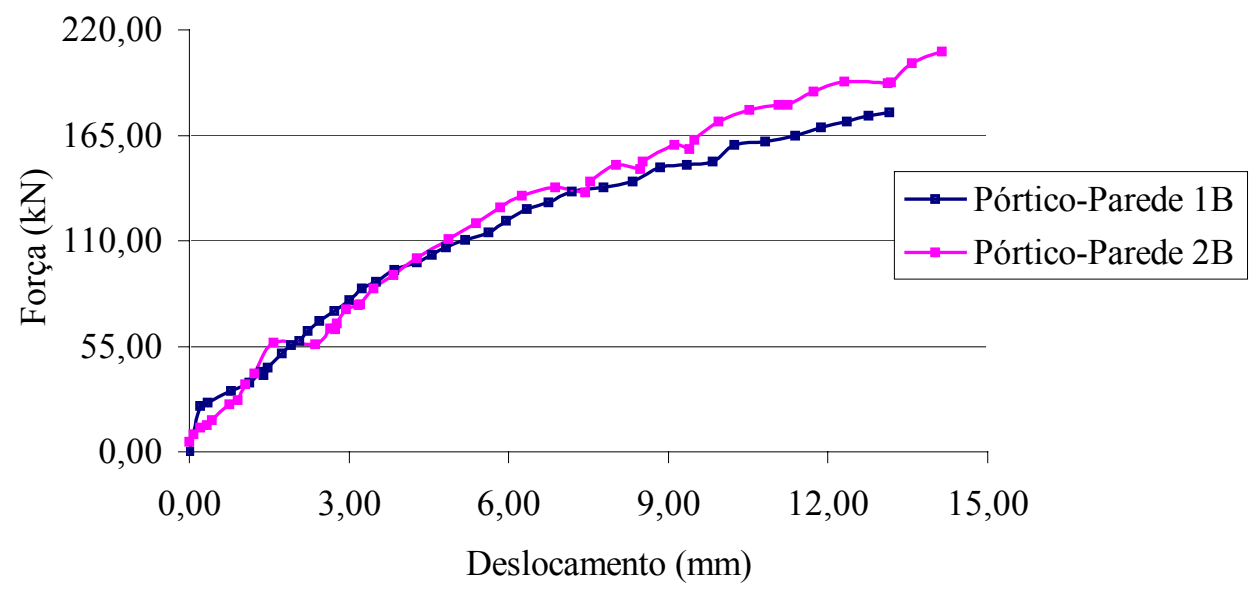

FIGURA 3.46 - Diagrama força-deslocamento dos ensaios 1B e 2B, correspondentes às paredes sem aberturas de blocos de CCA

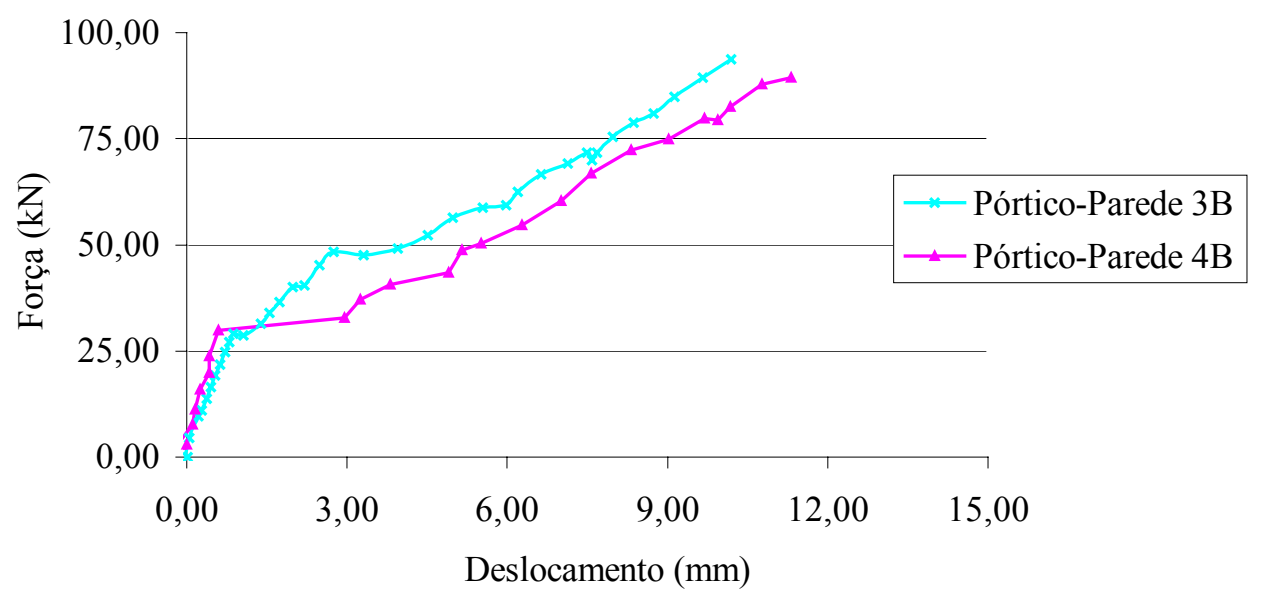

FIGURA 3.47 - Diagrama força-deslocamento dos ensaios 3B e 4B, correspondentes às paredes com abertura, de blocos de CCA 


\subsubsection{2 - DESCOLAMENTO DA INTERFACE PÓRTICO-PAINEL}

Para análise da interface pórtico-painel dos ensaios da série B (TIPO II), foram colocados transdutores de deslocamento e relógios comparadores nas mesmas posições já descritas para o pórtico TIPO I, quando foram ensaiadas paredes sem aberturas. Para as paredes com abertura, foram ainda utilizados dois transdutores de deslocamento horizontal e vertical dispostos nos comprimentos médios da abertura, com a finalidade de medir os deslocamentos verticais e horizontais relativos entre as faces paralelas da abertura.

No Anexo D são apresentados os diagramas força-descolamento para as paredes da série $B$.

Nas figuras 3.48 e 3.49 são apresentados os gráficos referentes às larguras dos descolamentos medidas nos ensaios da série B, nos dois cantos tracionados. Estão identificados os seguintes níveis de cargas: 20 kN, 60 kN, 100 kN e 170 kN.

Pelos gráficos apresentados, nota-se que, para carga de $20 \mathrm{kN}$, praticamente não surgiram fissuras na interface pórtico-painel. À medida que aumentou a carga, cresceu o descolamento. Para carga de 100 kN, apenas os relógios Rel 05 e Rel 06, correspondentes aos descolamentos horizontais inferiores, registraram um descolamento de $2 \mathrm{~mm}$; todos os demais apresentaram valores inferiores a $1 \mathrm{~mm}$. Os maiores deslocamentos relativos pórtico-painel surgiram na interface vertical inferior tracionada, onde para a carga de 170 kN, que corresponde à ruptura por fissuração da diagonal no ensaio $1 \mathrm{~B}$, os descolamentos assumiram valores de até $6 \mathrm{~mm}$. 


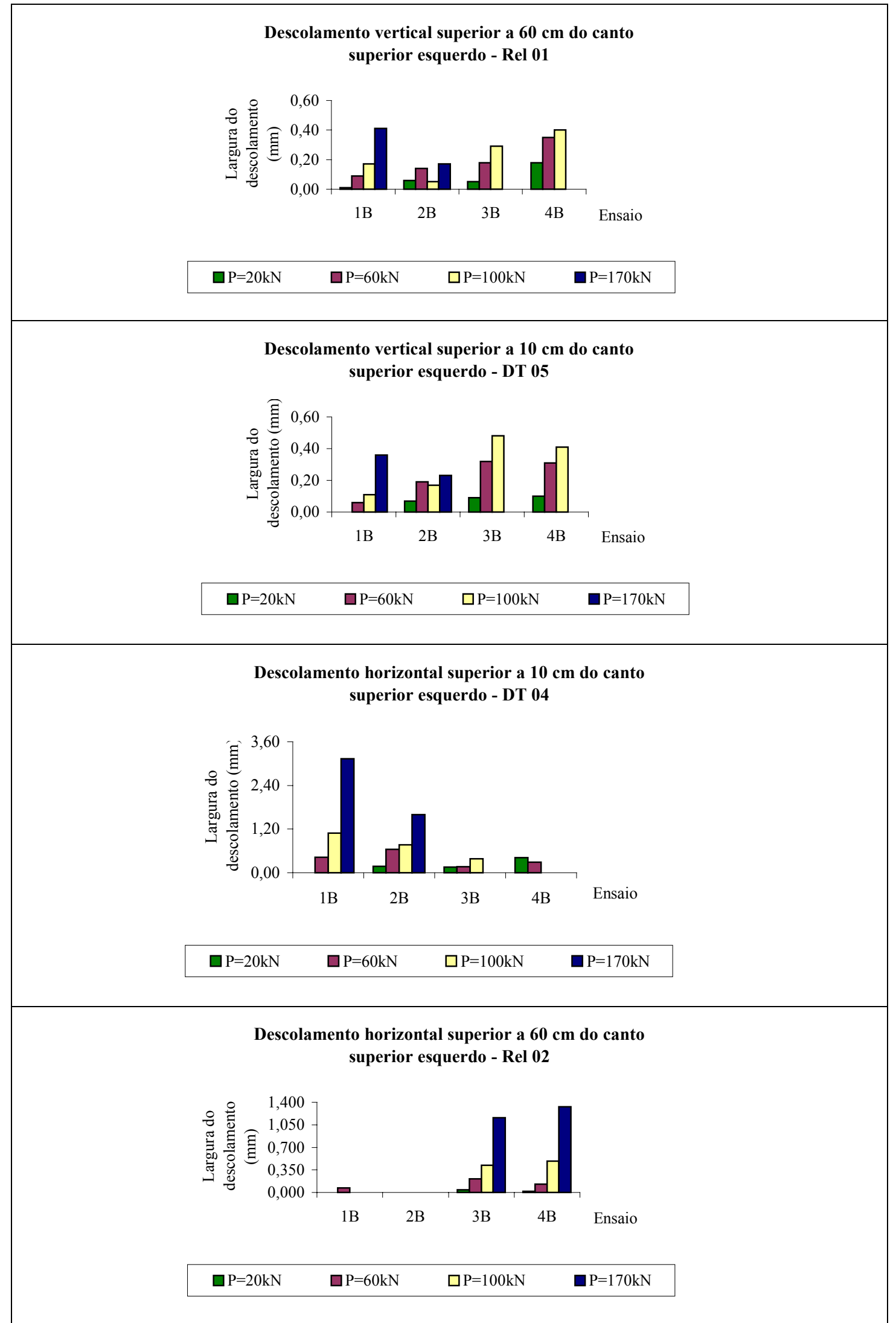

FIGURA 3.48 - Diagrama força-descolamento dos cantos tracionados: canto superior esquerdo (Rel 01, DT 05, DT 04 e Rel 02) 


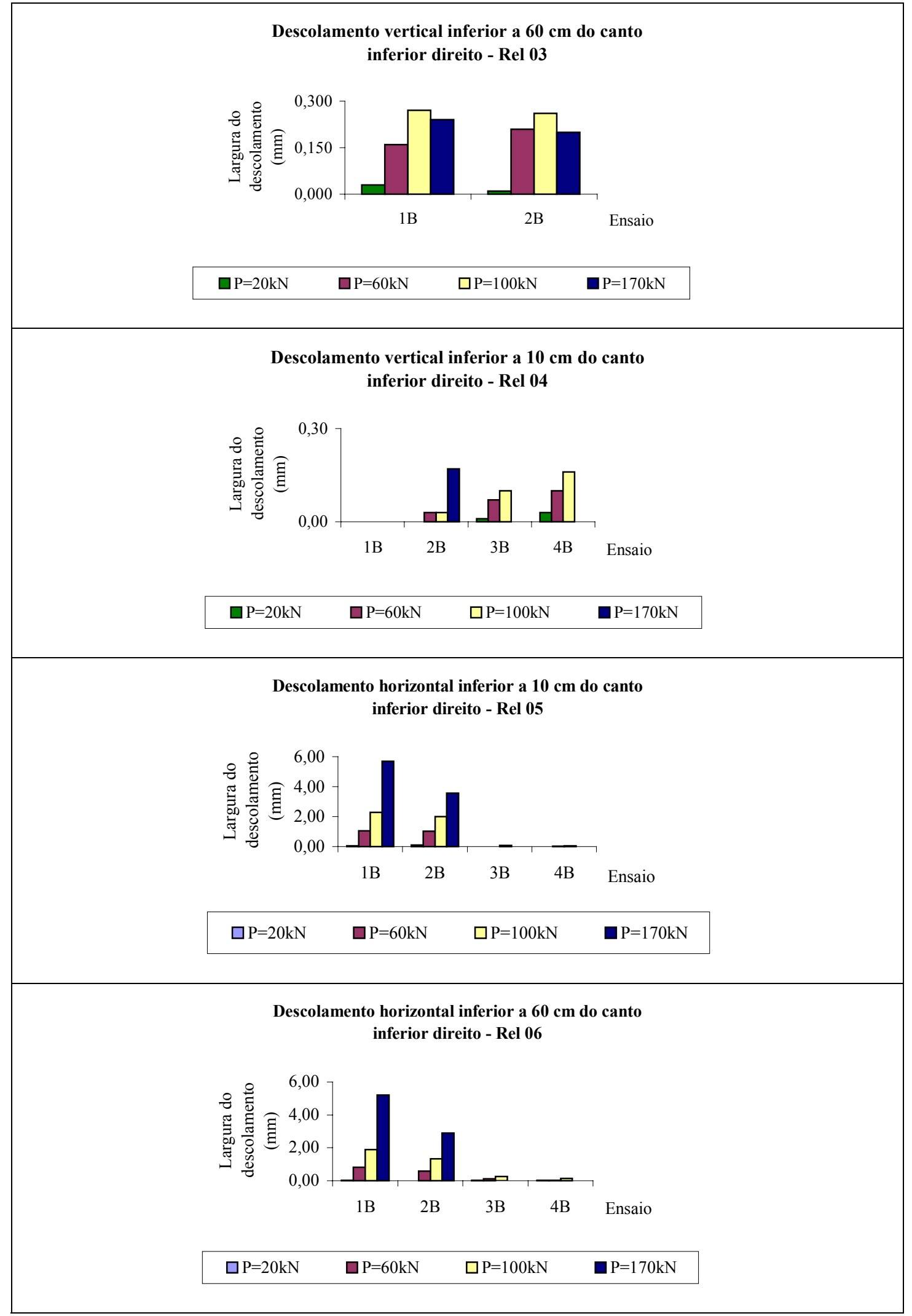

FIGURA 3.49 - Diagrama força-descolamento dos cantos tracionados: canto inferior direito (Rel 03, Rel 04, Rel 05 e Rel 06) 
Através dos ensaios realizados, observou-se que o descolamento das interfaces pórtico-painel ocorreu para níveis de carga muito inferiores aos das cargas de ruptura do painel. Dessa forma, tem-se configurado, a princípio, um estado-limite de utilização, em virtude da precoce plastificação das interfaces. No entanto, é importante observar que o caráter cíclico das ações horizontais oriundas do vento proporcionam diminuição na rigidez da estrutura ao longo do tempo, podendo ocorrer perda na eficiência do sistema de contraventamento, comprometendo a estabilidade da edificação.

Esse problema foi detectado em diversos trabalhos consultados. Alguns procedimentos práticos construtivos são apresentados no capítulo 8, como alternativas a serem utilizadas na solução desse problema. No entanto, qualquer solução adotada carece de validação experimental consistente. Nesta tese, realizaram-se ensaios utilizando o ferro-cabelo com o intuito de testá-lo como elemento resistente ao descolamento. No entanto, provou-se que, da forma como foi utilizado, o ferro-cabelo pouco influenciou no comportamento de pórticos preenchidos.

\subsubsection{3 - ANÁLISE DE TENSÕES E DEFORMAÇÕES}

Nos ensaios da série $B$, os estados de tensão e de deformação nos painéis de alvenaria foram avaliados utilizando-se extensômetros colocados nas mesmas posições dos ensaios da série $\mathrm{A}$, com exceção dos ensaios $3 \mathrm{~B}$ e $4 \mathrm{~B}$, de paredes com aberturas, nos quais o extensômetro e o DT da diagonal central foram substituídos por dois DT's colocados nas direções vertical e horizontal da abertura.

Os resultados obtidos nos extensômetros são apresentados no anexo E. Nas figuras E.8 a E.15, apresentam-se os diagramas força x deformação nos extensômetros, obtidos através dos ensaios.

Apresentam-se, na tabela E3, as deformações dos extensômetros para quatro níveis de carga, obtidos nos ensaios. A convenção de sinais adotada foi a seguinte: compressão-negativa e tração-positiva. 
A partir das deformações medidas nos extensômetros são calculadas as tensões nas mesmas direções e as deformações e tensões principais. Na tabela E4 são apresentadas as direções, deformações e tensões principais na região dos cantos comprimidos do conjunto pórtico-painel, para quatro níveis de carga.

No centro do painel, têm-se as deformações nas direções diagonais, fornecidas pelo extensômetro EXT 04 (diagonal comprimida) e pelo DT 03 (diagonal tracionada). Apresenta-se, na figura 3.50, o diagrama força-deformação diagonal comprimida (EXT 04), onde se nota um comportamento próximo ao linear em sistemas de pórticos-parede.

\section{Diagrama Força x Deformação} Extensômetro 04

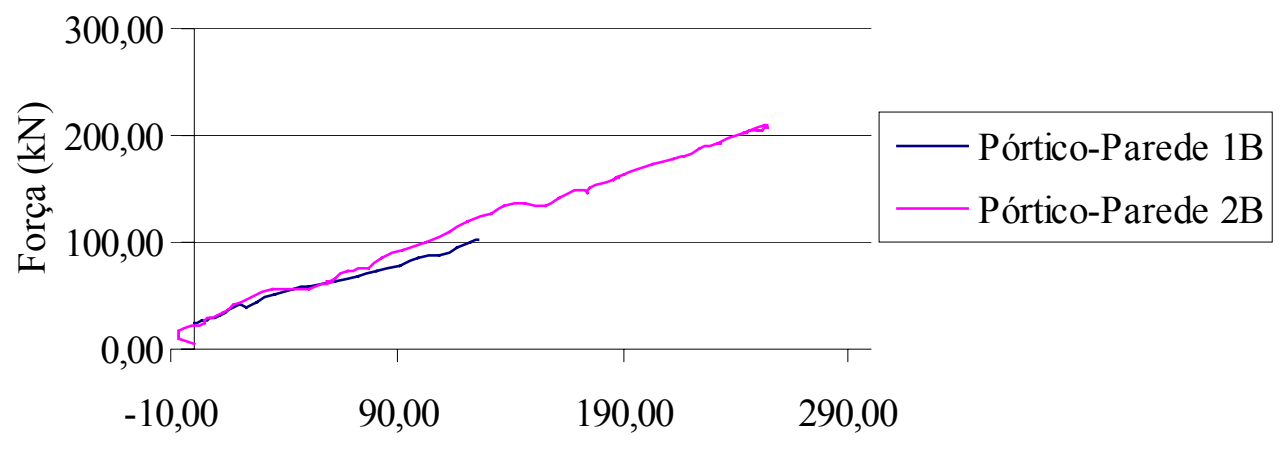

Deformação (mstrain)

FIGURA 3.50 - Diagramas força-deformação diagonal central do painel (encurtamento) - Ensaios da série B (ensaios 1B e 2B)

A partir das deformações medidas experimentalmente, foi determinado o campo de deformações nos cantos comprimidos e obtidos os diagramas tensões-deformações principais máximas e mínimas. 


\subsubsection{4 - INFLUÊNCIA DA ABERTURA NA PAREDE}

A literatura evidencia que não há muitos trabalhos relativos a paredes com aberturas. MALLICK e GARG (1971) estudaram a posição mais adequada para introdução de aberturas relativas às portas e janelas, através de ensaios experimentais e análises teóricas. Concluíram que, em projetos de edifícios de pórticos preenchidos com alvenaria estrutural, é recomendado que as aberturas relativas às portas sejam posicionadas no centro da metade inferior das paredes e que aquelas referentes às janelas estejam à meia altura, no centro de uma das metades esquerda ou direita. Estudaram também a conveniência da utilização de conectores de cisalhamento, concluindo que esse arranjo provoca aumento da rigidez, além de reduzir o risco de lacunas entre pórtico e painel, que é responsável pela redução de rigidez inicial do conjunto. Nos casos analisados, o modo de ruptura característico é por esmagamento dos cantos comprimidos.

Apresentam-se na figura 3.51 os diagramas força-deslocamento do pórtico TIPO II preenchido por parede sem abertura (ensaios 1B e 2B) e parede com abertura (ensaios 3B e 4B), de blocos de concreto celular autoclavado. Comparando a rigidez inicial dos ensaios com e sem abertura, percebe-se a perda de rigidez produzida pela introdução da abertura na parede.

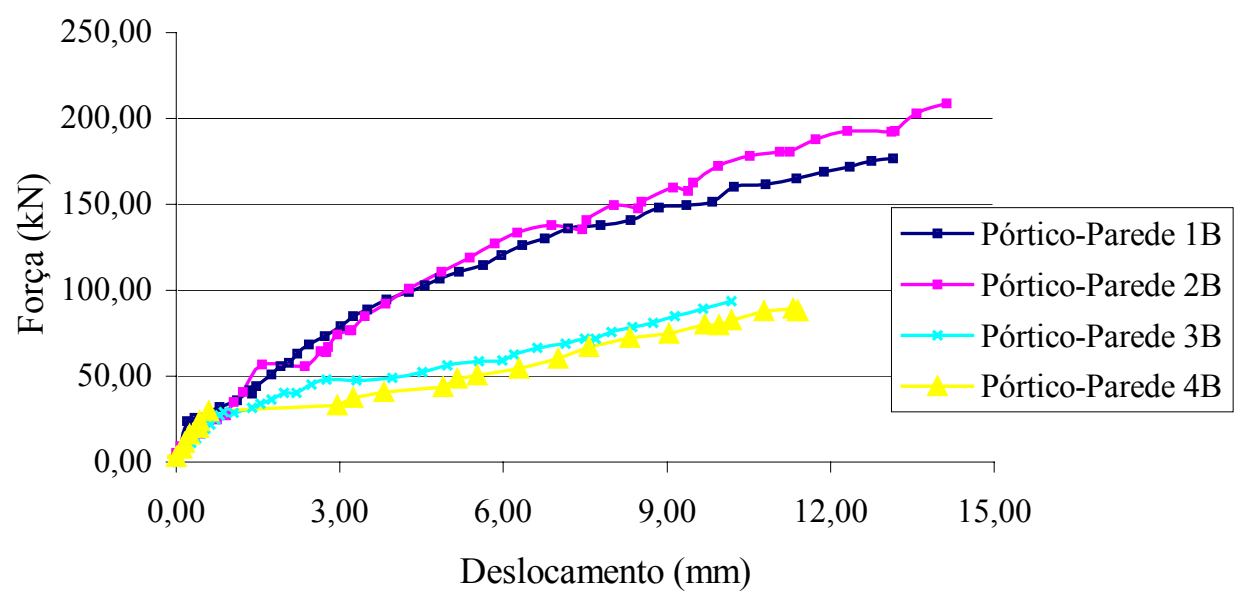

FIGURA 3.51 - Diagramas força-deslocamento para os pórticos preenchidos com parede sem abertura (ensaios 1B e 2B) e com parede com abertura (ensaios 3B e 4B) 
Para fins de comparação, considere a máxima força aplicada à estrutura e o deslocamento horizontal correspondente. Chamando-se de rigidez média horizontal a razão entre a força máxima e o deslocamento correspondente, tem-se que esta rigidez para o sistema sem abertura era de $14,00 \mathrm{kN} / \mathrm{mm}$, enquanto para o sistema com abertura a rigidez média tornava-se $8,36 \mathrm{kN} / \mathrm{mm}$, correspondendo a uma perda de rigidez em torno de $40 \%$. Se a comparação for feita em relação ao deslocamento de $10 \mathrm{~mm}$, as rigidezas médias das paredes sem e com abertura tornam-se, respectivamente, $16,7 \mathrm{kN} / \mathrm{mm}$ e $8,77 \mathrm{kN} / \mathrm{mm}$, correspondendo a uma perda de rigidez da ordem de 47,5\%; o mesmo acontece em termos de resistência. A média das forças máximas aplicadas nos ensaios das paredes sem abertura é de 191,5 kN, enquanto para as paredes com abertura esse valor é de $82,5 \mathrm{kN}$, correspondendo a uma diminuição de $57 \%$ no valor da carga.

Apresentam-se nas figuras 3.52 e 3.53 os diagramas força-deslocamentos relativos horizontal e vertical entre as laterais paralelas da abertura, obtidos a partir dos resultados experimentais dos ensaios $3 \mathrm{~B}$ e 4B. Pode-se perceber que os deslocamentos relativos horizontal e vertical da abertura crescem à medida que ocorrem as fissuras a partir dos dois cantos, cujas tensões principais de tração atingem valores máximos (inferior esquerdo e superior direito - face frontal), como visto na figura 3.54 .

\section{Diagrama força-deslocamento horizontal relativo entre faces verticais da abertura}

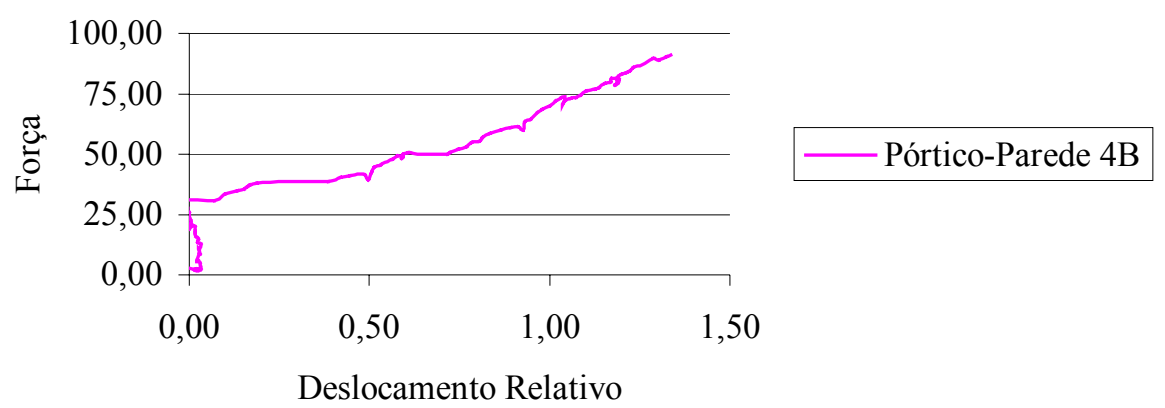

FIGURA 3.52 - Deslocamento relativo horizontal entre as faces verticais da abertura 
O descolamento máximo das interfaces ocorre no canto inferior direito tracionado, para paredes sem e com abertura. No entanto, os descolamentos em paredes com abertura, apresentam valores próximos a zero, figura 3.55. A explicação para esse fato está relacionada ao modo de ruptura por cisalhamento das juntas de argamassa, característico de paredes com abertura. As fissuras escalonadas que surgem a partir dos cantos da abertura, na direção da diagonal comprimida, tendem a provocar menor descolamento.

\section{Diagrama força-deslocamento vertical relativo entre faces horizontais da abertura}

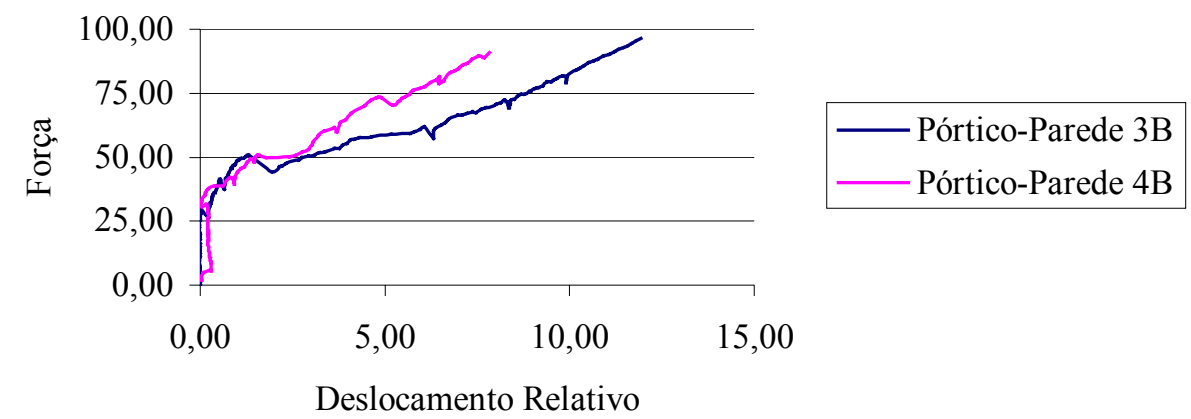

FIGURA 3.53 - Deslocamento relativo vertical entre as faces horizontais da abertura 


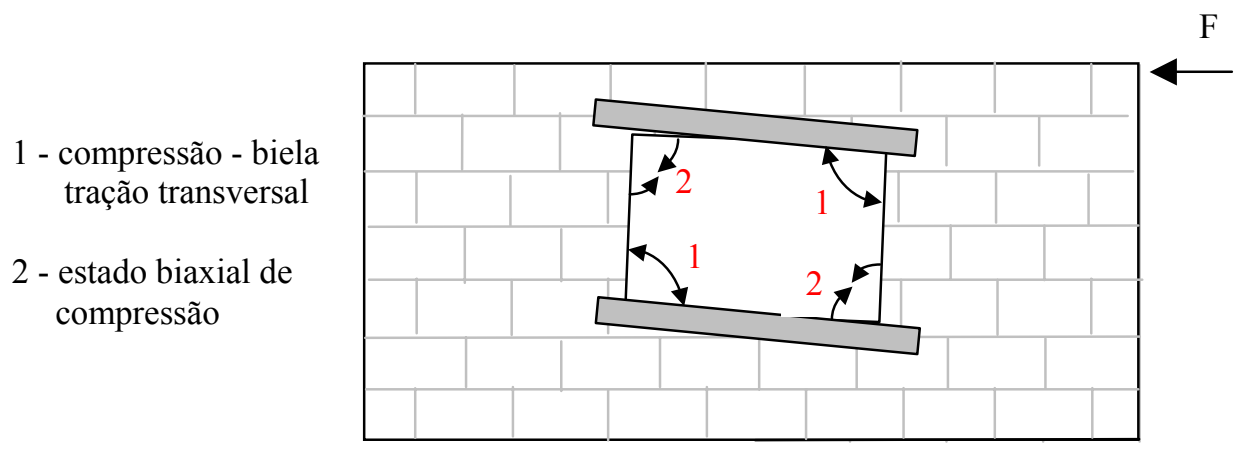

(a)
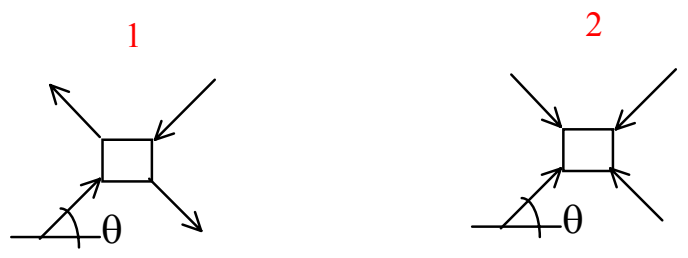

(b)

FIGURA 3.54 - Esquema do estado de tensões nos cantos da abertura:

a) comportamento dos cantos e b) elementos diferenciais localizados nos cantos 1 e 2 e direção principal $(\theta)$

Descolamento horizontal inferior a $10 \mathrm{~cm}$ do canto inferior direito - Rel 05

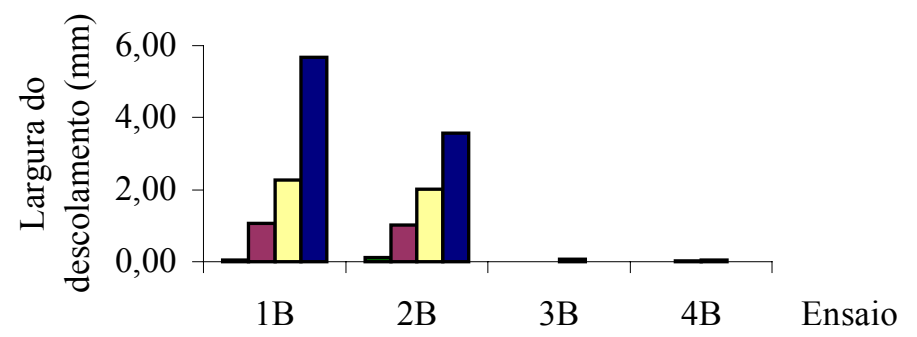

$\mathrm{P}=20 \mathrm{kN} \quad \square \mathrm{P}=60 \mathrm{kN} \quad \square \mathrm{P}=100 \mathrm{kN} \quad \square \mathrm{P}=170 \mathrm{kN}$

FIGURA 3.55 - Descolamento máximo horizontal da interface pórtico-painel 
$\mathrm{Na}$ figura 3.56, apresentam-se os diagramas força-deformação diagonal do canto inferior comprimido nos ensaios 2B e 4B da série B. Mesmo na presença de abertura, pode-se perceber que continua havendo a formação da biela, tendo em vista o comportamento do diagrama do ensaio 4B.

\section{Diagrama Força x Deformação \\ Extensômetro 03}

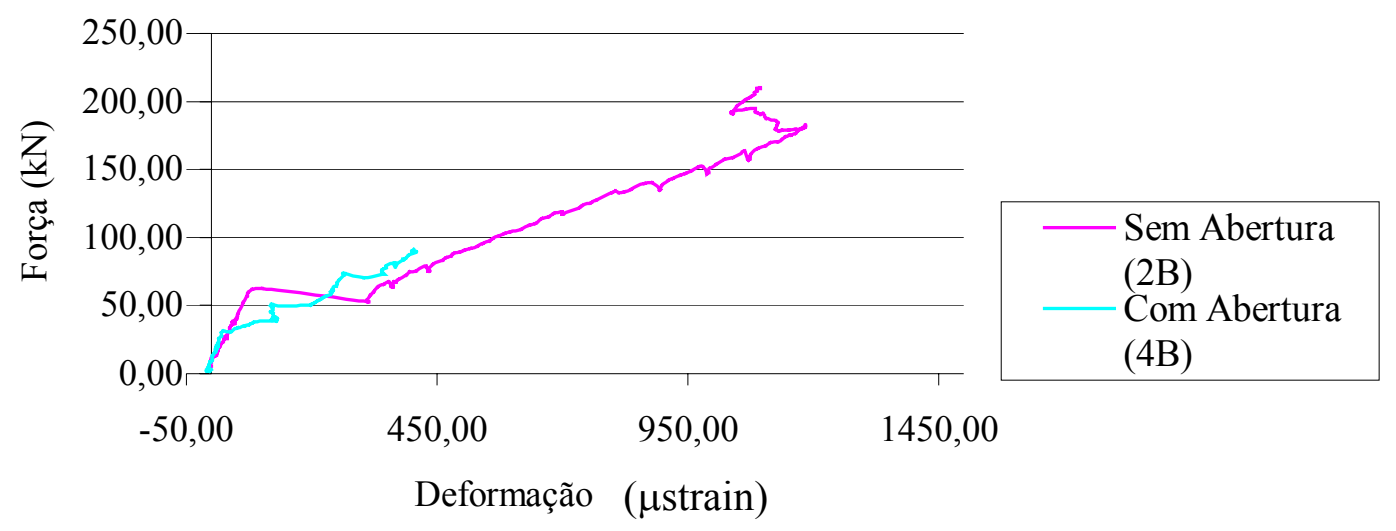

FIGURA 3.56 - Diagramas força-deformação diagonal do canto inferior direito do painel - ensaios da série B

\subsection{3 - INFLUÊNCIA DA RELAÇÃO ALTURA-COMPRIMENTO DOS PÓRTICOS NA RIGIDEZ E RESISTÊNCIA DE PÓRTICOS PREENCHIDOS}

Para avaliação da influência da relação altura-comprimento dos pórticos na rigidez e resistência de pórticos preenchidos, os resultados dos ensaios $5 \mathrm{~A}$ e $6 \mathrm{~A}$, realizados com o pórtico TIPO I $(\mathrm{H} / \mathrm{L}=0,83)$, são comparados com aqueles obtidos através dos ensaios $1 \mathrm{~B}$ e $2 \mathrm{~B}$, com o pórtico TIPO II $(\mathrm{H} / \mathrm{L}=0,51)$. Todos esses ensaios referem-se a paredes sem aberturas de blocos de CCA, com juntas e interface de argamassa Ciment-cola. 
$\mathrm{Na}$ figura 3.57 são apresentados os diagramas força-deslocamento dos ensaios realizados com os pórticos TIPO I (ensaios 5A e 6A) e TIPO II (ensaios 1B e 2B). Com o aumento da carga aplicada, o sistema TIPO I, que possui menor vão, ou seja, maior relação $\mathrm{H} / \mathrm{L}(\mathrm{H} / \mathrm{L}=0,83)$, apresenta maior rigidez que o sistema TIPO II $(\mathrm{H} / \mathrm{L}=0,51)$.

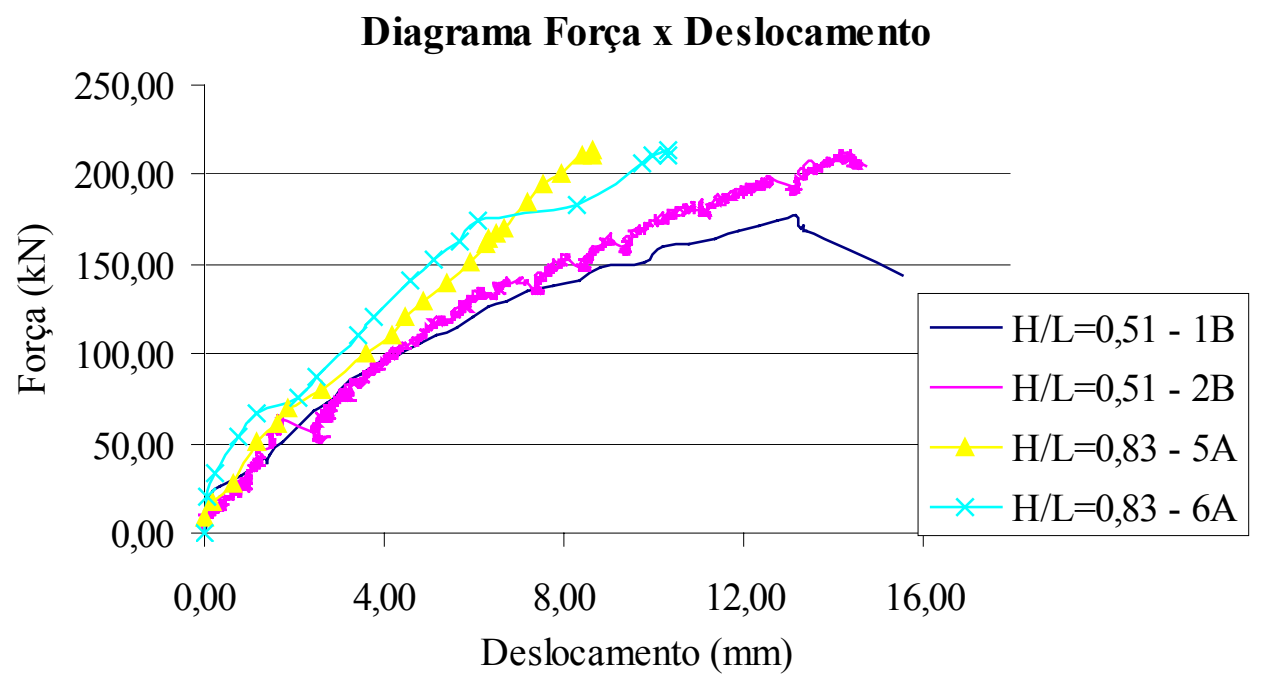

FIGURA 3.57 - Diagramas força-deslocamento dos sistemas $\mathrm{H} / \mathrm{L}=0,83$ - TIPO I (ensaios 5A e 6A) e H/L=0,51 - TIPO II (ensaios 1B e 2B)

Com relação à resistência, o sistema TIPO I comporta-se como um monolito até a carta de ruptura, não apresentando fissuras até o rompimento da diagonal, por fissuração, de uma forma frágil. Já para o sistema TIPO II, com vão de $5 \mathrm{~m}$, esse comportamento não se repete. Antes da ocorrência da ruptura frágil da diagonal, surgem fissuras verticais no canto superior tracionado.

Nos ensaios TIPO I, a carga média de fissuração da diagonal foi de $172 \mathrm{kN}$, enquanto no sistema TIPO II, em um dos ensaios realizados, ocorreu a fissuração da diagonal para uma carga de $173 \mathrm{kN}$ e no outro, até a carga de $210 \mathrm{kN}$, não houve ruptura da diagonal. Percebeu-se, dessa forma, tendência de aumento da carga de fissuração da diagonal à medida que aumenta o vão, ou seja, diminui-se a relação H/L. No entanto, as fissuras verticais no canto superior tracionado apresentam comprimento considerado. 
$\mathrm{Na}$ carga de $170 \mathrm{kN}$, as rigidezas nos ensaios $5 \mathrm{~A}$ e $6 \mathrm{~A}$ do pórtico TIPO I possuem os valores de $25,40 \mathrm{kN} / \mathrm{m}$ e $28,48 \mathrm{kN} / \mathrm{m}$, enquanto nos ensaios $1 \mathrm{~B}$ e $2 \mathrm{~B}$ esses valores valem $13,91 \mathrm{kN} / \mathrm{m}$ e $17,40 \mathrm{kN} / \mathrm{m}$.

Em termos de deslocamentos, para um deslocamento lateral máximo de $8 \mathrm{~mm}$, as rigidezas dos ensaios $5 \mathrm{~A}$ e $6 \mathrm{~A}$ do sistema TIPO I foram de $24,99 \mathrm{kN} / \mathrm{mm}$ e 22,05 $\mathrm{kN} / \mathrm{mm}$, ao passo que nos ensaios $1 \mathrm{~B}$ e $2 \mathrm{~B}$, no sistema TIPO II, seus valores foram de $16,91 \mathrm{kN} / \mathrm{mm}$ e $17,86 \mathrm{kN} / \mathrm{mm}$.

Com relação aos descolamentos das interfaces, esses aumentaram de forma mais acentuada em pórticos de maiores vãos e menores relações $\mathrm{H} / \mathrm{L}$, como pode ser percebido pelos diagramas apresentados na figura 3.58, em que são apresentados os maiores descolamentos ocorridos nas interfaces pórtico-painel. Esses descolamentos referem-se àqueles medidos pelo Rel 05 e Rel 06 (horizontal inferior) e DT 04 (horizontal superior). 


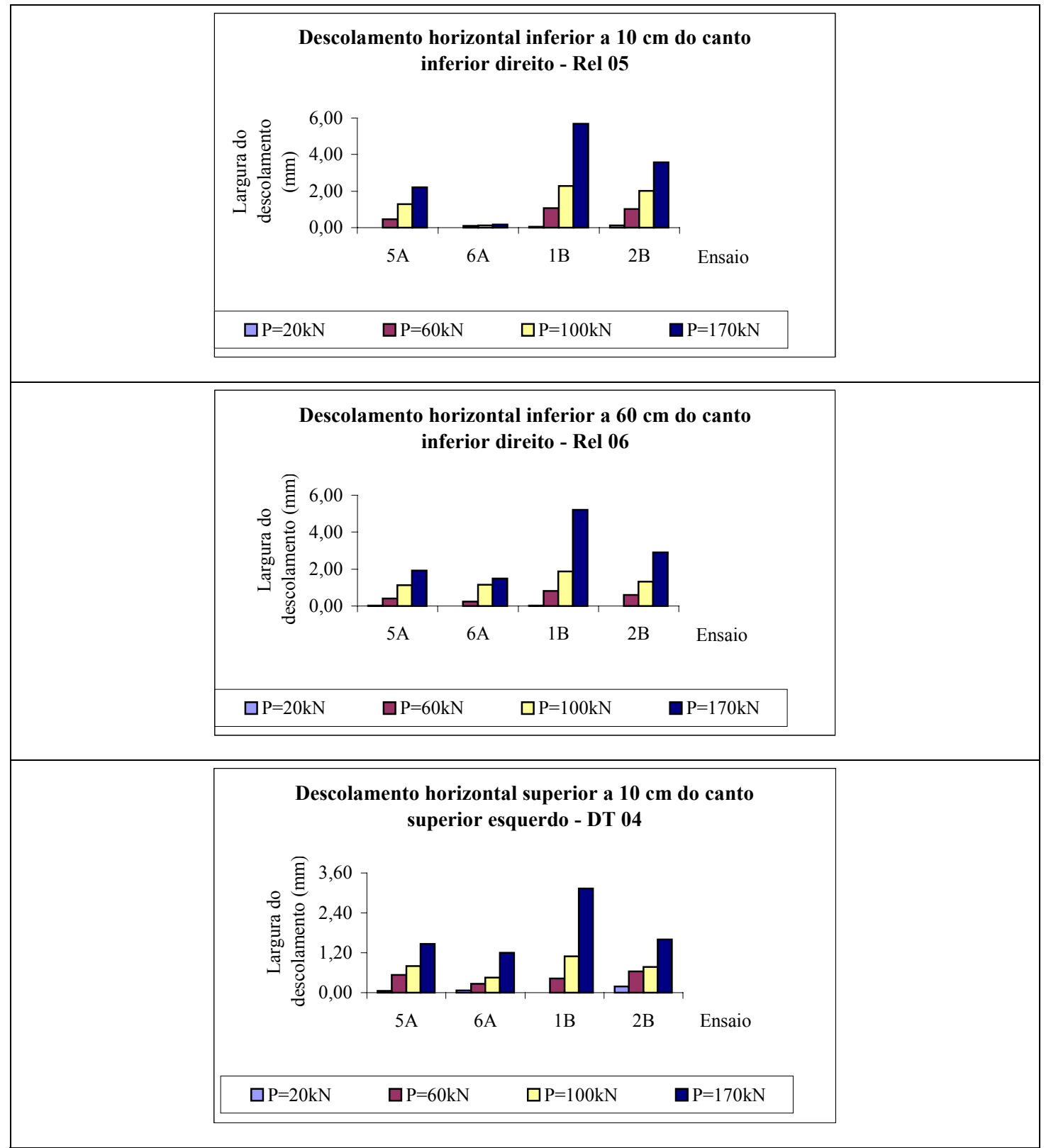

FIGURA 3.58 - Diagrama força-descolamento dos cantos tracionados:

(Rel 05, REL 06 e DT 04)

\section{6 - ALGUMAS CONSIDERAÇÕES SOBRE OS RESULTADOS EXPERIMENTAIS}

Apresenta-se neste capítulo uma avaliação experimental de pórticos preenchidos com alvenaria de CCA, variando parâmetros como: relação altura/comprimento de 
pórticos, argamassa de assentamento, elementos componentes da interface pórticopainel e a existência de abertura nas paredes.

No que se refere à relação altura/comprimento dos pórticos, foram avaliados dois pórticos com relação $\mathrm{H} / \mathrm{L}=0,83$ (TIPO I) e $\mathrm{H} / \mathrm{L}=0,51$ (TIPO II). Observou-se que, quanto menor a relação $\mathrm{H} / \mathrm{L}$ e, conseqüentemente, maior o vão do pórtico, maior a carga última do painel. No entanto, no sistema TIPO II foram observadas fissuras verticais na região tracionada antes da ocorrência da ruptura frágil da diagonal, enquanto o sistema TIPO I funcionou como monolito até a carga de ruptura por fissuração da diagonal.

Com relação às argamassas utilizadas nas juntas, foi verificado que a de traço 1:3:7,5 de cimento, cal e areia não teve bom desempenho quando submetida a carregamento horizontal, enquanto a argamassa Ciment-cola apresentou excelente "performance", aumentando consideravelmente a carga de ruptura, bem como a rigidez do conjunto.

Os ferros-cabelo utilizados nas interfaces pilar-painel, de $\left(\begin{array}{lll}10 & \mathrm{x} & 30\end{array}\right) \mathrm{cm}$, não apresentaram resultados satisfatórios no que se refere ao impedimento do descolamento. Também, não contribuíram para a resistência ou rigidez do conjunto.

As aberturas no painel conduziram a uma perda de rigidez e resistência quando comparada com paredes sem aberturas. Percebeu-se, ainda, o comportamento do painel como biela e concentração de tensões nos cantos da abertura. Nos dois cantos opostos, na direção da diagonal comprimida surgiram tensões principais máximas de tração que provocaram fissurações escalonadas a partir desses cantos. Essas tensões de tração apresentaram valores elevados para baixas cargas aplicadas. Observou-se, portanto, uma baixa resistência e rigidez dos painéis com esse tipo de abertura. 

COMPORTAMENTO DOS PROTÓTIPOS

Utilizando os métodos teóricos desenvolvidos por SMITH e CARTER (1969) e SMITH e RIDDINGTON (1977 e 1978) e segundo as prescrições italianas DM 16/01/96: "Prescrições técnicas para estruturas sujeitas a sismos" e Circ. 10/04/97, n. 65 , foram analisados os dois protótipos utilizados nos ensaios experimentais (TIPO I e TIPO II).

\section{1 - OBTENÇÃO DOS DESLOCAMENTOS LATERAIS DOS PROTÓTIPOS}

A partir da obtenção da largura equivalente do painel, é possível efetuar a previsão do deslocamento lateral do protótipo, na direção da ação aplicada. Os cálculos apresentados seguiram os procedimentos descritos por SMITH e CARTER(1969) e apresentados no capítulo 2 . 


\subsection{1 - DETERMINAÇÃO DO COMPRIMENTO DE CONTATO PÓRTICO- PAINEL}

Conhecidas as características geométricas dos protótipos, apresentadas nas tabelas 3.2 e 3.3 do capítulo 3, aqui apresentadas resumidamente pelas expressões 4.1 e 4.4, juntamente com as características elásticas dos sistemas, é possível obter o comprimento de contato $(\alpha)$ dos protótipos TIPO I e TIPO II, pelas expressões $4.2 \mathrm{e}$ 4.3 e 4.5 e 4.6 , respectivamente.

$$
\begin{aligned}
& \text { TIPO I } \\
& E_{\text {painel }}=1750 \mathrm{MPa} \\
& t=15 \mathrm{~cm} \\
& E_{p}=205000 \mathrm{MPa} \\
& I_{p}=4043 \mathrm{~cm}^{4} \\
& h=213 \mathrm{~cm} \\
& L^{\prime}=257 \mathrm{~cm} \\
& \lambda L^{\prime} \text { TIPOI }=257 \times \sqrt[4]{\frac{175 \times 15}{40500 \times 4043 \times 213} \operatorname{sen} 2(37,5)=3,54} \\
& \frac{\alpha}{L^{\prime}}=\frac{\pi}{2 \times 3,54}=0,44 \Rightarrow \alpha_{T I P O I}=114,12 \mathrm{~cm}
\end{aligned}
$$

\section{TIPO II}

$$
\begin{aligned}
& E_{\text {painel }}=1750 \mathrm{MPa} \\
& t=15 \mathrm{~cm} \\
& E_{p}=205000 \mathrm{MPa} \\
& I_{p}=4043 \mathrm{~cm}^{4} \\
& h=213 \mathrm{~cm} \\
& L^{\prime}=257 \mathrm{~cm}
\end{aligned}
$$




$$
\begin{aligned}
& \lambda L_{\text {TIPOII }}^{\prime}=257 \times \sqrt[4]{\frac{175 \times 15}{4 \times 20500 \times 4043 \times 213} \operatorname{sen} 2(24)}=3,31 \\
& \frac{\alpha}{L^{\prime}}=\frac{\pi}{2 \times 3,31}=0,47 \Rightarrow \alpha_{\text {TIPOII }}=121,96 \mathrm{~cm}
\end{aligned}
$$

\subsection{2 - DETERMINAÇÃO DA LARGURA DA BARRA DIAGONAL EQUIVALENTE}

\subsubsection{1 - VARIAÇÃO DE COMPRIMENTO DA DIAGONAL COMPRIMIDA}

De posse do comprimento de contato obtido no item anterior, foram determinadas as deformações no painel para uma carga horizontal de 10 kN. Essas deformações foram calculadas através da análise isolada do painel, pelo método dos elementos finitos, como estado plano de tensão, considerando-se um carregamento triangular aplicado nos nós, no comprimento de contato $(\alpha)$.

A largura da barra equivalente foi obtida como a largura de uma barra axialmente comprimida de mesmo comprimento da diagonal, que, submetida ao mesmo carregamento do painel, resultasse em um deslocamento nodal igual à variação do comprimento da diagonal do painel, como visto na equação 4.7:

$$
w=R \times d / t \times E_{\text {painel }} \times \Delta d
$$

em que

$\Delta d=\quad$ variação de comprimento da diagonal;

$R=$ força resultante na direção da diagonal;

$w=$ largura da diagonal equivalente;

$t=$ espessura do painel; 
$E_{\text {painel }}=$ módulo de deformação da diagonal; e

$d \quad=$ comprimento da diagonal.

\section{TIPO I}

Resultante das forças horizontais e verticais aplicadas no painel

$$
R=12,38 k N\left\{\begin{array}{c}
H=7,31 k N \\
V=10,00 k N
\end{array}\right\}
$$

Largura da diagonal equivalente

$$
w=12,38 \times 350,20 / 15 \times 175 \times 0,014182=116,46 \mathrm{~cm}
$$

\section{TIPO II}

Resultante das forças horizontais e verticais aplicadas no painel

$$
R=10,75 k N\left\{\begin{array}{l}
H=3,94 k N \\
V=10,00 k N
\end{array}\right\}
$$

Largura da diagonal equivalente

$$
w=10,75 \times 523,29 / 15 \times 175 \times 0,017128=125,11 \mathrm{~cm}
$$

\subsection{3 - DETERMINAÇÃO DO DESLOCAMENTO LATERAL}

Conhecidas as características geométricas da diagonal equivalente, o deslocamento lateral na direção da ação aplicada pode ser determinado através da análise de um pórtico plano. Foram consideradas duas situações extremas para ligação viga-pilar: articulada e rígida. Os resultados obtidos são apresentados na tabela 4.1. 
TABELA 4.1 - Deslocamentos laterais teóricos dos protótipos TIPO I e TIPO II $(\mathrm{cm} / \mathrm{kN})$

\begin{tabular}{|c|c|c|}
\hline \multirow{2}{*}{ ARTICULADA } & TIPO I & TIPO II \\
\cline { 1 - 3 } RÍGIDA & 0,002541 & 0,002722 \\
\hline
\end{tabular}

Tendo em vista que a diferença entre os deslocamentos laterais foi de 11,2\% e 5,5\%, respectivamente, nos sistemas TIPO I e TIPO II esses serão considerados, para fins de comparação, como articulados.

\section{2 - DETERMINAÇÃO DAS CARGAS DE RUPTURA DO PAINEL}

\subsection{1 - SEGUNDO SMITH e CARTER (1969)}

\subsubsection{1-RUPTURA POR FISSURAÇÃO DA DIAGONAL}

Do ábaco apresentado na figura 2.5, do capítulo 2, obtém-se a expressão 4.8 , a partir da qual se determina o valor da carga de colapso. Para a resistência à tração do material do painel, foi adotado o valor de 0,26 MPa, que corresponde a $10 \%$ da resistência média à compressão dos prismas ensaiados. Os valores obtidos para as cargas de ruptura dos protótipos TIPO I e TIPO II, nas direções diagonal e horizontal, respectivamente, são apresentados na expressão 4.9.

$$
\frac{R_{f i s}}{f_{t} \times h \times t}=\left\{\begin{array}{cl}
3,4286 & \text { para o sistema TIPOI } \\
5,7500 & \text { para o sistema TIPOII }
\end{array}\right.
$$

em que $f_{t}, h$ e $t$ são, respectivamente, a resistência média à tração, altura e espessura do painel, $R_{f i s}$ o valor da carga de ruptura na direção diagonal e $F_{f i s}$ a componente horizontal da carga de ruptura. 


$$
\begin{aligned}
& R_{\text {fis }}=\left\{\begin{array}{l}
284,81 \mathrm{kN} \text { para } \text { o sistema TIPO I } \\
477,65 \mathrm{kN} \text { para } \mathrm{o} \text { sistema TIPO II }
\end{array}\right. \\
& F_{\text {fis }}=\left\{\begin{array}{l}
225,95 \mathrm{kN} \text { para } \mathrm{o} \text { sistema TIPO I } \\
436,35 \mathrm{kN} \text { para } \mathrm{o} \text { sistema TIPO II }
\end{array}\right.
\end{aligned}
$$

\subsubsection{2 - RUPTURA POR CISALHAMENTO AO LONGO DAS JUNTAS DE ARGAMASSA}

Do ábaco apresentado na figura 2.6, do capítulo 2, obtiveram-se a equação 4.10 do sistema TIPO I e a 4.11, do sistema TIPO II, a partir das quais se determinou o valor da carga de ruptura, $F_{c i s}$, conhecendo-se a tensão de ruptura por cisalhamento puro, $f_{b s}$, na interface bloco-argamassa. Nos ensaios experimentais realizados, obteve-se um valor médio de $0,2 \mathrm{MPa}$ para $f_{b s}$.

\section{TIPO I}

$$
\frac{R_{c i s}}{f_{b s} \times h \times t}=1,9123
$$

\section{TIPO II}

$$
\frac{R_{c i s}}{f_{b s} \times h \times t}=2,7544
$$

Os valores obtidos das cargas de ruptura dos protótipos TIPO I e TIPO II, nas direções diagonal e horizontal, respectivamente, são apresentados na equação (4.12). 


$$
\begin{gathered}
R_{\text {cis }}=\left\{\begin{array}{l}
122,20 \mathrm{kN} \text { para } \text { o sistema TIPO I } \\
176,01 \mathrm{kN} \text { para o sistema TIPO II }
\end{array}\right. \\
F_{\text {cis }}=\left\{\begin{array}{l}
96,95 \mathrm{kN} \text { para o sistema TIPO I } \\
160,80 \mathrm{kN} \text { para o sistema TIPO II }
\end{array}\right.
\end{gathered}
$$

\subsubsection{3 - RUPTURA POR ESMAGAMENTO NOS CANTOS COMPRIMIDOS}

Para obtenção da carga de ruptura por esmagamento nos cantos comprimidos, utilizou-se o ábaco apresentado na figura 2.7, do capítulo 2. Os valores retirados do ábaco encontram-se na expressão (4.13). As cargas de ruptura $R_{e s m}$ e $F_{e s m}$ dos protótipos TIPO I e TIPO II, nas direções diagonal e horizontal, respectivamente, são apresentadas na expressão (4.14), em que $f_{c}, h$ e $t$ são, respectivamente, a resistência média à compressão, altura e espessura do painel.

$$
\frac{R_{\text {esm }}}{f_{c} \times h \times t}=\left\{\begin{array}{cc}
0,5189 & \text { para o sistema TIPOI } \\
0,4648 & \text { para o sistema TIPOII }
\end{array}\right.
$$

$$
\begin{aligned}
& R_{\text {esm }}=\left\{\begin{array}{l}
431,05 \mathrm{kN} \text { para } \text { o sistema TIPO I } \\
386,11 \mathrm{kN} \text { para } \mathrm{o} \text { sistema TIPO II }
\end{array}\right. \\
& F_{\text {esm }}=\left\{\begin{array}{l}
341,97 \mathrm{kN} \text { para } \mathrm{o} \text { sistema TIPO I } \\
352,73 \mathrm{kN} \text { para } \mathrm{o} \text { sistema TIPO II }
\end{array}\right.
\end{aligned}
$$

\subsection{2 - SEGUNDO SMITH e RIDDINGTON (1977)}

Esses autores apresentaram uma série de resultados teóricos obtidos utilizando o método dos elementos finitos. Segundo eles, são três os modos de ruptura possíveis: 
ruptura por cisalhamento, ruptura por tração na diagonal e ruptura por compressão com esmagamento dos cantos comprimidos do painel.

Os resultados das análises realizadas por aqueles autores foram utilizados para obtenção das expressões (4.15) a (4.17):

$$
\begin{aligned}
& \tau_{x y}=1,43 \times F^{\prime} / l \times t \\
& \sigma_{y c}=(0,80 \times h / l-0,20) \times F^{\prime} / l \times t \\
& \sigma_{d t}=0,58 \times F^{\prime} / l \times t
\end{aligned}
$$

em que

$$
\begin{aligned}
\tau_{x y} & =\text { tensão de cisalhamento no centro do painel; } \\
\sigma_{y c} & =\text { tensão vertical de compressão no centro do painel; } \\
\sigma_{d t} & =\text { tensão de tração na diagonal no centro do painel; } \\
F^{\prime} & =\text { força horizontal aplicada na estrutura; } \\
h & =\text { altura do painel; } \\
l & =\text { comprimento do painel; } \\
t & =\text { espessura do painel; } \\
\theta & =\text { ângulo entre a diagonal e a horizontal; e } \\
L^{\prime} & =\text { altura do pórtico. }
\end{aligned}
$$

\subsubsection{1 - RUPTURA POR FISSURAÇÃO DA DIAGONAL}

A tensão de tração no centro do painel é dada pela equação (4.17). Considerando a resistência à tração do material do painel como $10 \%$ da resistência média do prisma à compressão $\left(f_{t}=0,026 \mathrm{MPa}\right)$, igualando a $\sigma_{d t}$ e substituindo na expressão (4.17) $H$ por $H_{d r}$, a força horizontal que causa ruptura do painel por tração na diagonal é dada pela equação (4.18): 


$$
F_{\text {fis }}=l \times t \times f_{t} / 0,58
$$

\section{TIPO I}

$$
F_{\text {fis }}=278 \times 15 \times 0,026 / 0,58=186,93 \mathrm{kN}
$$

\section{TIPO II}

$$
F_{\text {fis }}=478 \times 15 \times 0,026 / 0,58=321,41 \mathrm{kN}
$$

\subsubsection{2 - RUPTURA POR CISALHAMENTO AO LONGO DAS JUNTAS DE ARGAMASSA}

A tensão de cisalhamento resistente para um painel de alvenaria pode ser expressa pela equação (4.19):

$$
f_{s} \leq\left\{\begin{array}{l}
f_{b s}+\mu \sigma_{y c} \\
f_{s}=0,05 \mathrm{kN} / \mathrm{cm}^{2}
\end{array}\right.
$$

em que $f_{b s}$ é a tensão de ruptura por cisalhamento puro na interface bloco-argamassa e $\mu$, o coeficiente de atrito da argamassa. Substituindo na expressão (4.20) as expressões (4.15) e (4.19), obtém-se a expressão (4.21):

$$
\begin{aligned}
& \tau_{c i s}=\boldsymbol{f}_{\boldsymbol{s}} \\
& \frac{1,43 F^{\prime}}{l \times t} \leq\left\{\begin{array}{l}
\left(f_{b s}+\mu \sigma_{y c}\right) \\
0,05 \mathrm{kN} / \mathrm{cm}^{2}
\end{array}\right.
\end{aligned}
$$

A força que provoca ruptura por cisalhamento pode ser escrita pela expressão (4.22): 


$$
F_{c i s} \leq\left\{\begin{array}{l}
\left(f_{b s}+\mu \sigma_{y c}\right) \frac{l \times t}{1,43} \\
0,035 l \times t \quad k N, \text { comletem } \mathrm{cm}
\end{array}\right.
$$

Substituindo a expressão (4.16) na expressão (4.22), obtém-se a expressão (4.23):

$$
F_{c i s}=\left[f_{b s}+\mu\left[\frac{(0,8 \times h / l-0,2)}{l \times t} \times F_{c i s}\right]\right] \frac{l \times t}{1,43}
$$

Os valores obtidos das cargas de ruptura por cisalhamento ao longo das juntas de argamassa são $70,54 \mathrm{kN}$ e 107,33 kN, respectivamente para os protótipos TIPO I e TIPO II. Para a tensão de cisalhamento puro, $f_{b s}$, na interface bloco-argamassa, utilizou-se o valor médio de 0,2 MPa, obtido a partir de ensaios experimentais. Para o coeficiente de atrito da junta de argamassa, adotou-se o valor $\mu=0,60$.

\subsubsection{3 - RUPTURA POR ESMAGAMENTO DOS CANTOS COMPRIMIDOS}

Para estimar a força horizontal na estrutura, correspondente à ruptura por compressão nos cantos opostos comprimidos, os referidos autores indicaram a expressão (4.24):

$$
F_{\text {esm }}=1,12 \times\left(\lambda L^{\prime}\right)^{-0,88} \times f_{c m} \times L^{\prime} \times t \times \cos ^{2} \theta
$$

em que

$F_{\text {esm }}=$ força horizontal de ruptura por compressão;

$f_{c m}=$ Tensão média de ruptura à compressão em prismas de alvenaria;

$h \quad=$ altura do painel; 
Utilizando a expressão (4.24), obtêm-se os valores dados pelas equações (4.25) e (4.26):

TIPO I

$F_{\text {esm }}=192,73 \mathrm{kN}$

TIPO II

$F_{\text {esm }}=270,74 \mathrm{kN}$

\subsection{3 - SEGUNDO PRESCRIÇÕES ITALIANAS: DM 16/01/96 "PRESCRIÇÕES TÉCNICAS PARA ESTRUTURAS SUJEITAS A SISMOS" E CIRC. 10/04/97, N. 65}

\subsubsection{1 - RUPTURA POR FISSURAÇÃO DA DIAGONAL}

Para ruptura por fissuração da diagonal, essas prescrições apresentam a expressão (4.27):

$$
F^{\prime} \leq \frac{f_{v k o}}{0,6 \times \phi} \times L \times t
$$

em que

$F^{\prime} \quad=$ força horizontal atuante na alvenaria;

$f_{v k o}=$ resistência característica ao cisalhamento puro;

$\phi=$ fator de redução de tensão $\phi\left\{\begin{array}{l}2-\text { Método das Tensões Admissíveis } \\ 1-\text { Método dos Estados -limite }\end{array}\right\} ;$

$L \quad=$ comprimento do pórtico; e

$t \quad=$ espessura do painel.

De forma a permitir comparações entre os métodos téoricos da literatura e a proposta desta tese apresentada no capítulo 7 , será utilizada a resistência média ao 
cisalhamento em vez de utilizar a resistência característica, conforme recomendado. Para os protótipos em estudo, obtiveram-se as expressões (4.28) e (4.29), para o TIPO I e para o TIPO II, respectivamente.

$$
\begin{aligned}
& F_{\text {fis }} \leq \frac{0,02}{0,6 \times 1} \times 300 \times 15=150 \mathrm{kN} \quad \text { TIPOI } \\
& F_{\text {fis }} \leq \frac{0,02}{0,6 \times 1} \times 500 \times 15=250 \mathrm{kN} \quad \text { TIPOII }
\end{aligned}
$$

\subsubsection{2 - RUPTURA POR CISALHAMENTO AO LONGO DAS JUNTAS DE ARGAMASSA}

A expressão (4.30) permite a obtenção da carga de ruptura ao cisalhamento ao longo das juntas de argamassa:

$$
F_{c i s} \leq \frac{\tau_{u}}{\phi} \times L \times t
$$

em que

$$
\tau_{u}=f_{v k o} \sqrt{1+\frac{\left(0,8 \times \frac{h}{l}-0,2\right)}{1,5 \times f_{v k o}} \times \frac{F^{\prime}}{L \times t}}
$$

$F^{\prime}=$ força horizontal atuante na alvenaria;

$f_{v k o}=$ resistência característica ao cisalhamento puro;

$\phi=$ fator de redução de tensão $\phi\left\{\begin{array}{c}2-\text { Método das Tensões Admissíveis } \\ 1-\text { Método dos Estados Limites }\end{array}\right\} ;$

$L=$ comprimento do pórtico; e

$t=$ espessura do painel. 
Substituindo a expressão (4.31) em (4.30), obtiveram-se as cargas de ruptura apresentadas nas expressões (4.32), para os protótipos TIPO I e TIPO II:

$$
\begin{aligned}
& \tau_{u}=0,02 \sqrt{1+\frac{\left(0,8 \times \frac{268}{300}-0,2\right)}{1,5 \times 0,02} \times \frac{F^{\prime}}{300 \times 15}} \\
& \tau_{u}=0,02 \sqrt{1+\frac{\left(0,8 \times \frac{268}{500}-0,2\right)}{1,5 \times 0,02} \times \frac{F^{\prime}}{500 \times 15}}
\end{aligned}
$$

\subsubsection{3 - RUPTURA POR ESMAGAMENTO DOS CANTOS COMPRIMIDOS}

Para obtenção da carga de ruptura relativa ao esmagamento dos cantos comprimidos, utilizou-se a expressão (4.33):

$$
F^{\prime}=0,80 \frac{f_{k c}}{\phi} \times \cos ^{2} \theta^{\prime} \sqrt[4]{\frac{E_{p}}{E_{\text {painel }}} \times I_{p^{\prime}} \times H \times t^{3}}
$$

em que

$$
\begin{array}{ll}
F^{\prime} & =\text { força horizontal atuante na alvenaria; } \\
f_{k c} & =\text { resistência característica à compressão do painel; }
\end{array}
$$

$\theta^{\prime}=\operatorname{arctg}\left(\frac{h}{l}\right)=$ ângulo entre a diagonal do pórtico e a direção horizontal; 


$$
\begin{aligned}
\phi & =\text { fator de redução de tensão } \phi=\left\{\begin{array}{c}
2-\text { Método das Tensões Admissíveis } \\
1-\text { Método dos Estados }- \text { Limites }
\end{array}\right\} ; \\
E_{p} & =\text { módulo de deformabilidade do material do pórtico; } \\
E_{\text {painel }} & =\text { módulo de deformabilidade da alvenaria; } \\
I_{p^{\prime}} & =\text { momento de inércia da seção transversal do pilar; } \\
t & =\text { espessura do painel de alvenaria; e } \\
H & =\text { altura do pórtico. }
\end{aligned}
$$

Nesse caso, também será utilizada a resistência média à compressão do painel, em vez da resistência característica, com vistas a comparações com outros métodos teóricos. Para os protótipos em estudo, os valores das cargas de ruptura ao esmagamento dos cantos são dados pelas expressões (4.34) e (4.35), para o TIPO I e TIPO II, respectivamente.

$$
\begin{aligned}
& F_{\text {esm }} \leq 0,80 \frac{0,26}{1} \times 0,76^{2} \sqrt[4]{\frac{20500}{175} \times 4043 \times 257 \times 15^{3}}=96,18 \mathrm{kN} \\
& F_{\text {esm }} \leq 0,80 \frac{0,26}{1} \times 0,889^{2} \sqrt[4]{\frac{20500}{175} \times 4043 \times 257 \times 15^{3}}=131,61 \mathrm{kN}
\end{aligned}
$$

\section{3 - RESUMO DOS RESULTADOS TEÓRICOS OBTIDOS}

Nas tabelas 4.2 e 4.3, apresenta-se um resumo dos resultados teóricos obtidos para os protótipos TIPO I e TIPO II, respectivamente.

Analisando os resultados teóricos obtidos, pode-se perceber que, segundo Smith e Carter, o modo de ruptura referente aos ensaios das séries A e B, isto é, com o sistema TIPO I e TIPO II, é por cisalhamento das juntas de argamassa. O mesmo modo de ruptura é caracterizado quando se avaliam os protótipos segundo Smith e Riddington. 
Segundo as prescrições italianas, para os sistemas TIPO I e TIPO II, o modo de ruptura é por esmagamento dos cantos comprimidos.

TABELA 4.2 - Quadro-resumo das cargas de ruptura teóricas do protótipo TIPO I

\begin{tabular}{|c|c|c|}
\hline MÉTODO TEÓRICO & MODO DE RUPTURA & $\begin{array}{c}\text { CARGA DE } \\
\text { RUPTURA (kN) }\end{array}$ \\
\hline \multirow{3}{*}{ Teórica: Smith e Carter } & Tração na diagonal & 222,95 \\
\hline & $\begin{array}{c}\text { Cisalhamento juntas de } \\
\text { argamassa }\end{array}$ & 96,95 \\
\hline & $\begin{array}{c}\text { Esmagamento cantos } \\
\text { comprimidos }\end{array}$ & 341,97 \\
\hline \multirow{3}{*}{$\begin{array}{c}\text { Teórica: Smith e } \\
\text { Riddington }\end{array}$} & Tração na diagonal & 186,93 \\
\hline & $\begin{array}{c}\text { Cisalhamento juntas de } \\
\text { argamassa }\end{array}$ & 70,54 \\
\hline & $\begin{array}{c}\text { Esmagamento cantos } \\
\text { comprimidos }\end{array}$ & 192,73 \\
\hline \multirow{3}{*}{$\begin{array}{c}\text { Teórica: prescrições } \\
\text { italianas }\end{array}$} & Tração na diagonal & 150,00 \\
\hline & $\begin{array}{c}\text { Cisalhamento juntas de } \\
\text { argamassa }\end{array}$ & 105,43 \\
\hline & $\begin{array}{c}\text { Esmagamento cantos } \\
\text { comprimidos }\end{array}$ & 96,18 \\
\hline
\end{tabular}


TABELA 4.3 - Quadro-resumo das cargas de ruptura teóricas do protótipo TIPO II

\begin{tabular}{|c|c|c|}
\hline MÉTODO TEÓRICO & MODO DE RUPTURA & $\begin{array}{c}\text { CARGA DE } \\
\text { RUPTURA (kN) }\end{array}$ \\
\hline \multirow{3}{*}{ Teórica: Smith e Carter } & Tração na diagonal & 436,35 \\
\hline & $\begin{array}{l}\text { Cisalhamento juntas de } \\
\text { argamassa }\end{array}$ & 160,80 \\
\hline & $\begin{array}{c}\text { Esmagamento cantos } \\
\text { comprimidos }\end{array}$ & 352,73 \\
\hline \multirow{3}{*}{$\begin{array}{l}\text { Teórica: Smith e } \\
\text { Riddington }\end{array}$} & Tração na diagonal & 321,41 \\
\hline & $\begin{array}{c}\text { Cisalhamento juntas de } \\
\text { argamassa }\end{array}$ & 107,33 \\
\hline & $\begin{array}{c}\text { Esmagamento cantos } \\
\text { comprimidos }\end{array}$ & 270,74 \\
\hline \multirow{3}{*}{$\begin{array}{c}\text { Teórica: prescrições } \\
\text { italianas }\end{array}$} & Tração na diagonal & 250,00 \\
\hline & $\begin{array}{c}\text { Cisalhamento juntas de } \\
\text { argamassa }\end{array}$ & 161,92 \\
\hline & $\begin{array}{l}\text { Esmagamento cantos } \\
\text { comprimidos }\end{array}$ & 131,61 \\
\hline
\end{tabular}

Nas tabelas 4.4 e 4.5, apresentam-se os valores das cargas de ruptura e os modos de ruptura dos dois protótipos, obtidos através de ensaios experimentais e de métodos teóricos. 
TABELA 4.4 - Quadro-resumo das cargas de ruptura do painel de alvenaria obtidas através de análises experimental e teórica, na série de ensaios A

\begin{tabular}{|c|c|c|c|c|}
\hline \multirow{2}{*}{ ENSAIO } & \multirow{2}{*}{$\begin{array}{c}|c| \\
\text { MODO DE } \\
\text { RUPTURA }\end{array}$} & \multicolumn{2}{|c|}{ CXRGA DE RUPTURA } & \multirow{2}{*}{$\begin{array}{c}\text { RELAÇÃO } \\
\text { RESULTADOS } \\
\text { EXPERIMENTAIS/ } \\
\text { TEÓRICOS }\end{array}$} \\
\cline { 3 - 4 } & EXPIMENTAL & TEÓRICO & \\
\hline 1A & Cisalhamento & 71,23 & $70,54^{1}$ & 1,01 \\
\hline 2A & Cisalhamento & 102,13 & $105,43^{2}$ & 0,97 \\
\hline 3A & Fissuração diagonal & 189,72 & $186,93^{3}$ & 1,01 \\
\hline 4A & Esmagamento cantos & 206,60 & $192,73^{4}$ & 1,07 \\
\hline 5A & Fissuração diagonal & 169,93 & $186,93^{3}$ & 0,91 \\
\hline 6A & Fissuração diagonal & 175,00 & $186,93^{3}$ & 0,94 \\
\hline
\end{tabular}

${ }^{1}$ Smith e Riddington - Cisalhamento, ${ }^{2}$ Prescrições italianas - Cisalhamento, ${ }^{3}$ Smith e RiddingtonFissuração e ${ }^{4}$ Smith e Riddington - Esmagamento.

TABELA 4.5 - Quadro-resumo das cargas de ruptura do painel de alvenaria obtidas através de análises experimental e teórica, na série de ensaios B

\begin{tabular}{|c|c|c|c|c|}
\hline \multirow{2}{*}{ ENSAIO } & \multirow{2}{*}{ MODO DE RUPTURA } & \multicolumn{2}{|c|}{ CARGA DE RUPTURA } & $\begin{array}{c}\text { c } \\
\text { RELAÇÃO } \\
\text { RESULTADOS } \\
\text { EXPERIMENTAIS/ } \\
\text { TEÓRICOS }\end{array}$ \\
\cline { 3 - 4 } & EXPERIMENTAL & TEÓRICO & \\
\hline 1B & Fissuração diagonal & 173,00 & $160,80^{1}$ & 1,08 \\
\hline 2B & Fissuração diagonal* & 210,00 & $250,00^{2}$ & 0,84 \\
\hline
\end{tabular}

${ }^{1}$ Smith e Carter - Cisalhamento para $\mu=0,60$ e ${ }^{2}$ Prescrições italianas - Fissuração. *Possibilidade caso continuasse a aplicação de carga.

Essas tabelas permitem observar que há concordância de valores entre os obtidos experimentalmente e aqueles obtidos através de métodos téoricos. 


\section{ANÁLISE NUMÉRICA DOS PROTÓTIPOS}

\section{1 - O MÉTODO DOS ELEMENTOS FINITOS NA ENGENHARIA ESTRUTURAL}

O método dos elementos finitos é uma técnica geral utilizada para resolver equações diferenciais parciais, cuja solução para um campo de variáveis como deslocamentos, tensões, temperaturas, velocidades e pressões em fluidos, entre outras, é procurada. Através da discretização apropriada da região de interesse em um número finito de elementos, o método dos elementos finitos permite ao analista determinar o valor do campo de variáveis em um número finito de pontos. Dessa forma, esta técnica reduz um sistema com infinitos graus de liberdade em um sistema com finitos graus de liberdade.

$\mathrm{Na}$ aplicação do método dos elementos finitos para a engenharia estrutural, a estrutura é subdividida em elementos interconectados em pontos nodais, onde os deslocamentos são procurados. São utilizadas funções de interpolação para descrever a variação de deslocamentos dentro de cada elemento como funções das coordenadas nodais. As tensões e deformações de cada elemento podem ser relacionadas com os 
deslocamentos dos nós associados ao elemento. A consideração conjunta de todos os elementos individuais, através das equações de equilíbrio, compatibilidade e relação constitutiva, resulta em uma equação da forma:

$$
\boldsymbol{f}^{\prime}=\boldsymbol{K u}
$$

que relaciona o vetor de forças nodais $\boldsymbol{f}^{\prime}$ com o vetor de deslocamentos nodais $\boldsymbol{u}$, em que $\boldsymbol{K}$ é a matriz de rigidez. Na análise linear, em que as ações nodais são diretamente proporcionais aos deslocamentos nodais correspondentes, a matriz de rigidez $\boldsymbol{K}$ é constante e a solução para $\boldsymbol{u}$ na equação (5.1) pode ser obtida por técnicas convenientes, como a técnica de eliminação de Gauss ou a técnica de decomposição de Cholesky. Conhecidos os deslocamentos, as forças e tensões na estrutura podem ser determinadas.

\section{2 - ANÁLISE NÃO-LINEAR}

Há várias situações nas quais o comportamento não-linear de uma estrutura deve ser considerado para obter uma análise mais realista. A não-linearidade pode ser física, quando o limite elástico do material é ultrapassado, conduzindo a uma matriz constitutiva não-linear; geométrica, quando as relações entre deformações e deslocamentos são não-lineares, estabelecendo-se, nesse caso, o equilíbrio na configuração deformada da estrutura; ou de contato, quando as alterações das condições de apoio ou de aplicação de cargas são suficientemente importantes para que as condições iniciais não possam mais ser utilizadas. Nesses casos, a matriz de rigidez não é constante e depende das cargas aplicadas, portanto são necessárias técnicas de solução não-linear. As técnicas incremental e iterativa, ZIENKIEWICZ e TAYLOR (1991) e BATHE (1996), apresentadas no Anexo F, são dois procedimentos comumente utilizados para análise não-linear de estruturas. 


\subsection{1 - TEORIA DA PLASTICIDADE}

Apresentam-se na figura 5.1 curvas de tensão-deformação para diferentes materiais de comportamento não-linear. Genericamente, os materiais que apresentam comportamento plástico deformam com a aplicação da carga e, ao serem descarregados, não retornam à geometria original, apresentando deformações residuais, figura 5.1a. Na figura 5.1b, c e d, apresentam-se diagramas de materiais de comportamento elastoplástico perfeito, elastoplástico com encruamento e elastoplástico com amolecimento.

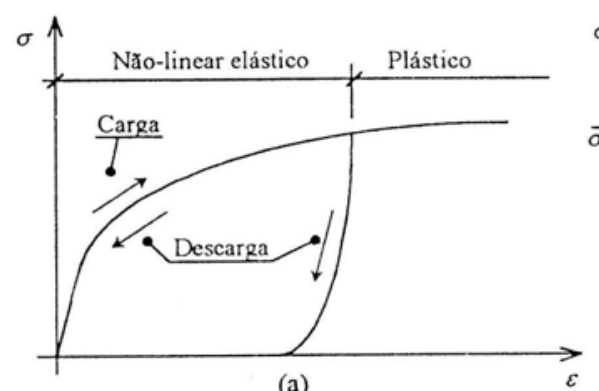

(a)

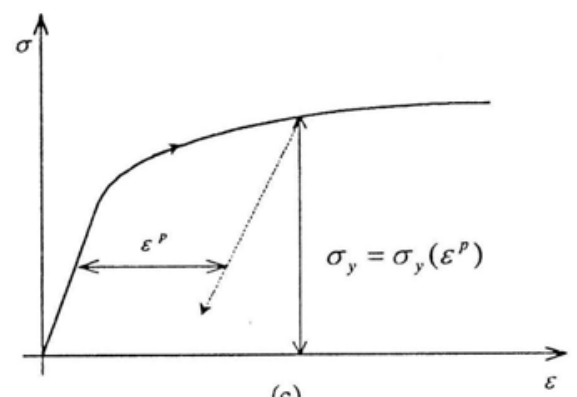

(c)
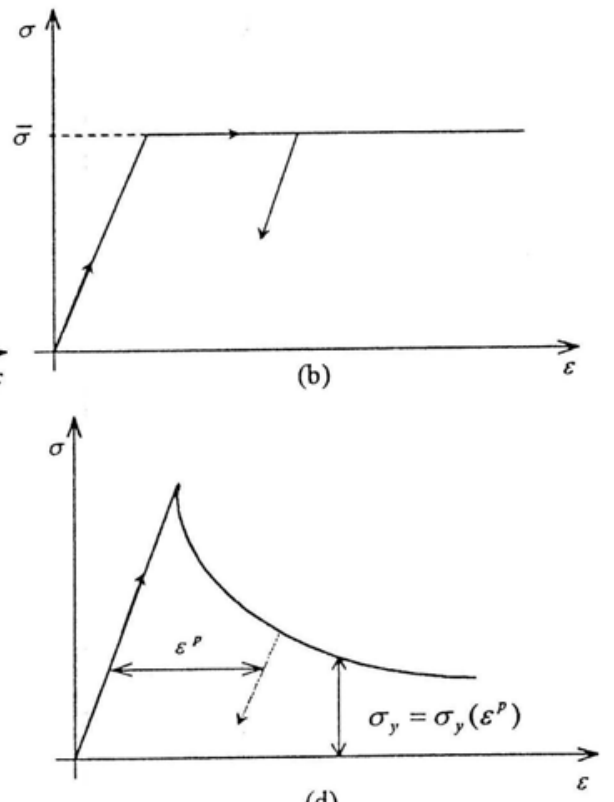

(d)

FIGURA 5.1- Comportamento uniaxial dos materiais: a) elasticidade não-linear genérica, b) material elastoplástico perfeito, c) material com deformação plástica e encruamento e d) material com deformação plástica e amolecimento

No regime de pequenas deformações, estas podem ser decompostas em uma parcela reversível ou elástica e outra irreversível o plástica, conforme a expressão (5.2):

$$
\boldsymbol{\varepsilon}=\boldsymbol{\varepsilon}^{e}+\boldsymbol{\varepsilon}^{p}
$$


Utilizando a formulação usual da teoria de fluxo da plasticidade, pode-se descrever todo o comportamento elastoplástico do material no tempo. A deformação (ou tensão) correspondente a certo nível de tensão (ou deformação) é dependente da história do carregamento, a qual é registrada pela deformação plástica acumulada.

A relação tensão-deformação do material é usualmente levada em conta, implicitamente, através da introdução de um parâmetro interno, denominado $\kappa$, que é dependente de uma lei de evolução específica. O comportamento elastoplástico pode, então, ser descrito pelas hipóteses a seguir:

- Relação elástica tensão-deformação, que especifica a relação entre a tensão total e a deformação elástica. Sem perder a generalidade, pode-se escrever que esta relação é dada pela expressão (5.3), sendo $\boldsymbol{D}$ a matriz constitutiva do material:

$$
\boldsymbol{\sigma}=\boldsymbol{D} \boldsymbol{\varepsilon}^{e}
$$

- Condição de plastificação, que especifica o estado de tensões no qual o fluxo plástico se inicia. Esta condição pode ser escrita como uma função do tensor de tensões e do parâmetro interno $\kappa$, conforme a expressão (5.4). Se a função de plastificação é menor que zero, o estado é elástico e não ocorre fluxo plástico. Um estado em que a função de plastificação torna-se maior que zero não é admissível.

$f(\sigma, \bar{\sigma}(\kappa))=0$

- A regra de fluxo, que especifica a taxa de deformações plásticas em função do estado de tensões e do parâmetro interno $\kappa$. De acordo com a teoria de fluxo da plasticidade, utilizando a regra de KOITER (1953), a taxa de deformação plástica é dada pela equação (5.5), em que as " $n$ " funções potenciais plásticas $g_{i}$ são funções do tensor de tensões e do parâmetro interno $\kappa$. Os multiplicadores plásticos $\lambda_{i}$ são restringidos pelas condições de 
Kuhn-Tucker, expressões (5.6) a (5.8), em que o ponto sobre o parâmetro indica sua variação no tempo.

$$
\begin{gathered}
\mathscr{\&}=\sum_{j=1}^{n} \oiint_{j}^{\&} \times \frac{\partial g_{j}}{\partial \boldsymbol{\sigma}} \\
\dot{\lambda}_{i} f_{i}=0 \\
f_{i} \leq 0 \\
\dot{\lambda}_{i} \geq 0
\end{gathered}
$$

- A evolução do parâmetro interno, em geral, é dada por uma função do tensor de tensões e do tensor de taxa de deformações, conforme a expressão (5.9):

$$
\dot{\kappa}_{i}=h\left(\boldsymbol{\sigma}, \dot{\varepsilon}^{p}\right)
$$

Pode-se estabelecer a relação entre os tensores de taxa de tensões e deformações, mediante as hipóteses anteriores e alguns manejos algébricos, resultando na expressão (5.10):

$$
\dot{\sigma}=\left[\boldsymbol{D}-\frac{\boldsymbol{D} \frac{\partial g}{\partial \sigma} \frac{\partial f^{T}}{\partial \sigma} \boldsymbol{D}}{\boldsymbol{E}^{\prime}{ }_{P}+\frac{\partial f^{T}}{\partial \sigma} \boldsymbol{D} \frac{\partial g}{\partial \sigma}}\right] \dot{\boldsymbol{\varepsilon}}
$$

em que $\boldsymbol{E}_{\boldsymbol{p}}^{\prime}$, dado pela expressão (5.11), é o módulo plástico. A matriz de rigidez tangente do material resulta assimétrica se a função de potencial plástico " $g$ " não for igual à função de plastificação " $f$ ".

$$
\boldsymbol{E}_{P}=-\frac{\partial f}{\partial \kappa} \frac{\partial \kappa}{\partial \lambda}
$$


A solução numérica de problemas de plasticidade requer a discretização das expressões anteriores e o cálculo de uma matriz de rigidez tangente consistente com esta discretização. Uma exposição detalhada dos conceitos anteriores pode ser encontrada na literatura especializada sobre o tema, por exemplo MENDELSON (1978), CRISFIELD (1991) e TNO (1996). No Anexo F, apresentam-se os procedimentos incrementais e iterativos de resolução de sistemas de equações algébricas não-lineares e os métodos para controle de deslocamentos utilizados na modelagem numérica (“Arc Length”), bem como os critérios de convergência usuais.

\section{3 - MODELAGEM NUMÉRICA DOS PROTÓTIPOS ENSAIADOS}

\subsection{1 - INTRODUÇÃO}

Os protótipos ensaiados TIPO I e TIPO II, com relações altura/comprimento respectivamente de 0,83 e 0,51, foram modelados numericamente através de análise não-linear, utilizando-se o software DIANA 7.2. Para o sistema TIPO I, foram modelados os ensaios 5A e 6A. Para o sistema TIPO II, foram modelados os ensaios 1B, 2B, 3B e 4B.

Optou-se por efetuar a modelagem nesse software, em virtude deste possuir em sua biblioteca modelos constitutivos apropriados para a análise não-linear de materiais quasifrágeis. As características geométricas dos protótipos TIPO I e TIPO II encontram-se, respectivamente, nas tabelas 3.2 e 3.3, do capítulo 3.

No que se refere aos painéis de alvenaria, como são formados por camadas de blocos e argamassas dispostos em planos bem definidos, eles apresentam propriedades distintas com as direções. Em geral, as aproximações para uma representação numérica de painéis de alvenaria podem centrar na micromodelagem dos componentes, ou seja, discretização individual das unidades de blocos e argamassa, ou na macromodelagem do composto alvenaria, conforme mostrado na figura 5.2. 
Entretanto, essa escolha dependerá do nível de exatidão e simplicidade requerido (LOURENÇO, 1996).

$\mathrm{Na}$ micromodelagem, as propriedades dos materiais bloco e argamassa, como módulo de deformação, coeficiente de Poisson e, opcionalmente, as propriedades inelásticas, são definidas individualmente. A caracterização de cada um desses componentes deve levar em conta o estado de tensão e de deformação a que estejam submetidos na situação de trabalho.

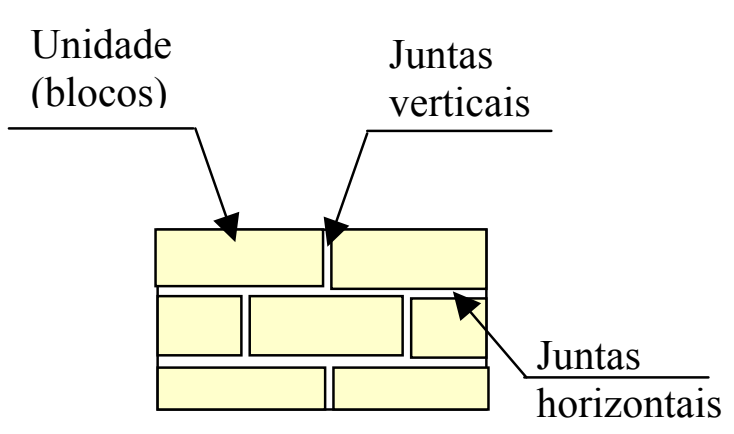

(a)

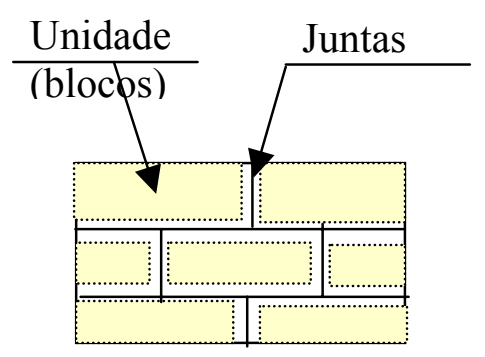

(c)

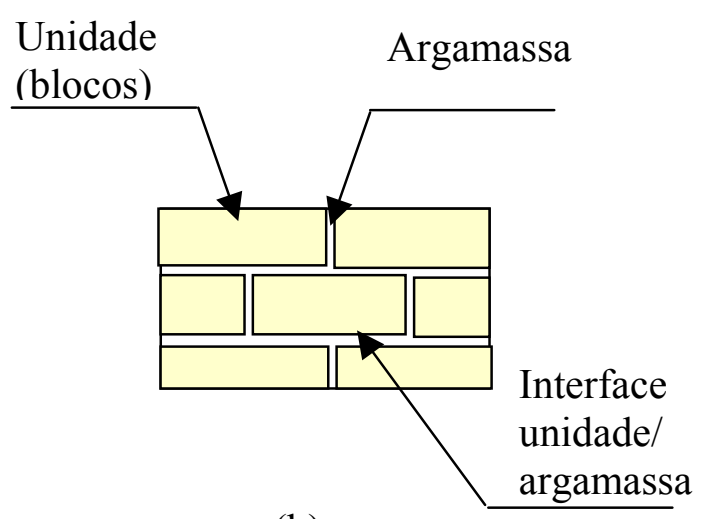

(b)

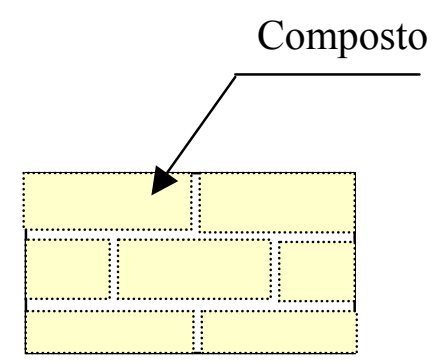

(d)

FIGURA 5.2 - Estratégias de modelagem para estruturas de alvenaria:

a) alvenaria simples, b) micromodelagem detalhada, c) micromodelagem simplificada e d) macromodelagem. Fonte: LOURENÇO (1996)

A macromodelagem não faz distinção entre os blocos e as juntas de argamassa, mas, ao contrário, trata a alvenaria como um material homogêneo, contínuo e anisotrópico. Nesse caso, as propriedades físicas são referentes ao composto, e para 
obtê-las são necessários ensaios em amostras com proporções tais que confiram maior homogeneidade ao material e estejam sujeitas a estados de tensão e deformação, condizentes com a situação real de uso da estrutura.

Uma macro ou micromodelagem de estruturas de alvenaria requer a descrição experimental do material. Entretanto, as propriedades da alvenaria são influenciadas por uma série de fatores, como: propriedades dos materiais dos blocos e da argamassa; juntas verticais e horizontais; anisotropia dos blocos; dimensões das unidades; espessura das juntas de argamassa; e qualidade da mão-de-obra, grau de cura, meio ambiente e idade.

A opção pela utilização da macro ou micromodelagem depende tanto da estrutura a ser estudada quanto do grau de precisão requerido. Neste trabalho, optou-se pela realização de macromodelagens, considerando as informações obtidas com os ensaios experimentais. Nesses ensaios, na maioria dos casos, o modo de ruptura foi a fissuração muito localizada da diagonal, através dos blocos e das juntas.

De fato, a elevada aderência da argamassa Ciment-cola e a reduzida resistência dos blocos de concreto celular autoclavado conduzem a um composto relativamente homogêneo, em que as juntas não representam planos preferenciais de fissuração. Por essa razão, adotou-se uma estratégia de modelagem essencialmente macro, com a fissuração direcionada para ocorrer em fendas pré-definidas com recurso de elementos de interface.

São apresentados nos itens subseqüentes os elementos finitos utilizados na análise numérica, os modelos constitutivos utilizados para a alvenaria, para as interfaces e para os pórticos e as propriedades dos materiais, além da descrição de cada uma das modelagens realizadas e dos resultados obtidos. 


\subsection{2 - ELEMENTOS FINITOS UTILIZADOS NA ANÁLISE NUMÉRICA}

Para modelagem dos protótipos ensaiados foram utilizados elementos contínuos para estado plano de tensão e elementos descontínuos tipo junta, de espessura zero, tanto para a representação das interfaces pórtico-painel e viga-pilar quanto para as regiões do painel de alvenaria onde havia grande possibilidade de ocorrência de fissuração, de acordo com os resultados obtidos experimentalmente e com a eventual correção em função dos resultados numéricos.

\subsubsection{1 - PÓRTICO DE AÇO}

Para representação do pórtico de aço, utilizaram-se elementos quadrilaterais isoparamétricos planos de quatro nós, denominados Q8MEM, que são baseados em interpolação linear e esquema de integração de Gauss 2 x 2, representados na figura 5.3. O polinômio para descrição dos deslocamentos $u_{x}$ e $u_{y}$ é expresso pela equação (5.12). Esse polinômio produz deformações $\varepsilon_{x x}$ constantes na direção x e com variação linear na direção y, bem como deformações $\varepsilon_{y y}$ constantes na direção y e com variação linear na direção $\mathrm{x}$. Para cisalhamento constante, esse elemento produz distorções $\varepsilon_{x y}$ constante sobre a sua área.

$$
u_{i}=a_{o}+a_{1} \xi+a_{2} \xi \eta+a_{3} \xi \eta
$$
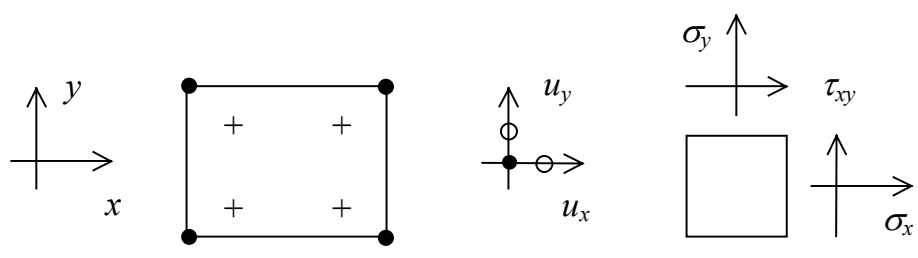

FIGURA 5.3 - Elemento finito utilizado para o pórtico de aço - Elemento finito plano para estado plano de tensões de quatro nós, com integração de Gauss 2 x 2 


\subsubsection{2 - PAINEL DE ALVENARIA}

Para representação do painel de alvenaria, foram utilizados elementos triangulares isoparamétricos planos de três nós, denominados T6MEM, que são baseados em interpolação linear e integração na área do elemento, representados na figura 5.4. Para um ponto $\mathrm{P}$, arbitrariamente localizado no elemento, os segmentos de área que ligam os vértices de um triângulo ao ponto $\mathrm{P}$ dividem o triângulo em três áreas $\mathrm{A}_{1}$, $\mathrm{A}_{2}$ e $\mathrm{A}_{3}$. As coordenadas naturais do ponto $\mathrm{P}$ são associadas aos vértices e definidas pelas razões entre a área oposta a cada vértice e a área total do triângulo. $\mathrm{O}$ polinômio para descrição dos deslocamentos $u_{x}$ e $u_{y}$ é expresso pela equação (5.13). Esse polinômio produz deformações constantes na área do elemento, e o esquema de integração é de um ponto de Gauss.

$$
u_{i}=a_{o}+a_{1} \xi+a_{2} \eta
$$
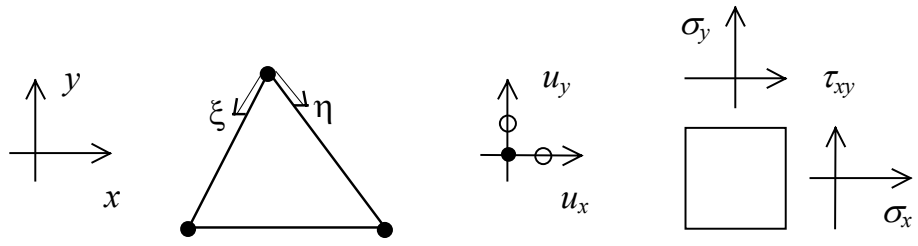

FIGURA 5.4 - Elemento finito utilizado para painel de alvenaria - Elemento finito plano de três nós para estado plano de tensões, com integração de um ponto de Gauss

Para elementos contínuos, o modelo constitutivo produz a relação entre tensão e deformação, definidos pelos vetores de tensão $\sigma$ e de deformação $\varepsilon$, respectivamente, expressões (5.14) e (5.15):

$$
\begin{aligned}
& \sigma=\left\{\begin{array}{lll}
\sigma_{x x} & \sigma_{y y} & \tau_{x y}
\end{array}\right\}^{T} \\
& \varepsilon=\left\{\begin{array}{lll}
\varepsilon_{x} & \varepsilon_{y} & \gamma_{x y}
\end{array}\right\}^{T}
\end{aligned}
$$


Esses valores são convenientemente definidos como vetores de tensões e deformações generalizados, de modo que a mesma notação possa ser adotada para os elementos contínuos e descontínuos.

\subsubsection{3 - INTERFACES VIGA-PILAR, PÓRTICO-ALVENARIA E ALVENARIA-ALVENARIA}

Para o contato entre as partes, foram utilizados elementos de interface entre duas linhas, com dois nós por linha e dois pontos de integração de Lobatto, conforme mostrado na figura 5.5. Esses elementos foram utilizados para as seguintes representações:

- Rigidez da ligação viga-pilar.

- Interface entre pórtico e alvenaria.

- Interface potencial entre alvenaria-alvenaria nas regiões suscetíveis ao surgimento de fissuras.

Esses elementos, denominados L8IF, descrevem a relação entre a tração t e o deslocamento relativo $\Delta \mathrm{u}$, através da interface. $\mathrm{O}$ eixo $t$ é tangencial à interface e o eixo $n$, é perpendicular à interface. O elemento é baseado em interpolação linear. Optou-se por utilizar o esquema de integração de Lobatto, uma vez que o esquema de Gauss para elementos de interface conduz a oscilações significativas de tensão, se a rigidez dos elementos de interface é relativamente grande quando comparada com a rigidez da estrutura (TNO, 1996).
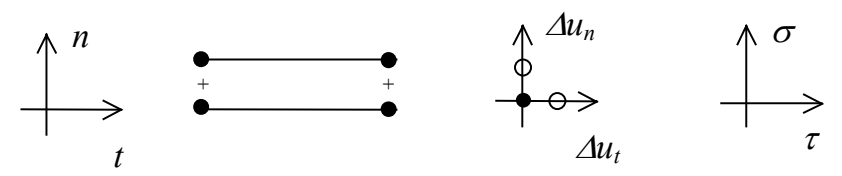

FIGURA 5.5 - Elemento finito utilizado para as interfaces viga-pilar, pórticoalvenaria e alvenaria-alvenaria. Elemento de junta de quatro nós, com dois pontos de integração de Lobatto 


\subsubsection{4 - CONEXÃO PROTÓTIPO-PÓRTICO DE REAÇÃO (ROLOS)}

Para representação dos rolos existentes no modelo experimental que liberam o deslocamento horizontal do protótipo e impedem o seu livre deslocamento vertical, foram utilizados apoios elásticos, através de elementos denominados SP1TR com um nó. As variáveis básicas do elemento SP1TR são translação, deformação e força axial na direção $x$, conforme figura 5.6 e expressões (5.16).

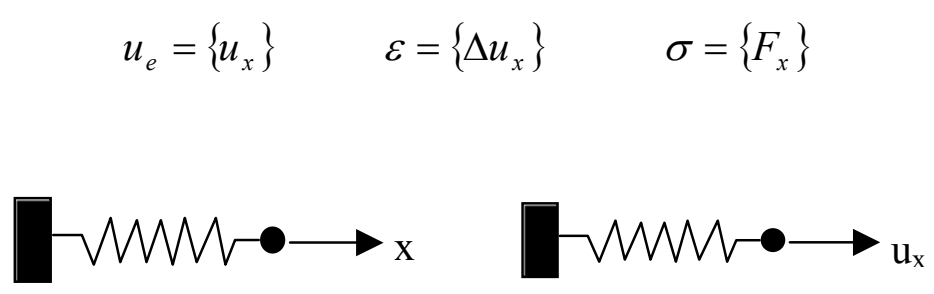

(a) (b)

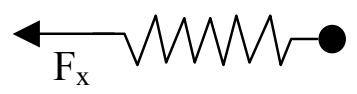

(c)

FIGURA 5.6 - Elemento finito utilizado para ligação protótipo-pórtico de reação (rolos): a) topologia, b) deslocamento e c) esforço

\subsection{3 - MODELOS CONSTITUTIVOS UTILIZADOS NA ANÁliSE NUMÉRICA}

\subsubsection{1 - MODELO CONSTITUTIVO PARA ALVENARIA}

No presente trabalho, foram efetuadas modelagens considerando ou não as interfaces alvenaria-alvenaria. Quando essas interfaces foram consideradas, adotou-se para o painel de alvenaria o critério de plastificação de Von Mises para descrever o regime de compressão. O critério de Von Mises pode ser entendido como a regularização do hexágono de Tresca, sendo habitualmente adotado para metais. É, no entanto, possível adotar esse critério para a ruptura em compressão de materiais quasifrágeis (FEENSTRA, 1996).

A função de plastificação de Von Mises é dada pela expressão (5.17). 
$f(\sigma, \kappa)=\sqrt{3 J_{2}}-\bar{\sigma}(\kappa)=\sqrt{\frac{1}{2} \sigma^{T} \boldsymbol{P}_{v m} \sigma}-\bar{\sigma}(\kappa)=\sqrt{\frac{1}{2} \sigma^{T} \boldsymbol{P}_{v m} \sigma}-f_{c m}$

em que $\bar{\sigma}_{1}(\kappa)$ representa a resistência média à compressão uniaxial $\left(f_{c m}\right)$ e $J_{2}$ é o segundo invariante do tensor desviador. A matriz de projeção $\boldsymbol{P}_{v m}$ é dada pela expressão (5.18), e a regra de fluxo é associativa, resultando no vetor de taxa de deformações plásticas dado pela expressão (5.19).

$$
\begin{aligned}
& \boldsymbol{P}_{v m}=\left[\begin{array}{cccccc}
2 & -1 & -1 & 0 & 0 & 0 \\
-1 & 2 & -1 & 0 & 0 & 0 \\
-1 & -1 & 2 & 0 & 0 & 0 \\
0 & 0 & 0 & 6 & 0 & 0 \\
0 & 0 & 0 & 0 & 6 & 0 \\
0 & 0 & 0 & 0 & 0 & 6
\end{array}\right] \\
& \dot{\varepsilon}^{P}=\lambda \frac{P \boldsymbol{P}}{2 \sigma}
\end{aligned}
$$

Quando a alvenaria foi modelada como um contínuo, adotou-se a combinação dos critérios de plastificação de Rankine e Von Mises, que descrevem, respectivamente, os regimes de tração e de compressão. Essa combinação de superfícies de plastificação é especialmente aplicada a situações planas e expressa por (5.20) e (5.21), sendo $\boldsymbol{P}_{v m}$ dado por (5.18) e $\boldsymbol{P}_{r a}$ pela expressão (5.22). O vetor de projeção $\pi_{1}$ é dado por (5.23), e $\bar{\sigma}_{1}\left(\kappa_{1}\right)$ e $\bar{\sigma}_{2}\left(\kappa_{2}\right)$ são as resistências uniaxiais à tração $\left(f_{t}\right)$ e à compressão $\left(f_{c m}\right)$, respectivamente.

A resistência à compressão utilizada nesta tese corresponde ao valor médio obtido através de ensaios de prismas. Para a resistência à tração, adotou-se a recomendação prática de 1/10 da resistência média à compressão. 
$f_{1}\left(\boldsymbol{\sigma}, \kappa_{1}\right)=\sqrt{\frac{1}{2} \cdot \boldsymbol{\sigma}^{T} \boldsymbol{P}_{r a} \boldsymbol{\sigma}}+\frac{1}{2} \boldsymbol{\pi}_{\boldsymbol{1}}^{T} \boldsymbol{\sigma}-\bar{\sigma}_{1}\left(\kappa_{1}\right)=\sqrt{\frac{1}{2} \cdot \boldsymbol{\sigma}^{T} \boldsymbol{P}_{r a} \boldsymbol{\sigma}}+\frac{1}{2} \boldsymbol{\pi}_{\boldsymbol{1}}^{T} \boldsymbol{\sigma}-f_{t}$

$f_{2}\left(\boldsymbol{\sigma}, \kappa_{2}\right)=\sqrt{\frac{1}{2} \boldsymbol{\sigma}^{\boldsymbol{T}} \boldsymbol{P}_{\boldsymbol{v} \boldsymbol{m}} \boldsymbol{\sigma}}-\bar{\sigma}_{2}\left(\kappa_{2}\right)=\sqrt{\frac{1}{2} \boldsymbol{\sigma}^{\boldsymbol{T}} \boldsymbol{P}_{\boldsymbol{v} \boldsymbol{m}} \boldsymbol{\sigma}}-f_{c m}$

$$
\begin{aligned}
& \boldsymbol{P}_{\boldsymbol{r a}}=\left[\begin{array}{cccccc}
\frac{1}{2} & -\frac{1}{2} & 0 & 0 & 0 & 0 \\
-\frac{1}{2} & \frac{1}{2} & 0 & 0 & 0 & 0 \\
0 & 0 & 0 & 0 & 0 & 0 \\
0 & 0 & 0 & 2 & 0 & 0 \\
0 & 0 & 0 & 0 & 0 & 0 \\
0 & 0 & 0 & 0 & 0 & 0
\end{array}\right] \\
& \boldsymbol{\pi}_{\boldsymbol{1}}=\left\{\begin{array}{llllll}
1 & 1 & 0 & 0 & 0 & 0
\end{array}\right\}^{T}
\end{aligned}
$$

A figura 5.7 representa a superfície de plastificação adotada, em que $f_{t}$ e $f c m$ são, respectivamente, as resistências à tração e à compressão uniaxiais da alvenaria.

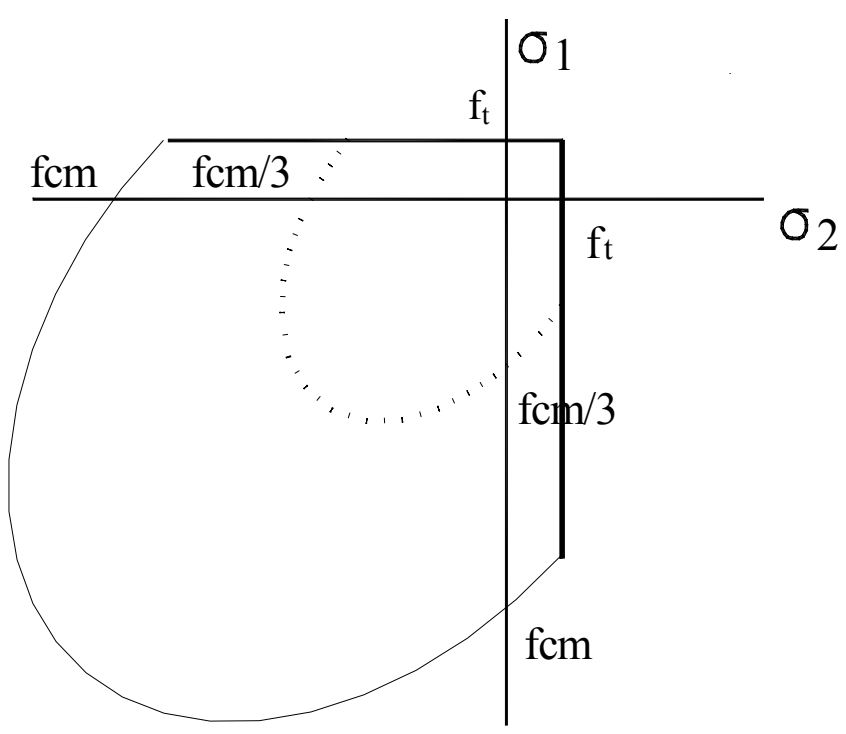

FIGURA 5.7 - Superfície de plastificação dada pela combinação das superfícies Rankine e Von Mises 
As energias de fratura à tração $\left(G_{f}\right)$ e à compressão $\left(G_{c}\right)$ são dadas pelas áreas correspondentes aos diagramas tensão-deformação uniaxial à tração e à compressão, ou seja, as integrais $\int \sigma d u$, figura 5.8. Para a energia de fratura à tração de blocos sílico-calcários e cerâmicos, nas direções normais e longitudinais, VAN DER PLUIJM (1992) ${ }^{1}$ recomendou valores entre 0,06 e $0,13 \mathrm{Nmm} / \mathrm{mm}^{2}$ para resistências à tração entre 1,5 e $3,5 \mathrm{~N} / \mathrm{mm}^{2}$.

Com relação à energia de fratura à compressão para blocos de alvenaria, não há recomendações sobre valores, tendo em vista o desconhecimento do comportamento dos blocos à compressão uniaxial pós-ruptura (LOURENÇO, 1996).

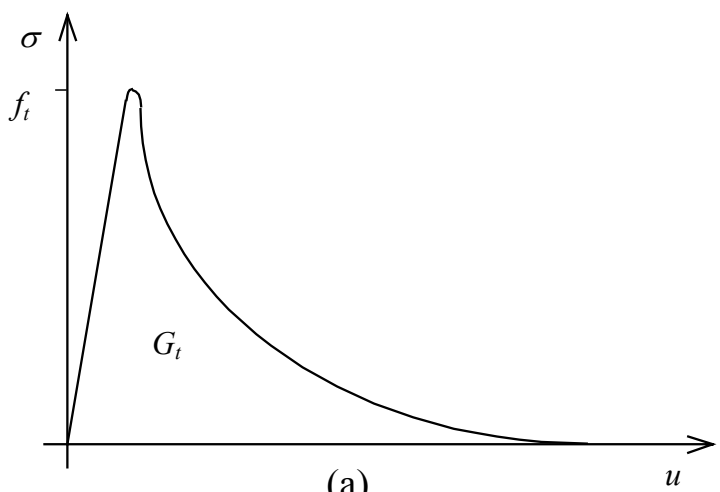

(a)

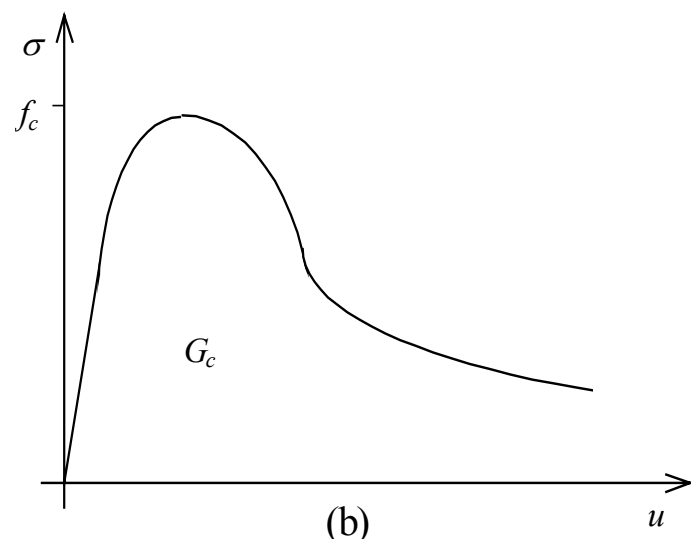

(b)

FIGURA 5.8 - Comportamento típico de materiais quasifrágeis submetidos a carregamento uniaxial e definição de energia de fratura: a) carregamento à tração e b) carregamento à compressão

Nas interfaces bloco-argamassa ocorrem dois modos de ruptura: o modo de ruptura à tração, que possui uma energia de fratura $\left(G_{f}^{I}\right)$ em modo I associado, e a ruptura por deslizamento da interface sob ação do cisalhamento, que possui energia de fratura $\left(G_{f}^{I I}\right)$ em modo II associado, figura 5.9.

${ }^{1}$ Apud LOURENÇO (1996) 
VAN DER PLUIJM (1992) ${ }^{1}$, realizando ensaios com deformação controlada em corpos-de-prova formados por blocos sílico-calcários ligados por argamassa submetidos à tração, obteve uma curva exponencial para o amolecimento, para o modo I da energia de fratura variando entre 0,005 e $0,02 \mathrm{Nmm} / \mathrm{mm}^{2}$, correspondente à resistência à tração das juntas variando de 0,3 a $0,9 \mathrm{~N} / \mathrm{mm}^{2}$.

De maneira similar, esse mesmo autor realizou ensaios em corpos-de-prova formados por blocos sílico-calcários ligados por argamassa submetidos ao cisalhamento. Foram obtidas curvas exponenciais para o amolecimento, para o modo II da energia de fratura variando entre 0,01 e $0,25 \mathrm{Nmm} / \mathrm{mm}^{2}$ e valores da coesão inicial variando entre 0,1 e $1,8 \mathrm{~N} / \mathrm{mm}^{2}$. Quando se utiliza o modelo contínuo, esse modo de fratura não pode ser diretamente incluído na análise, sendo considerado de forma indireta através do modelo de multissuperfícies plásticas.

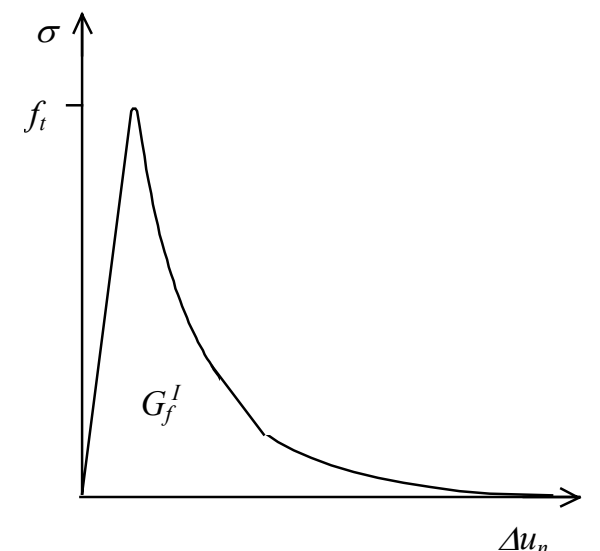

(a) Modo de falha I

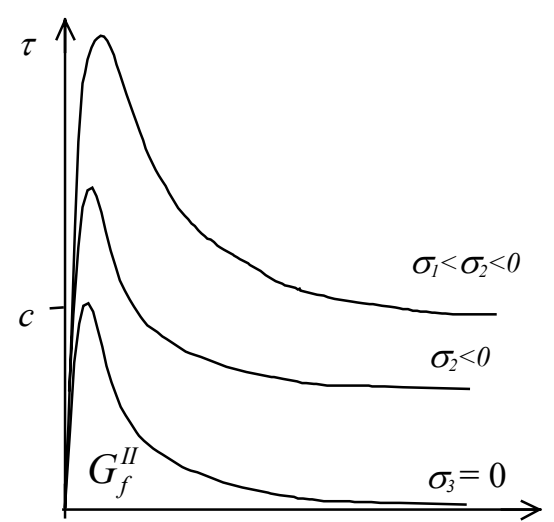

(b) Modo de falha II $\Delta u_{s}$

FIGURA 5.9 - Comportamento típico das juntas bloco-argamassa: (a) ruptura por tração, modo I $\left(G_{f}^{I}\right)$ e (b) ruptura por cisalhamento, modo II $\left(G_{f}^{I I}\right)$

Para a argamassa, há uma lacuna de conhecimento sobre o seu complexo comportamento à tração e à compressão (LOURENÇO, 1996). 
No estudo realizado, utilizou-se a recomendação de aproximar a energia de fratura à tração $\left(G_{f}\right)$ pela expressão $(5.24)$, sendo $f_{t}$ o valor da resistência à tração do material do painel, sem restrição quanto à unidade a utilizar.

$$
G_{f}=f_{t} \times 0,1 \mathrm{~mm}
$$

\subsubsection{2 - MODELO CONSTITUTIVO PARA AS INTERFACES}

A interface pórtico-painel tem considerável influência no comportamento do sistema de pórticos preenchidos. Quando existe contato inicial, pode-se considerar uma pequena resistência a esforços de tração, devida à aderência entre pórtico e argamassa. No entanto, uma vez ultrapassado esse nível de tensões, ocorre o descolamento dessa interface. Quando não existe o contato inicial ou a aderência entre as partes é desprezível, o descolamento ocorre desde o momento em que surgem deslocamentos relativos entre as partes, oriundos de tensões de tração.

Nas partes da interface em que ocorrem tensões de compressão, em se tratando de um macromodelo, pode-se modelar a interface como elemento de rigidez infinita, de modo a evitar que haja penetração entre os materiais ou, se pretender incluir certo refinamento, pode-se modelar a junta de argamassa considerando sua espessura. Dessa forma, quando ocorre deslocamento relativo entre pórtico e painel resultante de tensões de compressão e, conseqüentemente, tendência de penetração do elemento painel no elemento pórtico, haverá a deformação dessa junta.

No que se refere aos deslocamentos tangenciais, se ocorre o descolamento, não se geram tensões e o deslizamento ocorre livremente. No entanto, se existe o contato entre as partes, surgem tensões tangenciais, que geralmente são limitadas pelo modelo de Coulomb, definido pela expressão (5.25):

$$
\sigma_{t}=c+\sigma_{n} \operatorname{tg} \phi
$$


em que $\sigma_{t}$ e $\sigma_{n}$ são as tensões tangencial e normal (positivo - compressão) na interface, $c$ é a coesão e $\phi$ é o ângulo de atrito entre as superfícies.

Quando o esforço tangencial é maior que aquele obtido pela expressão (5.25), ocorre o deslizamento entre as superfícies do painel e do pórtico, devido à rugosidade destas. Esse deslocamento tangencial é acompanhado de um deslocamento normal à superfície da interface, chamado de dilatância e medido através do ângulo $(\psi)$, definido na figura 5.10 .

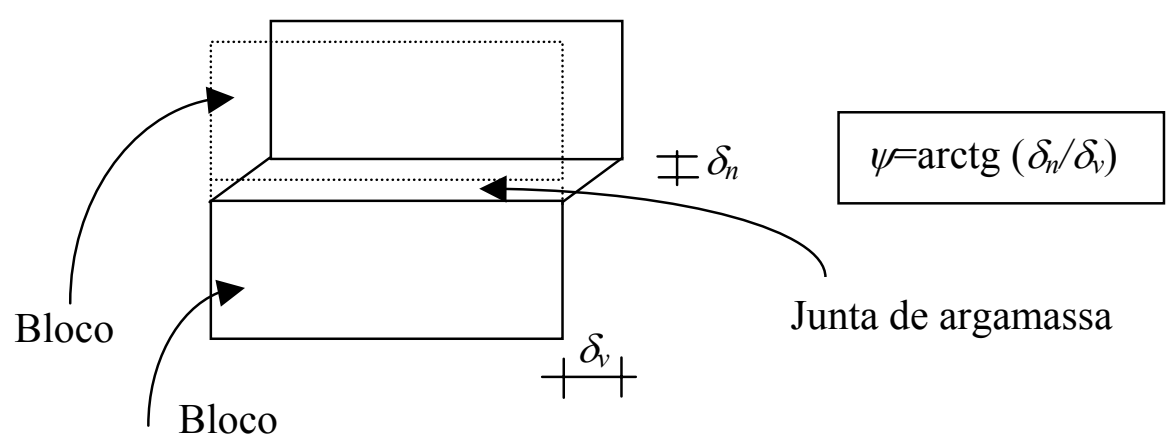

FIGURA 5.10 - Ângulo de dilatância ( $\psi)$

A dilatância depende do nível de tensões de confinamento, sendo inversamente proporcional tanto ao grau de rugosidade das superfícies em contato quanto ao deslocamento tangencial. Para baixos níveis de tensões de confinamento, o valor médio de $\operatorname{tg}(\psi)$ varia de 0,20 a 0,70 , dependendo da rugosidade das superfícies. Para altas tensões de confinamento, $\operatorname{tg}(\psi)$ tende a zero (LOURENÇO, 1996). À medida que ocorre o deslizamento, $\operatorname{tg}(\psi)$ também tende a zero, devido à regularização da superfície de contato.

Com relação às tensões tangenciais, o comportamento da interface pórtico-painel depende da história do carregamento. Ao aplicar carga inicialmente ao sistema, a coesão e a resistência tendem a seus valores originais.

No entanto, se o sistema já esteve submetido a outros ciclos de carga, as partes da interface que já ficaram sujeitas a tensões de tração e, conseqüentemente, se 
separaram em algum momento já não possuem nenhuma resistência à tração. $\mathrm{O}$ mesmo acontece com as partes da interface nas quais já houve o deslizamento; nesse caso já não há coesão, em virtude da diminuição da rugosidade e da conseqüente regularização da interface. Acontece ainda com o ângulo de dilatância e, inclusive, com ângulo de atrito, ainda que este último não chegue a atingir um valor nulo. Dessa forma, para painéis com alto nível de dano em suas interfaces, podem-se considerar valores nulos para a coesão e para o ângulo de dilatância, além de um valor reduzido para o ângulo de atrito.

LOURENÇO (1996) desenvolveu um modelo composto para análise da interface, o qual foi implementado no DIANA 7.2 (TNO, 1996). O modelo composto é subdividido em três partes, que se referem aos modos de ruptura por atrito, por fissuração e por esmagamento da interface, respectivamente.

Esse modelo é definido por um critério de escoamento composto e convexo, que consiste do critério de Coulomb para o atrito $f_{2}\left(\sigma, \kappa_{2}\right)$, de um limitador de tração ("tension cut-off") $f_{t}\left(\sigma, \kappa_{l}\right)$ para a fissuração e de um modelo elipsóide $f_{3}\left(\sigma, \kappa_{3}\right)$ para a compressão, conforme apresentado na figura 5.11, no plano $\sigma-\tau$.

O comportamento da interface é considerado linear até a tensão máxima, e a partir daí há um amolecimento do tipo exponencial. O modelo leva também em conta o fenômeno da dilatância, que, entretanto, tende a zero com o aumento do deslocamento tangencial e da tensão de confinamento. Na tração, o descolamento se inicia quando se atinge a resistência máxima, e o amolecimento ocorre da mesma forma que no cortante. Na compressão, incorpora um critério de ruptura elipsoidal e o comportamento é não-linear, tanto antes quanto depois de atingir a tensão máxima. 


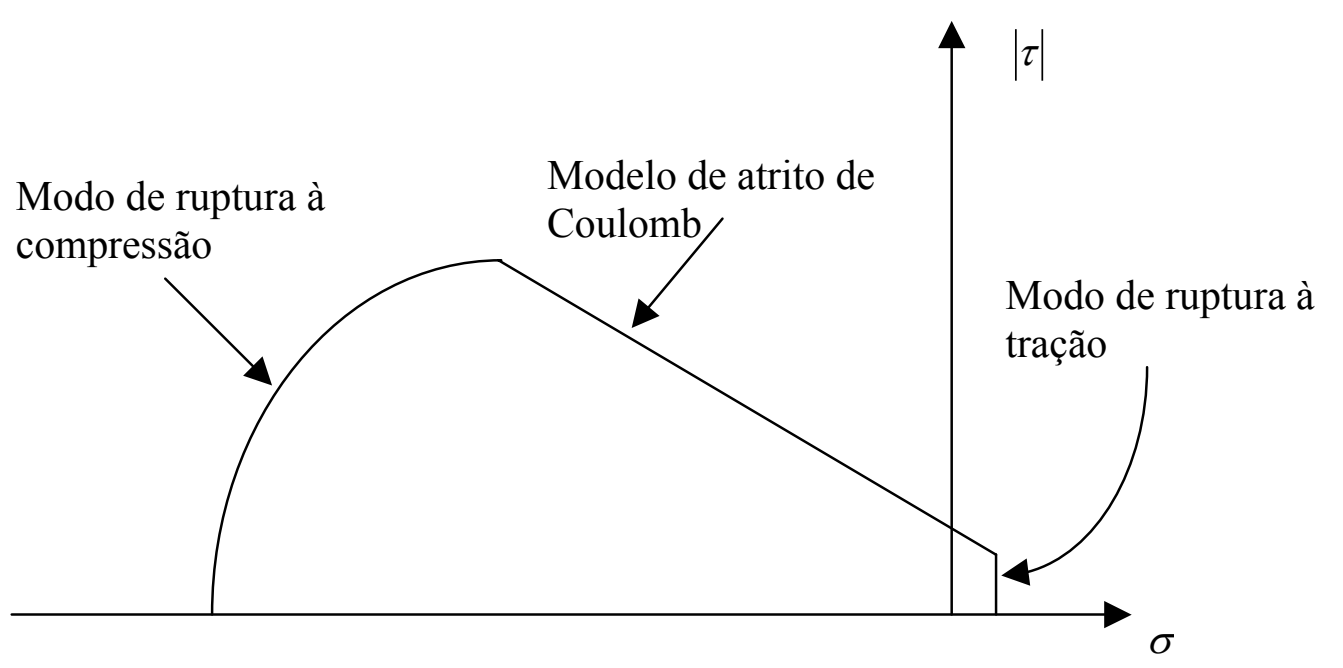

FIGURA 5.11 - Modelo geral para as interfaces desenvolvido por LOURENÇO

Para cada modo de ruptura constituinte do modelo composto, devem ser fornecidos os parâmetros relacionados à superfície de plastificação, como: tensões de plastificação, energia de fratura, coesão, ângulo de atrito e ângulo de dilatância, cujos valores para as modelagens realizadas estão apresentados no item 5.3.4, especificamente na tabela 5.1 .

Nas modelagens numéricas realizadas nesta tese, adotou-se para as interfaces pórtico-alvenaria e alvenaria-alvenaria o modelo composto de multissuperfícies, desenvolvido por LOURENÇO (1996) e implementado no DIANA 7.2 (TNO, 1996). No entanto, para ambas as interfaces, considerou-se a resistência à compressão infinita. Para a interface pórtico-alvenaria, considerou-se, também, a resistência à tração nula, enquanto para a interface alvenaria-alvenaria se considerou o valor da resistência à tração como $1 / 10$ da resistência à compressão resultante dos ensaios experimentais de caracterização do painel, conforme mostrado na figura 5.12. 


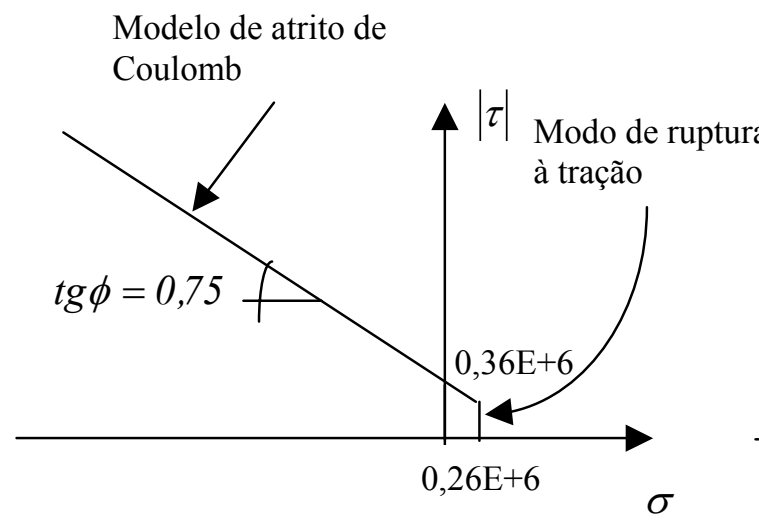

(a)

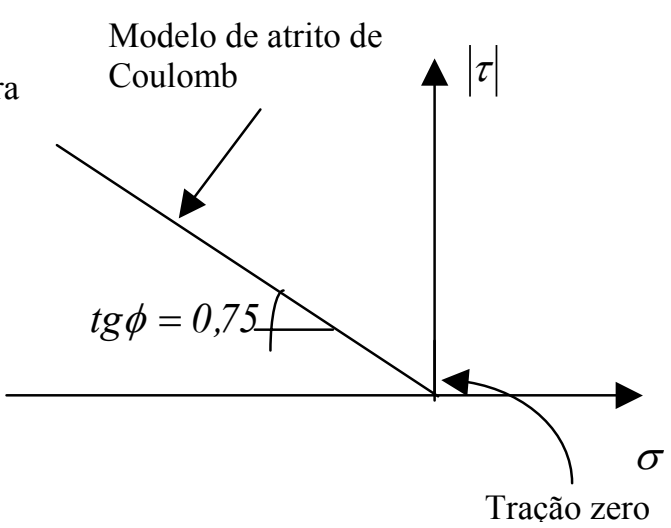

(b)

FIGURA 5.12 - Modelos utilizados para as interfaces nas análises numéricas realizadas nesta tese: a) interface alvenaria-alvenaria e b) interface pórtico-alvenaria. Unidades: $\mathrm{N} / \mathrm{m}^{2}$

\subsubsection{3 - MODELO CONSTITUTIVO PARA O PÓRTICO DE AÇO}

Os pórticos de aço foram modelados como de comportamento elástico-linear, de modo a representar as condições dos ensaios experimentais. Nesses ensaios, isso foi comprovado, comparando-se os diagramas força-deslocamento dos pórticos sem preenchimento, antes e depois dos ensaios realizados com esses pórticos. As propriedades utilizadas na análise numérica encontram-se na tabela 5.1.

\subsection{4 - PROPRIEDADES DA ALVENARIA E ARGAMASSA UTILIZADAS NA ANÁLISE NUMÉRICA}

O comportamento não-linear do composto alvenaria pode ser interpretado através da figura 5.13. Na tração uniaxial, têm-se uma resistência muito baixa e um comportamento praticamente linear até a tensão máxima, quando ocorre a ruptura frágil. $\mathrm{Na}$ compressão uniaxial, a resistência é muito maior e o comportamento, 
marcadamente não-linear, com tensões crescentes com as deformações até um máximo, seguida de diminuição das tensões até um valor residual.

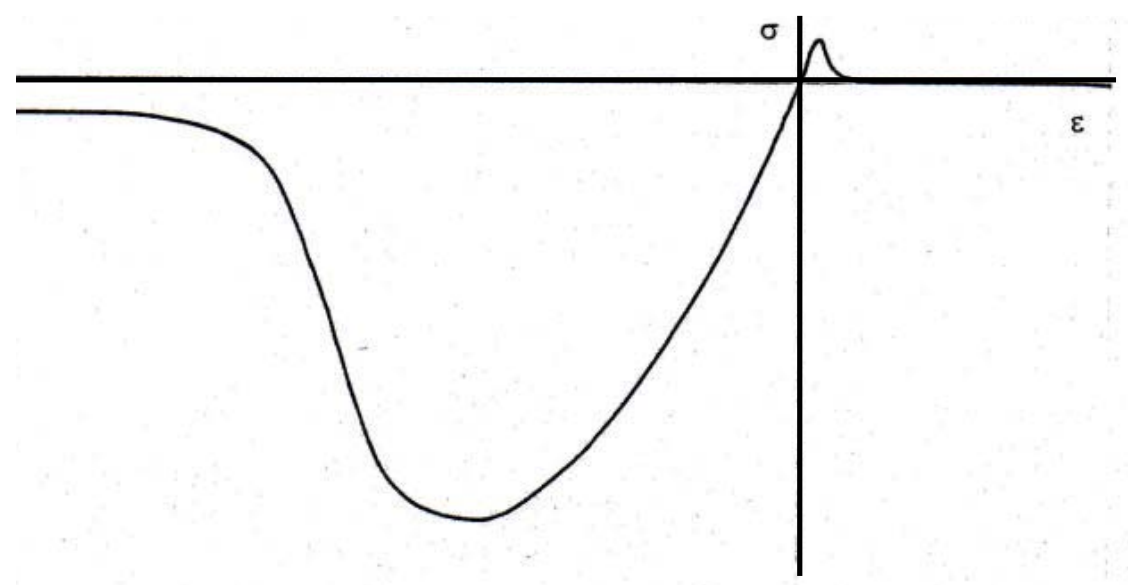

FIGURA 5.13 - Diagrama tensão-deformação uniaxial para o painel de alvenaria, na tração e na compressão

As propriedades utilizadas nas análises numéricas foram essencialmente obtidas através dos ensaios experimentais de caracterização dos materiais e também através de ensaios com outras alvenarias, além de algumas que foram obtidas por tentativas, como o caso da ligação semi-rígida viga-pilar. Os ensaios realizados não foram suficientes para caracterização da alvenaria em regime plástico, necessária à análise não-linear.

Na modelagem numérica dos ensaios foram utilizados grupos de elementos, reunidos de acordo com suas semelhanças físicas, elásticas e geométricas. Ao todo, foram seis grupos, citados a seguir:

- Painel de alvenaria.

- Pórtico de aço.

- Interfaces viga-pilar.

- Interfaces viga-alvenaria e pilar-alvenaria.

- Interfaces alvenaria-alvenaria.

- Apoios elásticos. 
O painel de alvenaria foi modelado considerando ou não elementos de interface. Quando foram considerados elementos de interface alvenaria-alvenaria, o critério de plastificação utilizado para o painel quando submetido à compressão foi Von Mises. Para a resistência média à compressão $\left(f_{c m}\right)$, o valor adotado foi de $2,6 \mathrm{E} 6 \mathrm{~N} / \mathrm{m}^{2}$ e a energia de fratura à compressão $\left(G_{c}\right)$, estimada segundo LOURENÇO (1996).

Quando foi modelado o painel sem a interface alvenaria-alvenaria, adotou-se a combinação dos critérios de plastificação de Rankine e Von Mises, para descrever os regimes de tração e compressão, respectivamente. Para resistência à tração $\left(f_{t}\right)$, o valor assumido foi $0,10 f_{c m}$, e para a energia de fratura à tração $\left(G_{t}\right)$ o valor adotado, descrito na tabela 5.1, seguiu as recomendações de LOURENÇO (1996). Apresentam-se ainda, nessa tabela, o módulo de deformação $\left(E_{\text {painel }}\right)$ e o coeficiente de Poisson (v). O diagrama tensão-deformação assumido para o painel de alvenaria consta de um trecho elástico até $1 / 3 f_{c m}$, a partir do qual se inicia a plastificação, que se estende linearmente até a deformação de $2 \%$, correspondente à tensão média de compressão $\left(f_{c m}=2,6 \mathrm{MPa}\right)$. A partir daí há amolecimento, levado em conta através da energia de fratura à compressão adotada: $G_{c}=4,00 \mathrm{E} 3 \mathrm{Nm} / \mathrm{m}^{2}$.

A fim de descrever o comportamento dos pórticos de aço durante os ensaios experimentais, estes foram modelados elasticamente. As propriedades elásticas dos pórticos TIPO I e TIPO II, ensaiados experimentalmente, estão apresentadas na tabela 5.1.

As ligações vigas-pilar relativas aos ensaios experimentais foram modeladas como semi-rígidas. A semi-rigidez dessas ligações foi obtida por tentativas, de modo a reproduzir o comportamento experimental do pórtico isolado. $\mathrm{O}$ valor obtido para a rigidez $\left(k_{v p}\right)$ foi de 2,0E6 N/m² $/ \mathrm{m}$. Para simular computacionalmente essas ligações, foram inicialmente introduzidos seis elementos de interface nas ligações viga-pilar e em seguida, através do recurso denominado TYINGS, disponível no DIANA 7.2, foi realizada uma condensação estática dos graus de liberdade dos dois elementos centrais, eliminando-os. 
As interfaces viga-alvenaria e pilar-alvenaria foram modeladas como inelásticas, com rigidez $\left(k_{\text {palv }}\right)$ igual a $1,0 \mathrm{E} 11 \mathrm{~N} / \mathrm{mm}^{2} / \mathrm{mm}$. As interfaces foram modeladas sem qualquer resistência à tração $(f t=0)$ e ao cisalhamento (coesão $(c)=0)$, além de resistência à compressão infinita. A coesão $(c)$ adotada foi zero, e considerou-se como ângulo de atrito interno $(\phi)$ o valor cuja tangente era 0,75 . O ângulo de dilatância foi considerado nulo.

Nas regiões do painel de alvenaria onde ocorreu ruptura por fissuração da diagonal, foram modelados elementos de interface, considerando-se a resistência à tração como $1 / 10$ da resistência média à compressão e a energia de fratura à tração como $G_{f}=f_{t} \times 0,1 \mathrm{~mm}$. Adotou-se para a coesão o valor de $0,36 \mathrm{E} 6 \mathrm{~N} / \mathrm{m}^{2}$, que corresponde a $1,4 f_{t}$.

Para o ângulo de atrito, adotou-se o valor cuja tangente é 0,75 , e a dilatância foi considerada nula. A resistência à compressão na interface alvenaria-alvenaria foi considerada infinita. A rigidez adotada foi a mesma da interface pórtico-alvenaria, ou seja, $k_{\text {alv }}$ igual a $1,0 \mathrm{E} 11 \mathrm{~N} / \mathrm{m}^{2} / \mathrm{m}$.

Foram ainda modelados como apoios elásticos os rolos entre os protótipos ensaiados e o pórtico de reação. As rigidezas dos apoios elásticos foram obtidas através da relação força/deslocamento vertical, na posição dos rolos, obtida através de análises elásticas lineares do pórtico de reação, submetido à ação unitária vertical na direção do rolo considerado. Os resultados obtidos são apresentados na tabela 5.1, em que $k_{1}$, $k_{2}$ e $k_{3}$ se referem à rigidez dos rolos situados a $3,50 \mathrm{~m}, 5,50 \mathrm{~m}$ e $6,50 \mathrm{~m}$ do pilar esquerdo do pórtico de reação. Nos ensaios da série A, com o sistema TIPO I, utilizaram-se os rolos 1 e 2, enquanto nos ensaios com o sistema TIPO II (série B) foram usados os rolos 2 e 3 . 
TABELA 5.1 - Propriedades dos materiais utilizados na análise numérica

\begin{tabular}{|c|l|}
\hline & $\begin{array}{l}f_{\mathrm{t}}=0,26 \mathrm{E} 6 \mathrm{~N} / \mathrm{m}^{2} \\
f_{c m}=2,6 \mathrm{E} 6 \mathrm{~N} / \mathrm{m}^{2}\end{array}$ \\
$G_{f}=0,026 \mathrm{E} 3 \mathrm{Nm} / \mathrm{m}^{2}$ \\
$G_{c}=4,00 \mathrm{E} 3 \mathrm{Nm} / \mathrm{m}^{2}$ \\
$E_{p a i n e l}=1,75 \mathrm{E} 9 \mathrm{~N} / \mathrm{m}^{2}$ \\
$v_{\text {alvenaria }}=0,16$
\end{tabular}




\subsection{5 - RESULTADOS DA ANÁLISE NUMÉRICA DOS PROTÓTIPOS}

\subsubsection{1 - PROTÓTIPO TIPO I}

O protótipo TIPO I, com relação altura/comprimento igual a 0,83 , foi modelado considerando-se elementos de interface na direção da diagonal comprimida, de modo a simular os resultados experimentais referentes aos ensaios $5 \mathrm{~A}$ e $6 \mathrm{~A}$. $\mathrm{Na}$ figura 5.14, apresentam-se as malhas utilizadas para representação do painel de alvenaria, do pórtico de aço e das interfaces: viga-pilar, pórtico-alvenaria e alvenaria-alvenaria. O carregamento foi aplicado de forma incremental, visando obter a curva completa de comportamento do sistema, desde o descolamento da interface, passando pela fissuração da diagonal até a carga correspondente ao esmagamento.

Nas figuras 5.15 a 5.18, apresentam-se os resultados numéricos correspondentes a diferentes níveis de carga. Os resultados da figura 5.15 referem-se a uma ação horizontal de $60 \mathrm{kN}$ aplicada na extremidade direita da viga superior. Nesse nível de carga já ocorria o descolamento das interfaces pórtico-alvenaria, uma vez que estas foram modeladas sem resistência à tração; também, já se percebia o comportamento de biela.

No centro do painel, têm-se tensões principais máximas de tração e mínimas de compressão. As tensões principais máximas são de tração em uma faixa correspondente a aproximadamente $60 \%$ do comprimento da diagonal, atingindo no centro do painel o valor máximo de $0,528 \mathrm{E} 5 \mathrm{~N} / \mathrm{m}^{2}$. Já as deformações principais máximas referem-se a alongamento em todo o comprimento da diagonal. As tensões principais mínimas apresentam valores em torno de $-0,33 \mathrm{E} 6 \mathrm{~N} / \mathrm{m}^{2}$. As deformações principais máximas e mínimas no centro do painel assumem valores de 0,847E-4 e 0,249E-3, respectivamente.

Nos cantos comprimidos, tem-se um estado de compressão biaxial, em que as tensões principais máximas assumem valores em compressão, ainda que pequena. As tensões principais mínimas apresentam valores em torno de $1,1 \mathrm{E} 6 \mathrm{~N} / \mathrm{m}^{2}$ e as 
deformações principais máximas (alongamento) e mínimas (encurtamento), os valores a seguir: 0,246E-3 e -0,742E-3, respectivamente.

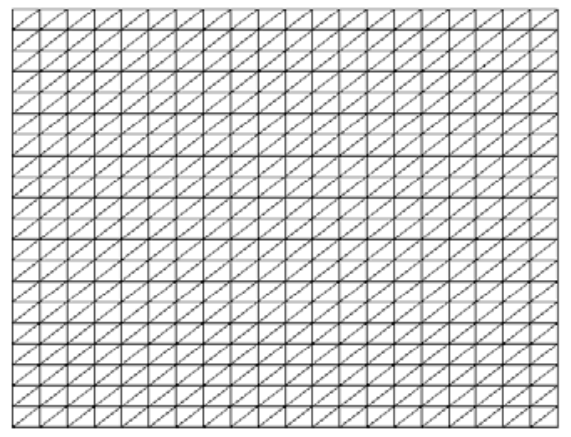

(a)

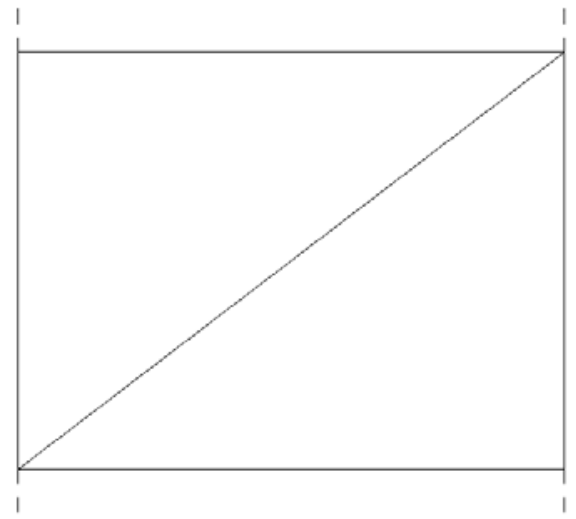

(c)

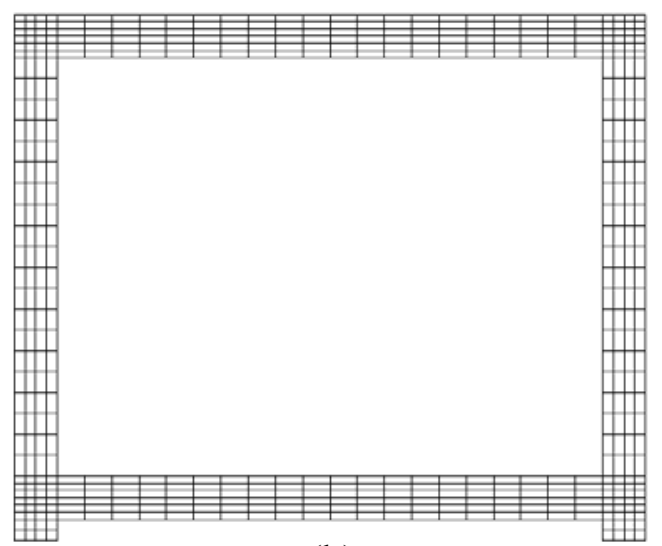

(b)

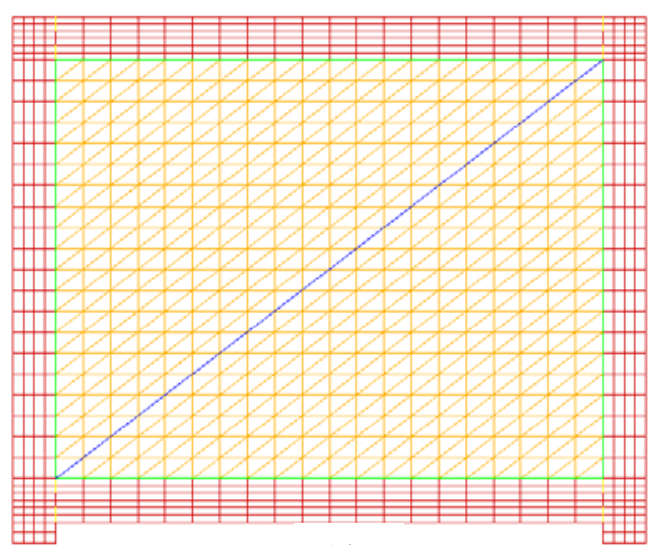

(d)

FIGURA 5.14 - Malhas utilizadas na análise numérica do sistema TIPO I: a) painel de alvenaria; b) pórtico de aço; c) interfaces viga-pilar, pórtico-alvenaria e alvenariaalvenaria; e d) malha completa

Os resultados obtidos para uma ação de $175 \mathrm{kN}$, correspondente à carga de fissuração da diagonal, tanto nos ensaios experimentais como na modelagem numérica, são apresentados na figura 5.16, em que a deformada apresenta o início da abertura da interface diagonal. Pode-se notar que no centro do painel as tensões 
principais máximas de tração atingem valores correspondentes à resistência à tração do painel, provocando a fissuração da diagonal. Percebe-se também redução na faixa de atuação das tensões de tração, que passam a ocupar mais ou menos $45 \%$ do comprimento da diagonal. No centro do painel, as tensões principais mínimas apresentam valores em torno de $-0,97 \mathrm{E} 6 \mathrm{~N} / \mathrm{m}^{2}$.

Nos cantos comprimidos do painel, permanece o estado biaxial de compressão. As tensões principais mínimas apresentam valores próximos à tensão de compressão média do painel. As deformações principais máximas e mínimas apresentam valores de $0,102 \mathrm{E}-2$ e $-0,202 \mathrm{e}-2$.

São apresentados na figura 5.17 os resultados numéricos para uma ação horizontal de $250 \mathrm{kN}$, portanto superior à carga de fissuração da diagonal. O deslocamento máximo obtido numericamente é de $11,2 \mathrm{~mm}$. As tensões principais máximas assumem valores de compressão em quase todo o painel, com exceção dos dois cantos tracionados, em que se podem perceber tensões de tração presentes. As tensões mínimas de compressão tendem a 1,7E6 N/m² no centro do painel e, nos cantos, atinge o valor de 2,4E6 N/m², aproximando-se, assim, da tensão média de compressão do painel.

As deformações principais mínimas e máximas no centro do painel apresentam valores de 0,114E-2 e -0,231E-2, enquanto nos cantos comprimidos essas deformações assumem os seguintes valores: 0,474E-2 e -0,308E-2. Para esse nível de carga não é mais possível uma comparação com os resultados experimentais, uma vez que o pórtico foi descarregado após a fissuração da diagonal, nos ensaios experimentais.

Por fim, apresentam-se na figura 5.18 os resultados obtidos para ação de $316 \mathrm{kN} \mathrm{e}$ deslocamento numérico de $17,8 \mathrm{~mm}$, correspondente ao esmagamento dos cantos comprimidos. Pode-se notar o estado biaxial de compressão nos cantos comprimidos do painel e tensões principais mínimas (compressão), que se estendem do canto para o centro do painel, de forma decrescente. Nos resultados experimentais não foi 
atingida a força correspondente ao esmagamento, uma vez que havia a preocupação de manter o pórtico trabalhando em regime elástico, e, dessa forma, o pórtico foi descarregado após a fissuração da diagonal.

Percebe-se que o modelo utilizado representa exatamente o comportamento do sistema TIPO I ocorrido nos ensaios experimentais. Na modelagem numérica, o deslocamento máximo correspondente a esse nível de carga é de $6,16 \mathrm{~mm}$, enquanto nos ensaios experimentais foram obtidos os valores de $6,8 \mathrm{~mm}$ e $6,16 \mathrm{~mm}$, respectivamente nos ensaios $5 \mathrm{~A}$ e $6 \mathrm{~A}$. 


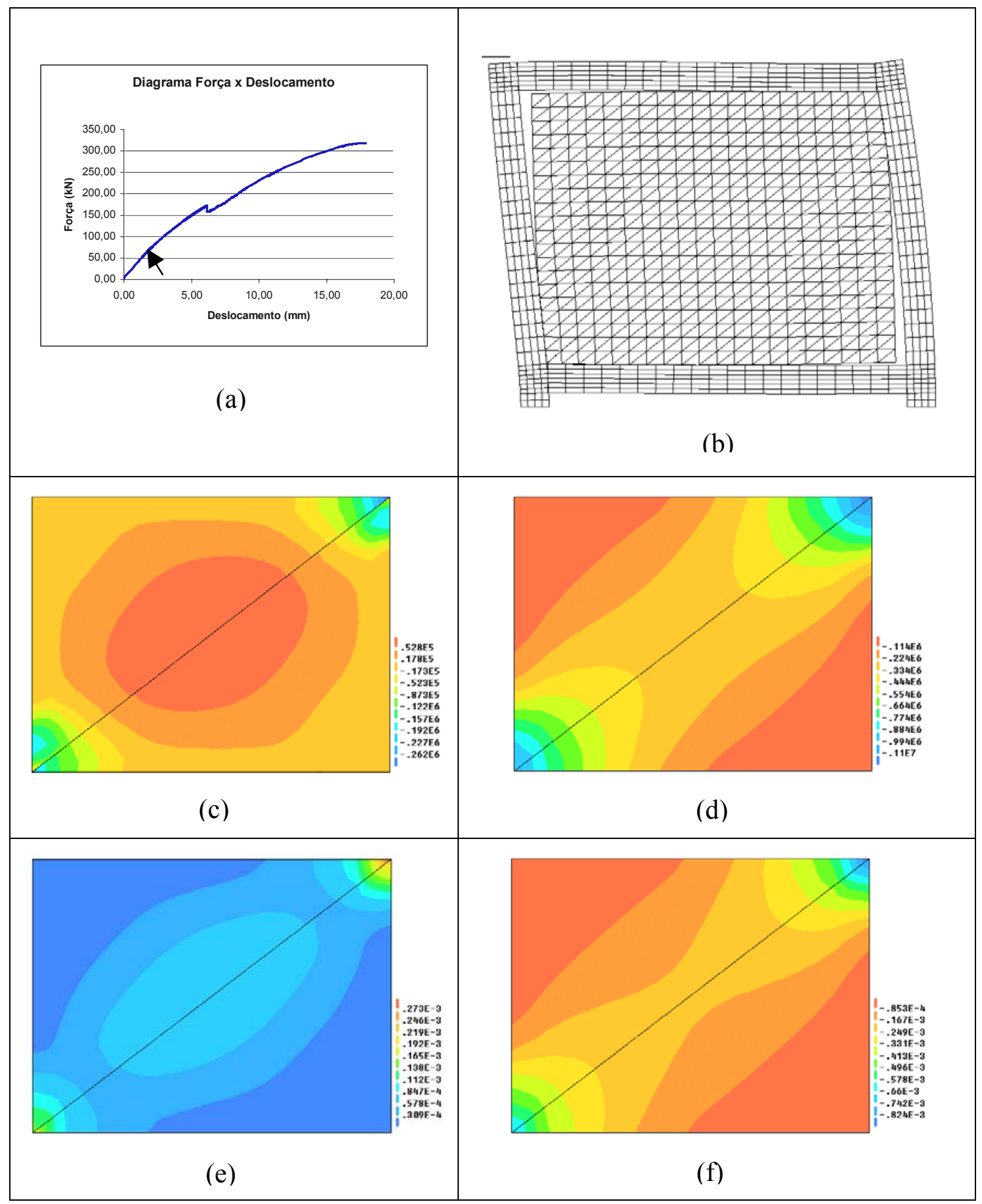

FIGURA 5.15 - Resultados da análise numérica dos ensaios 5A e 6A: ação horizontal de $60 \mathrm{kN}$ : a) diagrama força-deslocamento, b) deslocamentos incrementais, c) tensões principais máximas, d) tensões principais mínimas, e) deformações principais máximas e f) deformações principais mínimas. Unidades 


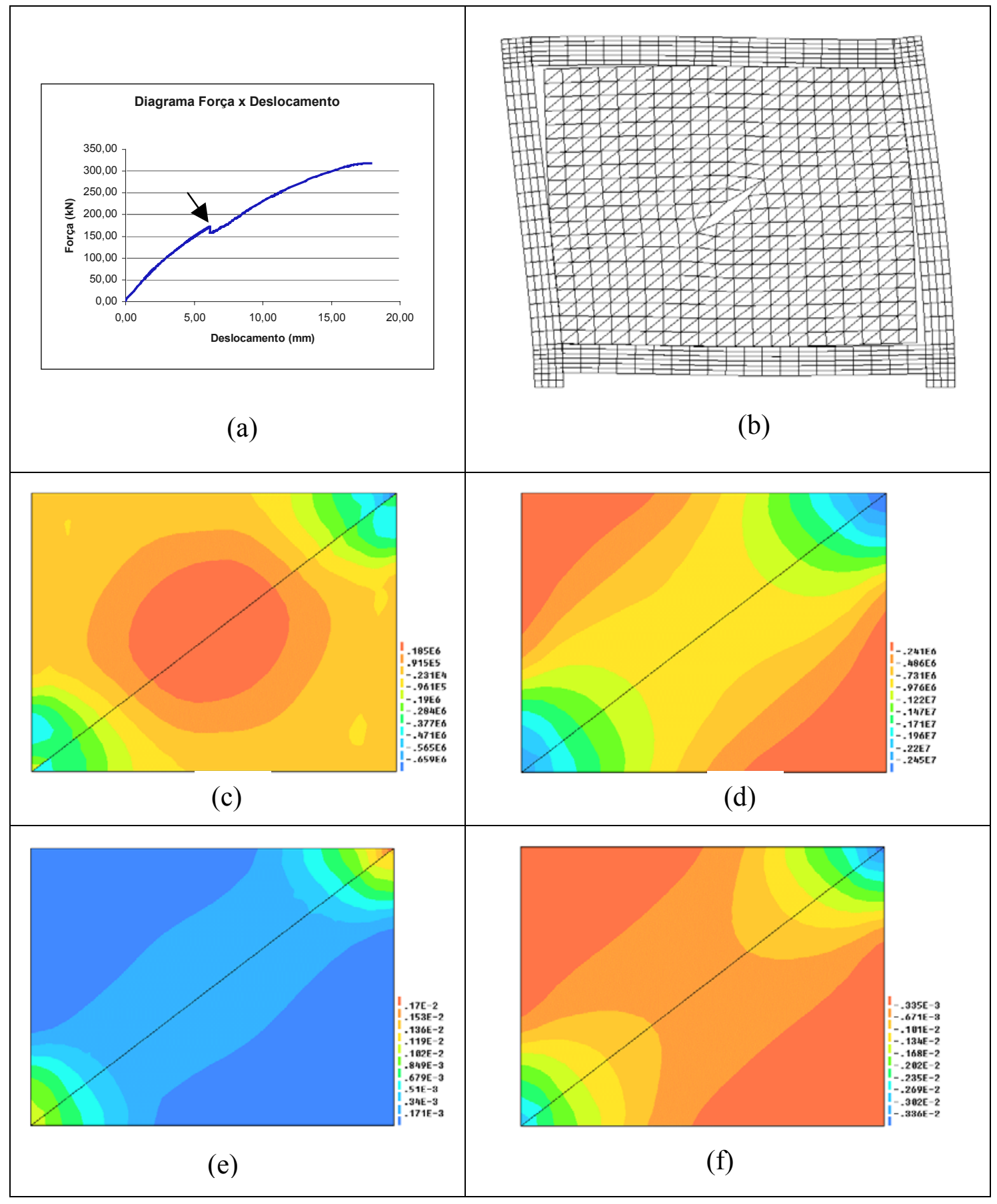

FIGURA 5.16 - Resultados da análise numérica dos ensaios 5A e 6A: ação horizontal de $175 \mathrm{kN}$ : a) diagrama força-deslocamento, b) deslocamentos incrementais, c) tensões principais máximas, d) tensões principais mínimas, e) deformações principais máximas e f) deformações principais mínimas. Unidades (Newton e metro) 


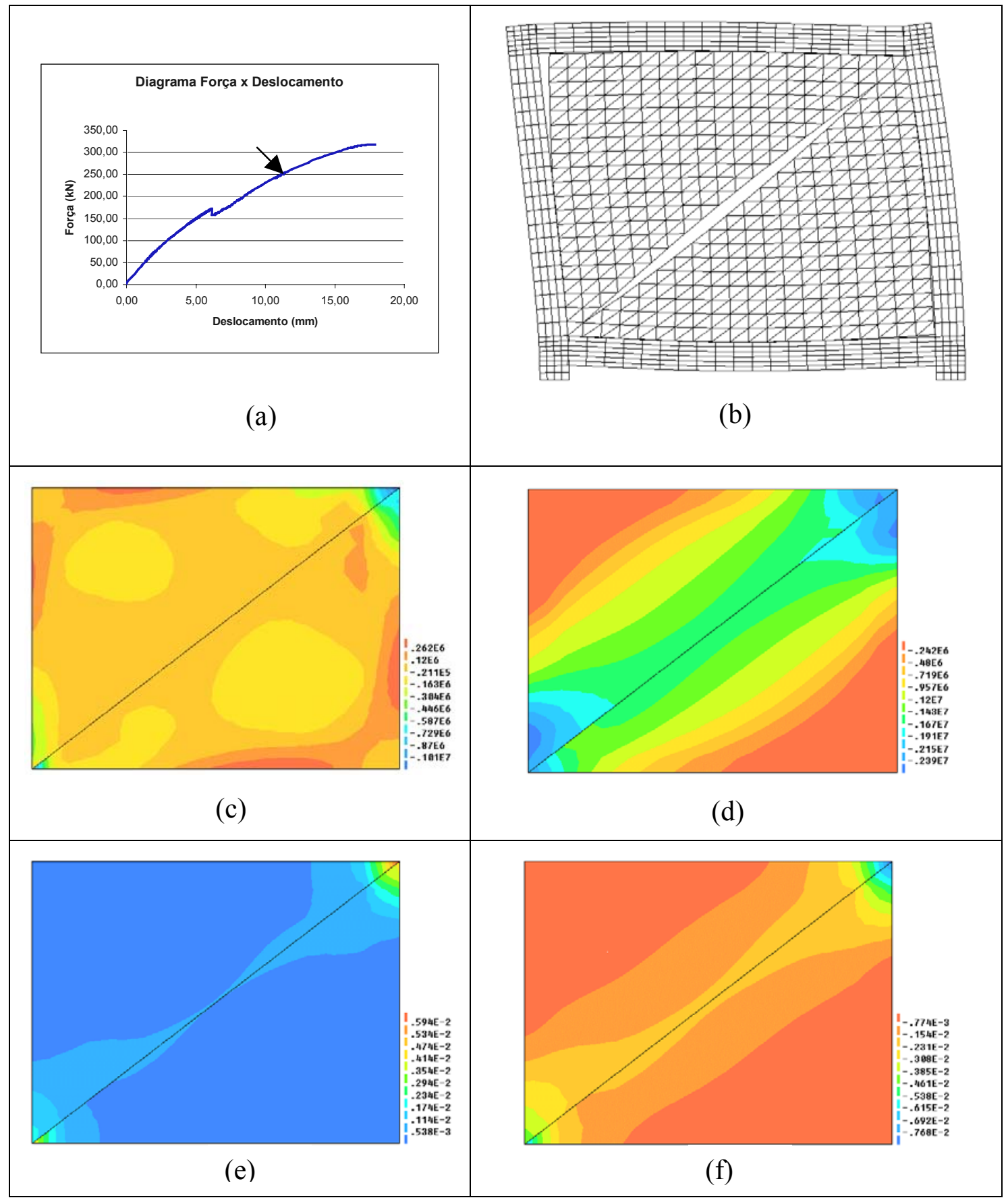

FIGURA 5.17 - Resultados da análise numérica dos ensaios 5A e 6A: ação horizontal de $250 \mathrm{kN}$ : a) diagrama força-deslocamento, b) deslocamentos incrementais, c) tensões principais máximas, d) tensões principais mínimas, e) deformações principais máximas e f) deformações principais mínimas. Unidades 


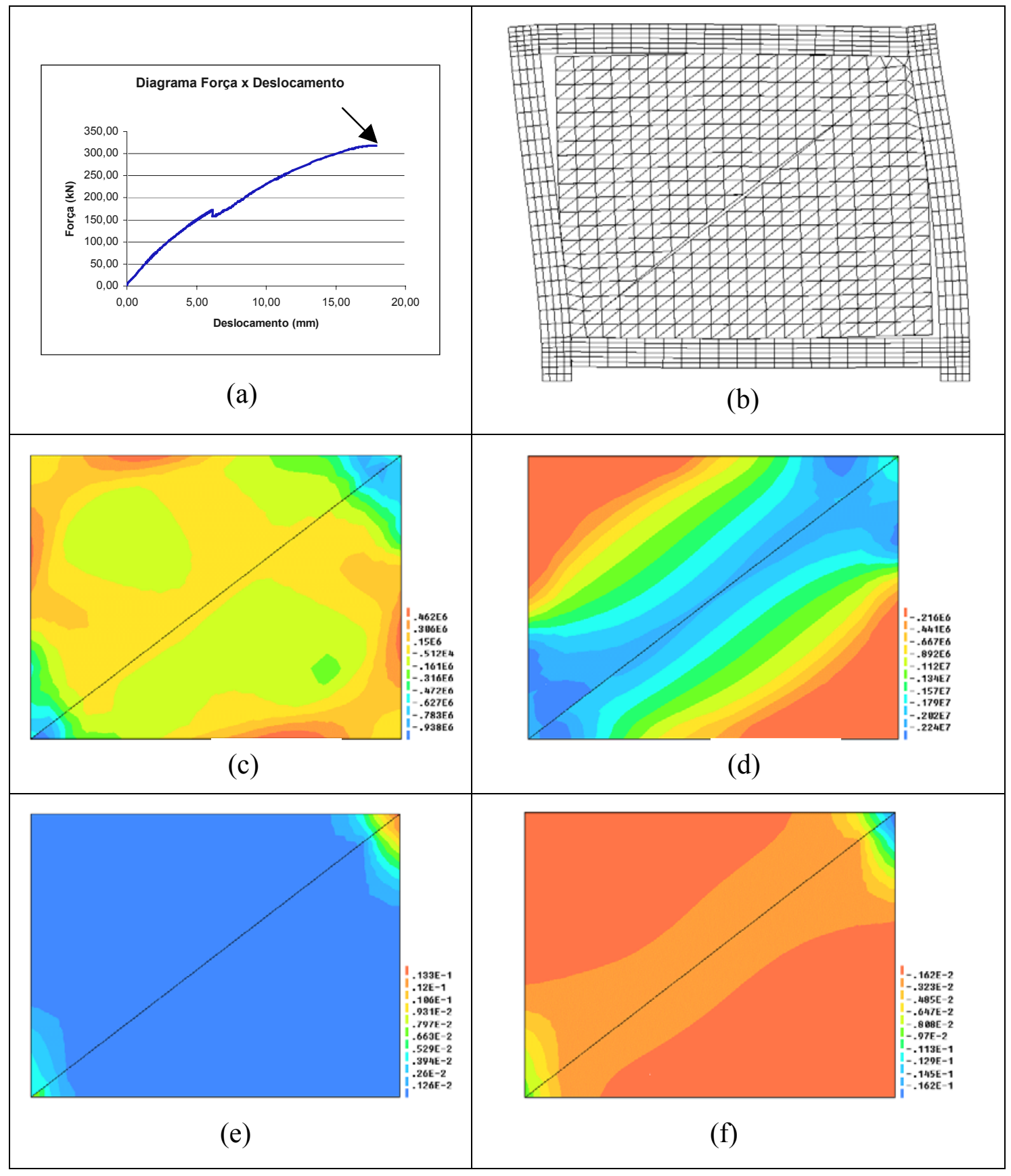

FIGURA 5.18 - Resultados da análise numérica dos ensaios 5A e 6A: ação horizontal de $316 \mathrm{kN}$ : a) diagrama força-deslocamento, b) deslocamentos incrementais, c) tensões principais máximas, d) tensões principais mínimas, e) deformações principais máximas e f) deformações principais mínimas. Unidades (Newton e metro) 


\subsubsection{2 - ANÁLISE COMPARATIVA ENTRE RESULTADOS NUMÉRICOS E EXPERIMENTAIS: SÉRIE A}

Os estudos disponíveis na literatura reproduzem o comportamento da estrutura através de modelos numéricos somente até a carga de fissuração da diagonal. A partir daí, dada a complexidade do comportamento da estrutura, não se têm resultados numéricos disponíveis. Neste trabalho, em virtude do modelo utilizado, foi possível a obtenção da curva numérica completa força-deslocamento. No entanto, tendo em vista que nos ensaios experimentais da série A foi utilizado um único pórtico, teve-se o cuidado de não ultrapassar o seu regime elástico-linear. Dessa forma, a comparação entre os resultados numéricos e teóricos não atinge o esmagamento dos cantos do painel.

Apresentam-se na figura 5.19 as curvas força-deslocamento obtidas através dos ensaios experimentais $5 \mathrm{~A}$ - 6A e pela modelagem numérica efetuada. Nesses ensaios experimentais, realizados no protótipo TIPO I $(\mathrm{H} / \mathrm{L}=0,83)$, as interfaces pórticopainel, bem como as juntas verticais e horizontais, foram constituídas de argamassa Ciment-cola.

$\mathrm{Na}$ análise numérica, utilizou-se o critério de Von Mises para o painel de alvenaria e um modelo de multissuperfícies para a interface diagonal alvenaria-alvenaria (LOURENÇO, 1996).

Os resultados obtidos através da modelagem numérica concordam plenamente com os resultados experimentais em termos de rigidez inicial, força de fissuração da diagonal e comportamento pós-fissuração. A força correspondente à fissuração da diagonal, tanto nos ensaios quanto na modelagem, é de $172 \mathrm{kN}$. A partir daí, no ensaio 5A houve o descarregamento do pórtico. No ensaio 6A, continuou-se a aplicação da força até o valor de $210 \mathrm{kN}$, podendo notar que a rigidez desse trecho continua a coincidir com o resultado da análise numérica. A partir de $210 \mathrm{kN}$ não é mais possível uma comparação entre os modelos experimentais e numéricos, uma vez que houve o descarregamento dos pórticos nos ensaios experimentais. No 
entanto, deu-se continuidade à análise numérica, e pode-se perceber, pelo diagrama apresentado, que a força de esmagamento dos cantos comprimidos corresponde ao valor de $316 \mathrm{kN}$.

\section{Diagrama Força x Deslocamento}

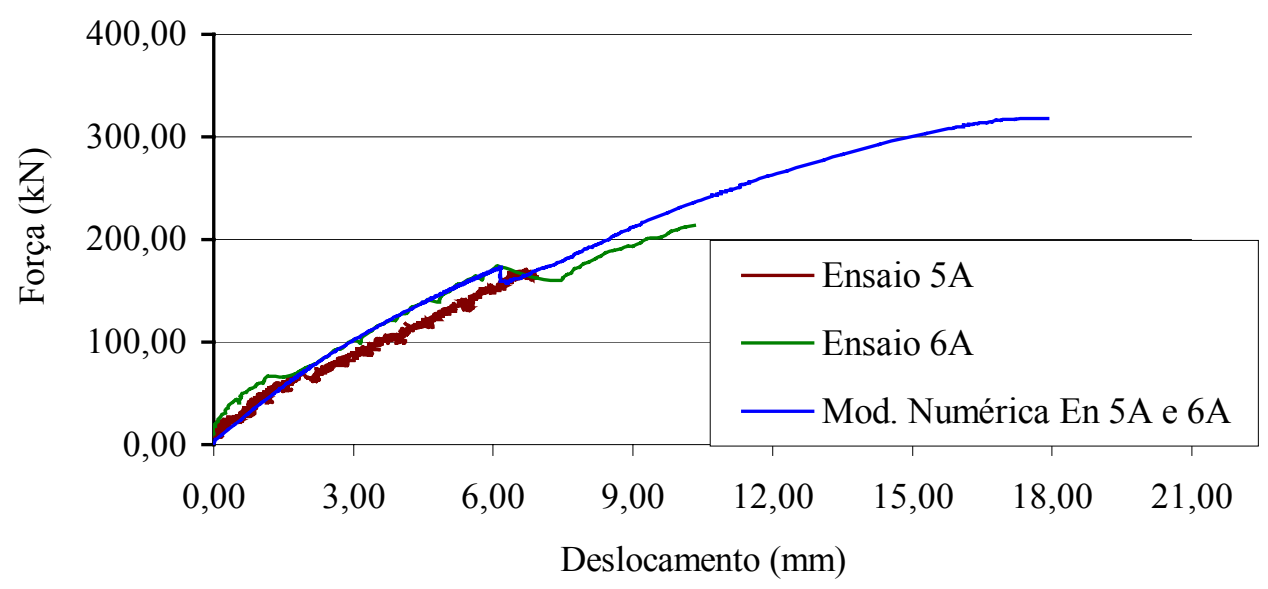

FIGURA 5.19 - Diagramas força-deslocamento para os ensaios 5A e 6A, obtidos através dos ensaios experimentais e da modelagem numérica

\section{DESCOLAMENTO DA INTERFACE PÓRTICO-PAINEL}

A partir dos resultados dos ensaios experimentais e da modelagem numérica, fez-se uma avaliação dos descolamentos dos cantos tracionados. Para uma ação de $170 \mathrm{kN}$ aplicada na extremidade superior direita do protótipo, os comprimentos dos descolamentos verticais, que foram os mais acentuados, são apresentados na figura 5.20, para os resultados experimentais (ensaio 5A) e numéricos. Para obtenção dos comprimentos dos descolamentos oriundos dos ensaios experimentais, foi assumida uma variação linear destes. 


\section{Descolamento Vertical dos Cantos Tracionados}

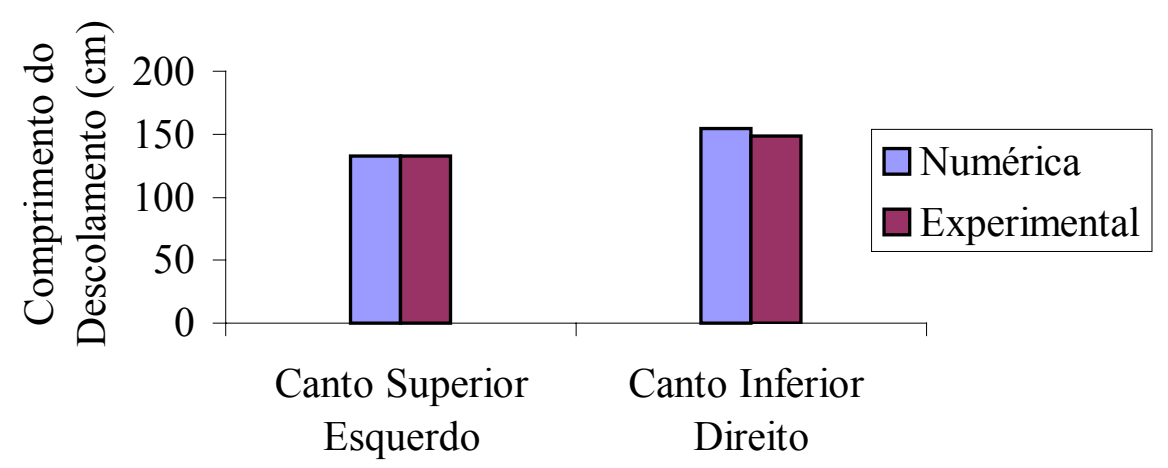

FIGURA 5.20 - Comprimento dos descolamentos verticais dos cantos tracionados

Os descolamentos verticais obtidos, tanto nos ensaios experimentais quanto na modelagem, foram bastante próximos. Dessa forma, os comprimentos de contato também foram concordantes. Apresentam-se, na figura 5.21, os comprimentos de contato obtidos na análise numérica e nos ensaios experimentais. Já os descolamentos horizontais não apresentaram concordância tão perfeita de valores. Nos ensaios experimentais ocorreu o descolamento precoce da interface painel-viga superior. Esse fato pode advir da flexão da viga inferior devida ao peso-próprio da parede, que não foi considerado na análise numérica. Na viga inferior, esse confinamento provocou retardamento no descolamento.

\section{TENSÕES E DEFORMAÇÕES}

As deformações principais nos cantos comprimidos do painel, obtidas numérica e experimentalmente, estão apresentadas nas figuras 5.22 a 5.25. Nas figuras 5.22 e 5.23, apresentam-se as deformações principais máximas e mínimas, respectivamente, atuantes no canto inferior comprimido do painel, para forças correspondentes a 60 $\mathrm{kN}$ e $170 \mathrm{kN}$. Pode-se notar que os resultados se aproximam consideravelmente, indicando enorme concordância. 

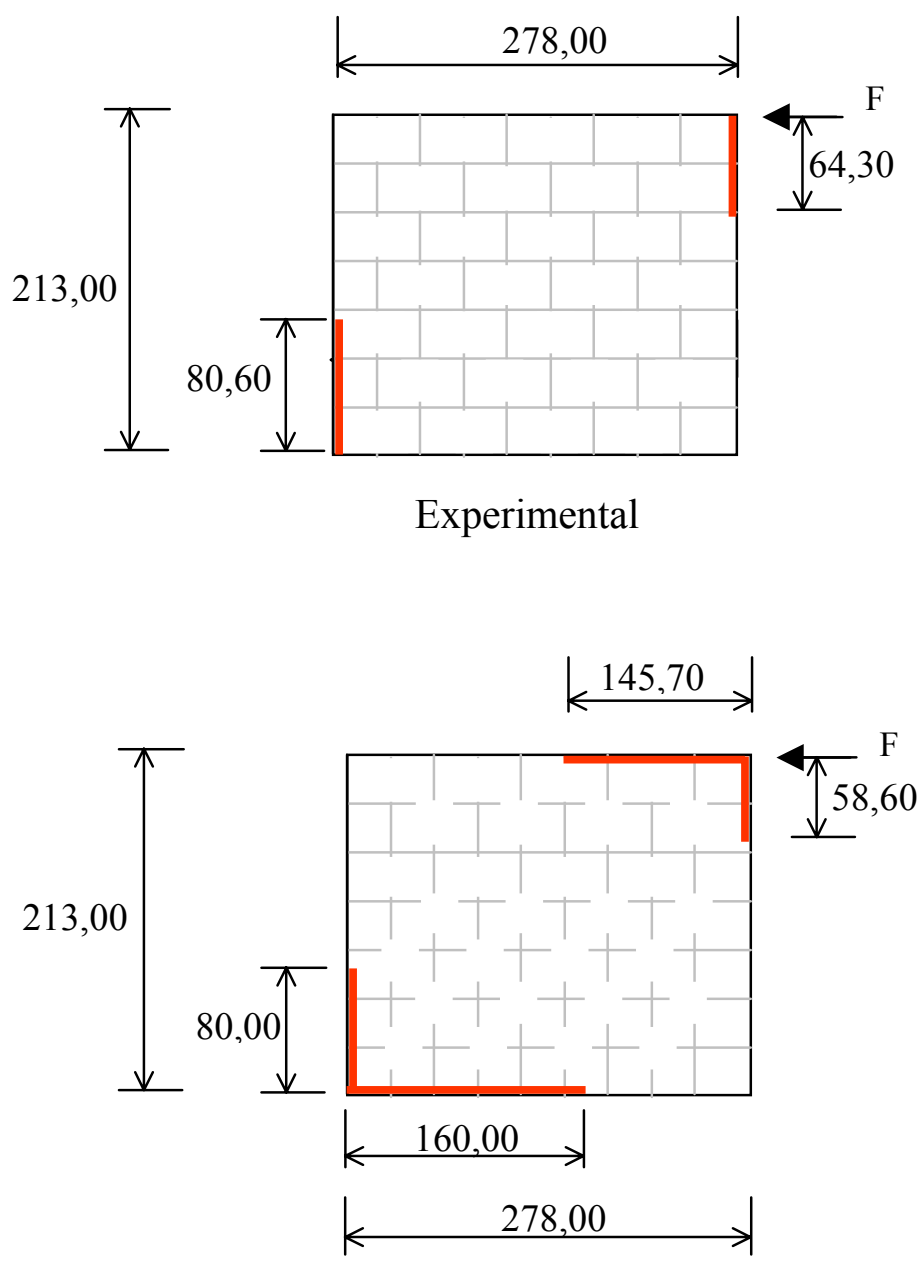

Numérico

Figura 5.21 - Comprimento de contato nas interfaces comprimidas pórtico-painel. Dimensões $(\mathrm{cm})$

Nas figuras 5.24 e 5.25 são apresentadas as deformações principais máximas e mínimas, respectivamente, atuantes no canto superior comprimido do painel. Nesse caso, embora a ordem de grandeza tenha se mantido, os resultados apresentam algumas diferenças. Isso pode ser devido à pouca distância entre a roseta de deformações superior e o ponto de aplicação de carga.

Não foi possível uma comparação em termos de tensões principais, uma vez que a modelagem numérica foi não-linear e as tensões foram obtidas dos ensaios experimentais através de análise linear. No entanto, comparando-se as deformações principais, é visível a concordância entre os resultados experimentais e numéricos. 
Deformações Principais Máximas no Canto Inferior Comprimido

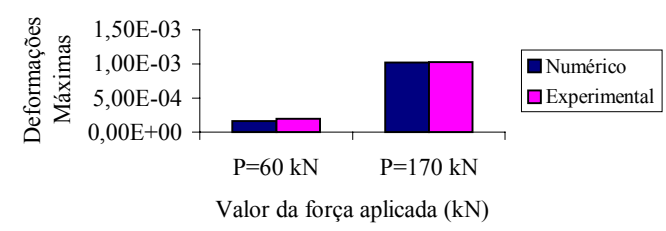

Figura 5.22 - Deformações principais máximas no canto inferior comprimido, obtidas numérica e experimentalmente (ensaio 5A)

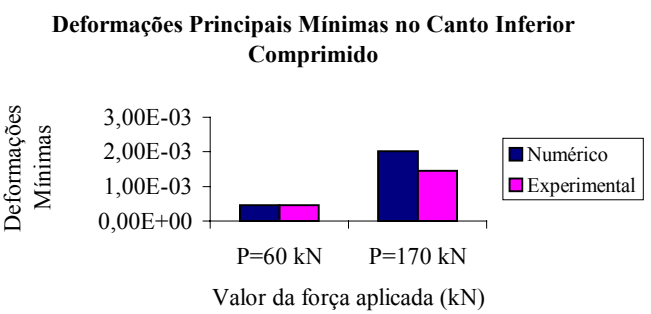

Figura 5.23 - Deformações principais mínimas no canto inferior comprimido, obtidas numérica e experimentalmente (ensaio 5A)

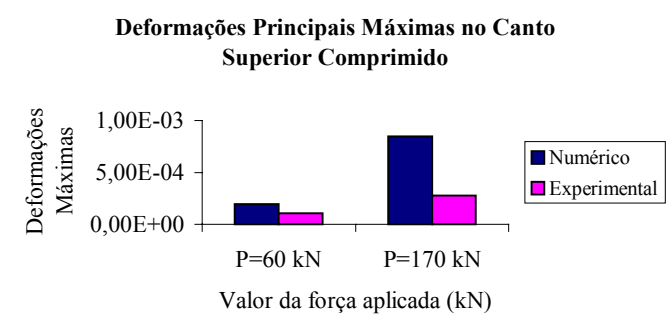

Figura 5.24 - Deformações principais máximas no canto superior comprimido, obtidas numérica e experimentalmente (ensaio 5A)

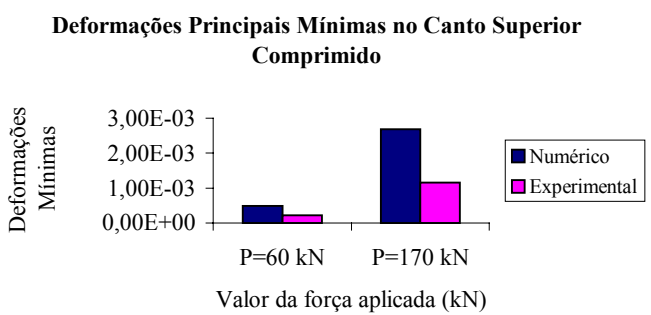

Figura 5.25 - Deformações principais mínimas no canto superior comprimido, obtidas numérica e experimentalmente (ensaio 5A) 
Comparando os resultados numéricos com os resultados experimentais, em termos de rigidez, resistência, descolamento e carga de fissuração, percebe-se que o modelo numérico consegue representar muito bem o modelo experimental. Dessa forma, é possível e justificável analisar diferentes variáveis que interferem no comportamento de pórticos preenchidos, através de análises numéricas. Com o modelo numérico idealizado nesta tese, realizou-se um estudo paramétrico, cujos resultados são apresentados no capítulo 6 .

O comportamento do painel como uma biela é claro quando se avaliam as tensões, as deformações e os descolamentos. Esse fato vem ao encontro tanto dos resultados numéricos e experimentais avaliados quanto dos métodos teóricos disponíveis na literatura, que tratam o painel como uma barra birrotulada equivalente. Dessa forma, fica patente que a proposição de um método simplificado para determinação da carga de ruptura em painéis de pórticos preenchidos passa pela consideração do painel como uma biela. 


\subsubsection{3 - PROTÓTIPO TIPO II COM PAREDES SEM ABERTURAS}

\section{ENSAIOS $1 B$ e $2 B$}

O protótipo TIPO II, com relação altura/comprimento igual a 0,51 , foi inicialmente modelado considerando-se elementos de interface na direção da diagonal comprimida e na direção vertical, de modo a simular os resultados experimentais referentes aos ensaios 1B e 2B. Na figura 5.26, apresentam-se as malhas inicialmente utilizadas para a representação do painel de alvenaria, do pórtico de aço e das interfaces: viga-pilar, pórtico-alvenaria e alvenaria-alvenaria.

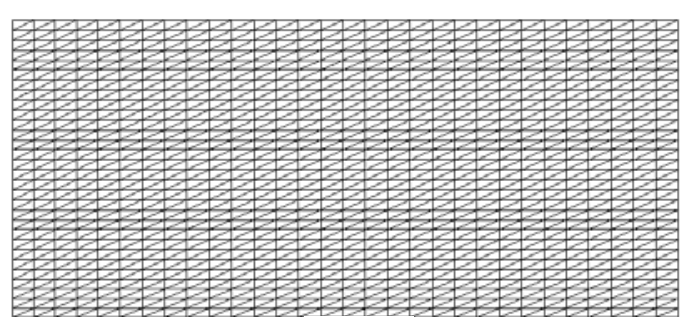

(a)

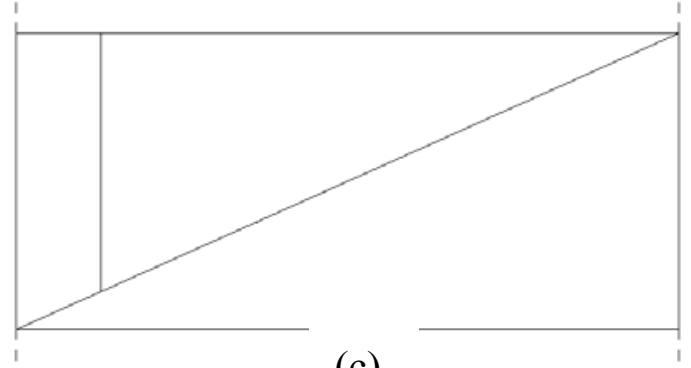

(c)

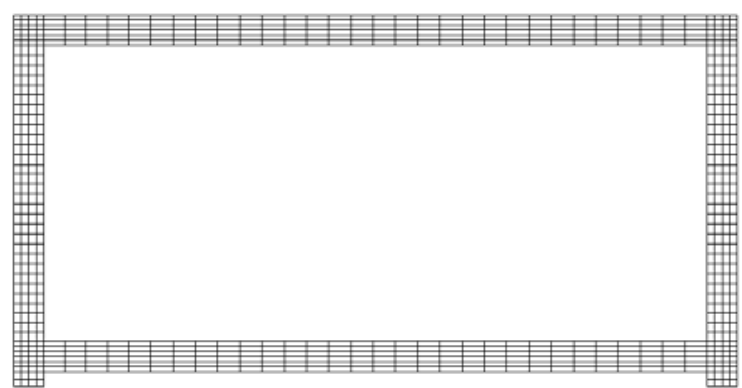

(b)

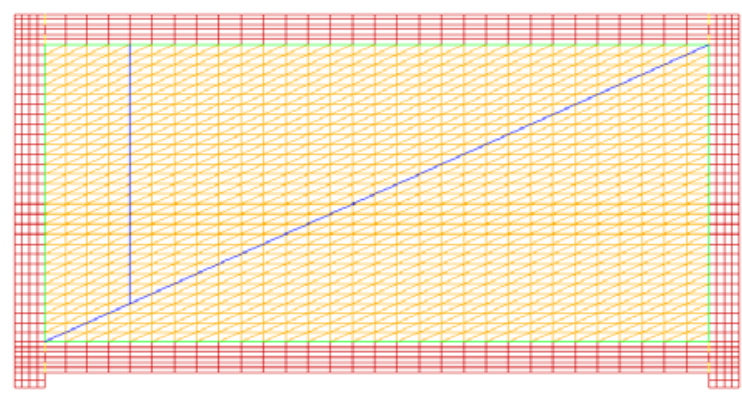

(d)

FIGURA 5.26 - Malhas inicialmente utilizadas na análise numérica do sistema TIPO II, para a representação dos ensaios 1B e 2B: a) painel de alvenaria; b) pórtico de aço; c) interfaces viga-pilar, pórtico-alvenaria e alvenaria-alvenaria; e d) malha completa 
A interface diagonal alvenaria-alvenaria tem como objetivo representar a ruptura por fissuração diagonal, que se inicia no centro do painel, região em que as tensões principais máximas de tração atingem o pico e se estende aos cantos comprimidos.

A interface vertical alvenaria-alvenaria visa à representação de fissuras surgidas nos ensaios experimentais nessas regiões, resultantes da atuação de tensões de tração. Dessa forma, adotou-se uma interface vertical localizada a uma distância de $50 \mathrm{~cm}$ da extremidade superior esquerda frontal do painel, estendendo-se até a interface diagonal alvenaria-alvenaria.

No entanto, durante a modelagem se percebeu que as fendas verticais surgiam em uma posição antissimétrica em relação à interface vertical inicialmente considerada e que as interfaces adotadas não estavam submetidas a elevadas tensões principais máximas. Os resultados da modelagem apontavam um bulbo de tensões principais máximas de tração surgido no canto inferior direito do painel, para uma ação de 170 $\mathrm{kN}$, mostrado na figura 5.27.

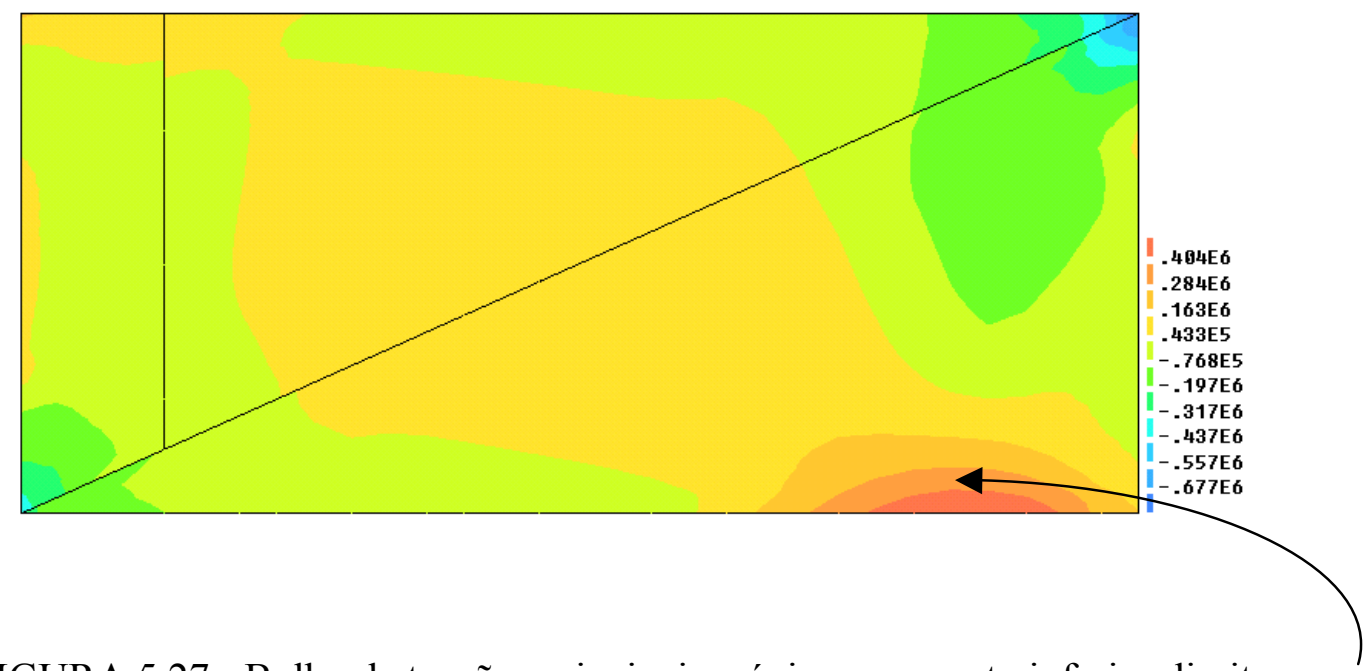

FIGURA 5.27 - Bulbo de tensões principais máximas no canto inferior direito, resultantes da modelagem numérica dos ensaios 1B e 2B. Unidades (Newton e metro) 
Dessa forma, optou-se por utilizar uma nova malha, representada na figura 5.28, para representação do sistema pórtico-painel.

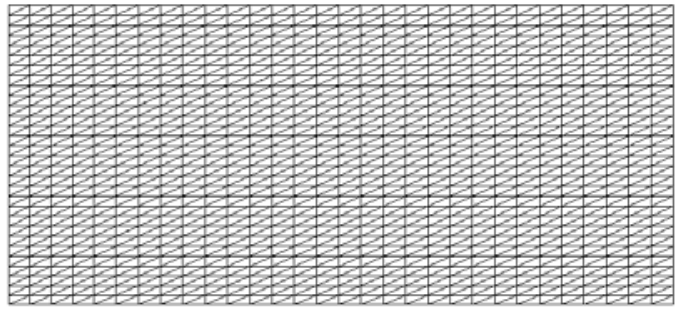

(a)

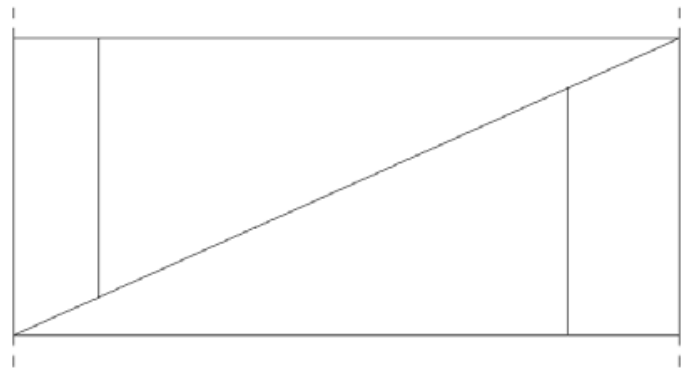

(c)

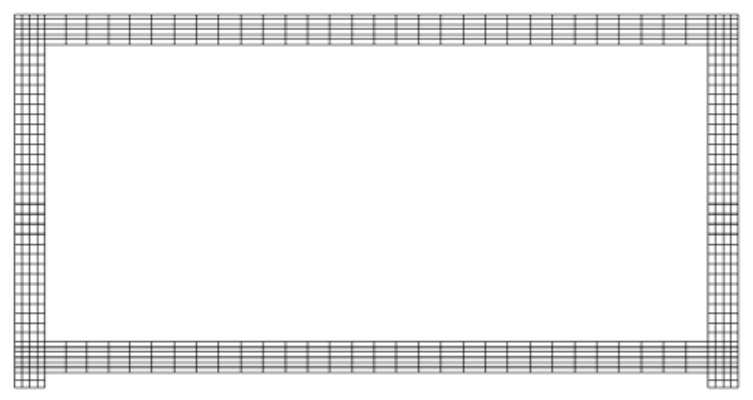

(b)

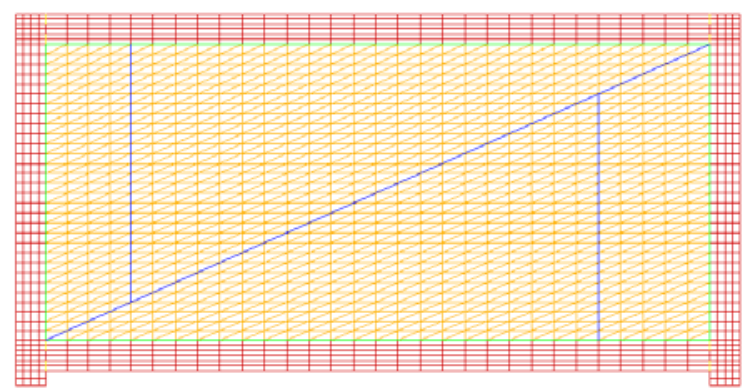

(d)

FIGURA 5.28 - Malhas utilizadas na análise numérica do protótipo TIPO II:

a) painel de alvenaria; b) pórtico de aço; c) interfaces viga-pilar, pórtico-alvenaria e alvenaria alvenaria; e d) malha completa

Com relação aos ensaios experimentais 1B e 2B, que possuem as mesmas características, os resultados obtidos não foram idênticos. No ensaio $1 \mathrm{~B}$ ocorreu ruptura por fissuração da diagonal, para uma força de aproximadamente $173 \mathrm{kN}$. Já no ensaio 2B foi aplicada uma força de até $210 \mathrm{kN}$ sem que ocorresse a ruptura por fissuração da diagonal e para que o pórtico se mantivesse em regime elástico-linear, o mesmo foi descarregado sem que houvesse caracterizado um modo de ruptura. No entanto, em se tratando de alvenaria, um material anisotrópico e não-homogêneo pode ser considerado razoável coeficiente de variação elevado. 
Para simular as condições experimentais e dar consistência ao modelo numérico, as mesmas propriedades de materiais, definidas para os ensaios da série A, foram também utilizadas, as quais são apresentadas na tabela 5.1.

Nas figuras 5.29 a 5.36, apresentam-se os resultados numéricos correspondentes a diferentes níveis de carga, nos ensaios 1B e 2B. Os resultados apresentados nas figuras 5.29 e 5.30 referem-se ao início do processo, com uma ação horizontal de 40 $\mathrm{kN}$ aplicada na extremidade direita da viga superior, correspondente a um deslocamento lateral de $1 \mathrm{~mm}$.

Para esse nível de carga já ocorre o descolamento das interfaces pórtico-alvenaria, uma vez que estas foram modeladas sem resistência à tração, conforme mostrado na figura 5.29. O painel funciona monoliticamente, e não se percebe qualquer fissura, além do descolamento. No entanto, na figura 5.30a, referente às tensões principais máximas, nota-se a formação de um bulbo de tensões de tração, na extremidade inferior direita frontal do painel. Na figura 5.30b, observa-se a formação da biela, com crescimento acentuado das tensões principais mínimas na direção dos dois cantos comprimidos.

No que se refere às deformações, mesmo nos cantos comprimidos, onde se tem um estado biaxial de tensões de compressão, as deformações principais máximas referem-se a alongamento, figura $5.30 \mathrm{c}$, e as deformações principais mínimas acompanham a distribuição das tensões principais mínimas, figura 5.30d.

Nas figuras 5.31 e 5.32, apresentam-se os resultados referentes a uma ação de 100 $\mathrm{kN}$, para um deslocamento correspondente de 3,6 mm. Inicia-se uma fissura vertical no canto inferior direito, que tende a crescer ao longo da altura, conforme mostrado na figura 5.31. Na região inferior direita, crescem as tensões principais máximas, com valores de até $0,176 \mathrm{MPa}$. Esse valor é superior à tensão principal máxima no centro do painel, que é de 0,077 MPa, figura 5.32a. Esse fato está indicando uma potencial fissuração vertical nessa região, antes da ocorrência da fissuração da diagonal. Os cantos comprimidos continuam submetidos a um estado biaxial de 
compressão, atingindo tensões principais mínimas de -1,8 $\mathrm{MPa}$, e a biela apresenta esforços crescentes, figura 5.32b. As deformações principais máximas indicam alongamento em todo o painel, com efeito acentuado nos cantos comprimidos, enquanto as deformações principais mínimas informam encurtamento desse painel.

Nas figuras 5.33 e 5.34 são apresentados os resultados numéricos para uma ação de 172 kN. Para esse nível de carga não ocorre a fissuração da diagonal, e a tensão de tração máxima no centro foi de $0,2 \mathrm{E} 6 \mathrm{~N} / \mathrm{m}^{2}$. No entanto, já é visível a abertura da interface vertical na parte inferior direita, conforme apresentado na figura 5.33, através dos deslocamentos incremental e total.

As fissuras verticais tendem a se propagar de forma ascendente, como pode ser observado na figura 5.34a. O comportamento como uma biela é bem caracterizado na figura 5.34b, em que se tem nos cantos comprimidos um estado biaxial de compressão. O deslocamento obtido no modelo numérico correspondente a esse nível de carga foi de 7,2 mm. Nos ensaios experimentais, esse deslocamento foi de 9,8 mm. Nos cantos comprimidos do painel, as deformações principais máximas (alongamento) e mínimas (encurtamento) atingem valores máximos.

O esmagamento dos cantos comprimidos ocorre para uma ação de $242 \mathrm{kN}$, como pode ser percebido pelas deformadas incremental e total apresentadas na figura 5.35. Pode-se notar, nesta figura, que houve estabilidade no deslocamento incremental da abertura vertical. Na figura 5.36, apresentam-se as tensões e deformações principais correspondentes a esse nível de carga. Os cantos comprimidos do painel, submetidos a um estado biaxial de compressão, começam a sofrer esmagamento, e as tensões principais mínimas atingem o valor de $-0,24 \mathrm{E} 7 \mathrm{~N} / \mathrm{m}^{2}$. As tensões principais máximas atingem valores máximos ao longo da interface vertical, evidenciando-se o desenvolvimento ascendente da fissura.

As deformações principais máximas são de alongamento e as mínimas, de encurtamento, em todo o painel. 


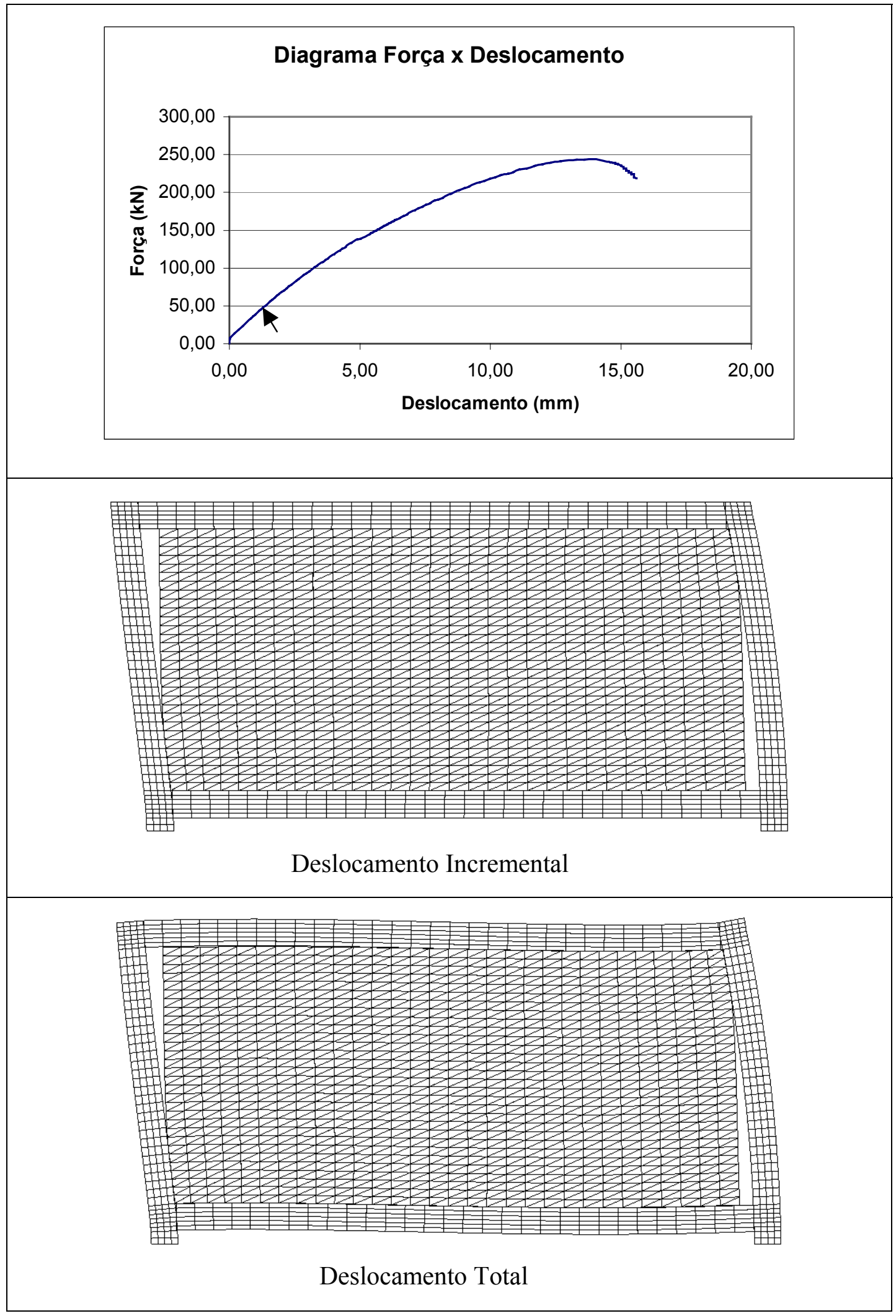

FIGURA 5.29 - Resultados da análise numérica do sistema TIPO II - Ensaios 1B e 2B, para uma ação de $40 \mathrm{kN}$ 
(a)

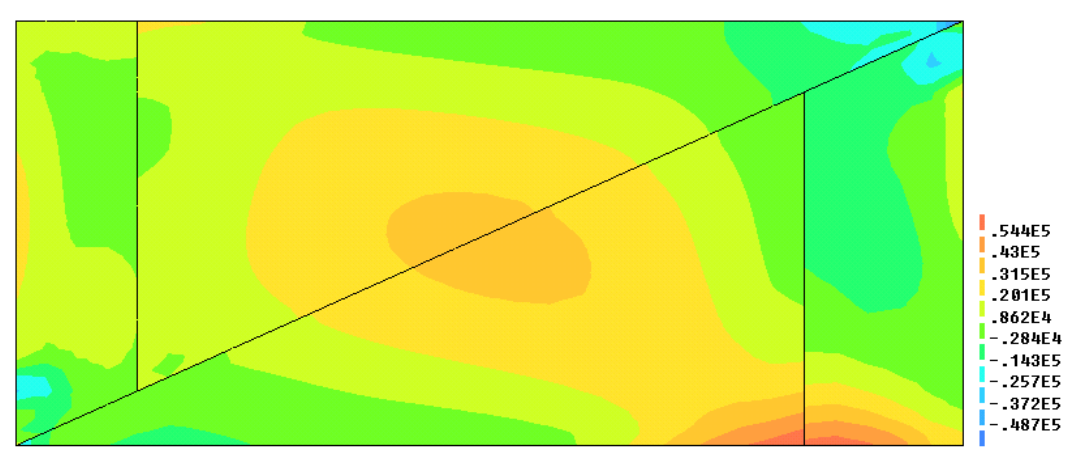

(b)

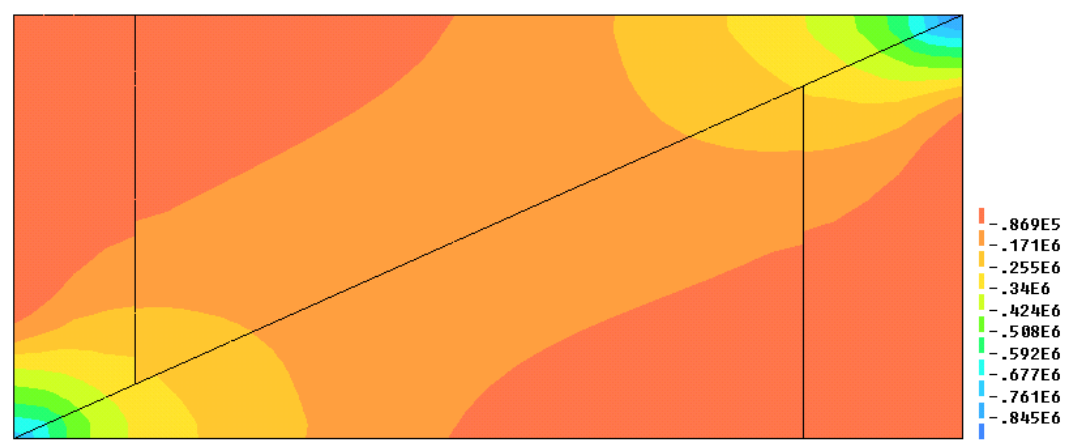

(c)

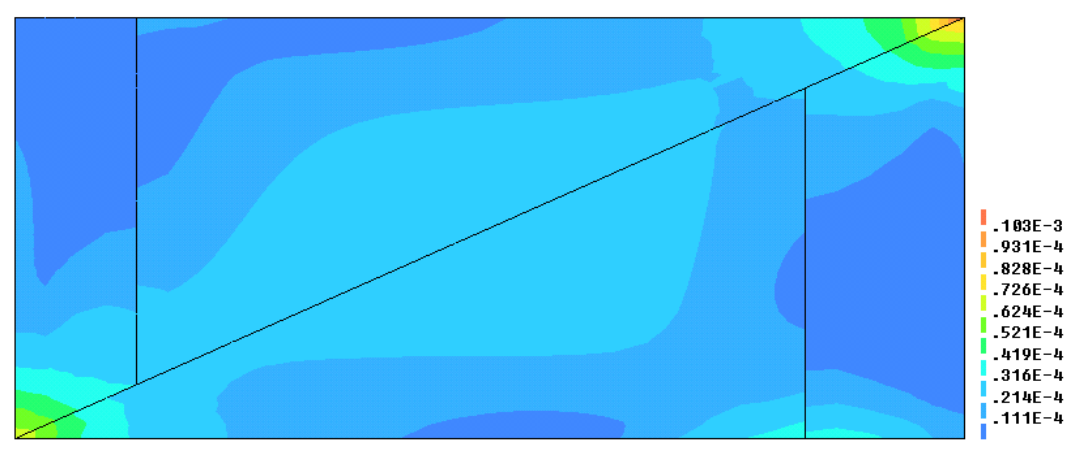

(d)

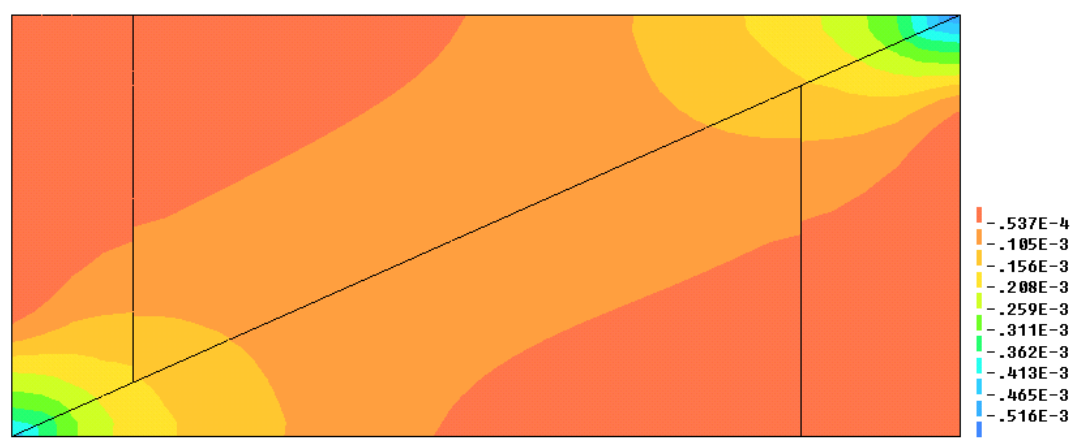

FIGURA 5.30 - Resultados da análise numérica do sistema TIPO II - Ensaios 1B e

2B, para uma ação horizontal de $40 \mathrm{kN}$ : a) tensões principais máximas, b) tensões principais mínimas, c) deformações principais máximas e d) deformações principais mínimas. Unidades (Newton e metro) 

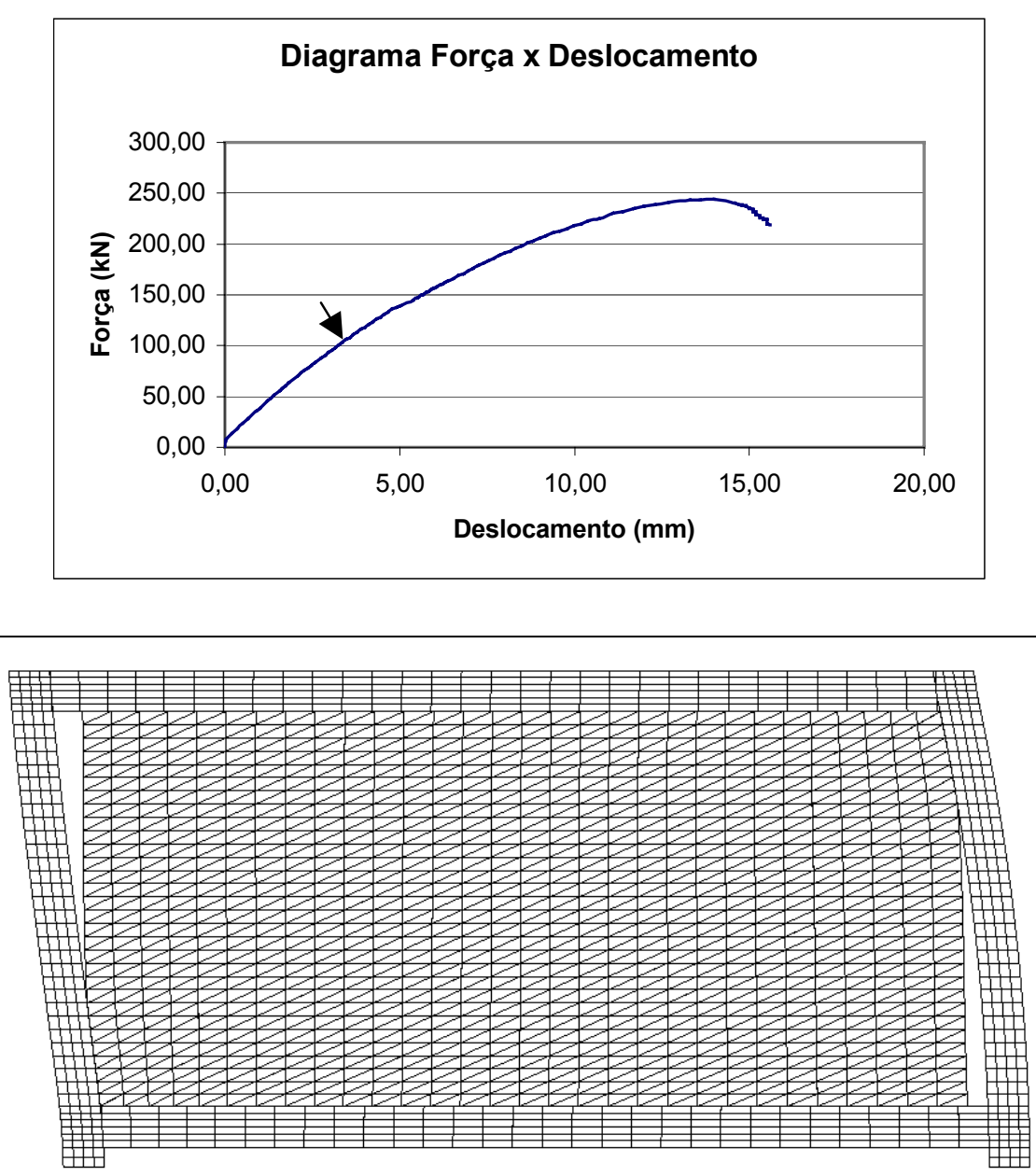

Deslocamento Incremental

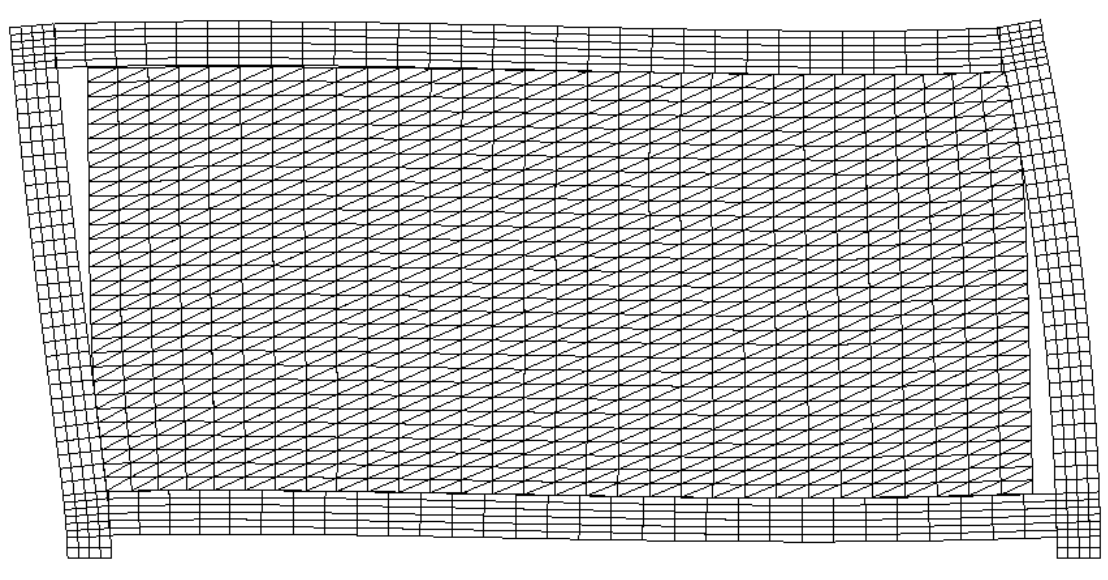

Deslocamento Total

FIGURA 5.31 - Resultados da análise numérica do sistema TIPO II - Ensaios 1B e 2B, para uma ação de $100 \mathrm{kN}$ 
(a)

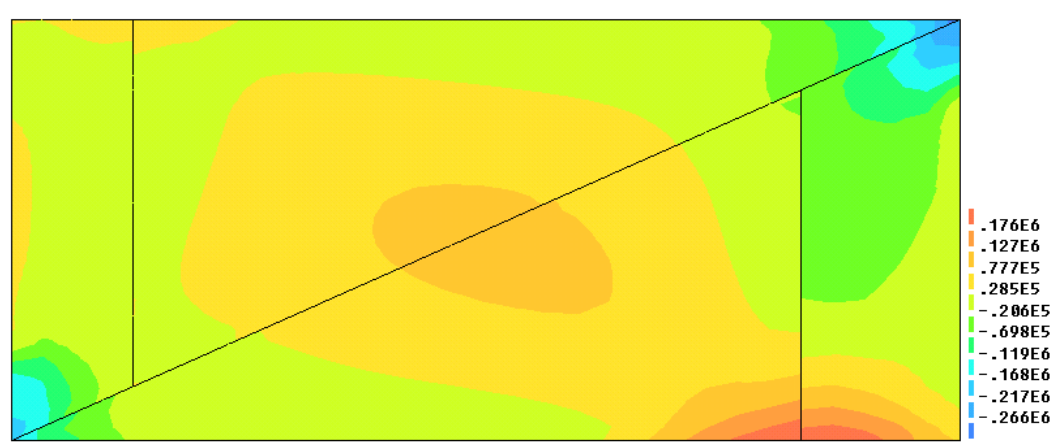

(b)

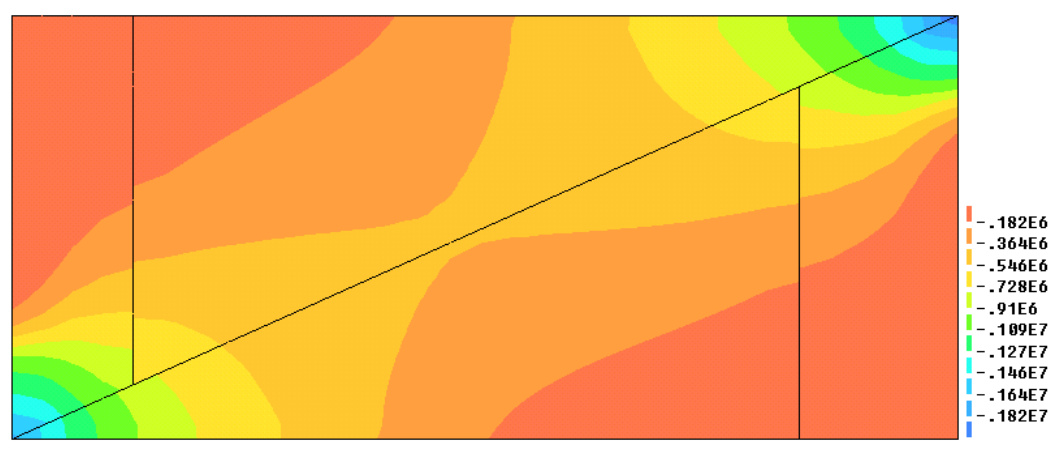

(c)

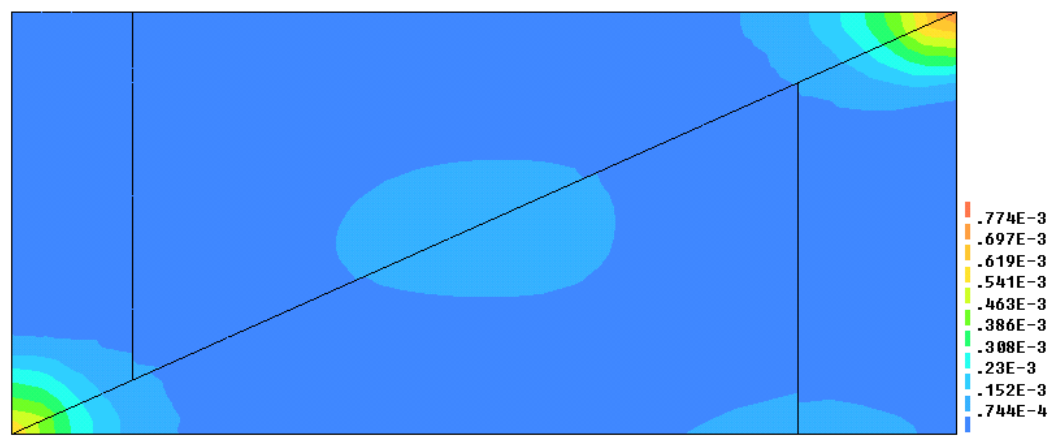

(d)

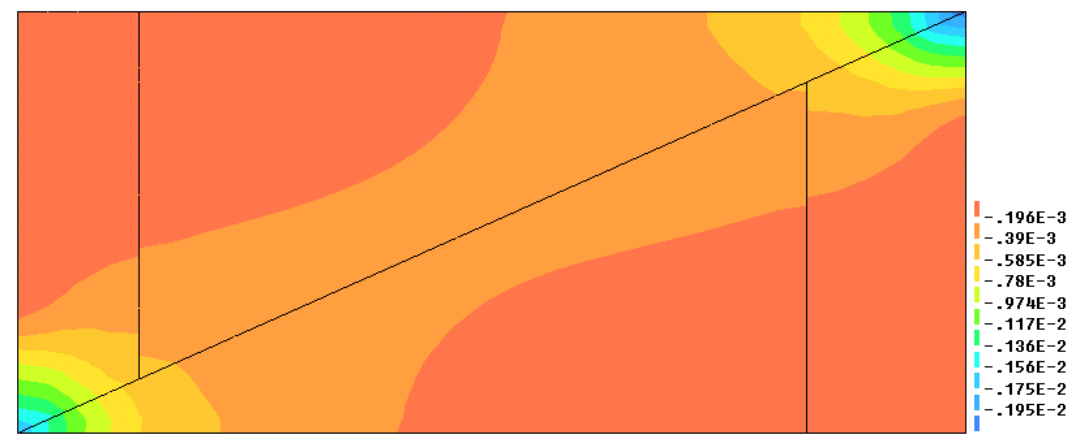

FIGURA 5.32 - Resultados da análise numérica do sistema TIPO II - Ensaios 1B e 2B, para uma ação horizontal de $100 \mathrm{kN}$ : a) tensões principais máximas, b) tensões principais mínimas, c) deformações principais máximas e d) deformações principais mínimas. Unidades (Newton e metro) 


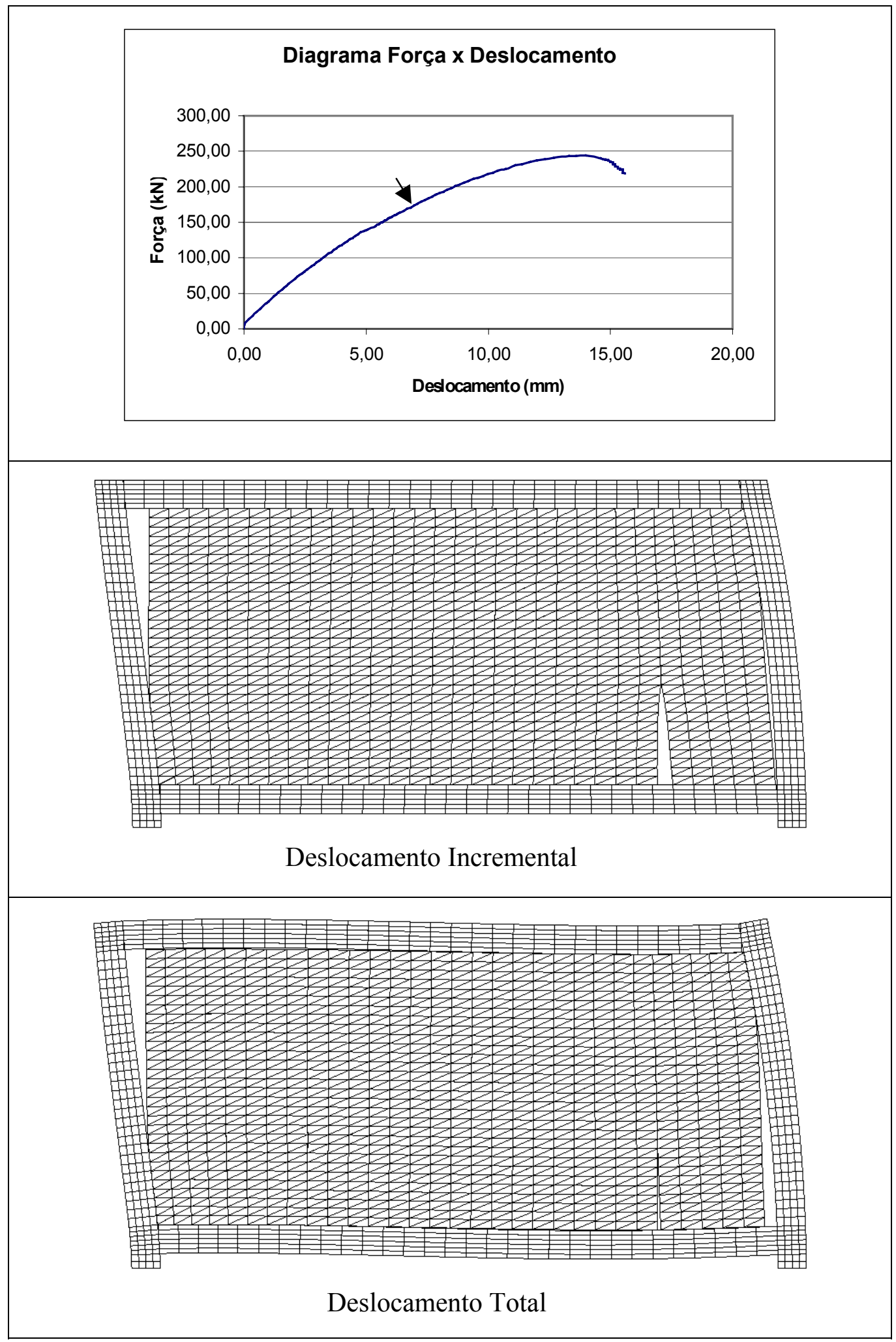

FIGURA 5.33 - Resultados da análise numérica do sistema TIPO II - Ensaios 1B e 2B, para uma ação de $172 \mathrm{kN}$ 
(a)

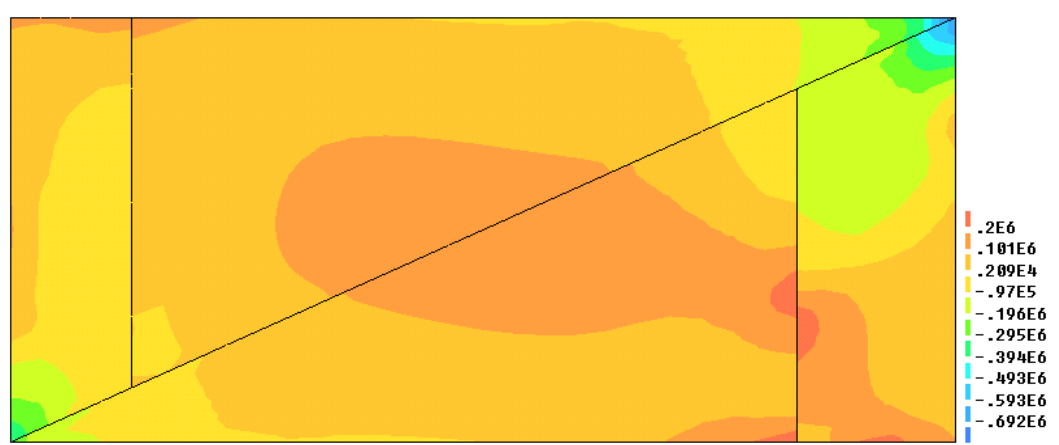

(b)

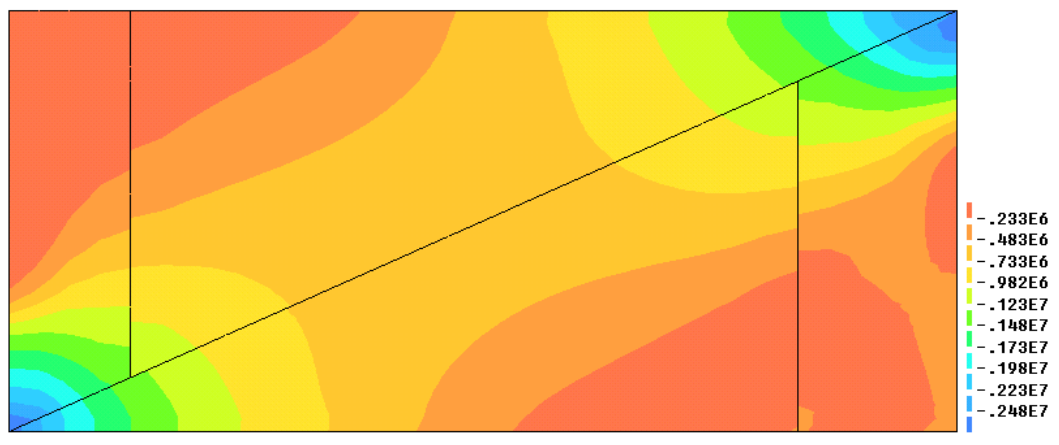

(c)

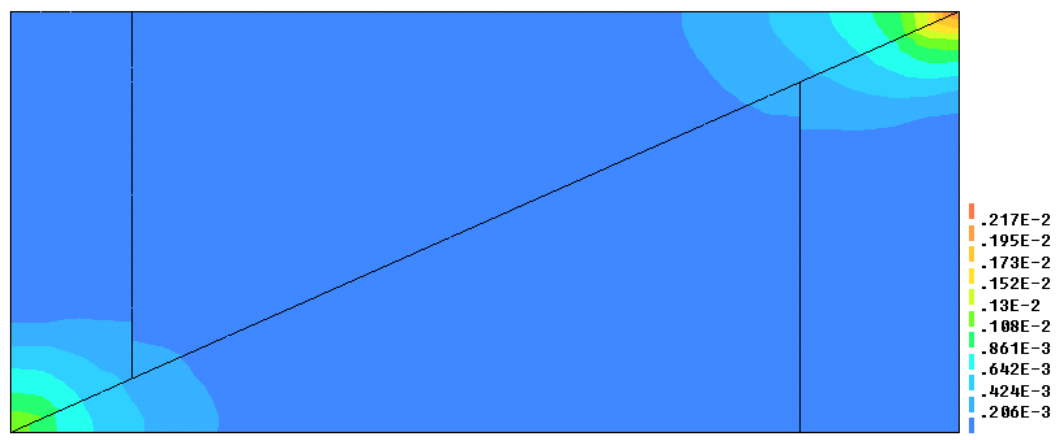

(d)

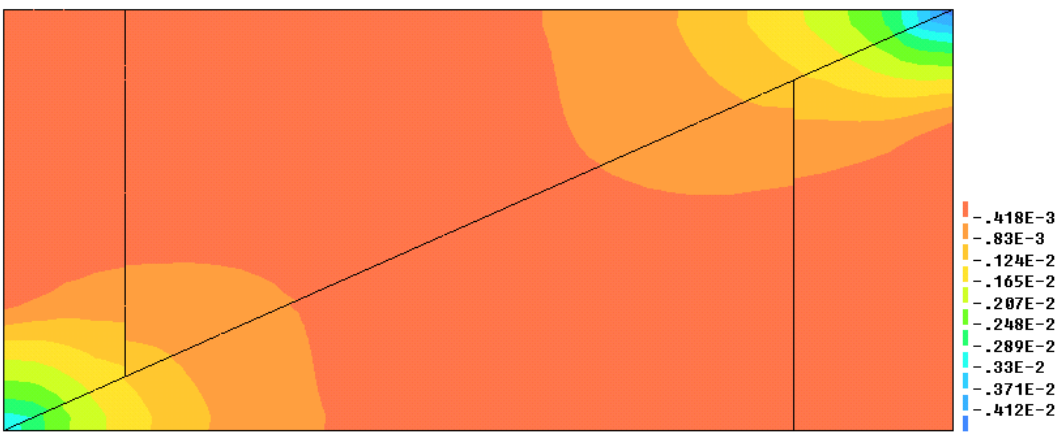

FIGURA 5.34 - Resultados da análise numérica do sistema TIPO II - Ensaios 1B e 2B, para uma ação horizontal de $172 \mathrm{kN}$ : a) tensões principais máximas, b) tensões principais mínimas, c) deformações principais máximas e d) deformações principais mínimas. Unidades (Newton e metro) 


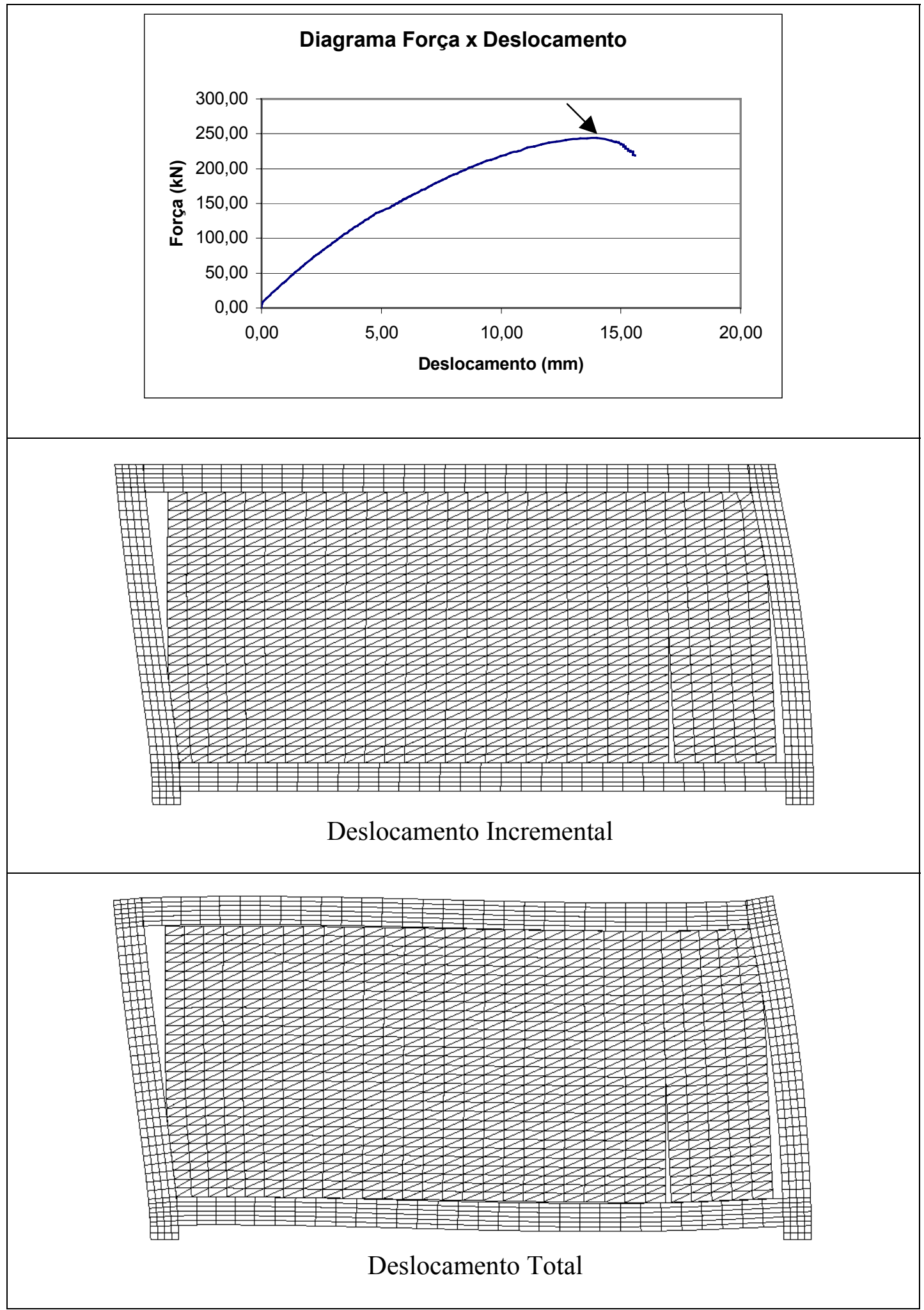

FIGURA 5.35 - Resultados da análise numérica do sistema TIPO II - Ensaios 1B e 2B, para uma ação de $242 \mathrm{kN}$ 
(a)

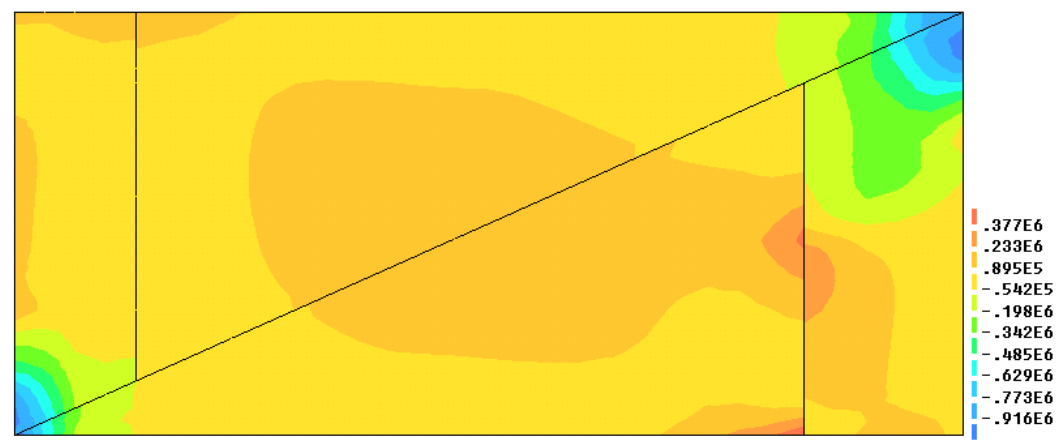

(b)

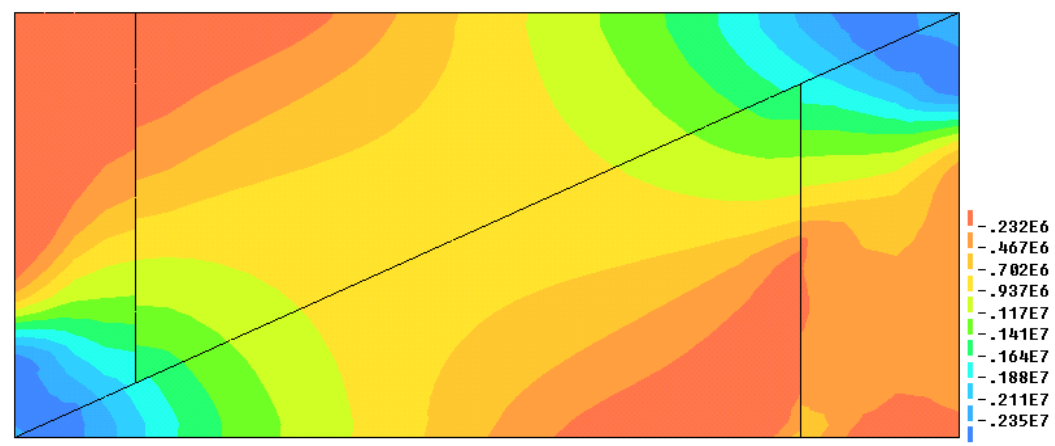

(c)

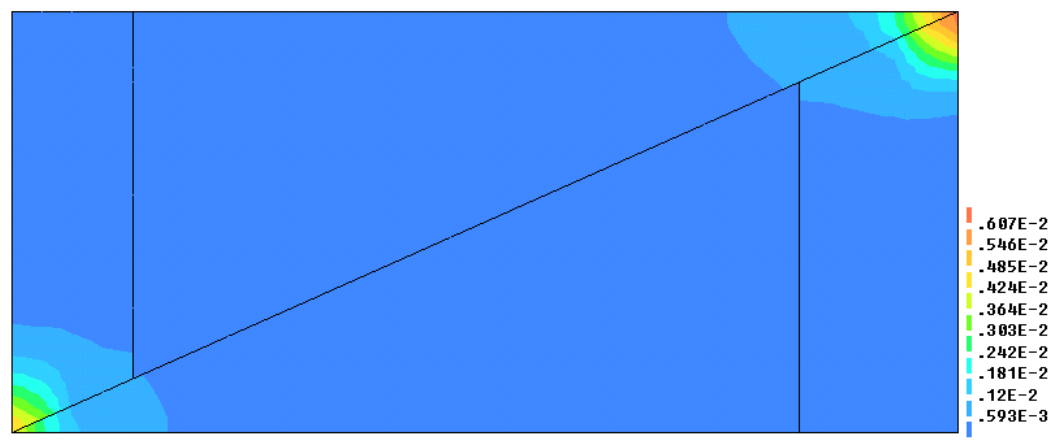

(d)

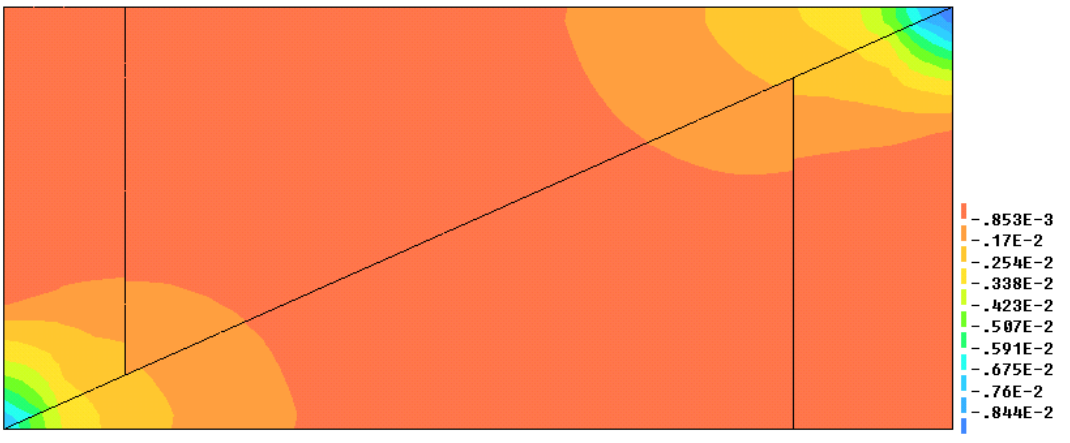

FIGURA 5.36 - Resultados da análise numérica do sistema TIPO II - Ensaios 1B e 2B, para uma ação horizontal de $242 \mathrm{kN}$ : a) tensões principais máximas, b) tensões principais mínimas, c) deformações principais máximas e d) deformações principais mínimas. Unidades (Newton e metro) 
Na modelagem realizada anteriormente ocorreram a fissura vertical e o esmagamento dos cantos comprimidos sem, contudo, acontecer a fissuração da diagonal. Nos ensaios experimentais 1B e 2B, realizados nas mesmas condições, o comportamento do sistema de pórtico preenchido avaliado apresentou variações. No primeiro, ocorreu a fissuração da diagonal para uma força de $172 \mathrm{kN}$, enquanto no segundo não ocorreu a fissuração para força de até $210 \mathrm{kN}$, quando o sistema foi descarregado, tendo em vista a necessidade de mantê-lo trabalhando em regime elástico-linear.

A fissuração repentina da diagonal, ocorrida no ensaio 1B para uma carga de $172 \mathrm{kN}$, pode ser resultante de uma má formação das juntas, durante a execução do painel. Assim, na tentativa de representar essa falha na execução, adotou-se para resistência à tração da alvenaria o fator $1 / 20$ da resistência média à compressão $\left(f_{c m}\right)$, e efetuouse uma nova modelagem numérica.

Os resultados obtidos com essa consideração são apresentados nas figuras 5.37 a 5.44. Nas figuras 5.37 e 5.38, apresentam-se os resultados para uma ação de $40 \mathrm{kN}$. $\mathrm{Na}$ figura 5.37, é possível observar que, nessa fase, já ocorre o descolamento da interface pórtico-painel. O deslocamento correspondente a esse nível de carga obtido numericamente é de 1,0 mm, enquanto no ensaio $1 \mathrm{~B}$ ele foi de 1,05 $\mathrm{mm}$. Comparando as figuras 5.30 e 5.38, percebe-se que, para esse nível de carga, a redução na resistência à tração não interfere nos resultados, sendo essas duas figuras praticamente idênticas, para as quais vale o mesmo comportamento descrito anteriormente.

São apresentados nas figuras 5.39 e 5.40 os resultados obtidos para uma força aplicada de $100 \mathrm{kN}$. Pela deformada incremental, apresentada na figura 5.39, pode-se perceber o início da abertura da fissura vertical. O deslocamento obtido no modelo numérico para esse nível de carga é de 3,8 mm, valor equivalente ao obtido no ensaio experimental. As tensões principais mínimas assumem valores bastante próximos da modelagem anterior, e as tensões principais máximas apresentam valores inferiores. 
A fissuração da diagonal iniciou-se para uma ação de aproximadamente $172 \mathrm{kN}$, como pode ser observado pela figura 5.41, em que se nota, através do deslocamento incremental, a abertura da fissura da diagonal. Esse valor concorda com os resultados experimentais obtidos no ensaio $1 \mathrm{~B}$.

As tensões e deformações principais são apresentadas na figura 5.42. Persiste um comportamento semelhante à modelagem anterior, como pode ser observado pela comparação dos diagramas apresentados nas figuras 5.34 e 5.41. As tensões principais mínimas nos cantos comprimidos aproximam-se da tensão de compressão média. O deslocamento correspondente a essa ação foi de 7,96 mm. No ensaio experimental, esse deslocamento atingiu $9,8 \mathrm{~mm}$.

Nas figuras 5.43 e 5.44, apresentam-se os resultados correspondentes à ação de 268 $\mathrm{kN}$. Nesse nível de carga ocorreu o esmagamento dos cantos comprimidos, como pode ser verificado pelas deformadas incremental e total apresentadas na figura 5.34. O deslocamento obtido no modelo numérico, nesse nível de carga, foi de $17 \mathrm{~mm}$. As tensões principais mínimas apresentaram valores crescentes ao longo de toda a diagonal, atingindo valores máximos nos cantos comprimidos. As tensões principais máximas atingiram valores de compressão até mesmo na direção da diagonal comprimida. Nessa carga não foi mais possível uma comparação com os resultados experimentais, tendo em vista que os ensaios não foram conduzidos até esse nível de carga, conforme comentado anteriormente. 


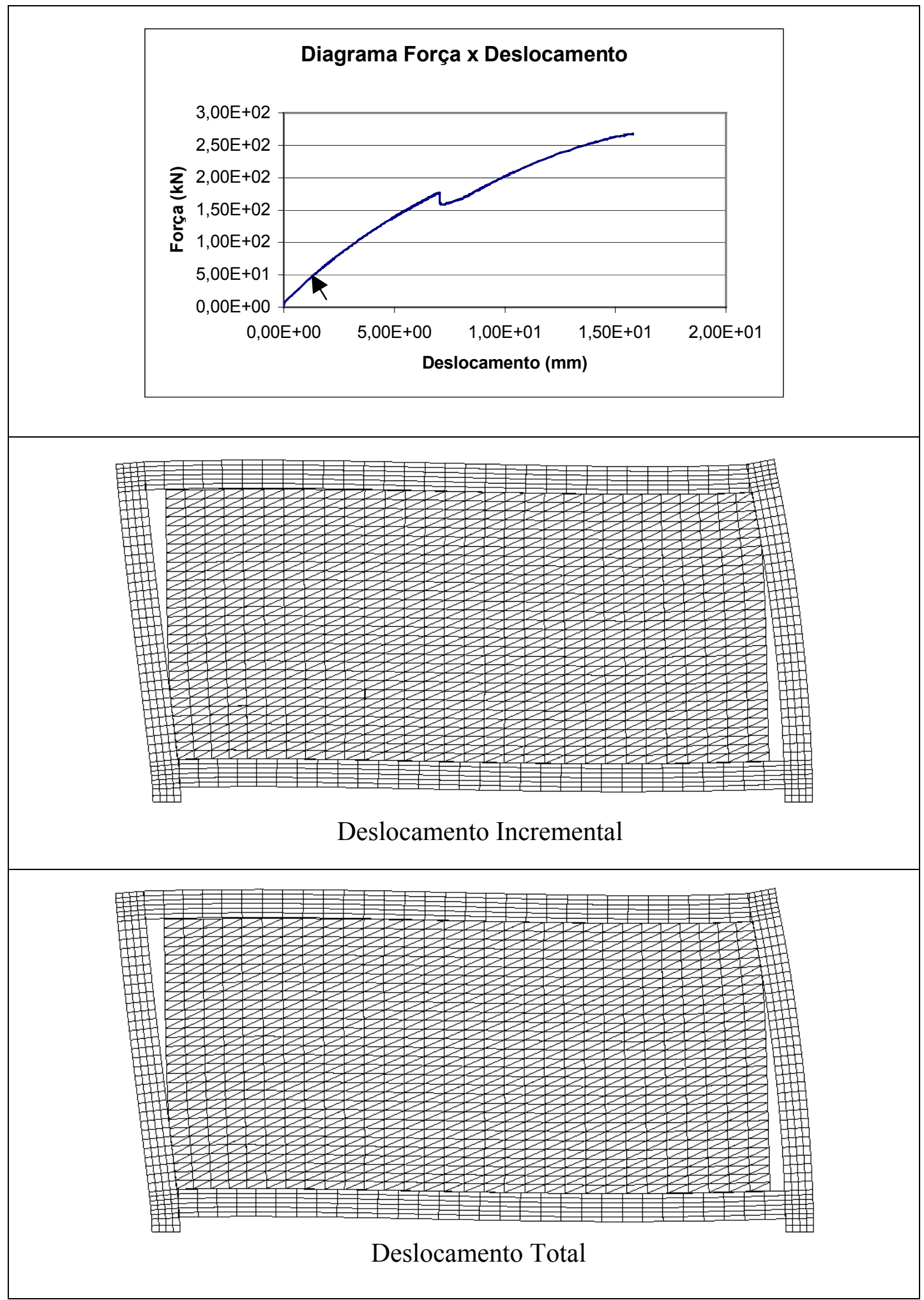

FIGURA 5.37 - Resultados da análise numérica do sistema TIPO II - Ensaios 1B e 2B, para uma ação de $40 \mathrm{kN}$ 
(a)

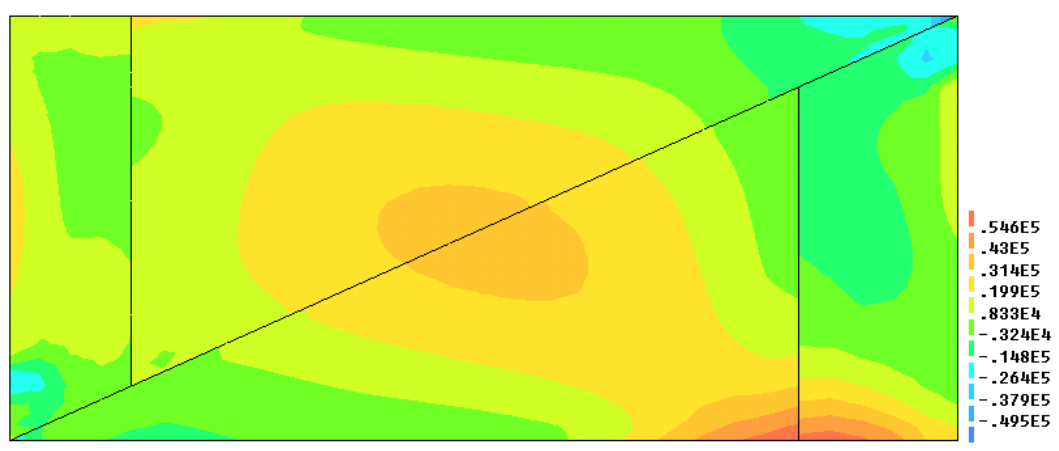

(b)

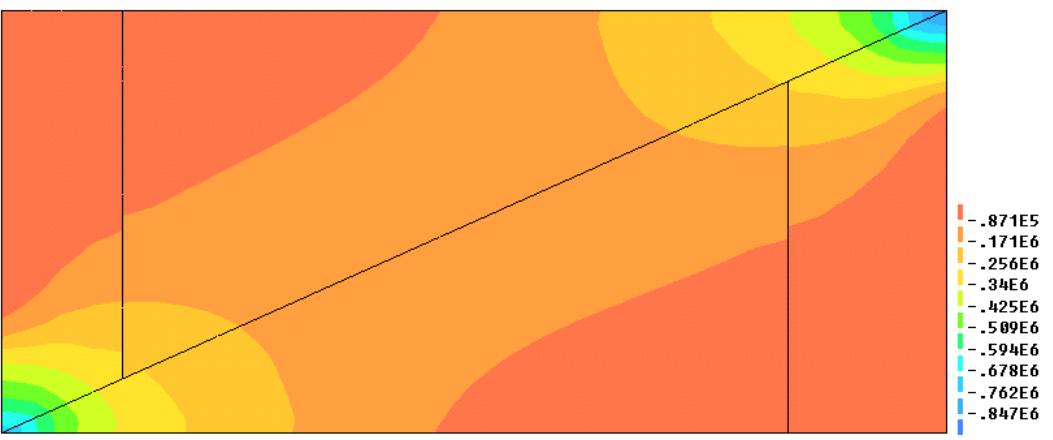

(c)

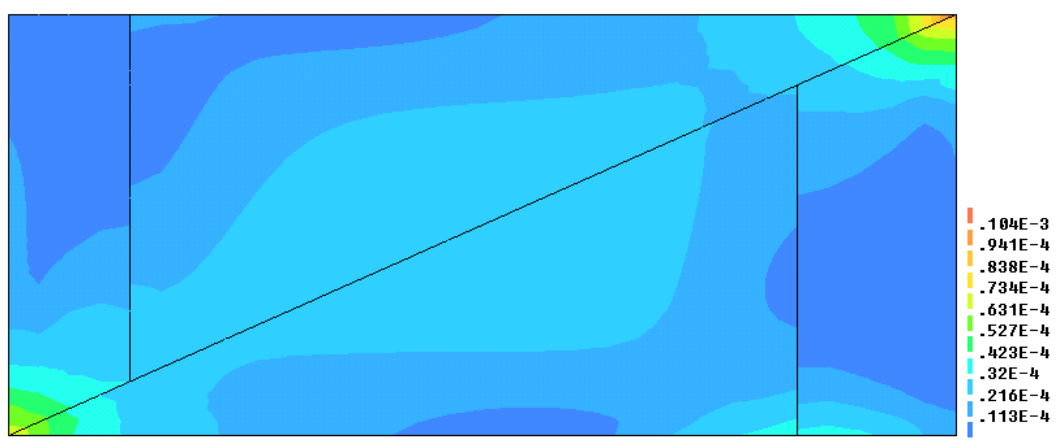

(d)

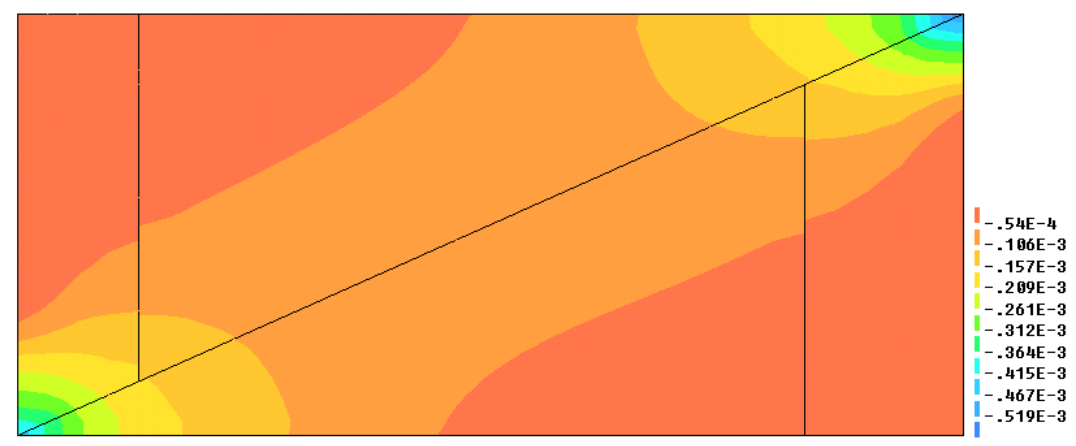

FIGURA 5.38 - Resultados da análise numérica do sistema TIPO II - Ensaios 1B e 2B, para uma ação horizontal de $40 \mathrm{kN}$ : a) tensões principais máximas, b) tensões principais mínimas, c) deformações principais máximas e d) deformações principais mínimas. Unidades (Newton e metro) 

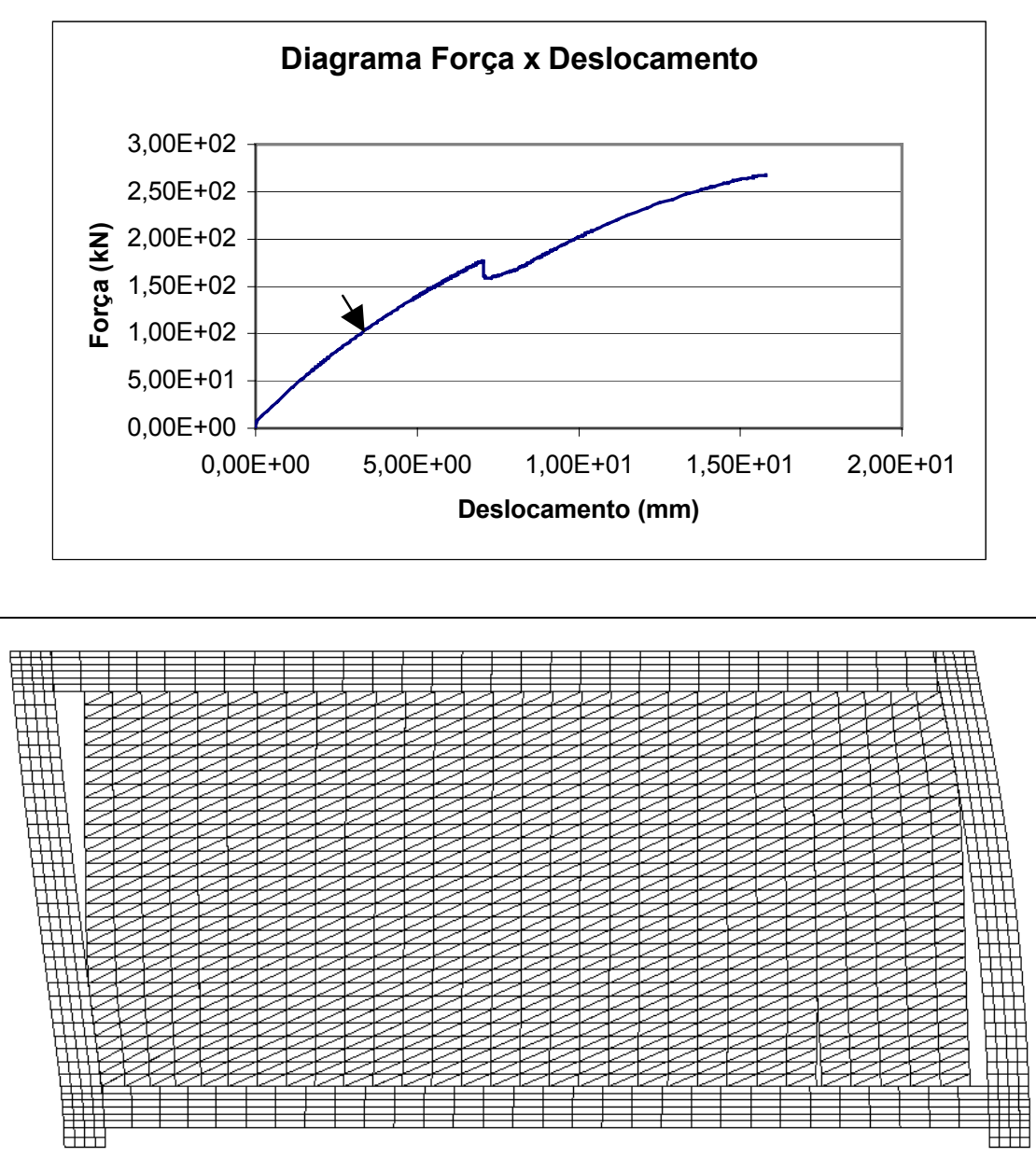

Deslocamento Incremental

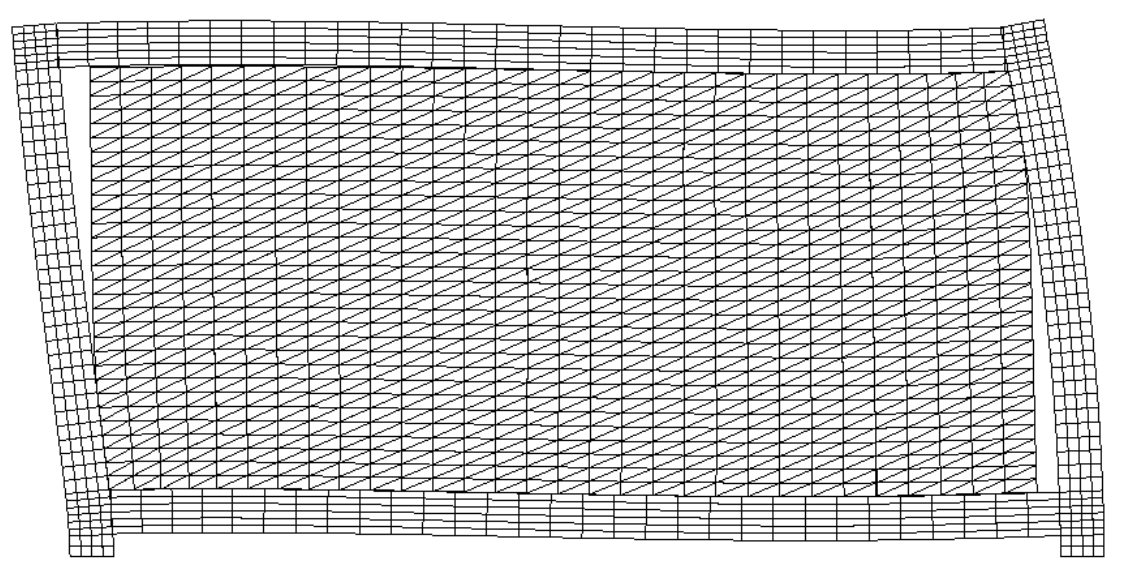

Deslocamento Total

FIGURA 5.39 - Resultados da análise numérica do sistema TIPO II - Ensaios 1B e 2B, para uma ação de $100 \mathrm{kN}$ 
(a)

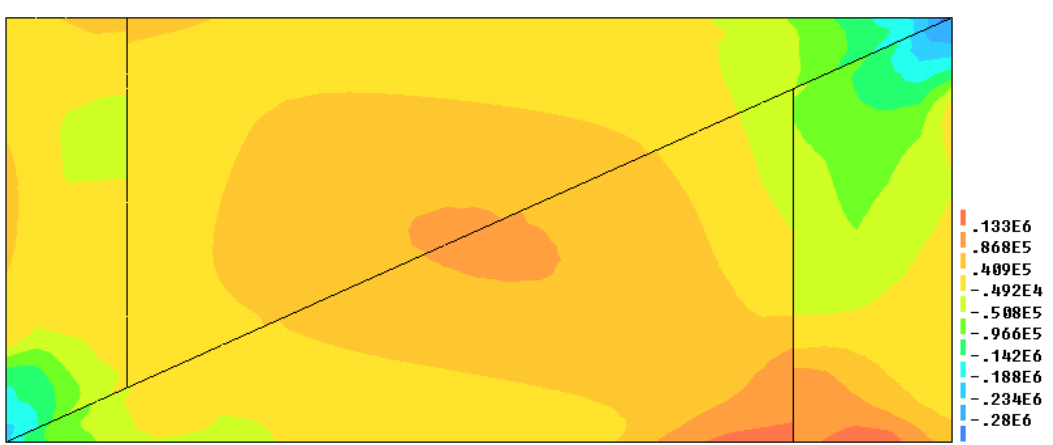

(b)

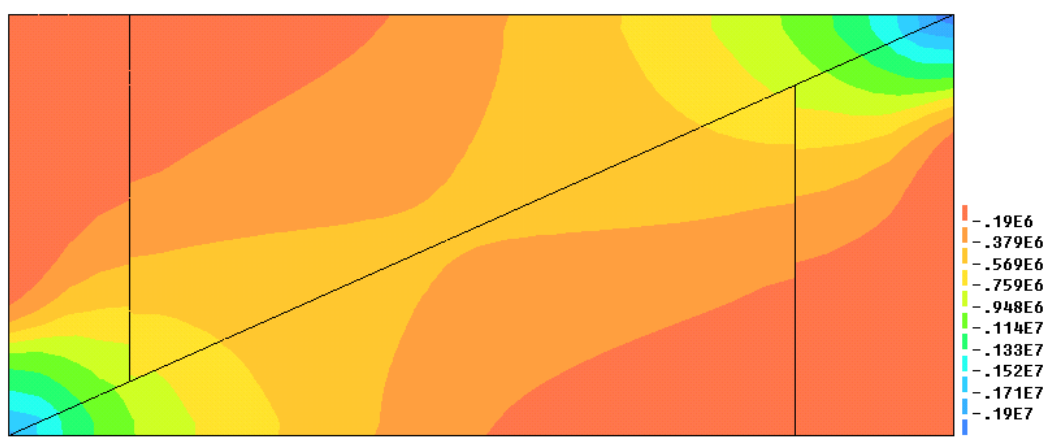

(c)

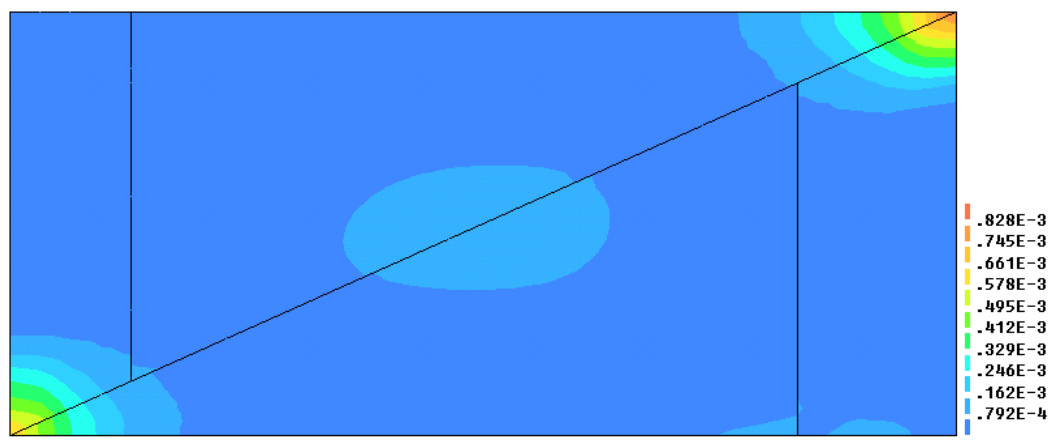

(d)

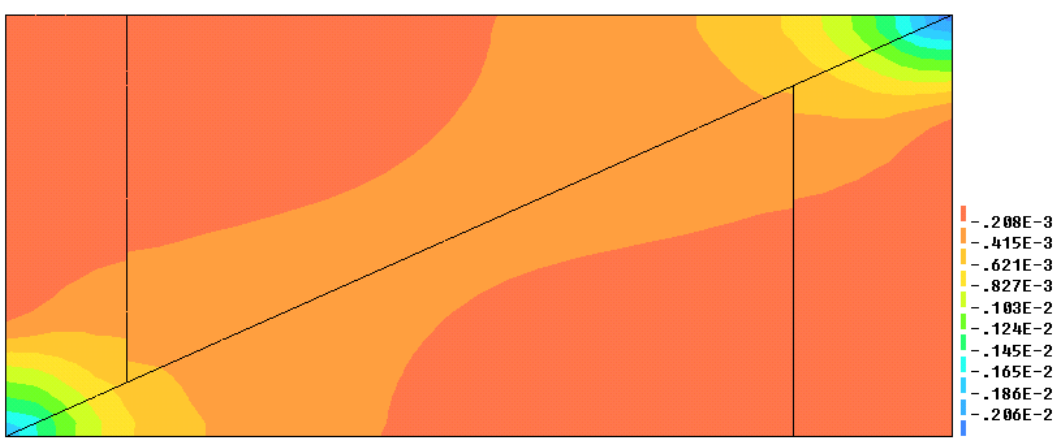

FIGURA 5.40 - Resultados da análise numérica do sistema TIPO II - Ensaios 1B e 2B, para uma ação horizontal de $100 \mathrm{kN}$ : a) tensões principais máximas, b) tensões principais mínimas, c) deformações principais máximas e d) deformações principais mínimas. Unidades (Newton e metro) 


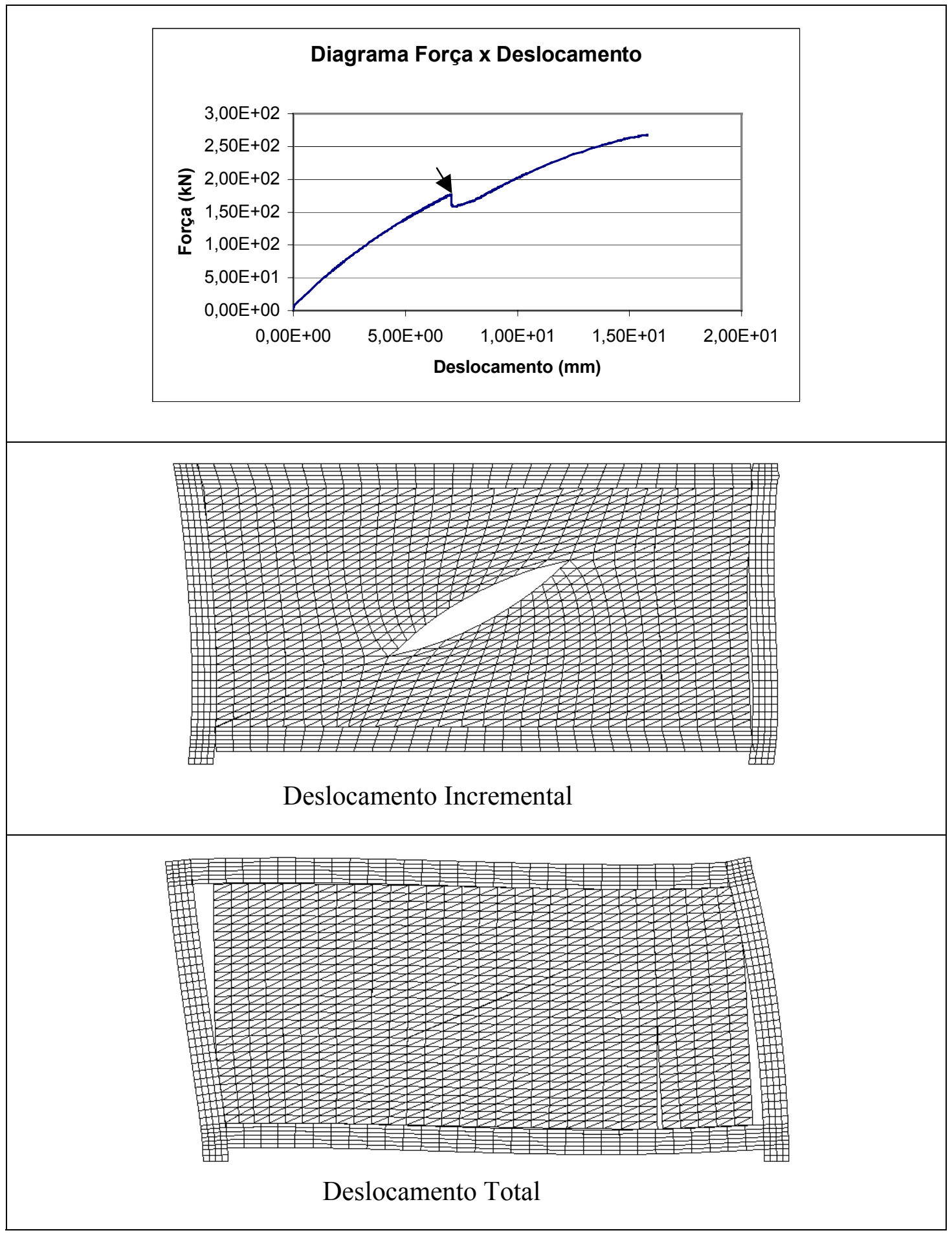

FIGURA 5.41 - Resultados da análise numérica do sistema TIPO II - Ensaios 1B e 2B, para uma ação de $172 \mathrm{kN}$ 


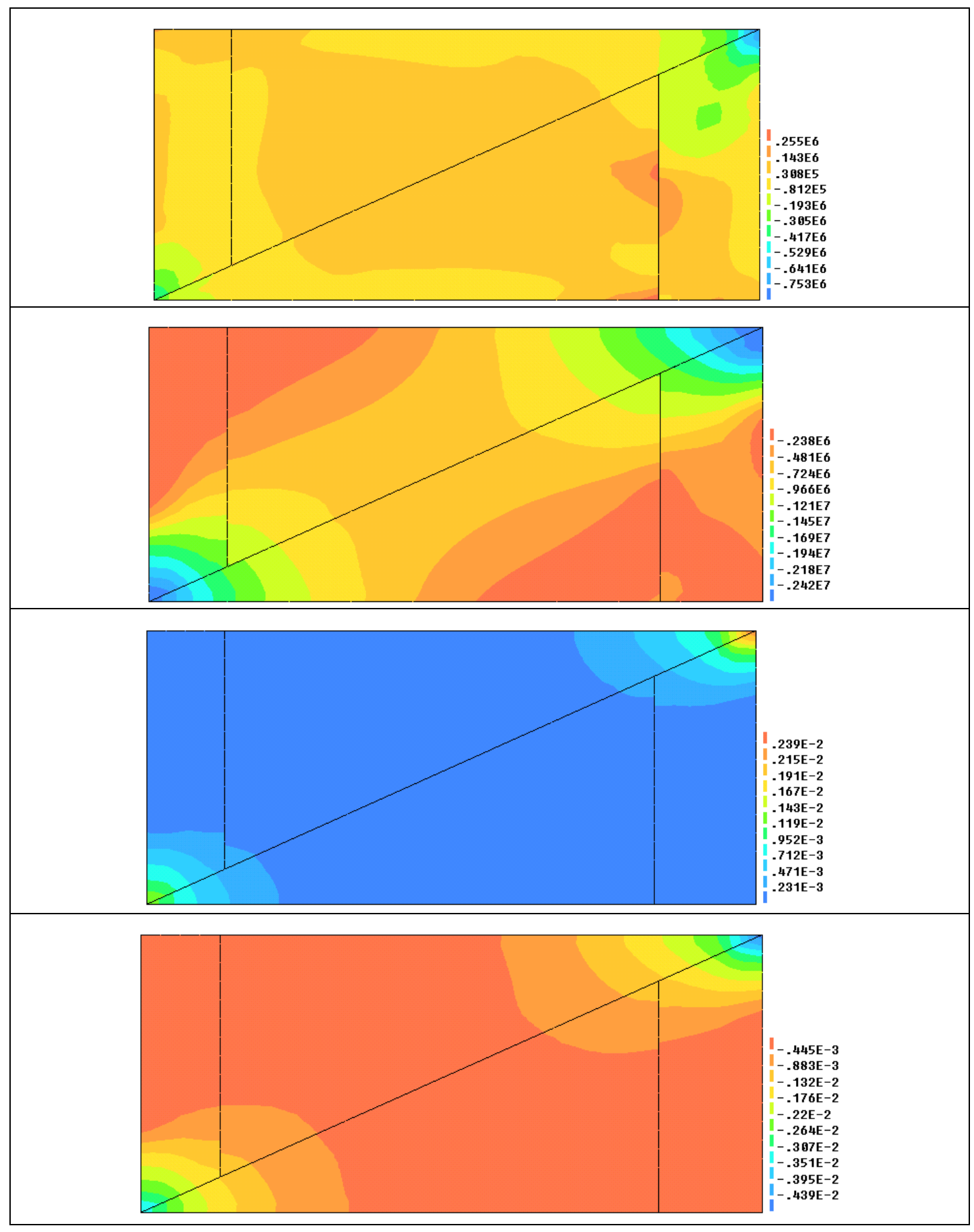

FIGURA 5.42 - Resultados da análise numérica do sistema TIPO II - Ensaios 1B e 2B, para uma ação horizontal de $172 \mathrm{kN}$ : a) tensões principais máximas, b) tensões principais mínimas, c) deformações principais máximas e d) deformações principais mínimas. Unidades (Newton e metro) 


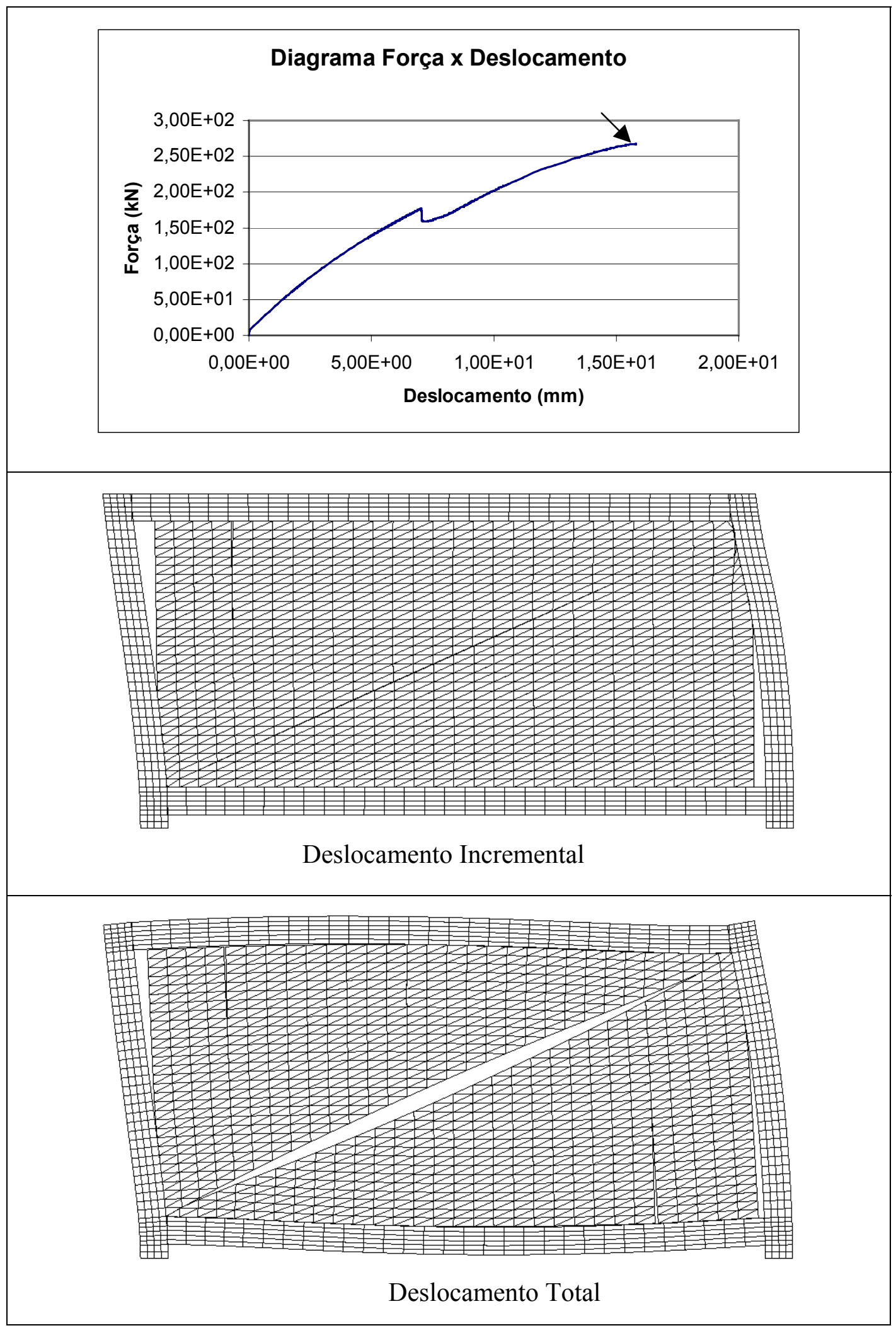

FIGURA 5.43 - Resultados da análise numérica do sistema TIPO II - Ensaios 1B e 2B, para uma ação de $268 \mathrm{kN}$ 


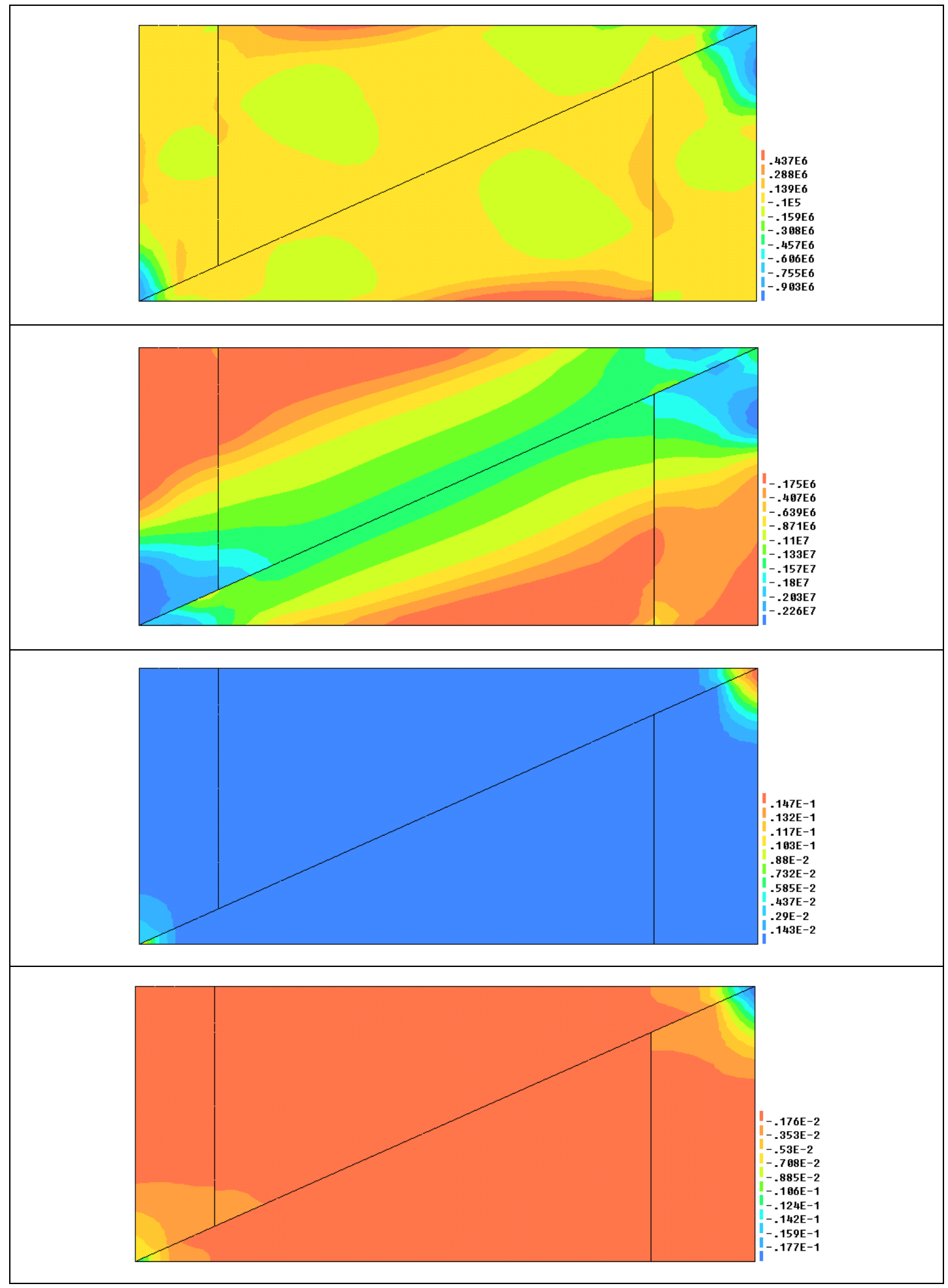

FIGURA 5.44 - Resultados da análise numérica do sistema TIPO II - Ensaios 1B e 2B, para uma ação horizontal de $268 \mathrm{kN}$ : a) tensões principais máximas, b) tensões principais mínimas, c) deformações principais máximas e d) deformações principais mínimas. Unidades (Newton e metro) 


\subsubsection{4 - ANÁLISE COMPARATIVA ENTRE RESULTADOS NUMÉRICOS E EXPERIMENTAIS: SÉRIE B COM PAREDES SEM ABERTURAS}

Na figura 5.45 são apresentadas as curvas força $\mathrm{x}$ deslocamento obtidas através dos ensaios experimentais $1 \mathrm{~B}$ e $2 \mathrm{~B}$ e pelas modelagens numéricas efetuadas. Nesses ensaios experimentais, realizados com o protótipo TIPO II $(\mathrm{H} / \mathrm{L}=0,51)$, as interfaces pórtico-painel, bem como as juntas verticais e horizontais, foram constituídas de argamassa Ciment-cola.

$\mathrm{Na}$ análise numérica, continuou-se utilizando o critério de Von Mises para o painel de alvenaria e um modelo de multissuperfícies para a interface diagonal alvenariaalvenaria, comentado anteriormente.

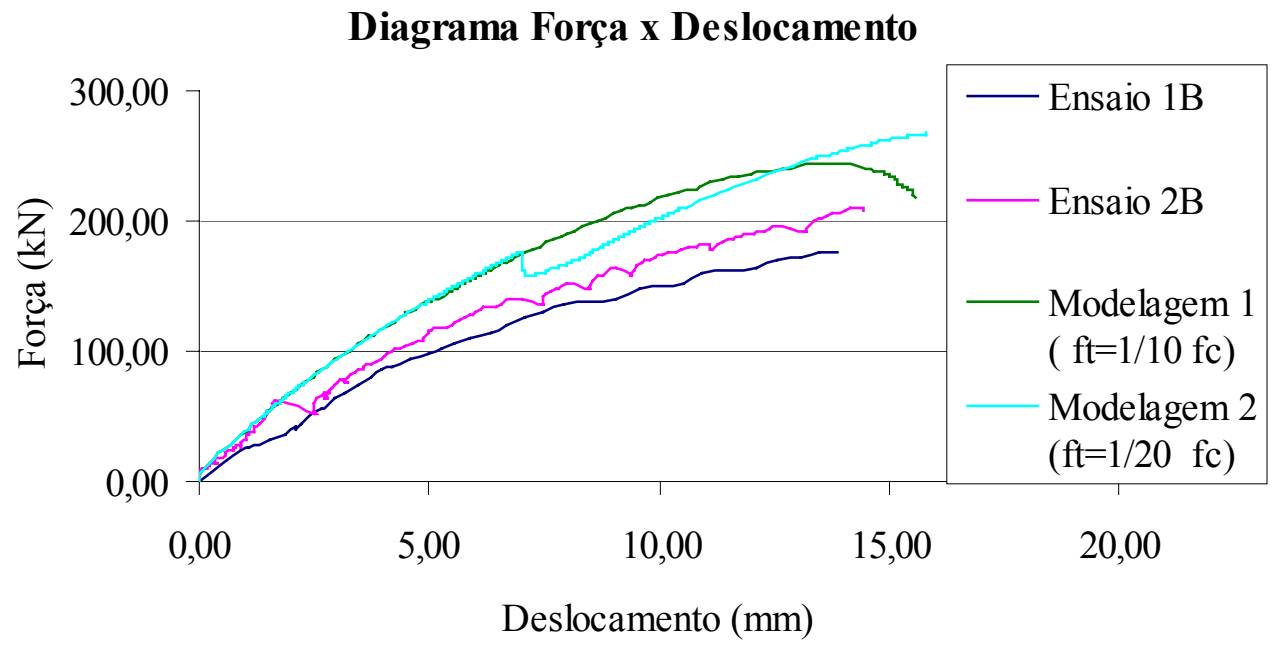

FIGURA 5.45 - Diagramas força $\mathrm{x}$ deslocamento para os ensaios $1 \mathrm{~B}$ e $2 \mathrm{~B}$, obtidos através dos ensaios experimentais e da modelagem numérica

Os resultados obtidos através da modelagem numérica aproximam-se dos resultados experimentais em termos de rigidez inicial. No que se refere à força de fissuração da diagonal, quando se efetua a modelagem considerando a resistência à tração do painel de alvenaria igual a 1/10 da resistência à compressão, não há fissuração da diagonal, da mesma forma que no ensaio 2B. No entanto, quando se adota a 
resistência à tração da alvenaria igual a 1/20 da resistência à compressão, justificada por possíveis problemas na execução da parede, a força de fissuração da diagonal coincide com aquela obtida no ensaio $1 \mathrm{~B}$, de $172 \mathrm{kN}$.

Com relação à força de esmagamento dos cantos comprimidos, não foi possível efetuar comparações entre resultados numéricos e experimentais, visto que nos ensaios houve o descarregamento do pórtico antes disso, de modo a mantê-lo trabalhando no regime elástico. $\mathrm{Na}$ análise numérica, os diagramas apresentados na figura 5.45 indicam forças de esmagamento de $242 \mathrm{kN}$ e $268 \mathrm{kN}$, para a resistência à tração igual a 1/10 e 1/20 da resistência à compressão, respectivamente.

Nos estudos numéricos realizados, mais uma vez foi possível a obtenção da curva completa força $\mathrm{x}$ deslocamento. A diferença de comportamento ocorrida nos dois ensaios experimentais de mesmas características, que levou à realização de duas modelagens distintas, deve-se, possivelmente, ao fato de as interfaces pórtico-painel não estarem bem preenchidas durante sua execução, o que modifica, consideravelmente, o comportamento do sistema estudado, ocasionando a fissuração da diagonal no ensaio 1B.

\section{DESCOLAMENTO DA INTERFACE PÓRTICO-PAINEL}

Para avaliação dos cantos tracionados, considerou-se uma ação de $170 \mathrm{kN}$ aplicada na extremidade superior direita do protótipo, e os resultados dos ensaios experimentais e da modelagem numérica foram comparados. Nas figuras 5.46 e 5.47, apresentam-se os valores dos comprimentos de descolamentos obtidos através de análises numérica e experimental. Para obtenção dos comprimentos dos descolamentos oriundos dos ensaios experimentais, foi assumida uma variação linear para eles. Os descolamentos obtidos, tanto nos ensaios experimentais quanto na modelagem, foram relativamente próximos. 


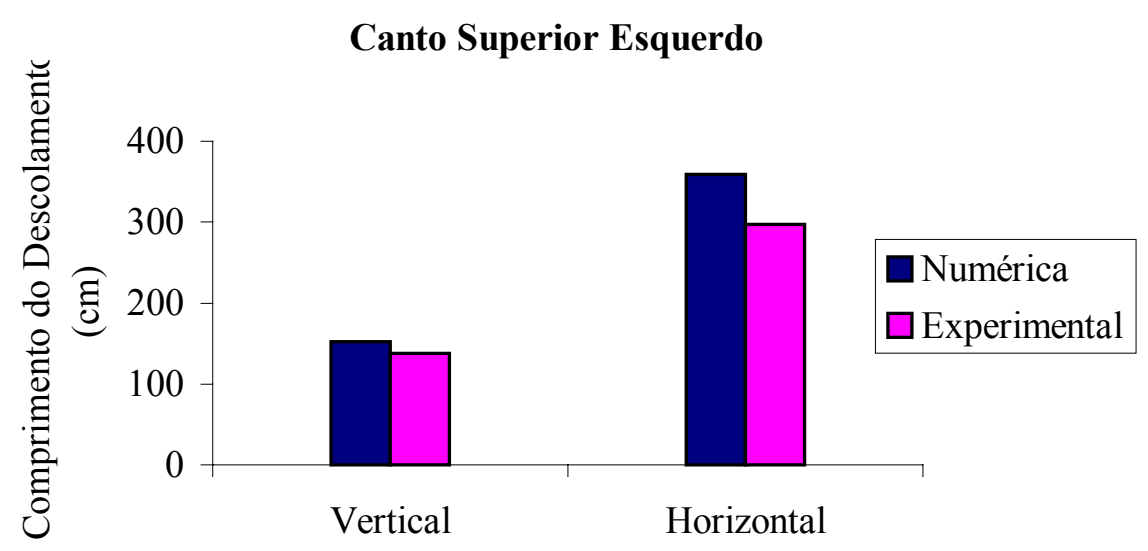

FIGURA 5.46 - Comprimento dos descolamentos, sistema TIPO II, ensaios 1B e 2B

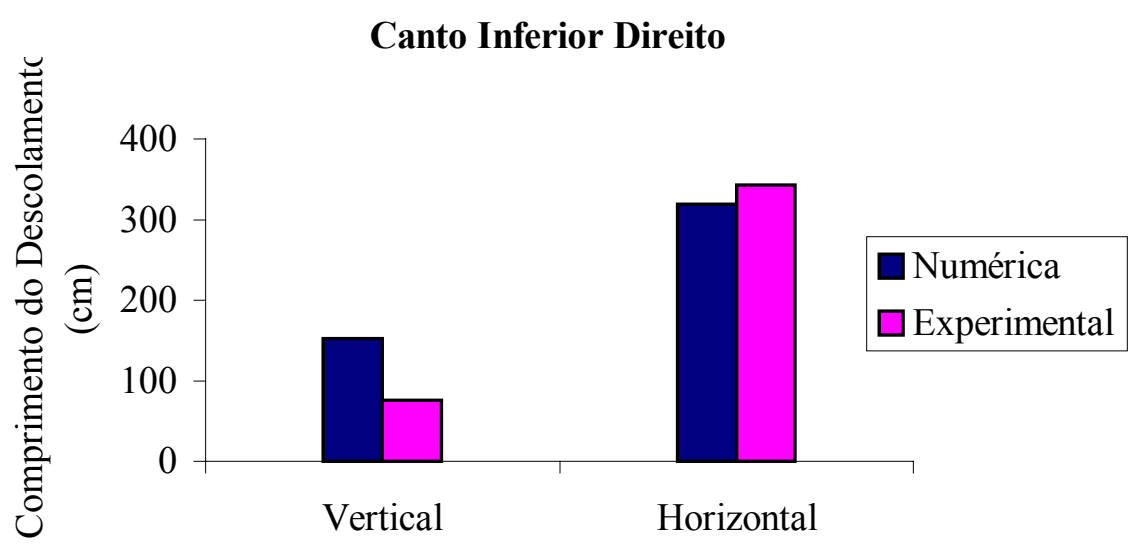

FIGURA 5.47 - Comprimento dos descolamentos, sistema TIPO II, ensaios 1B e 2B

Os comprimentos de contato entre pórtico-painel "concordam" razoavelmente. Apresentam-se, na figura 5.48, os comprimentos de contato obtidos na análise numérica e nos ensaios experimentais. Na modelagem numérica, observou-se que não houve o descolamento do canto horizontal inferior direito, como se esperava. Esse fato pode ser verificado nos diagramas de tensões principais apresentados, nos quais se pode observar o bulbo de tensões principais máximas (tração) nessa região. Acredita-se que essa ocorrência é por causa do fato de ser pequena a relação altura/comprimento do sistema TIPO II $(0,51)$. Esse valor é, em determinadas prescrições normativas, o mínimo admitido para se considerar a contribuição da alvenaria na rigidez de pórticos preenchidos. 


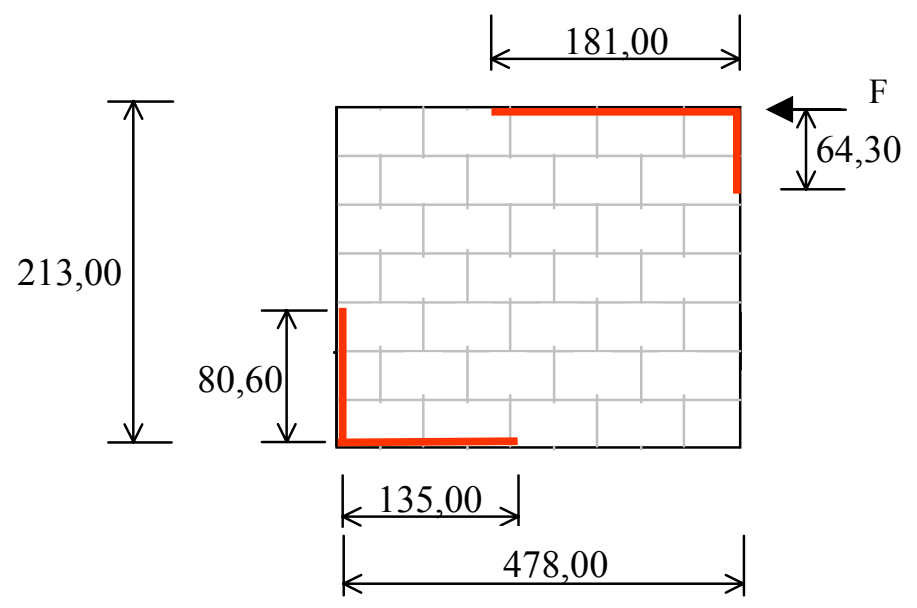

Experimental

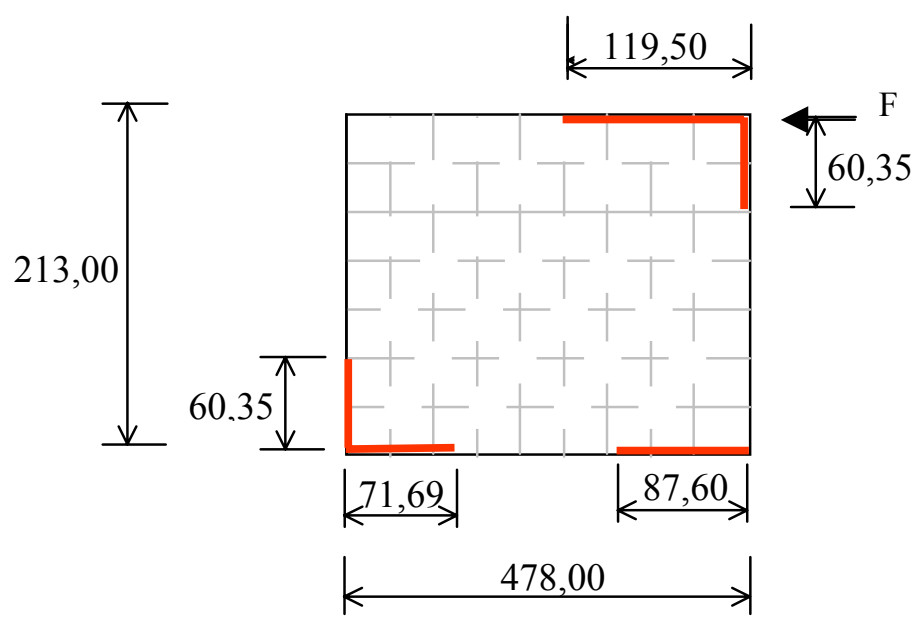

Numérico

FIGURA 5.48 - Comprimento de contato nas interfaces comprimidas pórtico-painel.

Dimensões $(\mathrm{cm})$

\section{TENSÕES E DEFORMAÇÕES}

Para fins de comparação entre os valores de deformações obtidos numérica e experimentalmente, apresentam-se nas figuras 5.49 a 5.52 os valores das deformações principais máximas e mínimas, no ensaio 1B. 
Nas figuras 5.49 e 5.50, apresentam-se as deformações principais máximas e mínimas, respectivamente, atuantes no canto inferior comprimido do painel, para forças correspondentes a $40 \mathrm{kN}$ e $170 \mathrm{kN}$. Percebe-se, nessas figuras, uma considerável aproximação entre os resultados obtidos, o que evidencia que a modelagem numérica consegue representar satisfatoriamente o comportamento dos sistemas de pórtico-painel nos ensaios experimentais.

Nas figuras 5.51 e 5.52 são apresentadas as deformações principais máximas e mínimas, respectivamente, atuantes no canto superior comprimido do painel. Como existe uma proximidade da roseta de deformações superior em relação ao ponto de aplicação de carga, os resultados obtidos numérica e experimentalmente indicam uma menor concordância.

Tendo em vista os estudos experimentais e numéricos efetuados, pode-se certificar de que a modelagem numérica realizada consegue representar o comportamento experimental de paredes sem abertura de forma adequada. Compararam-se as deformações principais, as cargas de fissuração e o descolamento da interface, e, de forma geral, os resultados numéricos concordam com os valores experimentais. Desse modo, no capítulo 6 será apresentado um estudo paramétrico, em que a influência das principais variáveis é avaliada numericamente, permitindo a identificação dos principais fatores que afetam o comportamento de pórticos preenchidos.

Nesse estudo, tanto na modelagem como nos ensaios experimentais, conclui-se que as cargas caminham por bielas diagonais e, dessa forma, uma proposição teórica para a representação desse comportamento passa pela consideração do painel como uma barra diagonal equivalente. No capítulo 7 é proposta uma expressão para obtenção da carga de ruptura em painel de pórticos preenchidos, de forma a contribuir para a geração de uma ferramenta que seja útil no projeto estrutural de sistemas de pórticos preenchidos. 
Deformações Principais Máximas no Canto Inferior Comprimido

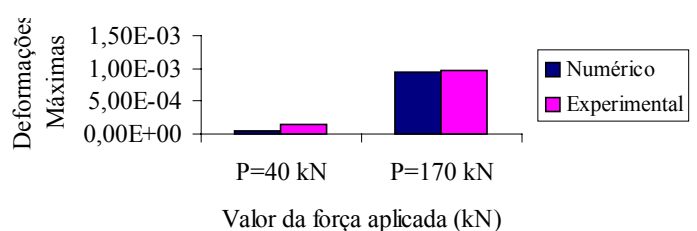

FIGURA 5.49 - Deformações principais máximas no canto inferior comprimido, obtidas numérica e experimentalmente (ensaio 1B)

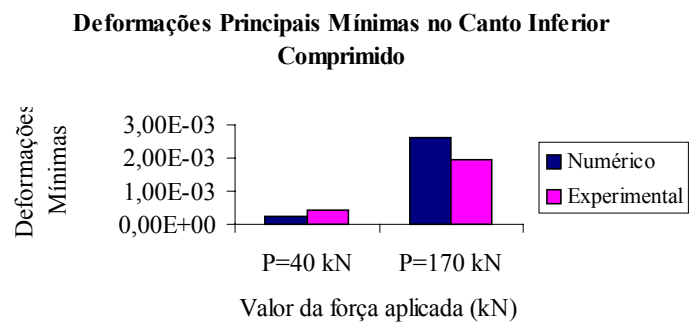

FIGURA 5.50 - Deformações principais mínimas no canto inferior comprimido, obtidas numérica e experimentalmente (ensaio 1B)

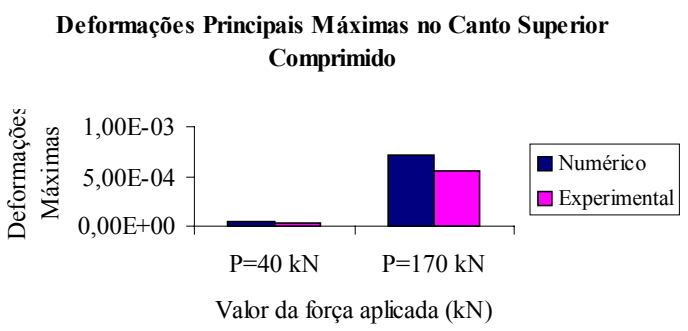

FIGURA 5.51 - Deformações principais máximas no canto superior comprimido, obtidas numérica e experimentalmente (ensaio 1B)

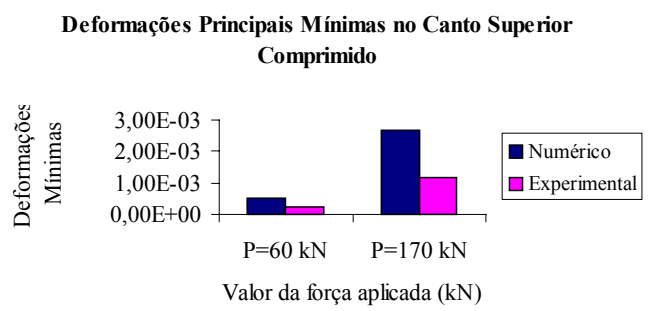

FIGURA 5.52 - Deformações principais mínimas no canto superior comprimido, obtidas numérica e experimentalmente (ensaio 1B) 


\subsubsection{5 - PROTÓTIPO TIPO II: PAREDES COM ABERTURA}

\section{ENSAIOS $3 B$ e $4 B$}

Para os ensaios 3B e 4B, relativos ao protótipo TIPO II com abertura central de $150 \mathrm{x}$ $90 \mathrm{~cm}^{2}$, realizaram-se dois tipos de modelagens. Na primeira, foram considerados elementos de interface no painel de alvenaria, a partir dos quatro cantos da abertura, de modo a simular as fissuras surgidas nos resultados experimentais, e não se fez distinção entre alvenaria, verga e contraverga. No entanto, os resultados obtidos na análise numérica se afastam dos experimentais com o acréscimo da carga aplicada, e o modelo numérico mantém uma rigidez superior ao experimental.

Atendendo aos deficientes resultados obtidos, realizou-se uma segunda modelagem, na qual a verga e a contraverga foram modeladas separadamente da alvenaria, admitindo-se elementos de interface entre elas. Essa consideração permitiu o deslocamento relativo verga-painel e contra-verga-painel, reduzindo a rigidez e aproximando melhor dos resultados experimentais. A seguir serão apresentadas as duas modelagens realizadas.

\section{A) MODELAGEM SEM DISTINÇÃO ENTRE ALVENARIA, VERGA E CONTRAVERGA E COM INTERFACES ALVENARIA-ALVENARIA INCLINADAS}

Na figura 5.53, apresentam-se as malhas utilizadas para representação do painel de alvenaria, do pórtico de aço e das interfaces viga-pilar, pórtico-alvenaria e alvenariaalvenaria.

As inclinações das interfaces alvenaria-alvenaria foram obtidas por tentativas, de forma a posicioná-las no centro dos bulbos de tensões principais máximas, surgidos nos cantos tracionados da abertura. Inicialmente, esses ângulos foram considerados de $45^{\circ}$ com a horizontal e, em seguida, de $90^{\circ}$ (interfaces verticais), mas nos dois 
casos não houve o descolamento da interface. Por fim, foram adotados ângulos de $84^{\circ}$ a partir dos dois cantos opostos na direção da diagonal tracionada e ângulos de $68^{\circ}$ a partir dos cantos opostos na direção da diagonal comprimida, a contar do eixo horizontal e no sentido anti-horário.

As propriedades dos materiais utilizadas na análise numérica estão descritas na tabela 5.1, sendo elas empregadas nas modelagens anteriores. Nas figuras 5.54 a 5.61, apresentam-se os resultados numéricos correspondentes a diferentes níveis de solicitação, nos ensaios 3B e 4B.

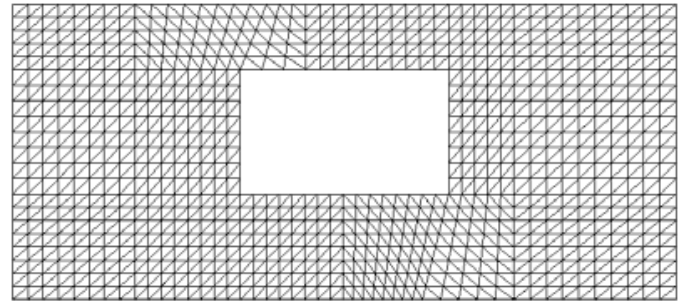

(a)

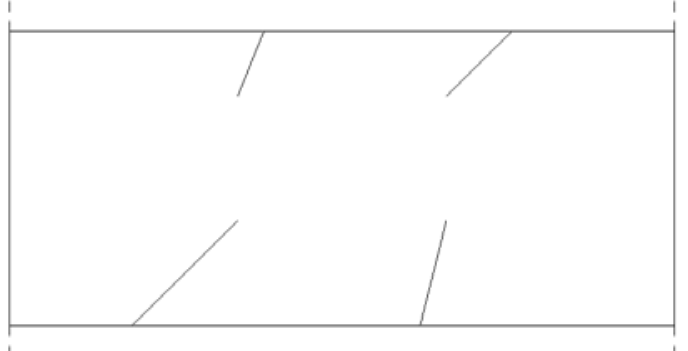

(c)

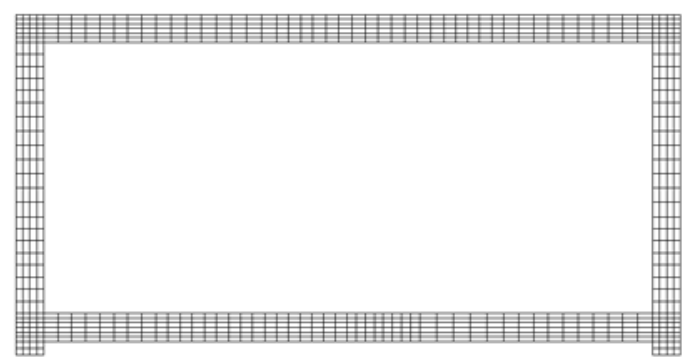

(b)

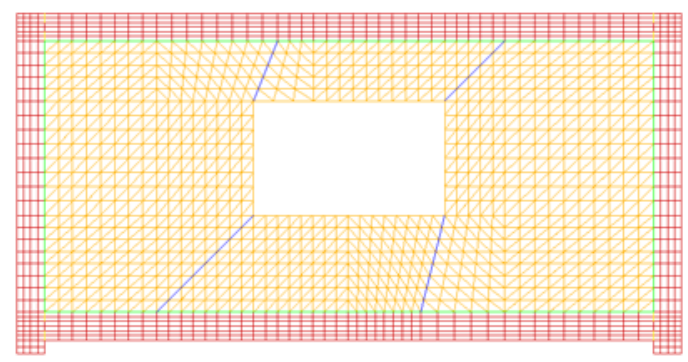

(d)

FIGURA 5.53 - Malhas utilizadas na análise numérica do sistema TIPO II, para a representação dos ensaios 3B e 4B: a) painel de alvenaria; b) pórtico de aço; c) interfaces viga-pilar, pórtico-alvenaria e alvenaria-alvenaria; e d) malha completa

Os resultados apresentados nas figuras 5.54 e 5.55 se referem ao início da análise, com uma ação horizontal de $18,3 \mathrm{kN}$, aplicada na extremidade direita da viga superior, correspondente a um deslocamento lateral de 0,67 mm. Nesse nível de carga já ocorre o descolamento das interfaces pórtico-alvenaria. Nos ensaios 
experimentais, os descolamentos correspondentes a $18,3 \mathrm{kN}$ foram iguais a $0,52 \mathrm{~mm}$ e $0,47 \mathrm{~mm}$, nos ensaios 3B e 4B, respectivamente. Pelas deformadas incremental e total, figura 5.54, é possível verificar o início da abertura das interfaces alvenariaalvenaria, nos dois cantos opostos, na direção da diagonal comprimida. Os diagramas correspondentes às tensões principais máximas e mínimas, apresentados na figura 5.55, indicam uma concentração de tensões nos cantos da abertura. Nos dois cantos comprimidos dos painéis, apresenta-se um estado biaxial de compressão, como no caso das paredes sem aberturas.

Nas figuras 5.56 e 5.57, apresentam-se os resultados referentes a uma ação de $40 \mathrm{kN}$, para um deslocamento correspondente de 2,3 $\mathrm{mm}$. Nos ensaios experimentais esse deslocamento foi de $2,87 \mathrm{~mm}$ no ensaio $3 \mathrm{~B}$ e de $5,00 \mathrm{~mm}$ no ensaio 4B. As deformadas incremental e total apresentadas na figura 5.56 permitem observar a abertura das interfaces tracionadas alvenaria-alvenaria. Nos cantos opostos da abertura e na direção da diagonal comprimida, tiveram-se tensões principais máximas de tração ocasionando a abertura desses cantos. $\mathrm{O}$ mesmo aconteceu nas outras duas interfaces, porém a partir da interface viga-alvenaria, onde se tem uma concentração de tensões de tração.

Para esse nível de carga, as concentrações de tensões nos cantos da abertura, na direção da diagonal, indicam ser essas as regiões críticas na análise de sistemas pórtico-painel com abertura. A abertura tende a "fechar" na direção da diagonal tracionada e a "abrir" na direção da biela. Pelos diagramas correspondentes às tensões principais máximas e mínimas, notam-se que, como era de se esperar, as tensões principais máximas (tração) ocorrem nos cantos cujas arestas tendem a ângulos maiores que $90^{\circ}$, enquanto as tensões principais mínimas (compressão) ocorrem nos cantos onde as arestas tendem a formar ângulos menores que $90^{\circ}$.

Mesmo com a existência da abertura impedindo a continuidade da biela, pôde-se notar que houve desvio das tensões, porém o fluxo continuou existindo, como no caso de paredes sem aberturas. Nos dois cantos opostos da abertura, na direção da diagonal tracionada, teve-se um estado biaxial de compressão. As deformações 
principais máximas foram de tração em grande parte do painel, enquanto as deformações principais mínimas foram de compressão em todo o painel.

Nas figuras 5.58 e 5.59 são apresentados os resultados numéricos para uma ação de 160 kN. Nesse ponto, não foi mais possível uma comparação com os resultados experimentais, pois nos ensaios $3 \mathrm{~B}$ e $4 \mathrm{~B}$ as cargas máximas atingidas foram de 70 $\mathrm{kN}$ e $95 \mathrm{kN}$, respectivamente. O deslocamento obtido no modelo numérico correspondente a esse nível de carga foi de 10,2 mm. Até uma ação de $65 \mathrm{kN}$, os dois diagramas se mantiveram bastante próximos. Como pode ser observado na figura 5.58 , praticamente não houve deslocamentos incrementais nas interfaces alvenariaalvenaria, uma vez que as fissuras já atravessavam todo o painel a partir dos cantos da abertura.

Na figura 5.59, observa-se que as tensões principais máximas foram de tração em grande parte do painel, enquanto nos dois cantos opostos da abertura, na direção da diagonal tracionada, persistiu o estado biaxial de compressão. Já as deformações principais máximas se referiam a alongamento em todo o painel e as principais mínimas, a encurtamento em todo o painel.

O esmagamento dos cantos comprimidos da abertura ocorreu para uma ação de 240 $\mathrm{kN}$, como pode ser percebido pelas deformadas incremental e total apresentadas na figura 5.60. Nos dois cantos opostos da abertura, na direção da diagonal tracionada, ocorre o esmagamento do painel. $\mathrm{Na}$ figura 5.61, apresentam-se as tensões e deformações principais correspondentes a esse nível de carga. Persistiu um estado biaxial de compressão nos cantos comprimidos do painel e nos cantos opostos da abertura, na direção da diagonal tracionada. 


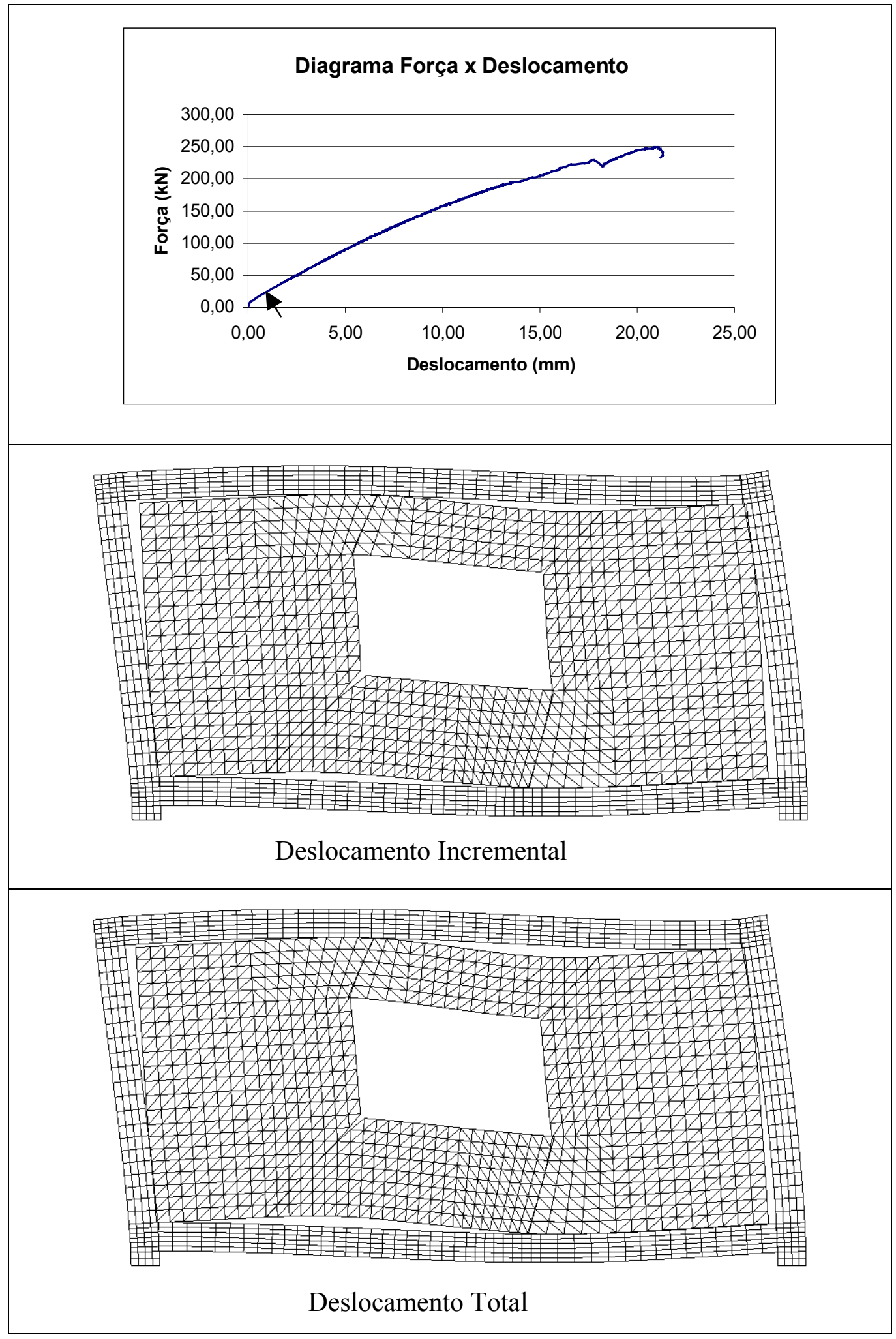

FIGURA 5.54 - Resultados da análise numérica do sistema TIPO II - Ensaios 3B e 4B, para uma ação de $18,3 \mathrm{kN}$ 
(a)

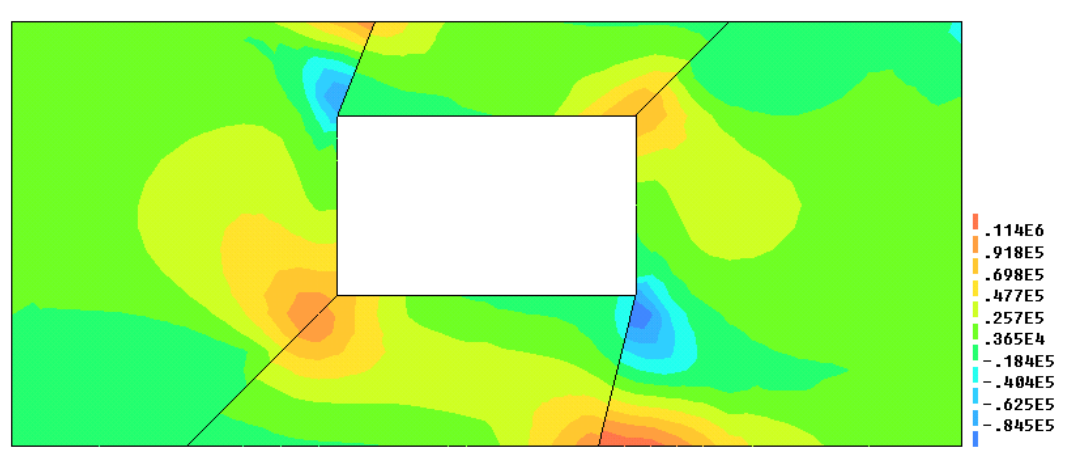

(b)

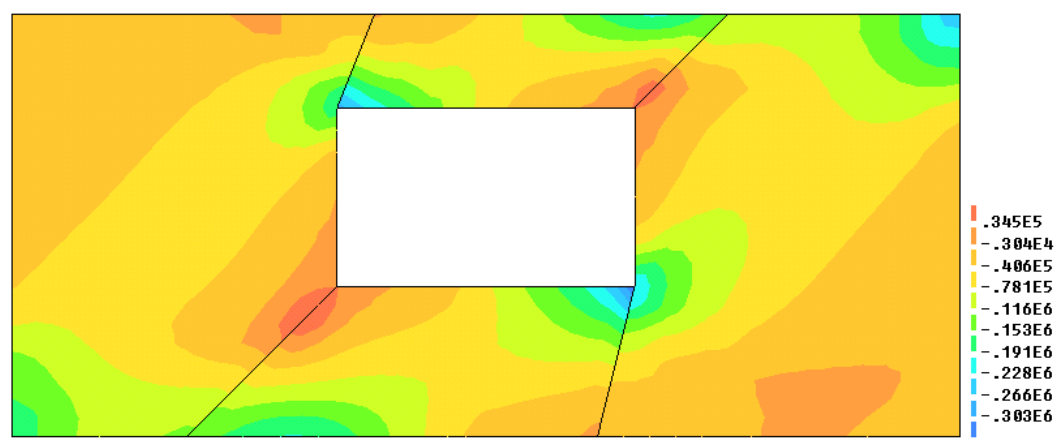

(c)

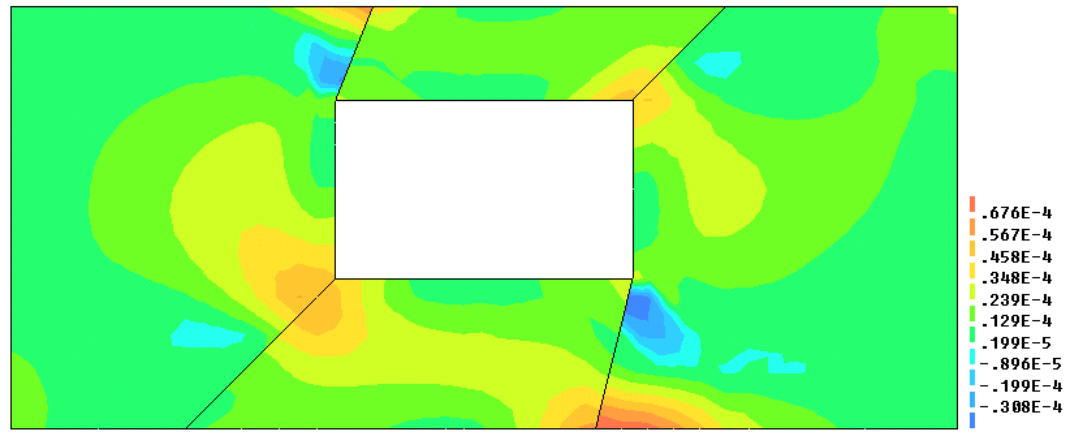

(d)

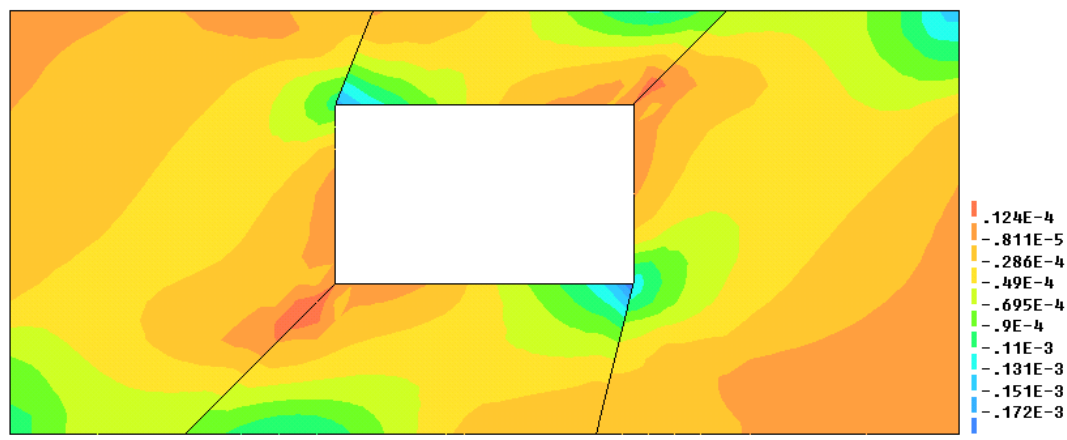

FIGURA 5.55 - Resultados da análise numérica do sistema TIPO II - Ensaios 3B e 4B, para uma ação horizontal de 18,3 kN: a) tensões principais máximas, b) tensões principais mínimas, c) deformações principais máximas e d) deformações principais mínimas. Unidades (Newton e metro) 


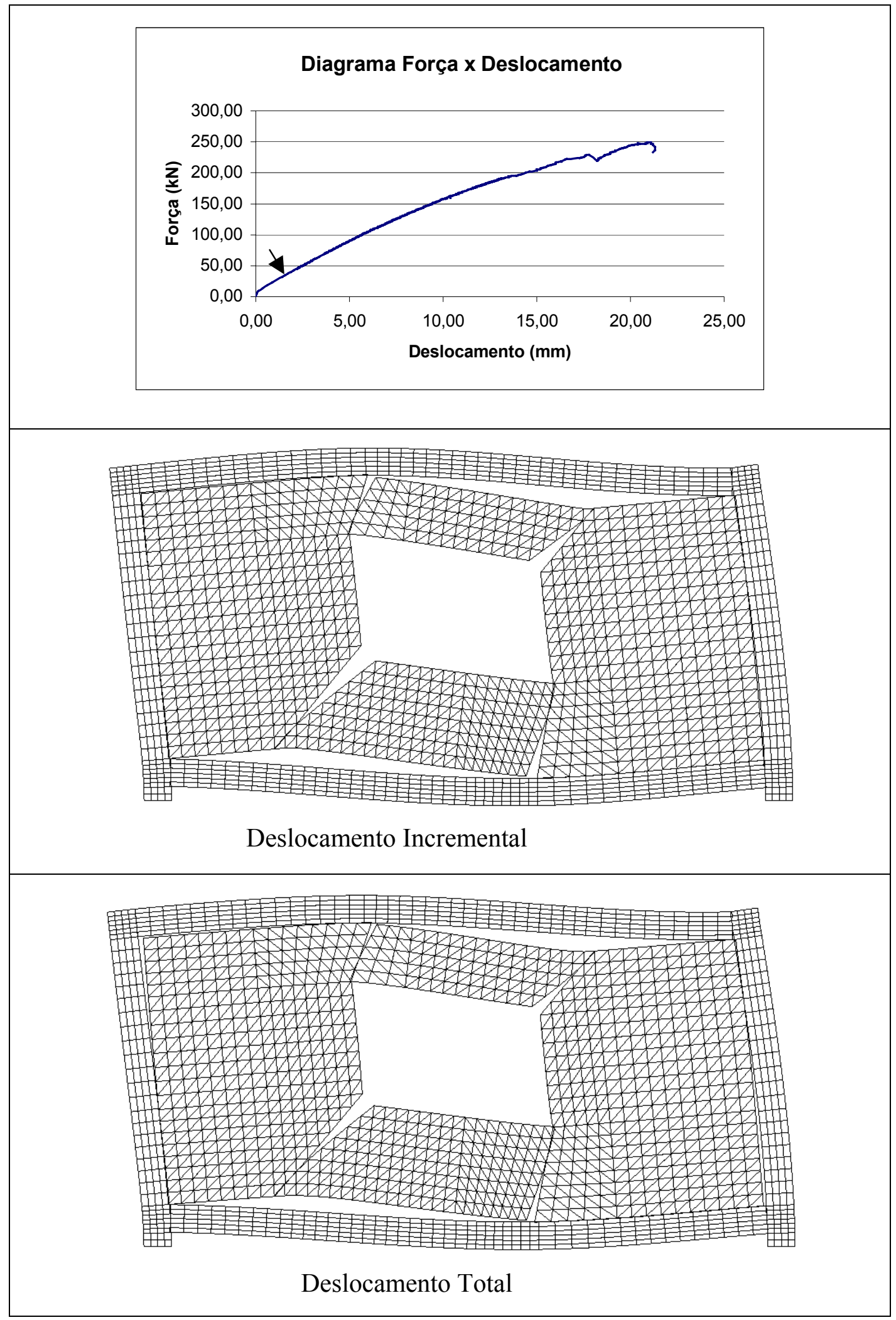

FIGURA 5.56 - Resultados da análise numérica do sistema TIPO II - Ensaios 3B e 4B, para uma ação de $40 \mathrm{kN}$ 
(a)

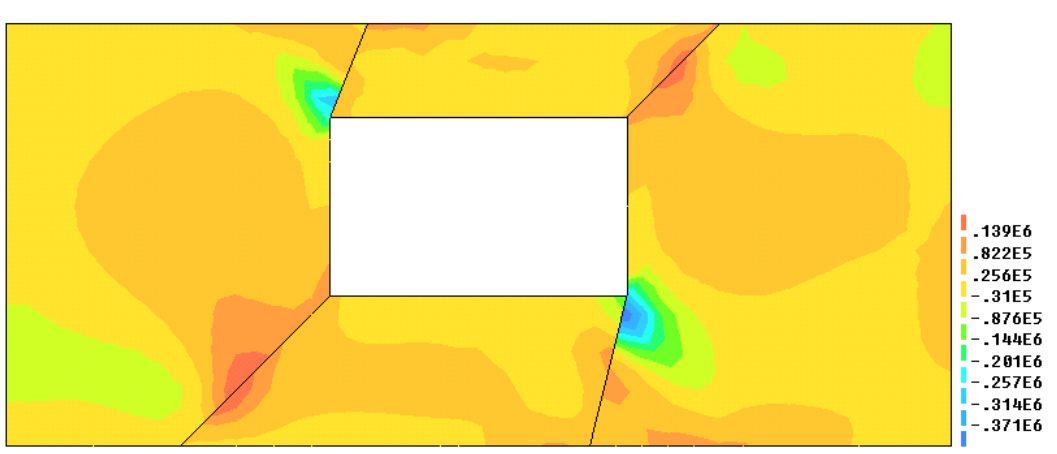

(b)

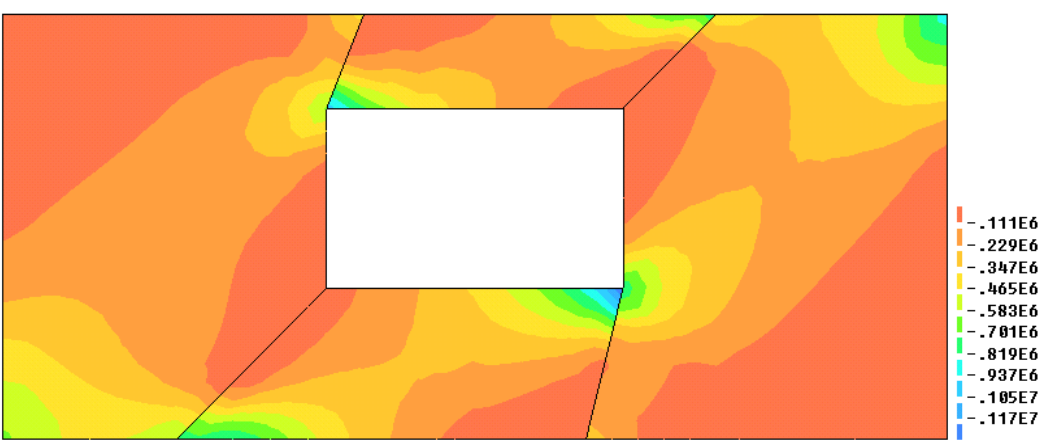

(c)

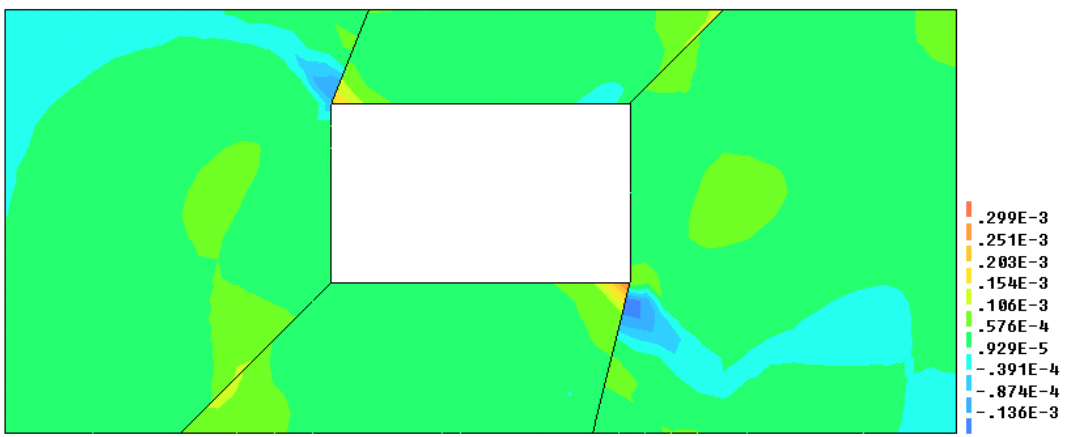

(d)

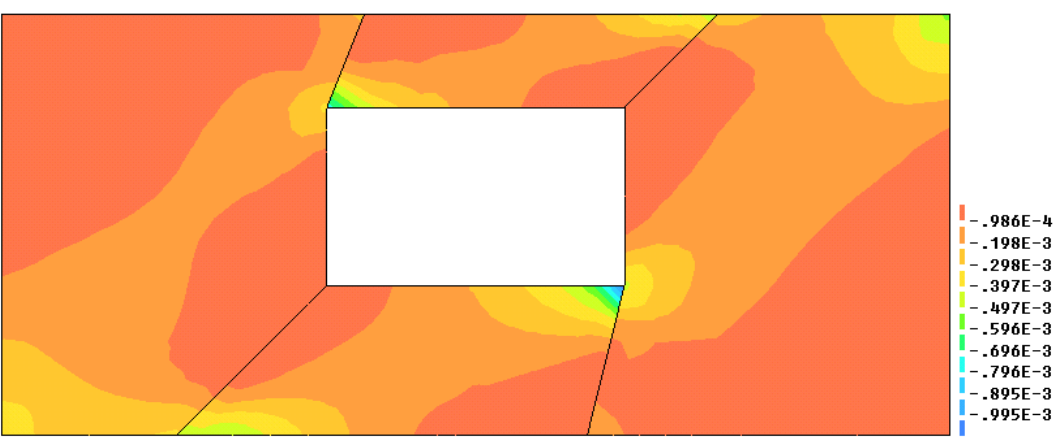

FIGURA 5.57 - Resultados da análise numérica do sistema TIPO II - Ensaios 3B e

4B, para ação horizontal de $40 \mathrm{kN}$ : a) tensões principais máximas, b) tensões principais mínimas, c) deformações principais máximas e d) deformações principais mínimas. Unidades (Newton e metro) 


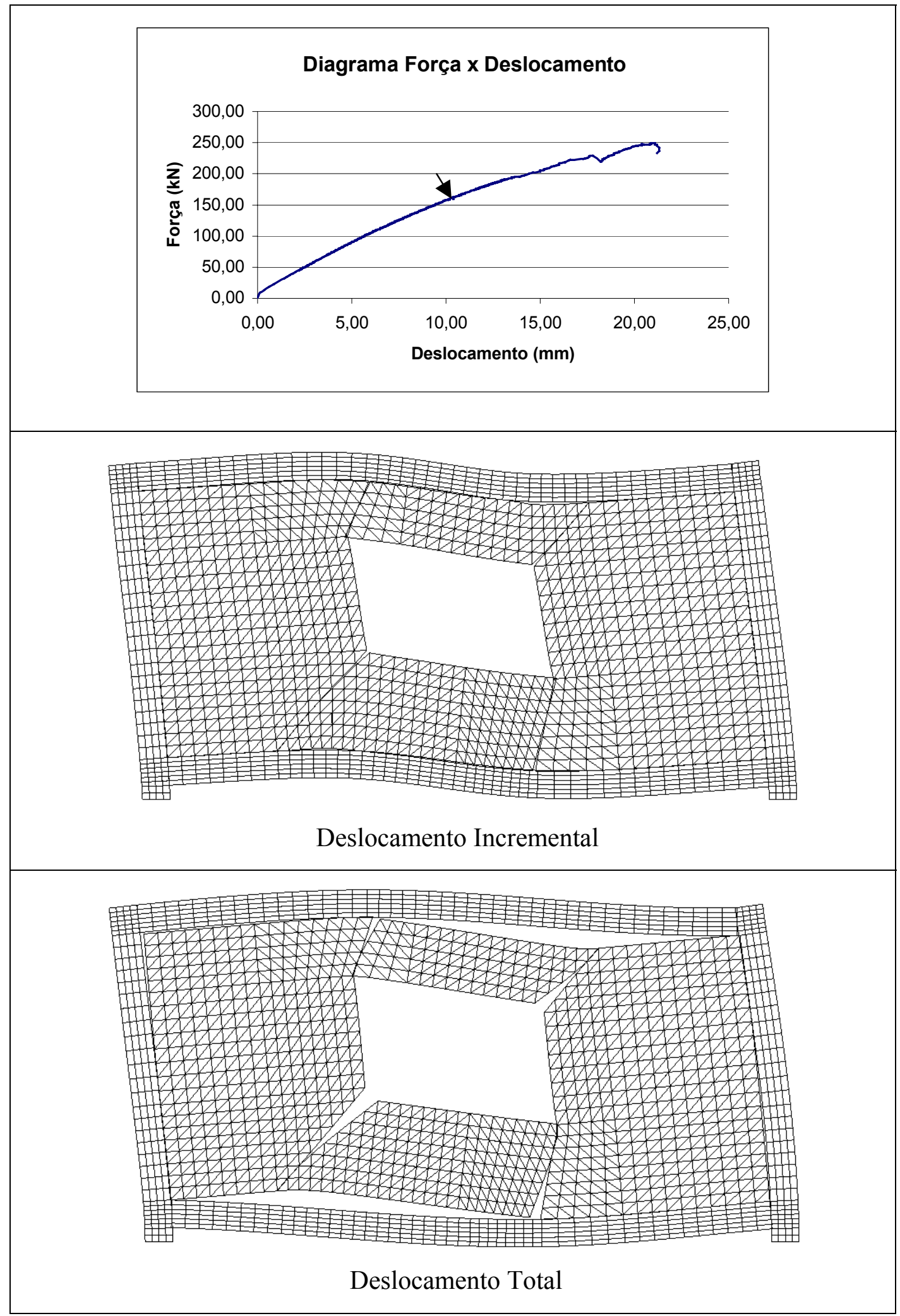

FIGURA 5.58 - Resultados da análise numérica do sistema TIPO II - Ensaios 3B e 4B, para uma ação de $160 \mathrm{kN}$ 
(a)

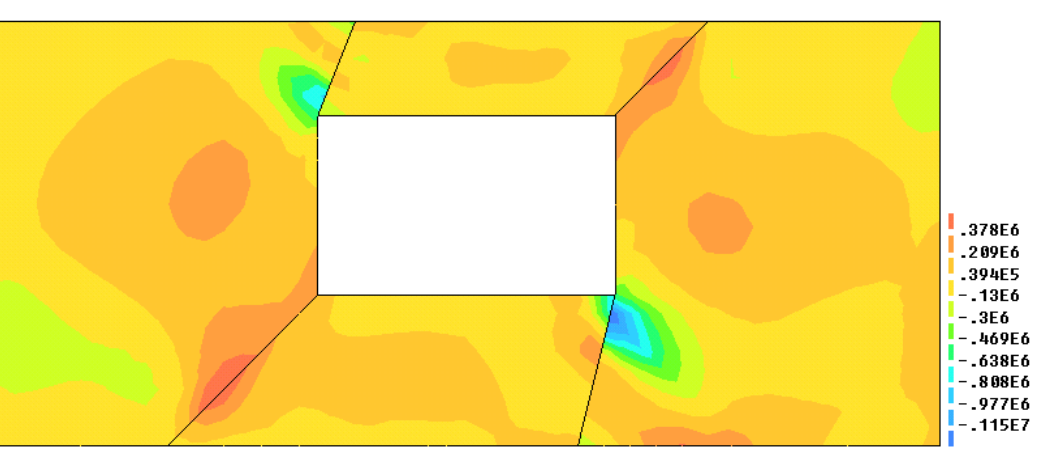

(b)

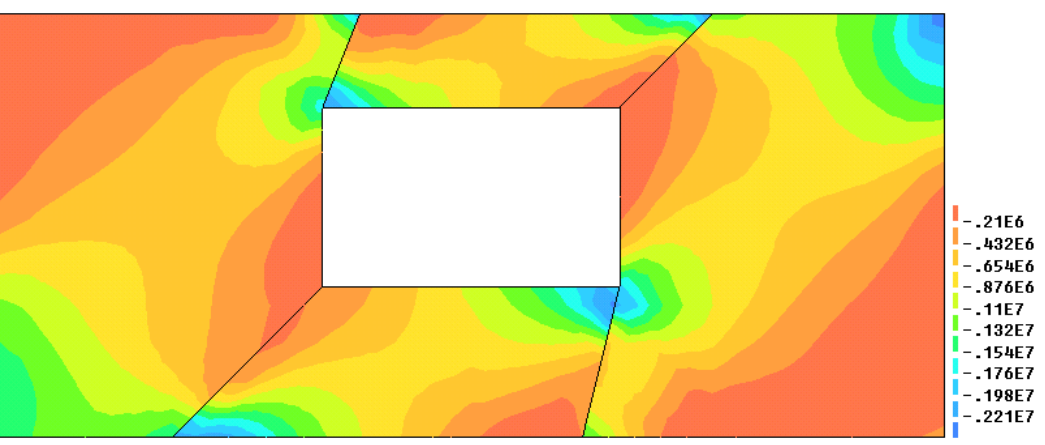

(c)

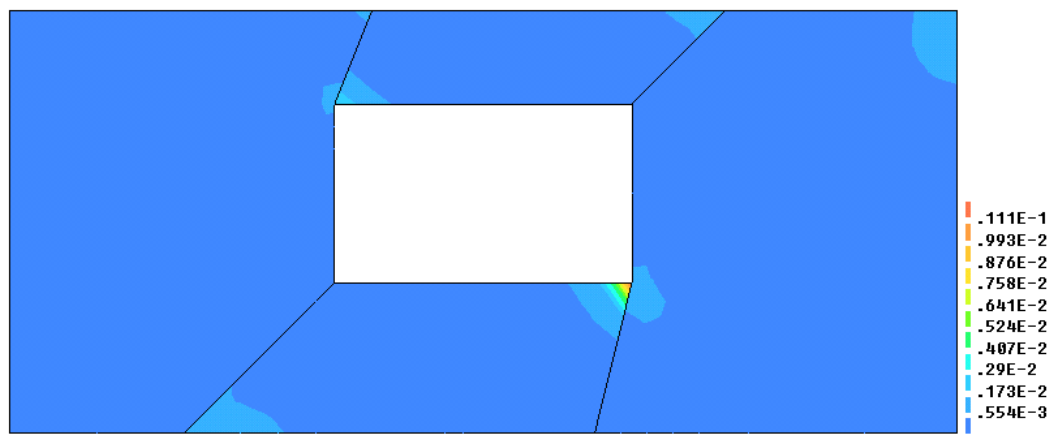

(d)

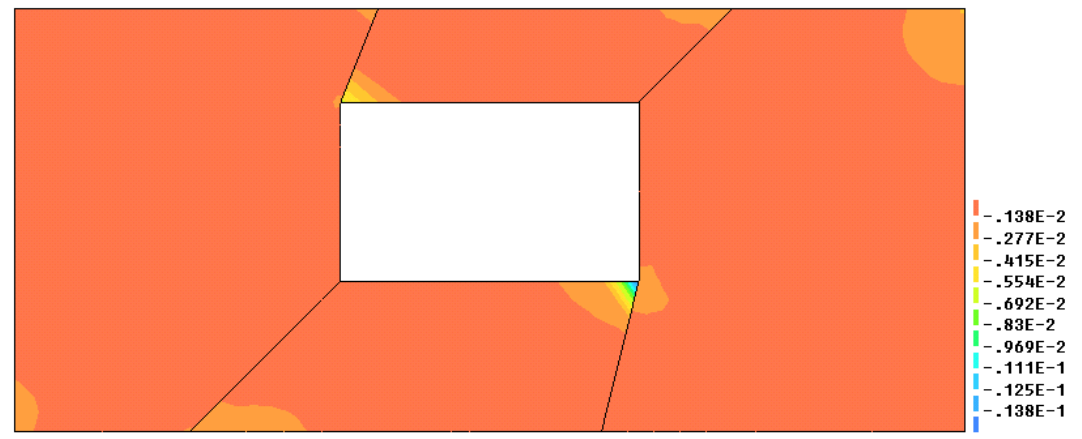

FIGURA 5.59 - Resultados da análise numérica do sistema TIPO II - Ensaios 3B e

4B, para ação horizontal de $160 \mathrm{kN}$ : a) tensões principais máximas, b) tensões principais mínimas, c) deformações principais máximas e d) deformações principais mínimas. Unidades (Newton e metro) 


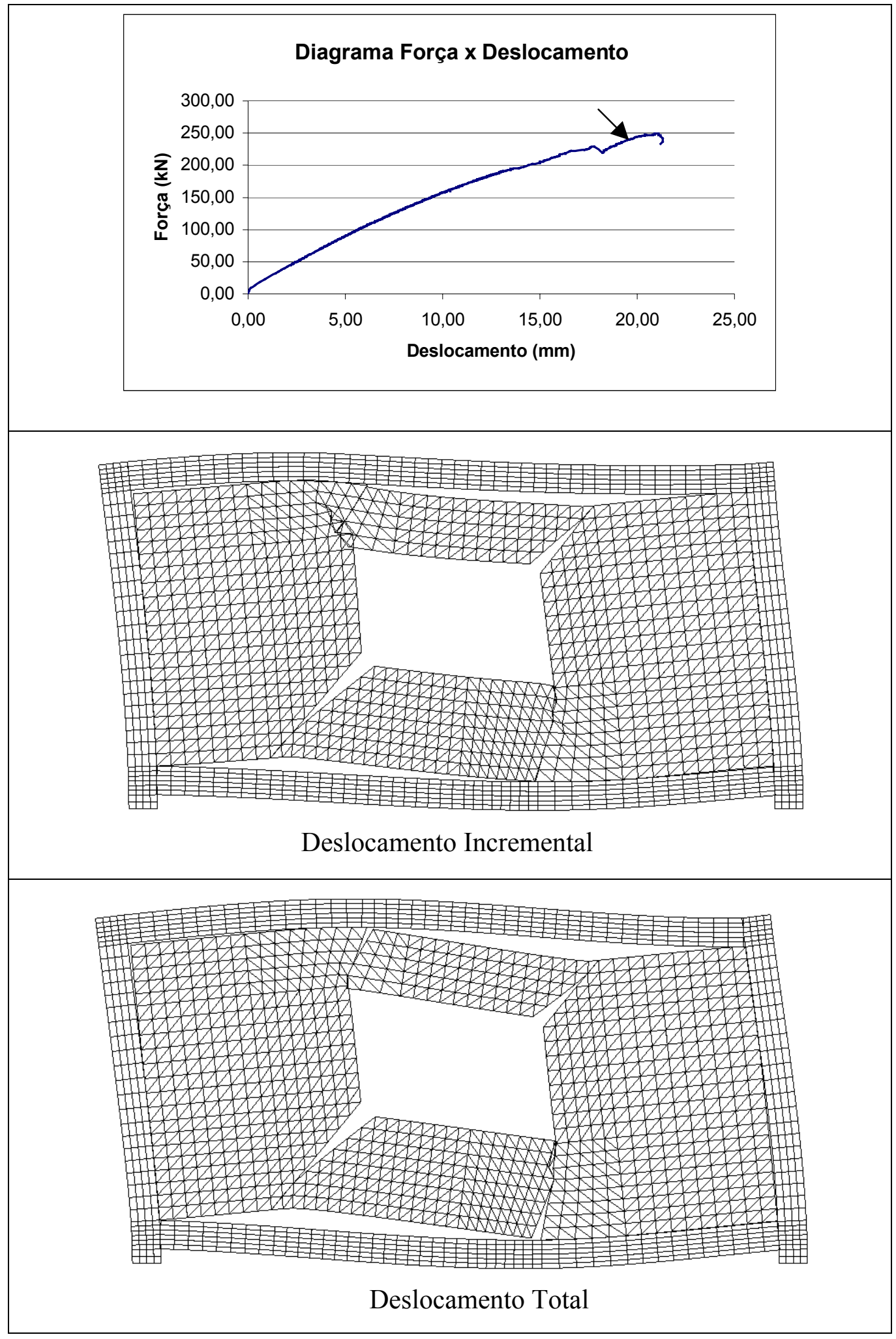

FIGURA 5.60 - Resultados da análise numérica do sistema TIPO II - Ensaios 3B e 4B, para uma ação de $240 \mathrm{kN}$ 
(a)

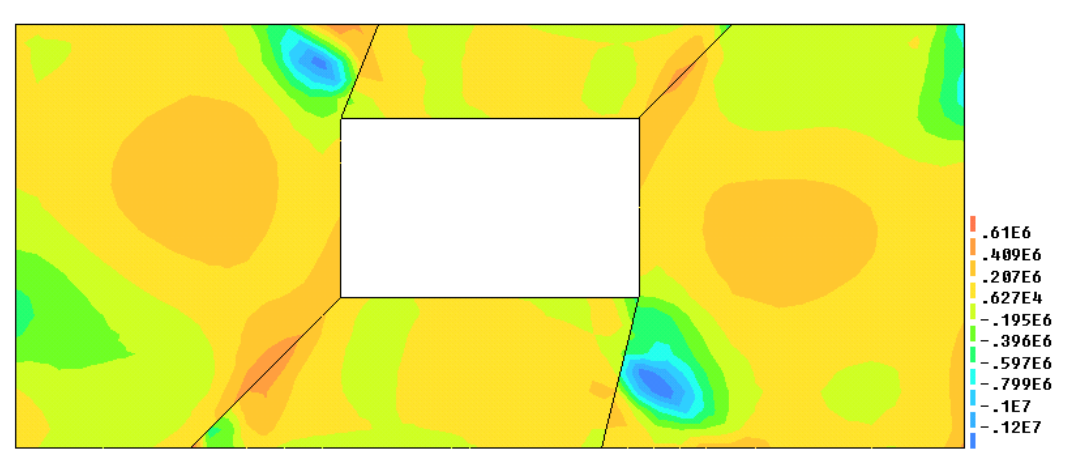

(b)

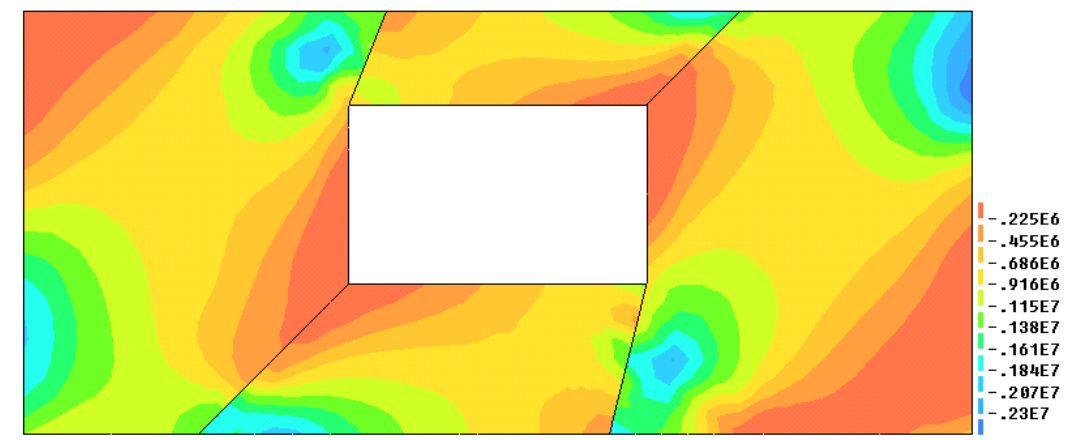

(c)

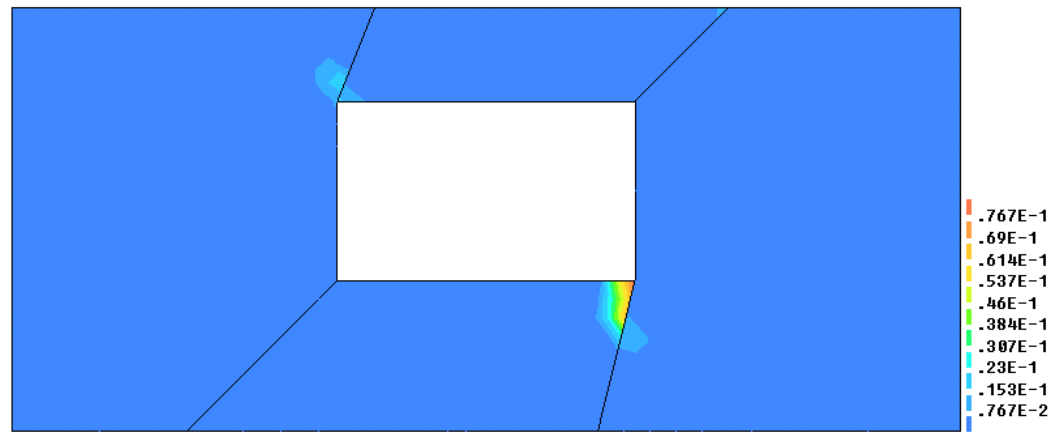

(d)

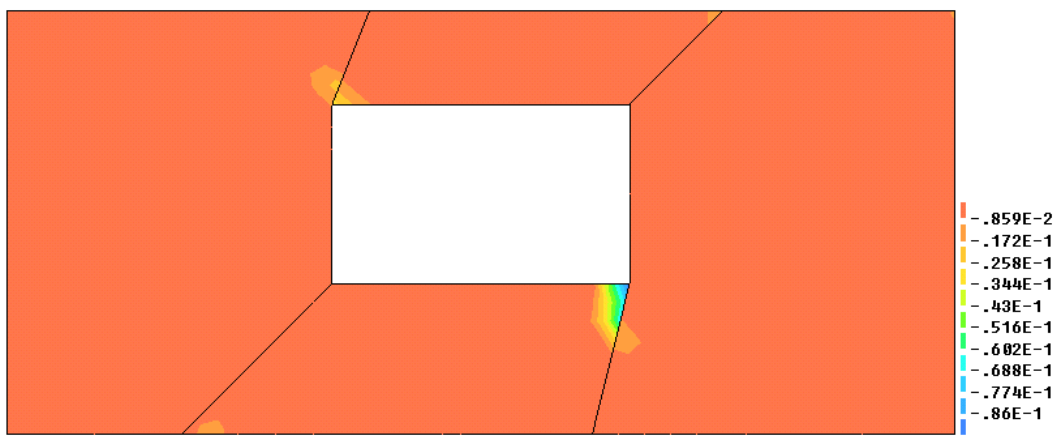

FIGURA 5.61 - Resultados da análise numérica do sistema TIPO II - Ensaios 3B e

4B, para ação horizontal de $240 \mathrm{kN}$ : a) tensões principais máximas, b) tensões principais mínimas, c) deformações principais máximas e d) deformações principais mínimas. Unidades (Newton e metro) 


\section{B) MODELAGEM DA ALVENARIA COMO UM CONTÍNUO E ELEMENTOS DE INTERFACE ENTRE VERGA-ALVENARIA E CONTRAVERGA- ALVENARIA}

Tendo em vista que a modelagem do sistema da forma como foi efetuada anteriormente, isto é, sem distinção entre verga, contraverga e painel, conduziu a um modelo mais rígido que o experimental, realizou-se uma nova modelagem considerando a interface entre verga-alvenaria e contraverga-alvenaria. Assim, qualquer falha na execução do painel e na colocação das vergas e contravergas pode ser computada através das propriedades da interface. Com o objetivo de corrigir possíveis falhas no processo de execução do painel, optou-se por reduzir a rigidez das interfaces verga-alvenaria e contraverga-alvenaria para o valor de $1 \mathrm{E}+6 \mathrm{~N} / \mathrm{m}^{2} / \mathrm{m}$.

Na figura 5.62, apresentam-se as malhas utilizadas para representação do painel de alvenaria, do pórtico de aço, da verga e contraverga e das interfaces: viga-pilar, pórtico-alvenaria, alvenaria-verga e alvenaria-contraverga.

Nas figuras 5.63 a 5.70, apresentam-se os resultados numéricos correspondentes a diferentes níveis de solicitação, nos ensaios 3B e 4B.

Os resultados mostrados nas figuras 5.63 e 5.64 se referem ao início da análise, com uma ação horizontal de $23,3 \mathrm{kN}$, aplicada na extremidade direita da viga superior, correspondente a um deslocamento lateral de 1,27 mm. Nessa carga já há o descolamento das interfaces pórtico-painel que estão tracionadas e já é perceptível o movimento relativo verga-painel e contraverga-painel, conforme figura 5.63.

No que se refere às tensões principais máximas, em quase todo o painel estas assumem valores de compressão, com focos de tração nos cantos diagonais da abertura, na direção da diagonal comprimida e na parte inferior direita do painel, próximo à interface inferior viga-painel, conforme figura 5.64. No canto inferior esquerdo da abertura, tem-se um estado de tração biaxial, com pequenos valores para 
as tensões principais mínimas. Estas são de compressão em quase todo o painel, e nos cantos comprimidos tem-se um estado biaxial de compressão.

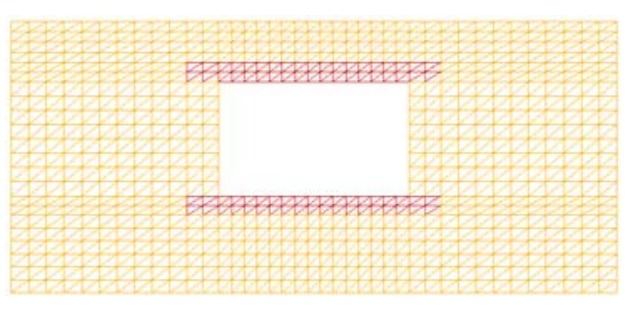

(a)

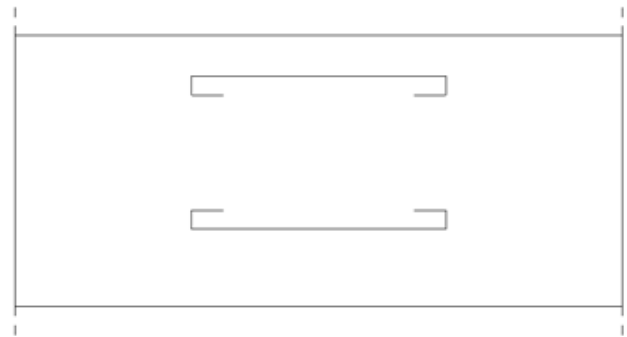

(c)

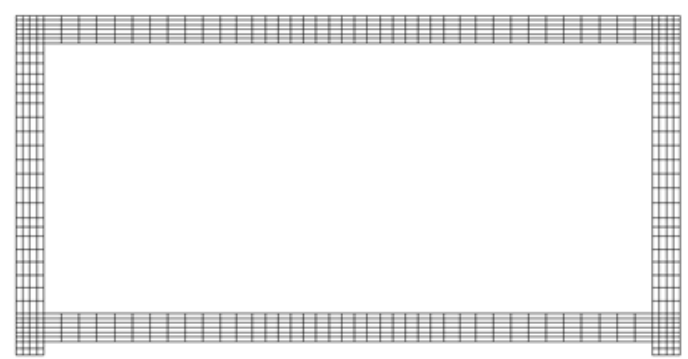

(b)

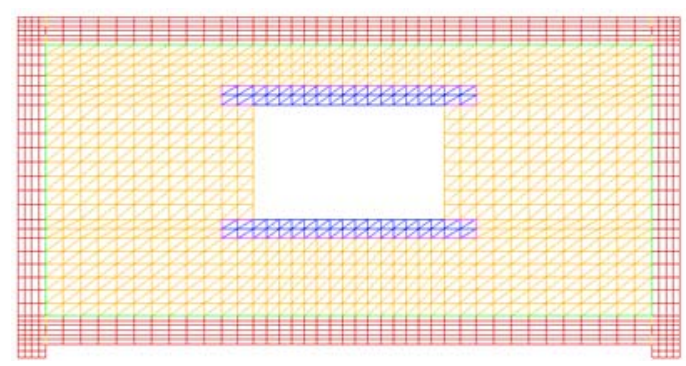

(d)

FIGURA 5.62 - Malhas utilizadas na análise numérica do sistema TIPO II, para a representação dos ensaios 3B e 4B: a) alvenaria, verga e contraverga; b) pórtico de aço; c) interfaces verga-alvenaria, contraverga-alvenaria, viga-pilar e pórticoalvenaria; e d) malha completa

As deformações principais máximas atingem seus valores críticos no canto inferior esquerdo, com alongamento de 0,698E-3, em que as deformações principais mínimas também são de alongamento. No canto inferior direito ocorrem os valores críticos para as deformações principais mínimas (encurtamento), que atingem valores até 0,169 E-4.

Nas figuras 5.65 e 5.66, apresentam-se os resultados referentes a uma ação de 41,3 $\mathrm{kN}$, para um deslocamento correspondente de $2,81 \mathrm{~mm}$. Nos ensaios experimentais, esse deslocamento foi de $2,24 \mathrm{~mm}$ no ensaio $3 \mathrm{~B}$ e $4,50 \mathrm{~mm}$ no ensaio 4B. Através das deformadas incremental e total, apresentadas na figura 5.65, pode-se notar o 
surgimento de fendas a partir do canto inferior esquerdo. Os dois cantos opostos, na direção da diagonal tracionada, apresentam um estado biaxial de compressão, da mesma forma que os cantos comprimidos do painel, segundo a figura 5.66. As deformações principais máximas, alongamento em todo o painel, atingem seu pico no canto inferior esquerdo, com valores de até 0,769E-2. Nesse nível de carga, as concentrações de tensões nos cantos já indicam as regiões críticas na análise de sistemas de pórtico-painel com abertura.

Esse comportamento se acentua, conforme figuras 5.67 e 5.68, com uma ação de $76,50 \mathrm{kN}$. Nesse nível de carga, ao contrário da primeira análise, os resultados continuam próximos. $\mathrm{O}$ deslocamento obtido no modelo numérico correspondente a esse nível de carga é de $6,16 \mathrm{~mm}$. Nos ensaios experimentais $3 \mathrm{~B}$ e $4 \mathrm{~B}$, os deslocamentos correspondentes a essa força foram de $8,30 \mathrm{~mm}$ e 9,50 mm, respectivamente. Na figura 5.67, podem-se ver a formação de uma nova fenda, no canto superior direito, e o movimento relativo pórtico-painel. Os diagramas apresentados na figura 5.68 se assemelham aos da figura 5.66, com valores mais elevados, evidentemente.

Aplicou-se força de até $188 \mathrm{kN}$ durante a análise numérica, como pode ser observado nas figuras 5.69 e 5.70. Nesse nível de carga ainda não havia ocorrido o esmagamento dos cantos comprimidos. No entanto, as fissuras diagonais e o deslizamento da verga já apresentavam valores consideráveis, e, dessa forma, a análise foi encerrada. 


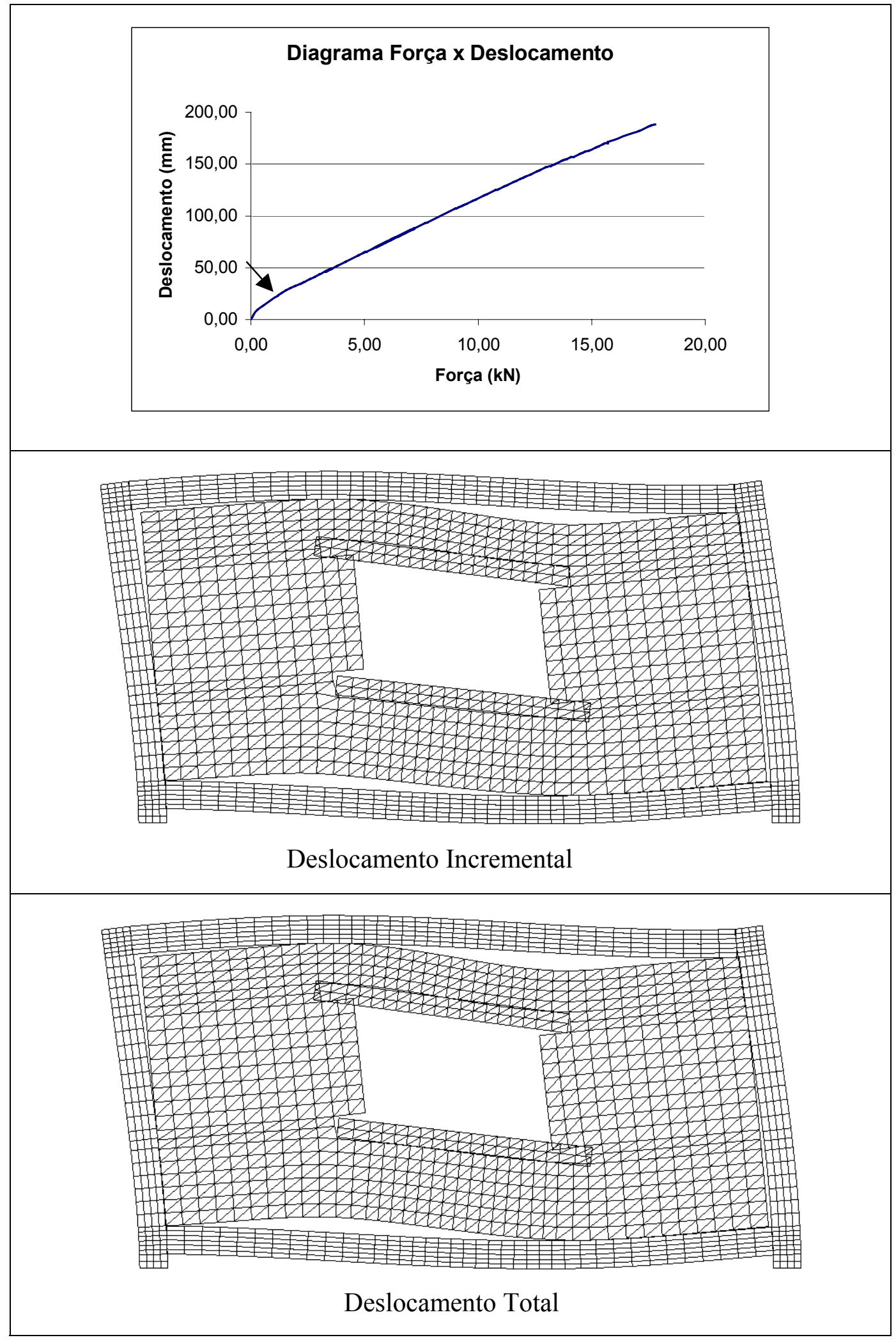

FIGURA 5.63 - Resultados da análise numérica do sistema TIPO II - Ensaios 3B e 4B, para uma ação de $23,3 \mathrm{kN}$ 
(a)

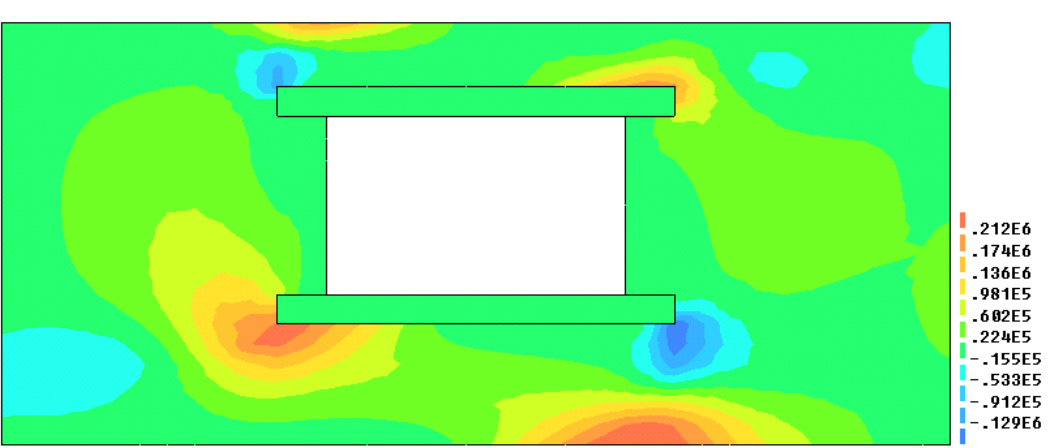

(b)

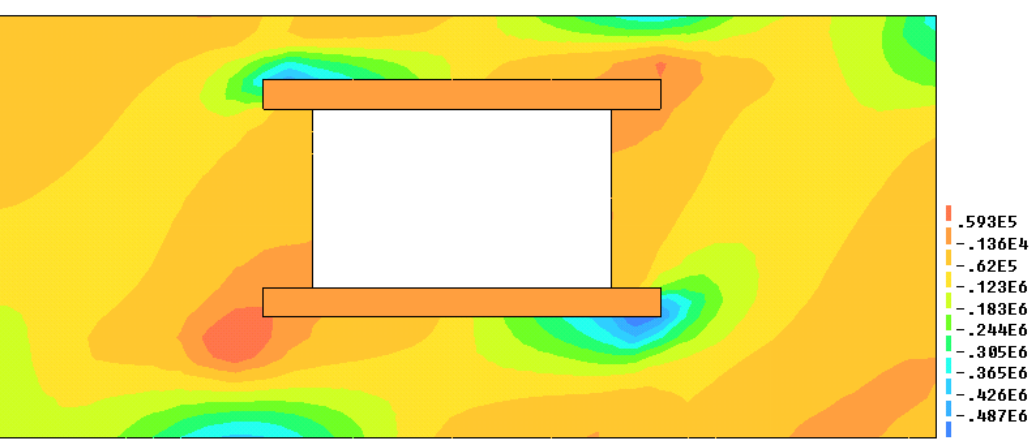

(c)

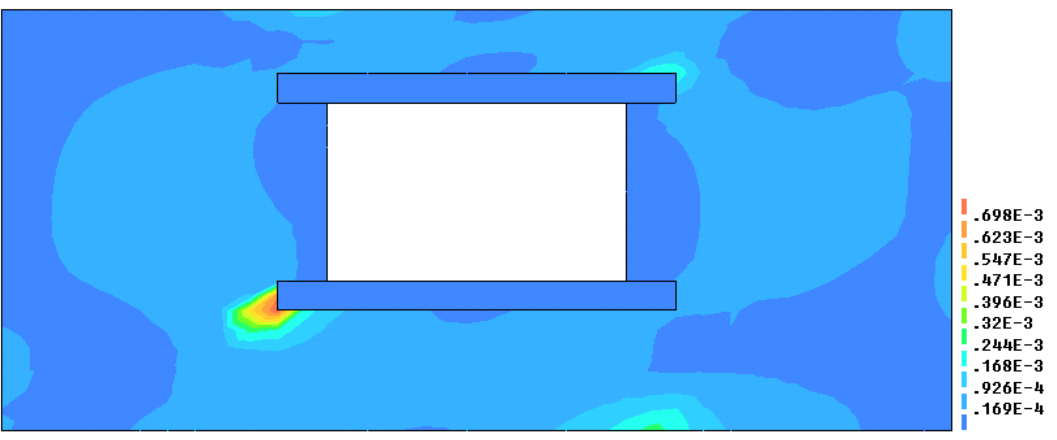

(d)

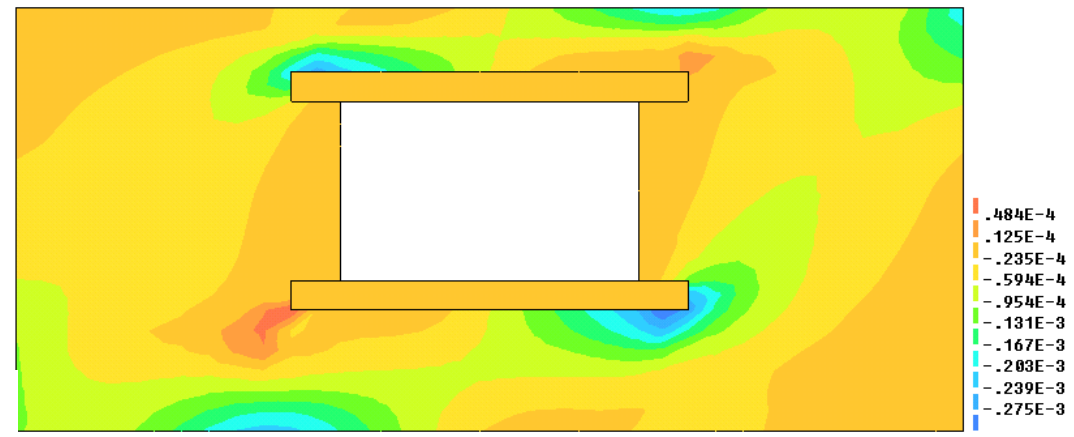

FIGURA 5.64 - Resultados da análise numérica do sistema TIPO II - Ensaios 3B e 4B, para uma ação horizontal de 23,3 kN: a) tensões principais máximas, b) tensões principais mínimas, c) deformações principais máximas e d) deformações principais mínimas. Unidades (Newton e metro) 


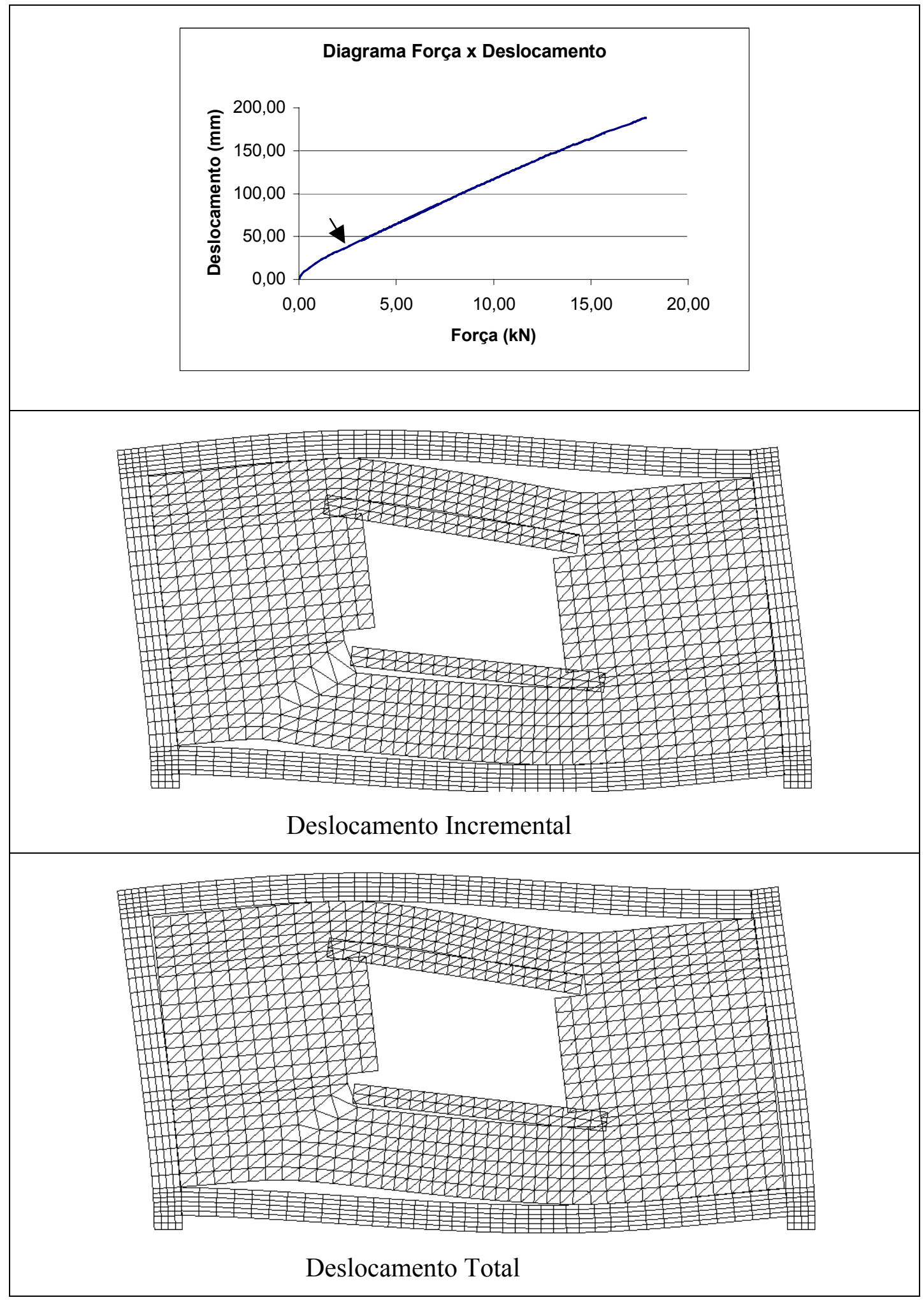

FIGURA 5.65 - Resultados da análise numérica do sistema TIPO II - Ensaios 3B e 4B, para uma ação de $41,3 \mathrm{kN}$ 
(a)

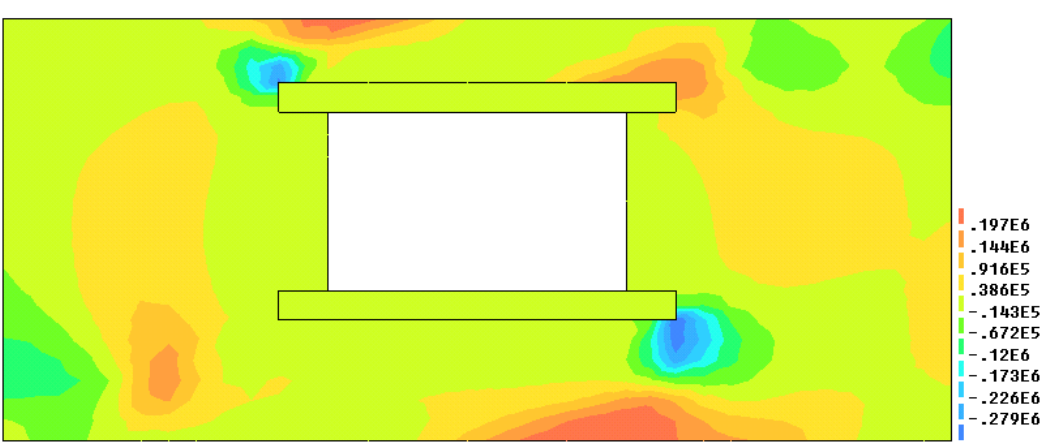

(b)

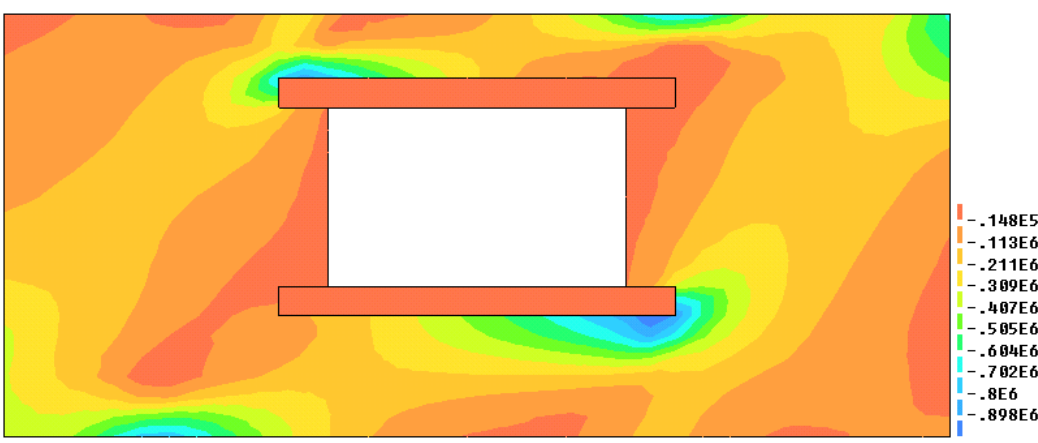

(c)

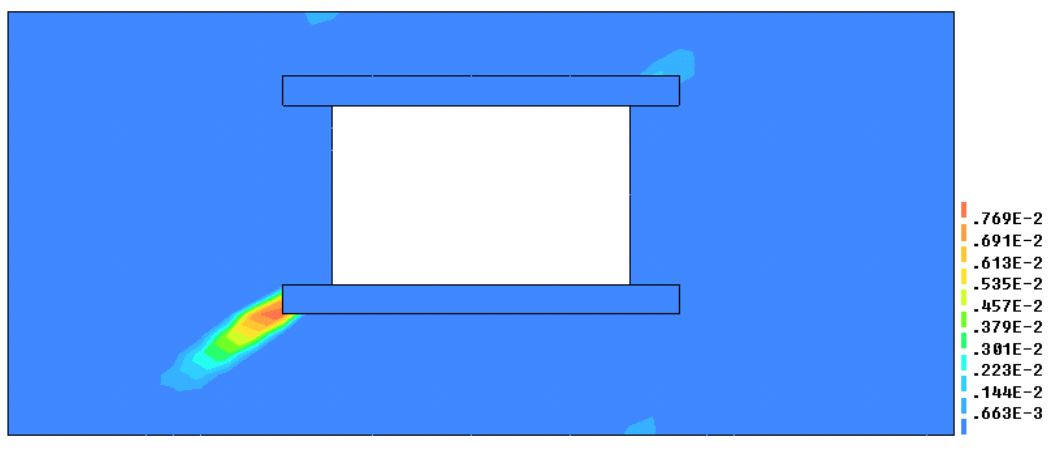

(d)

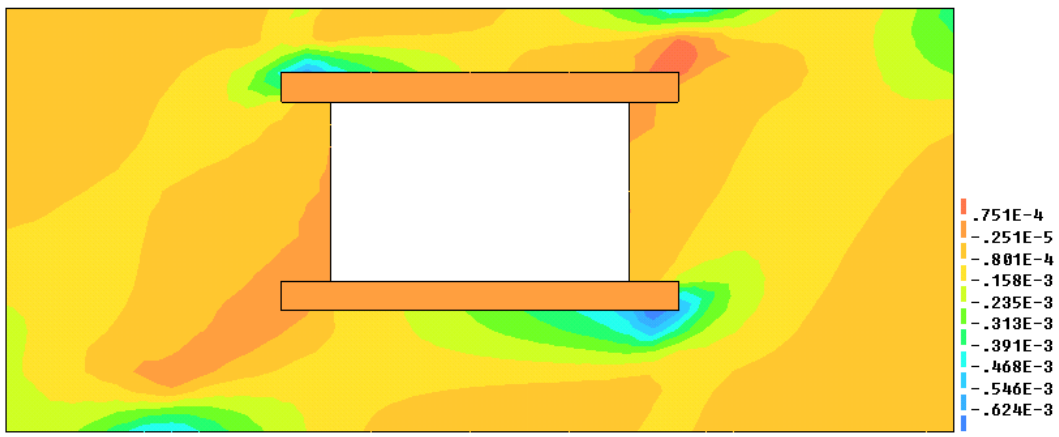

FIGURA 5.66 - Resultados da análise numérica do sistema TIPO II - Ensaios 3B e 4B, para uma ação horizontal de 41,3 kN: a) tensões principais máximas, b) tensões principais mínimas, c) deformações principais máximas e d) deformações principais mínimas. Unidades (Newton e metro) 


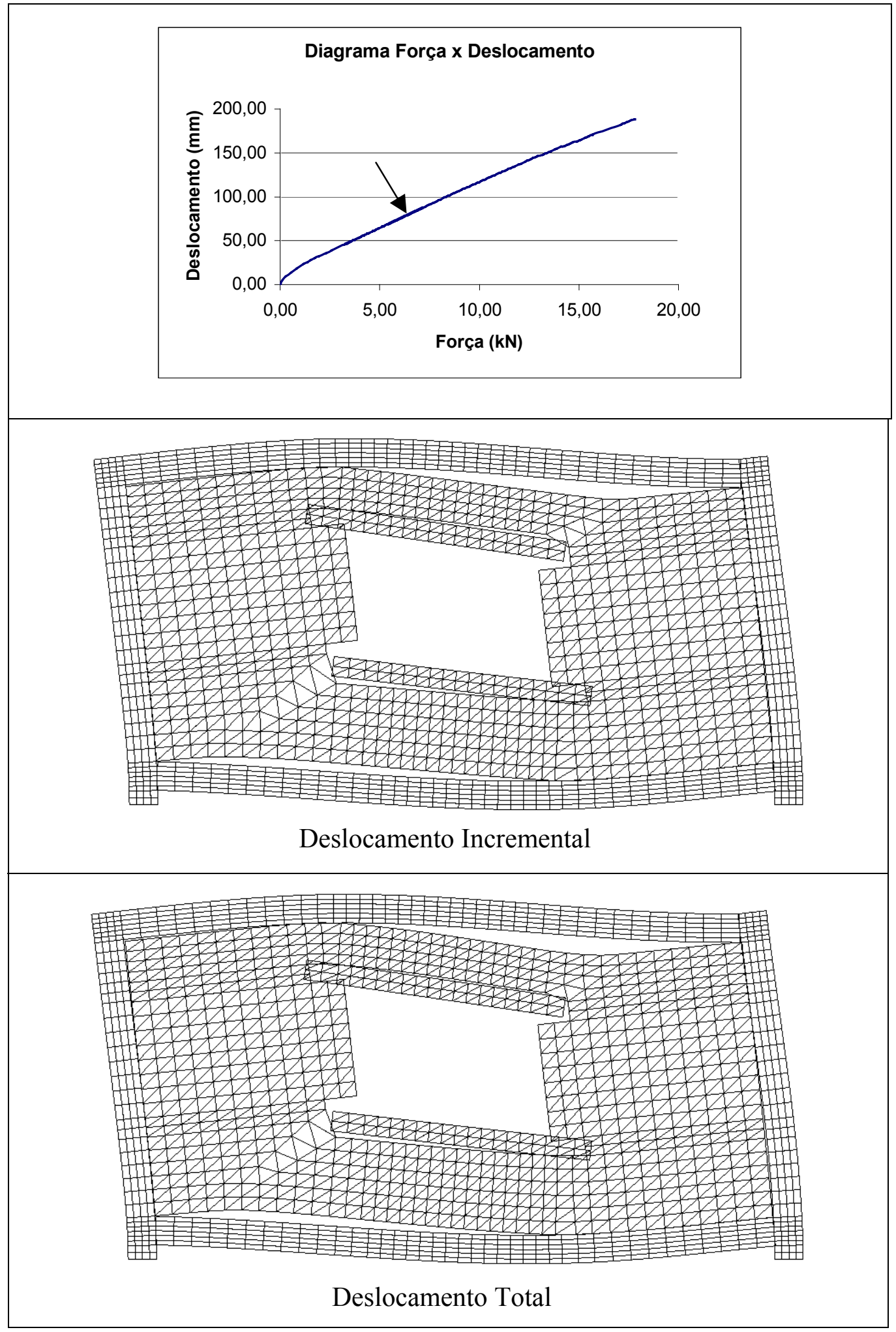

FIGURA 5.67 - Resultados da análise numérica do sistema TIPO II - Ensaios 3B e 4B, para uma ação de $76,5 \mathrm{kN}$ 
(a)

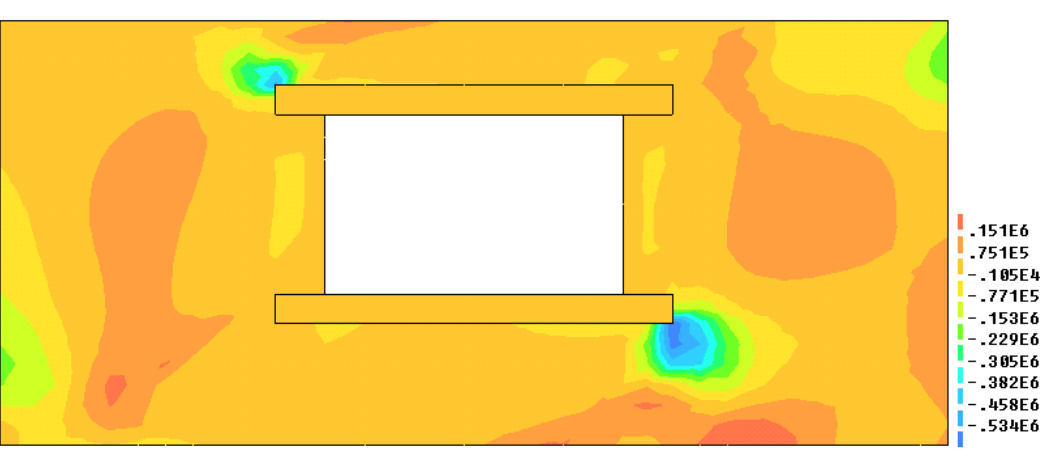

(b)

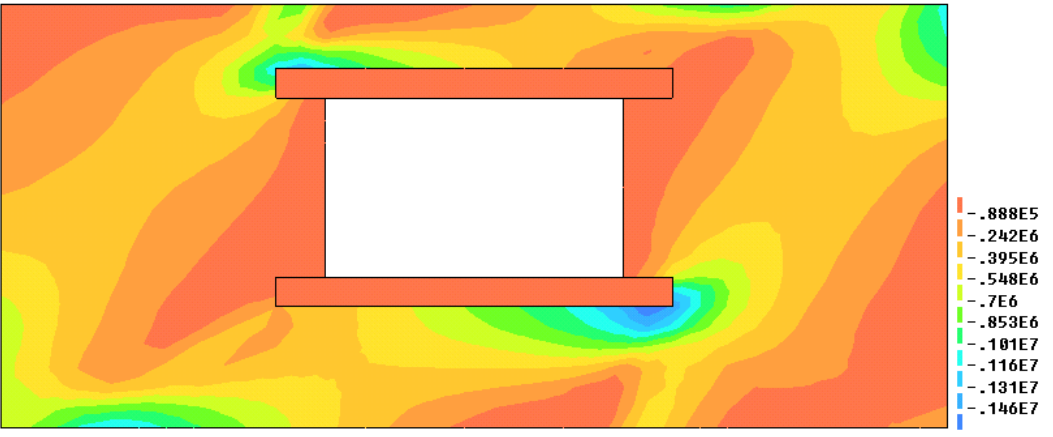

(c)

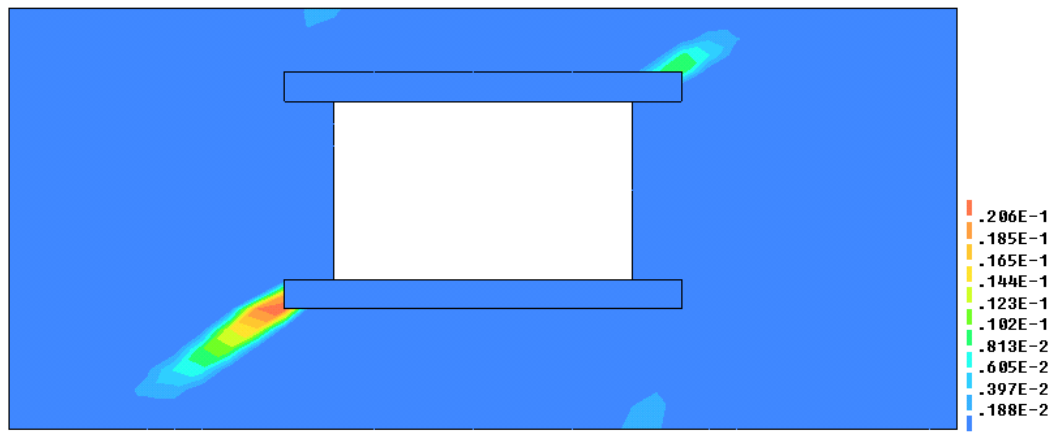

(d)

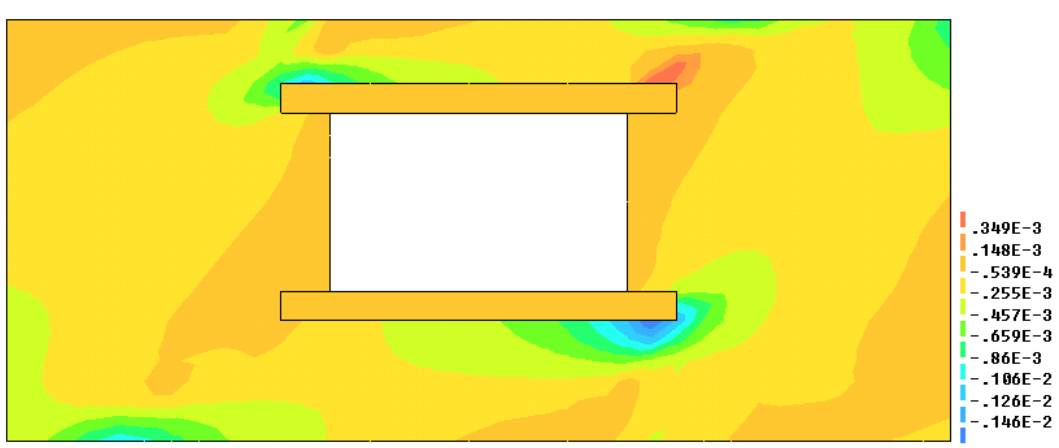

FIGURA 5.68 - Resultados da análise numérica do sistema TIPO II - Ensaio 3B e

4B, para ação horizontal de $76,5 \mathrm{kN}$ : a) tensões principais máximas, b) tensões principais mínimas, c) deformações principais máximas e d) deformações principais mínimas. Unidades (Newton e metro) 


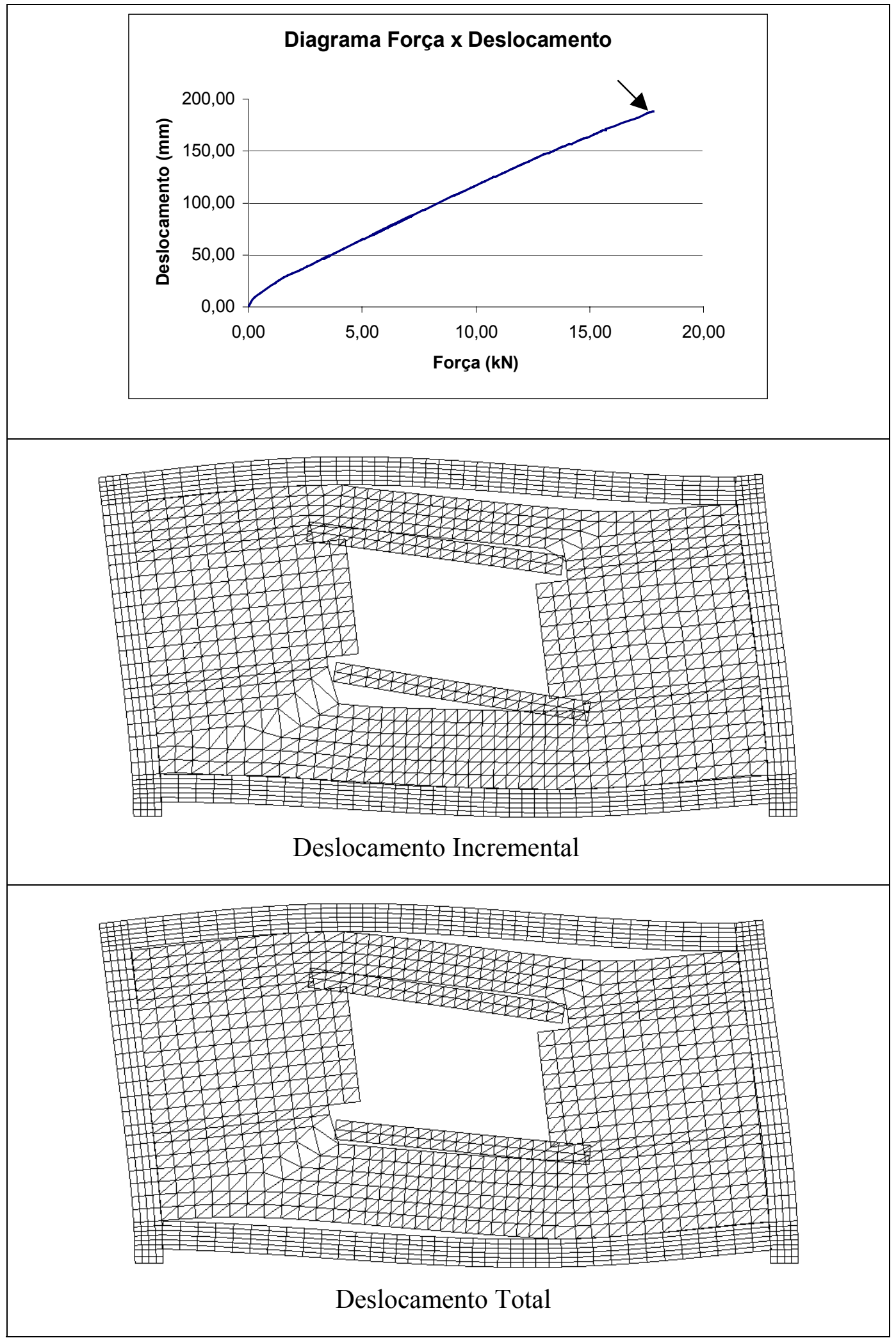

FIGURA 5.69 - Resultados da análise numérica do sistema TIPO II - Ensaios 3B e 4B, para uma ação de $188 \mathrm{kN}$ 
(a)

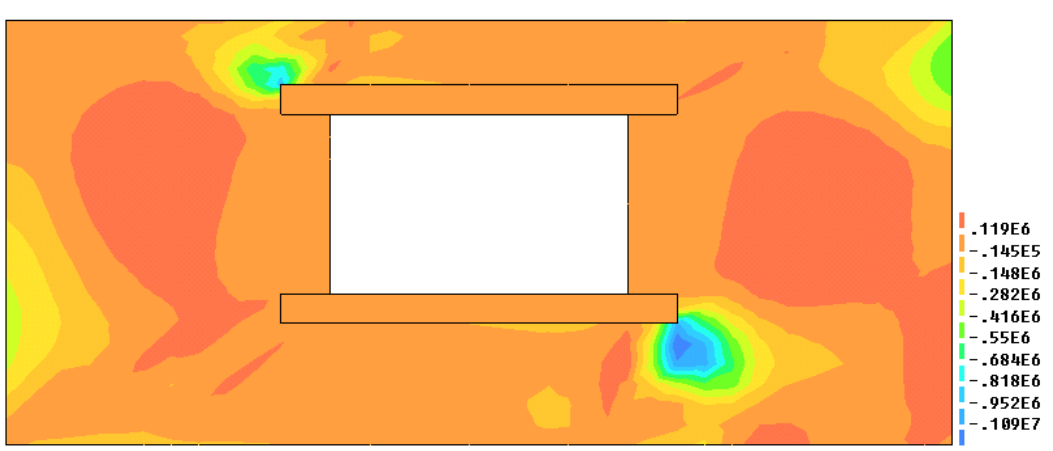

(b)

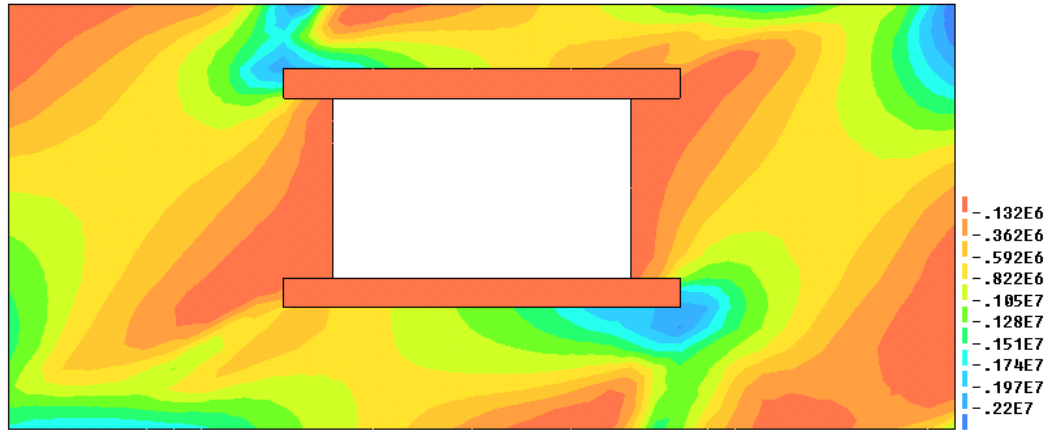

(c)

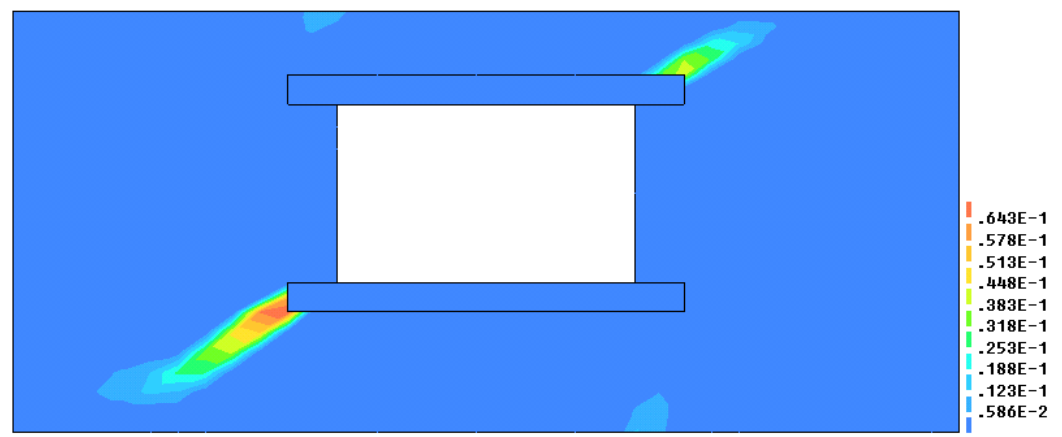

(d)

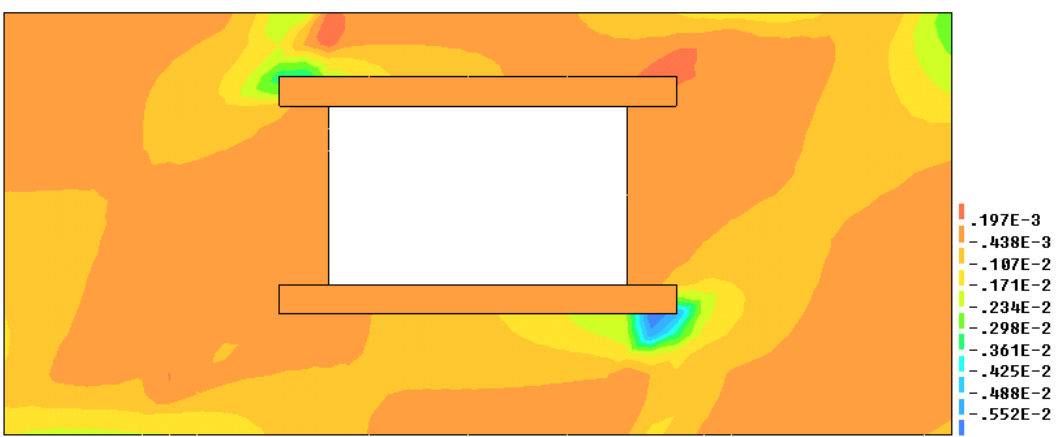

FIGURA 5.70 - Resultados da análise numérica do sistema TIPO II - Ensaios 3B e 4B, para uma ação horizontal de 41,3 kN: a) tensões principais máximas, b) tensões principais mínimas, c) deformações principais máximas e d) deformações principais mínimas. Unidades (Newton e metro) 


\subsubsection{6 - ANÁLISE COMPARATIVA ENTRE RESULTADOS NUMÉRICOS E EXPERIMENTAIS: SÉRIE B, PAREDES COM ABERTURA}

$\mathrm{Na}$ figura 5.71, apresentam-se os diagramas força-deslocamento obtidos através de ensaios experimentais e das modelagens numéricas realizadas. $\mathrm{Na}$ primeira modelagem não se fez distinção entre alvenaria, verga e contraverga, e a modelagem numérica apresentou um modelo mais rígido que o experimental. Na segunda modelagem, a alvenaria foi modelada como um contínuo, sendo utilizados elementos de interface entre verga-alvenaria e contraverga-alvenaria.

$\mathrm{Na}$ primeira modelagem, foi possível a obtenção da curva completa, apresentada anteriormente. Para facilitar a comparação entre os resultados numéricos e experimentais, nesse item são apresentados os diagramas numéricos até a forçalimite obtida nos ensaios. Pôde-se notar que a rigidez inicial em todos os casos foi quase a mesma. No entanto, com o acréscimo de carga, o modelo numérico tornou-se mais rígido que o experimental. Para uma força de $90 \mathrm{kN}$, a rigidez obtida numericamente tornou-se cerca de $90 \%$ superior à experimental.

$\mathrm{Na}$ segunda modelagem, tanto a rigidez inicial quanto aquela correspondente à força de $90 \mathrm{kN}$ se aproximam da experimental. Para uma força de $90 \mathrm{kN}$, a rigidez obtida numericamente foi cerca de $25 \%$ superior à experimental.

Pôde-se notar que os valores apresentados pela segunda modelagem se aproximaram melhor dos resultados experimentais, pois permitiram o deslocamento relativo verga (contraverga) e painel. $\mathrm{O}$ fato de se considerar o deslizamento entre verga (contraverga) e alvenaria, através da introdução da interface nessa posição, justificou-se em virtude de ambos terem dimensões consideráveis: 15 x 30 x 200 $\mathrm{cm}^{3}$, o que dificultou o assentamento sobre os blocos. Dessa forma, é possível que tenha havido falhas no preenchimento das juntas entre elas e os blocos, provocando perda de rigidez para o conjunto. Pôde-se perceber que a análise numérica permite salientar a influência significativa da rigidez verga-painel na resposta da estrutura. 


\section{Diagrama Força x Deslocamento}

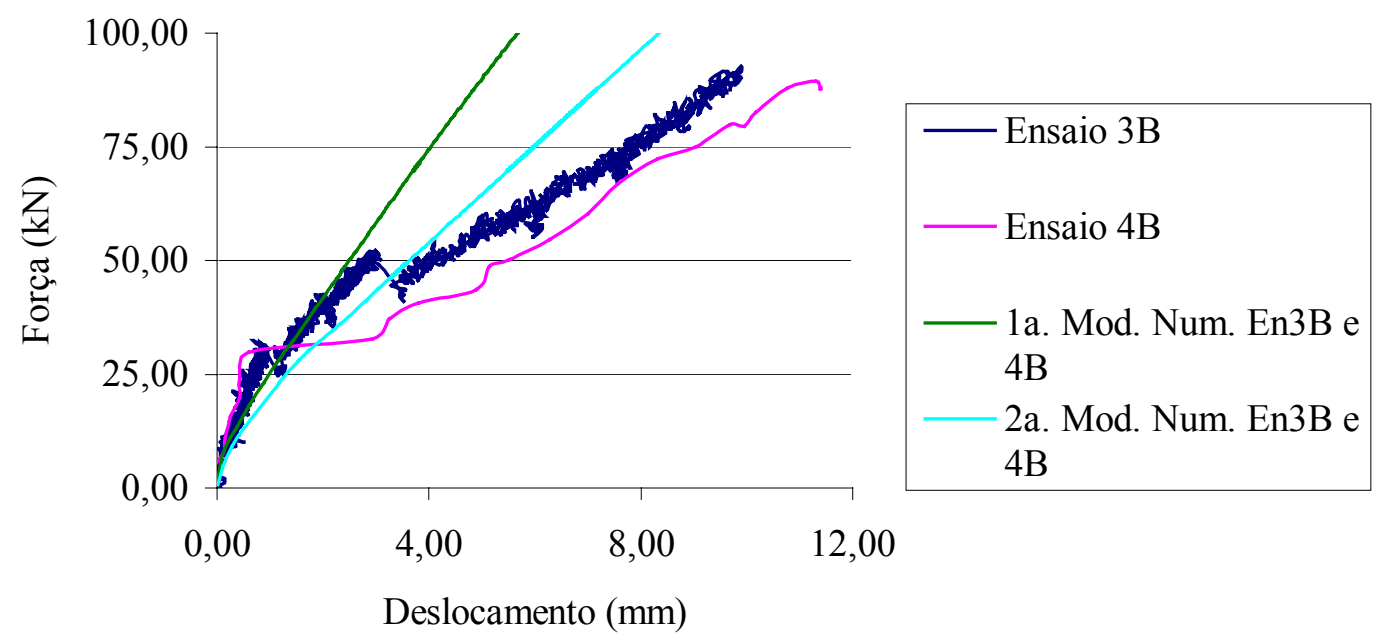

FIGURA 5.71 - Diagrama força-deslocamento para o sistema TIPO II: ensaios 3B e 4B e primeira e segunda modelagens

\section{4 - CONCLUSÕES}

Neste capítulo, apresenta-se a modelagem numérica relativa aos protótipos ensaiados, comparando os resultados obtidos com os experimentais. Foram modelados os ensaios $5 \mathrm{~A}$ e $6 \mathrm{~A}$ da série $\mathrm{A}$ e os ensaios $1 \mathrm{~B}, 2 \mathrm{~B}, 3 \mathrm{~B}$ e $4 \mathrm{~B}$ da série $\mathrm{B}$. Para fins de comparação entre resultados numéricos e experimentais, foi obtida a rigidez da estrutura correspondente a um deslocamento de $6 \mathrm{~mm}$, cujos valores são apresentados na tabela 5.2.

Comparando a rigidez dos ensaios $5 \mathrm{~A}$ e $6 \mathrm{~A}$ com a obtida através do modelo numérico, percebe-se que há grande concordância entre valores, no deslocamento de $6 \mathrm{~mm}$. As rigidezas obtidas foram, respectivamente, de 25,40 kN/mm, 29,17 kN/mm e $29,17 \mathrm{kN} / \mathrm{mm}$, correspondendo a 12,57; 14,44; e 14,44 vezes, respectivamente, a rigidez do pórtico sem preenchimento. A modelagem numérica concordou exatamente com o comportamento do ensaio $6 \mathrm{~A}$. 
No sistema TIPO II, nomeadamente os ensaios $1 \mathrm{~B}$ e $2 \mathrm{~B}$, os valores de rigidez correspondentes a um deslocamento de $6 \mathrm{~mm}$ valem, respectivamente, $18,83 \mathrm{kN} / \mathrm{mm}$ e $21,88 \mathrm{kN} / \mathrm{mm}$, enquanto nas duas modelagens numéricas o valor encontrado foi de $24,97 \mathrm{kN} / \mathrm{mm}$. Esses valores correspondiam a 9,32; 10,83; e 12,36 vezes, respectivamente, a rigidez do pórtico sem preenchimento. $\mathrm{O}$ modelo numérico foi, para o deslocamento de $6 \mathrm{~mm}, 21 \%$ mais rígido que a média dos resultados dos ensaios experimentais.

Nos ensaios 3B e 4B, os valores das rigidezas obtidos com as modelagens e experimentalmente foram, respectivamente, de $17,00 \mathrm{kN} / \mathrm{mm}, 12,50 \mathrm{kN} / \mathrm{mm}, 10,42$ $\mathrm{kN} / \mathrm{mm}$ e $8,75 \mathrm{kN} / \mathrm{mm}$, que corresponderam a 8,$42 ; 6,19 ; 5,16$; e 4,33 vezes a rigidez do pórtico sem preenchimento. A segunda modelagem apresentou um valor 30,5\% superior ao da média dos valores experimentais, enquanto a primeira modelagem foi $77,82 \%$ maior. Essa diferença entre as duas modelagens numéricas permitiu salientar a influência significativa da rigidez verga-painel na resposta da estrutura.

Tendo em vista os resultados apresentados na tabela 5.2, verifica-se que os painéis de alvenaria contribuem, de forma muito significativa, para a rigidez de pórticos preenchidos, apresentando aumento de até 14 vezes a rigidez global da estrutura. $\mathrm{O}$ modelo numérico utilizado para análise indicou ser adequado para análise de pórticos sem aberturas, como pode ser observado no caso dos ensaios $5 \mathrm{~A}$ e $6 \mathrm{~A}$, em que os valores numéricos e experimentais coincidiram. 
TABELA 5.2 - Valores da rigidez obtida nos ensaios experimentais e nas modelagens numéricas realizadas $(\mathrm{kN} / \mathrm{mm})$

\begin{tabular}{|c|c|c|}
\hline MODELO & $\begin{array}{c}\text { FATOR DE RIGIDEZ } \\
\qquad K=\Delta P / \Delta u\end{array}$ & $\begin{array}{c}\text { RELAÇÃO } \\
\text { K/K PÓRTICO SEM } \\
\text { PREENCHIMENTO }\end{array}$ \\
\hline Ensaio Experimental $5 \mathrm{~A}^{1}$ & 25,40 & 12,57 \\
\hline Ensaio Experimental $6 \mathrm{~A}^{1}$ & 29,17 & 14,44 \\
\hline Modelo Numérico Ens. $5 \mathrm{~A}$ e $6 \mathrm{~A}^{1}$ & 29,17 & 14,44 \\
\hline Ensaio Experimental $1 \mathrm{~B}^{1}$ & 18,83 & 9,32 \\
\hline Ensaio Experimental 2B ${ }^{1}$ & 21,88 & 10,83 \\
\hline $1^{\circ}$ Modelo Numérico Ens. $1 \mathrm{~B}$ e $2 \mathrm{~B}^{1}$ & 24,97 & 12,36 \\
\hline $2^{\circ}$ Modelo Numérico Ens. 1B e $2 \mathrm{~B}^{1}$ & 24,97 & 12,36 \\
\hline Ensaio Experimental $3 \mathrm{~B}^{2}$ & 10,42 & 5,16 \\
\hline Ensaio Experimental 4B ${ }^{2}$ & 8,75 & 4,33 \\
\hline $1^{\circ}$ Modelo Numérico Ens. 3B e $4 \mathrm{~B}^{2}$ & 17,00 & 8,42 \\
\hline $2^{\circ}$ Modelo Numérico Ens. 3B e $4 \mathrm{~B}^{2}$ & 12,50 & 6,19 \\
\hline Pórtico TIPOI - Pré-Ensaio & 2,02 & 1,00 \\
\hline Pórtico TIPOI - Pré-Ensaio & 2,02 & 1,00 \\
\hline Pórtico TIPO II - Pré-Ensaio & 2,02 & 1,00 \\
\hline Pórtico TIPO II - Pré-Ensaio & 2,02 & 1,00 \\
\hline
\end{tabular}

${ }^{1}$ Rigidez correspondente a um deslocamento de $6 \mathrm{~mm} \mathrm{e}^{2}$ rigidez correspondente a um deslocamento de $5 \mathrm{~mm}$. 


\section{CAPÍtulo 06}

\section{ESTUDO PARAMÉTRICO}

Como discutido anteriormente, vários pesquisadores em todo o mundo têm realizado testes experimentais, com o objetivo de avaliar os parâmetros que afetam o comportamento de pórticos preenchidos. No entanto, a validade dos resultados obtidos são, muitas vezes, discutíveis, em virtude da grande variabilidade das propriedades físicas dos painéis de alvenaria, aliada ao grande número de variáveis que influenciam o comportamento desse tipo de estrutura. Além disso, o comportamento força-deslocamento de sistemas de pórticos preenchidos pode ser significativamente influenciado por certos parâmetros que não foram especificamente estudados no programa experimental.

No que diz respeito a esta tese, no programa experimental se avaliou o comportamento de pórticos com relações altura/comprimento 0,83 e 0,51, respectivamente, sob a ação de uma força horizontal aplicada no eixo da viga superior. No entanto, somente os resultados desses dois pórticos não são suficientes para uma avaliação ampla do comportamento de sistemas de pórticos preenchidos. Dessa forma, realizou-se um estudo paramétrico, através de modelagens numéricas, cujos resultados analíticos, na forma de curvas de comportamento força- 
deslocamento, são apresentados e discutidos neste capítulo, para uma gama de pórticos preenchidos com dimensões e rigidezas variáveis. O modelo numérico utilizado, apresentado no capítulo 5, representa, de forma satisfatória, o comportamento experimental de pórticos preenchidos com alvenaria.

Os principais objetivos deste estudo foram avaliar e identificar os efeitos dos principais parâmetros que afetam o comportamento de pórticos preenchidos, a fim de que seja possível a proposição de recomendações práticas de projeto, que será objeto de estudo do capítulo 7.

\section{1 - RELAÇÃO ALTURA/COMPRIMENTO (H/L)}

Para avaliar o efeito da relação altura/comprimento dos pórticos no comportamento dos sistemas compostos, foi realizado um estudo paramétrico considerando relações $\mathrm{H} / \mathrm{L}$ iguais a 0,$51 ; 0,60 ; 0,70 ; 0,83$ e 1,00 , em que $\mathrm{H}$ e $\mathrm{L}$ são, respectivamente, a altura e o comprimento dos pórticos. Os sistemas TIPO I e TIPO II, ensaiados experimentalmente, correspondem às relações $\mathrm{H} / \mathrm{L}$ iguais a 0,51 e 0,83 , respectivamente. Todos os pórticos possuíam altura de $268 \mathrm{~cm}$ e comprimento variável, conforme representado na figura 6.1. Para fins de avaliação do parâmetro H/L e comparação com os resultados experimentais, todos os pórticos foram modelados com as mesmas propriedades físicas, descritas na tabela 5.1. As ligações viga-pilar foram consideradas rígidas, semi-rígidas e articuladas.

Em todas as análises numéricas, adotou-se o mesmo modelo, que consistiu da associação do painel de alvenaria com o pórtico de aço e elementos de interface vigapilar, pórtico-alvenaria e alvenaria-alvenaria, esta última na direção da diagonal comprimida do painel, conforme modelagem dos ensaios 5A e 6A. Os resultados das análises foram sintetizados nos diagramas força-deslocamento, apresentados nas figuras 6.2, 6.3 e 6.4, para ligações viga-pilar articuladas, semi-rígidas e rígidas, respectivamente. Em todos os casos, o descolamento da interface pórtico-painel ocorreu para baixos níveis de carga, tendo em vista que a tensão de tração nessa 
região foi considerada nula nas modelagens efetuadas. Pode-se perceber que as curvas força-deslocamento cresciam monotonicamente até a força correspondente à fissuração da diagonal, e a rigidez pós-descolamento dos pórticos preenchidos praticamente não variava com a relação altura/comprimento.

No que se refere aos modos de ruptura, notou-se que a força correspondente à fissuração da diagonal foi inversamente proporcional à relação altura/comprimento, ou seja, quanto menor o comprimento do pórtico e, conseqüentemente, maior a relação $\mathrm{H} / \mathrm{L}$, menor a força de fissuração da diagonal. Em todos os casos estudados, com exceção daquele referente à relação $\mathrm{H} / \mathrm{L}=0,51$ e ligações articuladas, o modo de ruptura foi a fissuração da diagonal. Nesse caso específico, o modo de ruptura foi por esmagamento dos cantos comprimidos. Ainda para a relação $H / L=0,51$, à medida que aumenta a rigidez da ligação, surge a ruptura por fissuração da diagonal. No caso da ligação semi-rígida, esse nível de carga foi equivalente àquele que provocava o esmagamento dos cantos comprimidos, enquanto na ligação rígida a ruptura ocorria por fissuração da diagonal.

No que se refere à força correspondente ao esmagamento dos cantos comprimidos, seus valores foram proporcionais à relação altura/comprimento e, também, à rigidez da ligação viga-pilar.

A ocorrência da fissuração da diagonal nos pórticos preenchidos com alvenaria não implica esgotamento de sua capacidade resistente. O painel fissurado, que é confinado pelo pórtico, pode desenvolver novos caminhos para as tensões e absorver acréscimos de carga. O esmagamento dos cantos comprimidos configura um estadolimite último, como pode ser observado pelas figuras $6.2,6.3$ e 6.4 , já referidas. No entanto, a fissuração da diagonal corresponde a um estado-limite de utilização e, como tal, deve também ser limitada. 

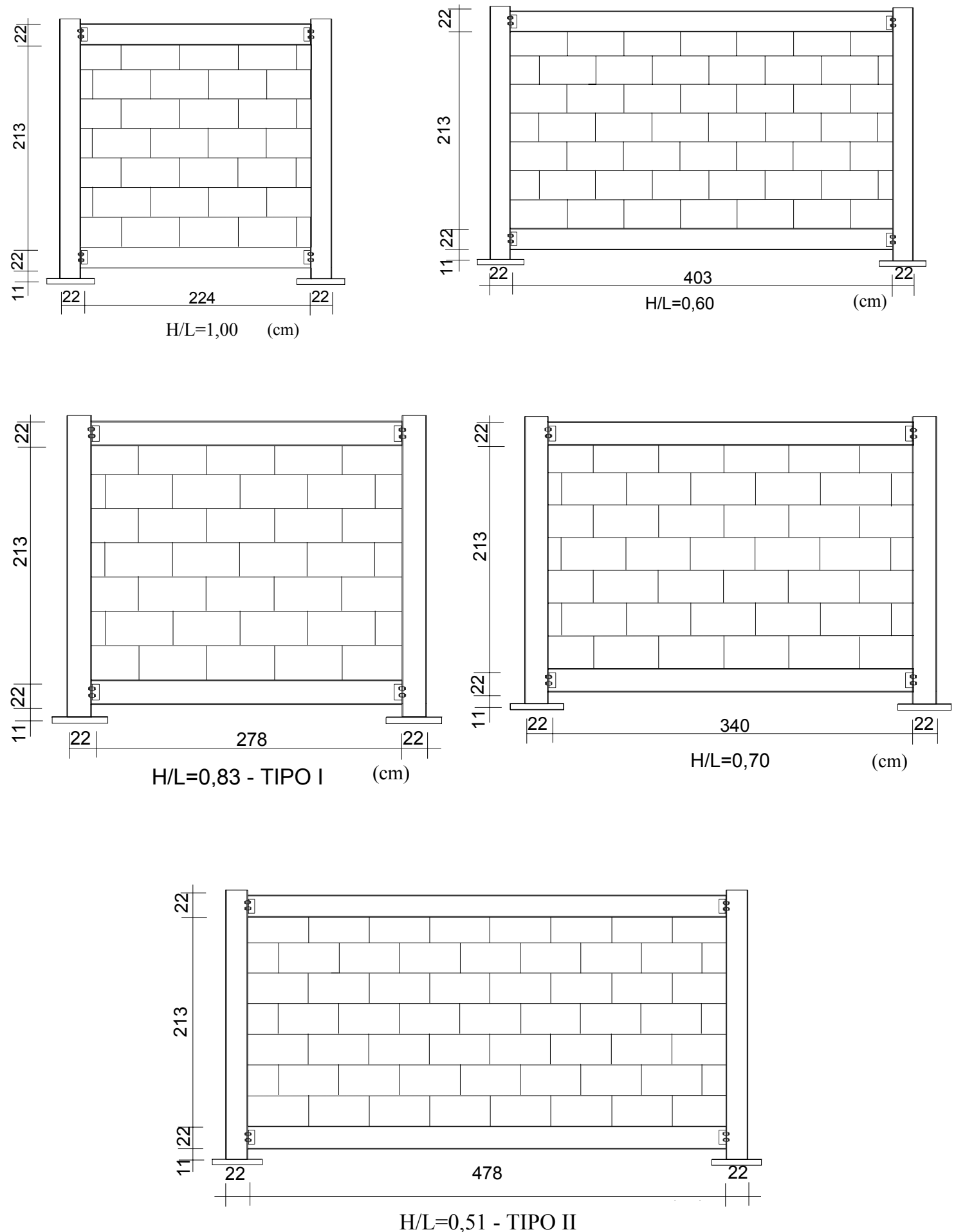

FIGURA 6.1 - Modelos de sistemas de pórticos preenchidos utilizados no estudo paramétrico 


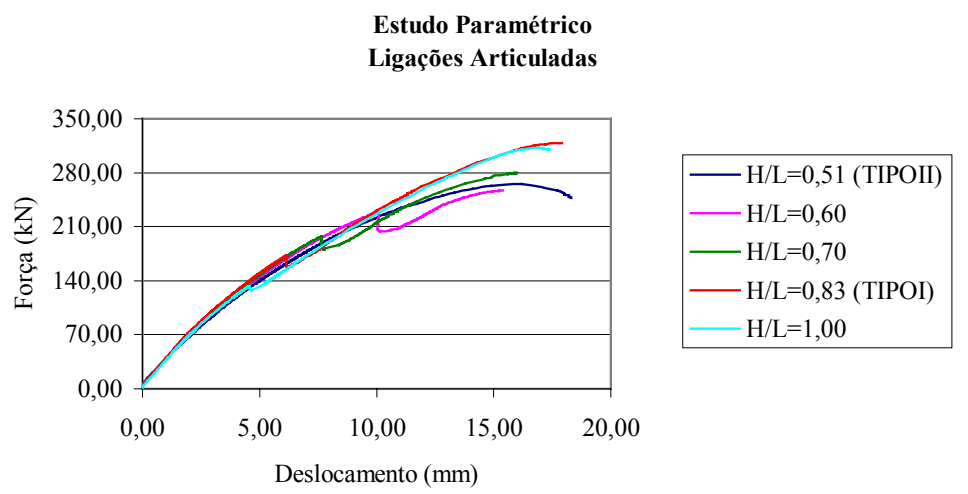

FIGURA 6.2 - Diagrama força-deslocamento para diferentes relações H/L e ligações viga-pilar articuladas

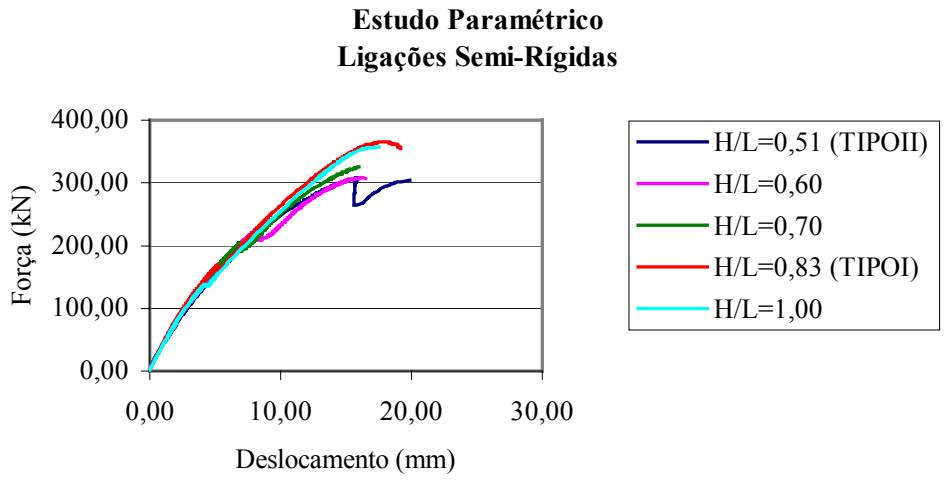

FIGURA 6.3 - Diagrama força-deslocamento para diferentes relações H/L e ligações viga-pilar semi-rígidas

\section{Estudo Paramétrico}

Ligações Rígidas
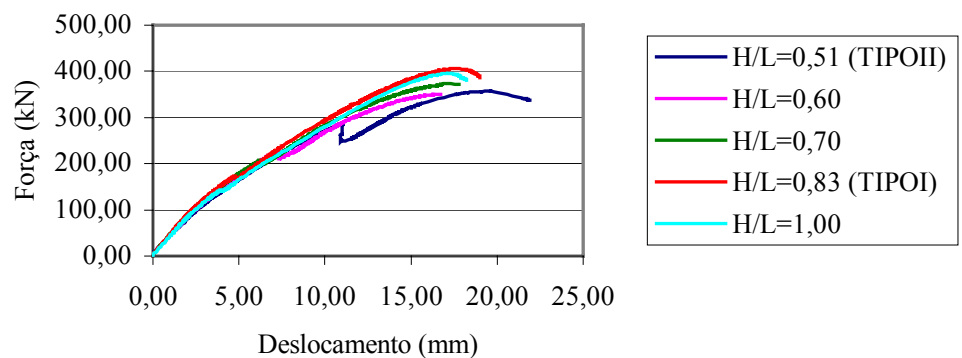

FIGURA 6.4 - Diagrama força-deslocamento para diferentes relações H/L e ligações viga-pilar rígidas 


\section{2 - RIGIDEZ DA LIGAÇÃO VIGA-PILAR}

Para avaliar o efeito da rigidez das ligações viga-pilar em sistemas de pórticos preenchidos com alvenaria, apresenta-se a figura 6.5 para as relações $\mathrm{H} / \mathrm{L}$ iguais a 0,$51 ; 06 ; 0,70 ; 0,83 ;$ e 1,00, respectivamente. Em cada gráfico é mostrado o diagrama força-deslocamento correspondente às ligações articulada, rígida e semi-rígida, respectivamente. Esses diagramas se referem aos resultados obtidos da análise apresentada no item 6.1. No entanto, com o intuito de avaliar a rigidez da ligação, cada uma das relações H/L são apresentadas individualmente para cada tipo de ligação: rígida, semi-rígida e articulada.

Pelas figuras apresentadas, nota-se que o valor da força correspondente à fissuração da diagonal pouco se altera com a variação de rigidez das ligações viga-pilar. Esse efeito fica mais claro à medida que a relação $\mathrm{H} / \mathrm{L}$ cresce. No caso da menor relação analisada, $\mathrm{H} / \mathrm{L}=0,51$, com o aumento da rigidez da ligação surge o modo de ruptura por fissuração da diagonal, que para as ligações articuladas não se manifesta. No entanto, a força correspondente à fissuração é praticamente equivalente àquela que provoca o esmagamento dos cantos comprimidos. Esse esmagamento cresce com o aumento da rigidez da ligação viga-pilar, mas como se procura a menor força entre aquelas que provocam a ruptura, quer por fissuração, quer por esmagamento, pode-se perceber que em todos os casos analisados a ruptura deu-se, primeiramente, por fissuração. Dessa forma, pode-se concluir que a força correspondente ao primeiro modo de ruptura não varia significativamente com a rigidez da ligação.

Na tabela 6.1, apresentam-se as forças correspondentes à fissuração da diagonal e ao esmagamento dos cantos comprimidos, para cada uma das relações altura/comprimento e condições de vinculação viga-pilar. 


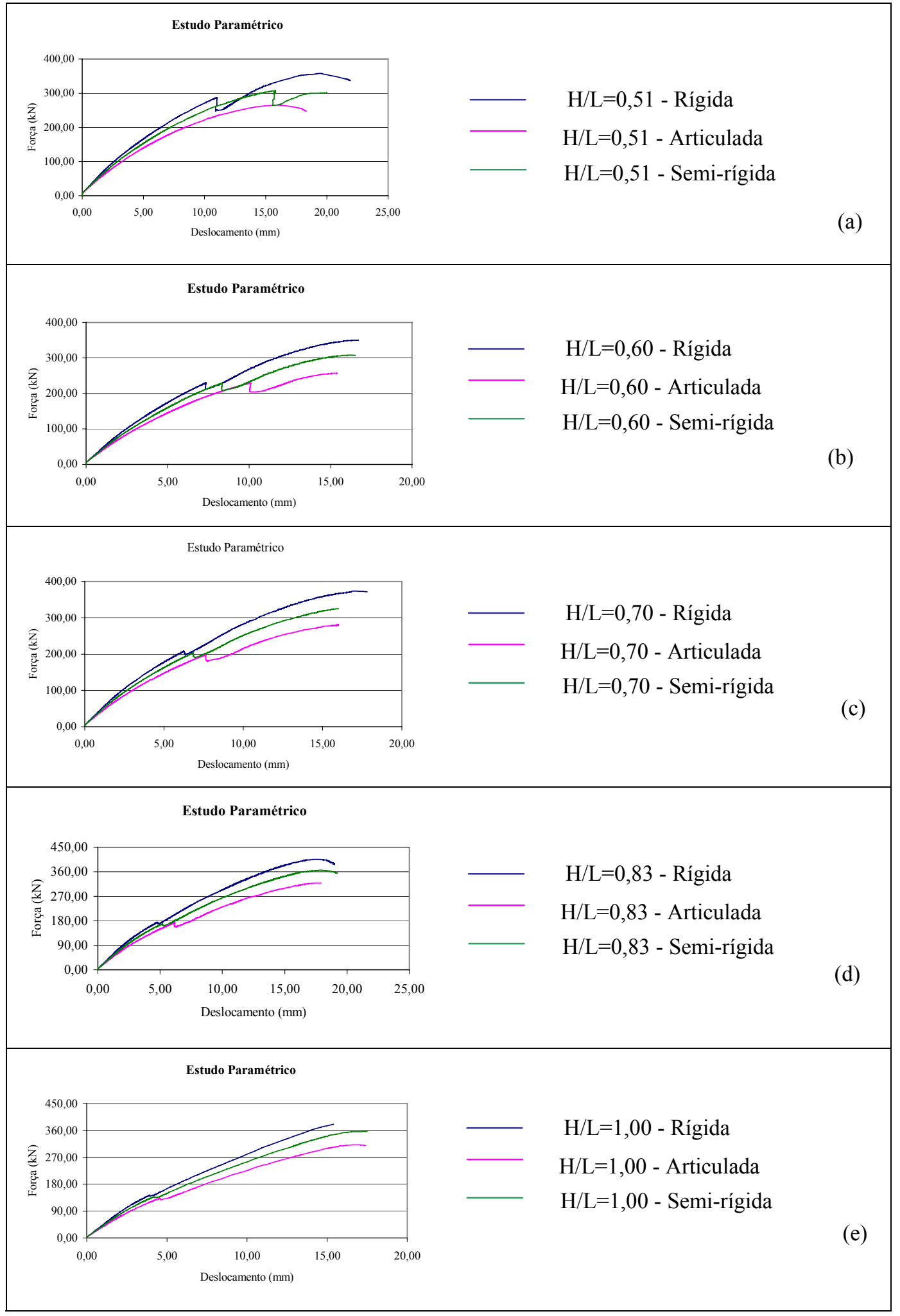

FIGURA 6.5 - Diagrama força-deslocamento para diferentes relações H/L e diferentes rigidezas para as ligações viga-pilar 
$\mathrm{Na}$ figura 6.6, apresentam-se para cada relação $\mathrm{H} / \mathrm{L}$ os valores das forças de fissuração da diagonal para ligações rígidas, semi-rígidas e articuladas. Nessa figura, fica nítida a pouca influência da rigidez da ligação na força de fissuração da diagonal. $\mathrm{O}$ mesmo não se pode dizer com relação à força de esmagamento dos cantos comprimidos. Pela figura 6.7, pode-se perceber que essa força é mais sensível à variação da rigidez da ligação.

TABELA 6.1 - Forças correspondentes aos modos de ruptura para cada uma das relações $\mathrm{H} / \mathrm{L}$ (unidade $\mathrm{kN}$ )

\begin{tabular}{|c|c|c|c|c|c|c|}
\hline \multirow{2}{*}{ Lig.VP/L } & $\begin{array}{c}\text { MODO } \\
\text { RUPTURA }\end{array}$ & $\mathbf{0 , 5 1}$ & $\mathbf{0 , 6 0}$ & $\mathbf{0 , 7 0}$ & $\mathbf{0 , 8 3}$ & $\mathbf{1 , 0 0}$ \\
\hline \multirow{2}{*}{ Articulada } & Fissuração & - & 230,00 & 197,00 & 165,00 & 133,00 \\
\cline { 2 - 7 } & Esmagamento & 265,00 & 257,00 & 280,00 & 311,00 & 312,00 \\
\hline \multirow{2}{*}{$\begin{array}{c}\text { Semi- } \\
\text { rígida }\end{array}$} & Fissuração & 308,00 & 229,00 & 204,00 & 167,00 & 138,00 \\
\cline { 2 - 7 } & Esmagamento & 307,00 & 308,00 & 325,00 & 355,00 & 357,00 \\
\hline \multirow{2}{*}{ Rígida } & Fissuração & 288,00 & 230,00 & 208,00 & 174,00 & 143,00 \\
\cline { 2 - 7 } & Esmagamento & 357,00 & 350,00 & 373,00 & 403,00 & 395,00 \\
\hline
\end{tabular}

Fissuração da Diagonal

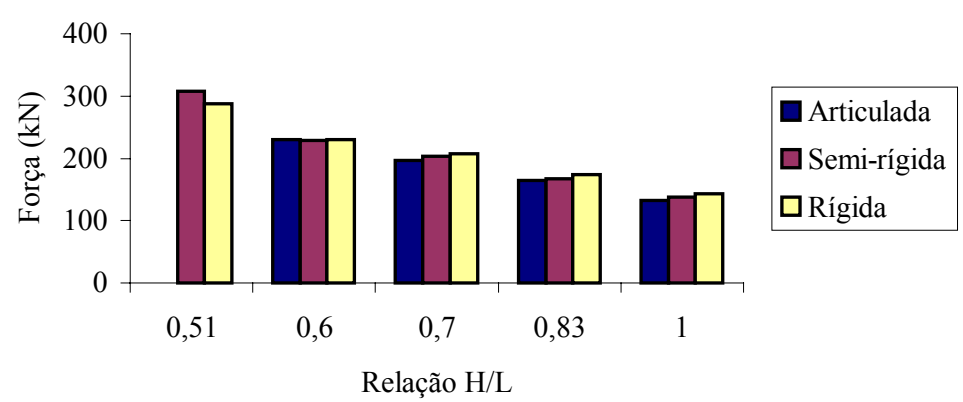

FIGURA 6.6 - Forças correspondentes à fissuração da diagonal para as relações H/L analisadas 
Para melhor interpretação dessa ocorrência, apresenta-se a figura 6.8, na qual são mostradas curvas relacionando o acréscimo da força de esmagamento dos cantos comprimidos com o aumento da rigidez da ligação (abscissa 1 se ligação rígida e 0 se articulada). Pode-se perceber que, no caso de ligações rígidas, a força de esmagamento cresce em até $35 \%$ em relação ao valor correspondente à ligação articulada.

\section{Esmagamento dos Cantos Comprimidos}

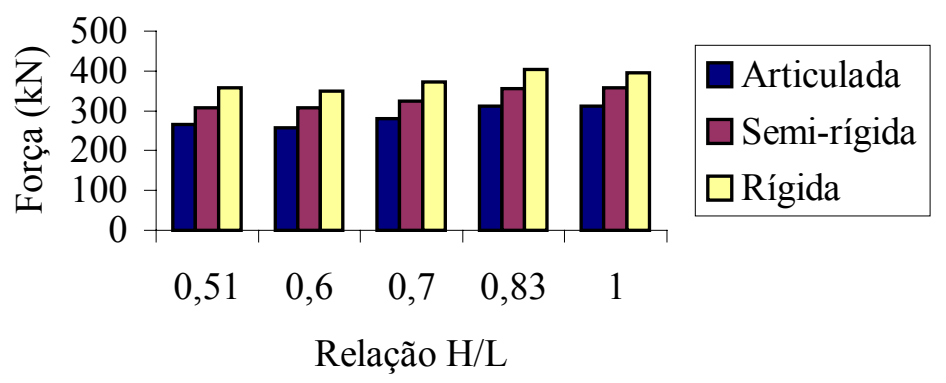

FIGURA 6.7 - Forças correspondentes ao esmagamento dos cantos comprimidos para as relações $\mathrm{H} / \mathrm{L}$ analisadas

\section{Variação da Força de Esmagamento com a Rigidez \\ Viga-Pilar}
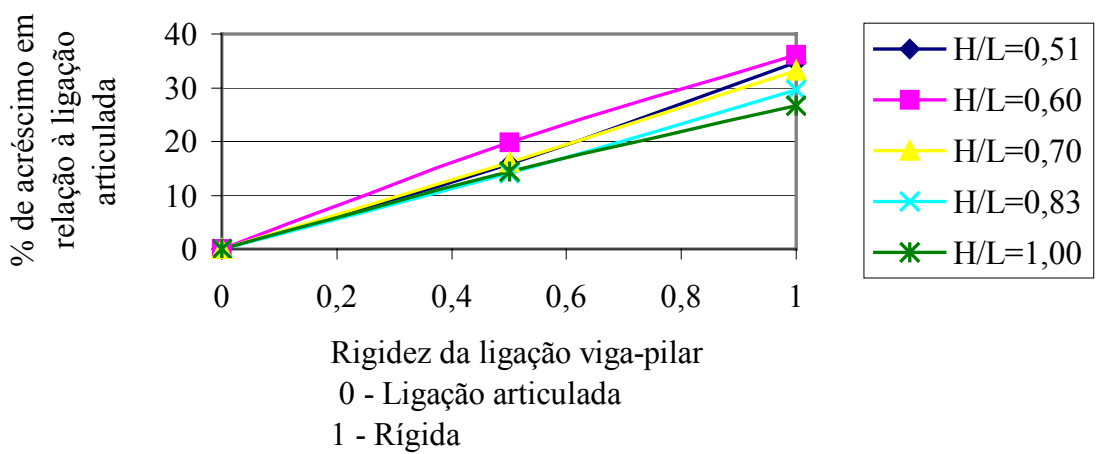

FIGURA 6.8 - Forças correspondentes ao esmagamento dos cantos comprimidos para as relações $\mathrm{H} / \mathrm{L}$ analisadas 


\section{3 - RIGIDEZ RELATIVA PÓRTICO-PAINEL DE ALVENARIA}

Para avaliar a influência da rigidez relativa pórtico-painel no comportamento de pórticos preenchidos com alvenaria, foram analisados sistemas cujos painéis apresentam módulos de deformações iguais a $875 \mathrm{MPa}, 1325 \mathrm{MPa}, 1750 \mathrm{MPa}, 2625$ MPa e $3500 \mathrm{MPa}$, que correspondem, respectivamente, a 0,$5 ; 0,75 ; 1,0 ; 1,5$; e 2 vezes o módulo de deformação obtido experimentalmente.

$\mathrm{Na}$ figura $6.9 \mathrm{a}$ a 6.9e, apresentam-se os diagramas força-deslocamento correspondentes a cada um dos módulos de deformação supracitados, para todas as relações $\mathrm{H} / \mathrm{L}$ consideradas. Em todos os casos, a rigidez inicial se manteve praticamente constante nas diferentes relações $\mathrm{H} / \mathrm{L}$, e as forças correspondentes à fissuração da diagonal foram inversamente proporcionais à relação $\mathrm{H} / \mathrm{L}$. Já aquelas relativas ao esmagamento dos cantos comprimidos cresceram proporcionalmente à relação $\mathrm{H} / \mathrm{L}$.

$\mathrm{Na}$ figura $6.10 \mathrm{a}$ a $6.10 \mathrm{e}$, são apresentados os diagramas força-deslocamento para cada uma das relações $\mathrm{H} / \mathrm{L}$ e para todas as variações atribuídas ao módulo de deformação da alvenaria.

Como era de se esperar, as forças correspondentes à fissuração da diagonal diminuíam com o aumento desses módulos, configurando-se mais uma vez como o primeiro modo de ruptura, com exceção da relação $\mathrm{H} / \mathrm{L}=0,51$ e do módulo de deformação de $875 \mathrm{MPa}$, em que esse tipo de ruptura não se manifestou.

Já as forças correspondentes ao esmagamento dos cantos comprimidos pouco variaram com o aumento do módulo de deformação e apresentaram valores maiores que aqueles relativos à fissuração da diagonal. São apresentados na tabela 6.2 os valores das forças correspondentes à fissuração da diagonal e ao esmagamento dos cantos comprimidos, para cada um dos módulos de deformação adotados para alvenaria. 


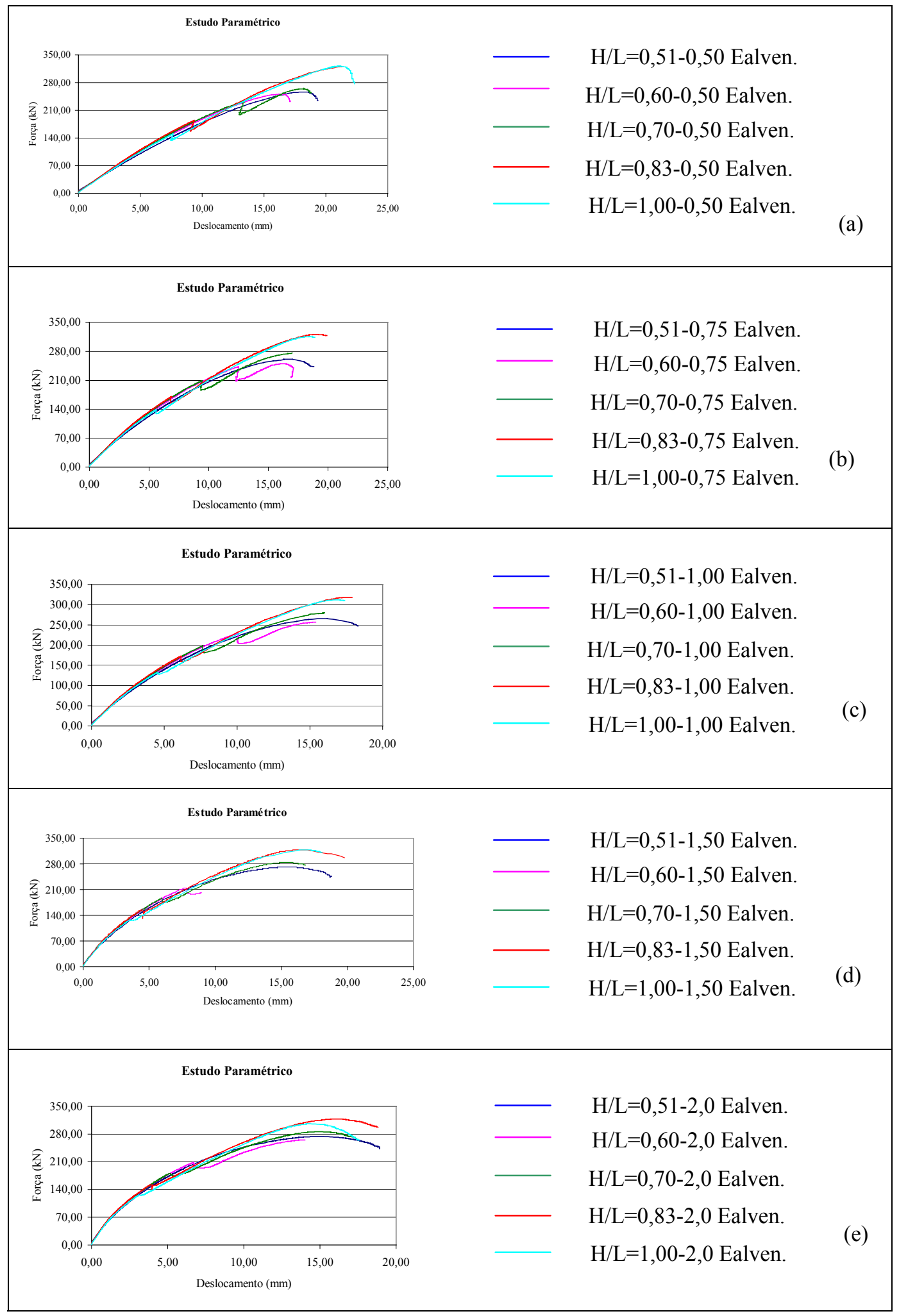

FIGURA 6.9 - Diagrama força-deslocamento para diferentes relações H/L e diferentes módulos de deformação para alvenaria 


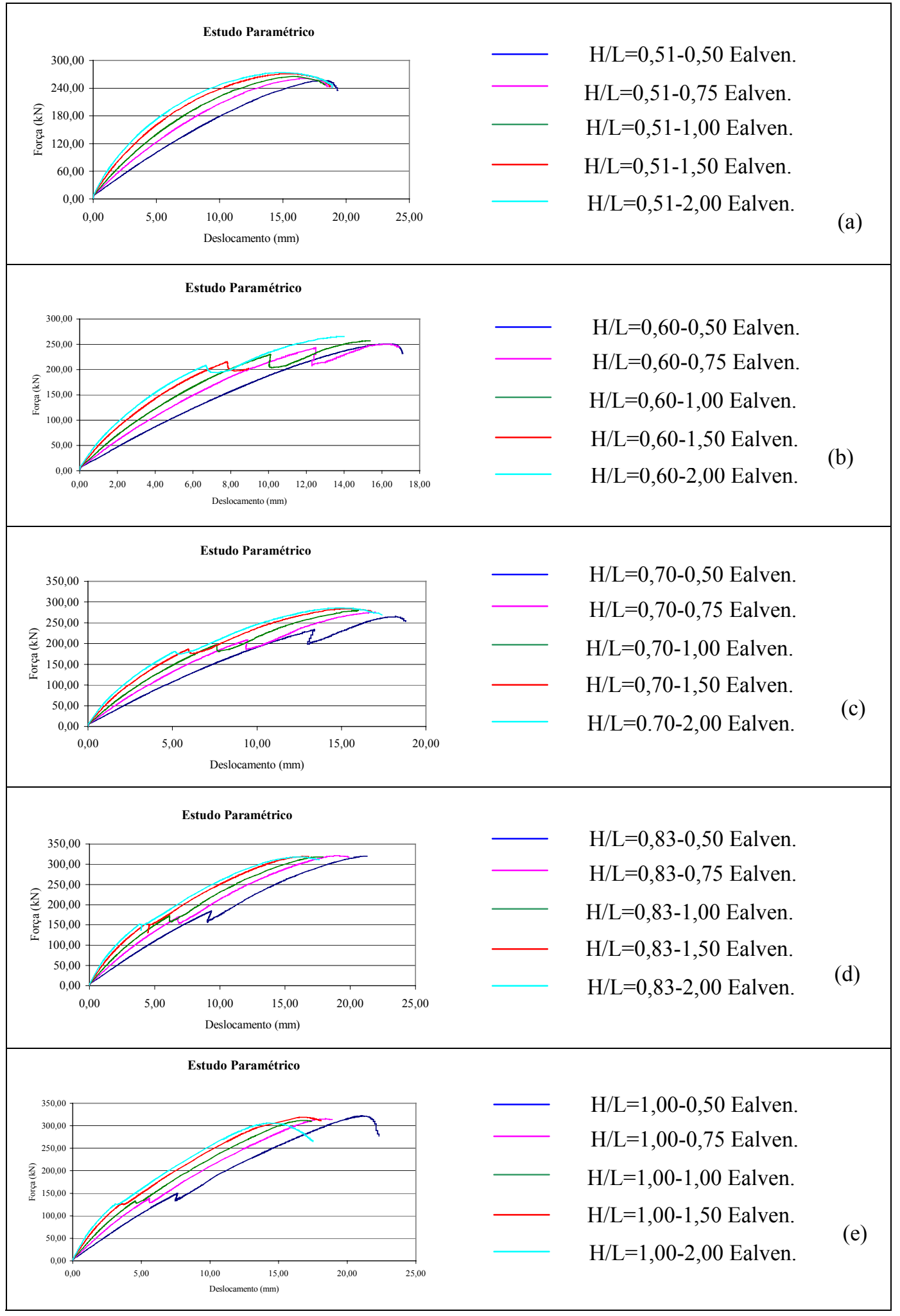

FIGURA 6.10 - Diagrama força-deslocamento para diferentes relações H/L e diferentes módulos de deformação para alvenaria 
TABELA 6.2 - Forças correspondentes aos modos de ruptura para cada uma das relações $\mathrm{H} / \mathrm{L}$ e para um dos módulos de deformação adotados para o painel de alvenaria (unidade $\mathrm{kN}$ )

\begin{tabular}{|c|c|c|c|c|c|c|}
\hline$E_{\text {painel }}$ & $\begin{array}{c}\text { MODO } \\
\text { RUPTURA }\end{array}$ & $\mathbf{0 , 5 1}$ & 0,60 & $\mathbf{0 , 7 0}$ & $\mathbf{0 , 8 3}$ & 1,00 \\
\hline \multirow{2}{*}{$\begin{array}{l}875 \mathrm{MPa} \\
\left(0,50 \mathrm{E}_{\text {exp }}\right)\end{array}$} & Fissuração & - & - & 234,00 & 185,00 & 150,00 \\
\hline & Esmagamento & 256,00 & 251,00 & 264,00 & 320,00 & 322,00 \\
\hline \multirow{2}{*}{$\begin{array}{c}1312,5 \mathrm{MPa} \\
\left(0,75 \mathrm{E}_{\mathrm{exp}}\right)\end{array}$} & Fissuração & - & 243,00 & 209,00 & 171,00 & 139,00 \\
\hline & Esmagamento & 261,00 & 250,00 & 276,00 & 321,00 & 316,00 \\
\hline \multirow{2}{*}{$\begin{array}{l}1750 \mathrm{MPa} \\
\left(1,00 \mathrm{E}_{\exp }\right)\end{array}$} & Fissuração & - & 230,00 & 197,00 & 165,00 & 133,00 \\
\hline & Esmagamento & 265,00 & 257,00 & 280,00 & 318,00 & 312,00 \\
\hline \multirow{2}{*}{$\begin{array}{l}2625 \mathrm{MPa} \\
\left(1,50 \mathrm{E}_{\mathrm{exp}}\right)\end{array}$} & Fissuração & - & 215,00 & 186,00 & 155,00 & 127,00 \\
\hline & Esmagamento & 271,00 & 263,00 & 284,00 & 319,00 & 319,00 \\
\hline \multirow{2}{*}{$\begin{array}{l}3500 \mathrm{MPa} \\
\left(2,00 \mathrm{E}_{\exp }\right)\end{array}$} & Fissuração & - & 208,00 & 180,00 & 152,00 & 127,00 \\
\hline & Esmagamento & 274,00 & 265,00 & 286,00 & 318,00 & 306,00 \\
\hline
\end{tabular}

\section{4 - CONCLUSÃO}

Realizou-se neste capítulo um estudo paramétrico, utilizando cinco pórticos com relações $\mathrm{H} / \mathrm{L}=0,51 ; 0,60 ; 0,70 ; 0,83$; e 1,00, variando os tipos de ligações viga-pilar e as rigidezas relativas entre painéis de alvenaria e pórticos.

Evidentemente, o número de propriedades que influenciam o comportamento de sistemas de pórticos preenchidos foi superior ao das analisadas. No entanto, procurou-se enfocar aquelas consideradas mais críticas e que afetavam, consideravelmente, o comportamento desses sistemas. 
Dessa forma, os fatores listados a seguir influenciam consideravelmente o comportamento de pórticos preenchidos e devem ser incluídos no desenvolvimento de uma proposta para cálculo da carga de ruptura. São eles:

- Geometria do pórtico e do painel.

- Resistência e rigidez do painel de alvenaria.

- Resistência e rigidez do pórtico.

- Ligação viga-pilar (carga relativa ao esmagamento dos cantos).

SEAH (1998) avaliou efeitos como condições de carregamento, efeito de cargas verticais, ligação pórtico-painel e atrito na interface pórtico-painel. Desses estudos, ele concluiu que a forma de aplicação do carregamento não interfere significativamente no comportamento global do sistema e que a ação do carregamento vertical implica acréscimo na resistência e rigidez do conjunto. Isso pode ser atribuído ao aumento da resistência ao cisalhamento das juntas de argamassa, em virtude do incremento no nível de tensões normais de compressão causado pela presença das cargas.

SEAH (1998) também não recomendou o uso de elementos resistentes ao cisalhamento, na interface pórtico-painel. Concluiu que o atrito entre pórtico e painel pouco influenciou o comportamento dos sistemas até a carga correspondente à fissuração da diagonal, tendo maior influência no comportamento desses sistemas nos últimos estágios de carga, pelo fato de ocorrer a separação entre pórtico e painel. 


\section{PROPOSTA PARA ANÁLISE DE PÓRTICOS} PREENCHIDOS COM ALVENARIA

\section{1 - INTRODUÇÃO}

Considerando os resultados obtidos em todo o desenvolvimento deste trabalho, apresenta-se neste capítulo uma proposta para obtenção da carga de ruptura em painéis de alvenaria constituintes de pórticos preenchidos. Os resultados considerados referem-se àqueles obtidos nos ensaios experimentais, nas previsões teóricas disponíveis na literatura e no estudo paramétrico realizado, que envolveu a modelagem numérica de diferentes relações altura/comprimento para os pórticos, diferentes relações de rigidez entre pórtico e alvenaria e diferentes rigidezas para as ligações viga-pilar.

É, ainda, apresentada uma proposta empírica para avaliação da largura da diagonal equivalente, de modo a considerar a contribuição dos painéis na rigidez de pórticos preenchidos. Entretanto, é importante observar que um estudo paramétrico mais extenso deve ser conduzido, de modo a ampliar o universo de validade da expressão apresentada. 


\section{2 - RESISTENCIA LATERAL DE PÓRTICOS PREENCHIDOS}

\subsection{1 - MODOS DE RUPTURA}

Tendo em vista os resultados ocorridos nos ensaios experimentais no que se refere à ruptura, serão aqui considerados dois possíveis modos para obtenção da carga máxima: ruptura por fissuração da diagonal e ruptura por esmagamento dos cantos comprimidos. O modo de ruptura correspondente ao cisalhamento ao longo das juntas de argamassa não se manifestou nos ensaios nos quais se utilizaram argamassa Ciment-cola para as juntas verticais e horizontais.

\subsection{2 - RESISTÊNCIA À COMPRESSÃO DA ALVENARIA EM ESTADO BIAXIAL}

A resistência da alvenaria, quando utilizada como elemento de preenchimento de pórticos, fica aumentada devido ao confinamento em que está sujeita. São aqui utilizadas as prescrições do MC90 (CEB-FIP, 1991) para o concreto, tendo em vista que a alvenaria apresenta comportamento similar ao do concreto, com relação à compressão e à tração. Os dois materiais apresentam comportamento quasifrágil, sendo caracterizados por fissuração quando submetidos à tração e por esmagamento quando submetidos à compressão, como pode ser observado na figura 5.13, do capítulo 5 .

Segundo MC90 (CEB-FIP, 1991), a resistência do concreto quando submetido a um estado biaxial de tensões pode ser estimada por um critério simplificado, a partir da majoração da tensão média de ruptura à compressão $\left(f_{\mathrm{cm}}\right)$ por um coeficiente $m$, dado pela expressão (7.1), sendo $m$ função do parâmetro $\eta$, que por sua vez é função da relação entre as duas tensões principais, dado pela expressão (7.2). Esses resultados se aproximam, satisfatoriamente, das prescrições dadas para o caso geral de estado multiaxial de tensões, em que as expressões são obtidas a partir de um critério de ruptura. A resistência à compressão em estado biaxial é dada pela expressão (7.3). 


$$
\begin{aligned}
& m=\frac{1+3,65 \eta}{(1+\eta)^{2}} \\
& \eta=\frac{\sigma_{2}}{\sigma_{1}} \\
& f_{c}^{*}=m f_{c m}
\end{aligned}
$$

\subsection{3 - RESISTÊNCIA EFETIVA DO PAINEL DE ALVENARIA}

A alvenaria apresenta comportamento análogo ao do concreto quando submetida a esforços de tração e compressão, e estes exibem comportamento quasifrágil, ocorrendo o amolecimento após atingir a resistência última. Dessa forma, o conceito de resistência efetiva que será apresentado a seguir para o concreto será adotado também para a alvenaria.

O concreto é um material complexo, e a sua descrição constitutiva completa exige número elevado de parâmetros, conforme o MC 90 (CEB-FIP, 1991). No entanto, pode ser considerado um material rígido-plástico, caracterizado unicamente por um parâmetro $f_{c}^{*}$. É evidente que essa simples descrição do material não pretende ser particularmente realista, mas exata o suficiente para o objetivo em causa.

A consideração do concreto como material rígido-plástico levanta algumas questões, já que na análise plástica se supõe que o material possa suportar grandes deformações sob tensão constante.

$\mathrm{Na}$ realidade, a ductilidade do concreto em compressão é limitada, e sua lei constitutiva possui um ramo descendente após o pico, conforme figura 5.13. Conseqüentemente, a redistribuição de tensões só pode ser obtida acompanhada de diminuição de resistência. 
Essa é a justificativa para o uso de uma tensão de ruptura efetiva, $f_{c}^{*}$, inferior à tensão obtida nos testes de compressão uniaxial em cilindros de concreto.

Além desse fato, NIELSEN (1999) observou que a resistência do concreto armado durante sua vida-útil difere consideravelmente da resistência obtida através de ensaios experimentais, pela presença das fissuras, que diminuem a sua resistência. A redução de resistência devida à fissuração pode ser dividida em:

a) Redução de resistência devida às microfissuras antes da aplicação das cargas.

b) Redução de resistência devida às microfissuras induzidas pelas cargas.

c) Redução de resistência devida às macrofissuras.

A principal conseqüência desse fato é que os parâmetros de resistência, necessários aos estudos teóricos, normalmente são mais baixos que os valores experimentais. Dessa forma, é recomendável trabalhar com resistências efetivas.

A resistência à compressão efetiva da alvenaria é definida pela expressão (7.4):

$$
f_{c e f}=v_{c}^{*} f_{c}^{*}=v_{c}^{*} m f_{c m}
$$

em que $v_{c}^{*} \leq 1$ é chamado de fator de eficiência para resistência à compressão e $f_{c}^{*}$, a resistência à compressão em estado biaxial, descrita no item 7.3.

De maneira similar, a resistência à tração efetiva pode ser definida pela expressão (7.5), em que $f_{\text {tef }}$ é a resistência efetiva à tração.

$$
f_{\text {tef }}=v_{t}^{*} f_{t}=\rho f_{c}^{*}
$$

em que $v_{t}^{*} \leq 1$ e $\rho<<1$ são fatores de eficiência para resistência à tração e $f_{t}$ é a resistência à tração. 
Enquanto as microfissuras surgidas antes da presença da carga podem conduzir a um material isotrópico, as micro e macrofissuras induzidas pelas cargas causam a anisotropia, ou seja, os parâmetros de resistência do material variam com as direções. Entretanto, essa consideração conduz a um difícil tratamento de maneira prática. A forma racional de considerar esse efeito, mantendo-se o material isotrópico, é através do uso de parâmetros de resistência efetiva.

$\mathrm{Na}$ expressão (7.6), apresenta-se uma forma aproximada para o cálculo do fator de redução $v_{c}^{*}$, aplicado para a resistência à compressão e ao cisallhamento (NIELSEN, 1999):

$$
v^{*}=0,70-\frac{f_{c}^{*}}{200} \quad\left(f_{c}^{*} \text { em MPa }\right)
$$

É importante observar que a utilização de resistências efetivas tem sentido em se tratando de distribuição uniforme de tensões, que é a forma de aplicação de cargas em ensaios experimentais para obtenção da resistência à compressão.

\subsection{4 - MODELO PROPOSTO}

\subsubsection{1 - RUPTURA POR FISSURAÇÃO DA DIAGONAL: MODELO DE BIELAS E TIRANTES PARA O PAINEL DE ALVENARIA}

Como foi visto no capítulo 2, podem ser descritos três estágios de comportamento para pórtico com preenchimento submetido a carregamento. No primeiro estágio, o painel de alvenaria e os membros da estrutura reticulada comportam-se como uma unidade monolítica. No segundo estágio, inicia-se o descolamento da interface pórtico-painel nas regiões tracionadas, e as regiões comprimidas permanecem em contato com o pórtico. Por esse comprimento de contato, as tensões de compressão são transmitidas do pórtico para o painel nos dois cantos diagonalmente opostos. 
Quando surgem as primeiras fissuras no painel, encerra-se o segundo estágio e iniciase a última etapa de comportamento. Nesse último estágio, a estrutura composta continua a resistir a incrementos de carga, apesar das fissuras na diagonal. Estas continuam a aumentar, e novas e maiores fissuras surgem até que a capacidade de carga do sistema atinge seu limite.

Tendo em vista o comportamento de estruturas de pórticos preenchidos, o painel de alvenaria pode ser idealizado a suportar as cargas por um conjunto de campos unidirecionais de tensões de compressão interligados por tirantes. Nesse caso, os tirantes são constituídos por campos unidirecionais de tração no painel. Para efeitos de cálculo, o modelo de bielas e tirantes condensa todas as tensões em barras sujeitas a esforços axiais de compressão ou tração ligadas por nós. No entanto, é importante esclarecer que se trata de uma idealização levada ao extremo e que permite um entendimento mais claro do comportamento da estrutura, já que evidencia o esqueleto resistente desta.

No que se refere às estruturas de concreto armado, o MC90 (CEB-FIP, 1991), bem como o Eurocódigo 2 (CEN, 1991), apresenta proposta para cálculo, utilizando-se esse modelo. No entanto, é interessante verificar que o MC90 (publicação mais teórica e fundamental) dá-lhe um tratamento substancialmente mais detalhado que o Eurocódigo 2 (publicação para aplicação prática). Esse fato parece comprovar a idéia de que, apesar de todo o valor pedagógico do modelo, a sua aplicabilidade por grande parte dos projetistas ainda é limitada. Isso pode ser devido à possível dificuldade em aplicar um método diferente do usual, que exige o empenho de toda a sensibilidade estrutural do projetista.

Os primeiros estudos nessa área são devidos a RITTER (1899) e MORSCH (1912). Posteriormente, o método foi refinado e expandido por vários autores. Os alemães criaram as bases científicas para aplicação racional do método apoiado na teoria da plasticidade. Na década de 80, SCHLAICH e SCHAFER (1987), pesquisadores de Stuttgart, Alemanha, sugeriram a utilização de modelos de bielas e tirantes de modo generalizado para o dimensionamento de outros elementos estruturais, como: 
viga-parede, apoios em dentes e aberturas em vigas, consolos, ligações viga-pilar, sapatas e blocos sobre estacas.

No caso de pórticos preenchidos, o caminho das cargas é bem conhecido. Dessa forma, o processo para escolha das direções para as bielas e tirantes fica facilitado. Como a direção média das tensões principais é próxima à direção da diagonal do painel, esta será considerada como a direção do esforço resultante das tensões de compressão.

Com o objetivo de obter a carga de ruptura correspondente à fissuração da diagonal em painéis constituintes de pórticos preenchidos, considere-se a estrutura da figura 7.1, submetida a uma ação diagonal $F / \cos \theta$, sendo $\theta$ o ângulo da diagonal do painel com a horizontal. O comprimento de contato pórtico-painel, por onde são transmitidas as tensões de compressão, é dado por $\alpha$ e o seu cálculo está definido no item 7.2.5.

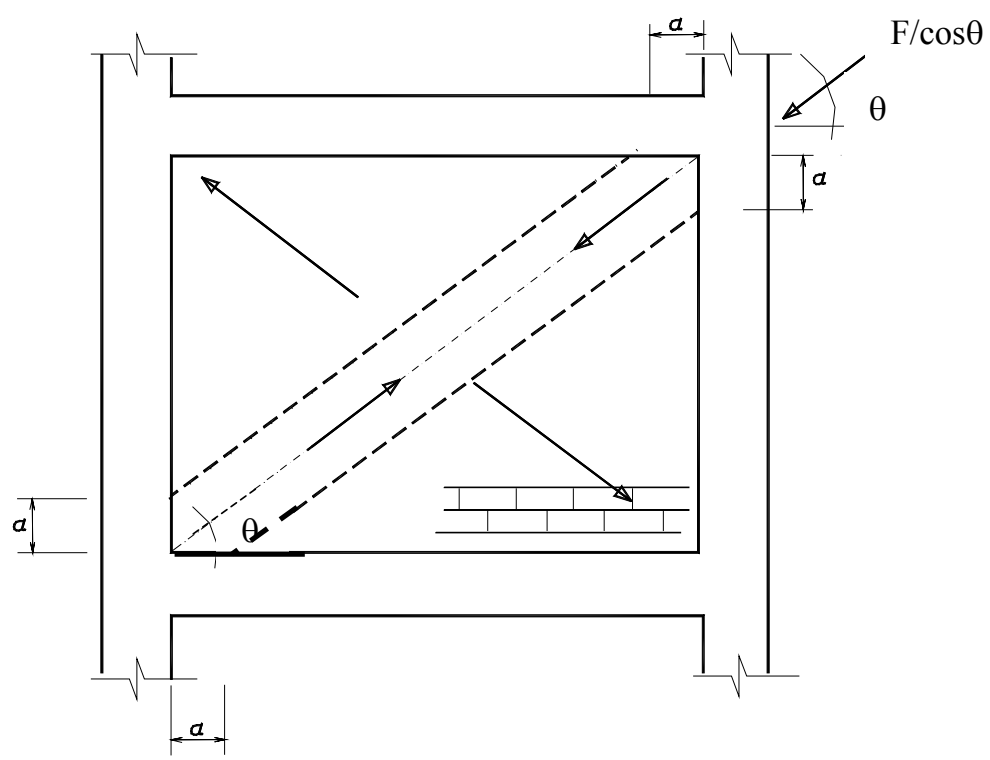

FIGURA 7.1 - Sistema pórtico-parede submetido a uma ação diagonal $F / \cos \theta$ 
Admitindo uma distribuição triangular de tensões de compressão na região do comprimento de contato $\alpha$ e analisando o painel isoladamente, tem-se o esquema representado na figura 7.2, em que $p_{x}$ e $p_{y}$ são as ordenadas máximas das forças por unidade de comprimento, distribuídas no comprimento $\alpha$, nas direções $\mathrm{x}$ e $\mathrm{y}$, respectivamente. A distribuição triangular de tensões nas regiões dos cantos comprimidos foi comprovada numericamente, através do estudo paramétrico apresentado no capítulo 6.

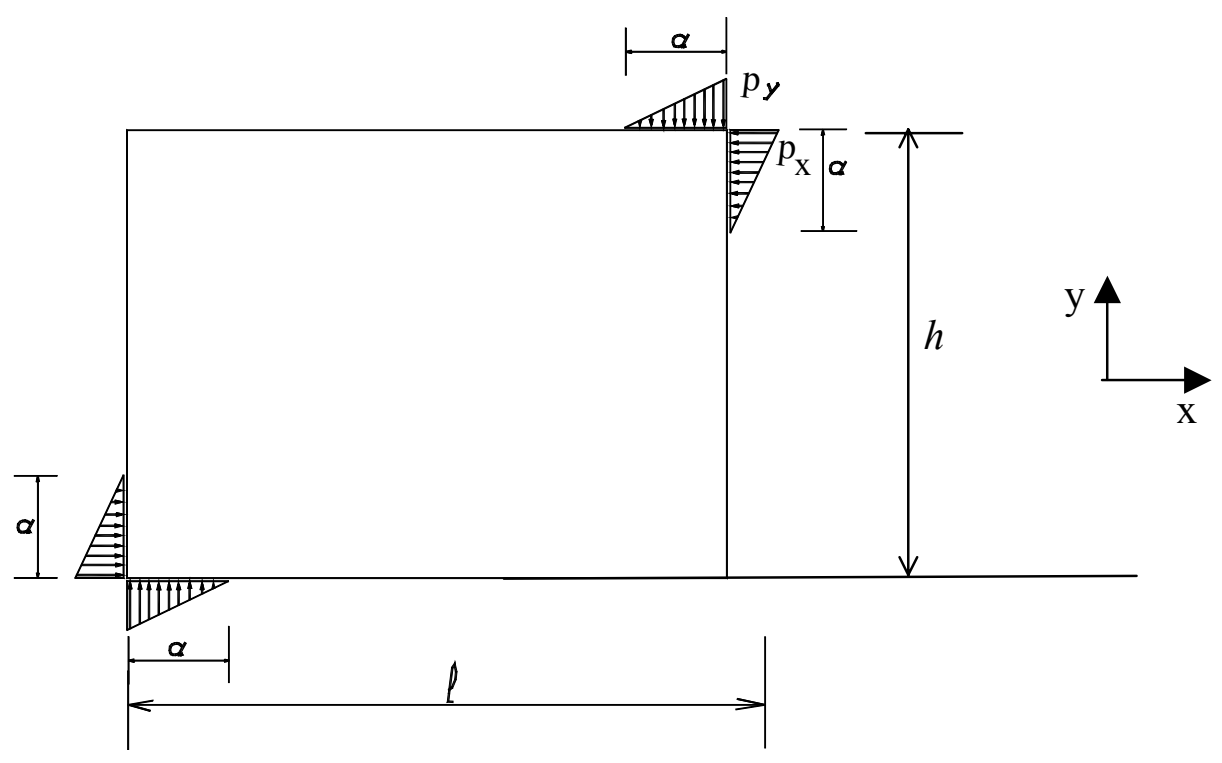

FIGURA 7.2 - Distribuição triangular de tensões no comprimento de contato pórticopainel

Escrevendo as ordenadas máximas da distribuição triangular de forças, $p_{x}$ e $p_{y}$, em função de $F$, têm-se as expressões (7.7) e (7.8):

$$
\begin{aligned}
& p_{x}=2 F / \alpha \\
& p_{y}=2 F \times \operatorname{tg} \theta / \alpha
\end{aligned}
$$


Considerando-se uma distribuição de tensões de compressão uniforme na região central do painel, na faixa de largura $\sqrt{2} \alpha$, o modelo de bielas e tirantes correspondente pode ser representado pelo esquema indicado na figura 7.3, em que o tirante é representado em vermelho e as bielas, em preto.

A adoção de uma distribuição uniforme de tensões de compressão no centro do painel é respaldada pelo Princípio de Saint -Venant, que postula que "a uma distância h da aplicação de uma carga concentrada tudo se passa como se essa carga estivesse uniformemente distribuída". A distância h é definida como a máxima dimensão da seção transversal da estrutura. Nesse caso, essa dimensão é função do comprimento de contato.

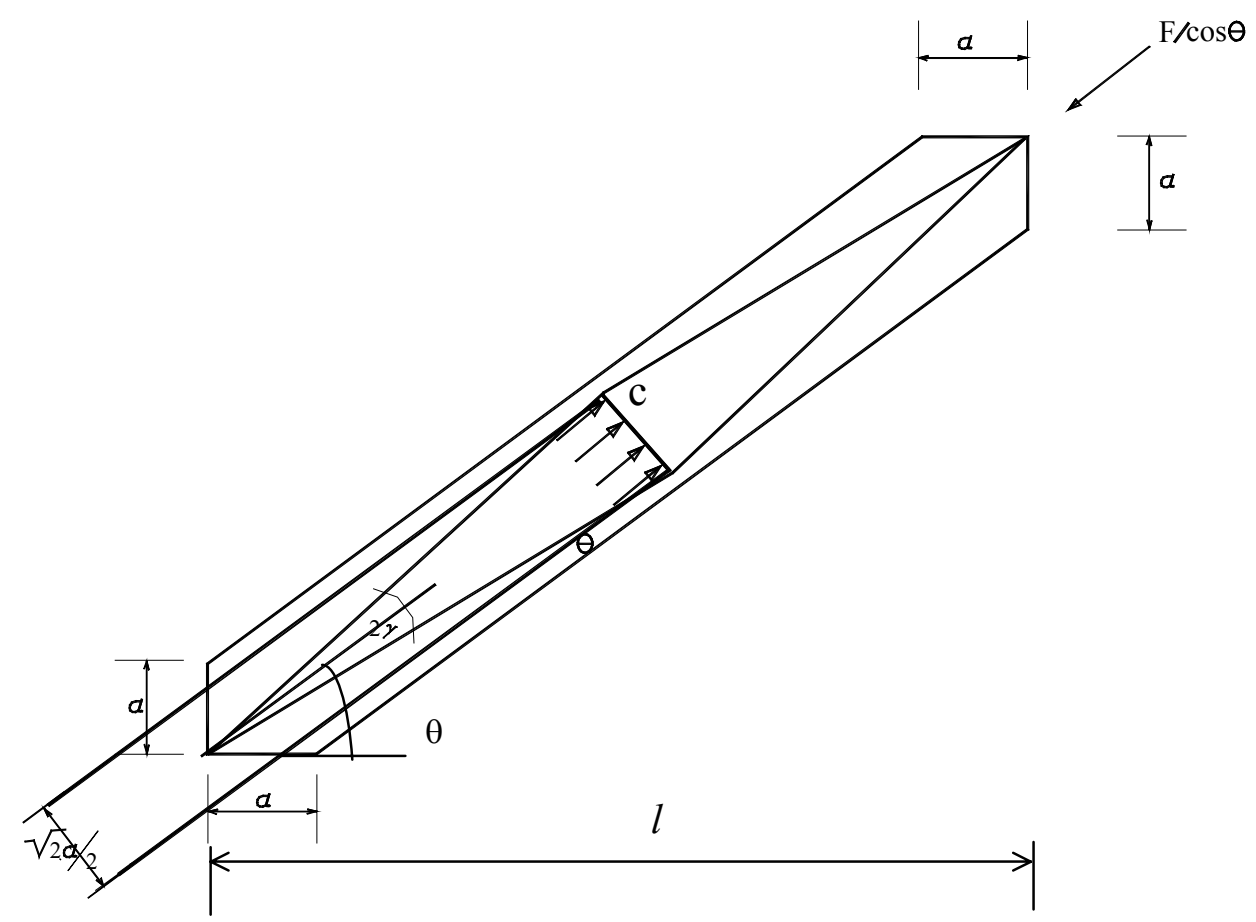

FIGURA 7.3 - Modelo de bielas e tirante para representação do painel de alvenaria

Através de equações de equilíbrio aplicadas sucessivamente aos nós A e C do modelo, podem-se obter os esforços nas barras. As expressões (7.9) e (7.10) representam os esforços nas bielas $(B)$ e no tirante $(T)$, respectivamente, e $\operatorname{tg} \gamma$ é dada pela expressão (7.11). 


$$
\begin{aligned}
& B=F^{\prime} / 2 \times \cos \gamma \times \cos \theta \\
& T=F^{\prime} \times \operatorname{tg} \gamma / \cos \theta \\
& \operatorname{tg} \gamma=\alpha \frac{\sqrt{2}}{2} \times \frac{\cos \theta}{l}
\end{aligned}
$$

As variáveis são definidas por:

$$
\begin{aligned}
& F^{\prime}=\text { força horizontal aplicada na estrutura } \\
& \theta=\text { ângulo entre a diagonal e a horizontal do painel de alvenaria } \\
& \alpha=\text { comprimento de contato entre pórtico e painel, definido no item } 7.6 \\
& 2 \gamma=\text { ângulo entre as bielas no modelo proposto } \\
& l=\text { comprimento do painel de alvenaria }
\end{aligned}
$$

Para obtenção da tensão de tração no centro do painel, admite-se uma distribuição constante numa faixa central igual à metade da diagonal, conforme representado na figura 7.4 .

Essa consideração de uma faixa inferior ao comprimento da diagonal advém do fato de o painel estar submetido, em suas extremidades, a um estado de compressão biaxial, fato comprovado pelos ensaios experimentais e pela modelagem numérica. Dessa forma, a resultante de tensões de tração, que corresponde ao máximo valor de esforço no tirante, é dada pela expressão (7.12), em que $t$ e $l$ são, respectivamente, a espessura e o comprimento do painel e $f_{\text {tef }}$ é a resistência efetiva à tração do painel, definida no item 7.4.

$$
T=f_{\text {tef }} \times l \times t / 2 \cos \theta
$$

Igualando as expressões (7.10) e (7.12), obtém-se o valor da força horizontal externa 
$F_{f i s}$, que causa a ruptura do painel por fissuração da diagonal, dada pela expressão (7.13).

$$
F_{f i s}=f_{t e f} \times l \times t / 2 \operatorname{tg} \gamma
$$

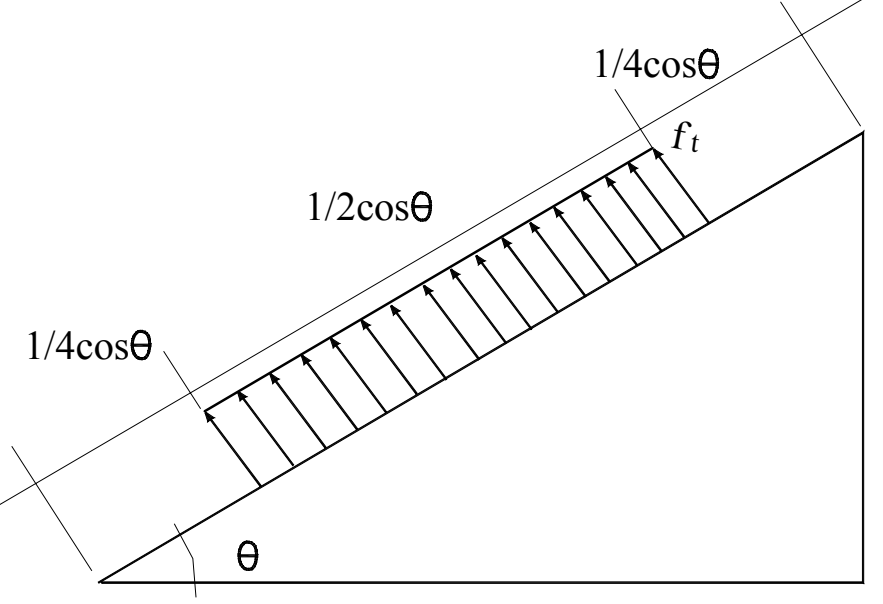

FIGURA 7.4 - Distribuição de tensões de tração no centro do painel

\subsubsection{2 - RUPTURA POR ESMAGAMENTO DOS CANTOS COMPRIMIDOS}

Dividindo as expressões (7.7) e (7.8) pela espessura do painel, obtêm-se as tensões nas direções x e y, dadas pelas expressões (7.14) e (7.15). Atribuindo às tensões o valor da resistência à compressão do material do painel em estado biaxial $\left(f_{c}^{*}\right)$, definida no item 7.3, pode-se obter o valor da força horizontal que causa o esmagamento dos cantos comprimidos, para o caso de ligações viga-pilar articuladas, conforme a expressão (7.16).

$$
\sigma_{x}=p_{x} / t=2 F^{\prime} / \alpha t
$$




$$
\begin{aligned}
& \sigma_{y}=p_{y} / t=2 F^{\prime} \operatorname{tg} \theta / \alpha t \\
& F_{\text {esm }} \leq\left\{\begin{array}{c}
f_{c}^{*} \alpha t / 2 \\
f_{c}^{*} \alpha t / 2 \operatorname{tg} \theta
\end{array}\right.
\end{aligned}
$$

\section{RESISTÊNCIA À COMPRESSÃO EM ESTADO BIAXIAL}

No caso de pórticos preenchidos, o coeficiente de majoração da resistência à compressão " $m$ " é obtido através da aplicação das expressões (7.1) e (7.2). Admitindo que $\sigma_{x}$ e $\sigma_{y}$ sejam as tensões principais nos cantos comprimidos, pode-se obter o valor de $\eta$, dividindo a expressão (7.15) pela (7.14), conforme a expressão (7.17). O valor de $m$ é, então, dado pela expressão (7.18), ou seja:

$$
\begin{aligned}
& \eta=\operatorname{tg} \theta \\
& m=\frac{1+3,65 \operatorname{tg} \theta}{(1+\operatorname{tg} \theta)^{2}}
\end{aligned}
$$

\section{INFLUÊNCIA DA LIGAÇÃO VIGA-PILAR}

Do estudo paramétrico efetuado, especificamente da figura 6.8 , observou-se que a força correspondente ao esmagamento dos cantos comprimidos cresce proporcionalmente à rigidez das ligações viga-pilar de forma próxima à linear, de acordo com a tabela 7.1. Para o pórtico com relação $\mathrm{H} / \mathrm{L}=0,51$ e ligações rígidas, por exemplo, a força correspondente ao esmagamento dos cantos comprimidos é 1,35 vez o valor da força para o caso de ligações viga-pilar articuladas. No que se refere à força de fissuração da diagonal, esta não apresenta variações consideráveis com a rigidez da ligação. Dessa forma, simplificadamente, recomenda-se que a força de 
esmagamento obtida pela expressão (7.16) seja majorada por um coeficiente $(1+\beta)$, conforme as expressões (7.19) e (7.20).

TABELA 7.1 - Acréscimo da força de esmagamento em relação à ligação articulada (\%), para ligações viga-pilar semi-rígidas e rígidas

\begin{tabular}{|l|c|c|c|c|c|}
\hline Lig. viga-pilar & 0,51 & 0,60 & 0,70 & 0,83 & 1,00 \\
\hline Semi-rígida & 15,85 & 19,84 & 16,07 & 14,15 & 14,42 \\
\hline Rígida & 34,70 & 36,19 & 33,21 & 29,58 & 38,97 \\
\hline
\end{tabular}

$$
F_{\text {esm }}^{\prime}=(1+\beta) F_{\text {esm }}
$$

$$
\beta=0,3 r
$$

em que $r$ corresponde ao fator de rigidez da ligação, variando de $0 \leq r \leq 1$, conforme sejam as ligações: articuladas $(r=0)$, semi-rígidas $(0<r<1)$ ou rígidas $(r=1)$.

\subsubsection{3 - RUPTURA POR ESMAGAMENTO NO CENTRO DO PAINEL, CONSIDERANDO-SE A RESISTÊNCIA EFETIVA}

Como se utilizou a resistência efetiva da alvenaria na avaliação das tensões no centro do painel, é necessária a verificação da resistência à compressão nessa região através da comparação entre a tensão de compressão atuante e a resistência à compressão efetiva.

Uma vez determinada a força externa $F$, que produz a ruptura do painel de alvenaria por fissuração ou por esmagamento, a tensão de compressão no centro do painel $\left(\sigma_{c}\right)$ pode ser obtida através da expressão (7.21), de acordo com a figura 7.5. O resultado dessa expressão deverá ser inferior ou igual à resistência à compressão efetiva do 
painel $\left(f_{c e f}\right)$, de modo a garantir a não-ocorrência da ruptura por esmagamento nessa região. Colocada de outra forma, a equação (7.22) deve ser satisfeita de modo a não haver ruptura por compressão no centro do painel.

$$
\begin{aligned}
& \sigma_{c}=\frac{F}{\cos \theta} \times \frac{1}{\alpha \sqrt{2} t} \\
& F \leq \sqrt{2} f_{\text {cef }} \times \alpha \times \cos \theta \times t
\end{aligned}
$$

Pode-se provar que o esmagamento no centro dos painéis não ocorre para forças inferiores àquelas que provocam o esmagamento dos cantos comprimidos. Para isso, considerem-se as expressões (7.16) e (7.22), transcritas na expressão (7.23).

$$
F \leq\left\{\begin{array}{c}
f_{c}^{*} \alpha t / 2 \\
f_{c}^{*} \alpha t / 2 \tan \theta \\
\sqrt{2} f_{\text {ef }} \times \alpha \times \cos \theta \times \mathrm{t}
\end{array}\right.
$$

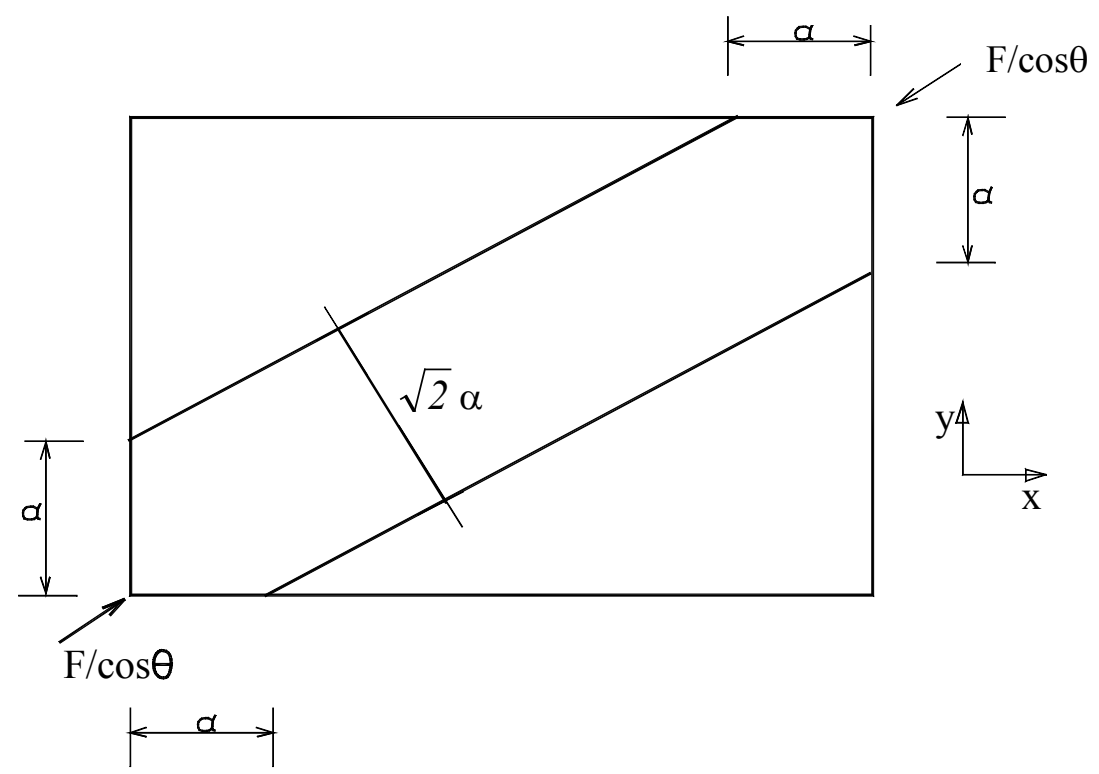

FIGURA 7.5 - Obtenção da tensão de esmagamento no centro do painel, considerando-se a tensão efetiva nessa região

Considerando duas situações para variação do ângulo $\theta$, como representado a seguir, tem-se: 


\section{A) $\mathbf{1}^{\mathrm{a}}$ SITUAÇÃO}

$\theta \leq 45^{\circ}$

Nesse caso $\operatorname{tg} \theta \leq 1 \Rightarrow F \leq\left\{\begin{array}{c}f_{c}^{*} \alpha t / 2 \\ \sqrt{2} f_{c e f} \times \alpha \times \cos \theta \times t\end{array}\right.$

Como $f_{\text {cef }}$ assume valores próximos ao intervalo $\left(0,65 f_{c}^{*} ; 0,70 f_{c}^{*}\right)$, pode-se afirmar que $\sqrt{2} f_{c e f} \rightarrow 0,90 f_{c}^{*}$, de modo que as expressões (7.24) podem ser, aproximadamente, escritas como em (7.25).

Para $\theta \leq 45^{\circ} \Rightarrow \cos \theta \geq 0,707 \Rightarrow 0,90 \times 0,707=0,6363>0,50$, dessa forma o mínimo valor assumido para $F$, com relação ao esmagamento, é o representado na expressão (7.26), que corresponde ao esmagamento dos cantos comprimidos.

$F \leq\left\{\begin{array}{c}f_{c}^{*} \alpha t / 2 \\ 0,90 \times f_{c}^{*} \times \alpha \times t \times \cos \theta\end{array}\right.$

$F \leq f_{c}^{*} \alpha t / 2$

\section{B) $2^{a}$ SITUAÇÃO}

$\theta \geq 45^{\circ}$

Nesse caso $\operatorname{tg} \theta \geq 1 \Rightarrow F \leq\left\{\begin{array}{c}f_{c}^{*} \alpha t / 2 \operatorname{tg} \theta \\ \sqrt{2} f_{c e f} \times \alpha \times \cos \theta \times t\end{array}\right.$

A expressão (7.27) pode ser escrita na forma expressa em (7.28):

$$
F \leq\left\{\begin{array}{c}
f_{c}^{*} \alpha t \cos \theta / 2 \operatorname{sen} \theta \\
0,90 \times f_{c}^{*} \times \alpha \times t \times \cos \theta
\end{array}\right.
$$


Para $\theta \geq 45^{\circ} \Rightarrow \operatorname{sen} \theta \geq 0,707 \Rightarrow 2 \operatorname{sen} \theta \geq 1,414 \Rightarrow 1 / 2 \operatorname{sen} \theta \leq 0,707$, dessa forma a menor força correspondente ao esmagamento é dada pela expressão (7.29), que se refere ao esmagamento dos cantos comprimidos.

$$
F \leq f_{c}^{*} \alpha t / 2 \operatorname{tg} \theta
$$

Assim, conforme se pretende demonstrar, o esmagamento dos cantos comprimidos sempre ocorre antes do esmagamento do centro do painel.

\subsection{5 - COMPRIMENTO DE CONTATO $(\alpha)$}

Em todas as modelagens realizadas, determinou-se o comprimento de contato entre pórtico e painel, de modo a trabalhar com valores que fossem realistas. Nos modelos analisados pela proposta, foram utilizadas as expressões (7.30) e (7.31), recomendadas por SMITH e CARTER (1969), cujos resultados encontrados foram considerados satisfatórios.

$$
\begin{aligned}
& \lambda L^{\prime}=L^{\prime} \times \sqrt[4]{\frac{E_{\text {painel }} t}{4 E_{p} I_{p} h} \operatorname{sen} 2 \theta} \\
& \frac{\alpha}{L^{\prime}}=\frac{\pi}{2 \lambda \cdot L^{\prime}}
\end{aligned}
$$

em que $E_{\text {painel, }} t e h$ são módulo de deformação, espessura e altura do painel, respectivamente. $E_{p} I_{p}$ e $L^{\prime}$ são, respectivamente, o produto de rigidez do pilar e o comprimento do pilar entre eixos.

São apresentados na tabela 7.2 os valores do parâmetro de rigidez relativa ( $\left.\lambda L^{\prime}\right)$ e do comprimento de contato $(\alpha)$ para cada um dos pórticos analisados e para cada um 
dos módulos de deformação utilizados para a alvenaria no estudo paramétrico, obtidos segundo as recomendações de SMITH e CARTER (1969).

TABELA 7.2 - Valores dos parâmetros de rigidez relativa e comprimentos de contato para os pórticos analisados, relativos a cada um dos módulos de deformação da alvenaria utilizados no estudo paramétrico

\begin{tabular}{|c|c|c|c|c|c|c|}
\hline $\begin{array}{c}\text { Mod. Def. } \\
\text { Alvenaria }\end{array}$ & & $\mathbf{0 , 5 1}$ & $\mathbf{0 , 6 0}$ & $\mathbf{0 , 7 0}$ & $\mathbf{0 , 8 3}$ & $\mathbf{1 , 0 0}$ \\
\hline \multirow{2}{*}{$875 \mathrm{MPa}$} & $\lambda L^{\prime}$ & 2,79 & 2,82 & 2,92 & 2,97 & 3,00 \\
\cline { 2 - 7 } & $\alpha$ & 144,87 & 143,30 & 138,13 & 135,71 & 134,57 \\
\hline \multirow{2}{*}{$1312,5 \mathrm{MPa}$} & $\lambda L^{\prime}$ & 3,08 & 3,12 & 3,23 & 3,29 & 3,32 \\
\cline { 2 - 7 } & $\alpha$ & 130,91 & 129,49 & 124,81 & 122,63 & 121,60 \\
\hline \multirow{2}{*}{$1750 \mathrm{MPa}$} & $\lambda L^{\prime}$ & 3,31 & 3,35 & 3,48 & 3,54 & 3,57 \\
\cline { 2 - 7 } & $\alpha$ & 121,96 & 120,50 & 116,50 & 114,12 & 113,16 \\
\hline \multirow{2}{*}{$2625 \mathrm{MPa}$} & $\lambda L^{\prime}$ & 3,67 & 3,71 & 3,85 & 3,91 & 3,95 \\
\cline { 2 - 7 } & $\alpha$ & 110,08 & 108,89 & 104,95 & 103,12 & 102,25 \\
\hline \multirow{2}{*}{$3500 \mathrm{MPa}$} & $\alpha L^{\prime}$ & 3,94 & 3,98 & 4,13 & 4,21 & 4,24 \\
\cline { 2 - 7 } & $\alpha$ & 102,44 & 101,33 & 97,67 & 95,96 & 95,16 \\
\hline
\end{tabular}

\subsection{6 - VALIDAÇÃO DO MODELO PROPOSTO}

A fim de validar o modelo proposto, foram analisados os pórticos ensaiados experimentalmente, TIPO I e TIPO II, com relações altura/comprimento iguais a 0,51 e 0,83 , respectivamente, além de novos pórticos com relações iguais a 0,60 ; 0,70; e 1,00. Para todos esses pórticos, foram consideradas diferentes relações de rigidez entre pórtico e painel e diferentes relações de rigidez para as ligações vigapilar, de forma a generalizar a proposta de cálculo. 
Foram efetuadas comparações entre o método proposto e os métodos teóricos disponíveis na literatura. Pode-se observar que os métodos teóricos diferem consideravelmente entre si, o que dificulta imensamente a comparação entre eles. No entanto, os resultados experimentais, bem como o estudo paramétrico realizado nesta pesquisa, permitiram uma comparação de forma segura e abrangente, conforme apresentado a seguir.

No item 7.2.6.1, apresenta-se uma comparação entre o método proposto neste trabalho, os resultados experimentais desta tese e os resultados obtidos através dos métodos teóricos. O item 7.2.6.2 indica uma análise comparativa entre os resultados obtidos por BRAGUIM (1989), a proposta apresentada nesta tese e os resultados teóricos da literatura.

O item 7.2.6.3 refere-se a um exemplo retirado do artigo de SMITH e CARTER (1969), que trata da análise de um pórtico de concreto armado de três pavimentos. Esse pórtico é analisado à luz da proposta aqui apresentada, e os resultados são comparados com os disponíveis na literatura, comprovando-se, mais uma vez, a boa "performance" da proposta aqui apresentada.

\subsubsection{1 - COMPARAÇÃO COM OS RESULTADOS DO ESTUDO PARAMÉTRICO}

Na tabela 7.3, apresentam-se os resultados obtidos nos ensaios experimentais, na modelagem numérica, nas previsões teóricas disponíveis na literatura e no modelo proposto neste trabalho, considerando-se todos os pórticos com as mesmas propriedades elásticas e geométricas dos pórticos ensaiados experimentalmente.

Na tabela 7.4, os valores obtidos nos ensaios experimentais, nas análises numéricas e nas prescrições teóricas da literatura são confrontados com os resultados obtidos pela proposta deste trabalho e apresentados relativamente a esses últimos valores. 
TABELA 7.3 - Valores das cargas de ruptura obtidos nos ensaios experimentais, na modelagem numérica, nos métodos teóricos da literatura e na proposta deste trabalho $(\mathrm{kN})$

\begin{tabular}{|c|c|c|c|c|c|c|}
\hline DESCRIÇÃO & $\begin{array}{l}\text { MODO DE } \\
\text { RUPTURA }\end{array}$ & $\begin{array}{l}\mathrm{H} / \mathrm{L}=0,51 \\
\text { (TIPOII) }\end{array}$ & $H / L=0,60$ & $H / L=0,70$ & $\begin{array}{c}\text { H/L }=0,83 \\
\text { (TIPOI) }\end{array}$ & $H / L=1,00$ \\
\hline \multirow{2}{*}{ Experimental } & Fissuração & 172,00 & - & - & 171,00 & - \\
\hline & Esmagam. & - & - & - & - & - \\
\hline \multirow{2}{*}{$\begin{array}{c}\text { Mod. } \\
\text { Numérica }\end{array}$} & Fissuração & 172,00 & 230,00 & 195,00 & 170,00 & 131,50 \\
\hline & Esmagam. & 265,00 & 257,00 & 280,00 & 311,00 & 312,00 \\
\hline \multirow{2}{*}{ Proposta } & Fissuração & 194,04 & 293,74 & 225,61 & 164,39 & 117,90 \\
\hline & Esmagam. & 301,7 & 294,59 & 282,24 & 270,84 & 259,20 \\
\hline \multirow{2}{*}{ Smith e Carter } & Fissuração & 218,76 & 347,54 & 287,86 & 229,46 & 170,92 \\
\hline & Esmagam. & 352,73 & 359,21 & 366,61 & 341,97 & 338,25 \\
\hline \multirow{2}{*}{$\begin{array}{c}\text { Smith e } \\
\text { Riddington }\end{array}$} & Fissuração & 160,71 & 270,98 & 228,62 & 186,93 & 150,62 \\
\hline & Esmagam. & 270,74 & 261,67 & 222,99 & 192,73 & 159,44 \\
\hline \multirow{2}{*}{$\begin{array}{l}\text { Prescrições } \\
\text { italianas }\end{array}$} & Fissuração & 250,00 & 212,5 & 181,00 & 150,00 & 118,00 \\
\hline & Esmagam. & 131,61 & 121,60 & 110,42 & 96,18 & 75,98 \\
\hline
\end{tabular}

*Experimental: $\mathrm{H} / \mathrm{L}=0,51$ - Ensaio $1 \mathrm{~B}-\mathrm{f}_{\mathrm{t}}=0,13 \mathrm{MPa}$ e $\mathrm{f}_{\mathrm{c}}=2,60 \mathrm{MPa}$; e $\mathrm{H} / \mathrm{L}=0,83$ - Ensaios $5 \mathrm{~A}$ e $6 \mathrm{~A}$ e nas demais relações $\mathrm{H} / \mathrm{L}-\mathrm{f}_{\mathrm{t}}=0,26 \mathrm{MPa}$.

TABELA 7.4 - Relação entre os valores das forças de ruptura obtidos nos ensaios experimentais, na modelagem numérica e nos métodos teóricos da literatura e os valores obtidos na proposta do presente trabalho

\begin{tabular}{|c|c|c|c|c|c|c|}
\hline \multirow{2}{*}{ RELAÇÃO } & $\begin{array}{c}\text { MODO DE } \\
\text { RUPTURA }\end{array}$ & $\begin{array}{c}\mathbf{H} / \mathbf{L}=\mathbf{0 , 5 1} \\
\text { (TIPOII) }\end{array}$ & $\mathbf{H} / \mathbf{L}=\mathbf{0 , 6 0}$ & $\mathbf{H} / \mathbf{L}=\mathbf{0 , 7 0}$ & $\begin{array}{c}\mathbf{H} / \mathbf{L}=\mathbf{0 , 8 3} \\
\text { (TIPOI) }\end{array}$ & $\mathbf{H} / \mathbf{L}=\mathbf{1 , 0}$ \\
\hline \multirow{2}{*}{$\begin{array}{c}\text { Experimental/ } \\
\text { Proposta }\end{array}$} & Fissuração & 0,89 & - & - & 1,06 & - \\
\cline { 2 - 7 } & Esmagam. & - & - & - & - & - \\
\hline \multirow{2}{*}{$\begin{array}{c}\text { Numérica/ } \\
\text { Proposta }\end{array}$} & Fissuração & 0,89 & 0,80 & 0,88 & 1,05 & 1,13 \\
\cline { 2 - 7 } & Esmagam. & 0,88 & 0,86 & 1,00 & 1,15 & 1,20 \\
\hline \multirow{2}{*}{$\begin{array}{c}\text { Smith e Carter/ } \\
\text { Proposta }\end{array}$} & Fissuração & 1,12 & 1,18 & 1,28 & 1,39 & 2,03 \\
\cline { 2 - 7 } & Esmagam. & 1,17 & 1,22 & 1,30 & 1,26 & 1,81 \\
\hline $\begin{array}{c}\text { Smith e } \\
\text { Riddington/ } \\
\text { Proposta }\end{array}$ & Fissuração & 0,83 & 0,94 & 1,03 & 1,16 & 1,30 \\
\cline { 2 - 7 } & Esmagam. & 0,90 & 0,88 & 0,80 & 0,71 & 0,62 \\
\hline $\begin{array}{c}\text { Prescriç̃ões } \\
\text { italianas/ } \\
\text { Proposta }\end{array}$ & Fissuração & 1,29 & 0,72 & 0,80 & 0,91 & 1,00 \\
\cline { 2 - 7 } & Esmagam. & 0,44 & 0,41 & 0,40 & 0,36 & 0,30 \\
\hline
\end{tabular}


Nas figuras 7.6 e 7.7, apresentam-se esses resultados na forma de diagrama de barras para as forças de fissuração da diagonal e esmagamento dos cantos comprimidos, respectivamente. Através dessas figuras, pode-se notar que existe boa concordância entre os valores obtidos numérica e experimentalmente e a proposta desta tese, havendo também boa aproximação com a proposta de SMITH e RIDDINGTON (1977). Já com relação a SMITH e CARTER (1969) e às prescrições italianas, existe discrepância de valores, principalmente com relação às prescrições italianas, que apresentam valores inferiores aos dos demais métodos.

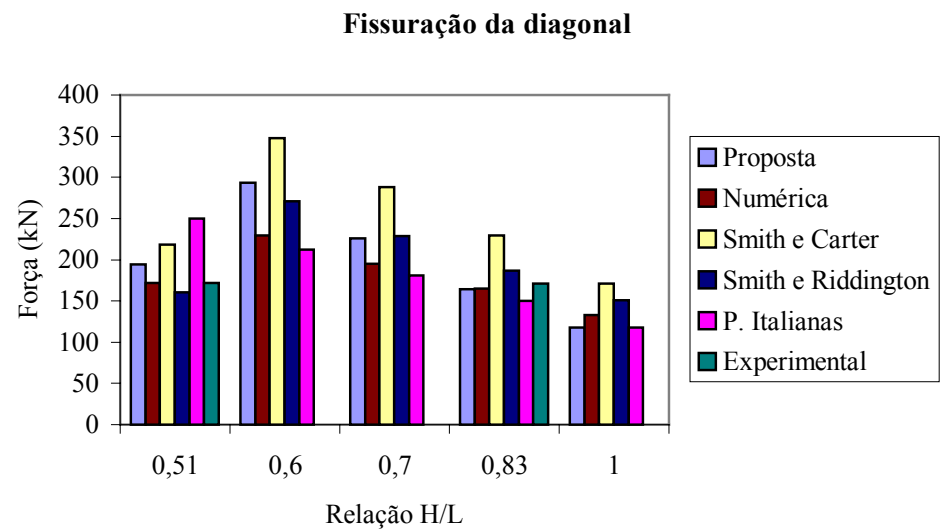

FIGURA 7.6 - Análise comparativa dos resultados obtidos das diversas relações H/L analisadas - Força de fissuração da diagonal $\mathrm{H} / \mathrm{L}=0,51-\mathrm{f}_{\mathrm{t}}=0,13 \mathrm{MPa}$, nas demais relações $\mathrm{H} / \mathrm{L}-\mathrm{f}_{\mathrm{t}}=0,26 \mathrm{MPa}$

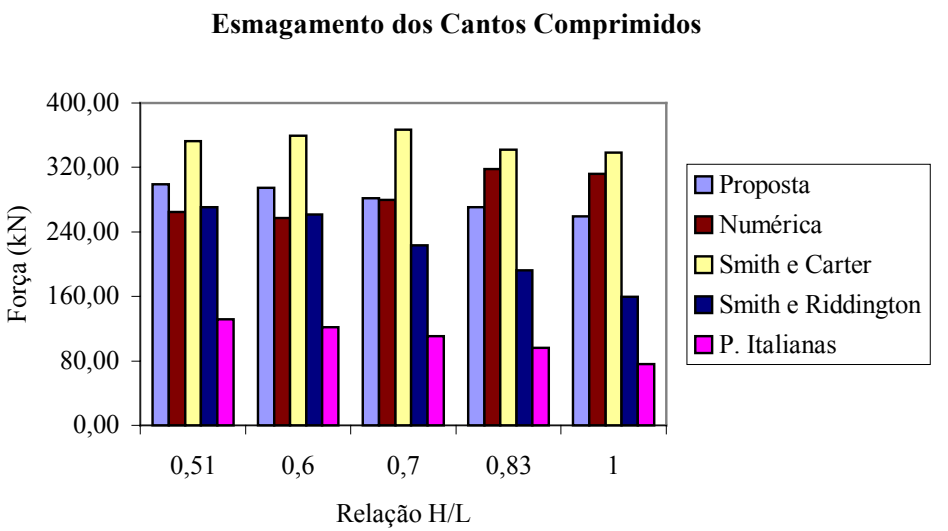

FIGURA 7.7 - Análise comparativa dos resultados obtidos das diversas relações H/L analisadas - Forças de esmagamento dos cantos comprimidos 


\section{A) VARIAÇÃO DO MÓDULO DE DEFORMAÇÃO DO PAINEL}

Nas figuras 7.8 e 7.9, apresentam-se os resultados referentes à proposta apresentada neste trabalho, à modelagem numérica e aos modelos teóricos da literatura, considerando diferentes relações de rigidez pórtico-painel.

Nas tabelas G.1, G.3, G.5, G.7 e G.9, do Anexo G, apresentam-se os valores das cargas de ruptura obtidos pelo método proposto, pelas modelagens numéricas e pelos métodos teóricos da literatura, para cada um dos cinco módulos de deformação assumidos para alvenaria.

Nas tabelas G.2,G.4,G.6,G.8 e G.10 são apresentadas as relações entre os valores das forças de ruptura obtidos na modelagem numérica e nos métodos teóricos da literatura, bem como os valores obtidos com o uso da proposta deste trabalho.

Esses gráficos permitem verificar que o modelo proposto apresenta resultados muito concordantes com o método proposto por SMITH e RIDDINGTON (1977) e com a modelagem numérica realizada nesta tese. As prescrições italianas exibem resultados inferiores aos dos demais métodos, mesmo trabalhando-se com tensões médias, enquanto o método de SMITH e CARTER (1969) apresenta valores superiores aos dos demais. 


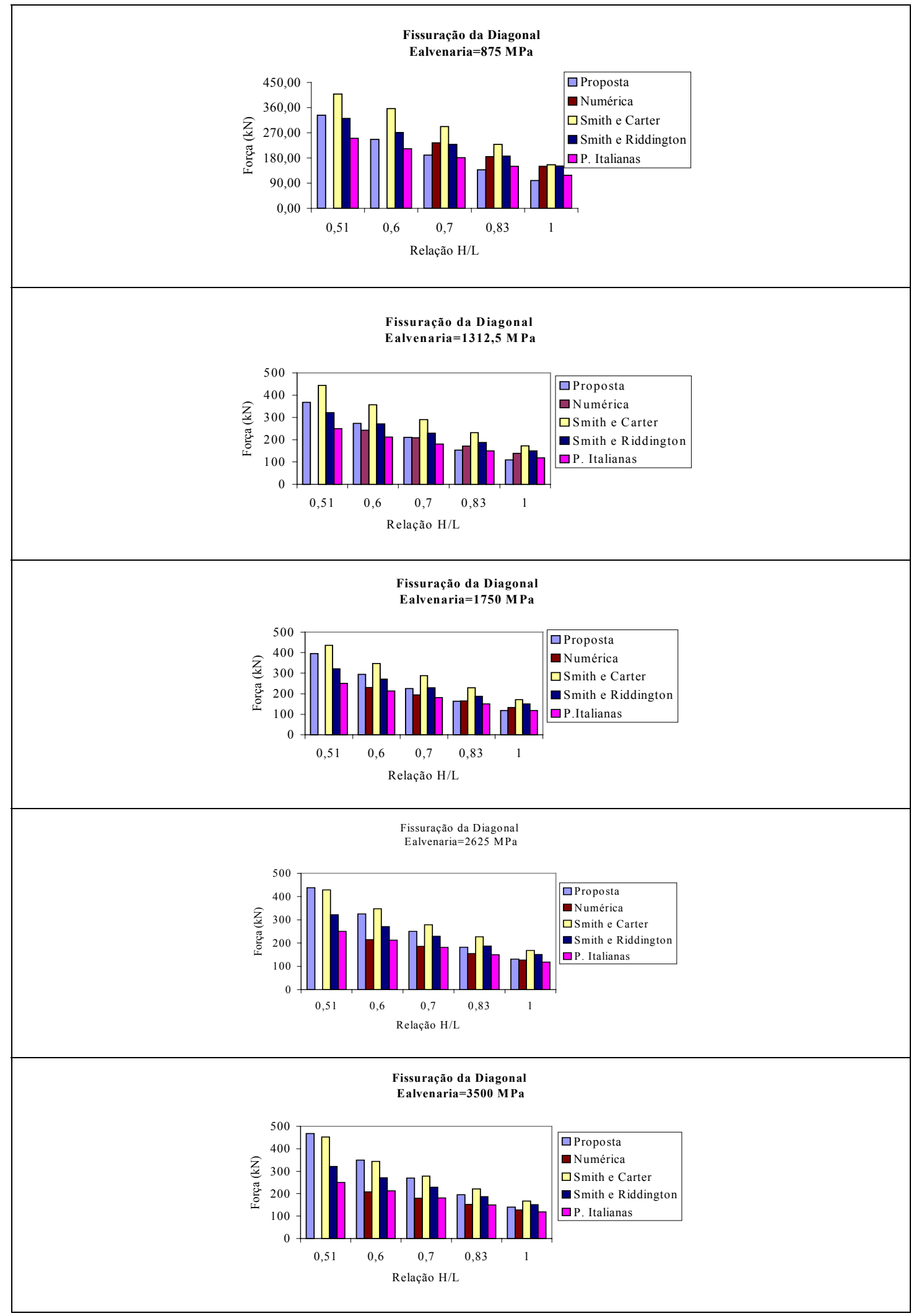

FIGURA 7.8 - Análise comparativa dos resultados obtidos dos módulos de deformação da alvenaria iguais a $875 \mathrm{MPa}, 1312,5 \mathrm{MPa}, 1750 \mathrm{MPa}, 2625 \mathrm{MPa}$ e $3500 \mathrm{MPa}$ - Força de fissuração da diagonal 


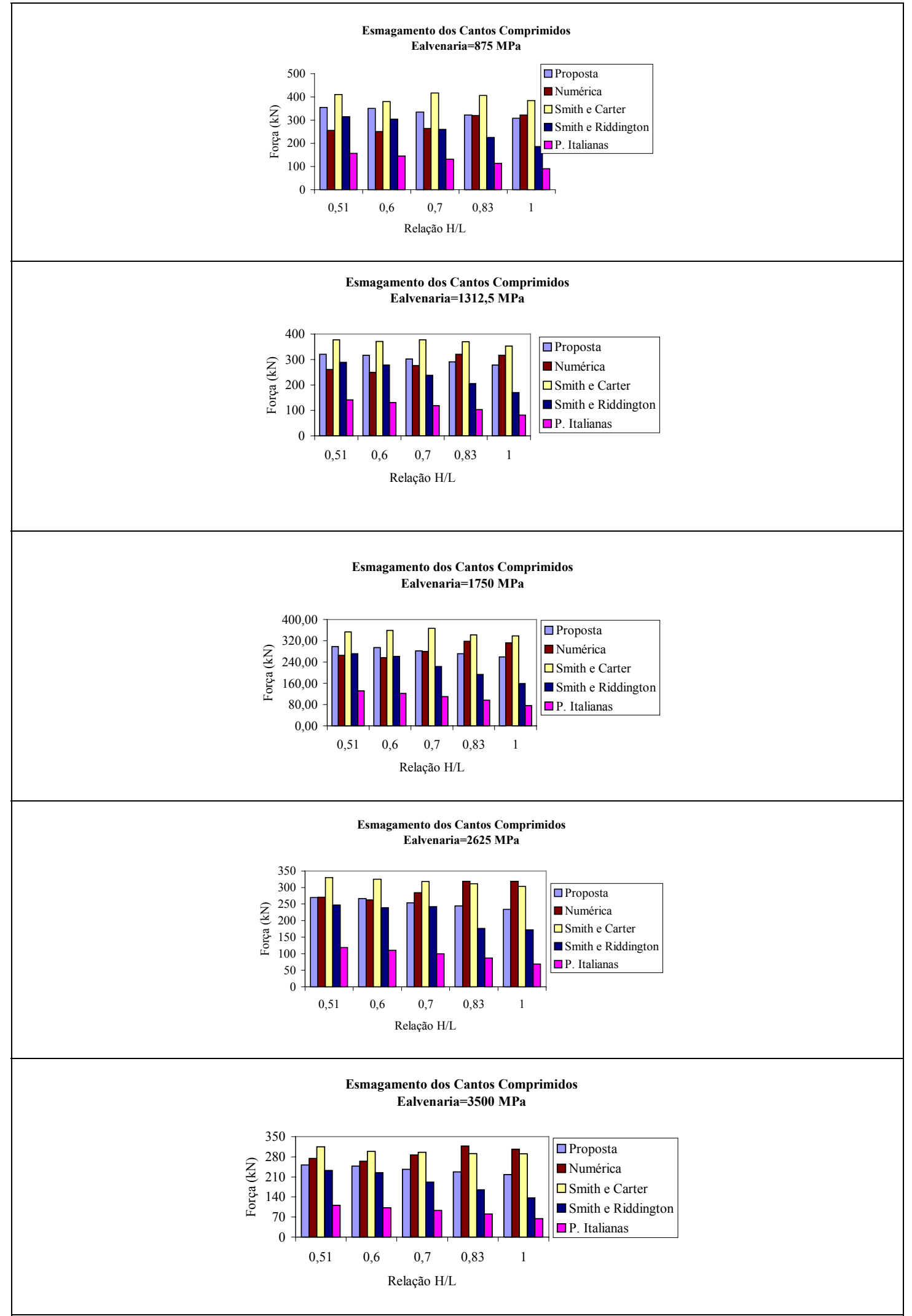

FIGURA 7.9 - Análise comparativa dos resultados obtidos para módulos de deformação da alvenaria iguais a $875 \mathrm{MPa}, 1312,5 \mathrm{MPa}, 1750 \mathrm{MPa}, 2625 \mathrm{MPa}$. e $3500 \mathrm{MPa}$ - Esmagamento dos cantos comprimidos 


\section{B) VARIAÇÃO DA RIGIDEZ VIGA-PILAR}

$\mathrm{Na}$ figura 7.10, apresentam-se os valores das forças de esmagamento dos cantos comprimidos obtidos através da modelagem numérica e da proposta apresentada, considerando as ligações viga-pilar articuladas, rígidas e semi-rígidas, respectivamente.

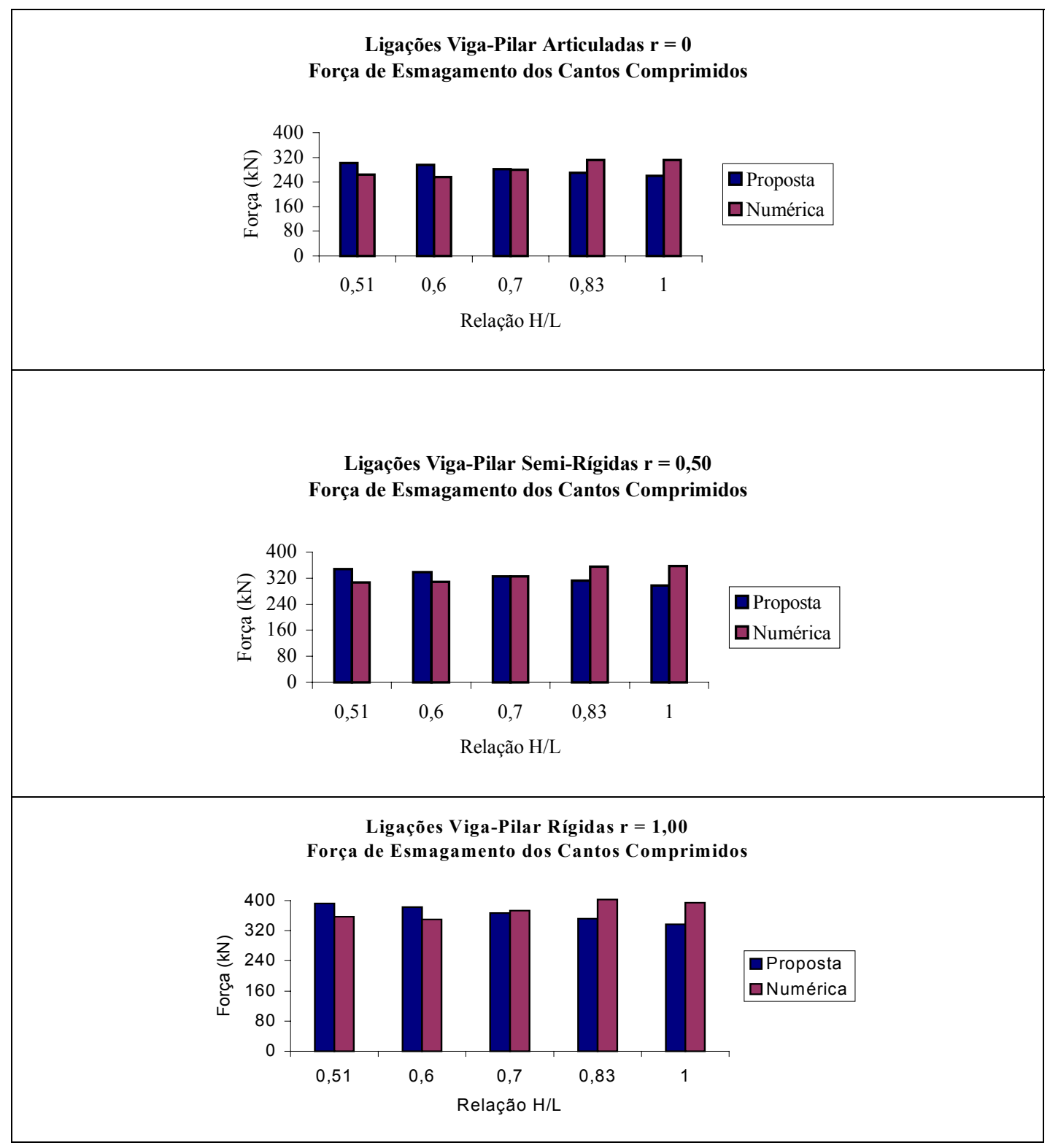

FIGURA 7.10 - Força de esmagamento nos cantos comprimidos, considerando-se as ligações viga-pilar: articuladas, semi-rígidas e rígidas 
Os resultados obtidos com o modelo proposto apresentaram excelente concordância com o modelo numérico analisado, para as várias condições de ligação viga-pilar e relações altura/comprimento.

\subsubsection{2 - COMPARAÇÃO COM OS RESULTADOS DE BRAGUIM}

BRAGUIM (1989) realizou ensaios experimentais em pórticos de aço preenchidos com alvenaria de blocos de concreto. Foram realizados 12 ensaios, descritos a seguir:

- Seis ensaios com pórtico metálico articulado, designados quadros 1 a 6 .

- Três ensaios com as ligações viga-pilar tipo 1.

- Três ensaios com as ligações viga-pilar tipo 2.

Ambas os tipos de ligações foram constituídos por cantoneiras soldadas à mesa da coluna, utilizando-se dois e quatro parafusos, designadas, respectivamente, tipo 1 e tipo 2. Os parafusos utilizados foram de 12,50 mm de diâmetro e aço ASTM A325.

Os pórticos ensaiados apresentaram as características descritas na tabela 7.5. O painel de alvenaria possuía as dimensões de $320 \times 280 \mathrm{~cm}^{2}$, módulo de deformação $5000 \mathrm{MPa}$ e espessura de $11,5 \mathrm{~cm}$. O comprimento de contato, calculado segundo as recomendações de STAFFORD-SMITH, é de 95,72 cm e o parâmetro de rigidez relativa $\left(\lambda L^{\prime}\right)$, igual a 4,92 .

TABELA 7.5 - Características dos elementos componentes dos pórticos ensaiados

\begin{tabular}{|c|c|c|c|}
\hline ELEMENTO & $\begin{array}{c}\text { MÓD. DEFORM. } \\
\left(\mathrm{kN} / \mathrm{cm}^{2}\right)\end{array}$ & $\begin{array}{c}\text { ÁREA } \\
\left(\mathrm{cm}^{2}\right)\end{array}$ & $\begin{array}{c}\text { MOM. INÉRCIA } \\
\left(\mathrm{cm}^{4}\right)\end{array}$ \\
\hline Vigas & 20500,00 & 32,20 & 2424,60 \\
\hline Colunas & 20500,00 & 42,40 & 3423,30 \\
\hline
\end{tabular}

A proposta apresentada neste trabalho foi comparada com os resultados experimentais obtidos por BRAGUIM (1989), com os resultados teóricos de SMITH 
e CARTER (1969), SMITH e RIDDINGTON (1977) e também com as prescrições italianas. Foram utilizados os valores médios obtidos por BRAGUIM (1989) nas séries 1 e 2 . Os resultados estão apresentados nas figuras 7.11 e 7.12, para as forças correspondentes à fissuração da diagonal e ao esmagamento dos cantos comprimidos, respectivamente.

Fissuração da Diagonal

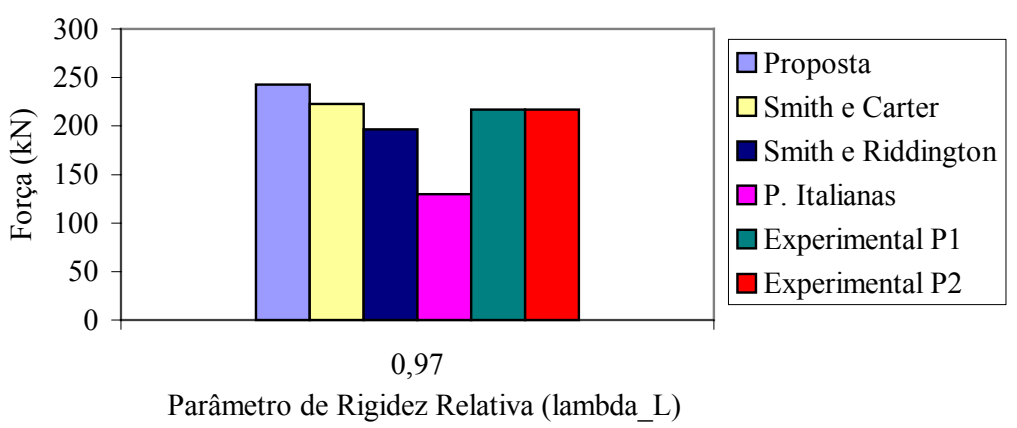

FIGURA 7.11 - Comparação entre os valores obtidos para a força correspondente à fissuração da diagonal através do modelo experimental de BRAGUIM (1989), dos modelos teóricos e da proposta desta tese

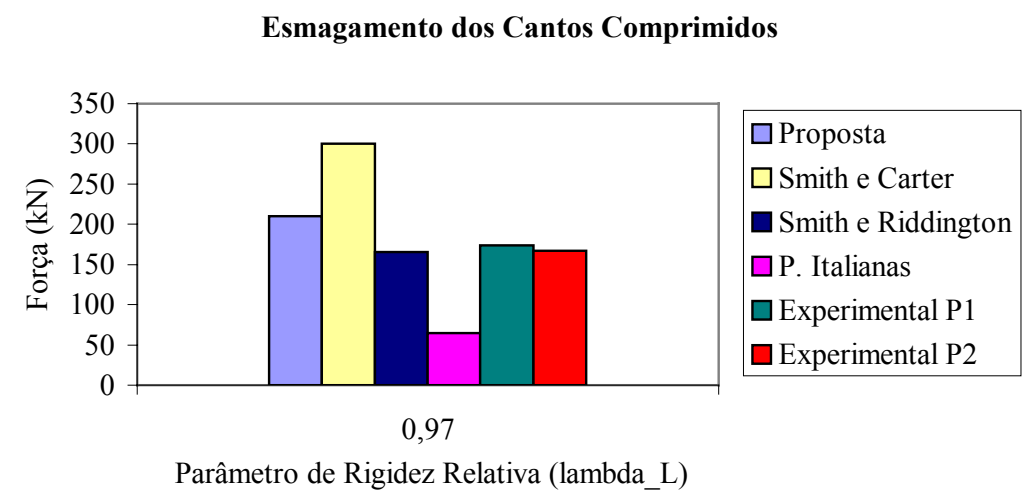

FIGURA 7.12 - Comparação entre os valores obtidos para a força correspondente ao esmagamento dos cantos comprimidos através do modelo experimental de BRAGUIM (1989), dos modelos teóricos e da proposta desta tese

Pelos resultados obtidos, comprova-se que a proposta apresentada nesse trabalho tem boa concordância com os valores experimentais obtidos por Braguim e também com aqueles obtidos através do modelo teórico de Smith e Carter. Já o método de Smith e 
Riddington apresentou valores superiores aos dos demais, enquanto as prescrições italianas apresentaram valores inferiores aos outros, mesmo trabalhando-se com valores médios para as tensões de ruptura.

\subsubsection{3 - COMPARAÇÃO COM OS RESULTADOS DE SMITH E CARTER}

SMITH e CARTER (1969) analisaram teoricamente o comportamento de um edifício de concreto armado de três pavimentos, construído em Johannesburg. O mesmo edifício foi submetido a ensaios de campo, cujos resultados experimentais detalhados são dados por OCKLESTON (1955). O carregamento constituiu-se de uma ação horizontal, ao nível da laje, aplicada no topo do edifício. Os painéis de preenchimento eram constituídos de blocos de alvenaria de $22,86 \mathrm{~cm}$ de espessura.

Apresenta-se na figura 7.13 um croquis do pórtico analisado e da seção transversal dos pilares, e na tabela 7.6 são mostradas as características elástico-geométricas do pórtico e do painel de alvenaria.

Nas figuras 7.14 e 7.15, encontram-se os resultados obtidos pelos métodos teóricos e pela proposta aqui apresentada. As cargas correspondentes à fissuração da diagonal e ao esmagamento dos cantos comprimidos são reapresentadas na tabela 7.7.

Foram também avaliados os parâmetros de resistência do pórtico, e concluiu-se que este era suficientemente seguro para permitir a ruptura dos painéis.

Pelos resultados obtidos, pode-se afirmar que a proposta deste trabalho representa, de forma satisfatória, o comportamento de pórticos preenchidos e constitui-se em ferramenta útil e versátil em projeto desse tipo de estrutura. 

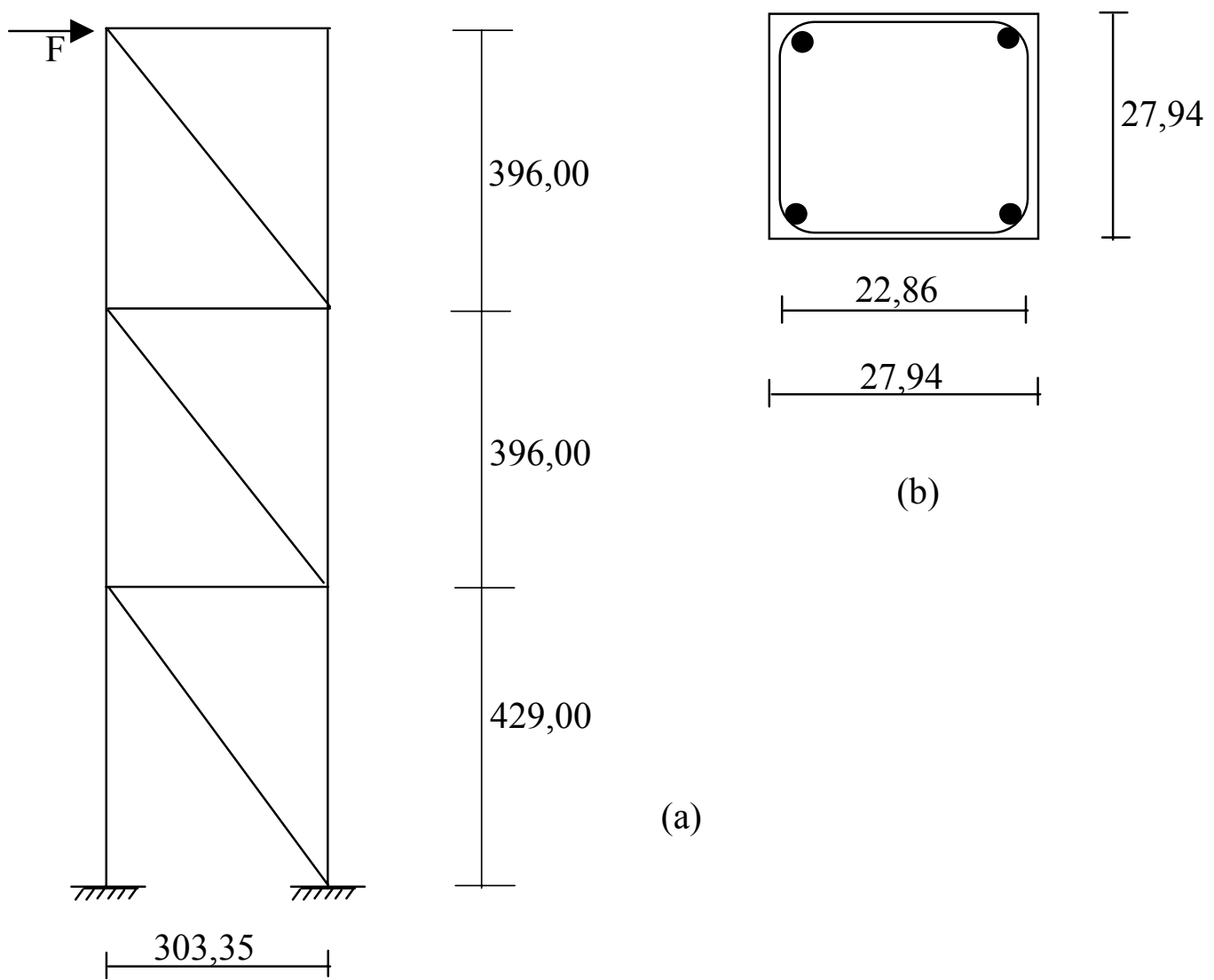

(b)

FIGURA 7.13 - Pórtico analisado: a) geometria e b) seção transversal dos pilares.

Dimensões $(\mathrm{cm})$

TABELA 7.6 - Características elástico-geométricas do pórtico de concreto e do painel de alvenaria

\begin{tabular}{|c|c|}
\hline \multicolumn{2}{|c|}{ Painel de Alvenaria } \\
\hline Comprimento de contato $(\alpha)$ & $136,91 \mathrm{~cm}$ \\
\hline Parâmetro de rigidez relativa $(\lambda \mathrm{l})$ & 4,48 \\
\hline Módulo de deformação $(\mathrm{E})$ & $1687,00 \mathrm{MPa}$ \\
\hline Resistência média à compressão & $2,74 \mathrm{MPa}$ \\
\hline Pórtico de Concreto Armado \\
\hline Módulo de deformação (e) $\left(\mathrm{kn} / \mathrm{cm}^{2}\right)$ & $21800 \mathrm{MPa}$ \\
\hline Momento de inércia do pilar $\left(\mathrm{cm}^{4}\right)$ & $61186 \mathrm{~cm}^{4}$ \\
\hline
\end{tabular}


TABELA 7.7 - Cargas de ruptura por fissuração da diagonal e por esmagamento dos cantos comprimidos para as análises efetuadas. Unidade $(\mathrm{kN})$

\begin{tabular}{|c|c|c|}
\hline \multirow{2}{*}{ DESCRIÇÃO } & $\begin{array}{c}\text { MODO DE } \\
\text { RUPTURA }\end{array}$ & $\begin{array}{c}\text { FORÇA DE } \\
\text { RUPTURA }\end{array}$ \\
\hline \multirow{2}{*}{ Proposta } & Fissuração & 271,12 \\
\cline { 2 - 3 } & Esmagamento & 477,01 \\
\hline \multirow{2}{*}{ Smith e Carter } & Fissuração & 275,40 \\
\cline { 2 - 3 } & Esmagamento & 743,57 \\
\hline \multirow{2}{*}{ Smith e Riddington } & Fissuração & 289,05 \\
\cline { 2 - 3 } & Esmagamento & 235,08 \\
\hline
\end{tabular}

Fissuração da Diagonal

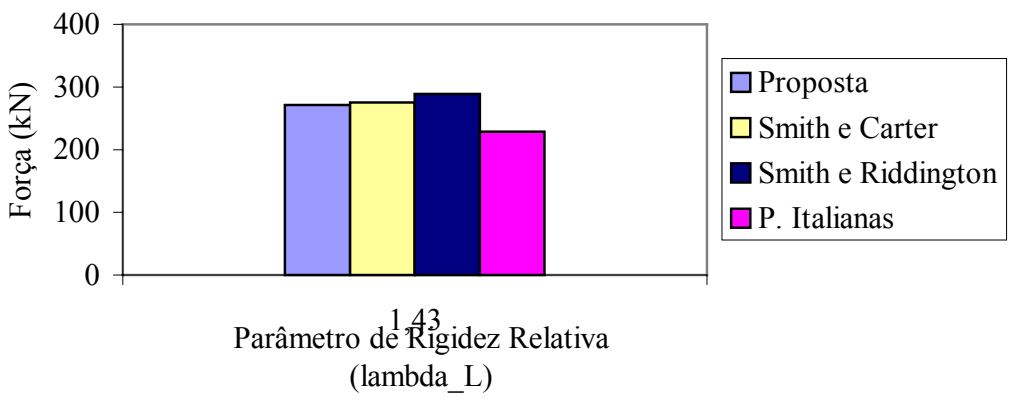

FIGURA 7.14 - Comparação entre os valores obtidos para a força correspondente à fissuração da diagonal através dos modelos teóricos e da proposta desta tese, para um pórtico de três pavimentos de concreto armado

Esmagamento dos Cantos Comprimidos

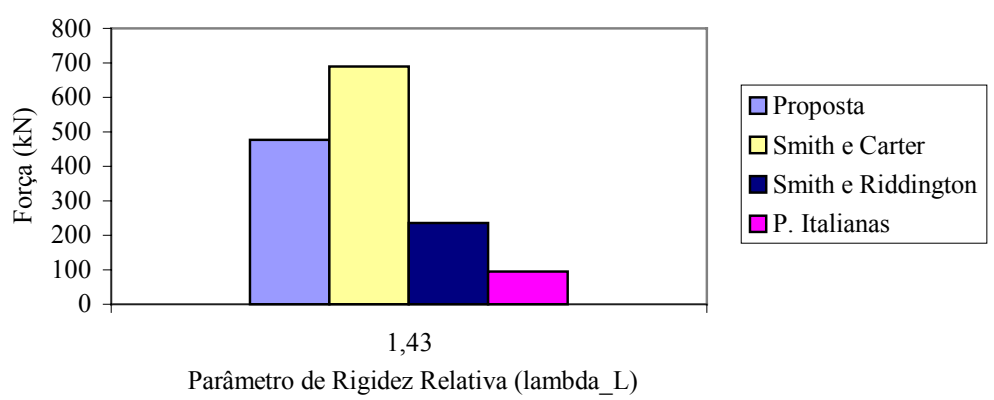

FIGURA 7.15 - Comparação entre os valores obtidos para a força correspondente ao esmagamento dos cantos comprimidos, através dos modelos teóricos e da proposta desta tese, para um pórtico de três pavimentos de concreto armado 


\section{3 - AVAliAÇÃo dA LARguRA EFETIVA de PAINÉIS DE PÓRTICOS PREENCHIDOS}

\subsection{1 - INTRODUÇÃO}

Em uma estrutura de pórticos preenchidos com alvenaria, quando as tensões de tração na interface pórtico-painel ultrapassam a sua resistência à tração, ocorre o descolamento das interfaces tracionadas, mantendo-se em contato as partes por onde são transmitidas as tensões de compressão do pórtico para o painel, conforme representado na figura 7.16.a. Dessa forma, apenas uma faixa diagonal do painel resiste às ações aplicadas, e pode-se postular que esse sistema se comporta como um pórtico com diagonal birrotulada e submetida a esforços de compressão, figura 7.16.b. Esse comportamento se mantém até que ocorre a ruptura do pórtico ou do painel.

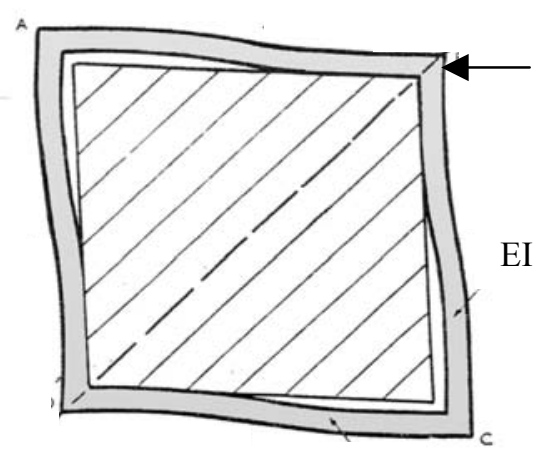

$\mathrm{EI}_{\mathrm{O}}$

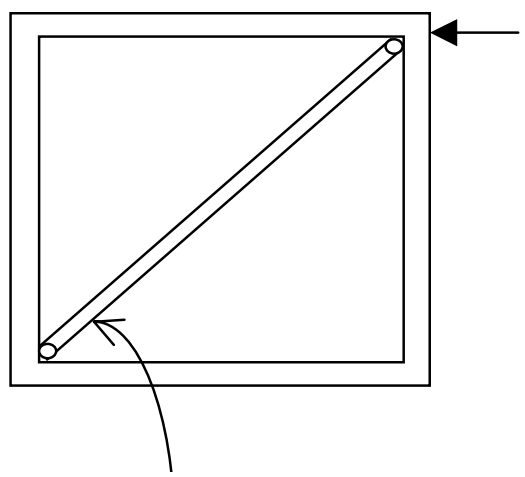

Barra

birrotulada

equivalente

(a)

(b)

FIGURA 7.16 - Tramo de pórtico preenchido com alvenaria submetido a carregamento diagonal 
Os modos de ruptura usuais no pórtico são por tração no pilar submetido ao carregamento ou por cisalhamento nas vigas e pilares. Entretanto, se o pórtico for suficientemente resistente para que não atinja um dos estados-limites últimos anteriormente referidos, a ruptura ocorre no painel.

As paredes de alvenaria com juntas de argamassa Ciment-cola apresentam um comportamento semelhante ao dos painéis de concreto. A ruptura, de maneira geral, inicia-se por fissuração ao longo da diagonal comprimida e, então, ocorre o esmagamento dos cantos comprimidos ou rompe-se apenas por esmagamento desses cantos.

\subsection{2 - OBTENÇÃO DA LARGURA EFETIVA DA DIAGONAL EQUIVALENTE}

A largura da diagonal equivalente não é constante para dado painel, mas decresce com o aumento do carregamento. Dessa forma, alguns autores propõem expressões distintas para esse cálculo, de acordo com o nível de carga atuante, como é o caso de MAINSTRONE (1971). SMITH e CARTER (1969) apresentaram curvas para cálculo da largura da diagonal equivalente, através da relação $w / d$, em que $w$ é a largura da diagonal equivalente e $d$ é a largura total da diagonal, para vários níveis de carga, variando também a relação altura/comprimento do pórtico, conforme apresentado no capítulo 2. Essas expressões são função do parâmetro de rigidez relativa $(\lambda L)$ ou do comprimento de contato $(\alpha)$, que utilizam o módulo de deformação inicial do material do painel. À medida que a força cresce, esse módulo diminui e, conseqüentemente, a largura efetiva da diagonal varia para cada um dos níveis de carga.

Considerando que a força correspondente à fissuração da diagonal representa um estado-limite de utilização e como tal é indesejável à estrutura, apresenta-se neste item uma proposta para o cálculo da largura da diagonal equivalente correspondente à atuação dessa força. 
Na figura 7.17, apresenta-se um dos diagramas força-deslocamento, obtido através do estudo paramétrico realizado, apresentado no capítulo 6, para sistemas de pórticos preenchidos. Substituindo o painel de alvenaria por uma diagonal equivalente, foram realizadas análises numéricas lineares, de forma a reproduzir a mesma rigidez obtida pela análise numérica não-linear do sistema pórtico-painel, para a força correspondente à fissuração da diagonal. Para isso foram atribuídos, por tentativas, valores à área correspondente à diagonal equivalente. Assumindo para a diagonal a mesma espessura, bem como as mesmas propriedades elásticas do painel, pode-se obter o valor da largura da diagonal equivalente, que corresponde à altura de sua seção transversal.

Os resultados obtidos para as larguras das diagonais são mostrados na tabela 7.8. Foram realizadas análises para as relações $\mathrm{H} / \mathrm{L}$ iguais a 0,$51 ; 0,60 ; 0,70 ; 0,83$; e 1,00, variando a relação de rigidez entre pórtico e painel, através de diferentes valores de módulo de deformação atribuídos à alvenaria (875 MPa, 1312,5 MPa, $1750 \mathrm{MPa}$, $2625 \mathrm{MPa}$ e $3500 \mathrm{MPa})$.

\section{Diagrama Força x Deslocamento}

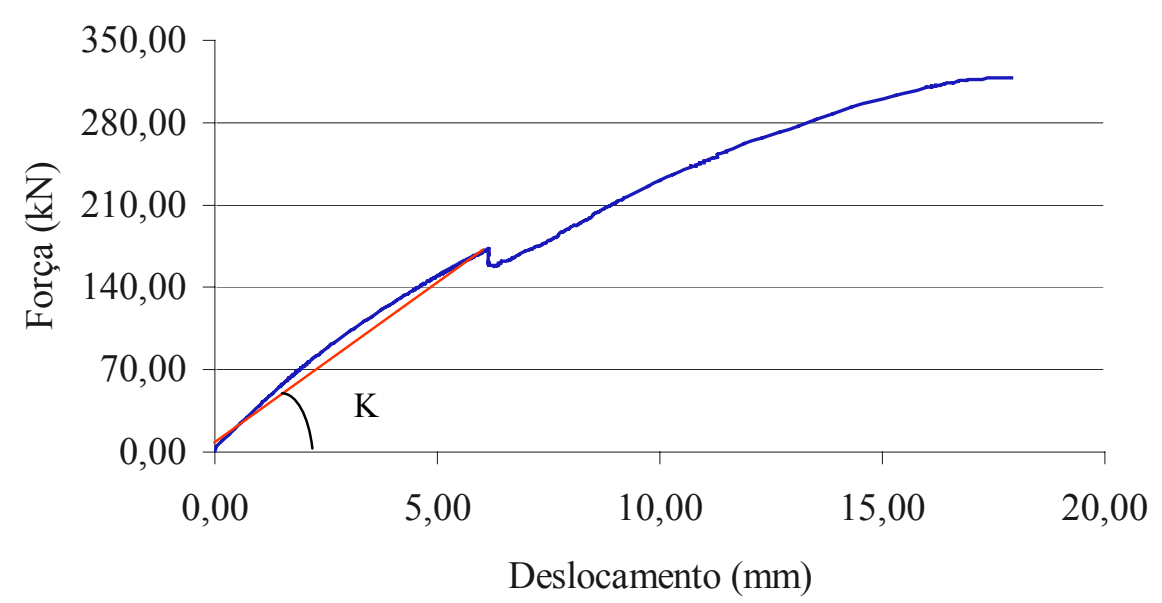

FIGURA 7.17 - Diagrama genérico força x deslocamento para pórticos preenchidos:

(-) modelagem numérica não-linear do sistema pórtico-painel e (-) modelagem numérica linear do pórtico com diagonal birrotulada equivalente 
A fim de obter uma expressão empírica para determinação da largura da diagonal equivalente, $w$, a partir dos resultados da tabela 7.8, tem-se a figura 7.18, na qual $\alpha$ representa o comprimento de contato pórtico-painel, apresentado por STAFFORDSMITH (1967a). Utilizando as propriedades elásticas iniciais do painel, esse comprimento corresponde ao contato pórtico-painel ainda na fase elástica, ou seja, no início do carregamento.

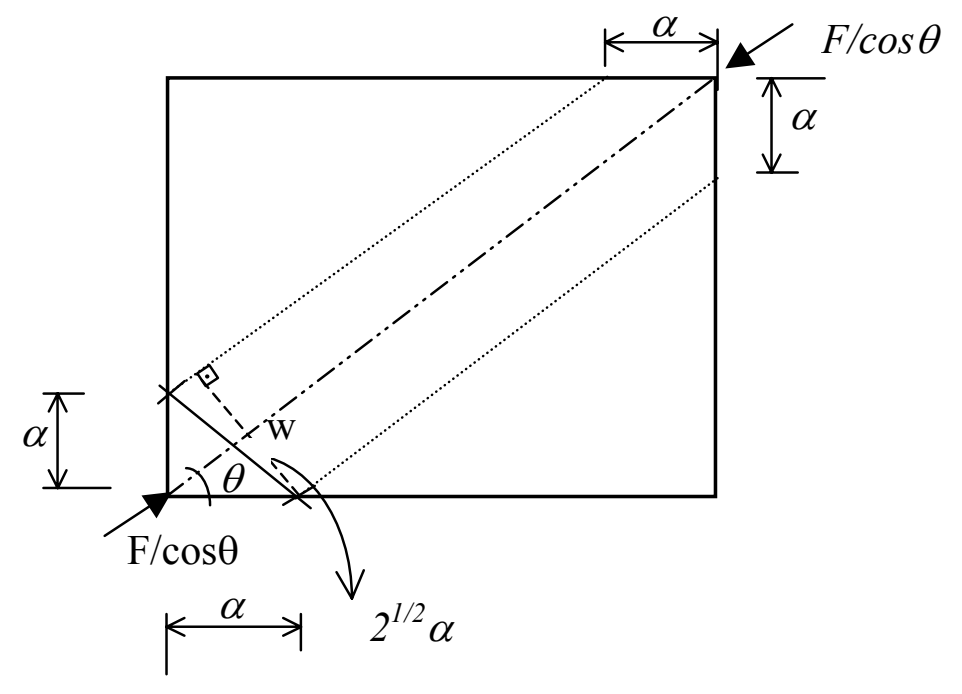

FIGURA 7.18 - Largura da diagonal equivalente correspondente ao início do carregamento

A largura da diagonal equivalente correspondente ao início do carregamento pode ser obtida pela expressão (7.32):

$$
\operatorname{sen} \theta=\frac{w}{2} \times \frac{1}{\alpha} \Rightarrow w=2 \times \alpha \times \operatorname{sen} \theta
$$

Tendo em vista que a largura da diagonal equivalente varia com a relação tensãodeformação do painel e que o comprimento de contato $\alpha$ é obtido em função das características elásticas iniciais, a expressão (7.32) conduz a valores para a largura da diagonal superiores àqueles correspondentes à força de fissuração. No entanto, através de uma avaliação empírica, percebe-se que, multiplicando a expressão (7.32) pelo fator 0,40 , os resultados aproximam-se, consideravelmente, daqueles obtidos 
através da análise linear com a barra diagonal equivalente, cujos valores são apresentados na tabela 7.8. Dessa forma, propõe-se a expressão (7.33) para avaliação da largura da diagonal equivalente correspondente à força de fissuração da diagonal.

$$
w=0,80 \times \alpha \times \operatorname{sen} \theta
$$

TABELA 7.8 - Valores obtidos para a largura da diagonal equivalente a partir da análise numérica linear, para a força correspondente à fissuração da diagonal

\begin{tabular}{|c|c|c|}
\hline $\begin{array}{l}\text { Módulo Deformação da Alvenaria - E } \\
(\mathrm{MPa})\end{array}$ & $\mathrm{H} / \mathrm{L}$ & Largura da Diagonal $(\mathrm{cm})$ \\
\hline \multirow{5}{*}{875,00} & 0,51 & 59,67 \\
\hline & 0,60 & 53,20 \\
\hline & 0,70 & 67,33 \\
\hline & 0,83 & 76,80 \\
\hline & 1,00 & 78,67 \\
\hline \multirow{5}{*}{1312,50} & 0,51 & 45,60 \\
\hline & 0,60 & 54,87 \\
\hline & 0,70 & 61,47 \\
\hline & 0,83 & 69,13 \\
\hline & 1,00 & 71,80 \\
\hline \multirow{5}{*}{1750,00} & 0,51 & 36,67 \\
\hline & 0,60 & 50,67 \\
\hline & 0,70 & 55,93 \\
\hline & 0,83 & 56,77 \\
\hline & 1,00 & 65,83 \\
\hline \multirow{5}{*}{2625,00} & 0,51 & 28,13 \\
\hline & 0,60 & 43,00 \\
\hline & 0,70 & 47,93 \\
\hline & 0,83 & 53,87 \\
\hline & 1,00 & 57,07 \\
\hline \multirow{5}{*}{3500,00} & 0,51 & 22,00 \\
\hline & 0,60 & 38,00 \\
\hline & 0,70 & 41,55 \\
\hline & 0,83 & 46,33 \\
\hline & 1,00 & 46,33 \\
\hline
\end{tabular}




\subsection{3 - VALIDAÇÃO DO MODELO PROPOSTO}

Neste item, os resultados obtidos pela proposta ora apresentada são comparados com os valores numéricos resultantes da análise linear do pórtico com a barra diagonal birrotulada equivalente e com o modelo proposto por HENDRY (1981). Como já comentado no capítulo 2, HENDRY (1981) propôs a expressão (2.5), transcrita na expressão (7.34), para obtenção da largura da diagonal equivalente a partir do comprimento de contato $\alpha$, definido por STAFFORD-SMITH (1967a) e reapresentado na expressão (7.31). No entanto, os valores obtidos pela expressão (7.34) diferem consideravelmente dos resultados apresentados na tabela 7.8.

$$
w=1 / 2 \sqrt{\left(\alpha_{l}^{2}+\alpha_{h}^{2}\right)}
$$

São indicados na tabela 7.9 os resultados para a largura da diagonal equivalente relativos à força de fissuração da diagonal, obtidos das seguintes maneiras: análise numérica linear do pórtico com a barra diagonal equivalente, proposta apresentada nesta tese, expressão (7.33), e proposta de HENDRY (1981), expressão (7.34). Para melhor comparação entre os resultados obtidos, apresenta-se a figura 7.29. Pode-se perceber que os resultados obtidos pela proposta desta tese aproximam-se satisfatoriamente dos valores correspondentes à análise numérica linear efetuada, sendo, portanto, uma ferramenta útil para avaliação dos esforços nas barras do pórtico e da rigidez do sistema pórtico com barra diagonal birrotulada equivalente, para a força correspondente à fissuração da diagonal.

Na tabela 7.10, apresenta-se a relação entre os resultados obtidos através da proposta apresentada e a análise numérica linear efetuada, bem como a relação entre essa proposta e a proposição de HENDRY (1981). 
TABELA 7.9 - Largura da diagonal equivalente correspondente à força de fissuração da diagonal segundo a proposta apresentada, a análise numérica linear e a proposta de Hendry

\begin{tabular}{|c|c|c|c|c|}
\hline \multirow{2}{*}{$\begin{array}{c}\text { Ealvenaria } \\
\text { (MPa) }\end{array}$} & \multirow{2}{*}{$\mathrm{H} / \mathrm{L}$} & \multicolumn{3}{|c|}{ Largura Diagonal Equivalente $(\mathrm{cm})$} \\
\hline & & Análise Linear & Proposta & Hendry \\
\hline \multirow{5}{*}{875} & 0,51 & 59,67 & 52,65 & 102,44 \\
\hline & 0,60 & 53,20 & 58,98 & 101,33 \\
\hline & 0,70 & 67,33 & 63,37 & 97,67 \\
\hline & 0,83 & 76,80 & 69,34 & 95,96 \\
\hline & 1,00 & 78,67 & 76,12 & 95,16 \\
\hline \multirow{5}{*}{1312,50} & 0,51 & 45,60 & 47,58 & 92,57 \\
\hline & 0,60 & 54,87 & 53,30 & 91,56 \\
\hline & 0,70 & 61,47 & 57,26 & 88,25 \\
\hline & 0,83 & 69,13 & 62,66 & 86,71 \\
\hline & 1,00 & 71,80 & 68,79 & 85,98 \\
\hline \multirow{5}{*}{1750} & 0,51 & 36,67 & 44,33 & 86,24 \\
\hline & 0,60 & 50,67 & 49,60 & 85,21 \\
\hline & 0,70 & 55,93 & 53,45 & 82,38 \\
\hline & 0,83 & 56,77 & 58,31 & 80,70 \\
\hline & 1,00 & 65,83 & 64,01 & 80,02 \\
\hline \multirow{5}{*}{2625} & 0,51 & 28,13 & 40,01 & 77,84 \\
\hline & 0,60 & 43,00 & 44,82 & 77,00 \\
\hline & 0,70 & 47,93 & 48,15 & 74,21 \\
\hline & 0,83 & 53,87 & 52,69 & 72,92 \\
\hline & 1,00 & 57,07 & 57,84 & 72,30 \\
\hline \multirow{5}{*}{3500} & 0,51 & 22,00 & 37,23 & 72,44 \\
\hline & 0,60 & 38,00 & 41,71 & 71,65 \\
\hline & 0,70 & 41,55 & 44,81 & 69,06 \\
\hline & 0,83 & 46,33 & 49,03 & 67,85 \\
\hline & 1,00 & 46,33 & 53,83 & 67,29 \\
\hline
\end{tabular}


TABELA 7.10 - Relação entre a largura da diagonal equivalente correspondente à força de fissuração da diagonal, segundo a proposta apresentada e a análise numérica linear efetuada, e entre a proposta apresentada e a proposta de Hendry

\begin{tabular}{|c|c|c|c|}
\hline $\begin{array}{c}\text { Ealvenaria } \\
(\mathrm{MPa})\end{array}$ & $\mathrm{H} / \mathrm{L}$ & \multicolumn{2}{|c|}{ Relação entre as Propostas para Cálculo da Largura Diagonal Equivalente } \\
\hline $\begin{array}{l}\text { Ealvenaria } \\
\text { (MPa) }\end{array}$ & $\mathrm{H} / \mathrm{L}$ & Análise Linear /Proposta & Hendry/Proposta \\
\hline \multirow{5}{*}{875} & 0,51 & 1,13 & 1,95 \\
\hline & 0,60 & 0,90 & 1,72 \\
\hline & 0,70 & 1,06 & 1,54 \\
\hline & 0,83 & 1,11 & 1,38 \\
\hline & 1,00 & 1,03 & 1,25 \\
\hline \multirow{5}{*}{1312,50} & 0,51 & 0,96 & 1,95 \\
\hline & 0,60 & 1,03 & 1,72 \\
\hline & 0,70 & 1,07 & 1,54 \\
\hline & 0,83 & 1,10 & 1,38 \\
\hline & 1,00 & 1,04 & 1,25 \\
\hline \multirow{5}{*}{1750} & 0,51 & 0,83 & 1,95 \\
\hline & 0,60 & 1,02 & 1,32 \\
\hline & 0,70 & 1,05 & 1,54 \\
\hline & 0,83 & 0,97 & 1,38 \\
\hline & 1,00 & 1,03 & 1,25 \\
\hline \multirow{5}{*}{2625} & 0,51 & 0,70 & 1,95 \\
\hline & 0,60 & 0,96 & 1,72 \\
\hline & 0,70 & 1,00 & 1,54 \\
\hline & 0,83 & 1,02 & 1,38 \\
\hline & 1,00 & 0,99 & 1,25 \\
\hline \multirow{5}{*}{3500} & 0,51 & 0,59 & 1,95 \\
\hline & 0,60 & 0,93 & 1,72 \\
\hline & 0,70 & 0,93 & 1,54 \\
\hline & 0,83 & 0,94 & 1,38 \\
\hline & 1,00 & 0,86 & 1,25 \\
\hline
\end{tabular}




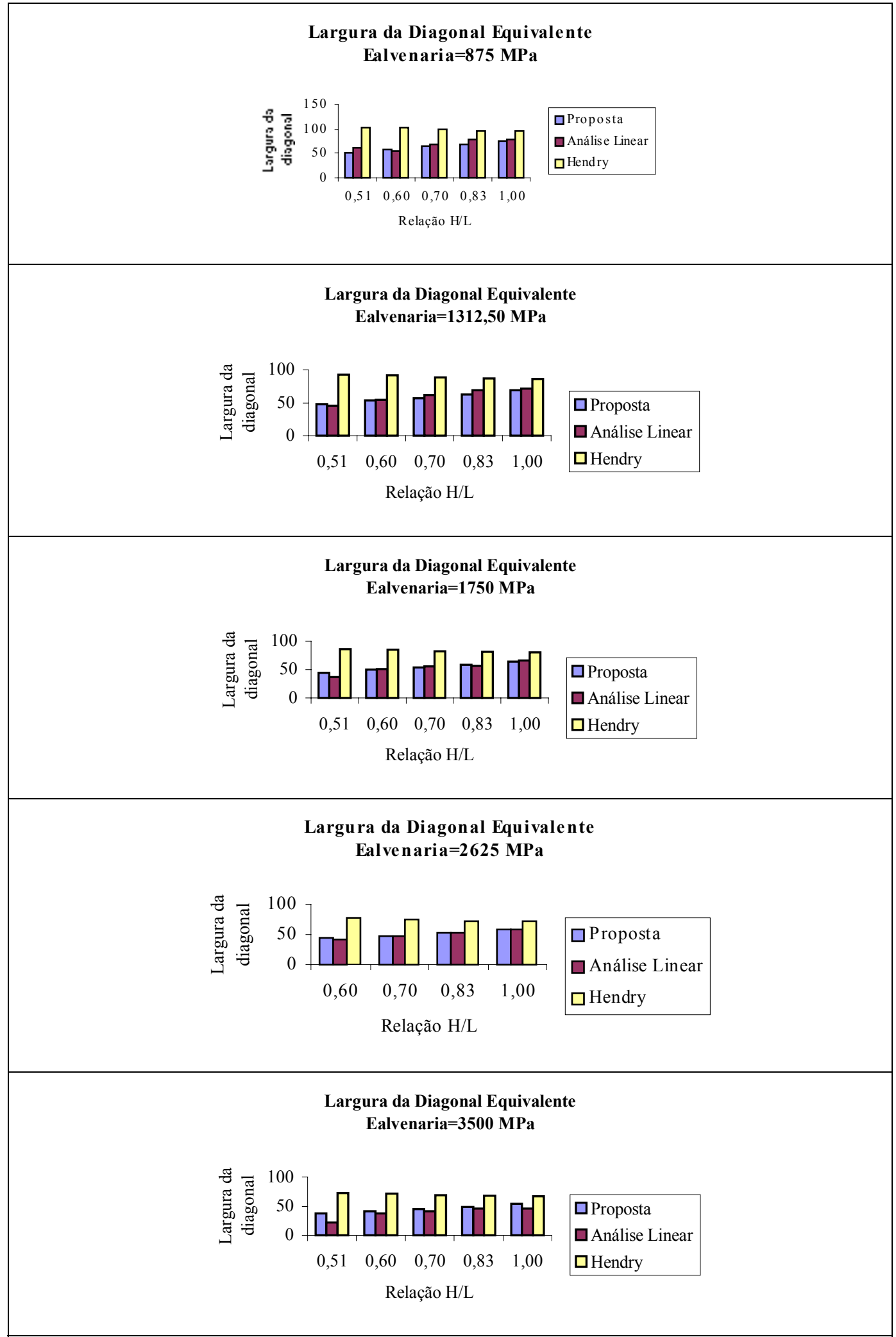

FIGURA 7.19 - Largura da diagonal equivalente correspondente à força de fissuração: modelo proposto, análise linear e modelo de Hendry - Ealvenaria=875 MPa, 1312,5 MPa, $1750 \mathrm{MPa}, 2625 \mathrm{MPa}$ e $3500 \mathrm{MPa}$ 


\section{4 - CONCLUSÃO}

Apresentou-se neste capítulo uma proposta para obtenção da força de ruptura em painéis de alvenaria, considerando dois modos de ruptura: fissuração da diagonal e esmagamento dos cantos comprimidos.

Na proposta apresentada, utilizou-se o conceito de resistência efetiva na avaliação da resistência à tração no centro do painel, uma vez que se adotou uma distribuição uniforme de tensões nessa região.

Na obtenção da carga de ruptura devida ao esmagamento dos cantos comprimidos, como se tem uma distribuição triangular de tensões, esse conceito não foi utilizado. Além disso, efetuou-se uma consideração adicional, que consiste na verificação do esmagamento no centro do painel onde se considerou a resistência à compressão efetiva, de forma a dar consistência ao método proposto. No entanto, provou-se que o esmagamento do centro do painel não ocorre antes do esmagamento dos cantos comprimidos, e, dessa forma, essa verificação já fica automaticamente satisfeita.

Analisando os resultados apresentados, percebe-se que aqueles obtidos pela proposta apresentada nesta tese se aproximam consideravelmente dos resultados experimentais e dos resultados numéricos, assim como do método teórico de Smith e Riddington. Já o método de Smith e Carter exibe valores superiores aos dos demais, na maioria dos casos, enquanto as prescrições italianas apresentam valores bastante inferiores aos dos outros métodos, mesmo quando se trabalha com valores médios para as resistências dos materiais. 


\section{CONSIDERAÇÕES FINAIS}

É inegável a contribuição dos painéis de alvenaria no enrijecimento de estruturas de pórticos. No entanto, mesmo com constatações a respeito de economia e eficiência no uso de pórticos preenchidos, a consideração em projeto deste tipo de estrutura não é usual. Há uma carência de ferramentas de projeto que viabilizem o cálculo desses sistemas.

Neste trabalho, confirmou-se mais uma vez a contribuição dos painéis na rigidez e resistência de pórticos preenchidos, sob os aspectos teórico, experimental e numérico. A partir daí, uma proposta para cálculo da carga de ruptura em painéis de pórticos preenchidos é apresentada, baseando-se no método das bielas e tirantes.

No que se refere ao aspecto teórico, apresentou-se inicialmente uma revisão bibliográfica sobre o assunto, procurando acompanhar a evolução dos estudos sobre o tema. Os dois protótipos foram avaliados analiticamente, através das proposições de SMITH e CARTER (1969), de SMITH e RIDDINGTON (1977) e das prescrições italianas DM 16/01/96 e Circ. 10/04/97, $\mathrm{n}^{\circ}$. 65, e os resultados foram apresentados no capítulo 4. Esses autores apresentaram métodos teóricos capazes de estimar 
quantitativamente a rigidez e a resistência proporcionada pelos painéis de alvenaria à estrutura como um todo.

Através de avaliações experimentais, procurou-se descrever o comportamento de pórticos de aço de perfis I soldados, preenchidos com alvenaria de concreto celular autoclavado, variando parâmetros, como: relação altura/comprimento dos pórticos, argamassa utilizada nas juntas, elementos componentes da interface pórtico-painel e a existência ou não de aberturas nas paredes. Foram idealizados e construídos, para os fins desta pesquisa, um pórtico de reação e o protótipo TIPO II. O protótipo TIPO I foi utilizado por FONSECA (1999). Avaliou-se ainda, a título de investigação, a influência de elementos componentes das paredes (blocos e painéis) no comportamento de pórticos preenchidos.

Efetuaram-se modelagens numéricas dos protótipos ensaiados, através de análise não-linear, e os resultados obtidos foram comparados com os experimentais, comprovando-se que o modelo numérico idealizado representa, de forma satisfatória, o comportamento de sistemas de pórticos preenchidos. O conjunto foi discretizado através de macromodelagem, considerando-se elementos de interface entre vigapilar, pórtico-alvenaria e alvenaria-alvenaria, estes últimos na direção da diagonal comprimida, de modo a representar as fissuras potenciais. Para caracterização da alvenaria, utilizou-se um modelo constitutivo implementado por LOURENÇO (1996), processado através do programa DIANA, versão 7.2.

De posse de um modelo numérico que representa de forma satisfatória o comportamento experimental de pórticos preenchidos, foi efetuado um estudo paramétrico, de modo a identificar os parâmetros que afetam o comportamento de pórticos preenchidos. Fatores como geometria do pórtico e do painel, resistência e rigidez do painel de alvenaria e do pórtico e rigidez da ligação viga-pilar (para a carga relativa ao esmagamento dos cantos), devem ser incluídos em uma proposta para cálculo da carga de ruptura. 
Com o intuito de sintetizar as informações anteriores, uma proposta para obtenção da carga de ruptura em painéis de alvenaria constituintes de pórticos preenchidos foi apresentada no capítulo 7. Utilizando o modelo de bielas e tirantes, apresentou-se uma expressão para cálculo da carga de ruptura em painéis. Os resultados obtidos foram comparados com os resultados numéricos e experimentais desenvolvidos nesta tese e com outros experimentais e teóricos disponíveis na literatura, comprovando o fato de que a proposta apresentada conduz a resultados satisfatórios, constituindo-se em uma ferramenta simples e útil em projetos de pórticos preenchidos.

Dos ensaios experimentais realizados, observou-se que o ferro-cabelo, da forma como foi aplicado, não atendeu à utilização requerida, além de seu uso tornar o processo de montagem da estrutura mais trabalhoso e, conseqüentemente, com custos mais elevados. Os diagramas força $\mathrm{x}$ deslocamento dos ensaios realizados, figura 3.38, permitem observar que o uso de ferro-cabelo não interfere na rigidez global da estrutura. Comparando os resultados dos ensaios 3A e 4A, em que foram utilizados ferros-cabelo, com os dos ensaios 5A e 6A, nos quais não se utilizaram ferros-cabelo, verificou-se que os valores das rigidezas praticamente não diferiram.

O descolamento da interface ocorre na presença ou não de ferros-cabelo. No entanto, o ferro-cabelo retarda o aparecimento do descolamento. Nos ensaios em que não foram utilizados ferros-cabelo, o descolamento das interfaces ocorreu para baixos níveis de carga, aproximadamente $10 \%$ da carga de ruptura. Essa semiplastificação poderia ser classificada como um estado-limite de utilização, não fossem as características cíclicas das ações horizontais, devidas ao vento. Assim, o canto do painel ora fissurado, em situação adversa, estará comprimido e, após sucessivos carregamentos de sentidos alternados, o painel poderá perder sua eficiência no contraventamento da estrutura. Nesse sentido, para ações horizontais inferiores àquelas que provocam o descolamento da interface com ferro-cabelo, este poderá contribuir para evitar essa perda de rigidez.

Existem na literatura sugestões para contornar o problema do descolamento precoce, como a utilização de malhas horizontais, de treliças ou mesmo de barras de aço. No 
entanto, qualquer recomendação quanto ao uso carece de um estudo mais abrangente, envolvendo necessariamente a execução de ensaios experimentais que comprovem sua eficiência e garantam segurança em seu uso.

É importante observar que, quando se diz descolamento precoce, pretende-se comparar as forças que causam o descolamento das interfaces tracionadas com as forças que causam a ruptura dos painéis, por fissuração ou esmagamento. No entanto, quando se comparam as forças que causam os descolamentos com as forças de projeto devidas ao vento, obtidas de prescrições normativas, a relação entre elas se modifica.

Para fins de comparação entre os valores de ações que provocam o descolamento da interface e os valores de projeto obtidos segundo recomendações da NBR 6123, apresentam-se as ações relativas ao vento em um edifício de quatro pavimentos, idealizado por BRAGUIM (1989), figura 8.1. Na tabela 8.1 são apresentadas as principais características geométricas do edifício e na figura 8.2, as ações devidas ao vento, obtidas segundo as prescrições da NBR 6123.

Tendo em vista os valores de projeto para as ações devidas ao vento, calculadas segundo a NBR 6123, percebe-se que essas ações são inferiores àquelas que provocam o descolamento da interface. Dessa forma, não é regra geral a ocorrência de descolamentos das interfaces para as cargas de serviço, devendo-se analisar caso a caso.

Com relação aos tipos de argamassa utilizados nos ensaios experimentais, é visível o importante papel desempenhado pela argamassa Ciment-cola. Nos dois primeiros ensaios, em que se utilizou argamassa traço 1:3:7,5, de cimento cal e areia, ela foi um fator limitante da carga última. Essa argamassa foi recomendada pelos fabricantes dos blocos, mas não se mostrou adequada nos ensaios realizados, ocorrendo a ruptura por cisalhamento das juntas de argamassa para ações bastante inferiores àquelas obtidas por ocasião do uso de argamassa Ciment-cola. 


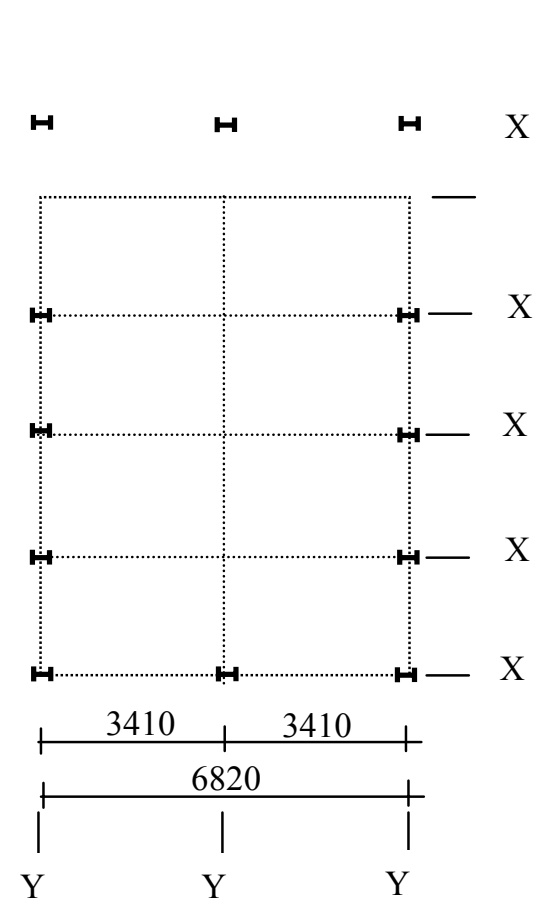

Paredes resistentes

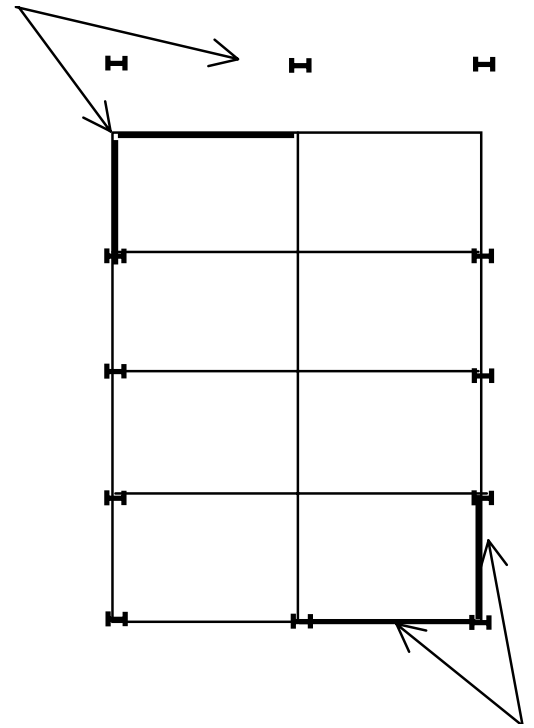

(b)

Paredes resistentes

(a)

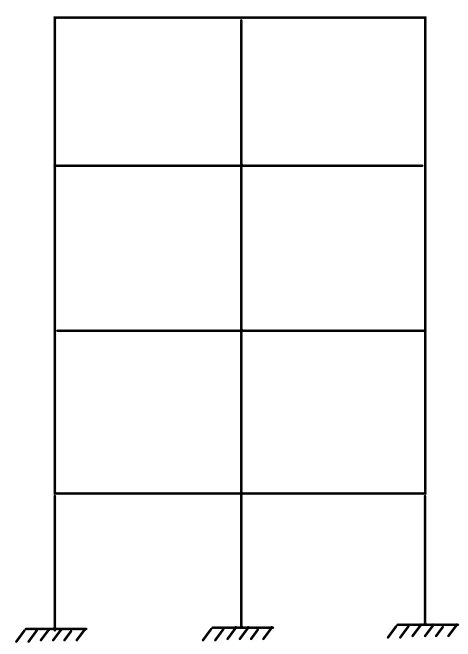

(d)

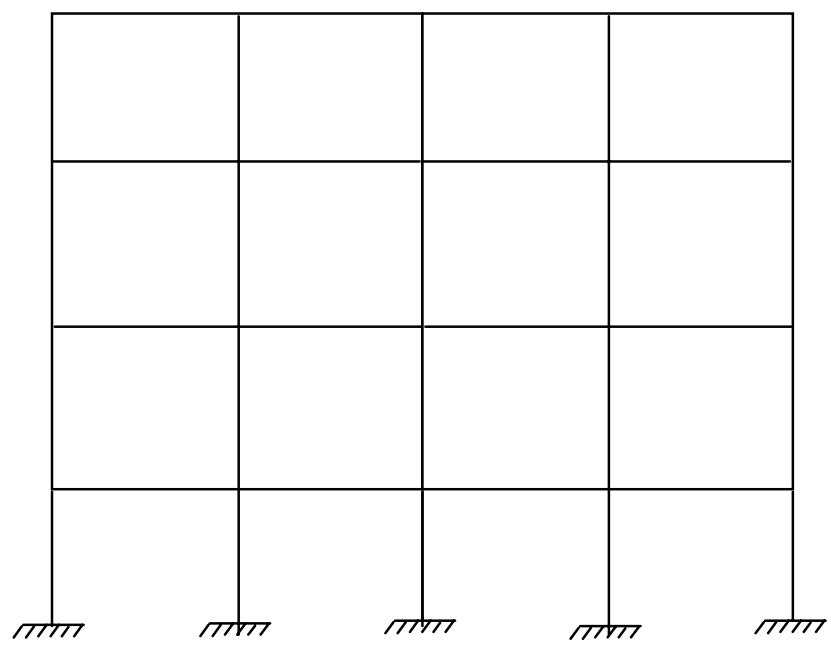

(c)

FIGURA 8.1 - Edifício idealizado por BRAGUIM (1989): a) arranjo em planta das vigas e colunas, b) arranjo das paredes resistentes a esforços horizontais, c) vista transversal e d) vista longitudinal 
TABELA 8.1 - Seções transversais de vigas e pilares

\begin{tabular}{|l|l|}
\hline Vigas: & IS $210 \times 125 \times 25,3$ \\
& $\mathrm{E}=20500 \mathrm{kN} / \mathrm{cm}^{2}$ \\
& Area $=32,2 \mathrm{~cm}^{2}$ \\
& Inércia $=2424,6 \mathrm{~cm}^{4}$
\end{tabular}

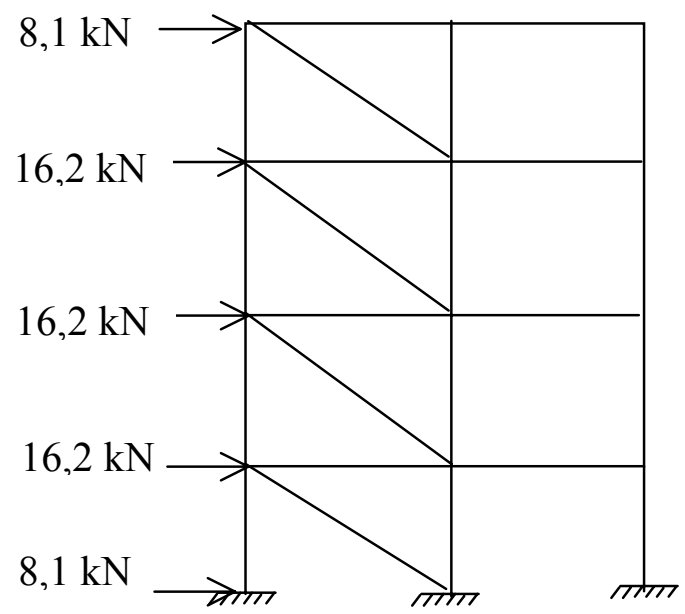

FIGURA 8.2 - Edifício idealizado por BRAGUIM (1989) - Ações devidas ao vento, segundo prescrições da NBR 6123

Quando foram avaliadas as paredes com abertura e efetuadas comparações com as paredes sem abertura, pôde-se constatar que houve perda de rigidez e resistência produzida pela introdução da abertura. No que se refere às cargas aplicadas, houve também diminuição de 57\% no valor da carga aplicada na parede com abertura, nos ensaios experimentais realizados. 
O modelo numérico utilizado para representar as paredes com abertura foi mais rígido que o necessário para representação desse tipo de estrutura. Como o modo de ruptura nesse caso é por cisalhamento das juntas de argamassa, uma micromodelagem poderia fornecer melhores resultados. Outro fator que contribuiu para tornar o modelo mais rígido foi a ausência do conhecimento de todas as propriedades dos materiais necessárias à análise não-linear.

No que se refere à influência da relação altura/comprimento dos pórticos na rigidez e resistência de pórticos preenchidos, foi constatada uma tendência de crescimento da carga de fissuração da diagonal à medida que se aumentava o vão, isto é, diminuía-se a relação altura/comprimento. No entanto, para relações altura/comprimento próximas de 0,5 , surgiram tensões principais de tração no canto inferior direito frontal do modelo, que provocaram fissuras nessas regiões, antes da ocorrência da fissuração da diagonal.

Do estudo realizado, pôde-se concluir que o bom desempenho da alvenaria com função estrutural, seja qual for sua aplicação, está intimamente ligado aos aspectos construtivos, desde a confecção até o assentamento dos blocos. Além disso, como qualquer outra edificação civil, também as edificações compostas por alvenaria têm vida-útil, estando sujeitas à ação das intempéries, e, portanto, a garantia de sua boa funcionalidade depende da manutenção e cuidados no uso da estrutura.

O trabalho apresentado não esgota os assuntos abordados, e, sim, abre novas portas para a compreensão do comportamento de sistemas de pórticos preenchidos. Em razão dessas análises, algumas sugestões para continuidade de pesquisas podem ser formuladas, as quais serão comentadas a seguir:

- É necessária a avaliação experimental de pórticos preenchidos por painéis de alvenaria, sujeitos a ações horizontais cíclicas. Dessa forma, será possível a avaliação da rigidez das interfaces ora tracionadas, ora comprimidas e da sua influência sobre o comportamento de sistemas de pórticos preenchidos. Associada a essa forma de aplicação de carga, uma avaliação experimental de 
elementos de ligação na interface pórtico-painel é de grande interesse. Elementos como malhas horizontais, treliças e mesmo barras de aço com comprimento superior ao utilizado nesta tese poderão ser ensaiados experimentalmente, com vistas ao retardamento do descolamento das interfaces pórtico-painel.

- Um estudo de sistemas de pórticos preenchidos com abertura no painel, através de micromodelagem, é recomendado. Dessa forma, é possível obter numericamente o modo de ruptura por cisalhamento nas juntas de argamassa, típico para esses sistemas. É importante assinalar a elevada importância de uma completa caracterização do material, de forma que o modelo numérico possa representar de forma coerente o comportamento estrutural.

- A consideração de diferentes tipos de blocos usualmente utilizados, a variação do arranjo de blocos e a influência da posição das juntas de argamassa merecem ser estudadas numérica e experimentalmente.

- Por fim, uma avaliação do comportamento de sistemas de pavimentos múltiplos e vãos diversos, tanto numérica quanto experimentalmente, é sugerida, de forma a melhor validar a teoria proposta no capítulo 7. 

PAINÉIS PRÉ-FABRICADOS DE ALVENARIA

\section{A1 - INTRODUÇÃO}

A título de investigação experimental, foram efetuados dois ensaios do pórtico TIPO II preenchido com painéis pré-fabricados de concreto celular autoclavado de dimensões $15 \times 35 \times 210 \mathrm{~cm}^{3}$. O objetivo desses ensaios foi comparar o comportamento dos painéis pré-fabricados de CCA com o comportamento dos blocos de CCA de dimensões 15 × 300 × $600 \mathrm{~mm}^{3}$, em termos de rigidez e resistência, quando utilizados como preenchimentos de pórticos.

\section{A2 - DESENVOLVIMENTO DOS ENSAIOS}

Nos dois ensaios realizados foram utilizados painéis pré-fabricados de CCA, dispostos verticalmente, unidos por juntas de $5 \mathrm{~mm}$ de argamassa colante. Um detalhe das armaduras utilizadas nos painéis encontra-se na figura A1: 


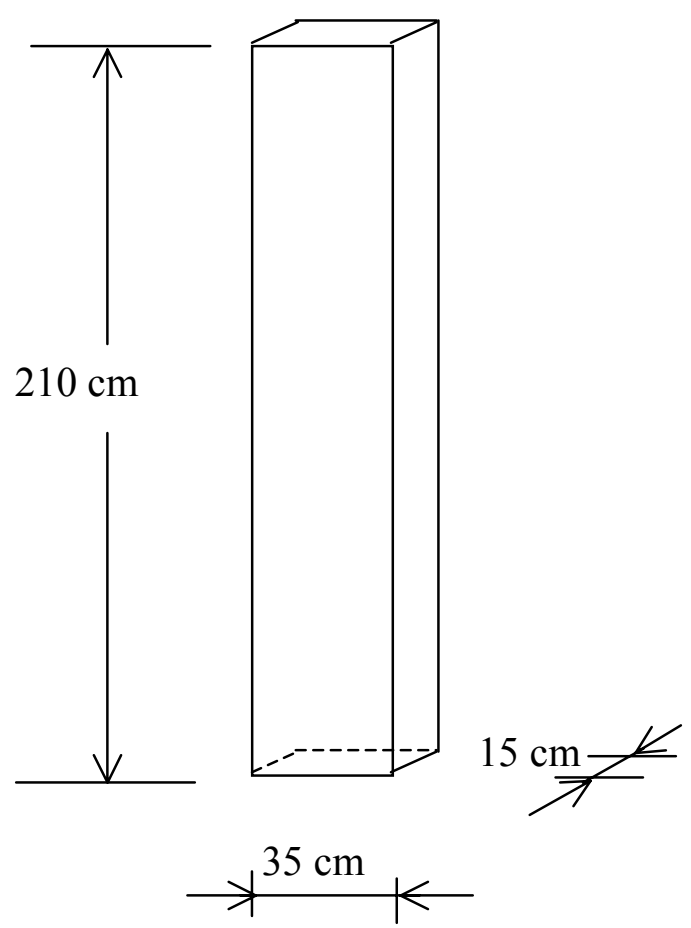

(a)

$$
2 \varnothing 6,3 \mathrm{~mm}
$$

(c)

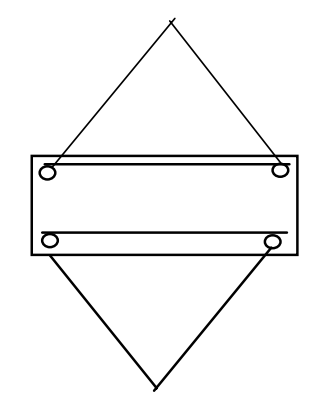

$2 \varnothing 6,3 \mathrm{~mm}$

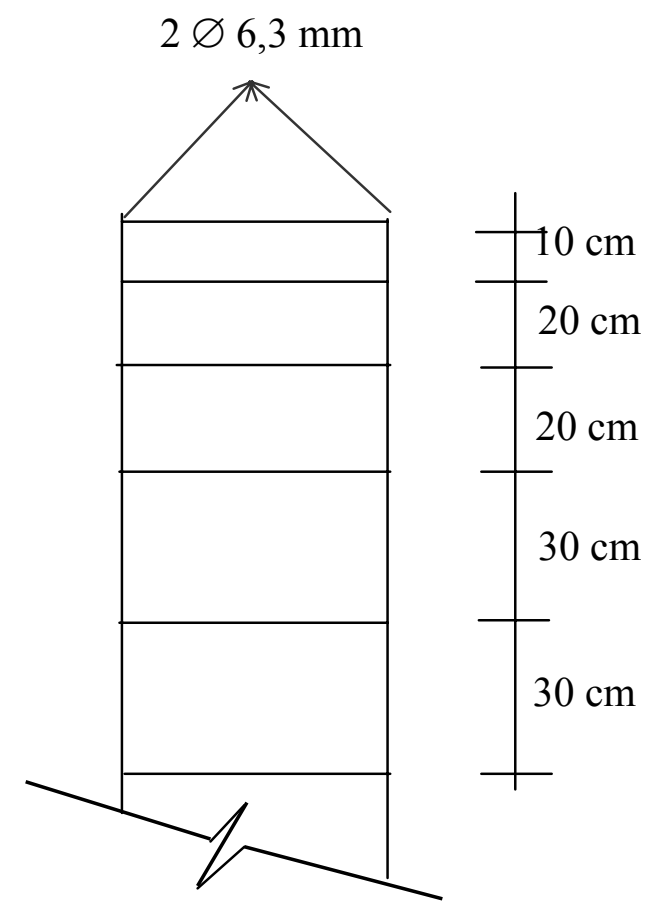

$\varnothing 5,0 \mathrm{~mm}$

FIGURA A.1 - Painéis pré-fabricados armados de CCA: a) perspectiva, b) seção transversal e c) armadura

A ação aplicada à estrutura consta de uma força horizontal aplicada no eixo da viga superior do protótipo.

No primeiro ensaio, surgiram as primeiras fissuras para uma carga de $40 \mathrm{kN}$, localizadas na extremidade frontal direita do painel, em uma das juntas de argamassa. Em seguida, com uma carga de $50 \mathrm{kN}$, ocorreu o descolamento da 
interface viga superior-painel e surgiram novas fissuras, novamente em juntas de argamassa. Essa configuração continuou até $90 \mathrm{kN}$, com aumento da abertura das fissuras. A parede foi, então, descarregada e novamente carregada.

Para uma carga de $114 \mathrm{kN}$ ocorreu ruptura frágil da junta vertical central, e a interface inferior horizontal se descolou quase que totalmente, restando $70 \mathrm{~cm}$ à direita. Com uma carga de $130 \mathrm{kN}$ ocorreu o descolamento da interface encunhamento-bloco, e iniciou-se o esmagamento nos cantos comprimidos, encerrando, assim, esse ensaio. O modo de ruptura caracterizado foi ruptura por cisalhamento e tração nas juntas de argamassa, figura A.2.

No segundo ensaio realizado, a parede encontrava-se fissurada em uma das juntas de argamassa antes do início do ensaio. Quando se iniciou a aplicação de carga, essas fissuras fecharam e ocorreu o descolamento da interface vertical direita, com exceção da parte comprimida $(50 \mathrm{~cm})$ e da interface horizontal superior em toda a sua totalidade. O descolamento da interface vertical esquerda, próximo ao ponto de aplicação de carga, ocorreu com uma força de $80 \mathrm{kN}$, mantendo-se ligada em uma extensão de $80 \mathrm{~cm}$, por onde as tensões de compressão interagiam. Quando a carga atingiu $110 \mathrm{kN}$, ocorreu o descolamento total da interface horizontal inferior, e as interfaces verticais da esquerda e direita mantiveram-se ligadas em uma faixa de 20 e $30 \mathrm{~cm}$, respectivamente.

O modo de ruptura caracterizado nesse ensaio foi o esmagamento dos cantos comprimidos do painel, que ocorreu com uma carga de $150 \mathrm{kN}$. 

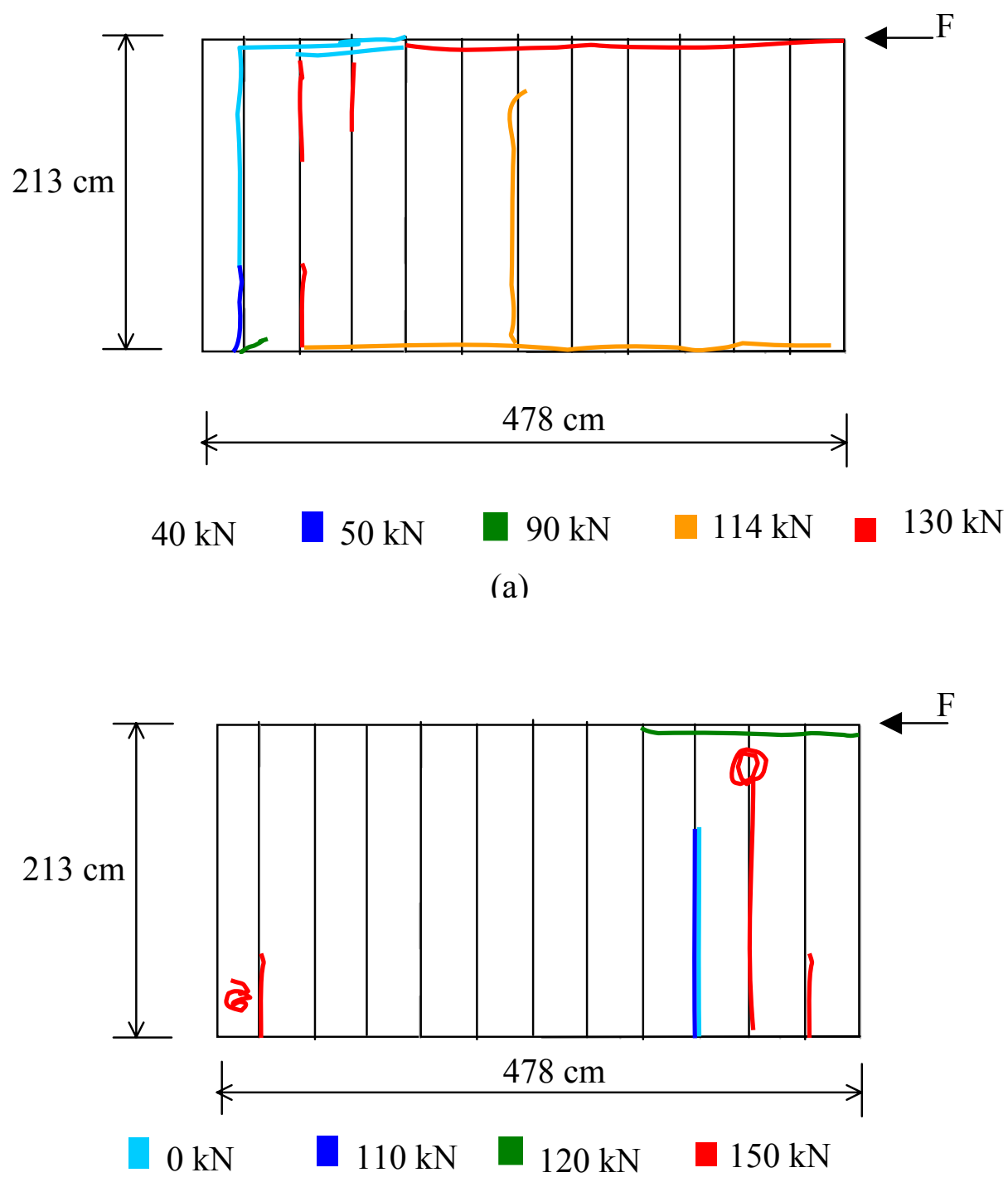

(b)

FIGURA A.2 - Modos de ruptura referentes aos ensaios de parede com painéis préfabricados armados de CCA: a) ensaio 5B e b) ensaio 6B 
Na figura A.3 é apresentado o diagrama força $\mathrm{x}$ deslocamento horizontal no topo do pilar, na direção do eixo da viga, para cada tipo de ensaio realizado na série B. Percebeu-se um comportamento linear até uma força em torno de $100 \mathrm{kN}$, quando ocorreu a ruptura frágil em uma das juntas de argamassa.

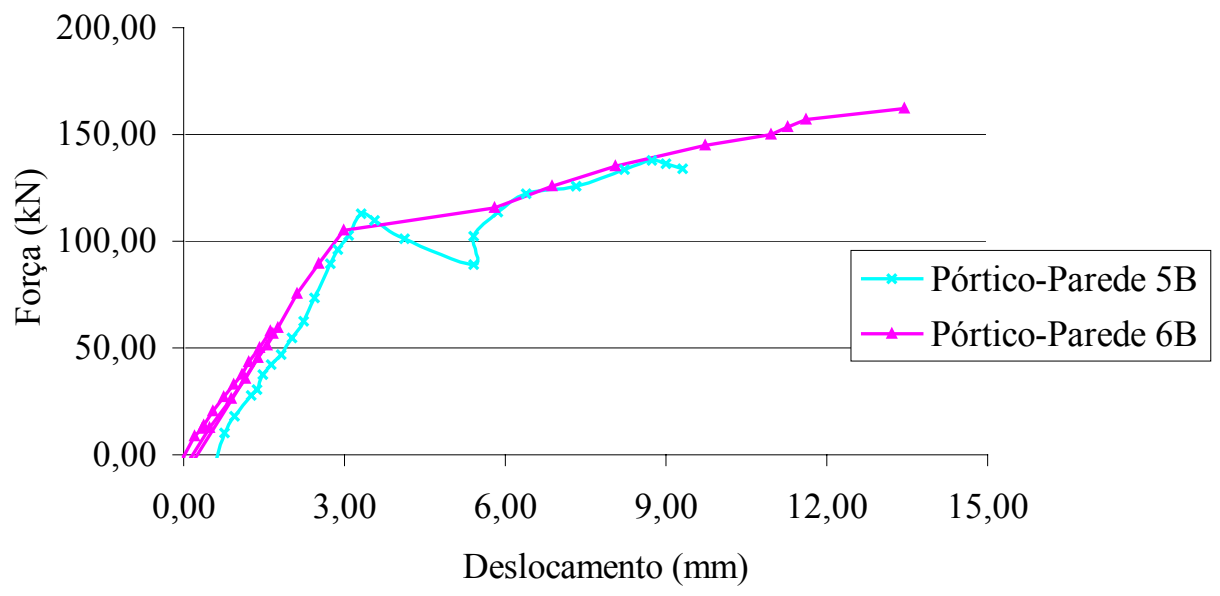

FIGURA A.3 - Diagrama força-deslocamento dos ensaios 5B e 6B, correspondentes a painéis pré-moldados armados de CCA

\section{A3 - CONCLUSÕES}

Nos ensaios de pórticos preenchidos com painéis pré-fabricados de CCA realizados, objetivou-se comparar o comportamento de painéis pré-fabricados com o comportamento de blocos de CCA, como preenchimento de pórticos. Para isso, apresentam-se, na figura A.4, os diagramas força-deslocamento correspondentes aos ensaios com bloco de CCA (ensaios 1B e 2B) e com painéis pré-fabricados de CCA (ensaios 5B e 6B).

Pode-se observar que o sistema de pórtico preenchido com painéis pré-fabricados apresenta um comportamento linear até a carga correspondente à ruptura frágil de uma das juntas verticais de argamassa (em torno de $100 \mathrm{kN}$ ), enquanto o 
comportamento de pórticos preenchidos com blocos de CCA já é não-linear para menores cargas. No entanto, nesses últimos a carga correspondente à ruptura frágil por fissuração da diagonal foi em torno de $175 \mathrm{kN}$.

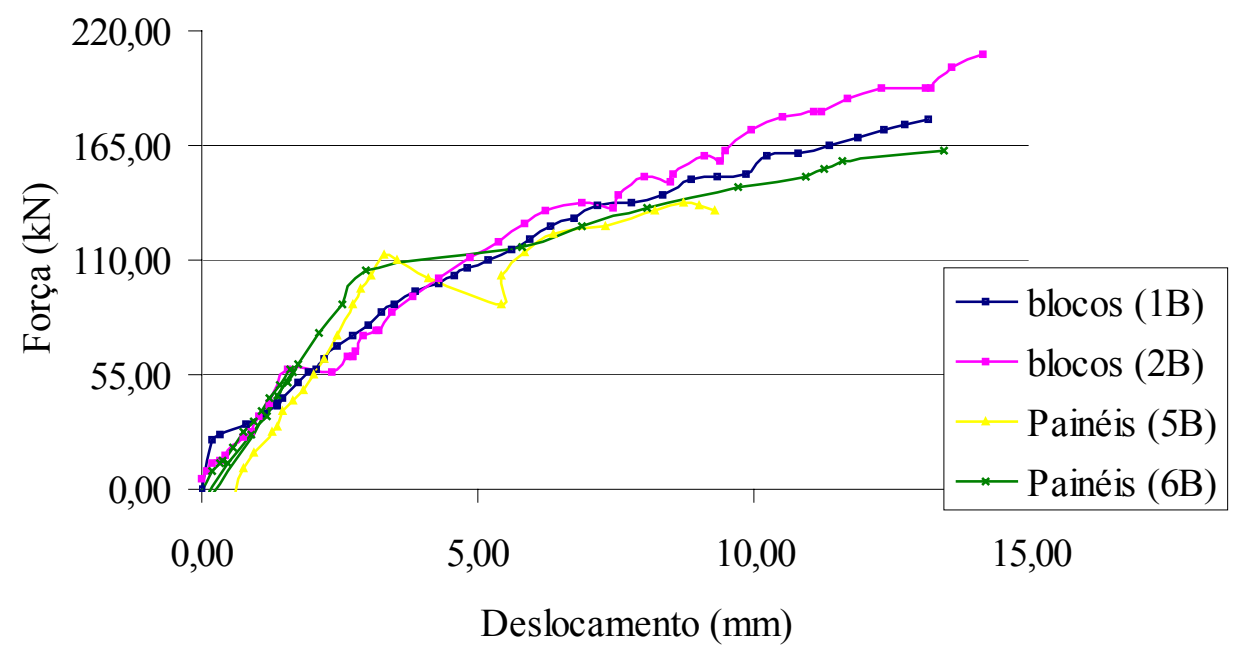

FIGURA A.4 - Análise comparativa entre os diagramas força-deslocamento para os ensaios com blocos (ensaios 1B e 2B) e com painéis pré-fabricados (5B e 6B) 


\section{B.1 - SISTEMA DE AQUISIÇÃO DE DADOS}

Nos ensaios realizados, utilizou-se o sistema de aquisição de dados, modelo CAD 12/32, da Lynx Tecnologia Eletrônica, conectado a um microcomputador. Através do software AqDados, também da Lynx, é possível fazer a coleta de dados e posterior tratamento destes.

Cada um dos instrumentos de medição, com exceção dos relógios comparadores, foram ligados ao Sistema de Aquisição de Dados por cabos de conexão, obedecendo à seguinte seqüência: E - excitação, + positivo, - negativo e T - terra. O MANUAL AQDADOS4 (1993) apresenta explicação detalhada do manuseio e operação do sistema. O sistema utilizado contém 32 canais, que permitem a aquisição de até 32 sinais analógicos, através do conversor de dados $\mathrm{A} / \mathrm{D}$, que converte sinais analógicos em digitais, figura B.1. Os sinais digitais são processados no computador por meio de placas de conversão A/D 2100 Lynx nele instaladas. 
Através do sistema AqDados, todo o desenvolvimento do ensaio pôde ser monitorado pelo vídeo, permitindo, dessa forma, a identificação de possíveis desajustes no processo.

A faixa de variação e a natureza dos sinais gerados pelos sensores que medem as grandezas físicas são informações necessárias para realização de ensaio no AqDados. Os sinais a serem medidos devem ser tensões elétricas que têm que variar dentro da faixa de aceitação de entrada do canal da placa conversora A/D (analógico/digital). As faixas são programáveis para cada canal.

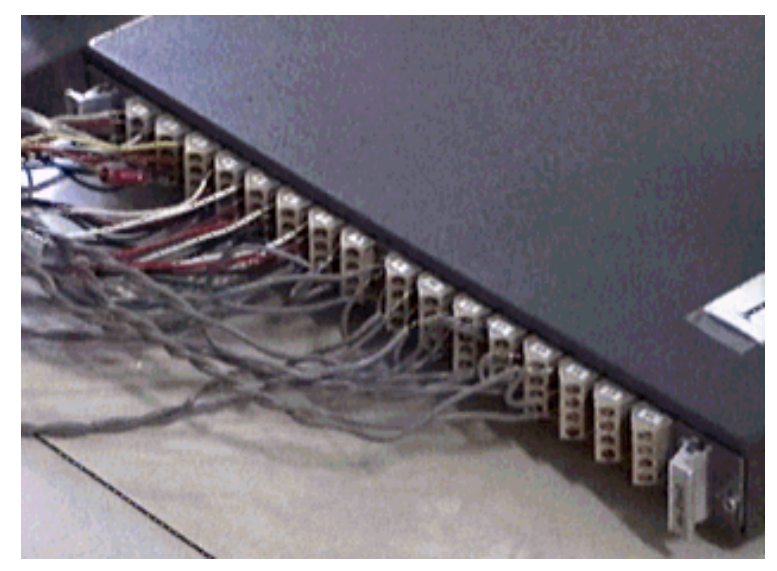

FIGURA B.1 - Conversor de dados A/D

Para parametrização de um ensaio, é necessário saber a relação entre os valores da grandeza física e a variação do sinal aquisitado pelo conversor. No caso dos ensaios realizados, em que a relação é linear, é necessário saber quais os valores das grandezas físicas correspondentes aos limites da faixa de entrada do canal onde o sinal é aquisitado. Se a relação não for linear, como no caso dos termopares, é necessário utilizar o recurso de linearização de sinais disponível no Aqdados.

Nos ensaios realizados, trabalhou-se com a freqüência de amostragem de $5 \mathrm{~Hz}$. A freqüência de amostragem não depende somente da freqüência do sinal e de seus componentes de maior freqüência, mas também da finalidade da aquisição. 
O sistema AqDados possui vários recursos que permitem configurar parâmetros, como: a freqüência de amostragem; a duração do ensaio; a conversão para unidade de engenharia; o tratamento dos dados após a aquisição; a geração de planilhas, gráficos; e a exportação para outros softwares para tratamento dos dados, como planilhas eletrônicas.

\section{B.2 - CALIBRAÇÃO DOS APARELHOS}

Para aplicação da força horizontal, utilizou-se um sistema de cilindro hidráulico, colocado na posição horizontal no pilar do pórtico de reação na direção do eixo da viga e acoplado a uma bomba. Todos os instrumentos foram ligados ao Sistema de Aquisição de Dados. Nesse sistema, cada instrumento é associado a um canal que executa a tarefa de transformar a voltagem lida nos seus terminais em grandezas reais. Cada número de canal deve estar relacionado ao nome que identifica o sinal emitido, à unidade da grandeza representada pelo sinal, ao tipo de leitura - que nesse caso será sempre linear - e à faixa de entrada das leituras de cada canal, em volts. De acordo com as características elétricas dos instrumentos e com a resistência da placa do Sistema de Aquisição de Dados, obtém-se a grandeza denominada Valor de Engenharia, que é dada pela expressão B.1 e permite que as leituras sejam convertidas em unidades de engenharia. Tem-se também para cada aparelho uma faixa de voltagem, geralmente sugerida pelo fabricante, na qual o equipamento trabalha melhor.

$$
V_{\text {eng }}=\frac{R_{g} \times 10^{6}}{k^{\prime}\left(R_{g}+R_{\text {cal }}\right)}
$$

em que:

$$
\begin{array}{ll}
R_{g} & =\text { resistência interna de fabricação do instrumento; } \\
R_{c a l} & =\text { resistência da placa do Sistema de Aquisição de Dados; } \\
k^{\prime} & =\text { constante do instrumento; e } \\
R_{g} \text { e } R_{c a l} & =\text { dados em ohms. }
\end{array}
$$


Cada um dos instrumentos foi calibrado com o fim de relacionar o sinal de tensão emitido pelo aparelho, com a respectiva grandeza medida. Essa operação só pode ser utilizada quando existe linearidade entre a variação do sinal e grandeza medida, como é o caso dos ensaios realizados. O recurso de calibração auxilia na determinação dos valores da grandeza para os limites inferior e superior da faixa de entrada, a serem especificados nos campos - limite inferior e superior da janela de configuração dos canais de entrada do sistema Aqdados. Foi realizada a calibração por regressão e, em seguida, a calibração por ganho. A calibração por regressão consiste na determinação de pares de valores, sendo o primeiro a tensão em volts, obtida pelo sinal emitido do aparelho; e o segundo, a grandeza medida, obtida por leitura direta no aparelho ou com o auxílio de equipamento similar acoplado, em que os valores obtidos são editados na tela de calibração. A partir de uma relação linear entre leituras, com até 15 pares de valores obtidos para relação tensão/grandeza, obtém-se um índice de correlação em porcentagem, indicando a linearidade das leituras e a relação tensão/grandeza.

Para realizar a calibração por ganho, deve-se conhecer o ganho $(\mathrm{K})$ para cada canal a ser calibrado, que é fornecido por ocasião da calibração por regressão. Dessa forma, é possível associar os sinais elétricos emitidos no momento do ensaio ao zero da grandeza correspondente.

Os transdutores de deslocamentos foram calibrados a cada ensaio. $\mathrm{O}$ transdutor de pressão foi calibrado quando ainda estava instalado na vertical, tabela B.1. Uma vez calibrado, o transdutor foi montado no pilar do pórtico de reação, na posição horizontal, e manteve-se fixo durante a realização de todos os ensaios. 
TABELA B.1 - Calibração do transdutor de pressão

\begin{tabular}{|c|c|c|}
\hline \multicolumn{3}{|c|}{ Calibração do Transdutor de Pressão } \\
\hline Transdutor & \multicolumn{2}{|l|}{ Anel } \\
\hline Tipo: HMI-2300 & \multicolumn{2}{|l|}{ Carga: $50 \mathrm{tf}$} \\
\hline EN: 700 bar & \multicolumn{2}{|c|}{ Const: $0,88946484 \mathrm{kN} /$ div. } \\
\hline \multirow{2}{*}{\multicolumn{3}{|c|}{$\begin{array}{c}\mathrm{N}^{\mathrm{o}} \text { série: } 8066 \\
\text { SENS: } 2008 \mathrm{mV} / \mathrm{V}\end{array}$}} \\
\hline & & \\
\hline Divisões & $\mathbf{k N}$ & Kgf \\
\hline 0 & 0 & 0,00 \\
\hline 20 & 17,7892968 & 1778,93 \\
\hline 40 & 35,5785936 & 3557,86 \\
\hline 60 & 53,3678904 & 5336,79 \\
\hline 80 & 71,1571872 & 7115,72 \\
\hline 100 & 88,946484 & 8894,65 \\
\hline 120 & 106,7357808 & 10673,58 \\
\hline 140 & 124,5250776 & 12452,51 \\
\hline 160 & 142,3143744 & 14231,44 \\
\hline 180 & 160,1036712 & 16010,37 \\
\hline 200 & 177,892968 & 17789,30 \\
\hline 220 & 195,6822648 & 19568,23 \\
\hline 240 & 213,4715616 & 21347,16 \\
\hline
\end{tabular}



PAINÉIS DE ALVENARIA E DE ARGAMASSAS

\section{C.1 - ENSAIOS DE PRISMAS À COMPRESSÃO}

TABELA C.1 - Resultados obtidos para os ensaios de prismas à compressão

\begin{tabular}{|c|c|c|c|c|c|c|}
\hline CP & $\begin{array}{c}\text { ENSAIO } \\
\mathbf{N}^{\circ} \cdot\end{array}$ & $\begin{array}{c}\text { TIPO DE } \\
\text { ARGA- } \\
\text { MASSA }\end{array}$ & IDADE & $\begin{array}{c}\text { RESISTÊNCIA } \\
\grave{A} \\
\text { COMPRESSÃO } \\
\text { (MPa) }\end{array}$ & $\begin{array}{c}\text { RESISTÊN } \\
\text { CIA } \\
\text { MÉDIA } \\
\text { (MPa) }\end{array}$ & $\begin{array}{c}\text { RESISTÊN } \\
\text { CIA } \\
\text { CARACT. } \\
\text { (MPa) }\end{array}$ \\
\hline 01 & $1 \mathrm{~A}$ & $1: 3: 7,5$ & 32 dias & 1,68 & & \\
\hline 02 & $1 \mathrm{~A}$ & $1: 3: 7,5$ & 32 dias & 1,72 & & \\
\hline 03 & $1 \mathrm{~A}$ & $1: 3: 7,5$ & 32 dias & 2,00 & - & - \\
\hline 04 & $2 \mathrm{~A}$ & $1: 3: 7,5$ & 29 dias & 2,50 & & \\
\hline 05 & $2 \mathrm{~A}$ & $1: 3: 7,5$ & 29 dias & 2,78 & & \\
\hline 06 & $2 \mathrm{~A}$ & $1: 3: 7,5$ & 29 dias & 2,78 & 2,69 & 2,42 \\
\hline
\end{tabular}




\begin{tabular}{|c|c|c|c|c|c|c|}
\hline $\mathbf{C P}$ & $\begin{array}{c}\text { ENSAIO } \\
\mathbf{N}^{0} \cdot\end{array}$ & $\begin{array}{l}\text { TIPO DE } \\
\text { ARGA- } \\
\text { MASSA }\end{array}$ & IDADE & $\begin{array}{c}\text { RESISTÊNCIA } \\
\text { À } \\
\text { COMPRESSÃo } \\
\text { (MPa) }\end{array}$ & $\begin{array}{c}\text { RESISTÊN } \\
\text { CIA } \\
\text { MÉDIA } \\
\text { (MPa) }\end{array}$ & $\begin{array}{l}\text { RESISTÊN } \\
\text { CIA } \\
\text { CARACT. } \\
\text { (MPa) }\end{array}$ \\
\hline 07 & $3 \mathrm{~A}$ & Ciment-cola & 16 dias & 2,11 & \multirow[b]{3}{*}{2,31} & \multirow[b]{3}{*}{1,99} \\
\hline 08 & $3 \mathrm{~A}$ & Ciment-cola & 16 dias & 2,33 & & \\
\hline 09 & $3 \mathrm{~A}$ & Ciment-cola & 16 dias & 2,50 & & \\
\hline 10 & $2 \mathrm{~B}$ & Ciment-cola & 17 dias & 2,68 & \multirow[b]{3}{*}{2,49} & \multirow[b]{3}{*}{2,03} \\
\hline 11 & $2 \mathrm{~B}$ & Ciment-cola & 17 dias & 2,17 & & \\
\hline 12 & 2B & Ciment-cola & 17 dias & 2,63 & & \\
\hline 13 & $2 \mathrm{~B}$ & Ciment-cola & 22 dias & 2,04 & \multirow[b]{3}{*}{2,37} & \multirow[b]{3}{*}{1,89} \\
\hline 14 & $2 \mathrm{~B}$ & Ciment-cola & 22 dias & 2,56 & & \\
\hline 15 & $2 \mathrm{~B}$ & Ciment-cola & 22 dias & 2,52 & & \\
\hline 16 & $5 \mathrm{~B}$ & Ciment-cola & 14 dias & 3,02 & \multirow[b]{3}{*}{2,79} & \multirow[b]{3}{*}{2,43} \\
\hline 17 & $5 \mathrm{~B}$ & Ciment-cola & 14 dias & 2,58 & & \\
\hline 18 & $5 \mathrm{~B}$ & Ciment-cola & 14 dias & 2,76 & & \\
\hline 19 & $6 \mathrm{~B}$ & Ciment-cola & 15 dias & 2,62 & \multirow[b]{3}{*}{2,87} & \multirow[b]{3}{*}{2,51} \\
\hline 20 & $6 \mathrm{~B}$ & Ciment-cola & 15 dias & 2,94 & & \\
\hline 21 & $6 \mathrm{~B}$ & Ciment-cola & 15 dias & 3,04 & & \\
\hline \multicolumn{4}{|c|}{ * 1:3:7,5 de cimento, cal e areia. } & Valores Médios & 2,57 & 2,17 \\
\hline
\end{tabular}

\section{C.2 - ENSAIOS DE PRISMAS AO CISALHAMENTO}

TABELA C.2 - Resultados dos ensaios de cisalhamento em prismas

\begin{tabular}{|c|c|c|c|c|c|c|}
\hline $\mathbf{C P}$ & $\begin{array}{c}\text { ENSAI } \\
\text { O N }^{\circ}\end{array}$ & $\begin{array}{c}\text { TIPO DE } \\
\text { ARGA- } \\
\text { MASSA }\end{array}$ & IDADE & $\begin{array}{c}\text { RESISTÊNCIA } \\
\text { AO } \\
\text { CISALHAMEN } \\
\text { TO (MPa) }\end{array}$ & $\begin{array}{c}\text { RESISTÊN } \\
\text { CIA } \\
\text { MÉDIA } \\
\text { (MPa) }\end{array}$ & $\begin{array}{c}\text { RESISTÊN } \\
\text { CIA } \\
\text { CARACT. } \\
\text { (MPa) }\end{array}$ \\
\hline $01^{1}$ & $2 \mathrm{~A}$ & $1: 3: 7,5$ & 30 dias & 0,05 & \multirow[b]{3}{*}{0,07} & \multirow[b]{3}{*}{0,04} \\
\hline $02^{1}$ & $2 \mathrm{~A}$ & $1: 3: 7,5$ & 30 dias & 0,08 & & \\
\hline $03^{1}$ & $2 \mathrm{~A}$ & $1: 3: 7,5$ & 30 dias & 0,07 & & \\
\hline & & & & Valores Médios & 0,07 & 0,04 \\
\hline
\end{tabular}




\begin{tabular}{|c|c|c|c|c|c|c|}
\hline $\mathbf{C P}$ & $\begin{array}{c}\text { EN- } \\
\text { SAIO } \\
\mathbf{N}^{\circ} \cdot \\
\end{array}$ & $\begin{array}{l}\text { TIPO DE } \\
\text { ARGA- } \\
\text { MASSA }\end{array}$ & IDADE & $\begin{array}{c}\text { RESISTÊNCIA } \\
\text { AO } \\
\text { CISALHAMEN } \\
\text { TO (MPa) } \\
\end{array}$ & $\begin{array}{c}\text { RESISTÊN } \\
\text { CIA } \\
\text { MÉDIA } \\
\text { (MPa) } \\
\end{array}$ & $\begin{array}{c}\text { RESISTEN } \\
\text { CIA } \\
\text { CARACT. } \\
\text { (MPa) } \\
\end{array}$ \\
\hline $04^{1}$ & $3 \mathrm{~A}$ & Ciment-cola & 16 dias & 0,14 & \multirow[b]{3}{*}{0,17} & \multirow[b]{3}{*}{0,10} \\
\hline $05^{1}$ & $3 \mathrm{~A}$ & Ciment-cola & 16 dias & 0,14 & & \\
\hline $06^{1}$ & $3 \mathrm{~A}$ & Ciment-cola & 16 dias & 0,22 & & \\
\hline $07^{2}$ & - & Ciment-cola & 28 dias & 0,33 & \multirow[b]{6}{*}{0,30} & \multirow[b]{6}{*}{0,27} \\
\hline $08^{2}$ & - & Ciment-cola & 28 dias & 0,29 & & \\
\hline $09^{2}$ & - & Ciment-cola & 28 dias & 0,31 & & \\
\hline $10^{2}$ & - & Ciment-cola & 28 dias & 0,30 & & \\
\hline $11^{2}$ & - & Ciment-cola & 28 dias & 0,32 & & \\
\hline $12^{2}$ & - & Ciment-cola & 28 dias & 0,27 & & \\
\hline
\end{tabular}

${ }^{1}$ Cisalhamento direto $\mathrm{e}^{2}$ Cisalhamento diagonal.

\section{C.3 - ENSAIOS DE CILINDROS DE ARGAMASSA À COMPRESSÃO}

Tabela C.3 - Resultados dos ensaios de compressão em cilindros de argamassa

\begin{tabular}{|c|c|c|c|c|c|c|}
\hline $\mathbf{C P}$ & $\begin{array}{c}\text { ENSAIO } \\
\mathbf{N}^{\circ} \cdot\end{array}$ & $\begin{array}{c}\text { TIPO DE } \\
\text { ARGA- } \\
\text { MASSA }\end{array}$ & IDADE & $\begin{array}{c}\text { RESISTÊNCIA } \\
\text { À } \\
\text { COMPRESSÃO } \\
\text { (MPa) }\end{array}$ & $\begin{array}{c}\text { RESISTÊN } \\
\text { CIA } \\
\text { MÉDIA } \\
\text { (MPa) }\end{array}$ & $\begin{array}{c}\text { RESISTÊN } \\
\text { CIA } \\
\text { CARACT. } \\
\text { (MPa) }\end{array}$ \\
\hline $01 \mathrm{~A}$ & $1 \mathrm{~A}$ & $1: 3: 7,5$ & 20 dias & 2,10 & \multirow[b]{3}{*}{2,42} & \multirow[b]{3}{*}{1,97} \\
\hline $02 \mathrm{~A}$ & $1 \mathrm{~A}$ & $1: 3: 7,5$ & 20 dias & 2,60 & & \\
\hline $03 \mathrm{~A}$ & $1 \mathrm{~A}$ & $1: 3: 7,5$ & 20 dias & 2,55 & & \\
\hline $04 \mathrm{~A}$ & $1 \mathrm{~A}$ & $1: 3: 7,5$ & 24 dias & 2,65 & \multirow[b]{4}{*}{3,00} & \multirow[b]{4}{*}{2,53} \\
\hline $05 \mathrm{~A}$ & $1 \mathrm{~A}$ & $1: 3: 7,5$ & 24 dias & 3,06 & & \\
\hline $06 \mathrm{~A}$ & $1 \mathrm{~A}$ & $1: 3: 7,5$ & 24 dias & 3,16 & & \\
\hline 07A & $1 \mathrm{~A}$ & $1: 3: 7,5$ & 24 dias & 3,11 & & \\
\hline $08 \mathrm{~A}$ & $1 \mathrm{~A}$ & $1: 3: 7,5$ & 33 dias & 3,72 & \multirow[b]{4}{*}{3,87} & \multirow[b]{4}{*}{3,48} \\
\hline 09A & $1 \mathrm{~A}$ & $1: 3: 7,5$ & 33 dias & 3,72 & & \\
\hline $10 \mathrm{~A}$ & $1 \mathrm{~A}$ & $1: 3: 7,5$ & 33 dias & 3,92 & & \\
\hline $11 \mathrm{~A}$ & $1 \mathrm{~A}$ & $1: 3: 7,5$ & 33 dias & 4,13 & & \\
\hline
\end{tabular}

Continua... 


\begin{tabular}{|c|c|c|c|c|c|c|}
\hline $\mathbf{C P}$ & $\begin{array}{c}\text { ENSAIO } \\
\mathbf{N}^{\circ} \cdot\end{array}$ & $\begin{array}{l}\text { TIPO DE } \\
\text { ARGA- } \\
\text { MASSA }\end{array}$ & IDADE & $\begin{array}{c}\text { RESISTÊNCIA } \\
\text { À } \\
\text { COMPRESSÃO } \\
\text { (MPa) }\end{array}$ & $\begin{array}{c}\text { RESISTÊN } \\
\text { CIA } \\
\text { MÉDIA } \\
\text { (MPa) }\end{array}$ & $\begin{array}{c}\text { RESISTÊN } \\
\text { CIA } \\
\text { CARACT. } \\
\text { (MPa) }\end{array}$ \\
\hline $16 \mathrm{~A}$ & $2 \mathrm{~A}$ & $1: 3: 7,5$ & 20 dias & 2,80 & \multirow[b]{5}{*}{3,12} & \multirow[b]{5}{*}{2,62} \\
\hline $17 \mathrm{~A}$ & $2 \mathrm{~A}$ & $1: 3: 7,5$ & 20 dias & 3,10 & & \\
\hline $18 \mathrm{~A}$ & $2 \mathrm{~A}$ & $1: 3: 7,5$ & 20 dias & 3,16 & & \\
\hline $19 \mathrm{~A}$ & $2 \mathrm{~A}$ & $1: 3: 7,5$ & 20 dias & 3,41 & & \\
\hline $20 \mathrm{~A}$ & $2 \mathrm{~A}$ & $1: 3: 7,5$ & 20 dias & 2,80 & & \\
\hline $12 \mathrm{~A}$ & $2 \mathrm{~A}$ & $1: 3: 7,5$ & 30 dias & 4,70 & \multirow[b]{4}{*}{5,03} & \multirow[b]{4}{*}{4,27} \\
\hline $13 \mathrm{~A}$ & $2 \mathrm{~A}$ & $1: 3: 7,5$ & 30 dias & 5,30 & & \\
\hline $14 \mathrm{~A}$ & $2 \mathrm{~A}$ & $1: 3: 7,5$ & 30 dias & 5,40 & & \\
\hline $15 \mathrm{~A}$ & $2 \mathrm{~A}$ & $1: 3: 7,5$ & 30 dias & 4,70 & & \\
\hline $26 \mathrm{~A}$ & $3 \mathrm{~A}$ & Ciment-cola & 15 dias & $5,10^{*}$ & \multirow[b]{5}{*}{8,21} & \multirow[b]{5}{*}{6,94} \\
\hline $27 \mathrm{~A}$ & $3 \mathrm{~A}$ & Ciment-cola & 15 dias & 7,39 & & \\
\hline $28 \mathrm{~A}$ & $3 \mathrm{~A}$ & Ciment-cola & 15 dias & 8,91 & & \\
\hline $29 \mathrm{~A}$ & $3 \mathrm{~A}$ & Ciment-cola & 15 dias & 8,15 & & \\
\hline $30 \mathrm{~A}$ & $3 \mathrm{~A}$ & Ciment-cola & 15 dias & 8,40 & & \\
\hline $21 \mathrm{~A}$ & $3 \mathrm{~A}$ & Ciment-cola & 20 dias & 9,42 & \multirow[b]{5}{*}{9,32} & \multirow[b]{5}{*}{8,61} \\
\hline $22 \mathrm{~A}$ & $3 \mathrm{~A}$ & Ciment-cola & 20 dias & 9,17 & & \\
\hline $23 \mathrm{~A}$ & $3 \mathrm{~A}$ & Ciment-cola & 20 dias & 8,91 & & \\
\hline $24 \mathrm{~A}$ & $3 \mathrm{~A}$ & Ciment-cola & 20 dias & 10,19 & & \\
\hline $25 \mathrm{~A}$ & $3 \mathrm{~A}$ & Ciment-cola & 20 dias & 8,91 & & \\
\hline $31 \mathrm{~B}$ & $4 \mathrm{~A}$ & Ciment-cola & 11 dias & 6,40 & \multirow[b]{2}{*}{6,67} & \multirow[b]{2}{*}{6,23} \\
\hline $32 \mathrm{~B}$ & $4 \mathrm{~A}$ & Ciment-cola & 11 dias & 6,94 & & \\
\hline
\end{tabular}




\begin{tabular}{|c|c|c|c|c|c|c|}
\hline $\mathrm{CP}$ & $\begin{array}{c}\text { ENSAIO } \\
\mathbf{N}^{\circ} \cdot\end{array}$ & $\begin{array}{l}\text { TIPO DE } \\
\text { ARGA- } \\
\text { MASSA }\end{array}$ & IDADE & $\begin{array}{c}\text { RESISTÊNCIA } \\
\grave{A} \\
\text { COMPRESSÃO } \\
\text { (MPa) }\end{array}$ & $\begin{array}{c}\text { RESISTÊN } \\
\text { CIA } \\
\text { MÉDIA } \\
\text { (MPa) }\end{array}$ & $\begin{array}{l}\text { RESISTÊN } \\
\text { CIA } \\
\text { CARACT. } \\
\text { (MPa) }\end{array}$ \\
\hline $33 \mathrm{~B}$ & $4 \mathrm{~A}$ & Encunham. & 38 dias & 20,2 & \multirow[b]{2}{*}{20,2} & \multirow[b]{2}{*}{20,2} \\
\hline 34B & $4 \mathrm{~A}$ & Encunham. & 38 dias & 20,2 & & \\
\hline $35 \mathrm{~A}$ & $5 \mathrm{~A}$ & Ciment-cola & 20 dias & 10,2 & \multirow[b]{4}{*}{9,42} & \multirow[b]{4}{*}{6,89} \\
\hline $36 \mathrm{~A}$ & $5 \mathrm{~A}$ & Ciment-cola & 20 dias & 9,41 & & \\
\hline $37 \mathrm{~A}$ & $5 \mathrm{~A}$ & Ciment-cola & 20 dias & 10,41 & & \\
\hline $38 \mathrm{~A}$ & $5 \mathrm{~A}$ & Ciment-cola & 20 dias & 7,64 & & \\
\hline $39 \mathrm{C}$ & $3 \mathrm{~B}$ & Encunham. & 14 dias & 14,00 & \multirow[b]{4}{*}{14,72} & \multirow[b]{4}{*}{12,87} \\
\hline $40 \mathrm{C}$ & $3 \mathrm{~B}$ & Encunham. & 14 dias & 14,00 & & \\
\hline $41 \mathrm{C}$ & $3 \mathrm{~B}$ & Encunham. & 14 dias & 14,93 & & \\
\hline $42 \mathrm{C}$ & $3 \mathrm{~B}$ & Encunham. & 14 dias & 15,93 & & \\
\hline $43 \mathrm{C}$ & $3 \mathrm{~B}$ & Encunham. & 21 dias & 16,20 & \multirow[b]{3}{*}{17,74} & \multirow[b]{3}{*}{16,01} \\
\hline $44 \mathrm{C}$ & $3 \mathrm{~B}$ & Encunham. & 21 dias & 15,90 & & \\
\hline $45 \mathrm{C}$ & $3 \mathrm{~B}$ & Encunham. & 21 dias & 15,93 & & \\
\hline
\end{tabular}




\section{C.4 - ENSAIOS DE TRAÇÃO POR COMPRESSÃO DIAMETRAL EM CILINDROS DE ARGAMASSA}

TABELA C.4 - Resultados dos ensaios de tração por compressão diametral em cilindros de argamassa de $10 \times 20 \mathrm{~cm}^{2}$

\begin{tabular}{|c|c|c|c|c|c|c|}
\hline $\mathbf{C P}$ & $\begin{array}{c}\text { ENSAIO } \\
\mathbf{N}^{0} \cdot\end{array}$ & $\begin{array}{l}\text { TIPO DE } \\
\text { ARGA- } \\
\text { MASSA }\end{array}$ & IDADE & $\begin{array}{c}\text { RESISTÊNCIA } \\
\text { À TRAÇÃO } \\
(\mathbf{M P a})\end{array}$ & $\begin{array}{c}\text { RESISTÊN } \\
\text { CIA } \\
\text { MÉDIA } \\
\text { (MPa) }\end{array}$ & $\begin{array}{c}\text { RESISTÊN } \\
\text { CIA } \\
\text { CARACT. } \\
\text { (MPa) }\end{array}$ \\
\hline 01B & $2 \mathrm{~A}$ & $1: 3: 7,5$ & 30 dias & 0,29 & \multirow[b]{4}{*}{0,42} & \multirow[b]{4}{*}{0,37} \\
\hline 02B & $2 \mathrm{~A}$ & $1: 3: 7,5$ & 30 dias & 0,33 & & \\
\hline 03B & $2 \mathrm{~A}$ & $1: 3: 7,5$ & 30 dias & 0,57 & & \\
\hline 04B & $2 \mathrm{~A}$ & $1: 3: 7,5$ & 30 dias & 0,49 & & \\
\hline 05B & $3 \mathrm{~A}$ & $1: 3: 7,5$ & 18 dias & 0,75 & \multirow[b]{2}{*}{0,75} & \multirow[b]{2}{*}{0,74} \\
\hline 06B & $3 \mathrm{~A}$ & $1: 3: 7,5$ & 18 dias & 0,74 & & \\
\hline 07B & $3 \mathrm{~A}$ & Ciment-cola & 20 dias & 1,01 & \multirow[b]{4}{*}{1,00} & \multirow[b]{4}{*}{0,65} \\
\hline 08B & $5 \mathrm{~A}$ & Ciment-cola & 20 dias & 1,23 & & \\
\hline 09B & $5 \mathrm{~A}$ & Ciment-cola & 20 dias & 0,94 & & \\
\hline 10B & $5 \mathrm{~A}$ & Ciment-cola & 20 dias & 0,82 & & \\
\hline
\end{tabular}

\section{C.5 - OBTENÇÃo DO MÓdULO DE DEFORMAÇÃo PARA PRISMAS E CILINDROS DE ARGAMASSA}

\section{PRISMAS}

O módulo de deformação de prismas de argamassa Ciment-cola foi obtido através de ensaios à compressão, nos quais se utilizaram 2 DT's colocados nas laterais do 
prisma, na direção longitudinal. Foi considerada a média dos deslocamentos registrados pelos dois DT's.

Os prismas ensaiados foram moldados segundo as recomendações da Norma ASTM E447-92b, sendo constituído de meio bloco/bloco inteiro/meio bloco, serrados na direção longitudinal. As dimensões dos prismas são: $15 \times 60 \mathrm{~cm}^{2}$ de área da seção transversal e $61 \mathrm{~cm}$ de altura. A argamassa foi moldada segundo recomendações do fabricante. Na tabela C.5, apresenta-se o valor médio obtido referente a uma mistura.

TABELA C.5 - Obtenção do módulo de deformação para prismas de argamassa Ciment-cola

\begin{tabular}{|c|c|c|}
\hline $\begin{array}{c}\text { NÚMERO DO } \\
\text { PRISMA }\end{array}$ & $\begin{array}{c}\text { E }_{\text {MÉdIO }} \\
\text { (MPa) }\end{array}$ & $\begin{array}{c}\text { E } \\
\text { MÉDIO } \\
\text { (MPa) }\end{array}$ \\
\cline { 1 - 2 } 01 & 2166 & \\
\cline { 1 - 2 } 02 & 1788 & \multirow{2}{*}{1932,67} \\
\hline 03 & 1896 & \\
\hline
\end{tabular}

\section{CILINDROS DE ARGAMASSA}

O mesmo esquema de montagem de ensaio de prismas foi utilizado nos cilindros de argamassa de $15 \mathrm{~cm}$ de base de $30 \mathrm{~cm}$ de altura. Os valores obtidos para os módulos de deformação foram: $4100 \mathrm{MPa}, 4420 \mathrm{MPa}$ e $4850 \mathrm{MPa}$, com média de 4457MPa. 


\section{ANEXO $\boldsymbol{D}$}

\section{DESCOLAMENTO DA INTERFACE PÓRTICO- PAINEL}

Na figura D.1, apresentam-se as posições dos DT's e dos relógios comparadores utilizados nos ensaios experimentais, e nas figuras D.2 a D.5 são apresentados os diagramas força-descolamento.

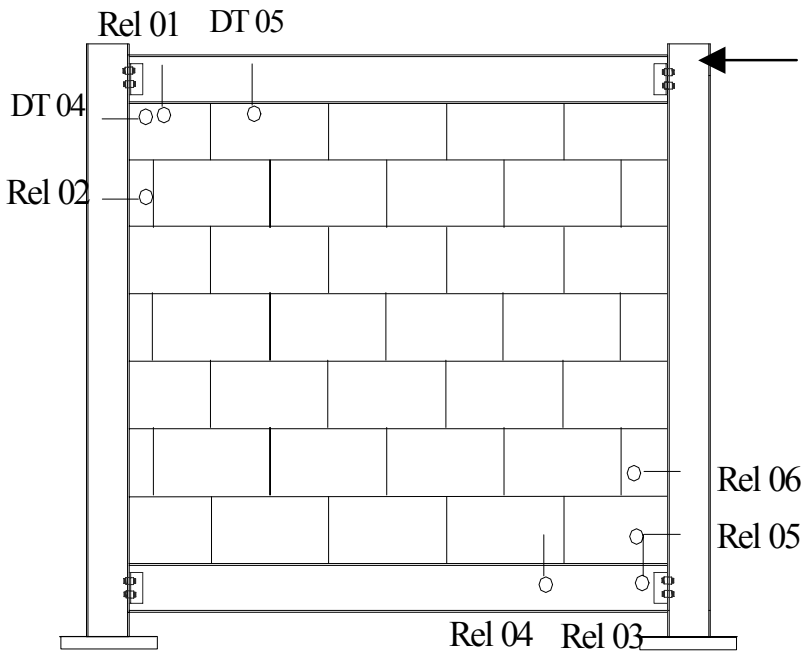

FIGURA D.1 - Disposição da instrumentação para medida dos descolamentos 


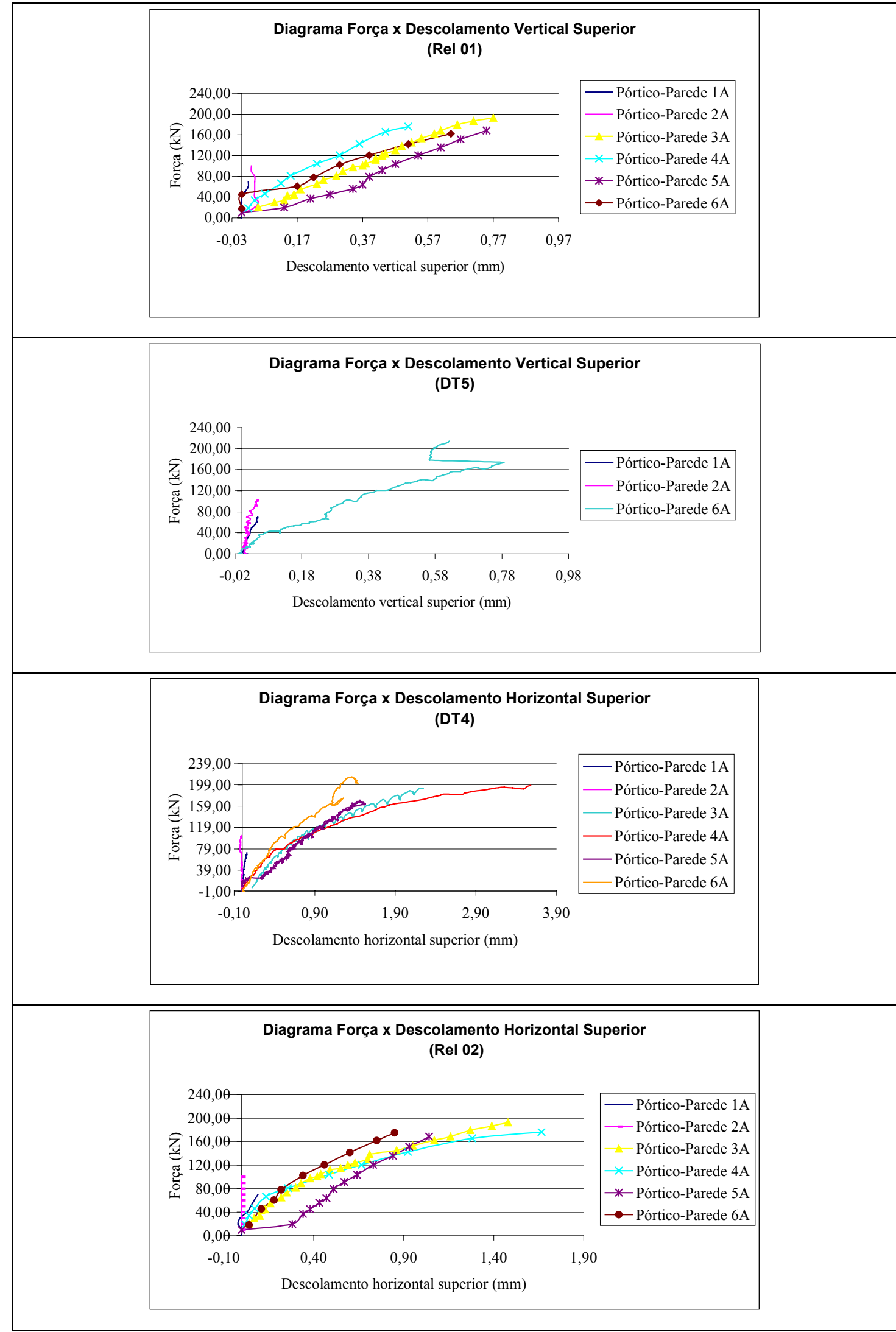

FIGURA D.2 - Diagrama força-descolamento do canto superior esquerdo tracionado (Rel 01, DT 05, DT 04 e Rel 02) 


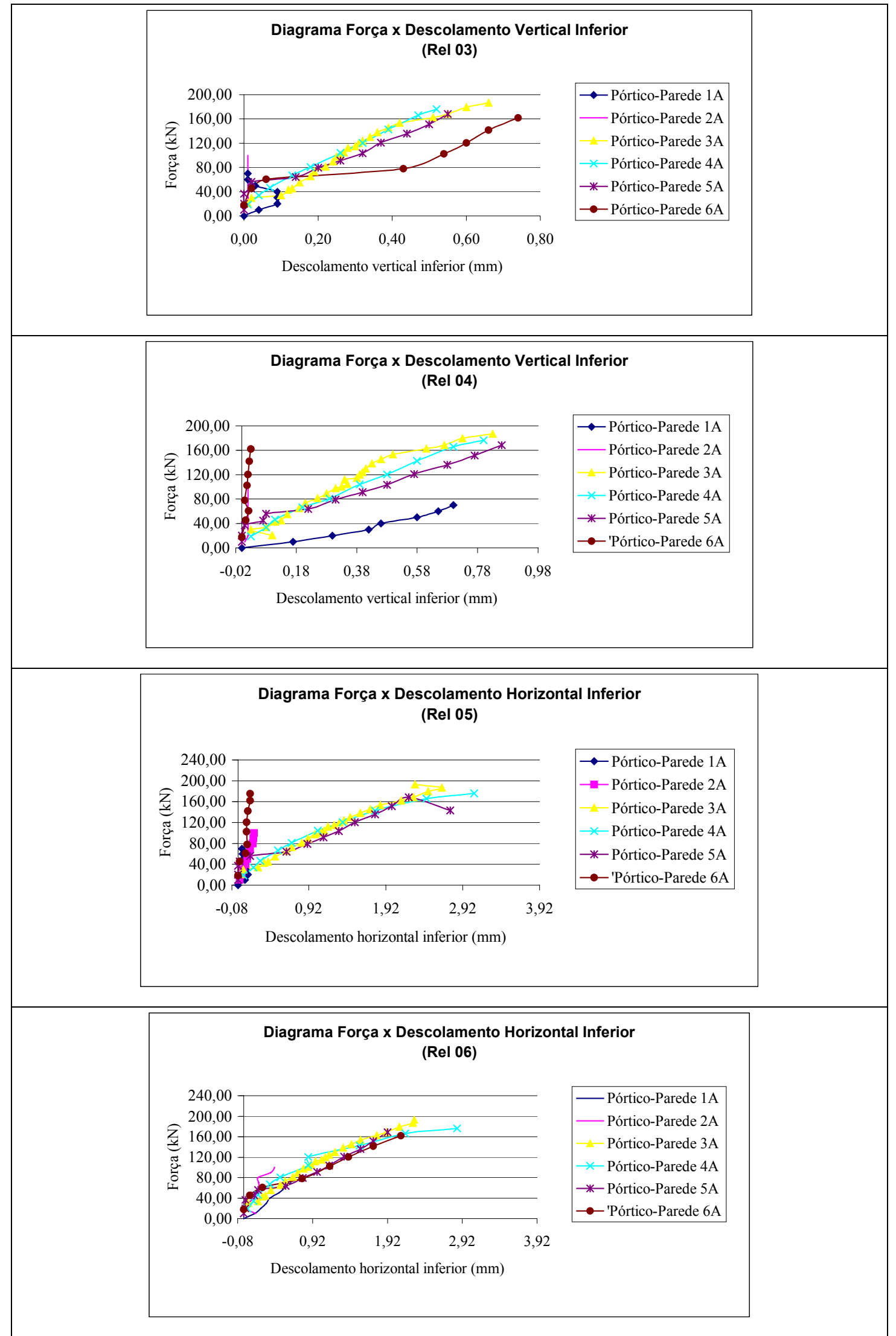

FIGURA D.3 - Diagrama força-descolamento do canto inferior direito tracionado

(Rel 03, Rel 04, Rel 05 e Rel 06) 


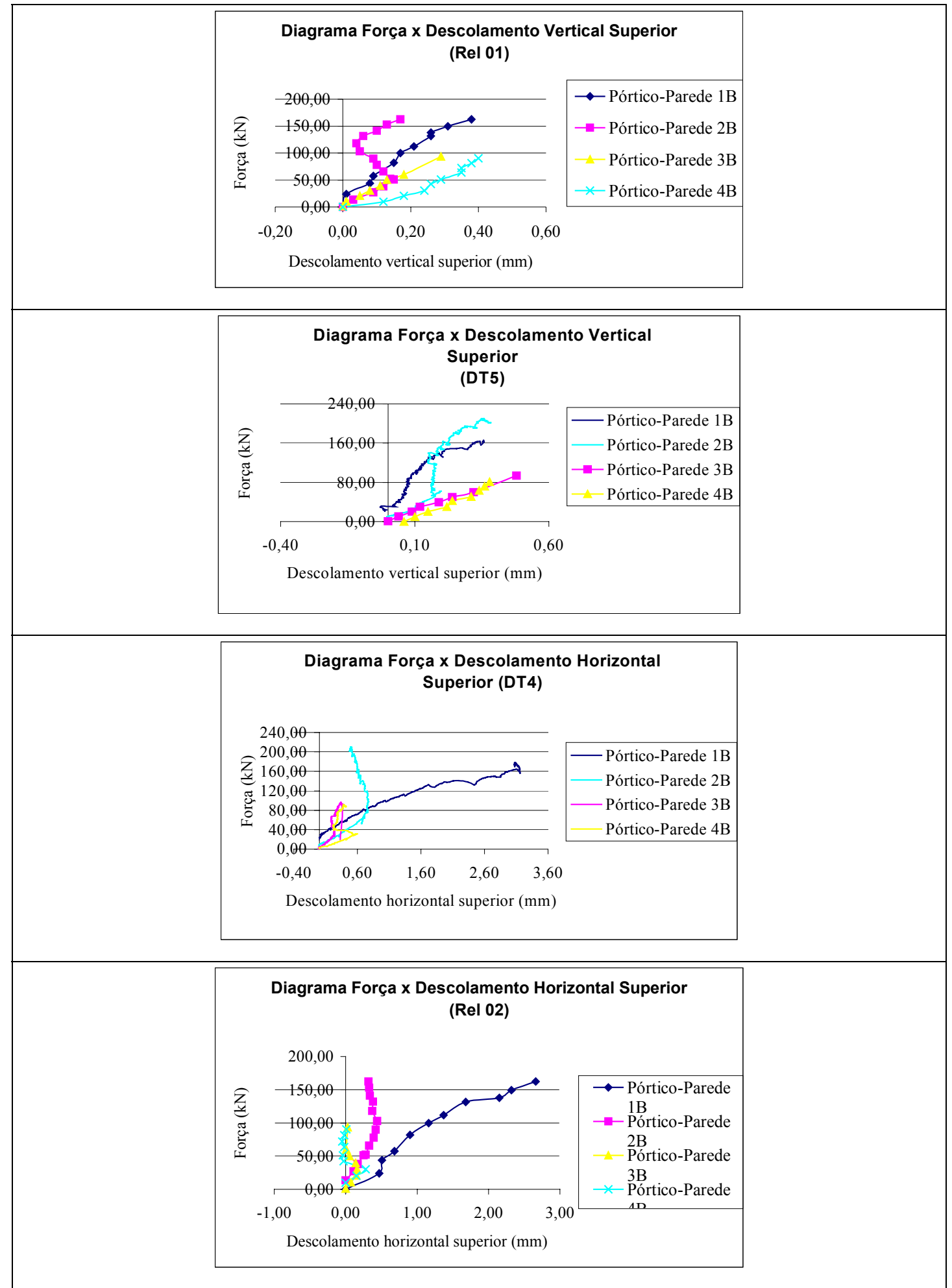

FIGURA D.4 - Diagrama força-descolamento do canto superior esquerdo tracionado (Rel 01, DT 05, DT 04 e Rel 02) 


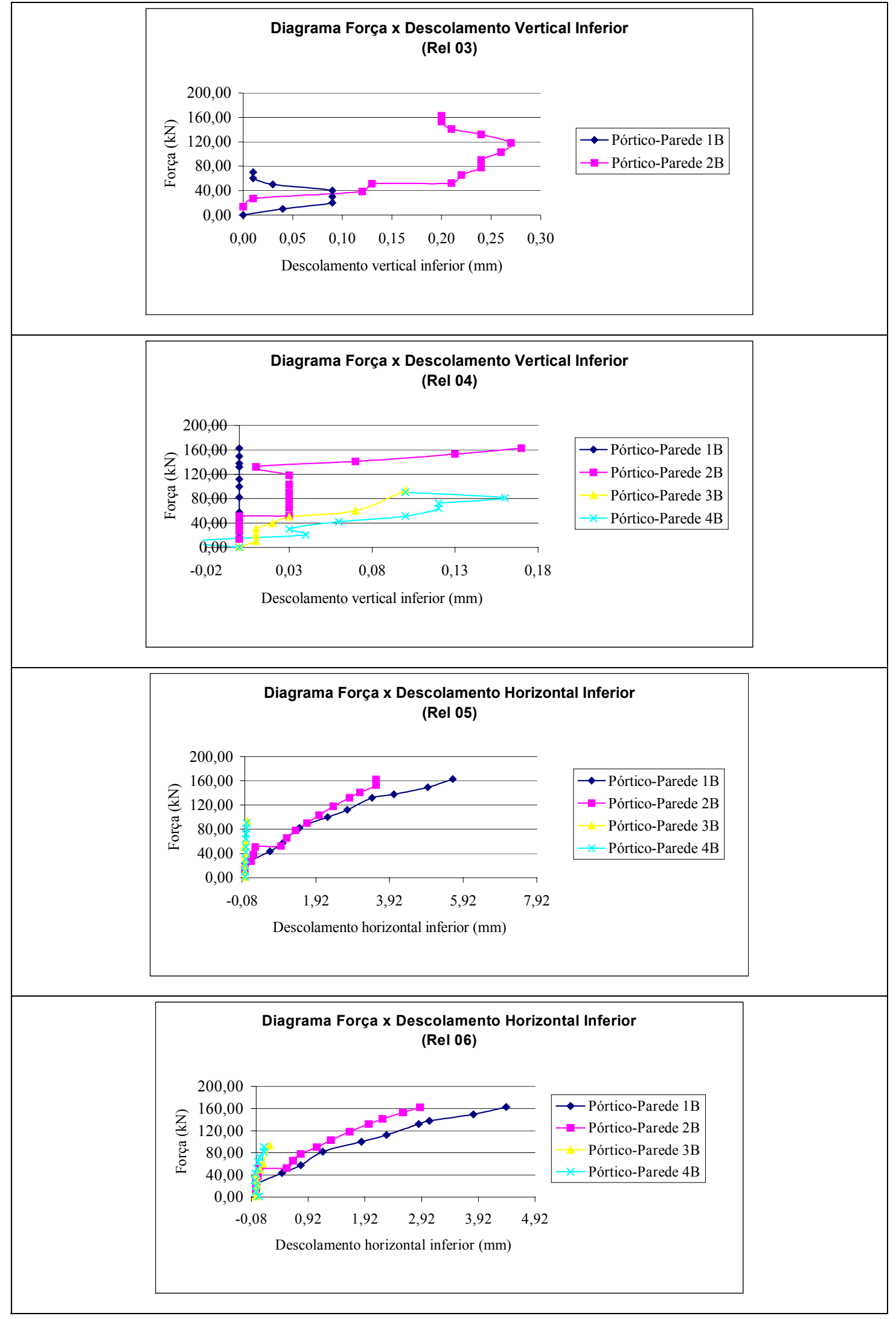

FIGURA D.5 - Diagrama força-descolamento do canto inferior direito tracionado

(Rel 03, Rel 04, Rel 05 e Rel 06) 


\section{DEFORMAÇÕES NAS REGIÕES DOS} EXTENSÔMETROS

\section{E.1 - ENSAIOS DA SÉRIE A - SISTEMA TIPO I}

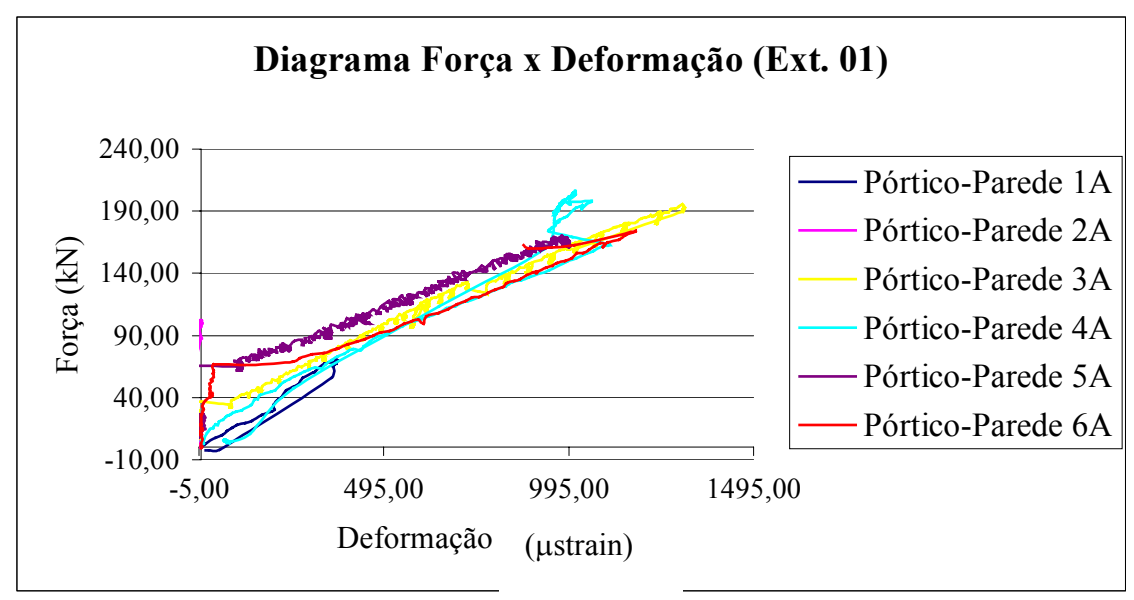

FIGURA E.1 - Diagrama força-deformação vertical no canto inferior comprimido (extensômetro 01) 
Análise Teórico-Experimental de Estruturas Compostas de Pórticos de Aço Preenchidos com 305 Alvenaria de Concreto Celular Autoclavado

Anexo E-Deformação nas Regiões dos Extensômetros

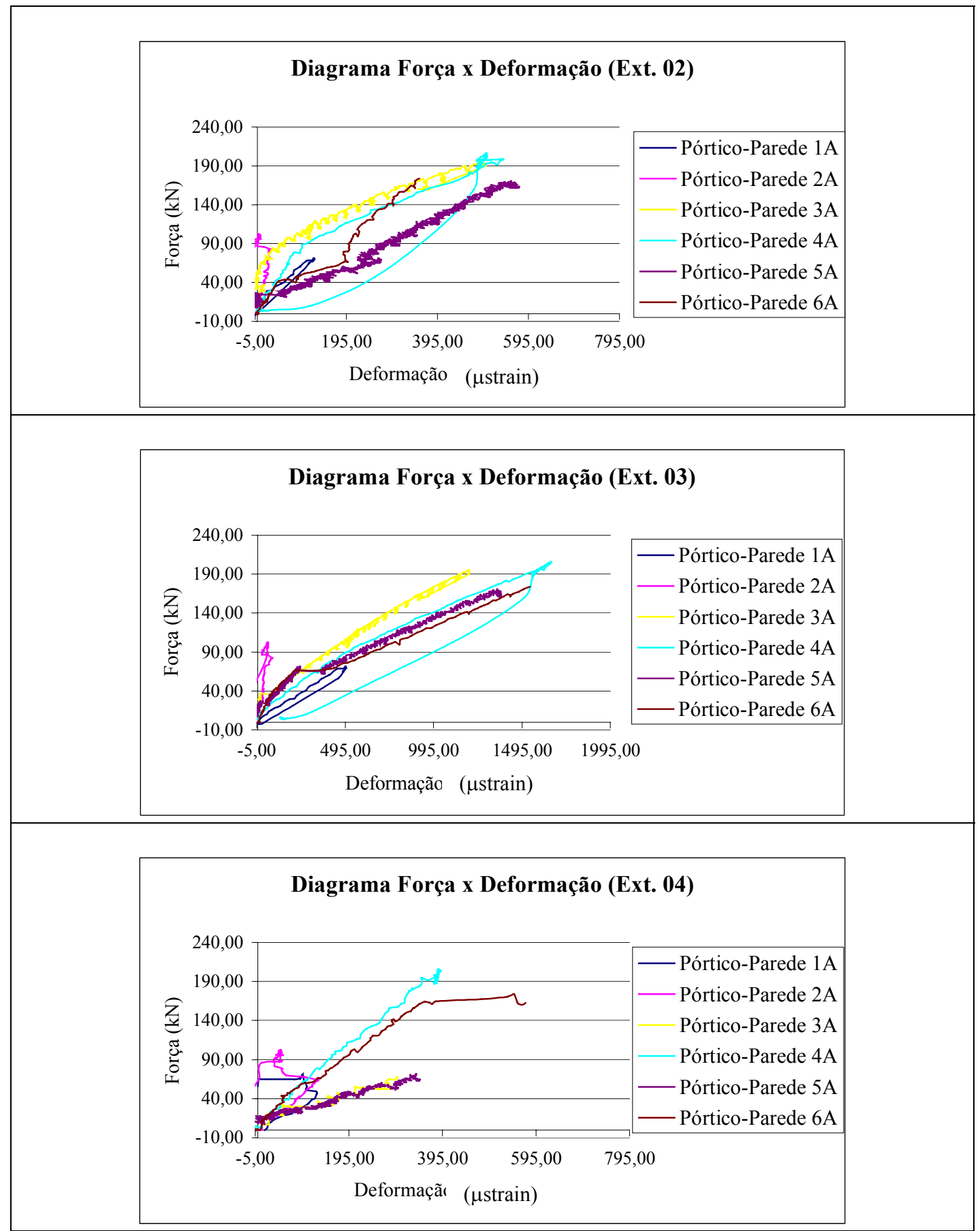

FIGURA E.2 - Diagrama força-deformação horizontal e diagonal no canto inferior comprimido (EXT 02 e 03) e diagonal central (EXT 04) 
Análise Teórico-Experimental de Estruturas Compostas de Pórticos de Aço Preenchidos com 306 Alvenaria de Concreto Celular Autoclavado

Anexo E-Deformação nas Regiões dos Extensômetros

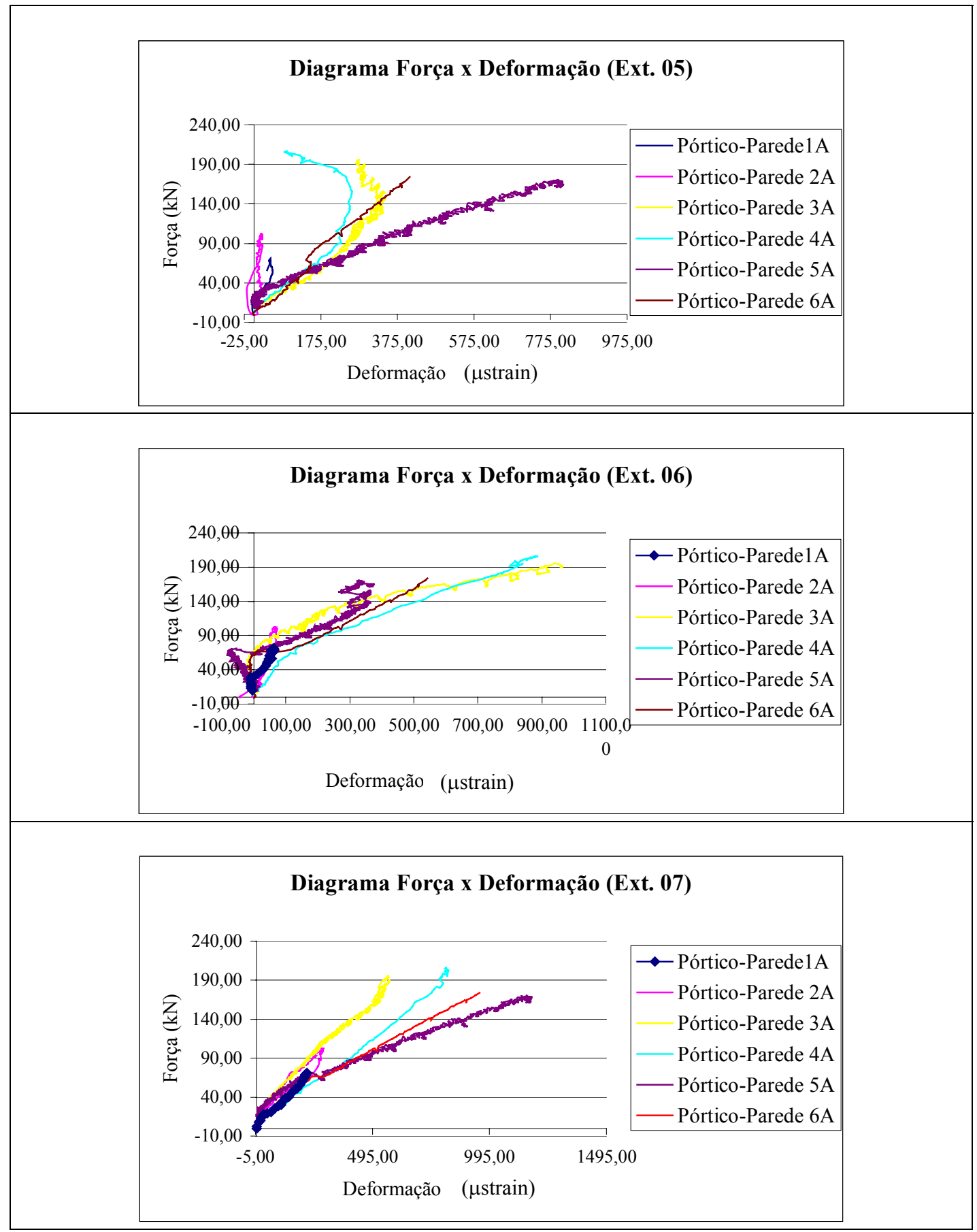

FIGURA E.3 - Diagrama força-deformação nas direções horizontal, vertical e diagonal do canto superior direito do painel (EXT 05, EXT 06, EXT 07) 
TABELA E.1 - Deformação nos cantos comprimidos dos painéis nos ensaios realizados

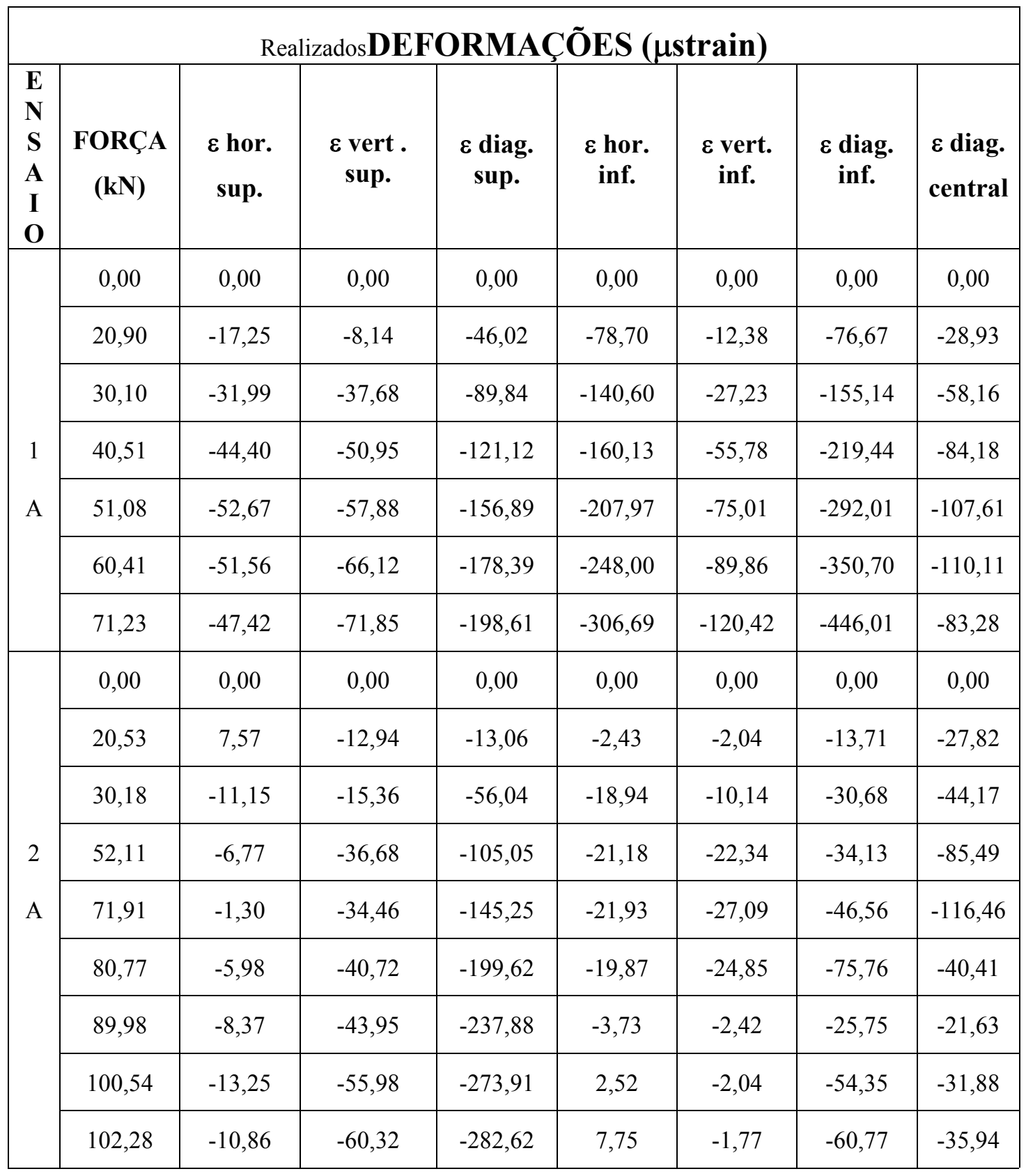




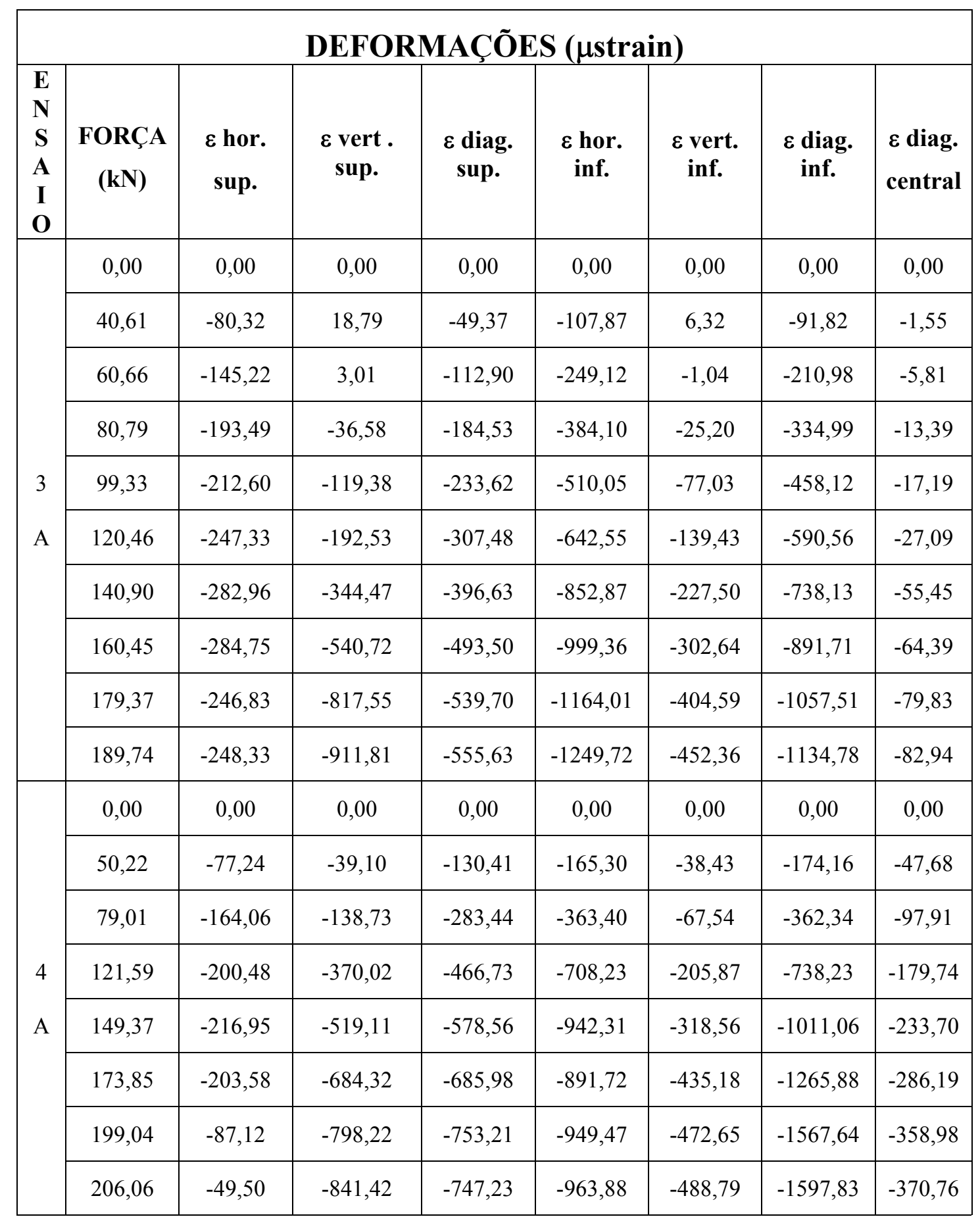




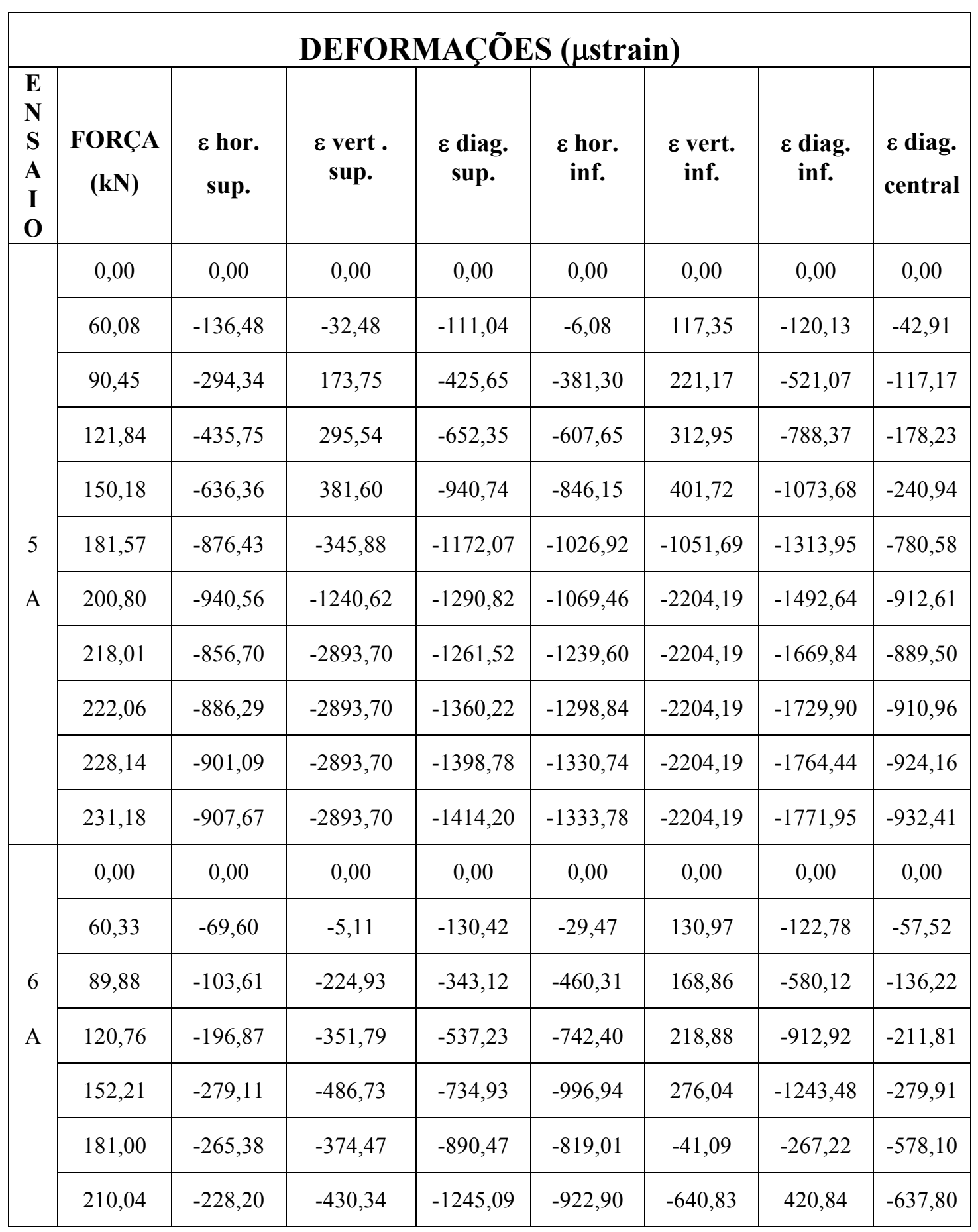


TABELA E.2 - Tensões e deformações principais nos cantos comprimidos dos painéis obtidos nos ensaios realizados

\begin{tabular}{|c|c|c|c|c|c|c|c|c|}
\hline \multirow[t]{2}{*}{$\begin{array}{c}\text { Força } \\
(\mathbf{k N})\end{array}$} & \multirow[t]{2}{*}{ Ensaio } & \multirow[t]{2}{*}{ Local } & \multicolumn{2}{|c|}{$\begin{array}{l}\text { Direções } \\
\text { Principais }\end{array}$} & \multicolumn{2}{|c|}{$\begin{array}{c}\text { Deformações } \\
\text { Principais ( } \mu \text { strain) }\end{array}$} & \multicolumn{2}{|c|}{$\begin{array}{c}\text { Tensões } \\
\text { Principais } \\
\text { (MPa) }\end{array}$} \\
\hline & & & $\theta_{\mathrm{p} 1}$ & $\theta_{\mathrm{p} 2}$ & $\varepsilon_{1}$ & $\varepsilon_{2}$ & $\sigma_{1}$ & $\sigma_{2}$ \\
\hline \multirow{12}{*}{$70 \mathrm{kN}$} & \multirow[t]{2}{*}{$1 \mathrm{~A}$} & C. superior & $-42,82$ & 47,18 & 111,58 & $-223,81$ & 0,15 & $-0,40$ \\
\hline & & C. inferior & 31,18 & 121,18 & 15,33 & $-503,67$ & $-0,13$ & $-0,98$ \\
\hline & \multirow[t]{2}{*}{$2 \mathrm{~A}$} & C. superior & $-41,10$ & 48,90 & 101,76 & $-153,26$ & 0,15 & $-0,27$ \\
\hline & & C. inferior & 27,59 & 117,59 & 46,46 & $-47,27$ & 0,08 & $-0,08$ \\
\hline & \multirow[t]{2}{*}{$3 \mathrm{~A}$} & C. superior & 7,24 & 97,24 & $-2,36$ & $-207,69$ & $-0,07$ & $-0,41$ \\
\hline & & C. inferior & 13,57 & 103,57 & $-1,92$ & $-327,34$ & $-0,11$ & $-0,64$ \\
\hline & \multirow[t]{2}{*}{$4 \mathrm{~A}$} & C. superior & 41,12 & 131,12 & $-6,52$ & $-298,41$ & $-0,11$ & $-0,58$ \\
\hline & & C. inferior & 19,92 & 109,92 & $-27,48$ & $-398,21$ & $-0,18$ & $-0,79$ \\
\hline & \multirow[t]{2}{*}{$5 \mathrm{~A}$} & C. superior & 26,92 & 116,92 & 33,55 & $-304,41$ & $-0,03$ & $-0,58$ \\
\hline & & C. inferior & 33,13 & 123,13 & 505,78 & $-401,70$ & $-0,86$ & $-0,63$ \\
\hline & \multirow[t]{2}{*}{$6 \mathrm{~A}$} & C. superior & 43,31 & 133,31 & 61,93 & $-312,35$ & 0,02 & $-0,59$ \\
\hline & & C. inferior & 40,05 & 130,05 & $-9,79$ & $-450,59$ & $-0,16$ & $-0,88$ \\
\hline \multirow{10}{*}{$100 \mathrm{kN}$} & \multirow[t]{2}{*}{$2 \mathrm{~A}$} & C. superior & $-42,14$ & 47,86 & 208,00 & $-292,31$ & 0,31 & $-0,51$ \\
\hline & & C. inferior & 27,23 & 117,23 & 42,69 & $-42,47$ & 0,07 & $-0,07$ \\
\hline & \multirow[t]{2}{*}{$3 \mathrm{~A}$} & C. superior & 17,18 & 107,18 & $-103,56$ & $-273,38$ & $-0,29$ & $-0,57$ \\
\hline & & C. inferior & 15,05 & 105,05 & $-64,50$ & $-559,81$ & $-0,30$ & $-1,11$ \\
\hline & \multirow[t]{2}{*}{$4 \mathrm{~A}$} & C. superior & $-41,02$ & 48,98 & $-58,17$ & $-452,45$ & $-0,25$ & $-0,90$ \\
\hline & & C. inferior & 20,76 & 110,76 & $-65,80$ & $-631,05$ & $-0,32$ & $-1,25$ \\
\hline & \multirow[t]{2}{*}{$5 \mathrm{~A}$} & C. superior & 35,28 & 125,28 & $-69,23$ & $-582,18$ & $-0,32$ & $-1,16$ \\
\hline & & C. inferior & 28,32 & 118,32 & 597,97 & $-695,12$ & 0,95 & $-1,17$ \\
\hline & \multirow[t]{2}{*}{$6 \mathrm{~A}$} & C. superior & 47,25 & 137,25 & 40,68 & $-511,66$ & $-0,08$ & $-0,99$ \\
\hline & & C. inferior & 30,74 & 120,74 & $-13,68$ & $-769,18$ & $-0,27$ & $-1,50$ \\
\hline \multirow{8}{*}{$200 \mathrm{kN}$} & \multirow[t]{2}{*}{$3 \mathrm{~A}$} & C. superior & $-3,48$ & 86,52 & $-271,12$ & $-944,03$ & $-0,82$ & $-1,93$ \\
\hline & & C. inferior & 13,14 & 103,14 & $-441,26$ & $-1348,72$ & $-1,28$ & $-2,77$ \\
\hline & \multirow[t]{2}{*}{$4 \mathrm{~A}$} & C. superior & $-25,47$ & 64,53 & 93,02 & $-1055,14$ & $-0,15$ & $-2,03$ \\
\hline & & C. inferior & 36,85 & 126,85 & 128,02 & $-1620,46$ & $-0,25$ & $-3,12$ \\
\hline & \multirow[t]{2}{*}{$5 \mathrm{~A}$} & C. superior & 24,24 & 114,24 & 1743,27 & $-1490,35$ & $-2,94$ & $-2,36$ \\
\hline & & C. inferior & $-9,53$ & 80,47 & $-1108,97$ & $-2162,31$ & $-2,84$ & $-4,56$ \\
\hline & \multirow[t]{2}{*}{$6 \mathrm{~A}$} & C. superior & 47,13 & 137,13 & 572,89 & $-1251,39$ & 0,73 & $-2,26$ \\
\hline & & C. inferior & 70,81 & 160,81 & 589,70 & $-1058,29$ & $-0,82$ & $-1,88$ \\
\hline
\end{tabular}




\section{E.2 - ENSAIOS DA SÉRIE B - SISTEMA TIPO II}

Na tabela E.3, apresentam-se as deformações dos extensômetros para alguns níveis de carga, obtidos nos ensaios realizados.

TABELA E.3 - Deformação nos cantos comprimidos dos painéis nos ensaios realizados

\begin{tabular}{|c|c|c|c|c|c|c|c|c|}
\hline \multicolumn{9}{|c|}{ DEFORMAÇÕES ( Sstrain) } \\
\hline $\begin{array}{l}\mathbf{E} \\
\mathbf{N} \\
\mathbf{S} \\
\mathbf{A} \\
\mathbf{I} \\
\mathbf{O}\end{array}$ & $\begin{array}{c}\text { FORÇA } \\
(\mathbf{k N})\end{array}$ & $\begin{array}{c}\varepsilon \text { hor. } \\
\text { sup. }\end{array}$ & $\begin{array}{c}\varepsilon \text { vert } . \\
\text { sup. }\end{array}$ & $\begin{array}{c}\varepsilon \text { diag. } \\
\text { sup. }\end{array}$ & $\begin{array}{c}\varepsilon \text { hor. } \\
\text { inf. }\end{array}$ & $\begin{array}{c}\varepsilon \text { vert. } \\
\text { inf. }\end{array}$ & $\begin{array}{c}\varepsilon \text { diag. } \\
\text { inf. }\end{array}$ & $\begin{array}{l}\varepsilon \text { diag. } \\
\text { central }\end{array}$ \\
\hline \multirow{17}{*}{$\begin{array}{l}1 \\
\text { B }\end{array}$} & 23,90 & 0,00 & 0,00 & 0,00 & 0,00 & 0,00 & 0,00 & 0,00 \\
\hline & 30,16 & $-19,31$ & 16,52 & $-16,47$ & 15,67 & $-132,22$ & $-139,68$ & $-8,79$ \\
\hline & 41,77 & $-108,44$ & $-15,18$ & $-116,44$ & 4,03 & $-242,26$ & $-240,98$ & $-45,72$ \\
\hline & 50,92 & $-181,82$ & $-31,18$ & $-203,94$ & $-4,43$ & $-341,45$ & $-335,11$ & $-77,57$ \\
\hline & 62,46 & $-231,11$ & $-5,70$ & $-255,08$ & 21,34 & $-392,11$ & $-390,29$ & $-76,95$ \\
\hline & 71,32 & $-322,57$ & $-33,22$ & $-345,81$ & $-15,20$ & $-501,95$ & $-479,88$ & $-129,39$ \\
\hline & 81,92 & $-304,89$ & 34,86 & $-329,81$ & 46,44 & $-490,71$ & $-484,32$ & $-77,78$ \\
\hline & 91,54 & $-437,62$ & $-19,26$ & $-473,26$ & 26,73 & $-626,71$ & $-614,07$ & $-139,53$ \\
\hline & 100,02 & $-441,99$ & 57,28 & $-471,88$ & 71,35 & $-610,63$ & $-629,29$ & $-101,46$ \\
\hline & 110,27 & $\mid-597,59$ & $-43,41$ & $-637,34$ & 8,27 & $-800,48$ & $-779,73$ & $-201,38$ \\
\hline & 121,85 & $-658,26$ & $-24,96$ & $-696,71$ & 18,46 & $-870,71$ & $-860,63$ & $-212,96$ \\
\hline & 132,22 & $-605,72$ & 65,74 & $-645,01$ & 91,54 & $-830,51$ & $-840,12$ & $-140,15$ \\
\hline & 141,68 & $-967,02$ & 100,09 & $-909,62$ & 110,58 & $-976,39$ & $-940,01$ & $-175,21$ \\
\hline & 153,67 & $-1127,90$ & 76,85 & $-1048,91$ & 72,50 & $-897,15$ & $-958,81$ & $-226,20$ \\
\hline & 163,86 & $-1168,15$ & 129,03 & $-1073,14$ & 93,66 & $-935,51$ & $-1012,11$ & $-211,82$ \\
\hline & 171,20 & $-1198,43$ & 132,29 & $-1077,76$ & 59,23 & $-1005,26$ & $-1132,04$ & $-233,03$ \\
\hline & 178,35 & $-1162,86$ & 190,48 & $-1030,23$ & 69,52 & $-962,44$ & $-1125,89$ & $-199,93$ \\
\hline
\end{tabular}




\begin{tabular}{|c|c|c|c|c|c|c|c|c|}
\hline \multicolumn{9}{|c|}{ DEFORMAÇÕES ( $\mu$ strain) } \\
\hline $\begin{array}{c}\mathbf{E} \\
\mathbf{N} \\
\mathbf{S} \\
\mathbf{A} \\
\mathbf{I} \\
\mathbf{O}\end{array}$ & $\begin{array}{c}\text { FORÇA } \\
(\mathbf{k N})\end{array}$ & $\begin{array}{c}\varepsilon \text { hor. } \\
\text { sup. }\end{array}$ & $\begin{array}{c}\varepsilon \text { vert } . \\
\text { sup. }\end{array}$ & $\begin{array}{c}\varepsilon \text { diag. } \\
\text { sup. }\end{array}$ & $\begin{array}{c}\varepsilon \text { hor. } \\
\text { inf. }\end{array}$ & $\begin{array}{c}\varepsilon \text { vert. } \\
\text { inf. }\end{array}$ & $\begin{array}{c}\varepsilon \text { diag. } \\
\text { inf. }\end{array}$ & $\begin{array}{l}\varepsilon \text { diag. } \\
\text { central }\end{array}$ \\
\hline \multirow{21}{*}{$\begin{array}{l}2 \\
\text { B }\end{array}$} & 5,37 & 0,00 & 0,00 & 0,00 & 0,00 & 0,00 & 0,00 & 0,00 \\
\hline & 15,05 & $-34,15$ & 3,56 & $-12,76$ & $-10,29$ & $-1,84$ & $-11,34$ & 3,83 \\
\hline & 25,52 & $-88,42$ & 7,95 & $-68,35$ & $-29,72$ & $-6,78$ & $-30,81$ & $-3,62$ \\
\hline & 39,95 & $-158,34$ & 12,02 & $-129,02$ & $-45,68$ & $-11,43$ & $-50,18$ & $-18,51$ \\
\hline & 51,78 & $-229,28$ & 18,54 & $-194,32$ & $-63,66$ & $-9,49$ & $-62,18$ & $-29,48$ \\
\hline & 61,71 & $-270,95$ & 20,38 & $-237,32$ & $-73,38$ & $-13,17$ & $-81,65$ & $-39,92$ \\
\hline & 72,44 & $-353,17$ & 27,92 & $-308,54$ & $-50,97$ & $-332,92$ & $-388,02$ & $-67,33$ \\
\hline & 82,12 & $-431,12$ & 47,28 & $-369,40$ & $-48,28$ & $-394,43$ & $-452,38$ & $-79,43$ \\
\hline & 90,57 & $-527,67$ & 59,82 & $-442,65$ & $-47,22$ & $-455,84$ & $-505,49$ & $-93,19$ \\
\hline & 101,36 & $-609,79$ & 77,76 & $-511,09$ & $-45,97$ & $-527,13$ & $\mid-572,49$ & $-102,91$ \\
\hline & 110,15 & $-693,23$ & 96,82 & $-573,98$ & $-40,01$ & $-600,07$ & $-646,67$ & $-112,53$ \\
\hline & 121,79 & $-775,86$ & 125,05 & $-633,82$ & $-23,85$ & $-674,17$ & $-733,33$ & $-122,67$ \\
\hline & 132,74 & $-849,95$ & 136,77 & $-689,77$ & $-19,72$ & $-742,07$ & $-799,39$ & $-136,73$ \\
\hline & 140,17 & $-995,69$ & 190,78 & $-793,36$ & 0,57 & $-823,44$ & $-877,92$ & $-156,39$ \\
\hline & 151,91 & $-1001,48$ & 200,87 & $-795,12$ & 17,98 & $-912,26$ & $-971,19$ & $-170,76$ \\
\hline & 163,55 & $-1058,90$ & 199,24 & $-827,40$ & 8,46 & $-1011,74$ & $-1063,14$ & $-190,10$ \\
\hline & 170,04 & $-1078,62$ & 199,75 & $-844,23$ & $-2,50$ & $-1061,43$ & $-1129,29$ & $-202,10$ \\
\hline & 180,95 & $-1108,70$ & 199,55 & $-854,40$ & $-4,81$ & $-1121,49$ & $-1182,40$ & $-215,45$ \\
\hline & 190,95 & $-1136,65$ & 188,54 & $-877,99$ & 2,78 & $-1086,91$ & $-1099,52$ & $-230,65$ \\
\hline & 201,46 & $-1162,36$ & 174,48 & $-912,76$ & $-16,16$ & $-1071,70$ & $-1066,92$ & $-240,27$ \\
\hline & 210,22 & $-1204,64$ & 175,49 & $-948,00$ & $-13,27$ & $-1113,35$ & $-1092,25$ & $-254,23$ \\
\hline
\end{tabular}




\begin{tabular}{|c|c|c|c|c|c|c|c|c|}
\hline \multicolumn{9}{|c|}{ DEFORMAÇÕES ( $\mu$ strain) } \\
\hline $\begin{array}{c}\mathbf{E} \\
\mathbf{N} \\
\mathbf{S} \\
\mathbf{A} \\
\mathbf{I} \\
\mathbf{O}\end{array}$ & $\begin{array}{c}\text { FORÇA } \\
(\mathbf{k N})\end{array}$ & $\begin{array}{c}\varepsilon \text { hor. } \\
\text { sup. }\end{array}$ & $\begin{array}{c}\varepsilon \text { vert } . \\
\text { sup. }\end{array}$ & $\begin{array}{c}\varepsilon \text { diag. } \\
\text { sup. }\end{array}$ & $\begin{array}{c}\varepsilon \text { hor. } \\
\text { inf. }\end{array}$ & $\begin{array}{c}\varepsilon \text { vert. } \\
\text { inf. }\end{array}$ & $\begin{array}{c}\varepsilon \text { diag. } \\
\text { inf. }\end{array}$ & $\begin{array}{l}\varepsilon \text { diag. } \\
\text { central }\end{array}$ \\
\hline \multirow{12}{*}{$\begin{array}{l}3 \\
\text { B }\end{array}$} & 0,15 & $-3,03$ & $-2,55$ & 1,60 & 2,44 & $-8,15$ & 3,02 & - \\
\hline & 10,62 & $-24,52$ & $-1,58$ & $-13,15$ & $-0,84$ & $-15,40$ & $-0,41$ & - \\
\hline & 20,18 & $-48,95$ & 1,23 & $-35,70$ & 141,75 & $-27,66$ & $-7,20$ & - \\
\hline & 30,01 & $-74,90$ & 5,79 & $-61,51$ & 141,75 & $-38,69$ & $-12,93$ & - \\
\hline & 40,39 & $-109,67$ & 9,31 & $-80,62$ & 21,32 & $-81,49$ & $-124,50$ & - \\
\hline & 50,67 & $-133,21$ & 1,40 & $-94,54$ & 15,25 & $-81,24$ & $-131,94$ & - \\
\hline & 60,89 & $-141,51$ & 25,03 & $-120,44$ & $-111,66$ & 307,34 & $-227,07$ & - \\
\hline & 70,60 & $-186,89$ & 16,16 & $-147,93$ & $-154,81$ & 1980,72 & $-387,88$ & - \\
\hline & 80,16 & $-219,26$ & 22,04 & $-176,59$ & $-239,08$ & 1980,72 & $-482,44$ & - \\
\hline & 90,35 & $-249,13$ & 17,12 & $-203,16$ & $-309,03$ & 1980,72 & $-565,87$ & - \\
\hline & 95,50 & $-259,47$ & 20,55 & $-214,14$ & $-345,60$ & 1980,72 & $-611,68$ & - \\
\hline & 96,42 & $-259,12$ & 20,11 & $-216,40$ & $-355,04$ & 1980,72 & $-619,86$ & - \\
\hline \multirow{9}{*}{$\begin{array}{l}4 \\
\text { B }\end{array}$} & 2,89 & 0,00 & 0,00 & 0,00 & 0,00 & 0,00 & 0,00 & - \\
\hline & 21,30 & $-42,66$ & $-18,22$ & $-60,38$ & 18,37 & $-42,30$ & $-12,30$ & - \\
\hline & 30,66 & $-63,67$ & $-37,95$ & $-96,32$ & 23,85 & $-78,65$ & $-37,23$ & - \\
\hline & 41,17 & $-90,97$ & $-63,54$ & $-147,23$ & $-62,29$ & $-64,98$ & $-126,31$ & - \\
\hline & 52,18 & $-109,21$ & $-123,53$ & $-191,63$ & $-165,21$ & $-45,28$ & $-206,47$ & - \\
\hline & 61,00 & $-129,77$ & $-142,64$ & $-226,64$ & $-198,76$ & $-39,08$ & $-240,82$ & - \\
\hline & 70,15 & $-158,60$ & $-158,01$ & $-262,33$ & $-209,89$ & $-28,55$ & $-257,99$ & - \\
\hline & 80,94 & $-210,24$ & $-177,56$ & $-330,99$ & $-329,33$ & $-13,27$ & $-368,70$ & - \\
\hline & 91,03 & $-245,00$ & $-207,42$ & $-380,64$ & $-426,85$ & $-10,93$ & $-402,87$ & - \\
\hline
\end{tabular}


TABELA E.4 - Tensões e deformações principais nos cantos comprimidos dos painéis obtidos nos ensaios realizados

\begin{tabular}{|c|c|c|c|c|c|c|c|c|}
\hline \multirow[t]{2}{*}{$\begin{array}{l}\text { Força } \\
(\mathrm{kN})\end{array}$} & \multirow[t]{2}{*}{ Ensaio } & \multirow[t]{2}{*}{ Local } & \multicolumn{2}{|c|}{$\begin{array}{l}\text { Direções } \\
\text { principais }\end{array}$} & \multicolumn{2}{|c|}{$\begin{array}{c}\text { Deformações } \\
\text { principais ( } \mu \text { strain) }\end{array}$} & \multicolumn{2}{|c|}{$\begin{array}{c}\text { Tensões } \\
\text { principais } \\
\text { (MPa) }\end{array}$} \\
\hline & & & $\theta_{\mathrm{p} 1}$ & $\theta_{\mathrm{p} 2}$ & $\varepsilon_{1}$ & $\varepsilon_{2}$ & $\sigma_{1}$ & $\sigma_{2}$ \\
\hline \multirow{8}{*}{$90 \mathrm{kN}$} & \multirow[t]{2}{*}{ P-P-1B } & C. superior & 17,00 & 107,00 & 23,88 & $-480,76$ & $-0,10$ & $-0,93$ \\
\hline & & C. inferior & $-32,56$ & 57,44 & 451,72 & $-1098,51$ & $-0,54$ & $-2,00$ \\
\hline & \multirow[t]{2}{*}{ P-P-2B } & C. superior & 1,60 & 91,60 & 60,28 & $-528,13$ & $-0,05$ & $-1,01$ \\
\hline & & C. inferior & $-34,38$ & 55,62 & 312,47 & $-815,53$ & $-0,36$ & $-1,49$ \\
\hline & \multirow[t]{2}{*}{ P-P-3B } & C. superior & $-0,56$ & 89,44 & 17,15 & $-249,16$ & $-0,04$ & $-0,48$ \\
\hline & & C. inferior & 855,34 & 0,75 & 36,76 & 18,38 & $-0,01$ & $-3,47$ \\
\hline & \multirow[t]{2}{*}{ P-P-4B } & C. superior & 51,03 & 25,51 & 115,51 & 341,53 & $-0,46$ & $-0,55$ \\
\hline & & C. inferior & 9,69 & 99,69 & 0,76 & $-426,31$ & $-0,83$ & $-0,35$ \\
\hline \multirow{4}{*}{$150 \mathrm{kN}$} & \multirow[t]{2}{*}{ P-P-1B } & C. superior & 7,19 & 97,19 & 82,69 & $-1147,80$ & $-0,20$ & $-2,21$ \\
\hline & & C. inferior & $-33,66$ & 56,34 & 800,78 & $-1615,65$ & $-1,06$ & $-2,90$ \\
\hline & \multirow[t]{2}{*}{ P-P-2B } & C. superior & $-0,48$ & 89,52 & 200,95 & $-1001,56$ & $-0,08$ & $-1,89$ \\
\hline & & C. inferior & $-33,76$ & 56,24 & 769,27 & $-1663,55$ & $-0,97$ & $-3,12$ \\
\hline \multirow{4}{*}{$180 \mathrm{kN}$} & \multirow[t]{2}{*}{ P-P-1B } & C. superior & $-1,87$ & 88,13 & 204,10 & $-1104,70$ & $-0,05$ & $-2,09$ \\
\hline & & C. inferior & $-34,74$ & 55,26 & 1025,77 & $-1918,69$ & $-1,40$ & $-3,42$ \\
\hline & \multirow[t]{2}{*}{ P-P-2B } & C. superior & 88,13 & 178,13 & 204,10 & $-1104,70$ & 0,05 & $-2,09$ \\
\hline & & C. inferior & $-33,66$ & 56,34 & 884,84 & $-2011,14$ & $-1,10$ & $-3,65$ \\
\hline \multirow[b]{2}{*}{$210 \mathrm{kN}$} & \multirow[t]{2}{*}{ P-P-2B } & C. superior & $-1,38$ & 88,62 & 175,59 & $-1206,87$ & $-0,03$ & $-2,30$ \\
\hline & & C. inferior & $-32,75$ & 57,25 & 761,02 & $-1889,67$ & $-0,90$ & $-3,45$ \\
\hline
\end{tabular}




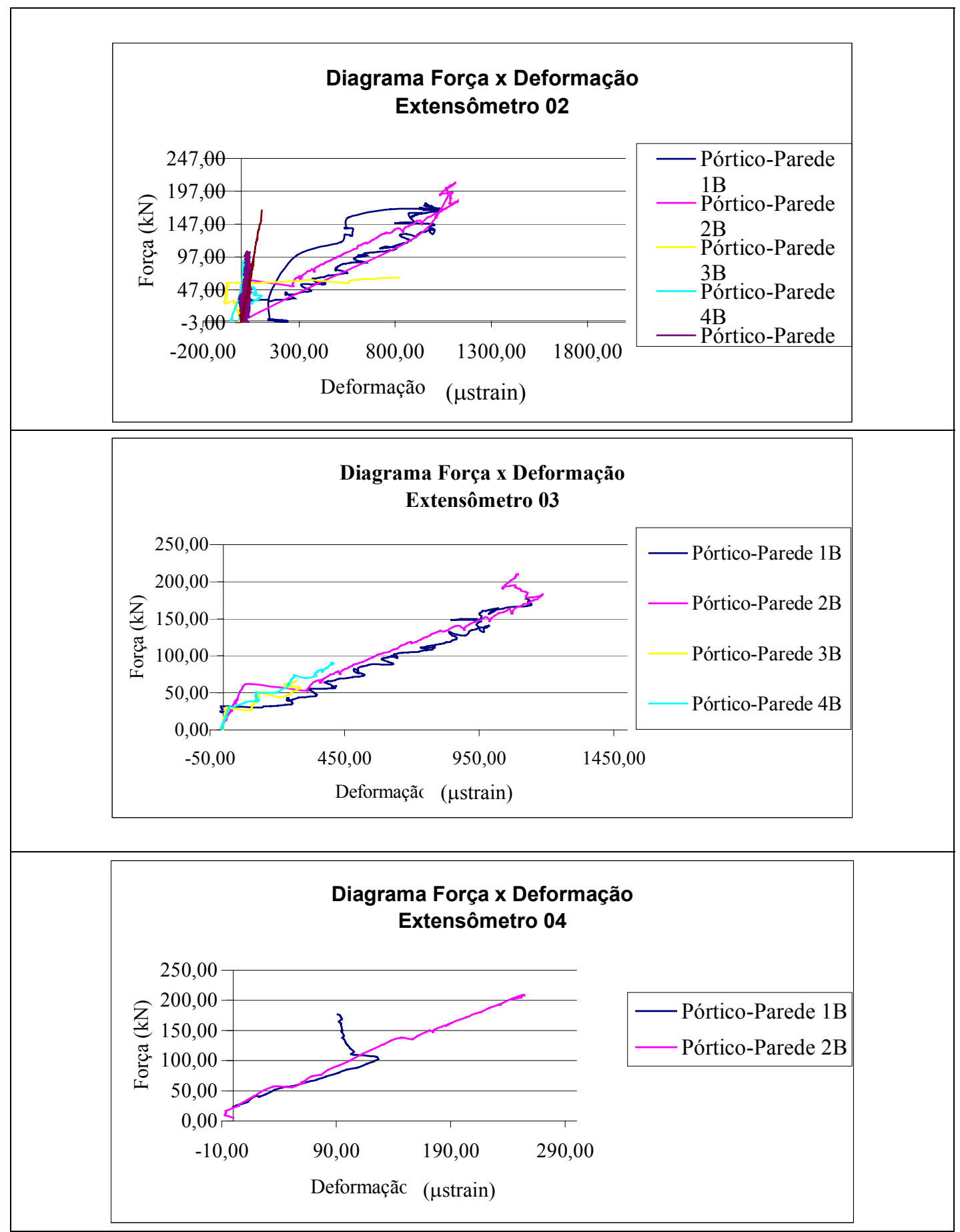

FIGURA E.4 - Diagrama força-deformação nas direções vertical e diagonal do canto inferior direito do painel (EXT 02, EXT 03) e diagonal central comprimida (EXT 04) 


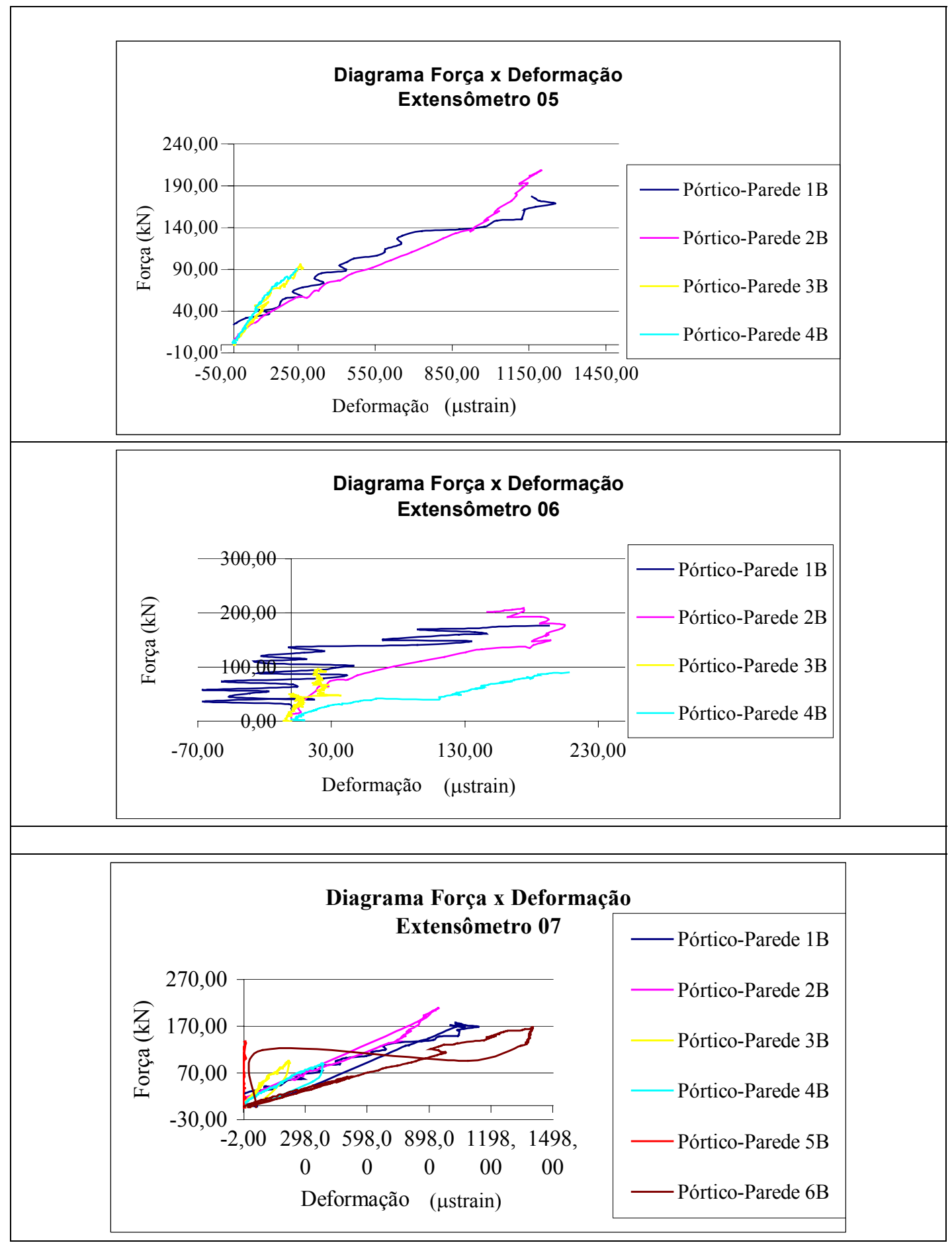

FIGURA E.5 - Diagrama força-deformação nas direções horizontal, vertical e diagonal do canto inferior direito do painel (EXT 05, EXT 06, EXT 07) 

CRITÉRIOS DE CONVERGÊNCIA

\section{F.1 - SOLUÇÃO DE SISTEMAS DE EQUAÇÕES NÃO-LINEARES}

\section{F.1.1 - PROCEDIMENTOS INCREMENTAIS}

$\mathrm{Na}$ formulação incremental, a carga é aplicada em pequenos incrementos, e a rigidez da estrutura é assumida constante durante a aplicação de cada incremento de carga. Os deslocamentos nodais e as tensões nos elementos para cada incremento de carga são calculados utilizando a rigidez da estrutura no início do incremento. Incrementos de deslocamentos e tensões são, então, adicionados àqueles obtidos nos passos anteriores, resultando em valores acumulados. A rigidez estrutural é, então, reavaliada com base no estado da estrutura no final de cada incremento de carga e usada na análise do próximo passo.

Um procedimento incremental pode ser direto ou iterativo. A forma geral das equações que devem ser resolvidas em um procedimento incremental é: 


$$
\boldsymbol{K}_{i} \boldsymbol{u}_{i}=\Delta \boldsymbol{f}^{\prime}{ }_{i} \quad i=1,2,3 \ldots
$$

em que $\boldsymbol{K}_{i}$ é a matriz de rigidez global correspondente ao nível de tensão e geometria do início do incremento de carga, $\boldsymbol{u}_{i}$ é o vetor de deslocamentos nodais que ocorrem devido à aplicação do incremento de carga corrente e $\Delta f_{i}$ é o vetor de incremento de cargas. Os deslocamentos e tensões no final de cada incremento de carga são obtidos pelas expressões F.2.

$$
\begin{aligned}
& \boldsymbol{u}_{i}=\boldsymbol{u}_{i-1}+\boldsymbol{u}_{i} \\
& \boldsymbol{\sigma}_{i}=\boldsymbol{\sigma}_{i-1}+\boldsymbol{\sigma}_{i}
\end{aligned}
$$

em que $\boldsymbol{u}_{i}$ e $\boldsymbol{\sigma}_{i}$ são os deslocamentos nodais e tensões acumulados no final do incremento de carga $i$, respectivamente, e $\boldsymbol{u}_{i-1}$ e $\boldsymbol{\sigma}_{i-1}$ são os valores correspondentes no final do incremento de carga anterior. Uma representação gráfica desse procedimento é mostrada na figura F.1, na qual se observa o erro acumulado em cada incremento de carga, visto que a relação carga-deslocamento curva é aproximada por uma sucessiva série de trechos retos. Esse erro pode ser minimizado, entretanto, com o uso de incrementos de cargas menores na análise. 


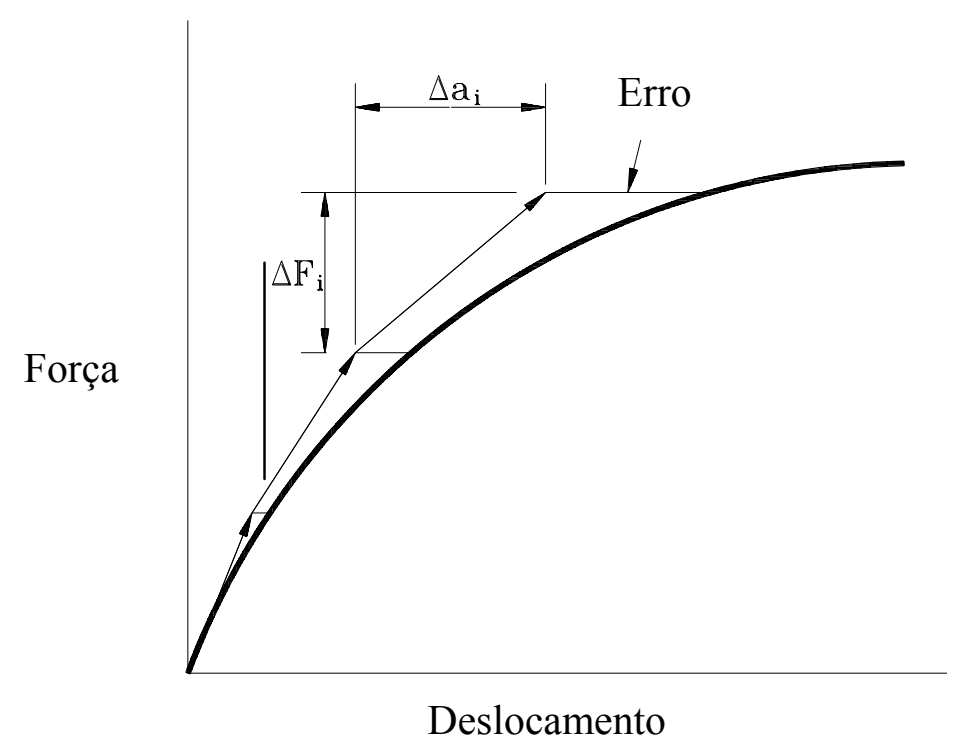

FIGURA F.1 - Formulação incremental direta

\section{F.1.2 - PROCEDIMENTOS ITERATIVOS}

$\mathrm{Na}$ formulação iterativa, os deslocamentos nodais são inicialmente calculados usando a matriz de rigidez tangente da estrutura indeformada. De posse de um conjunto inicial de deslocamentos, o estado da estrutura pode ser avaliado, e a rigidez correspondente pode ser determinada. De acordo com a nova rigidez, as tensões nos elementos e cargas nodais requeridas para manter o equilíbrio são calculadas, figura F.2.

Como a rigidez usada para calcular as tensões nos elementos é diferente da rigidez inicial usada para calcular os deslocamentos, o equilíbrio, em geral, não será satisfeito e, portanto, existirão cargas residuais nos nós. Essas cargas são aplicadas como um novo conjunto de cargas nodais, com a correspondente troca nos deslocamentos calculados usando a rigidez correspondente à nova posição deslocada da estrutura. Esse processo é repetido até que as cargas residuais no final de uma iteração estejam dentro de uma tolerância. 
Um dos procedimentos iterativos mais utilizados para solução do sistema de equações não-lineares é o método de Newton Raphson. Em geral, a aplicação do método de Newton Raphson leva a uma convergência mais rápida que o processo da iteração direta, seja o que utiliza a matriz secante atualizada ou o que mantém a matriz constante. Esse último é também conhecido como método de NewtonRaphson modificado. A escolha da matriz a ser utilizada para estimativa do incremento de deslocamentos apenas influencia a velocidade de convergência, podendo ser usada qualquer uma delas.

BATHE (1996) apresentou uma técnica utilizando a forma incremental do método iterativo de Newton-Raphson, que é uma das mais utilizadas e conhecidas técnicas de solução de problemas de equilíbrio não-linear. O processo incremental-iterativo é sempre preferível pela aproximação que produz do equilíbrio real. Como ilustrado na figura F.4, o equilíbrio é obtido por sucessivas aproximações da forma

$$
\boldsymbol{R}_{i_{n}}=\boldsymbol{f}_{i_{n}}^{\prime}-\boldsymbol{q}_{i_{n}}=\boldsymbol{K}_{\boldsymbol{i}_{n-1}} \Delta \boldsymbol{u}_{i_{n}}
$$

em que $\boldsymbol{K}_{i_{n-1}}$ é a matriz de rigidez tangente da estrutura no final da iteração $(n-1)^{t h}$, $\Delta \boldsymbol{u}_{i_{n}}$ é a $n^{\text {th }}$ correção a ser aplicada no vetor de deslocamentos nodais correntes, $\boldsymbol{f}^{\prime}{ }_{i n}$ é o vetor de forças externas aplicadas e $\boldsymbol{q}_{i_{n}}$ é o vetor de forças nodais equivalentes necessário para manter o equilíbrio com as tensões no elemento na corrente iteração. Como indicado na equação F.3, $\boldsymbol{R}_{i_{n}}$ é o vetor de cargas residuais na corrente iteração. Os deslocamentos no final de cada iteração são atualizados, e o processo é repetido até a convergência para uma tolerância previamente admitida. 


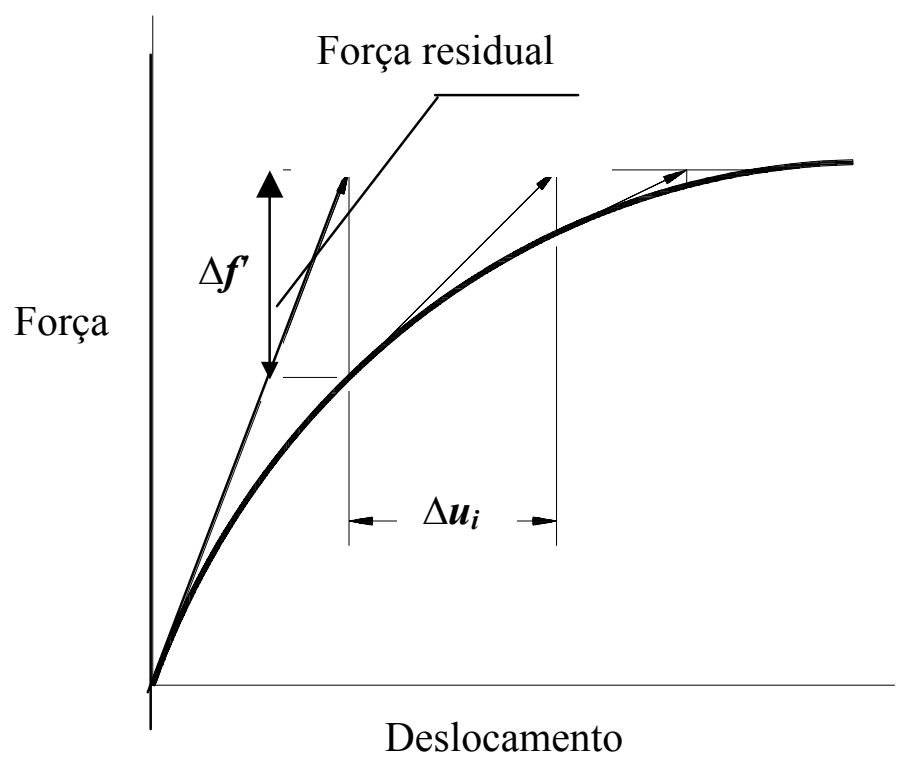

FIGURA F.2 - Formulação iterativa - Técnica de Newton Raphson

Geralmente, ambas as técnicas incremental e iterativa descritas aqui são convenientes para estruturas que exibem comportamento força $\mathrm{x}$ deslocamento contínuo $\mathrm{e}$ monotonicamente crescente, tal como representado pela curva (a) da figura F.3. Na análise de pórticos preenchidos com alvenaria, podem ocorrer variações abruptas de forças como indicado pela curva (b) da figura F.3, em virtude de ter sido excedida a capacidade à tração e ao cisalhamento das juntas de argamassa em uma porção da estrutura, posto que a estrutura como um todo é ainda capaz de resistir a acréscimos de carga. $\mathrm{O}$ esmagamento local do material também tem efeito similar. 


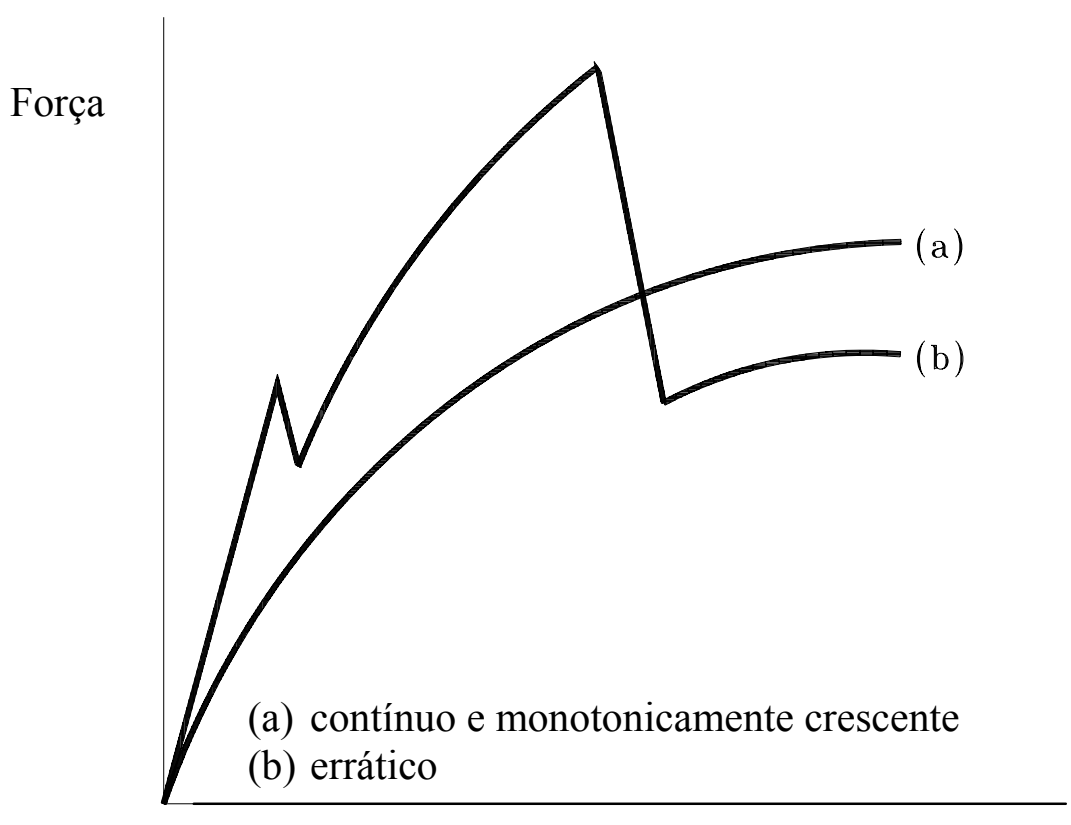

Deslocamento

FIGURA F.3 - Curvas força x deslocamento

(a) contínuo e monotonicamente crescente e b) errático

\section{F.2 - TÉCNICAS ADICIONAIS}

Existem diversas técnicas, tanto para tornar mais eficientes os procedimentos iterativos como para assegurar, dentro do possível, a convergência para a configuração de equilíbrio.

Uma das técnicas mais difundidas é a do controle de deslocamentos ou do comprimento de arco, conhecida na literatura em inglês como "arc-length control". Essa técnica é útil nos casos em que a sucessão de configurações deformadas se apresenta com níveis de carga que não são monotonicamente crescentes, como o apresentado na figura F.4.

O comportamento do tipo "Snap through", figura F.4a, pode ser analisado através de um deslocamento controlado. O método do comprimento de arco também é capaz de analisar o "snap-back", figura F.4.b, em que o controle dos deslocamentos não seja eficaz. O método do comprimento de arco limita os deslocamentos incrementais para 
dado valor prescrito. Isso é feito adaptando simultaneamente o tamanho do incremento. Nota-se que o tamanho do incremento é adaptado dentro do processo de iteração e não é fixado no momento do começo do incremento. Para isso, é definido o vetor de forças externas como $\Delta \lambda_{i} \boldsymbol{f}^{\prime}$. O fator de carga $\Delta \lambda_{i}$ multiplica a carga unitária $\boldsymbol{f}^{\prime}$ e pode ser modificado a cada iteração.

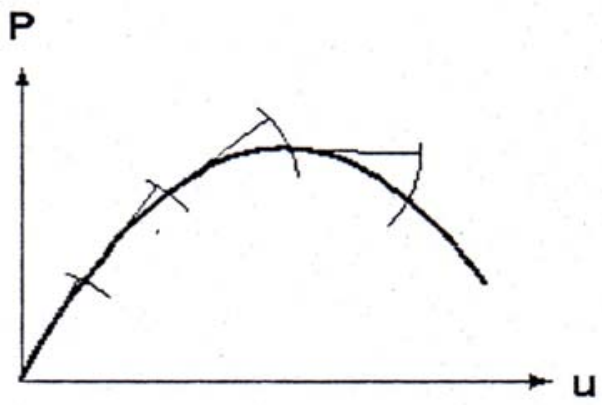

a)

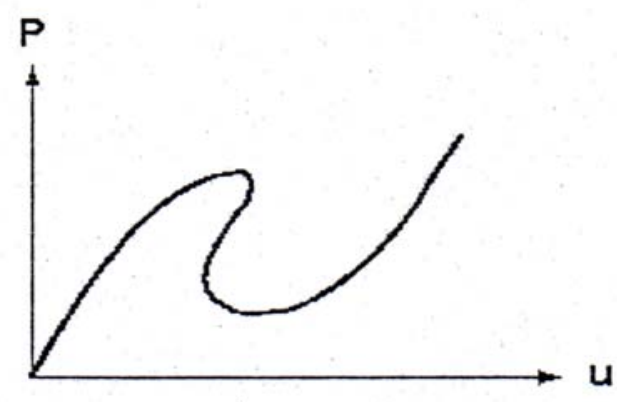

b)

FIGURA F.4 - Método do controle de deslocamento ("arc-length control"): a) "snapThrough"

\section{F.3 - CRITÉRIOS DE CONVERGÊNCIA}

Um processo iterativo deve ser definido através de um critério e segundo uma tolerância prédefinida. Há, basicamente, três critérios que envolvem, respectivamente, deslocamentos, esforços residuais e energia interna ou trabalho.

Como em análises não-lineares se procura obter a configuração da estrutura correspondente a determinado passo de carga, é natural que se pretenda que os deslocamentos no final de cada iteração estejam dentro de uma tolerância aceitável, próximos aos correspondentes à solução correta. Um critério relacionado ao deslocamento é dado pela expressão F.4:

$$
\frac{\left\|\Delta \boldsymbol{u}^{(i)}\right\|_{2}}{\| t+\Delta t} \boldsymbol{u} \|_{2} \times 100 \leq \varepsilon_{D}
$$


em que $\varepsilon_{\mathrm{D}}$ é a tolerância admitida para os deslocamentos em percentagem e $\left\|\Delta \boldsymbol{u}^{(i)}\right\|_{2}$ é a norma euclidiana do vetor de incrementos de deslocamentos na iteração i e dada por

$$
\left\|\Delta \boldsymbol{u}^{(i)}\right\|_{2}=\left|\sqrt{\sum_{j=1}^{n}\left(\boldsymbol{u}_{j}^{(i)}\right)^{2}}-\sqrt{\sum_{j=1}^{n}\left(\boldsymbol{u}_{j}^{(i-1)}\right)^{2}}\right|
$$

e $\|t+\Delta t u\|_{2}$ é a norma euclidiana do vetor dos deslocamentos nodais da estrutura obtido no final do incremento. Como esses deslocamentos são desconhecidos, eles devem ser aproximados. Freqüentemente, adota-se para esses deslocamentos aqueles obtidos na iteração atual i, obtendo

$$
\|t+\Delta t \boldsymbol{u}\|_{2}=\|\|{ }^{t+\Delta t} \boldsymbol{u}^{(i)}\left\|_{2}\right\|=\sqrt{\sum_{j=1}^{n}\left(\boldsymbol{u}_{j}^{(i)}\right)^{2}}
$$

em que $n$ é o número de graus de liberdade da estrutura.

Um segundo critério bastante utilizado, semelhante ao primeiro, baseia-se na medida do vetor de forças desequilibradas. A norma do vetor de desequilíbrio deve ser menor que uma percentagem preestabelecida da norma do vetor de forças correspondente ao incremento analisado.

$$
\frac{\left\|\Delta \boldsymbol{R}^{(i)}\right\|_{2}}{\left\|{ }^{t+\Delta t} \boldsymbol{R}-\boldsymbol{S}\right\|_{2}} \times 100 \leq \varepsilon_{F}
$$

em que $\left\|\Delta \boldsymbol{R}^{(i)}\right\|_{2}$ é a norma euclidiana do vetor de esforços residuais obtidos no final da iteração i, $\left\|{ }^{t+\Delta t} \boldsymbol{R}-\boldsymbol{S}\right\|_{2}$ é a norma euclidiana do incremento de cargas nodais e $\varepsilon_{\mathrm{F}}$ é a tolerância admitida para os esforços, em percentagem. A desvantagem desse critério é que, como ele não envolve deslocamentos, numa análise elastoplástica de uma estrutura de material com pequeno módulo de endurecimento, entrando na 
região plástica, os esforços residuais podem ser muito pequenos, enquanto os deslocamentos ainda podem variar muito.

Para contornar os problemas que possam surgir, um terceiro critério, baseado na energia incremental interna, envolvendo tanto deslocamentos quanto esforços, pode ser utilizado. É dado pela expressão F.8:

$$
\frac{\Delta \boldsymbol{u}^{(i)^{t}}\left({ }^{t+\Delta t} \boldsymbol{R}-{ }^{t+\Delta t} \boldsymbol{S}^{(i-1)}\right)}{\Delta \boldsymbol{u}^{(i)^{t}}\left({ }^{t+\Delta t} \boldsymbol{R}-{ }^{t} \boldsymbol{S}\right)} \times 100 \leq \varepsilon_{E}
$$

em que o numerador representa o incremento de energia interna durante a iteração $i$, o denominador representa o incremento de energia interna inicial e $\varepsilon_{E}$ é a tolerância admitida para a energia interna, em percentagem.

As tolerâncias admitidas para a convergência devem ser pequenas. OWEN e GOMES (1984) adotaram tolerâncias de 0,5\% e OWEN e HILTON (1980), de 1,0\%. 
TABELAS COM VALORES DAS CARGAS DE RUPTURA OBTIDOS PELO MÉTODO PROPOSTO, PELAS MODELAGENS NUMÉRICAS E PELOS MÉTODOS TEÓRICOS

TABELA G.1 - Valores das cargas de ruptura obtidos pelo método proposto, pelas modelagens numéricas e pelos métodos teóricos da literatura, para módulo de deformação da alvenaria igual a $875 \mathrm{MPa}$. Unidade $(\mathrm{kN})$

\begin{tabular}{|c|c|c|c|c|c|c|}
\hline \multirow{4}{*}{ DESCRIÇÃO } & $\begin{array}{c}\text { MODO DE } \\
\text { RUPTURA }\end{array}$ & $\begin{array}{c}\text { H/L=0,51 } \\
\text { (TIPO II) }\end{array}$ & $\mathbf{H} / \mathbf{L}=\mathbf{0 , 6 0}$ & $\mathbf{H} / \mathbf{L}=\mathbf{0 , 7 0}$ & $\begin{array}{c}\text { H/L=0,83 } \\
\text { (TIPO I) }\end{array}$ & H/L=1,00 \\
\hline \multirow{3}{*}{ Proposta } & Fissuração & 332,70 & 247,00 & 190,28 & 138,23 & 99,14 \\
\cline { 2 - 7 } & Esmagam. & 355,05 & 350,33 & 334,64 & 322,08 & 308,25 \\
\cline { 2 - 7 } & Esmag. Ce* & 917,28 & 876,04 & 802,11 & 723,13 & 631,81 \\
\hline \multirow{2}{*}{$\begin{array}{c}\text { Mod. } \\
\text { Numérica }\end{array}$} & Fissuração & - & - & 234,00 & 185,00 & 150,00 \\
\cline { 2 - 7 } \begin{tabular}{c} 
Smith e Carter \\
\cline { 2 - 7 }
\end{tabular} & Esmagam. & 256,00 & 251,00 & 264,00 & 320,00 & 322,00 \\
\cline { 2 - 7 } & Esmagação & 408,34 & 356,71 & 292,88 & 234,20 & 173,07 \\
\hline $\begin{array}{c}\text { Smith e } \\
\text { Riddington }\end{array}$ & Fissuração & 310,78 & 379,76 & 416,52 & 405,97 & 384,30 \\
\cline { 2 - 7 } & Esmagam. & 314,68 & 304,49 & 260,22 & 224,93 & 185,82 \\
\hline
\end{tabular}

*Esmag. Ce - Esmagamento no centro do painel devido à tensão efetiva adotada nesta região. 
TABELA G.2 - Relação entre os valores das forças de ruptura obtidos na modelagem numérica e nos métodos teóricos da literatura e os valores obtidos na proposta apresentada neste trabalho - Mod. Deform. Alvenaria $=875 \mathrm{MPa}$

\begin{tabular}{|c|c|c|c|c|c|c|}
\hline RELAÇÃO & $\begin{array}{l}\text { MODO DE } \\
\text { RUPTURA }\end{array}$ & $\begin{array}{l}\mathrm{H} / \mathrm{L}=\mathbf{0 , 5 1} \\
\text { (TIPO II) }\end{array}$ & $\mathrm{H} / \mathrm{L}=\mathbf{0 , 6 0}$ & $\mathbf{H} / \mathbf{L}=\mathbf{0 , 7 0}$ & $\begin{array}{l}\text { H/L=0,83 } \\
\text { (TIPO I) }\end{array}$ & $H / L=1,0$ \\
\hline \multirow{2}{*}{$\begin{array}{c}\text { Numérica/ } \\
\text { Proposta }\end{array}$} & Fissuração & - & - & 1,23 & 1,34 & 1,50 \\
\hline & Esmagam. & 0,72 & 0,72 & 0,79 & 0,99 & 1,04 \\
\hline \multirow{2}{*}{$\begin{array}{c}\text { Smith e Carter/ } \\
\text { Proposta }\end{array}$} & Fissuração & 1,34 & 1,44 & 1,54 & 1,70 & 1,75 \\
\hline & Esmagam. & 1,15 & 1,09 & 1,17 & 1,26 & 1,25 \\
\hline \multirow{2}{*}{$\begin{array}{c}\text { Smith Riddington/ } \\
\text { Proposta } \\
\end{array}$} & Fissuração & 0,97 & 1,10 & 1,20 & 1,35 & 1,52 \\
\hline & Esmagam. & 0,89 & 0,87 & 0,78 & 0,70 & 0,60 \\
\hline
\end{tabular}

TABELA G.3 - Valores das cargas de ruptura obtidos pelo método proposto, pelas modelagens numéricas e pelos métodos teóricos da literatura, para módulo de deformação da alvenaria igual a 1312,5 MPa. Unidade $(\mathrm{kN})$

\begin{tabular}{|c|c|c|c|c|c|c|}
\hline \multirow{2}{*}{ DESCRIÇãO } & $\begin{array}{c}\text { MODO DE } \\
\text { RUPTURA }\end{array}$ & $\begin{array}{c}\mathbf{H} / \mathbf{L}=\mathbf{0 , 5 1} \\
\text { (TIPO II) }\end{array}$ & $\mathbf{H} / \mathbf{L}=\mathbf{0 , 6 0}$ & $\mathbf{H} / \mathbf{L}=\mathbf{0 , 7 0}$ & $\begin{array}{c}\mathbf{H} / \mathbf{L}=\mathbf{0 , 8 3} \\
\mathbf{( T I P O} \mathbf{I})\end{array}$ & $\mathbf{H} / \mathbf{L = 1 , 0 0}$ \\
\hline \multirow{3}{*}{ Proposta } & Fissuração & 368,18 & 273,34 & 210,59 & 152,98 & 109,71 \\
\cline { 2 - 7 } & Esmagam. & 320,83 & 316,56 & 302,37 & 291,03 & 278,54 \\
\cline { 2 - 7 } & Esmag. Ce.* & 828,88 & 791,62 & 724,76 & 653,43 & 570,92 \\
\hline \multirow{2}{*}{ Smith e Carter Numérica } & Fissuração & - & 243,00 & 209,00 & 171,00 & 139,00 \\
\cline { 2 - 7 } & Esmagam. & 261,00 & 250,00 & 276,00 & 321,00 & 316,00 \\
\cline { 2 - 7 } & Fissuração & 443,13 & 356,71 & 290,37 & 231,84 & 173,07 \\
\hline \multirow{2}{*}{$\begin{array}{c}\text { Smith e } \\
\text { Riddington }\end{array}$} & Esmagam. & 376,90 & 371,54 & 377,10 & 370,31 & 352,81 \\
\cline { 2 - 7 } & Essuração & 321,41 & 270,98 & 228,62 & 186,93 & 150,62 \\
\hline \multirow{2}{*}{ Esmagam. } & 288,45 & 278,57 & 238,11 & 205,56 & 169,96 \\
\hline
\end{tabular}

*Esmag. Ce - Esmagamento no centro do painel devido à tensão efetiva adotada nesta região. 
TABELA G.4 - Relação entre os valores das forças de ruptura obtidos na modelagem numérica e nos métodos teóricos da literatura e os valores obtidos na proposta apresentada neste trabalho. Relação entre os métodos teóricos - Mod. Deform. Alvenaria $=1312,5 \mathrm{MPa}$

\begin{tabular}{|c|c|c|c|c|c|c|}
\hline RELAÇÃO & $\begin{array}{l}\text { MODO DE } \\
\text { RUPTURA }\end{array}$ & $\begin{array}{l}\text { H/L=0,51 } \\
\text { (TIPO II) }\end{array}$ & $\mathrm{H} / \mathrm{L}=\mathbf{0 , 6 0}$ & $\mathbf{H} / \mathbf{L}=\mathbf{0 , 7 0}$ & $\begin{array}{c}\text { H/L=0,83 } \\
\text { (TIPO I) }\end{array}$ & $H / L=1,0$ \\
\hline \multirow{2}{*}{$\begin{array}{c}\text { Numérica/ } \\
\text { Proposta }\end{array}$} & Fissuração & - & 0,89 & 0,99 & 1,12 & 1,26 \\
\hline & Esmagam. & 0,81 & 0,79 & 0,91 & 1,10 & 1,14 \\
\hline \multirow{2}{*}{$\begin{array}{c}\text { Smith e Carter/ } \\
\text { Proposta }\end{array}$} & Fissuração & 1,20 & 1,31 & 1,38 & 1,52 & 1,58 \\
\hline & Esmagam. & 1,18 & 1,18 & 1,25 & 1,27 & 1,27 \\
\hline \multirow{2}{*}{$\begin{array}{c}\text { Smith Riddington/ } \\
\text { Proposta }\end{array}$} & Fissuração & 0,87 & 0,99 & 1,09 & 1,22 & 1,37 \\
\hline & Esmagam. & 0,90 & 0,88 & 0,79 & 0,71 & 1,64 \\
\hline
\end{tabular}

TABELA G.5 - Valores das cargas de ruptura obtidos pelo método proposto, pelas modelagens numéricas e pelos métodos teóricos da literatura, para módulo de deformação da alvenaria igual a $1750 \mathrm{MPa}$. Unidade $(\mathrm{kN})$

\begin{tabular}{|c|c|c|c|c|c|c|}
\hline \multirow{2}{*}{ DESCRIÇÃO } & $\begin{array}{c}\text { MODO DE } \\
\text { RUPTURA }\end{array}$ & $\begin{array}{c}\mathbf{H} / \mathbf{L}=\mathbf{0 , 5 1} \\
\text { (TIPO II) }\end{array}$ & $\mathbf{H} / \mathbf{L}=\mathbf{0 , 6 0}$ & $\mathbf{H} / \mathbf{L}=\mathbf{0 , 7 0}$ & $\begin{array}{c}\text { H/L=0,83 } \\
\text { (TIPO I) }\end{array}$ & H/L=1,00 \\
\hline \multirow{3}{*}{ Proposta } & Fissuração & 395,19 & 293,74 & 225,61 & 164,39 & 117,90 \\
\cline { 2 - 7 } & Esmagam. & 298,90 & 294,59 & 282,24 & 270,84 & 259,20 \\
\cline { 2 - 7 } & Esmag. Ce.* & 772,21 & 736,65 & 676,50 & 608,09 & 531,29 \\
\hline \multirow{2}{*}{$\begin{array}{c}\text { Mod. } \\
\text { Numérica }\end{array}$} & Fissuração & - & 230,00 & 197,00 & 165,00 & 133,00 \\
\cline { 2 - 7 } \begin{tabular}{c} 
Smith e Carter \\
\cline { 2 - 7 }
\end{tabular} & Esmagam. & 265,00 & 257,00 & 280,00 & 318,00 & 312,00 \\
\cline { 2 - 7 } & Fissuração & 437,52 & 347,54 & 287,86 & 229,46 & 170,92 \\
\hline $\begin{array}{c}\text { Smith e } \\
\text { Riddington }\end{array}$ & Fissuraçãa & 321,41 & 270,98 & 228,62 & 186,93 & 150,62 \\
\cline { 2 - 7 } & Esmagam. & 270,74 & 261,67 & 222,99 & 192,73 & 159,44 \\
\hline
\end{tabular}

*Esmag. Ce - Esmagamento no centro do painel devido à tensão efetiva adotada nesta região. 
TABELA G.6 - Relação entre os valores das forças de ruptura obtidos na modelagem numérica e nos métodos teóricos da literatura e os valores obtidos na proposta apresentada neste trabalho. Relação entre os métodos teóricos - Mod. Deform. Alvenaria $=1750 \mathrm{MPa}$

\begin{tabular}{|c|c|c|c|c|c|c|}
\hline \multirow{2}{*}{ RELAÇÃO } & $\begin{array}{c}\text { MODO DE } \\
\text { RUPTURA }\end{array}$ & $\begin{array}{c}\mathbf{H} / \mathbf{L}=\mathbf{0 , 5 1} \\
\mathbf{( T I P O} \text { II) }\end{array}$ & $\mathbf{H} / \mathbf{L}=\mathbf{0 , 6 0}$ & $\mathbf{H} / \mathbf{L}=\mathbf{0 , 7 0}$ & $\begin{array}{c}\mathbf{H} / \mathbf{L}=\mathbf{0 , 8 3} \\
\mathbf{( T I P O} \mathbf{I})\end{array}$ & $\mathbf{H} / \mathbf{L}=\mathbf{1 , 0}$ \\
\hline \multirow{2}{*}{$\begin{array}{c}\text { Numérica/ } \\
\text { Proposta }\end{array}$} & Fissuração & - & 0,78 & 0,87 & 1,00 & 1,13 \\
\cline { 2 - 7 } & Esmagam. & 0,89 & 0,87 & 0,99 & 1,17 & 1,20 \\
\hline $\begin{array}{c}\text { Smith e Carter/ } \\
\text { Proposta }\end{array}$ & Fissuração & 1,10 & 1,36 & 1,47 & 1,73 & 2,00 \\
\cline { 2 - 7 } & Esmagam. & 1,18 & 1,20 & 1,49 & 1,59 & 1,77 \\
\hline $\begin{array}{c}\text { Smith } \\
\text { Riddington/ } \\
\text { Proposta }\end{array}$ & Fissuração & 0,81 & 0,93 & 1,01 & 0,69 & 1,28 \\
\cline { 2 - 7 } & Esmagam. & 0,91 & 0,89 & 0,79 & 0,71 & 0,62 \\
\hline
\end{tabular}

TABELA G.7 - Valores das cargas de ruptura obtidos pelo método proposto, pelas modelagens numéricas e pelos métodos teóricos da literatura, para módulo de deformação da alvenaria igual a $2625 \mathrm{MPa}$. Unidade $(\mathrm{kN})$

\begin{tabular}{|c|c|c|c|c|c|c|}
\hline \multirow{2}{*}{ DESCRIÇÃO } & MODO DE & $\mathbf{H} / \mathbf{L}=\mathbf{0 , 5 1}$ & $\mathbf{H} / \mathbf{L}=\mathbf{0 , 6 0}$ & $\mathbf{H} / \mathbf{L}=\mathbf{0 , 7 0}$ & $\begin{array}{c}\mathbf{H} / \mathbf{L}=\mathbf{0 , 8 3} \\
\mathbf{( T I P O} \mathbf{I})\end{array}$ & $\mathbf{H} / \mathbf{L}=\mathbf{1 , 0 0}$ \\
\hline \multirow{3}{*}{ Proposta } & RUPTURA & & & & \\
\cline { 2 - 7 } & Fissuração & 437,84 & 325,06 & 250,44 & 181,92 & 130,48 \\
\cline { 2 - 7 } & Esmagam. & 269,78 & 266,20 & 254,26 & 244,74 & 234,21 \\
\cline { 2 - 7 } & Esmag. Ce & 696,99 & 665,68 & 609,43 & 549,47 & 480,07 \\
\hline \multirow{2}{*}{$\begin{array}{c}\text { Mod. } \\
\text { Numérica }\end{array}$} & Fissuração & - & 215,00 & 186,00 & 155,00 & 127,00 \\
\cline { 2 - 7 } \begin{tabular}{c} 
Smith e Carter \\
\cline { 2 - 7 }
\end{tabular} & Esmagam. & 271,00 & 263,00 & 284,00 & 319,00 & 319,00 \\
\cline { 2 - 7 } & Esmagam. & 330,04 & 325,00 & 317,97 & 311,26 & 303,40 \\
\hline $\begin{array}{c}\text { Smith e } \\
\text { Riddington }\end{array}$ & Fissuração & 321,41 & 270,98 & 228,62 & 186,93 & 150,62 \\
\cline { 2 - 7 } & Esmagam. & 247,23 & 239,19 & 242,02 & 176,59 & 172,25 \\
\hline
\end{tabular}

*Esmag. Ce - Esmagamento no centro do painel devido à tensão efetiva adotada nesta região. 
TABELA G.8 - Relação entre os valores das forças de ruptura obtidos na modelagem numérica e nos métodos teóricos da literatura e os valores obtidos na proposta apresentada neste trabalho. Relação entre os métodos teóricos - Mod. Deform. Alvenaria $=2625 \mathrm{MPa}$

\begin{tabular}{|c|c|c|c|c|c|c|}
\hline \multirow{2}{*}{ RELAÇÃo } & $\begin{array}{c}\text { MODO DE } \\
\text { RUPTURA }\end{array}$ & $\begin{array}{c}\mathbf{H} / \mathbf{L}=\mathbf{0 , 5 1} \\
\mathbf{( T I P O} \text { II) }\end{array}$ & $\mathbf{H} / \mathbf{L}=\mathbf{0 , 6 0}$ & $\mathbf{H} / \mathbf{L}=\mathbf{0 , 7 0}$ & $\begin{array}{c}\mathbf{H} / \mathbf{L}=\mathbf{0 , 8 3} \\
\mathbf{( T I P O} \text { I) }\end{array}$ & $\mathbf{H} / \mathbf{L = 1 , 0 0}$ \\
\hline \multirow{2}{*}{$\begin{array}{c}\text { Numérica/ } \\
\text { Proposta }\end{array}$} & Fissuração & - & 0,66 & 0,74 & 0,85 & 0,97 \\
\cline { 2 - 7 } & Esmagam. & 1,00 & 0,99 & 1,11 & 1,30 & 1,36 \\
\hline $\begin{array}{c}\text { Smith e Carter/ } \\
\text { Proposta }\end{array}$ & Fissuração & 0,98 & 1,07 & 1,11 & 1,25 & 1,28 \\
\cline { 2 - 7 } $\begin{array}{c}\text { Smith } \\
\text { Riddington/ } \\
\text { Proposta }\end{array}$ & Esmagam. & 1,25 & 1,22 & 1,25 & 1,27 & 1,30 \\
\cline { 2 - 7 } & Eissuração & 0,73 & 0,83 & 0,91 & 1,03 & 1,19 \\
\hline \multirow{2}{*}{} & Esmagam. & 1,19 & 0,90 & 0,95 & 0,72 & 0,74 \\
\hline
\end{tabular}

TABELA G.9 - Valores das cargas de ruptura obtidos pelo método proposto, pelas modelagens numéricas e pelos métodos teóricos da literatura, para módulo de deformação da alvenaria igual a $3500 \mathrm{MPa}$. Unidade $(\mathrm{kN})$

\begin{tabular}{|c|c|c|c|c|c|c|}
\hline \multirow{2}{*}{ DESCRIÇÃO } & $\begin{array}{c}\text { MODO DE } \\
\text { RUPTURA }\end{array}$ & $\begin{array}{c}\mathbf{H} / \mathbf{L}=\mathbf{0 , 5 1} \\
\text { (TIPO II) }\end{array}$ & $\mathbf{H} / \mathbf{L}=\mathbf{0 , 6 0}$ & $\mathbf{H} / \mathbf{L}=\mathbf{0 , 7 0}$ & $\begin{array}{c}\mathbf{H} / \mathbf{L}=\mathbf{0 , 8 3} \\
\mathbf{( T I P O} \text { I) }\end{array}$ & $\mathbf{H} / \mathbf{L}=\mathbf{1 , 0 0}$ \\
\hline \multirow{3}{*}{ Proposta } & Fissuração & 468,00 & 349,31 & 269,11 & 195,50 & 140,20 \\
\cline { 2 - 7 } & Esmagam. & 251,06 & 247,72 & 236,62 & 227,74 & 217,97 \\
\cline { 2 - 7 } & Compr. Ef. & 648,62 & 619,46 & 567,16 & 511,32 & 446,78 \\
\hline \multirow{2}{*}{$\begin{array}{c}\text { Mod. } \\
\text { Numérica }\end{array}$} & Fissuração & - & 208,00 & 180,00 & 152,00 & 127,00 \\
\cline { 2 - 7 } \begin{tabular}{c} 
Smith e Carter \\
\cline { 2 - 7 }
\end{tabular} & Esmagam. & 274,00 & 265,00 & 286,00 & 318,00 & 306,00 \\
\cline { 2 - 7 } & Esmagam. & 314,50 & 298,83 & 295,65 & 291,56 & 290,00 \\
\hline $\begin{array}{c}\text { Smith e } \\
\text { Riddington }\end{array}$ & Fissuração & 321,41 & 270,98 & 228,62 & 186,93 & 150,62 \\
\cline { 2 - 7 } & Esmagam. & 232,25 & 224,85 & 191,80 & 165,46 & 137,05 \\
\hline
\end{tabular}

*Esmag. Ce - Esmagamento no centro do painel devido à tensão efetiva adotada nesta região. 
TABELA G.10 - Relação entre os valores das forças de ruptura obtidos na modelagem numérica e nos métodos teóricos da literatura e os valores obtidos na proposta apresentada neste trabalho. Relação entre os métodos teóricos - Mod. Deform. Alvenaria $=3500 \mathrm{MPa}$

\begin{tabular}{|c|c|c|c|c|c|c|}
\hline \multirow{2}{*}{ RELAÇÃO } & $\begin{array}{c}\text { MODO DE } \\
\text { RUPTURA }\end{array}$ & $\mathbf{H} / \mathbf{L}=\mathbf{0 , 5 1}$ & $\mathbf{H} / \mathbf{L}=\mathbf{0 , 6 0}$ & $\mathbf{H} / \mathbf{L}=\mathbf{0 , 7 0}$ & $\begin{array}{c}\mathbf{H} / \mathbf{L}=\mathbf{0 , 8 3} \\
\text { (TIPO II) }\end{array}$ & $\mathbf{H} / \mathbf{L}=\mathbf{1 , 0}$ \\
\hline \multirow{2}{*}{$\begin{array}{c}\text { Numérica/ } \\
\text { Proposta }\end{array}$} & Fissuração & - & 0,60 & 0,67 & 0,78 & 0,91 \\
\cline { 2 - 7 } & Esmagam. & 1,09 & 1,07 & 1,21 & 1,39 & 1,40 \\
\hline \multirow{2}{*}{$\begin{array}{c}\text { Smith e Carter/ } \\
\text { Proposta }\end{array}$} & Fissuração & 0,97 & 0,98 & 1,03 & 1,13 & 1,19 \\
\cline { 2 - 7 } & Esmagam. & 1,25 & 1,20 & 1,25 & 1,28 & 1,33 \\
\hline \multirow{2}{*}{$\begin{array}{c}\text { Smith Riddington/ } \\
\text { Proposta }\end{array}$} & Fissuração & 0,68 & 0,78 & 0,85 & 0,96 & 1,07 \\
\cline { 2 - 7 } & Esmagam. & 0,93 & 0,91 & 0,81 & 0,73 & 0,63 \\
\hline
\end{tabular}




\section{REFERÊNCIAS BIBLIOGRÁFICAS}

ALVARENGA, R.C.S.S.; OLIVEIRA, J.T.; SILVA, R.M.; ANTUNES, H.M.C.C;

LOURENÇO, P.B. (2000). Avaliação experimental do enrijecimento de pórticos metálicos com alvenaria. In: III SEMINÁRIO INTERNACIONAL "O USO DE ESTRUTURAS METÁlICAS NA CONSTRUÇÃO CIVIL". Belo Horizonte, MG, 2000. (CD ROM). 10 p.

ALY, V. L. C. (1991). Determinação da Capacidade Resistente do Elemento Parede de Alvenaria Armada de Blocos de Concreto, submetido à Esforços de Compressão. São Paulo. Dissertação (Mestrado) - Escola Politécnica da Universidade de São Paulo.

AMERICAN SOCIETY FOR TESTING AND MATERIALS (1993). ASTM E $447-$ 97 - Standard Test Method for Compressive Strength of Laboratory Constructed Masonry Prisms.

AMOS, K. A. (1985). The shear strength of masonry infilled steel frames. Tese (Doutorado) - Department of Civil Engineering, University of New Brunswick, Fredericton, N.B.

ARMHEIN, J. E. (1978). Reinforced Masonry Engineering Handbook: Clay and Concrete Masonry. Masonry Institute of America. 3 ed. Los Angeles. 
ASSOCIAÇÃO BRASILEIRA DA CONSTRUÇÃO INDUSTRIALIZADA (1990). Manual Técnico de Alvenaria. ABCI, 274p. São Paulo.

ASSOCIAÇÃO BRASILEIRA DE NORMAS TÉCNICAS (1980). NBR 6120 -

Cargas para o Cálculo de Estruturas de Edificações. 6p. Rio de Janeiro.

ASSOCIAÇÃO BRASILEIRA DE NORMAS TÉCNICAS (1980). NBR 6123 -

Forças Devidas ao Vento em Edificações. Rio de Janeiro.

ASSOCIAÇÃO BRASILEIRA DE NORMAS TÉCNICAS (1980). NBR 6136 -

Blocos Vazados de Concreto Simples para Alvenaria Estrutural. 7p. São Paulo.

ASSOCIAÇÃO BRASILEIRA DE NORMAS TÉCNICAS (1982). NBR 7173 -

Blocos Vazados de Concreto Simples para Alvenaria sem Função Estrutural. 6p.

Rio de Janeiro.

ASSOCIAÇÃO BRASILEIRA DE NORMAS TÉCNICAS (1982). NBR 7186 -

Blocos de Concreto Simples para Alvenaria com Função Estrutural - Método de

Ensaio. Rio de Janeiro.

ASSOCIAÇÃO BRASILEIRA DE NORMAS TÉCNICAS (1983). NBR 7222 Argamassas e concretos - Determinação da Resistência à Tração por compressão diametral de corpos de prova cilíndricos. 3p. Rio de Janeiro.

ASSOCIAÇÃO BRASILEIRA DE NORMAS TÉCNICAS (1984). NBR 8522 -

Determinação do Módulo de Deformação Estático e Diagrama Tensão $\times$ Deformação - Método de Ensaio.

ASSOCIAÇÃO BRASILEIRA DE NORMAS TÉCNICAS (1985). NBR 8798 Execução do Controle de Obras em Alvenaria Estrutural de Blocos Vazados de Concreto. 29p. Rio de Janeiro.

ASSOCIAÇÃO BRASILEIRA DE NORMAS TÉCNICAS (1985). NBR 8949 Paredes de Alvenaria Estrutural, Ensaios à Compressão Simples. Método de Ensaio. 7p. Rio de Janeiro.

ASSOCIAÇÃO BRASILEIRA DE NORMAS TÉCNICAS (1989). NB 1228 -

Cálculo de Alvenaria Estrutural de Blocos Vazados de Concreto. Rio de Janeiro. 
ASSOCIAÇÃO BRASILEIRA DE NORMAS TÉCNICAS (1991). MB-116 - Blocos de Concreto Simples para Alvenaria - Determinação da Resistência à Compressão. $2 \mathrm{p}$.

ASSOCIAÇÃO BRASILEIRA DE NORMAS TÉCNICAS (1991). NBR 7215 Cimento Portland Comum. Determinação da Resistência à Compressão - Método de Ensaio. Rio de Janeiro.

ASSOCIAÇÃO BRASILEIRA DE NORMAS TÉCNICAS (1999). NBR 14821 Paredes de Alvenaria Estrutural - Determinação da resistência ao cisalhamento. Rio de Janeiro.

ATKINSON, R. H.; HAMMONS, M. I. (1997). Tension Stiffening Behavior of Reinforced Masonry. Journal of Structural Engineering, v. 123, n. 5, p. 597-603.

BARAU, H. K.; MALLICK, S. K. (1977). Behaviour of mortar infilled steel frames under lateral load. Building and Environment, Pergamon Press, UK. Vol 12, pp. 263-272.

BATHE, K. J. (1996). Finite element procedures. Englewood Cliffs, New Jersey. Prentice-Hall, Inc.

BENJAMIN, J. R.; WILLIAMS, H. A. (1957). The Behavior of One-Storey Reinforced Concrete Shear Walls. Proc. Amer. Soc. Civ. Eng., v.83 -N. ST3 - p. $1-49$.

BENJAMIN, J. R.; WILLIAMS, H. A. (1958). The behaviour of one-storey brick shear walls. ASCE Journal of the Structural Division, Vol. 84, n. ST4.

BRAGUIM, J. R. (1989). Contribuições ao Estudo do Enrijecimento de Estruturas de Aço em Edifícios de Múltiplos Pavimentos. 130 p. Dissertação (Mestrado) Escola Politécnica, Universidade de São Paulo.

BRAGUIM, J. R. (1993). Painel de Alvenaria: Um Fator de Enrijecimento das Estruturas. Encarte Técnico Instituto de Pesquisas Tecnológicas / Divisão de Construção Civil - PINI, IPT.43, p. 19-22. São Paulo. 
BRAGUIM, J. R. (1993). Painel de Alvenaria: Um Fator de Enrijecimento das Estruturas. Encarte Técnico Instituto de Pesquisas Tecnológicas / Divisão de Construção Civil - PINI, IPT.44, p. 17-20. São Paulo.

CALVI, G. M. (2000). The behavior of frames infilled with non-reinforced and murfor - Reinforced clay brick masonry walls. Pávia. Itália. /Relatório técnico Universita degli studi di Pavia/

CARTER, C., STAFFORD-SMITH, B. (1969). Structural behaviour of masonry infilled frames subjected to racking loads. Designing, Engineering, and Construction with Masonry Products. Houston. Gulf Publishing Company, , pp. 226-233.

CHEN, W. F.; HAN, D. J. (1988). Plasticity for Structural Engineers. Springer Verlag, New York.

COMITÉ EURO-INTERNATIONAL DU BÉTON (1990). CEB-FIP model code 1990: first fraft, Addendum. Bulletim D'Information, n. 198, Sep.

COMITÉ EURO-INTERNATIONAL DU BÉTON (1991). CEB-FIP model code 1990: final fraft. Bulletim D'Information, n. 203,204,205, Jul.

CORRÊA, M. R. S. ; RAMALHO (1997). Notas de Aula. Escola de Engenharia de São Carlos. USP.

DANASEKAR, M.; PAGE, A. W. (1986). The Influence of Brick Masonry Infill Properties on the Behavior of Infilled Frames. Proc. Intsn. Civ. Engrs., part 2, 81, p. 593-605.

DANASEKAR, M.; PAGE, A. W; KLEEMAN, P. W. (1985). The Failure of Brick Masonry under Biaxial Stresses. Proc. Intsn. Civ. Engrs., part 2, 79, p. 295-313.

DAWE, J. L.; CHARALAMBOUS, P. D. (1983). Finite element analysis for wallframe interaction. Proceedings, Eight International Loadbearing Brickwork Symposium, British Ceramic Society, Stoke-on-Trent. UK.

DAWE, J. L.; SEAH, C. K. (1989). Analysis of concrete masonry infilled steel frames subjected to in-plane loads. Proceedings, $5^{\text {th }}$ Canadian Masonry Symposium. University of British Columbia, Vancouver, Canadá. p. 329-340. 
DHANASEKAR, M., PAGE, A. W. (1986). The influence of brick masonry infill properties on the behaviour of infilled frames. Proceedings of the Institution of Civil Engineers, Part 2, v. 81, p. 593-605.

DHANASEKAR, M., PAGE, A. W.; KLEEMAN, P. W. (1985). The failure of brick masonry under biaxial stresses. Proceedings of the Institution of Civil Engineers, Part 2, V. 79, p. 295-313.

DRYSDALE, R. G.; HAMID, A. A.; BAKER, L. R. (1994). Masonry structures Behaviour and design. New Jersey. Prentice-Hall, Inc. Englewood Cliffs.

EUROPEAN COMMITTEE STANDARDIZATION (1996). Eurocode 6 - Design of masonry structures. Part 1. London, BSI.

FILHO, A. V.; SILVA, R. P.; CAMPOS, M. R. (1995). Programa EPLENOR/PLENOR, versão 1.0. - DEES / EE-UFMG. Belo Horizonte.

FEENSTRA, P. H.; BORST, R. DE (1996). A composite plasticity model for concrete. Int. J. Solids Structures, n. 33(5), p. 707-730.

FLANAGAN, R. D.; BENNETT, R. M. (1994). Uniform lateral load capacity of infilled frames. Proceedings, Structures Congress XII, American Society of Civil Engineers, p. 785-790.

FONSECA, G. M. (1999). Análise numérico experimental da interação conjunta pórtico-alvenaria. Belo Horizonte. 145 p. Dissertação (Mestrado) - Escola de Engenharia da Universidade Federal de Minas Gerais.

GHAZALI, M. Z., RIDDINGTON, J. R. (1988). Simple test method for masonry shear strength. Proceedings of the Institution of Civil Engineers, Part 2, v. 85, p. $567-574$.

HENDRY, A. (1981). Structural brickwork, Macmillan, Londres.

HOLMES, M. (1961). Steel Frames with Brickwork and Concrete Infilling. Proc. Inst. Civ. Eng, v. 19, p. 473-478.

HOLMES, M. (1963). Combined Loading on Infilled Frames. ICE Proceedings, v. 25, p. 31-38.

JAMAL, B. D.; BENNETT, R. M.; AND FLANAGAN, R. D. (1992). Numerical analysis for in-plane behaviour of infilled frames. Proceedings, 6th. Canadian 
Masonry Symposium, Saskatoon, Saskatchewan. p. 633-644.

KADIR, M. R. A. (1974). The structural behaviour of masonry infilled panels in framed structures. Tese (Doutorado). Department of Civil Engineering, University of Edinburgh.

KARAMANSKI, T. (1967). Calculating infilled frames by the method of finite element, Tall Buildings, Pergamon Press, Oxford, p. 455-463.

KHATTAB, M. (1993). In-plane behaviour of grouted concrete masonry under biaxial state of stress. Tese (Doutorado). Hamilton, Ontario. Department of Civil Engineering, McMaster University.

KING, G. J. W.; PANDEY, P. C. (1978). The analysis of infilled frames using finite elements. Proceedings of the Institution of Civil Engineers, Part 2, v. 65, p. 749760.

KING, G. J. W.; PANDEY, P. C. (1978). The analysis of infilled frames using finite elements. Proceedings of the Institution of Civil Engineers, part 2, v. 65, p. 749760.

KOITER, W. T. (1977) Strength-Strain Relations, Uniqueness and Variational Theorems for Elastic-Plastic Materials with a Singular Yield Surface. Q. Appl. Mech. 11, p. 350-354.

KWAN, K. H., LO, C. Q.; LIAUW, T. C. (1990). Large -scale model tests and plastic analysis of multibay infilled frames. Proceedings of the Institution of Civil Engineers, Part 2, v. 89, p. 261-277.

LIAUW, T. C. (1970). Elastic behaviour of infilled frames. Proceedings of the Institution of Civil Engineers, v. 46, p.343-348.

LIAUW, T. C., e KWAN, K. H. (1982). Non-linear analysis of multi-storey infilled frames. Proceedings of the Institution of Civil Engineers, Part 2, v. 73, p. 441454.

LIAUW, T. C.; LEE, S. W. (1977). On the behaviour and the analysis of multi-storey infilled frames subjected to lateral loading. Proceedings of the Institution of Civil Engineers. Part 2, v. 63, p. 641-657. 
LOURENÇO, P. B. (1992). Novas metodologias para o dimensionamento de estruturas de betão armado. Porto, Portugal. 206 p. Dissertação (Mestrado) Faculdade de Engenharia, Universidade do Porto.

LOURENÇO, P. B. (1996). A User/Programmer's Guide for the Micro-modeling of Masonry Structures. Relatório n⿳003 03.21 .1 .31 .35 , Universidade Técnica de Delft, Delft, Países Baixos e Universidade do Minho. Guimarães, Portugal.

LOURENÇO, P. B. (1996). Computational Strategies for Masonry Structures. Delft, Holanda. 210 p. Tese (Doutorado) - Delft University of Technology - Delft University Press - I11.

LOURENÇO, P. B. (1999). Métodos Computationais na mecânica dos sólidos nãolinear. Guimarães, Portugal.

MAINSTONE, R. J. (1971). Supplementary Note on the Stiffness and Strength of Infilled Frames. CP13 74, Build. Res. Establishment. Londres, Inglaterra.

MAINSTONE, R. J. (1979). On the Stiffness and Strength of Infilled Frames. Proc. Supplement (IV), paper 7360S, Instn. of Civ. Engrg. Londres. Inglaterra.

MALLICK, D. V.; SEVERN, R. T. (1967). The behaviour of infilled frames under static loading. Proceedings of the Institution of Civil Engineers, v. 38, p. 639-656

MALLICK, S. K.; BARUA, H. K. (1977). Behavior of Mortar Infilled Steel Frames under Lateral Load. Building and Environment, v. 12, p. 263-272. Pergamon Press, 1977.

MANUAL DA SICAL (1999). Sistema construtivo sical em blocos de concreto celular autoclavados. Belo Horizonte.

MCBRIDE, R. T. (1984). The behaviour of masonry infilled steel frames subjected to racking. Dissertação (Mestrado). New Brunswick, Canadá. Department of Civil Engineering, University of New Brunswick, Fredericton, NB.

MEHRABI, A. B., SHING, P. B., SCHUllER, M., e NOLAND, J. (1996). Experimental evaluation of masonry-infilled RC frames. ASCE Journal of Structural Division, v. 122, n. ST3, p. 228-237. 
MEHRABI, A. B.; SHING, P. B. (1997). Finite Element Modeling of MasonryInfilled RC Frames. Journal of Structural Engineering, v. 123, n. 5, p. 604-613.

MORONI, M. O.; ASTROZA, M.; TAVONATTI, S. (1994). Nonlinear Models for Shear Failure in Confined Masonry Walls. IMS Journal, p. 72-78.

OLIVEIRA, J. T. (2001). Contribuição ao estudo de pórticos metálicos enrijecidos com alvenaria. Belo Horizonte. 195 p. Dissertação (Mestrado) - Escola de Engenharia, Universidade Federal de Minas Gerais.

ORDUÑA, A. B. (1999). Modelo de muros de mampostería para el análisis no lineal de marcos de concreto reforzado com muros diafragma. México D.F. 129 p. Dissertação (Mestrado) - Facultad de Ingeniería, Universidad Nacional Autónoma de México.

PAGE, A. W. (1979). A Non-Linear Analysis of the Composite Action of Masonry Walls on Beams. Proc. Inst. Civ. Eng., part 2, v. 67, p. 96-110.

PAGE, A. W. (1983). The Strength of Brick Masonry under Biaxial CompressionTension. Itn. J. Masonry Constr., 3 (1), p. 26-31.

POLYAKOV, S. V. (1956). Masonry in framed buildings (Godsudarstvenoe Isdatel' stvo Literatury Po Stroidal stvui Architecture. Moscow, 1956). Traduzido por G. L. Cairns, 1963. National Lending Library for Science and Technology, Boston.

POLYAKOV, S. V. (1960). On the interaction between masonry filler walls and enclosing frame when loaded in the plane of the wall. Earthquake Engineering. Earthquake Engineering Research Institute, São Francisco, CA, p. 36-42

PROENÇA, S.P.B. (1997). Análise não-linear de estruturas. Notas de Aulas.

RIDDINGTON, J. R. (1984). The Influence of Initial Gaps on Infilled Frame Behavior. Proc. Inst. Civ. Eng., part 2, p. 295-310.

RIDDINGTON, J. R.; STAFFORD SMITH, B. (1978). Composite Method of Design for Heavily Loaded Wall-Beam Structures. Proc. Inst. Civ. Eng., part 1, v. 64, p. 137-151.

RIVERO, C. D. (1982). An analytical study of the interaction of frames and infill masonry walls. Tese (Doutorado). Civil Engineering, University of Illinois, 
Illinois.

ROTS, J.G. (1992). Computational modeling of concrete fracture. Delft, Holanda. 132 p. Tese (Doutorado) - Delft University of Technology - Delft University Press - I11.

SABBATINI, F. H. (1984). O Processo Construtivo de Edificios de Alvenaria Estrutural Sílico-Calcária. Escola Politécnica da Universidade de São Paulo Dissertação de Mestrado, 298p. São Paulo.

SABBATINI, F. H. Dimensionamento de Edifícios de Alvenaria Estrutural NãoArmada. FDTE / EPUSP / IPT, s.d. 39p. São Paulo.

SACHANSKI, S. (1960). Analysis of the earthquake resistance of frame buildings taking into consideration the carrying capacity of the filling masonry. Proceedings of the Second World Conference on Earthquake Engineering, v. 3, Tokio, p. 2127-2141.

SANEINEJAD A. ; HOBBS, B. (1995). Inelastic design of infilled frames. ASCE Journal of Structural Division, v. 121, n. ST4, p. 634-650.

SEAH, C. K. (1998). A Universal approach for the analysis and design of masonry infilled frame structures. New Brunswick, Canadá. 273 p. Tese (Doutorado). University of New Brunswick.

SHING, P. B.; MEHRABI, A. B.; SCHULLER, M.; NOLAND, J. L. (1994). Experimental evaluation and finite element analysis of masonry infilled $\mathrm{r} / \mathrm{c}$ frames. Proceedings of the Eleventh Conference-Analysis and Computation, American Society of Civil Engineers. p. 84-93.

SILVA, R.C.; GIONGO, J.S. (2000). Modelos de bielas e tirantes aplicados a estruturas de concreto armado. São Carlos, EESC.

SMOLIRA, M. (1973). Analysis of Infilled Shear Walls. Proc. Instn Civ. Engrgs, part 2, v. 55, p. 895-912.

SMOLIRA, M. (1974). Discussion. Analysis of Infilled Shear Walls. Proc. Instn. Civ. Engrgs., part 2, v. 57, p. 777-782.

STAFFORD-SMITH, B. (1962). Lateral stiffness of infilled frames. ASCE Journal 
of Structural Division, v. 88, n. ST6, p. 183-199.

STAFFORD-SMITH, B. (1966). Behaviour of square infilled frames. ASCE Journal of the Structural Division, v. 92, n. ST1, p. 381-403.

STAFFORD-SMITH, B. (1967a). The composite behaviour of infilled frames. Tall Buildings, , Pergamon Press, Londres. p. 481-493.

STAFFORD-SMITH, B. (1967b). Methods of predicting the lateral stiffness and strength of multi-storey infilled frames. Building Science, v. 2, p. 247-257.

STAFFORD-SMITH, B.; CARTER, C. (1969). A method of analysis for infilled frames. Proceedings, the Institution of Civil Engineers, v. 44, p. 31-48.

STAFFORD-SMITH, B.; COULL, A. (1991). Tall building structures - Analysis and Design. John Wiley and Sons Inc., A Wiley-Interscience Publication, v. 91, p. 168.

STAFFORD-SMITH, B.; RIDDINGTON, J. R. (1977). Analysis of Infilled Frames Subject to racking with design Recommendations. The Structural Engineer, n. 6, v. 55, p. $263-268$.

STAFFORD-SMITH, B.; RIDDINGTON, J. R. (1978). The design of masonry infilled steel frames for bracing structures. The Structural Engineer, n. 1, v. 56B, p. 1-7.

THOMAS, F. G. (1953). The strength of brickwork. The Structural Engineer, Part 2, v. 36, p. $35-41$.

TNO BUILDING AND CONSTRUCTION RESEARCH (1996). DIANA user's manual, release 7.2. Delft, Holanda. 6v.

VIEIRA, L. F. C. (2000). WALLSYS: Programa Computacional para análise de pórticos preenchidos. Belo Horizonte.

WHITNEY C. S.; ANDERSON B. G.; COHEN E. (1955). Design of Blast Resistant Construction for Atomic Explosions. Journal, Amer. Concrete Inst. p 655-673.

WOOD, R. H. (1958). The Stability of Tall Buildings. Proc. Soc. Civ. Eng, v. 11, p. 60-101. 
WOOD, R. H. (1978). Plastic Composite Actions and Collapse Design of Unreinforced Shear Walls Panel in Frames. Proc. Soc. Civ. Engrgs., part 2, p. 381-411. Londres, Inglaterra.

Yong, T. C. (1984). Shear strength of masonry panels in steel frames. Dissertação (Mestrado). Canadá. Department of Civil Engineering, University of New Brunswick.

ZIENKIEWICZ, O. C.; TAYLOR R. L. (1991). The Finite Element Method: Volume 2, Solid and Fluid Mechanics, Dynamics and Non-Linearity. Berkshire, Inglaterra. Mc-Graw Hill. 